\title{
Final Report - Effects of High Spinel and Chromium Oxide Crystal Contents on Simulated HLW Vitrification in DM100 Melter Tests, VSL-09R1520-1, Rev. 0, dated 6/22/09
}

Prepared for the U.S. Department of Energy

Assistant Secretary for Environmental Management

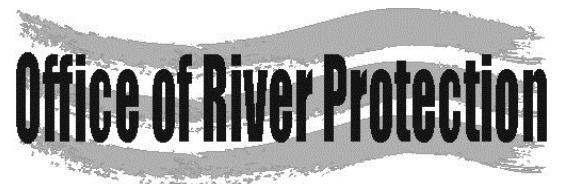

P.O. Box 450

Richland, Washington 99352 
ORP-56294

Revision 0

Final Report - Effects of High Spinel and Chromium Oxide Crystal Contents on Simulated HLW Vitrification in DM100 Melter Tests, VSL-09R1520-1, Rev. 0, dated $6 / 22 / 09$

\author{
A. A. Kruger \\ Department of Energy - Office of River Protection \\ K. S. Matlack \\ The Catholic University of America \\ W. Kot \\ The Catholic University of America
}

\author{
I. L. Pegg \\ The Catholic University of America \\ M. Chaudhuri, \\ The Catholic University of America \\ W. Lutze \\ The Catholic University of America
}

Date Published

June 2009

Prepared for the U.S. Department of Energy Assistant Secretary for Environmental Management

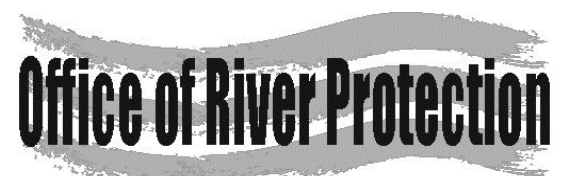

\section{P.O. Box 450}

Richland, Washington 99352

\section{APPROVED}

By G.E. Bratton at 2:37 pm, Nov 13, 2013 
ORP-56294

Revision 0

TRADEMARK DISCLAIMER

Reference herein to any specific commercial product, process, or service by tradename, trademark, manufacturer, or otherwise, does not necessarily constitute or imply its endorsement, recommendation, or favoring by the United States Government or any agency thereof or its contractors or subcontractors.

This report has been reproduced from the best available copy.

Printed in the United States of America 
VSL-09R1520-1

\title{
Final Report
}

\section{Effects of High Spinel and Chromium Oxide Crystal Contents on Simulated HLW Vitrification in DM100 Melter Tests}

\author{
prepared by
}

Keith S. Matlack, Wing K. Kot, Weiliang Gong, Werner Lutze, and Ian L. Pegg

\author{
Vitreous State Laboratory \\ The Catholic University of America \\ Washington, DC 20064 \\ and \\ Innocent Joseph \\ EnergySolutions Federal EPC, Inc. \\ Laurel, MD \\ for \\ Department of Energy \\ Office of River Protection
}

February 27, 2009

Rev. 0; 6/22/09 
Document Title: Effects of High Spinel and Chromium Oxide Crystal Contents on Simulated HLW Vitrification in DM100 Melter Tests

Document Number and Revision:

VSL-09R1520-1, Rev. 0

Issue Date:

$6 / 22 / 09$

Performing Organization: Vitreous State Laboratory, The Catholic University of America

Test Plan:

HLW Glass Formulation Development and Testing, VSL-08 T1520-1, Rev. 0

This report describes the results of testing specified by the above Test Plan. The work was performed in compliance with the quality assurance requirements specified in the Test Plan Results required by the Test Plan are reported. The test results and this report have been reviewed for correctness, technical adequacy, completeness, and accuracy

I.L. Pegg:

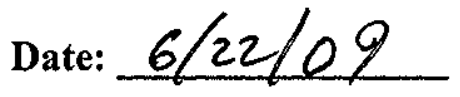

I. Joseph: Imocentyoscpb EnergySolutions Sub-Contract Manjaer

Date: $6 / 22 / 09$ 
LIST OF TABLES.

\section{TABLE OF CONTENTS}

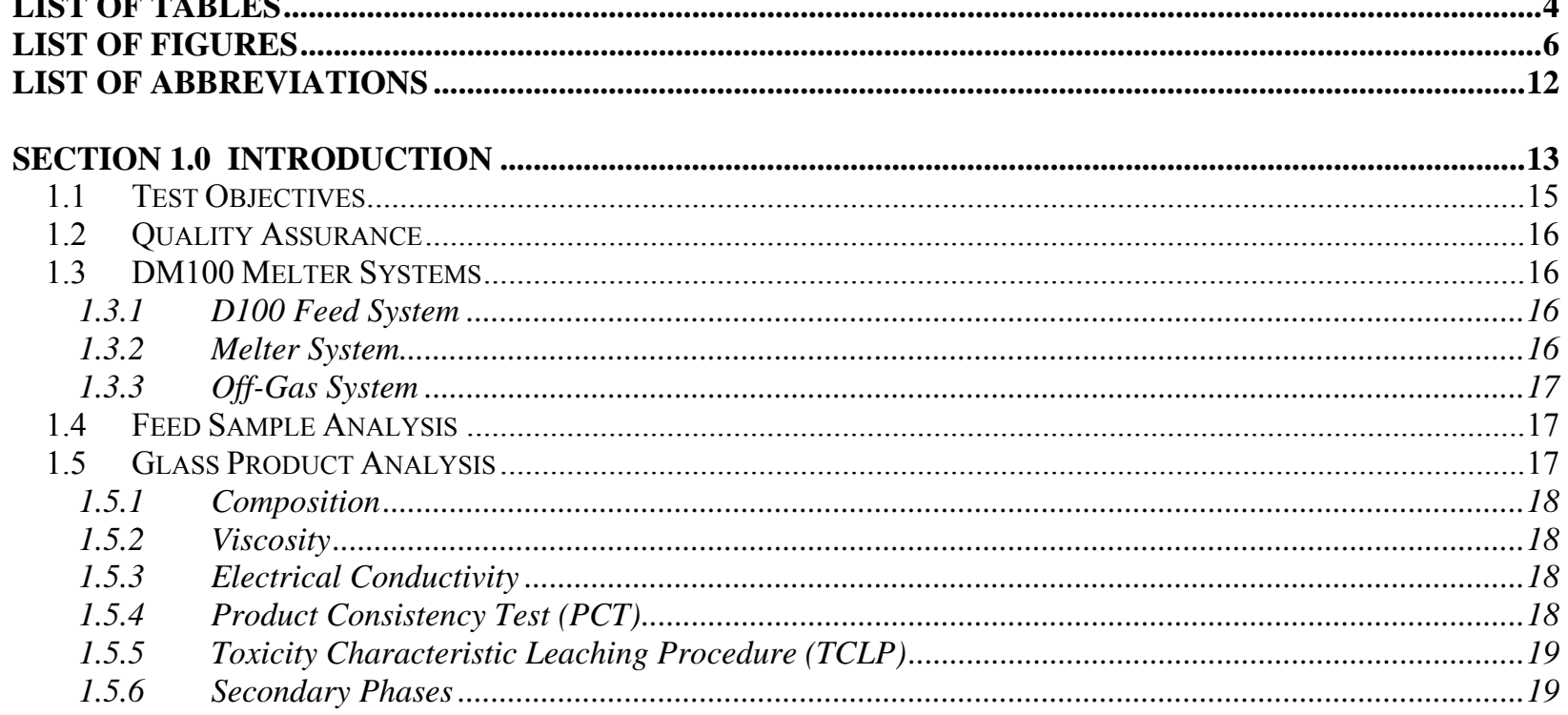

SECTION 2.0 FORMULATION OF HLW GLASSES AND MELTER FEEDS .............................................20

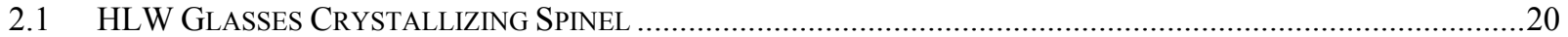

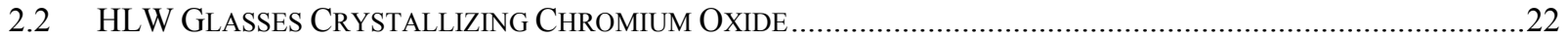

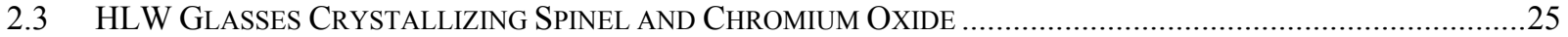

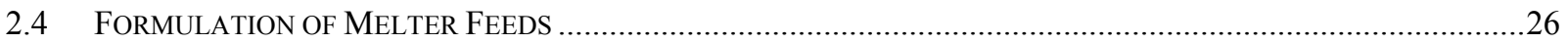

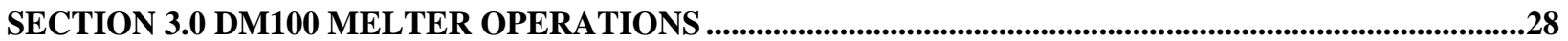

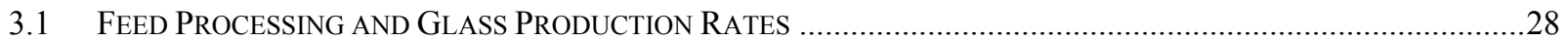

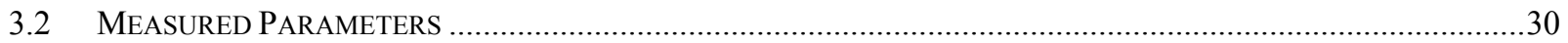

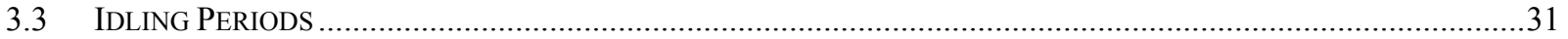

SECTION 4.0 FEED SAMPLE AND GLASS PRODUCT ANALYSIS .............................................................33

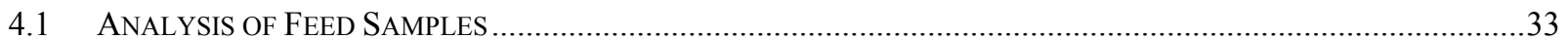

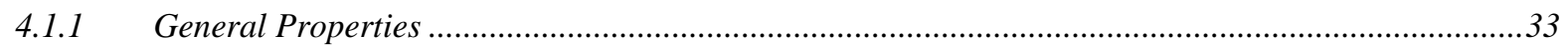

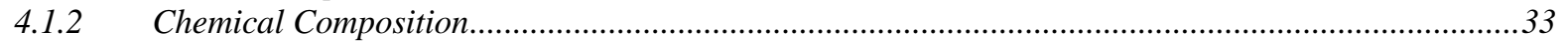

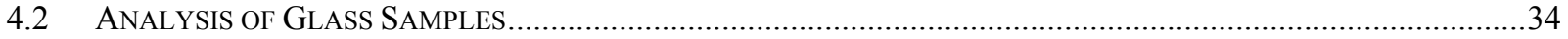

4.2.1 Compositional Analysis of Discharge Glasses ..................................................................................

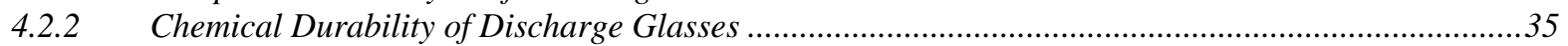

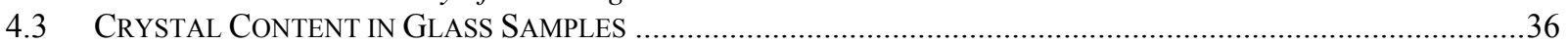

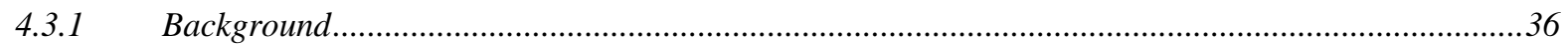

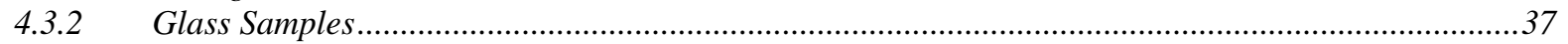

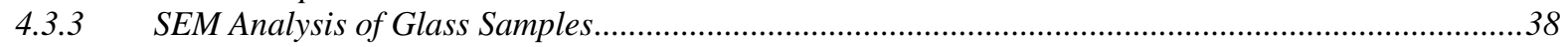

4.3.4 Discussion of Glass Sample Results ...............................................................................................39

4.3.5 Appearance of Hematite in DM100 Tests ..........................................................................................43

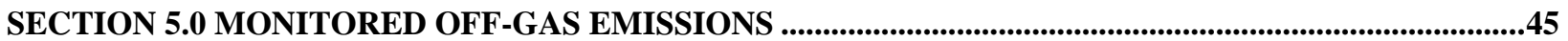

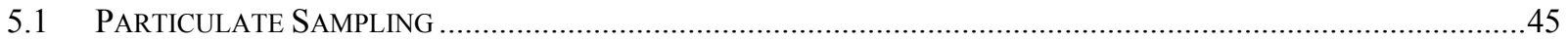

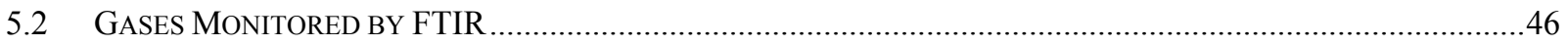

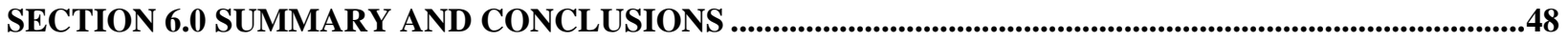

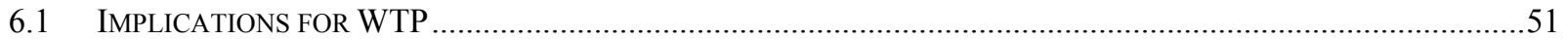

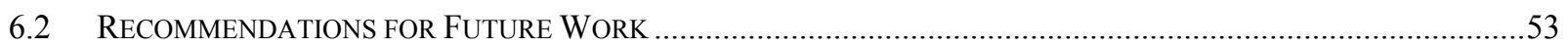

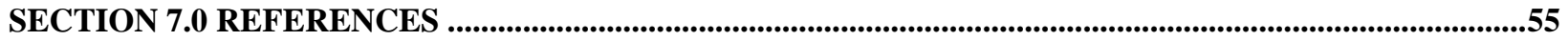




\section{List of Tables}

Table 2.1 Oxide Composition (wt\%) of Waste Streams Used in Development of HLW Glass Formulations.

$\mathrm{T}-1$

$\mathrm{T}-2$

Table 2.2 Reference Starting HLW Glass Compositions.

Table 2.3 Target Compositions of HLW Glasses (HLW-E-SP) Formulated to Study Crystallization of Spinel Phase.

Table 2.4 Analyzed (XRF) Compositions of the HLW-E-SP Glasses.

Table 2.5 Characterization Data for the HLW-E-SP Series of Glasses.

Table 2.6 Target Compositions of HLW Glasses (HLW-E-ES) Formulated to Study Crystallization of Chromium Oxide (Eskolaite) Phase.

Table 2.7 Analyzed (XRF) Compositions of the HLW-E-ES Glasses.

Table 2.8 Characterization Data for the HLW-E-ES Series of Glasses.

Table 2.9 Target Compositions of HLW Glasses (HLW-E-M) Formulated to Study Crystallization of Spinel and Chromium Oxide (Eskolaite) Phases.

Table 2.10 Analyzed (XRF) Compositions of the HLW-E-M Glasses.

Table 2.11 Characterization Data for the HLW-E-M Series of Glasses.

Table 2.12 Summary of Target Compositions of HLW Glasses Selected for Melter Tests.

Table 2.13 Compositional Summary of the HLW Simulant, Glass Formers and Target Glass (HLW-E-SP-06) for Melter Test 1.

Table 2.14 Compositions of the HLW Melter Feed (Simulant and Glass Forming Additives) to Produce $600 \mathrm{~kg}$ of Target Glass for Test 1.

$\mathrm{T}-3$

$\mathrm{T}-5$

$\mathrm{T}-7$

$\mathrm{T}-10$

$\mathrm{T}-14$

$\mathrm{T}-18$

$\mathrm{T}-23$

$\mathrm{T}-26$

$\mathrm{T}-29$

$\mathrm{T}-33$

$\mathrm{T}-34$

$\mathrm{T}-35$

$\mathrm{T}-36$ (HLW-E-SP-05) for Melter Test 2.

Table 2.15 Compositional Summary of the HLW Simulant, Glass Formers and Target Glass

Table 2.16 Compositions of the HLW Melter Feed (Simulant and Glass Forming Additives) to Produce $600 \mathrm{~kg}$ of Target Glass for Test 2 .

$\mathrm{T}-37$

$\mathrm{T}-38$ (HLW-E-M-03) for Melter Test 3.

Table 2.17 Compositional Summary of the HLW Simulant, Glass Formers and Target Glass

Table 2.18 Compositions of the HLW Melter Feed (Simulant and Glass Forming Additives) to Produce $600 \mathrm{~kg}$ of Target Glass for Test 3.

Table 2.19 Compositional Summary of the HLW Simulant, Glass Formers and Target Glass (HLW-E-ES-05) for Melter Test 4.

Table 2.20 Compositions of the HLW Melter Feed (Simulant and Glass Forming Additives) to Produce $600 \mathrm{~kg}$ of Target Glass for Test 4. (HLW-E-SP-09) for Melter Test 5.

Table 3.1 Summary of Results from DM100 Tests.

Table 3.2 Steady-State Production Rates Achieved on the DM100 with HLW Compositions at a Glass Temperature of $1150^{\circ} \mathrm{C}$ and Solids Content near $500 \mathrm{~g}$ glass/liter.

Table 3.3 Summary of Measured DM100 Parameters.

$\mathrm{T}-47$

$\mathrm{T}-48$

$\mathrm{T}-51$

$\mathrm{T}-52$

$\mathrm{T}-53$

$\begin{array}{ll}\text { Table 4.1 } & \text { Characteristics of Melter Feed Samples from DM100 Tests. } \\ \text { Table 4.2 } & \text { XRF Analyzed Compositions of Vitrified Melter Feed Samples (wt\%). }\end{array}$ 
Table 4.3 XRF and DCP Analyzed Compositions of Selected Vitrified Melter Feed Samples during DM100 Tests (wt\%).

Table 4.4 List of Glass Discharged, Masses, and Analysis Performed.

Table 4.6 List of Boat, Suction and Cold Cap Glass Samples with Secondary Phase Observations. T-65

Table 4.7 XRF Analyzed Composition for Glass Discharged During DM100 Tests (wt\%). T-67

Table 4.8 Results of PCT (ASTM C1285, 7-days at $90^{\circ} \mathrm{C}$, Stainless Steel Vessel; S/V=2000m ${ }^{-1}$ ). T-75

Table 4.9 TCLP Results for Discharged Glass Samples (mg/L).

Table 4.10 Representative Compositions of Major Crystalline Phases in Melter Glass Pool Sampled by Dipping (atom\%).

Table 5.1 Results from Melter Off-Gas Emission Samples.

Table 5.2 Concentrations [ppmv] of Selected Species in Off-Gas Measured by FTIR Spectroscopy. 


\section{List of Figures}

Figure 1.1 Schematic diagram of DuraMelter 100-BL vitrification system.

$\underline{\text { Page }}$

Figure 1.2.a Schematic diagram showing cross-section through the DM100-BL-melter.

Plan view showing locations of lid ports.

F-1

Figure 1.2.b

Schematic diagram showing cross-section through the DM100-BL melter.

Figure 1.2.c

Schematic diagram showing cross-section through the DM100-BL melter.

Figure 2.1

Electron micrograph of heat-treated HLW-E-SP-05 glass $\left(1150^{\circ} \mathrm{C}\right.$ for 70 hours $)$

showing spinel crystals.

F-2

F-3

F-4

Figure 2.2 Spinel crystallization in HLW-E-SP glasses as a function of heat treatment

F-5 temperature after 70 hours (Data for $1200^{\circ} \mathrm{C}$ were collected on as-melted glasses; melting time $=2$ hours; $. \mathrm{WL}=$ Waste Loading).

F-6

Figure 2.3 Electron micrograph of heat-treated HLW-E-ES-02 glass $\left(950^{\circ} \mathrm{C}\right.$ for 70 hours $)$ showing chromium oxide crystals as elongated platelets.

Figure 2.4 X-ray diffraction patterns of heat-treated samples of HLW-E-ES-03 (top) and HLW-E-ES-02 (bottom).

Figure 2.5 Eskolaite crystallization in HLW-E-ES glasses as a function of heat treatment temperature after 70 hours (Data for $1200^{\circ} \mathrm{C}$ were collected on as-melted glasses; melting time $=2$ hours).

Figure 2.6 Electron micrograph of heat-treated HLW-E-M-03 glass $\left(950^{\circ} \mathrm{C}\right.$ for 70 hours) showing spinel and chromium oxide crystals.

Figure 2.7 Estimated proportion of eskolaite observed in crystalline phases in HLW-E-M-01 and HLW-E-M-06 as a function of heat treatment temperature after 70 hours (Data were not collected for $1050^{\circ} \mathrm{C}$; Data for $1200^{\circ} \mathrm{C}$ were collected on as-melted glasses; melting time $=2$ hours).

F-11

Figure 2.8 Crystallization in glasses selected for melter tests (HLW-E-M-03 and HLW-E-M-09) as a function of heat treatment temperature after 70 hours (Data for $1200^{\circ} \mathrm{C}$ were collected on as-melted glasses; melting time $=2$ hours).

Figure 3.1.a

Figure 3.1.b

Figure 3.1.c

Figure 3.1.d

Figure 3.1.e

Figure 3.1.f

Figure 3.2.a

Figure 3.2.b

Figure 3.2.c

Figure 3.2.d

Figure 3.2.e

Figure 3.3.a

Figure 3.3.b

Figure 3.3.c

Figure 3.3.d

Figure 3.3.e

Figure 3.4.a

Figure 3.4.b

Figure 3.4.c

Figure 3.4.d
Glass production rates (hourly moving averages) for DM100 Tests 1a and $1 \mathrm{~b}$.

Glass production rates (hourly moving averages) for DM100 Tests $2 \mathrm{a}$ and $2 \mathrm{~b}$.

Glass production rates (hourly moving averages) for DM100 Tests $3 \mathrm{a}$ and $3 \mathrm{~b}$.

Glass production rates (hourly moving averages) for DM100 Tests $4 \mathrm{a}$ and $4 \mathrm{~b}$.

Glass production rates (hourly moving averages) for DM100 Tests 5a and 5b.

Steady state glass production rates and boron content for the five glass

compositions processed on the DM100.

Glass pool bubbling rate for DM100 Tests $1 \mathrm{a}$ and $1 \mathrm{~b}$.

Glass pool bubbling rate for DM100 Tests $2 \mathrm{a}$ and $2 \mathrm{~b}$.

Glass pool bubbling rate for DM100 Tests $3 \mathrm{a}$ and $3 \mathrm{~b}$.

Glass pool bubbling rates for DM100 Tests $4 \mathrm{a}$ and $4 \mathrm{~b}$.

Glass pool bubbling rates for DM100 Tests 5a and 5b.

Glass temperatures (hourly averages) during DM100 Tests $1 \mathrm{a}$ and $1 \mathrm{~b}$.

Glass temperatures (hourly averages) during DM100 Tests $2 \mathrm{a}$ and $2 \mathrm{~b}$.

Glass temperatures (hourly averages) during DM100 Tests $3 a$ and $3 b$.

Glass temperatures (hourly averages) during DM100 Tests $4 \mathrm{a}$ and $4 \mathrm{~b}$.

Glass temperatures (hourly averages) during DM100 Tests 5a and 5b.

Plenum temperatures (hourly averages) during DM100 Tests $1 \mathrm{a}$ and $1 \mathrm{~b}$.

Plenum temperatures (hourly averages) during DM100 Tests $2 \mathrm{a}$ and $2 \mathrm{~b}$.

Plenum temperatures (hourly averages) during DM100 Tests $3 \mathrm{a}$ and $3 \mathrm{~b}$.

Plenum temperatures (hourly averages) during DM100 Tests $4 \mathrm{a}$ and $4 \mathrm{~b}$.
F-12

F-13

F-14

F-15

F-16

F-17

F-18

F-19

F-20

F-21

F-22

F-23

F-24

F-25

F-26

F-27

F-28

F-29

F-30

F-31

F-32 
Figure 3.4.e Figure 3.5.a Figure 3.5.b Figure 3.5.c Figure 3.5.d Figure 3.5.e Figure 3.6.a Figure 3.6.b Figure 3.6.c Figure 3.6.d Figure 3.6.e Figure 3.7

Figure 3.8.a

Figure 3.8.b

Figure 3.8.c

Figure 3.8.d

Figure 3.8.e

Figure 3.9.a

Figure 3.9.b

Figure 3.9.c

Figure 3.9.d

Figure 3.9.e

Figure 3.10.a

after Test 1.

Figure 3.10.b Electrode temperatures and power (hourly averaged) during idling period after Test 2.

Figure 3.10.c Electrode temperatures and power (hourly averaged) during idling period after Test 3.

Figure 3.10.d Electrode temperatures and power (hourly averaged) during idling period after Test 4.

Figure 3.10.e Electrode temperatures and power (hourly averaged) during idling period after Test 5.

Figure 3.11 Single sample boat removed after Test 1 prior to idling period. Note secondary sulfur phases on external glass surface.

Figure 3.12 Lower sampling boat removed after Test 2 idling period.

Figure 3.13 Upper sampling boat removed after Test 2 idling period. Note secondary sulfur phases on external glass surface.

Figure 3.14 Cross-sectioned, lower sampling boat removed after Test 1 idling period. Note hole in the bottom of the boat.

Figure 3.15 Lower sampling boat removed after Test 4 idling period. Note the lack of glass in the boat.

Figure 4.1.a Tests 1 and 2 (HLW-E-SP-06 and HLW-E-SP-05) product glass compositions determined by XRF.

Figure 4.1.b Tests 1 and 2 (HLW-E-SP-06 and HLW-E-SP-05) product glass compositions determined by XRF.

Figure 4.1.c Tests 1 and 2 (HLW-E-SP-06 and HLW-E-SP-05) product glass compositions determined by XRF.

Figure 4.2.a Tests 3, 4 and 5 (HLW-E-M-03, HLW-ES-05 and HLW-E-M-09) product glass compositions determined by XRF.
F-33

F-34

$\mathrm{F}-35$

F-36

$\mathrm{F}-37$

F-38

F-39

F-40

F-41

F-42

F-43

F-44

F-45

F-46

F-47

F-48

F-49

F-50

F-51

F-52

F-53

F-54

F-55

F-56

F-57

F-58

F-59

F-60

F-61

F-62

F-63

F-64

F-65

F-66

F-67

F-68 
Figure 4.2.b Tests 3, 4 and 5 (HLW-E-M-03, HLW-ES-05 and HLW-E-M-09) product glass compositions determined by XRF.

F-69

Figure 4.2.c Tests 3, 4 and 5 (HLW-E-M-03, HLW-ES-05 and HLW-E-M-09) product glass compositions determined by XRF.

Figure 4.2.d Tests 3, 4 and 5 (HLW-E-M-03, HLW-ES-05 and HLW-E-M-09) product glass compositions determined by XRF.

Figure 4.3a SEM image showing hematite and spinel crystallization in discharge glass after idling for $302 \mathrm{~h}$ (Test 1, BLZ-G-131A).

Figure 4.3b SEM image showing hematite and spinel crystallization in discharge glass after idling for $302 \mathrm{~h}$; lower magnification (Test 1, BLZ-G-131A).

Figure 4.4a SEM image showing hematite and spinel crystallization in dip sample after idling for $303 \mathrm{~h}$ (Test 1, BLZ-D-131A).

Figure 4.4b SEM image showing hematite and spinel crystallization in dip sample after idling for $303 \mathrm{~h}$; lower magnification (Test 1, BLZ-D-131A).

Figure 4.5a SEM image showing hematite and spinel crystallization in dip sample after idling for $222 \mathrm{~h}$ (Test 2, ABL-D-63B).

Figure 4.5b SEM image showing hematite and spinel crystallization in dip sample after idling for $222 \mathrm{~h}$; lower magnification (Test 2, ABL-D-63B).

Figure 4.6a SEM image showing hematite and spinel crystallization in glass discharge after idling for $230 \mathrm{~h}$ (Test 2, ABL-G-71A).

Figure 4.6b SEM image showing hematite and spinel crystallization in glass discharge after idling for $230 \mathrm{~h}$; lower magnification (Test 2, ABL-G-71A).

Figure 4.7a SEM image showing spinel crystallization in dip sample after idling for $60 \mathrm{~h}$ (Test 3, ABL-D-140A). See chemical zoning in a large spinel crystal.

Figure 4.7b SEM image showing primary spinel crystallization in dip sample after idling for $60 \mathrm{~h}$; lower magnification (Test 3, ABL-D-140A).

Figure 4.8a SEM image showing primary spinel crystallization in glass discharge after idling for $231 \mathrm{~h}$ (Test 3, ABL-G-141B).

Figure 4.8b SEM image showing primary spinel crystallization in glass discharge after idling for $231 \mathrm{~h}$; lower magnification (Test 3, ABL-G-141B).

Figure 4.9a SEM image showing primary eskolaite crystallization in dip sample after idling for $239 \mathrm{~h}$ (Test 4, BBL-D-60B). Some spinel crystals are present.

Figure 4.9b SEM image showing primary eskolaite crystallization in dip sample after idling for $239 \mathrm{~h}$; lower magnification (Test 4, BBL-D-60B). Some spinel crystals are present.

Figure 4.10a SEM image showing primary eskolaite and spinel crystallization in glass discharge after idling for 404h (Test 4, BBL-G-60B).

Figure 4.10b SEM image showing primary eskolaite and spinel crystallization in glass discharge after idling for 404h; lower magnification (Test 4, BBL-G-60B).

Figure 4.11a SEM image showing primary spinel crystallization in glass discharge after idling for $181 \mathrm{~h}$ (Test 5, BBL-G-130A). Note skeleton crystal of spinel.

Figure $4.11 \mathrm{~b}$ SEM image showing primary spinel crystallization in glass discharge after idling for $181 \mathrm{~h}$; lower magnification (Test 5, BBL-G-130A).

F-70

F-71

F-72

F-73

F-74

F-75

F-76

F-77

F-78

F-79

F-80

F-81

F-82

F-83

F-84

F-85

F-86

F-87

F-88

F-89

F-90 for $186 \mathrm{~h}$ (Test 5, BBL-D-130B).

F-91 idling for $186 \mathrm{~h}$; lower magnification (Test 5, BBL-D-130B).

Figure 4.13a SEM image showing microstructure of spinel settling on the boat bottom during testing (Test 1, BLZ-O-130A, 1" from bottom). Spinel crystals are very large in size. 
Figure 4.13b SEM image showing primary spinel crystallization in the settling zone 1" from bottom of the boat (Test 1, BLZ-O-130A).

Figure 4.14a SEM image showing microstructure of spinel settling on the boat bottom after idling (Test 1, BLZ-O-131B, 13" from bottom). Note clusters of large spinel crystals in highly dense settling zone composed of smaller spinel crystals.

Figure 4.14b SEM image showing typical microstructure of spinel settling zone away from the affected zone (Test 1, after idling, BLZ-O-131B, 13" from bottom).

Figure 4.14c SEM image showing typical microstructure of the upper settling zone (Test 1, after idling, BLZ-O-131B, 13" from bottom). Note hematite platelet rich region near top of image.

Figure 4.14d SEM image showing typical microstructure of the upper spinel settling zone at higher magnification (Test 1, after idling, BLZ-O-131B, 13" from bottom).

Figure 4.15a SEM image showing cross-sectional microstructure of the settling zone on the boat bottom after idling (Test 1, BLZ-O-131A, 1" from bottom). Note large spinel crystals in a settling zone composed of smaller spinel crystals. The arrow shows the direction of settling.

Figure 4.15b SEM image showing sodalite crystallization in the settling zone (Test 1, BLZ-O-131A, 1" from bottom). Sodalite crystals are in dark grey as indicated by the arrow.

Figure 4.16a SEM image showing a cross-sectional microstructure of the settling zone on the boat bottom after idling (Test 2, ABL-O-71A, 1" from bottom). The settling zone is composed of spinel crystals in high packing density close to the bottom of the boat.

Figure 4.16b SEM image showing a cross-sectional microstructure of the settling zone (upper region, Test 2, ABL-O-71A, 1" from bottom). The settling zone is composed of spinel crystals and hematite platelets. Hematite platelets dominate the region above primary spinel setting zone.

Figure 4.16c SEM image showing microstructure of the top region of the settling zone (Test 2, ABL-O-71A, 1" from bottom). Hematite platelets dominate the settling zone.

Figure 4.17a SEM image showing cross-sectional microstructure of the settling zone close to bottom of the boat after idling (Test 2, ABL-O-71B, 13" from bottom). The settling zone is composed of spinel crystals in high packing density.

Figure 4.17b SEM image showing cross-sectional microstructure of the settling zone in the upper region (Test 2, ABL-O-71B, 13" from bottom). Hematite platelets are abundant in the region above the primary spinel settling zone.

Figure 4.18 SEM image showing cross-sectional microstructure of the settling zone close to bottom of the boat after idling (Test 3, ABL-O-141A, 13" from bottom). The settling zone is composed of smaller spinel crystals at lower packing density. The reaction of the boat alloy with glass melt is extensive.

Figure 4.19a SEM image showing cross-sectional microstructure of the settling zone close to bottom of the boat after idling (Test 3, ABL-O-141B, 1" from bottom). The settling zone is composed of smaller spinel crystals at lower packing density. The reaction of the boat alloy with glass melt is extensive.

Figure 4.19b SEM image showing cross-sectional microstructure of the settling zone in the upper region after idling (Test 3, ABL-O-141B, 1" from bottom). The concentration gradient in smaller spinel crystals is visible.

Figure 4.20a SEM image showing microstructure of a partial settling zone (Test 4, BBL-O-60B, 13" from bottom). More eskolaite platelets are present in the upper region in this image. 
Figure 4.20b SEM image showing microstructure of the region above the primary spinel settling zone. (Test 4, BBL-O-60B, 13" from bottom). The eskolaite platelets are dominate in the form of clusters of $50-150 \mu \mathrm{m}$ in size.

Figure 4.21 SEM image showing microstructure of a suction sample 1" from bottom of the melter (Test 4, BBL-O-60C). The eskolaite platelets are present in clusters.

Figure 4.22a SEM image showing microstructure in a partial cross-section of the settling zone in a suction sample (Test 4, after idling, BBL-O-60D, just off bottom of melter). The primary phase is spinel.

Figure 4.22b SEM image showing typical microstructure of the settling zone in a suction Sample (Test 4, after idling, BBL-O-60D, just off bottom of melter). Some of these large crystals of spinel are present in a skeleton form.

Figure 4.23a SEM image showing typical microstructure of a partial cross-section of the settling zone at 1 " from bottom of melter in a suction sample (Test 5, end of test, BBL-O-124B). The settling zone is composed primarily of spinel crystals.

Figure 4.23b SEM image showing typical microstructure of the settling zone at 1 " from bottom of melter in a suction sample at higher magnification (Test 5, end of test, BBL-O-124B). The settling zone is composed primarily of spinel crystals and eskolaite platelets.

Figure 4.24a SEM image showing typical microstructure of a partial settling zone (Test 5, after idling, BBL-O-124D). The studied region is near the bottom of the boat. The settling zone is composed primarily of small spinel crystals.

Figure 4.24b SEM image showing typical microstructure of a partial settling zone (Test 5, after idling, BBL-O-124D). The studied region is away from the bottom of the boat. The concentration of spinel is much less compared to that near the bottom.

Figure 4.25a SEM image showing typical microstructure of the affected zone between the settling zone and the boat alloy (Test 5, after idling, BBL-O-124E, 13" from bottom). The bright particles are Bi rich phases.

Figure 4.25b SEM image showing typical microstructure of the settling zone composed primarily of spinel at high packing density (Test 5 , after idling, BBL-O-124E, 13" from bottom).

Figure 4.25c SEM image showing typical microstructure of the settling zone primarily in the upper region (Test 5, after idling, BBL-O-124E, 13" from bottom).

Figure 4.26 SEM image showing typical microstructure of the dense settling zone in a suction sample (Test 5, after idling, BBL-O-130B, 1" from bottom of melter). The settling zone is a mixture of large skeletons and smaller spinel crystals.

Figure 4.27a SEM image showing typical microstructure in cross-section of the settling zone composed primarily of spinel at high packing density (Test 5, after idling, BBL-O-130A, just from bottom).

Figure 4.27b SEM image showing typical microstructure of the settling zone composed Primarily of spinel at high packing density (Test 5, after idling, BBL-O-130A, just from bottom).

Figure 4.28 Fractions of crystals in dip and discharge glass samples taken at the end of Test 1 and during subsequent melter idling.

Figure 4.29 Fractions of crystals in dip, discharge, and boat glass samples taken during and at the end of Test 1 , and during subsequent melter idling.

Figure 4.30 Fractions of crystals in dip and discharge glass samples taken at the end of Test 2 and during subsequent melter idling.

Figure 4.31 Fraction of crystals in dip, discharge, and boat glass samples during and at the end of Test 2, and during subsequent melter idling. 
Figure 4.32 Fractions of crystals in dip and discharge glass samples taken at the end of Test 3 and during subsequent melter idling.

Figure 4.33 Fractions of crystals in dip and discharge glass samples taken at the end of Test 4 and during subsequent melter idling.

Figure 4.34 Fractions of crystals in dip, discharge, and suction glass samples taken at the end of Test 4 and during subsequent melter idling.

Figure 4.35 Fractions of crystals in dip and discharge glass samples taken at the end of Test 5 and during subsequent melter idling.

Figure 4.36 Fractions of crystals in dip, discharge, and suction glass samples taken at the end of Test 5 and during subsequent melter idling.

Figure 5.1 FTIR monitored NO and water emissions during Tests $1 \mathrm{a}$ and $1 \mathrm{~b}$.

Figure 5.2 FTIR monitored NO and water emissions during Tests $2 \mathrm{a}$ and $2 \mathrm{~b}$. 


\section{List of Abbreviations}

$\begin{array}{ll}\text { AA } & \text { Atomic Absorption Spectroscopy } \\ \text { ADS } & \text { Air Displacement Slurry } \\ \text { ANL-LRM Argonne National Laboratory - Low Activity Waste Reference Material } \\ \text { DCP-AES } & \text { Direct Current Plasma Atomic Emission Spectroscopy } \\ \text { DF } & \text { Decontamination Factor } \\ \text { DM } & \text { DuraMelter } \\ \text { DOE } & \text { Department of Energy } \\ \text { DRE } & \text { Destruction \& Removal Efficiency } \\ \text { DWPF } & \text { Defense Waste Processing Facility } \\ \text { EA } & \text { Environmental Assessment } \\ \text { EDS } & \text { Energy Dispersive X-Ray Spectroscopy } \\ \text { EPA } & \text { Environmental Protection Agency } \\ \text { FTIR } & \text { Fourier Transform Infrared Spectroscopy } \\ \text { GC } & \text { Gas Chromatography } \\ \text { HEPA } & \text { High-Efficiency Particulate Air Filter } \\ \text { HLW } & \text { High Level Waste } \\ \text { IC } & \text { Ion Chromatography } \\ \text { LAW } & \text { Low Activity Waste } \\ \text { M } & \text { Molarity } \\ \text { N } & \text { Normality } \\ \text { NIST } & \text { National Institute of Standards and Technology } \\ \text { NRI } & \text { Nuclear Research Institute, Czechoslovakia } \\ \text { ORP } & \text { Office of River Protection } \\ \text { PCT } & \text { Product Consistency Test } \\ \text { QA } & \text { Quality Assurance } \\ \text { QAPjP } & \text { Quality Assurance Project Plan for Testing Programs Generating Environmental Regulatory Data } \\ \text { QAPP } & \text { Quality Assurance Project Plan } \\ \text { RPP } & \text { River Protection Project } \\ \text { SEM } & \text { Scanning Electron Microscopy } \\ \text { SOP } & \text { Standard Operating Procedure } \\ \text { SRM } & \text { Standard Reference Material } \\ \text { TCLP } & \text { Toxicity Characteristic Leaching Procedure } \\ \text { VSL } & \text { Vitreous State Laboratory } \\ \text { WTP } & \text { Hanford Tank Waste Treatment and Immobilization Plant } \\ \text { XRD } & \text { X-ray Diffraction } \\ \text { XRF } & \text { X-Ray Fluorescence } \\ & \\ & \end{array}$




\section{SECTION 1.0 INTRODUCTION}

The radioactive tank waste treatment programs at the U. S. Department of Energy (DOE) have featured joule heated ceramic melter technology for the vitrification of high level waste (HLW) and that technology has also been selected for the Hanford Tank Waste Treatment and Immobilization Plant (WTP). The melter technology used at the West Valley Demonstration Project (WVDP) in New York and at the Defense Waste Processing Facility (DWPF) at the Savannah River Site (SRS) process(ed) HLW in ceramic melters at an operating temperature of $1150^{\circ} \mathrm{C}$. Those melter designs rely on natural convection in the viscous molten glass for melt pool mixing in order to provide heat and mass transport to and from the cold cap reaction zone. In advancing the technology, EnergySolutions/VSL have demonstrated on very large scale melters (EnergySolutions M-Area facility, WTP HLW pilot melter, and the WTP LAW pilot melter) that active mixing of the glass pool using EnergySolutions's patented bubbler technology increases heat and mass transport, which leads to significantly increased melt rates and reduced temperature gradients within the glass pool. In addition, the active melt pool mixing tends to promote the suspension of crystalline phases. The present WTP HLW melter design has a nominal operating temperature of $1150^{\circ} \mathrm{C}$ and incorporates an active glass bubbler system which provides improved glass production rate (up to 7.5 MT of glass per day for two HLW melters).

In addition to, and in parallel with improved melter design, enhanced glass formulations are being explored to increase waste loadings in HLW glasses. The waste loading for high-level nuclear waste streams at the WTP is typically limited by crystal formation because of the relatively high concentrations of elements such as $\mathrm{Fe}, \mathrm{Cr}, \mathrm{Ni}, \mathrm{Zr}, \mathrm{Al}, \mathrm{Bi}, \mathrm{P}$, etc., in the waste and their tendency to form crystalline phases. While the presence of crystalline phases seldom affects the quality of the glass product, it can present a significant processing concern since such phases can settle and accumulate in the melter, adversely affecting melter operations and ultimately reducing the life of the melter. For this reason, HLW glasses (e.g., DWPF and WVDP) have traditionally been designed to have a liquidus temperature that is lower than the nominal processing temperature by some target value. The liquidus temperature restriction is met by reducing waste loadings in glass (together with appropriately designed glass formulations), thus eliminating the risk of crystal formation. However, since the basic practical issue is crystal settling and accumulation, depending upon the crystal size and density, non-zero amounts of near-liquidus phases can often be maintained in suspension and, therefore, tolerated in bubbled melters. These considerations have led EnergySolutions/VSL to develop and implement an "operational liquidus" constraint in which a non-zero fraction of crystals is tolerated at a given temperature. Glasses designed for DuraMelter vitrification systems have employed a limit of $<1$ vol\% crystals at a reference temperature (typically $950^{\circ} \mathrm{C}$ ) below the operating temperature. Based on extensive testing and demonstration, this constraint has now been formally adopted for use at the Hanford WTP in place of the traditional, more conservative, liquidus-temperature constraint. Further increasing the amount of crystals allowable in the glass would further increase waste loadings and therefore further reduce waste treatment costs. The DOE Office of River Protection (ORP) has initiated a testing program to develop and characterize HLW glasses with 
increased waste loadings, with the results obtained clearly demonstrating the feasibility of HLW glasses with enhanced waste loading [1]. However, although it is presently expected that the actively mixed DuraMelter systems should be able to tolerate a larger amount of crystals than is the case for conventional melters, the maximum concentration of crystals such melter systems can tolerate is not yet known. This report describes results from work to support the development and testing of enhanced glass formulations to evaluate the possibility of further raising the tolerance for crystalline phases in the WTP HLW vitrification process in order to achieve increased waste loadings and HLW processing rates.

As described above, many of the WTP HLW waste streams contain high concentrations of elements such as $\mathrm{Fe}, \mathrm{Cr}$, and $\mathrm{Ni}$. There is, therefore, a high tendency to form crystalline phases of spinel and/or chromium oxide during processing of these wastes. The glass formulation work described here investigated glass compositions that exhibit formation of crystalline spinel and/or chromium oxide phases up to relatively high crystal contents (i.e., $>1 \mathrm{vol} \%$ ). In this regard, the work herein is complementary to and necessarily of a more exploratory nature than the work in support of the current WTP baseline, the glass formulations for which were designed to limit the amounts of crystallization to $<1 \mathrm{vol} \%$. It should be noted, therefore, that to the extent that the present effort is successful, considerable further work would be required to bring the level of confidence in the new glass composition regions to a similar level of maturity to that of the current WTP baseline. Additional testing in larger melters such as the DM1200 will be needed to confirm feed processing characteristics at larger scales. Additional testing at the crucible and melter scales will be needed to determine the robustness of the new compositions with respect to variations in the feed compositions that may result from process variations. Off-gas characteristics will have to be determined and data to support engineering and permitting requirements will need to be collected using a WTP prototypic off-gas system. Furthermore, since the high waste loading glass compositions are likely to be in a new composition space as compared to the current WTP compositions, additional effort will be required to develop and extend the current qualified glass composition region and supporting models to include these new compositions.

The present work was built on previous work performed at VSL for ORP to increase waste loading and processing rates for high-iron and high-chromium HLW waste streams $[1,2]$. Glass formulation work involving crucible melts and characterization of crucible glasses and DM100 melter testing was used to investigate the effects of increased crystallinity in HLW glass formulations on melter operations, waste processing rate, and product quality. DM100 tests were performed on five glass formulations that were designed to have crystal contents that exceed the current WTP upper processing limit $\left(<1 \mathrm{vol} \%\right.$ at $\left.950^{\circ} \mathrm{C}\right)$. Two tests were performed with spinel as the primary crystalline phase $\left(2.2\right.$ and $4.2 \mathrm{vol} \%$ at $\left.950^{\circ} \mathrm{C}\right)$; one test was performed with eskolaite $\left(2 \mathrm{vol} \%\right.$ at $\left.950^{\circ} \mathrm{C}\right)$; one test with a mixture of spinel and eskolaite $\left(4.2 \mathrm{vol} \%\right.$ at $\left.950^{\circ} \mathrm{C}\right)$; and one test was performed with addition of zinc to convert eskolaite to spinel $(1.6 \mathrm{vol} \%$ at $\left.950^{\circ} \mathrm{C}\right)$. A Test Plan was prepared for this work [3] in response to a statement of work provided by ORP [4]. 


\subsection{Test Objectives}

The principal objective of the work was to evaluate the effects of spinel and chromium oxide particles on WTP HLW melter operations and potential impacts on melter life. This was accomplished through a combination of crucible-scale tests, settling and rheological tests, and tests on the DM100 melter system. Crucible testing was designed to develop and identify HLW glass compositions with high waste loadings that exhibit formation of crystalline spinel and/or chromium oxide phases up to relatively high crystal contents (i.e., $>1$ vol\%). Characterization of crystal settling and the effects on melt rheology was performed on the HLW glass formulations. Appropriate candidate HLW glass formulations were selected, based on characterization results, to support subsequent melter tests. A secondary objective of this work was to measure the thermal conductivity, specific heat, and density of selected glasses over a range of temperatures from significantly below the glass transition temperature to significantly above it $\left(\approx 1000^{\circ} \mathrm{C}\right)$; these results will be reported separately with the crucible-scale crystal settling and rheology results.

Development of HLW glass formulations was based on earlier work performed for ORP [1]. In particular, glass formulations developed previously for wastes with high concentrations of aluminum and chromium were used as starting points (HLW glasses developed for high aluminum waste also showed crystallization of spinel). These earlier HLW glass formulations were supplemented by other HLW glasses tested previously, especially those designed for high-iron wastes [2], since they were also found to have waste loadings that were limited by spinel crystallization. Waste loadings were increased in these glasses until the desired amounts of crystalline spinel and/or chromium oxide phases resulted. Glass properties for evaluation included viscosity, electrical conductivity, crystallinity, glass phase separation, and the 7- day Product Consistency Test (PCT; ASTM-1285). Glass property limits were based upon the reference properties for the WTP HLW melter except for the WTP crystallinity limit $(<1 \mathrm{vol} \%$ at $950^{\circ} \mathrm{C}$ ); instead, in the present work, crucible melts were formulated that exhibit up to about 4.4 vol $\%$ crystallization.

Of the two DM100 systems available at VSL, the DM100-BL unit was selected for the present melter tests. The DM100-BL was used for previous tests on HLW glass compositions [5-11] that were used to support subsequent tests on the HLW Pilot Melter [10-18]. It was also used to process compositions with waste loadings limited by aluminum, bismuth, and chromium [1]; to investigate the volatility of cesium and technetium during the vitrification of an HLW AZ-102 composition [7]; to process glass formulations at compositional and property extremes $[8,9]$; and to investigate crystal settling on a composition that exhibited one percent crystals at $963^{\circ} \mathrm{C}$ (i.e., close to the WTP limit) [8]. The same melter was selected for the present tests in order to maintain comparisons between the previously collected data. The tests provided information on melter processing characteristics and off-gas data, including formation of secondary phases and crystal settling rates. 


\subsection{Quality Assurance}

This work was conducted under a quality assurance program that is based on NQA-1 (2000) and NQA-2a (1990) Part 2.7 and which is compliant with applicable criteria of 10 CFR 830.120; Office of Civilian Waste Management DOE/RW-0333P, Quality Assurance Requirements and Description (QARD) Revision 18; and DOE Order 414.1 C, Quality Assurance. This program is supplemented by a Quality Assurance Project Plan for RPP-WTP work [19] that is conducted at VSL. Test and procedure requirements by which the testing activities are planned and controlled are also defined in this plan. The program is supported by VSL standard operating procedures that were used for this work [20]. The requirements of DOE/RW-0333P were applicable to the following specific aspects of this work:

- Crucible melt preparation

- Analysis of crucible melt glasses

- PCT

\subsection{DM100 Melter Systems}

\subsubsection{D100 Feed System}

A schematic diagram of the DM100 vitrification system is shown in Figure 1.1. The melter feed is introduced in batches into a feed container that is mounted on a load cell for weight monitoring. The feed is stirred with a variable speed mixer and constantly recirculated except for periodic, momentary interruptions during which the weight is recorded. Feed is normally introduced into the melter via a system designed to mimic the operation of an ADS pump, which is the present WTP baseline; however, a peristaltic pump was used in these tests to facilitate observations of any differences in processing rates and feed behavior. In this system, a recirculation loop extends to the top of the melter where feed is diverted from the recirculation loop to the peristaltic pump and subsequently into the melter through a Teflon-lined feed line and water-cooled, vertical feed tube.

\subsubsection{Melter System}

Cross-sectional diagrams of the DM100-BL melter are shown in Figures 1.2.a-c. The DM100-BL unit is a ceramic refractory-lined melter fitted with a total of five electrodes: two pairs of opposing Inconel 690 plate electrodes and a bottom electrode. Power can be supplied in either three-phase or single-phase configurations. All of the tests in the present work were performed with the upper and lower electrodes on each side connected together and powered by a single-phase supply; the bottom electrode was not powered. Melt pool agitation is achieved by either a removable lance entering from the top of the melter or a permanent bubbler installed through the bottom electrode. In these tests the lance bubbler was used. The glass product is removed from the melter by means of an airlift discharge system. The melter has a melt surface area of $0.108 \mathrm{~m}^{2}$ and a variable glass inventory of between $110 \mathrm{~kg}$, when only the bottom pair of 
electrodes is used and about $170 \mathrm{~kg}$ when both pairs of electrodes are used, which was the case in the present tests.

\subsubsection{Off-Gas System}

For operational simplicity, the DM100-BL is equipped with a dry off-gas treatment system involving gas filtration operations only. Exhaust gases leave the melter plenum through a film cooler device that minimizes the formation of solid deposits. The film-cooler air has constant flow rate and its temperature is thermostatically controlled. Consequently, under steady-state operating conditions, the exhaust gases passing through the transition line (between the melter and the first filtration device) can be sampled at constant temperature and airflow rate. The geometry of the transition line conforms to the requirements of the 40-CFR-60 air sampling techniques. Immediately downstream of the transition line are cyclonic filters followed by conventional pre-filters and HEPA filters. The temperature of the cyclonic filters is maintained above $150^{\circ} \mathrm{C}$ while the temperatures in the HEPAs are kept sufficiently high to prevent moisture condensation. The entire train of gas filtration operations is duplicated and each train is used alternately. An induced draft fan completes the system.

\subsection{Feed Sample Analysis}

Feed samples were taken directly from the feed recirculation line during each test. Feed samples were poured into a platinum/gold crucible that was placed into a programmed furnace for drying and fusion to form a glass. The glass produced from this fusion was ground to less than 200 mesh and sealed in 20-ml vials for subsequent analysis by X-ray fluorescence spectroscopy (XRF), or by acid digestion followed by direct-current plasma atomic emission spectroscopy (DCP-AES) on the resulting solution. The feed samples were also characterized for their rheological properties, density, $\mathrm{pH}$, water content, and glass yield.

\subsection{Glass Product Analysis}

The glass product is discharged from the melter into 5-gallon steel pails periodically using an air-lift system. The discharged product glass was sampled at the end of each test by removing sufficient glass from the top of the cans for compositional analysis and secondary phase determinations. In addition, the Product Consistency Test (PCT; 7 days at $90^{\circ} \mathrm{C}$ ) and Toxicity Characteristic Leaching Procedure (TCLP) were performed on samples of the glass product from the DM100 melter tests. Prior to those tests, the PCT and TCLP were also performed on the crucible melt compositions that were selected for the melter tests to ensure their compliance with the present WTP contract requirements. All of these procedures are routinely conducted at VSL and, therefore, standard operating procedures (SOPs) are in place. 


\subsubsection{Composition}

Sample preparation for chemical analysis typically involves size reduction and sieving. All samples were subjected to XRF to determine the concentration of all elements except boron and lithium. The XRF method for fluorine is a separate procedure using a polished solid monolith as opposed to the less than 200 mesh glass powders used for analysis of all other elements. A series of National Institute of Standards and Technology (NIST) reference materials were used for confirmation of the XRF data. Boron and lithium were determined by total acid dissolution of ground glass samples in $\mathrm{HF} / \mathrm{HNO}_{3}$ and subjecting the resulting solutions to DCPAES analysis.

\subsubsection{Viscosity}

The melt viscosity, $\eta$, is measured using a Brookfield viscometer. Measurements are performed in the temperature range of $950-1250^{\circ} \mathrm{C}$ and the data are interpolated to standard temperatures using the Vogel-Fulcher equation: $\ln \eta=\left[\mathrm{A} /\left(\mathrm{T}-\mathrm{T}_{\mathrm{o}}\right)\right]+\mathrm{B}$, where $\mathrm{A}, \mathrm{B}$, and $\mathrm{T}_{\mathrm{o}}$ are fitting parameters. The equipment is calibrated at room temperature using standard oils of known viscosity and then checked at $950-1250^{\circ} \mathrm{C}$ using a NIST standard reference glass (SRM 711). Both precision and accuracy of the viscosity measurements are estimated to be within \pm 15 relative $\%$.

\subsubsection{Electrical Conductivity}

The electrical conductivity, $\sigma$, of each glass melt is determined by measuring the resistance of the glass melt as a function of frequency using a calibrated platinum/rhodium electrode probe attached to a Hewlett-Packard model 4194A impedance analyzer. Measurements are performed over similar temperature ranges to those employed for the melt viscosity measurements. The results are analyzed and modeled to obtain the DC electrical conductivity. The electrical conductivity data are then interpolated to standard temperatures using the VogelFulcher equation: $\ln \sigma=\left[\mathrm{A} /\left(\mathrm{T}-\mathrm{T}_{\mathrm{o}}\right)\right]+\mathrm{B}$, where $\mathrm{A}, \mathrm{B}$ and $\mathrm{T}_{\mathrm{o}}$ are fitting parameters. Estimated uncertainties in the electrical conductivity measurements are \pm 20 relative $\%$.

\subsubsection{Product Consistency Test (PCT)}

The product consistency test (PCT; ASTM C 1285) is used to evaluate the relative chemical durability of glasses by measuring the concentrations of the chemical species released from 100-200 mesh crushed glass $(75-149 \mu \mathrm{m})$ to the test solution (de-ionized water in this case). PCT tests on the HLW glasses are performed at $90^{\circ} \mathrm{C}$, in accordance with the current WTP contract requirement. The ratio of the glass surface area to the solution volume for this test is about $2000 \mathrm{~m}^{-1}$ (typically, $10 \mathrm{~g}$ of 100-200 mesh glass is immersed in $100 \mathrm{ml}$ deionized water). All tests are conducted in triplicate, in 304L stainless steel vessels, and in parallel with a standard glass included in each test set. The internal standard is the Argonne National Laboratory - Low Activity Waste Reference Material (ANL-LRM) reference glass [21] and/or the Defense Waste 
Processing Facility - Environmental Assessment (DWPF-EA) glass, both of which have undergone round-robin testing. The leachates are sampled at predetermined times, the first of which is seven days. One milliliter of sampled leachate is mixed with $20 \mathrm{ml}$ of $1 \mathrm{M} \mathrm{HNO}_{3}$ and the resulting solution is analyzed by DCP-AES; another $3 \mathrm{ml}$ of sampled leachate is used for $\mathrm{pH}$ measurement.

\subsubsection{Toxicity Characteristic Leaching Procedure (TCLP)}

The TCLP tests were performed at VSL using SW-846 Method 1311, which employs leaching of crushed glass $\left(<3 / 8\right.$ ") in a sodium acetate buffer solution for 18 hours at $22^{\circ} \mathrm{C}$ with constant end-over-end agitation. A mass of about 100 grams of glass is leached in 2 liters of TCLP extract, according to the extraction method for non-volatiles. The surface area to volume ratio for this test is about $20 \mathrm{~m}^{-1}$, which is about two orders of magnitude lower than that in the PCT. The leachates are analyzed by DCP-AES according to VSL standard operating procedures.

\subsubsection{Secondary Phases}

Secondary phases in the glass samples were determined by optical microscopy and scanning electron microscopy (SEM) coupled with energy dispersive x-ray spectroscopy (EDS). Secondary phases due to crystallization and phase separation can be identified using these methods. Quantitative determination of the amount and type of crystals in glass samples was made by SEM in conjunction with image analysis. 


\section{SECTION 2.0 \\ FORMULATION OF HLW GLASSES AND MELTER FEEDS}

The primary objective of the glass formulation work was to develop and identify highwaste-loading glass compositions that exhibit crystallization of (i) spinel, (ii) chromium oxide (eskolaite), and (iii) a mixture of spinel and chromium oxide phases over a range of relatively high crystal contents $(>1 \mathrm{vol} \%$ ). Characterization of the formulated glasses provided the data required in the selection of target glass compositions subsequently used in five DM100 melter tests. Previously developed HLW glass formulations with high waste loadings were used as references in the present work [1]. Formulation of these earlier glasses was based on waste compositions provided by ORP; waste loadings in the formulated glasses for each of these wastes were limited by different components (i.e., $\mathrm{Bi}, \mathrm{Cr}, \mathrm{Al}$, and $\mathrm{Al} / \mathrm{Na}$ ). In the present context, the Al- and Cr-limited wastes and the associated HLW glasses from earlier testing formed the bases for glass formulation development. Another starting point for glass formulation development was an Fe-limited waste stream based on the HLW composition found in Hanford Tank AZ-102 and the associated glasses. This waste stream has been studied previously at the VSL to examine increased waste loadings [2].

After identification of target glass compositions to support DM100 melter tests, additional glass formulation work was performed to study the impacts of noble metals on crystallization in selected glasses and to study the behavior of chromium phase in HLW glasses, with an emphasis on increasing the incorporation of chromium.

This section also describes the compositions of the melter feeds, which were formulated to support the DM100 melter tests after the target glass compositions were identified.

\subsection{HLW Glasses Crystallizing Spinel}

The oxide composition of the Al-limited waste provided by ORP [4] contains considerable amounts of $\mathrm{Fe}_{2} \mathrm{O}_{3}$ and $\mathrm{Cr}_{2} \mathrm{O}_{3}$, in addition to the high concentration of $\mathrm{Al}_{2} \mathrm{O}_{3}$. All three oxides are major spinel-forming components. A review of the data for the $30 \mathrm{HLW}$ glass formulations tested for this waste reveals that the majority of them contained undissolved crystalline phases in the as-melted glass [1]. Heat treatment of 18 glasses (from $800^{\circ} \mathrm{C}$ to $950^{\circ} \mathrm{C}$ ) resulted in spinel crystallization in all cases, although it should be noted that spinel was not the most abundant phase in some cases. The waste loadings of these 30 glasses range from $35 \mathrm{wt} \%$ to $55 \mathrm{wt} \%$ (waste oxide basis). From the thirty Al-limited glasses tested, the formulation HLW-E-Al-27 was selected to support an earlier melter test [1]. This glass was chosen as the reference starting composition for the development of glasses that exhibit spinel crystallization since it has properties that meet all relevant processing and product quality requirements. Tables 2.1 and 2.2 present, respectively, the compositions of the Al-limited waste and HLW-E-Al-27 glass. This glass has a waste loading of $45 \mathrm{wt} \%$ and forms spinel and other phases upon heat treatment, ranging in concentration from $1.0 \mathrm{vol} \%$ at $950^{\circ} \mathrm{C}$ to $7.2 \mathrm{vol} \%$ at $800^{\circ} \mathrm{C}$. 
Three glasses were formulated by increasing the waste loading and decreasing the amount of glass former additives in HLW-E-Al-27, while maintaining the same relative ratios of glass forming oxides added: HLW-E-SP-01 (waste loading $48 \mathrm{wt} \%$ ), HLW-E-SP-02 (51 wt\%), and HLW-E-SP-03 (54 wt\%). Table 2.3 gives the compositions of these three glasses. Tables 2.4 and 2.5 present, respectively, the compositions, as analyzed by XRF, and measured properties of the glasses. As seen in Table 2.3, these glasses contain high concentrations of $\mathrm{Al}_{2} \mathrm{O}_{3}(25.57 \mathrm{wt} \%$ to $28.77 \mathrm{wt} \%)$, with moderate amounts of $\mathrm{Fe}_{2} \mathrm{O}_{3}(\approx 7 \mathrm{wt} \%)$ and $\mathrm{Cr}_{2} \mathrm{O}_{3}(\approx 0.6 \mathrm{wt} \%)$. As expected, all three glasses showed heavier crystallization after heat treatment for 70 hours at $850^{\circ} \mathrm{C}$ to $1150^{\circ} \mathrm{C}$ than found in HLW-E-Al-27. For example, glasses heat-treated at $950^{\circ} \mathrm{C}$ resulted in 2.4 vol $\%$ crystals in HLW-E-SP-01 to 4.7 vol\% in HLW-E-SP-03, compared with $1 \mathrm{vol} \%$ of crystals for $\mathrm{HLW}-\mathrm{E}-\mathrm{Al}-27$. For heat treatment temperatures at or above $1050^{\circ} \mathrm{C}$, spinel was the only crystalline phase observed. However, crystals of calcium phosphate (apatite) were also found in samples heat treated at lower temperatures. The proportion of apatite crystals apparently increased with decreasing heat treatment temperatures, approaching 40 relative $\%$ of the total crystal volume at $850^{\circ} \mathrm{C}$. It was, therefore, determined that these glasses would not be suitable candidates for melter testing.

Because of the crystallization of the calcium phosphate phase, progressively increasing the waste loading in the reference formulation HLW-E-Al-27 did not result in the appropriate target glass and, therefore, the glass formulation strategy was changed. The new options considered included (i) minimizing formation of the phosphate phase by reducing the concentration(s) of $\mathrm{P}_{2} \mathrm{O}_{5}$ and/or $\mathrm{CaO}$ in the glass and (ii) adopting a different reference starting glass formulation before varying the waste loadings. Since the concentrations of $\mathrm{P}_{2} \mathrm{O}_{5}$ and $\mathrm{CaO}$ in HLW-E-SP-01 through HLW-E-SP -03 are not uncommon for typical HLW glasses, the second option was pursued. The new reference starting glass formulation was INEL-HLW-B10. This glass was developed and tested for the high-iron waste found in Hanford Tank AZ-102 [2]. Compared to the ORP Al-limited waste, the AZ-102 waste has a much higher concentration of $\mathrm{Fe}_{2} \mathrm{O}_{3}$ but lower concentrations of $\mathrm{Cr}_{2} \mathrm{O}_{3}, \mathrm{CaO}$ and $\mathrm{P}_{2} \mathrm{O}_{5}$, providing a reduced likelihood of apatite formation. Tables 2.1 and 2.2 list the compositions of the AZ-102 waste and INEL-HLWB10 glass, respectively. With a waste loading of $38.73 \mathrm{wt} \%$, this glass showed spinel crystallization of $4.6 \mathrm{vol} \%$ after heat treatment at $900^{\circ} \mathrm{C}$ for 70 hours.

Four glasses were formulated with waste loadings ranging from $32.73 \mathrm{wt} \%$ to $41.23 \mathrm{wt} \%$ that bracketed the target of $38.73 \mathrm{wt} \%$. Instead of maintaining the same relative proportions of glass forming oxides added in these formulations, they were actively varied in order to achieve processable viscosity for the glass melts $\left(10-150 \mathrm{P}\right.$ at $\left.1100^{\circ} \mathrm{C}\right)$. This was necessary because the glass INEL-HLW-B10 was designed to be tested at higher temperatures (up to $1225^{\circ} \mathrm{C}$ ) than the current melter tests $\left(1150^{\circ} \mathrm{C}\right)$. The resulting glass compositions, HLW-E-SP-04 through HLW-E-SP-07, are given in Table 2.3. Heat treatment of these glasses resulted in crystallization of spinel only, with no calcium phosphate phase observed. A typical electron micrograph of heat-treated samples of these glasses is shown in Figure 2.1. In general, the amounts of crystallization increased with increasing waste loading. Figure 2.2 graphically presents the amount of crystals as a function of heat treatment temperature. Both HLW-E-SP-05 and HLW-E-SP-06 showed more than 2 vol\% spinel crystals after heat treatment at $950^{\circ} \mathrm{C}$; they were characterized further with respect to processability and product quality, the data for which are 
given in Table 2.5. During viscosity measurements of these glasses, suspended crystalline phases were observed in the glass melts, and the measurements showed significant deviations from a Newtonian fluid. Consequently, fitting of the viscosity data using the Vogel-Fulcher equation was not performed and the data are reported for a selected shear rate $(1.51 / \mathrm{s})$ at the measurement temperatures. (The rheological properties and settling behavior of these glass melts will be discussed in a separate report.) This can be compared with HLW-E-SP-07, which showed the least crystallization and no significant deviations from Newtonian behavior during viscosity measurements. The normalized 7-day PCT releases of both HLW-E-SP-05 and HLW-E-SP-06 are all well below those for the benchmark DWPF-EA glass (16.695 g/1 (B), 9.565 (Li), and $13.346(\mathrm{Na})$ ). Based on these data, HLW-E-SP-06 was selected as the target glass composition for melter test 1, and HLW-E-SP-05 for melter test 2.

Three additional glasses in the HLW-E-SP series were formulated and characterized. The glass HLW-E-SP-08 was formulated to support the measurements of thermal conductivity and diffusivity of HLW glasses. It was formulated with a considerably lower waste loading of $26.73 \%$ in order to minimize spinel crystallization. As expected, all heat-treated samples of this glass showed no spinel formation (Table 2.5). Ultimately, however, this glass was not used for measurements of thermal conductivity and diffusivity because of the relatively large amount of sample required. A separate report will discuss the measurements of thermal conductivity and diffusivity of HLW glasses.

The final two glasses in the series, HLW-E-SP-09 and HLW-E-SP-10 were, respectively, formulated with addition of noble metals to HLW-E-SP-06 and HLW-E-SP-05 to investigate their effects on the phase stability of the glasses. The concentrations of noble metals added were based on glass formulations previously developed for an actual Hanford waste sample (C-106/AY-102) and were about twice the anticipated concentrations in the actual waste [22]. Since the primary objective of testing these glasses was to determine the effects of the noble metals on crystallization, they were added during glass batching as a solution, which consisted of $\mathrm{Pd}, \mathrm{Rh}$, and $\mathrm{Ru}$ in nitric acid. Addition of the noble metals as a solution instead of as a solid was found to aid in their dispersion in the glass. Table 2.5 gives the heat-treatment data for HLW-E-SP-09 and HLW-E-SP-10. It is seen that the presence of noble metals noticeably increased spinel crystallization, especially in the glass with lower waste loading (HLW-E-SP-06). There were no substantial differences, however, in the observed particle sizes of the spinel crystals.

\subsection{HLW Glasses Crystallizing Chromium Oxide}

The presence of chromium in HLW glasses increases the liquidus temperature and the formation of crystalline phases, thereby reducing the achievable waste loadings. The most common Cr-containing phase encountered in HLW glasses is spinel. All glasses previously prepared for the Cr-limited waste did not result in any crystallization of pure chromium oxide [1]. To meet the objective of formulating glasses that exhibit chromium oxide crystallization, it was expected that, in addition to increasing the waste loading, significant changes in the waste/glass compositions would be required. The reference starting glass composition was HLW-E-Cr-10, which has a waste loading of $40 \mathrm{wt} \%$ and a moderately high $\mathrm{Cr}_{2} \mathrm{O}_{3}$ content of 
$1.33 \mathrm{wt} \%$ (Table 2.2). Upon heat treatment, this glass crystallized spinel as the primary phase [1]. In order to suppress spinel formation, divalent metals (i.e., $\mathrm{Ni}$ and $\mathrm{Zn}$ ) were removed from the reference waste/glass compositions in formulating the current test glasses (HLW-E-ES series). Furthermore, sulfur was removed in order to minimize the formation of a sulfate/chromate-rich salt layer during glass melting [1]. With these modifications to the waste/glass compositions, HLW-E-ES-01 was formulated by increasing the waste loading in HLW-E-Cr-10 to $44 \mathrm{wt} \%$. Additional glasses, HLW-E-ES-02 through HLW-E-ES-04, were formulated with stepwise increases in $\mathrm{Cr}_{2} \mathrm{O}_{3}$ (to $6 \mathrm{wt} \%$ ) in HLW-E-ES-01, with renormalization of the other oxide components. Tables 2.6 and 2.7, respectively, present the target and analyzed compositions of these glasses. Table 2.8 summarizes the measured properties of the glasses.

In the absence of divalent spinel-forming components, heat-treated samples of all four glasses showed chromium oxide (eskolaite) as the only crystalline phase; spinel was not observed. While the morphology of the chromium oxide crystals was distinctly different from that of spinel crystals, they typically incorporated a small amount of iron. Figure 2.3 is a micrograph showing that the chromium oxide crystals appear as elongated platelets, with an average dimension of about $20 \mu \mathrm{m}$. The identity of the crystals was further confirmed by x-ray diffraction (Figure 2.4). The amounts of crystallization varied from $0.3 \mathrm{vol} \%$ to over $5 \mathrm{vol} \%$, with a fairly uniform increase in crystal content with the increase in waste loadings. Figure 2.5 shows the crystallization data as a function of heat treatment temperature. The amounts of crystals in most glasses showed a general increasing trend with temperature, in direct contrast with the decreasing trend found for spinel in the HLW-E-SP series of glasses (see Figure 2.2). This unusual temperature effect on crystallization of chromium oxide crystals (in high-chromium glasses) is well known and can be explained by the shift in redox equilibrium whereby trivalent chromium species ( $\mathrm{Cr}(\mathrm{III})$ ) is oxidized to hexavalent chromium $(\mathrm{Cr}(\mathrm{VI}))$ as the temperature decreases, which results in an increase in chromium solubility in the borosilicate glass [23-25]. Since glasses with high optical basicity also favor the formation of $\mathrm{Cr}(\mathrm{VI})$, the combination of high optical basicity and lower melting temperatures has been suggested as a possible approach to developing HLW glasses with high chromium concentration (about $2 \mathrm{wt} \% \mathrm{Cr}_{2} \mathrm{O}_{3}$ ) for wastes that do not contain high concentrations of other spinel-forming components.

Although the amounts of crystallization found in HLW-E-ES-02 and HLW-E-ES-03 were suitable for melter testing, the viscosity data measured for HLW-E-ES-02 was deemed too high (Table 2.8). The composition of HLW-E-ES-03 is similar to that of HLW-E-ES-02 and, therefore, its viscosity also is likely to be too high for melter testing. Therefore, two more glasses were formulated to identify a better candidate for melter testing. The glass HLW-E-ES-05 was based on HLW-E-ES-02 but contained lower $\mathrm{Al}_{2} \mathrm{O}_{3}$ and $\mathrm{SiO}_{2}$ but increased alkalis and $\mathrm{B}_{2} \mathrm{O}_{3}$, while HLW-E-ES-06 was based on the reference glass HLW-E-Cr-10 but with increased $\mathrm{Cr}_{2} \mathrm{O}_{3}$ ( $3 \mathrm{wt} \%$ ) and without $\mathrm{SO}_{3}$ and divalent metals. Heat treatment of HLW-E-ES-05 and HLW-E-ES06 resulted in eskolaite crystallization of about $1.5 \mathrm{vol} \%$, which is comparable to that found for HLW-E-ES-02, while the viscosity data collected for HLW-E-ES-05 appeared to be more suited for melter tests; it was therefore selected as the target formulation for melter testing.

The effects of chromium on crystallization in HLW glasses have been reported primarily for the spinel phase. The role of chromium as a nucleating agent in precipitating spinel and its effect on crystal size have been discussed [26]. In the current tests, different starting materials for 
chromium addition were used in crucible melts (and re-melts of selected formulations, which were required to provide sufficient glass samples for settling and rheology tests). These included chromium (III) oxide, chromate salts, and aqueous solution of chromium. No evidence was found to suggest that eskolaite crystallization was affected by the starting chemical form of chromium. Moreover, addition of noble metals in HLW-E-ES-14 (which was formulated by adding $\mathrm{PdO}, \mathrm{Rh}_{2} \mathrm{O}_{3}$, and $\mathrm{RuO}_{2}$ to HLW-E-ES-05, at the same concentrations as those used in the HLW-E-SP glasses) also did not result in significant changes in crystallization behavior for HLW-E-ES-05 (Table 2.8).

The HLW-E-ES series includes 10 other glasses with high $\mathrm{Cr}_{2} \mathrm{O}_{3}$ concentrations. These glasses were formulated and tested after selection of the target glass for melter tests, and were used to investigate chromium solubility in HLW glasses.

Chromium has limited solubility in borosilicate glasses. Glasses with $4 \mathrm{wt} \%$ of $\mathrm{Cr}_{2} \mathrm{O}_{3}$ have been prepared by the Nuclear Research Institute (NRI) in the Czech Republic as a fluorescence spectroscopy standard [25]. However, those glasses were made with high alkali concentrations and melted at high temperature $\left(>1500^{\circ} \mathrm{C}\right)$. Further, no durability and other measurements of properties important to nuclear waste disposal were made on these glasses. Based on many other studies of nuclear waste glasses (e.g., Composition Variation Study at Pacific Northwest National Laboratory), a more practical solubility limit of $<2 \mathrm{wt} \%$ is expected for $\mathrm{Cr}_{2} \mathrm{O}_{3}[1,23-25,27,28]$.

Addition of $\mathrm{TiO}_{2}$ and $\mathrm{B}_{2} \mathrm{O}_{3}$ has been reported to increase the incorporation of $\mathrm{Cr}$ into glass [29, 30]. The use of $\mathrm{B}_{2} \mathrm{O}_{3}$ as an additive in the formulation of high-chromium glasses at VSL has previously been reported [1]. For the present work, five glasses with relatively high concentrations $(>5.0 \mathrm{wt} \%)$ of $\mathrm{TiO}_{2}$ as additive were prepared and tested. The glass HLW-E-ES-C16 is identical in composition to the C16 glass, a high-chromium $(2.85 \mathrm{wt} \%)$ glass prepared at the NRI; no crystallization behavior has been reported for the NRI glass. Another version of $\mathrm{C} 16$ was prepared with the addition of divalent metals (HLW-E-ES-08). The other 3 glasses prepared (HLW-E-ES-09, HLW-E-ES-11, and HLW-E-ES-12) were based on either the reference glass HLW-E-Cr-10 $\left(\mathrm{Cr}_{2} \mathrm{O}_{3}=1.33 \mathrm{wt} \%\right)$ or HLW-E-ES-07 $\left(\mathrm{Cr}_{2} \mathrm{O}_{3}=3.00 \mathrm{wt} \%\right)$. Isothermal heat treatment resulted in substantial crystallization of spinel and/or eskolaite for all five glasses (see Table 2.8). These results suggest that $\mathrm{TiO}_{2}$ does not appear to be beneficial to chromium incorporation in the glasses studied, especially when compared to $\mathrm{K}_{2} \mathrm{O}$ as an additive. For example, HLW-E-ES-09, which is identical to HLW-E-Cr-10 except for the substitution of $5.25 \mathrm{wt} \% \mathrm{TiO}_{2}$ for $\mathrm{K}_{2} \mathrm{O}$, showed 2 vol\% of spinel crystals after heat treatment at $950^{\circ} \mathrm{C}$, which can be compared with 0.6 vol\% spinel found for a heat-treated sample of HLW-E-Cr-10. A comparison of HLW-E-ES-12 with HLW-E-ES-07 results in a similar conclusion: partial replacement of $\mathrm{B}_{2} \mathrm{O}_{3}$ and $\mathrm{SiO}_{2}$ in HLW-E-ES-07 with $\mathrm{TiO}_{2}$ did not noticeably change the amounts of crystallization during heat treatment.

In addition to temperature, basicity of the glass melt is important to the $\mathrm{Cr}(\mathrm{III}) / \mathrm{Cr}$ (VI) equilibrium. Increased basicity of silicate glass melts favor $\mathrm{Cr}(\mathrm{VI})$, while acidic glasses favor $\mathrm{Cr}$ (III) [31]. In terms of relative basicity of glass melts, the following trend has been observed: $\mathrm{K}_{2} \mathrm{O}>\mathrm{Na}_{2} \mathrm{O}>\mathrm{BaO}>\mathrm{Li}_{2} \mathrm{O}>\mathrm{SrO}>\mathrm{CaO}$ [32]. Previous formulation work for Cr-limited waste at VSL that employed $\mathrm{K}_{2} \mathrm{O}$ suggested that it is a beneficial additive [1], but its use was limited by the 
formation of a sulfate/chromate-rich salt layer. The glasses HLW-E-ES-07, HLW-E-ES-10, and HLW-E-ES-13 were formulated with high concentrations of $\mathrm{K}_{2} \mathrm{O}(>10 \mathrm{wt} \%)$. The minor component $\mathrm{SO}_{3}$ was removed from these formulations to minimize the formation of a salt layer, while the $\mathrm{Cr}_{2} \mathrm{O}_{3}$ content $(>1.9 \mathrm{wt} \%)$ was higher than that in the reference glass HLW-E-Cr-10. As seen in Tables 2.6 and 2.8, high concentrations of $\mathrm{K}_{2} \mathrm{O}(15.25 \mathrm{wt} \%)$ and $\mathrm{Cr}_{2} \mathrm{O}_{3}(3.00 \mathrm{wt} \%)$ resulted in the formation of a chromate salt layer in HLW-E-ES-10, even in the absence of $\mathrm{SO}_{3}$, while lower $\mathrm{K}_{2} \mathrm{O}$ did not appreciably reduce crystallization of chromium-containing phases.

The last two glasses formulated for the series (HLW-E-ES-15 and HLW-E-ES-16) contained $\mathrm{CaO}$ as an additive (HLW-E-ES-16 also included $\mathrm{TiO}_{2}$ ), again using HLWE-Cr-10 as a starting point. Addition of $\mathrm{CaO}$ increases acidity of the glass melt [29], which in turn favors formation of $\mathrm{Cr}$ (III) over $\mathrm{Cr}(\mathrm{VI})$ [31]. Both glasses formed a calcium phosphate phase upon heat treatment, in addition to spinel and eskolaite. The amounts of $\mathrm{Cr}$-containing crystals in heat treated samples of these glasses did not show appreciable differences from those in heated treated HLW-E-CR-10 glass samples.

\subsection{HLW Glasses Crystallizing Spinel and Chromium Oxide}

A third series of HLW glasses was formulated and tested to identify compositions that precipitate both spinel and chromium oxide. Since chromium is the major constituent in both of these crystalline phases, the Cr-limited waste and the HLW-E-ES series of glasses were used as the starting point.

The series of glasses formulated to study crystallization of both spinel and chromium oxide was designated as HLW-E-M. Tables 2.9 and 2.10 present the target and analyzed compositions of the HLW-E-M glasses, respectively. Table 2.11 provides the formulation basis and the characterization data. The strategy of formulating HLW-E-M glasses involved addition of various amounts of divalent metals to selected glasses from the HLW-E-ES series. The divalent metals added were nickel and manganese. X-ray spectroscopy studies have shown manganese to exist mainly in the divalent state (i.e., MnO) in HLW glasses [33]. The concentrations of added $\mathrm{NiO}$ and $\mathrm{MnO}$ ranged from $0.5 \mathrm{wt} \%$ to $1.2 \mathrm{wt} \%$, and were typically lower than those of divalent metals in the HLW-E-SP glasses, while the concentrations of $\mathrm{Cr}_{2} \mathrm{O}_{3}$ varied from $1.5 \mathrm{wt} \%$ to $4.5 \mathrm{wt} \%$. Heat treatment of the prepared glasses (HLW-E-M-01 through HLW-E-M-07) in all cases resulted in the crystallization of both spinel and chromium oxide. Figure 2.6 is an example of the crystalline phases observed. The total amounts of crystalline phases showed a general dependence on the concentrations of $\mathrm{Cr}_{2} \mathrm{O}_{3}, \mathrm{MnO}$, and $\mathrm{NiO}$. The relative amounts of the two crystalline phases varied according to the heat treatment temperature, following the same temperature-vol\% relationships seen in the other two series of glasses. Figure 2.7 provides two examples of the observed trend: the amount of chromium oxide phase increased relative to the spinel phase as the temperature increased; at temperatures $\geq 1150^{\circ} \mathrm{C}$, only chromium oxide was observed. HLW-E-M-03 was selected as the target glass composition for melter testing after further characterization of the glass sample with respect to melt viscosity and electrical conductivity. PCT was also performed using HLW-E-M-03; its leaching performance was significantly better than that of the reference DWPF-EA glass (Table 2.11). 
Additional glasses were formulated for this series (HLW-E-M-08 through HLW-E-M-13) with the addition of $\mathrm{ZnO}$ as the divalent metal to selected HLW-E-ES glasses. Zinc oxide is typically not a major component in HLW compositions (e.g., Hanford tank waste) but has been used extensively as a glass forming additive in WTP HLW (and LAW) glass formulations developed at VSL [5-15]. As a result, $\mathrm{ZnO}$ is one of the baseline glass forming chemicals (GFCs) that is already available in the WTP GFC addition system design. In the present context, addition of $\mathrm{ZnO}$ in the vitrification of high-chromium waste is of interest because it offers the potential to replace eskolaite as the liquidus phase by a zinc-based spinel; the resulting spinel crystals are smaller in size and more compact, which tends to facilitate their suspension in the glass-melt. Thus, addition of $\mathrm{ZnO}$ may have advantages for the vitrification of high-chromium wastes, and especially those that are low in spinel-forming divalent species. The concentrations of $\mathrm{ZnO}$ added varied from $1.5 \mathrm{wt} \%$ to $4.5 \mathrm{wt} \%$. Heat treatment data for HLW-E-M-08 through HLW-E-M-13 showed that, with the addition of zinc, spinel was the only crystalline phase formed (Table 2.11), highlighting its effectiveness in converting eskolaite to spinel. Interestingly, HLW-E-M-11, which is identical in composition to HLW-E-M-03 except for a weight-for-weight replacement of $\mathrm{MnO}$ and $\mathrm{NiO}$ by $\mathrm{ZnO}$, showed only spinel, whereas HLW-E-M-03 showed both spinel and eskolaite with eskolaite being the dominant phase at high temperature. The amounts of spinel crystals found in these glasses, which were rich in $\mathrm{Cr}$ and $\mathrm{Zn}$, ranged from $1.5 \mathrm{vol} \%$ to $4.2 \mathrm{vol} \%$. Moreover, the particle size of the spinel crystals observed in heat treated glasses with $\mathrm{ZnO}$ added (HLW-E-M-08 through HLW-E-M-13) was generally smaller than those found in other glasses in this series and significantly smaller than for those forming eskolaite. The glass HLW-E-M-09, which was formulated by adding $1.5 \mathrm{wt} \%$ of $\mathrm{ZnO}$ to the glass HLW-E-ES-05, followed by renormalization, was selected for melter testing.

Figure 2.8 shows the crystallization characteristics of the two glasses selected for melter tests, HLW-E-M-03 and HLW-E-M-03-09, as a function of heat treatment temperature.

\section{$2.4 \quad$ Formulation of Melter Feeds}

Table 2.12 summarizes the selection of target glasses to support the melter runs. The glass compositions selected for Tests 1 and 2 are based on the Fe-limited waste while the other three glasses are based on the Cr-limited waste (Table 2.1). Formulation of the HLW feeds for melter testing normally begins with the definition of the waste compositions. In the current work, adjustments were made to the reference waste compositions in Table 2.1 in order to produce the desired crystallization behavior in the HLW glasses, resulting in new waste compositions that are artificially high in selected components (e.g., $\mathrm{Cr}_{2} \mathrm{O}_{3}$ ). The new waste compositions, which are still quite comparable to the starting waste compositions, formed the bases for formulating melter feeds.

For each of the five melter tests, information on the waste composition and glass forming additives (in oxide wt $\%$ ) are given in Tables 2.13, 2.15, 2.17, 2.19, and 2.21. Concentrations of volatile components in the wastes (i.e., carbonate, nitrite, nitrate, and organic carbon) are assumed to be the same as those found for the Hanford AZ-102 HLW waste [15]. Chemical compositions of the melter feeds are given in Tables 2.14, 2.16, 2.18, 2.20, and 2.22. To the extent possible, all melter feeds made use of the same chemicals for the waste components, 
which primarily consisted of oxides and hydroxides, and the same glass forming additives. Finally, for comparison with results from earlier melter tests, the water content was adjusted to produce a target glass yield of $500 \mathrm{~g}$ glass per liter of melter feed for each test.

All melter feeds were prepared by NOAH Technologies, Inc. according to feed recipes specified by VSL, and shipped to VSL in 55 gallon containers. 


\section{SECTION 3.0 DM100 MELTER OPERATIONS}

Melter tests were conducted on the DM100-BL melter system between 9/15/08 and $12 / 11 / 08$. These tests produced over two and half metric tons of glass from more than seven metric tons of feed. Prior to feeding a new glass composition, the glass inventory was reduced from about $180 \mathrm{~kg}$ to about $110 \mathrm{~kg}$ to reduce the feeding time required to change the composition of the glass pool. The series of ten nominally 50 hour tests were divided as follows:

- $539 \mathrm{~kg}$ of glass produced from HLW-SP-06 glass composition $\left(2.2 \%\right.$ spinel at $\left.950^{\circ} \mathrm{C}\right)$

- $\quad 1150^{\circ} \mathrm{C}$ glass temperature, $9 \mathrm{lpm}$ bubbling, $500 \mathrm{~g}$ glass per liter feed.

- $1150^{\circ} \mathrm{C}$ glass temperature, optimized bubbling, $500 \mathrm{~g}$ glass per liter feed.

- $\quad 339 \mathrm{~kg}$ of glass produced from HLW-SP-05 glass composition $\left(4.2 \%\right.$ spinel at $\left.950^{\circ} \mathrm{C}\right)$

- $1150^{\circ} \mathrm{C}$ glass temperature, $9 \mathrm{lpm}$ bubbling, $500 \mathrm{~g}$ glass per liter feed.

- $1150^{\circ} \mathrm{C}$ glass temperature, optimized bubbling, $500 \mathrm{~g}$ glass per liter feed.

- $566 \mathrm{~kg}$ of glass produced from HLW-M-03 glass composition (4.2\% spinel/eskolaite at $\left.950^{\circ} \mathrm{C}\right)$

- $\quad 1150^{\circ} \mathrm{C}$ glass temperature, $9 \mathrm{lpm}$ bubbling, $500 \mathrm{~g}$ glass per liter feed.

- $1150^{\circ} \mathrm{C}$ glass temperature, optimized bubbling, $500 \mathrm{~g}$ glass per liter feed.

- $594 \mathrm{~kg}$ of glass produced from HLW-E-ES-05 glass composition (2\% eskolaite at $\left.950^{\circ} \mathrm{C}\right)$

- $\quad 1150^{\circ} \mathrm{C}$ glass temperature, 9 lpm bubbling, $500 \mathrm{~g}$ glass per liter feed.

- $1150^{\circ} \mathrm{C}$ glass temperature, optimized bubbling, $500 \mathrm{~g}$ glass per liter feed.

- $567 \mathrm{~kg}$ of glass produced from HLW-M-09 glass composition (1.6\% Zn-based spinel at $\left.950^{\circ} \mathrm{C}\right)$

- $\quad 1150^{\circ} \mathrm{C}$ glass temperature, $9 \mathrm{lpm}$ bubbling, $500 \mathrm{~g}$ glass per liter feed.

- $\quad 1150^{\circ} \mathrm{C}$ glass temperature, optimized bubbling, $500 \mathrm{~g}$ glass per liter feed.

Subsequent to tests with each glass composition, the melter was idled for about eight days at a melt temperature of about $950^{\circ} \mathrm{C}$. A series of glass samples were taken before and after the idling period to assess the extent of crystallization and crystal settling in the melt pool.

\subsection{Feed Processing and Glass Production Rates}

Summaries of feeding periods during each test are provided in Table 3.1. Attempts were made to replicate the melter configuration and operating conditions used for previous tests with HLW simulants $[1,5-12,18,34]$. These conditions include a near complete cold cap, which is between $80-95 \%$ melt surface coverage for the DM100 since a $100 \%$ cold cap tends to lead to 
"bridging" in smaller melters. The bubbling rate was fixed at $91 \mathrm{pm}$ and the feed rate was adjusted to maintain a complete cold cap during the first portion of testing with each glass composition; the bubbling rate was optimized to achieve the maximum production rate in the second portion of testing. This use of bubbling is in contrast to some previous tests where the production rate was fixed between 1000 to $1050 \mathrm{~kg} / \mathrm{m}^{2} /$ day and the bubbling rate adjusted to maintain the complete cold cap [7, 10, 11, 12]. The approach used in the present tests permits the evaluation of effects of waste/glass composition and glass pool bubbling with respect to production rate.

Figures 3.1.a - 3.1.e illustrate the glass production rates as moving hourly averages throughout the tests. Steady state production rates for current and previous tests $[1,5,6,18,34]$ are tabulated for comparison in Table 3.2. Glass production rates varied significantly with changes in waste/feed composition and glass pool bubbling optimization. As expected, glass production rates increased by as much as a factor of more than two (from 700 to $1500 \mathrm{~kg} / \mathrm{m}^{2} /$ day with the HLW-E-SP-06 composition) as bubbling rate was optimized. Increases with bubbling optimization for the other compositions were between 170 and 180 percent. Similar increases with bubbling optimization were observed with slow melting aluminum-limited waste compositions [1, 34]. Processing rates also varied by a factor of about two for the five waste/glass compositions. The two glass compositions with target iron oxide concentrations over $20 \mathrm{wt} \%$ had low production rates of 700 and $500 \mathrm{~kg} / \mathrm{m}^{2} /$ day at constant bubbling rate. These rates are comparable to those obtained with an aluminum-limited waste composition [1] and considerably lower than those for three other compositions [1] tested $\left(900-1250 \mathrm{~kg} / \mathrm{m}^{2} /\right.$ day at constant bubbling) and for previously processed iron-limited compositions (1100-1400 $\mathrm{kg} / \mathrm{m}^{2} /$ day at constant bubbling) [5, 6, 18]. The rates for Tests 1 and 2 were limited by the formation of thick, hard cold caps that tended to bridge wall-to-wall across the melt pool surface. Upon discharge of glass, these cold caps were often left suspended above the molten glass pool and, therefore, required manual removal. Because of these effects, production rates with these feeds may be higher on a melter with larger surface area as a result of the cold cap less effectively bridging the greater distance between the walls.

Glass compositional and property differences have demonstrated effects on production rates [8, 9]. Many elements which have a discernable effect on production rate, including aluminum, boron, silicon, potassium, and sodium, have similar concentrations in the five glass compositions tested. Differences that do exist between glasses processed in Tests 1 and $2\left(\mathrm{Fe}_{2} \mathrm{O}_{3}\right.$ $>20 \%$ ) in comparison to Tests 3, 4, and 5 (less silicon and more potassium) in these major oxides resulted in higher production rates in previous tests [9], whereas the opposite trend was observed in the present tests. Conversely, the results from the present tests are in agreement with previous tests [9] that showed higher production rates with higher boron, chromium, lithium, and zinc concentrations, as well as with lower zirconium concentrations. Although differences in boron concentration are relatively small in the glasses tested, increases in production rate directly correlate with the measured concentrations of boron in the feed, as shown in Figure 3.1.f. Similar increases in production rate with increasing boron concentration were found previously with high-aluminum compositions [34]. It is also noteworthy that the production rate increases with increasing boron concentration were observed despite a wide iron concentration range and was evident for both fixed and optimized bubbling rates. No previous studies on the DM100 that systematically vary iron and boron to determine the effect on production rate have been 
conducted. The correlation of high iron concentrations and low production rate and the cold cap observations in these tests indicate that high iron concentrations, significantly above those previously tested $\left(>13 \mathrm{wt}^{\mathrm{t}} \% \mathrm{Fe}_{2} \mathrm{O}_{3}\right.$ [5-18]), create poor cold cap conditions that limit glass production rate.

The feed and glass compositions were processed without major difficulties during these tests. Cold cap conditions were similar to the range of conditions observed in previous tests with HLW feeds $[1,5,6,18,34]$ except during Tests 1 and 2 . The feeds used in Tests 3, 4, and 5 formed a more fluid cold cap which spread more evenly across the melt surface and was less likely to adhere to melter walls, thus resulting in higher processing rates. Conversely, the feed used in Tests 1 and 2 formed extensive shelves and bridges, similar to some aluminum-limited waste streams that limited the steady state production rates [1]. Review of operational logs from the current and previous DM100 tests with HLW waste compositions indicates that the bridging deposits observed during Test 2 and to a lesser extent Test 1 were the most extensive and tenacious formed to date. Considerable manual force was required to dislodge the deposits that formed during Tests 1 and 2, in some instances requiring sustained feeding interruptions. Shorter, routine interruptions were required during testing to energize the top pair of electrodes, transfer feed to the feed tank, to adjust the feed line in the peristaltic pump as a result of wear from the pump rollers, and to perform other maintenance activities. Spikes in feed rate often occurred immediately after feed transfers due to adjustments in tank mixer speeds and pump settings. During steady state feeding periods, production rates typically vary by about ten percent from the mean rate. No foamy glass was observed in the glass discharge and no foam was observed on the melt pool surface or cold cap.

\subsection{Measured Parameters}

The results of various operational measurements that were made during these tests are given in Table 3.3. Glass bubbling rates are shown in Figures 3.2.a - 3.2.e, glass temperatures are shown in Figures 3.3.a - 3.3.e, plenum temperatures in Figures 3.4.a - 3.4.e, electrode temperatures in Figures 3.5.a - 3.5.e, and glass resistance in Figures 3.6.a - 3.6.e; electrode power is included in the figures with electrode temperatures and glass resistance. The target bubbling rate of $9 \mathrm{lpm}$ was maintained throughout the first segment of each test. Conversely, in the second segment of each test, the cold cap was constantly monitored and the bubbling rate frequently adjusted to achieve the maximum cold-cap-limited feed rate. The test average optimized bubbling rates were 1.9 to 2.6 times higher than the nominal bubbling rate of $9 \mathrm{lpm}$ in Tests 1 and 2 and 1.6 times higher in Tests 3, 4, and 5. Bulk glass temperatures (measured 5 and 10 inches from the bottom of the melt pool) were largely within $10^{\circ} \mathrm{C}$ of the target glass temperature of $1150^{\circ} \mathrm{C}$ throughout the vast majority of the tests. Exceptions were Test 2, where the thermocouple 10 inches from the bottom of the melt pool averaged $1172^{\circ} \mathrm{C}$ while the thermocouple 5 inches from the bottom of the melt pool averaged $1146^{\circ} \mathrm{C}$; and Test 3 , where the thermocouple 5 inches from the bottom of the melt pool was about $1080^{\circ} \mathrm{C}$ at the beginning of that test. Glass temperatures closer to the top of the melt pool (measured 16 and 27 inches from the bottom) are not reliable indicators of bulk glass temperatures as a result of their sensitivity to variations in the level of glass in the melter and gradients near the melt surface. Glass temperatures measured at these locations were even lower at the beginning of tests with each 
waste composition prior to the glass level in the melter being increased to above the upper pair of electrodes. Once the melter was filled with glass, the airlift and discharge chamber were maintained above $1000^{\circ} \mathrm{C}$ to facilitate the discharge of the glass product. Plenum temperatures typically ranged from 300 to $500^{\circ} \mathrm{C}$, which is lower than the 550 to $650^{\circ} \mathrm{C}$ target. These lower temperatures were the consequence of maintaining a more complete cold cap. Plenum temperatures were lower in Tests 1 and 2 than the other tests as a result of the extensive bridging deposits partially shielding the thermocouples. Higher and less uniform plenum temperatures were measured in the second test segment for each composition in response to the higher bubbling rates. The exposed thermocouple gives a reading 30 to $70^{\circ} \mathrm{C}$ higher than the thermowell thermocouple due to shine from the melt surface. The lower pair of electrodes was hotter than the upper pair of electrodes at the beginning of tests with each composition due to the lower glass levels at the beginning and end of the tests with each composition. Once the melter was filled with glass above the top electrodes, the two electrode pairs typically averaged 50 to 100 degrees less than the glass pool. The bottom electrode was typically about $350^{\circ} \mathrm{C}$ colder than the side electrodes. The side and bottom electrode temperatures increased by 30 to $50^{\circ} \mathrm{C}$ in response to the increase in bubbling during the second test segment of each test. Power supplied to the electrodes typically varied between 14 and $32 \mathrm{~kW}$. As expected, more power was required as the bubbling rate and, therefore, production rate increased. The opposite trend is observed when power usage is normalized to glass production due to the amount of energy required to maintain the glass pool at the target melting temperature. The calculated glass pool resistance decreased as the melter was filled with glass. Once the melter was filled with glass, the resistivity was relatively constant; the calculated resistance for Tests 1 and 2 was between 0.12 and 0.15 ohms and for Tests $3-5$ was between 0.08 and 0.11 ohms. Only in Test 1 were increases in resistance observed in response to bubbling.

The gas temperature at the film cooler averaged between $275-295^{\circ} \mathrm{C}$ and depended on the plenum temperature, the amount of added film cooler air, and the temperature of the added film cooler air. Drops of ten to twenty degrees in gas temperature were observed across the (insulated) transition line; the temperature is maintained well above $100^{\circ} \mathrm{C}$ in order to prevent condensation in the downstream filtration units.

\subsection{Idling Periods}

An idling period at a glass temperature of about $950^{\circ} \mathrm{C}$ was conducted to determine the extent of glass crystallization and crystal settling at these extreme conditions for each of the five glass compositions. Two sampling boats were positioned one foot apart on an Inconel lance entering through the top of the melter, and lowered to the melter bottom. A picture of the sampling boats is given in Figure 3.7. The sampling boats are $20 \mathrm{ml}$ (cylinder of $31 \mathrm{~mm}$ internal diameter and $29 \mathrm{~mm}$ height) Inconel 601 beakers with $1 \mathrm{~mm}$ wall thickness. A similar lance with a single sampling boat was installed in the melter during feeding periods. Idling periods occurred immediately after conducting tests with each composition after the bubbler lance was removed (no bubbling occurred during the idling periods). The depth of the glass pool at the start of this idling period was about 30 inches. The electrode firing pattern during idling was changed from side electrode to side electrode during feed processing to side to bottom in order to maintain a relatively uniform temperature without bubbling. A summary of the idling period durations and 
measurements of glass pool conditions is provided in Table 3.4. Glass temperatures, plenum temperatures, electrode temperature, and electrode power are depicted for the idling period in Figures 3.8.a - 3.10.e. Idling periods ranged from 181 to 299 hours. The glass temperature profile during the idling periods of Tests 1 and 2 is similar to that during feed processing: hottest in the center of the glass pool and coldest near the surface and bottom of the melt pool. Vertical temperature gradients during these tests were as high as $200^{\circ} \mathrm{C}$ due to freezing of glass at the melt surface. Plenum heaters were brought on line in the middle of the idling period for Test 1 and all subsequent idling periods to lessen the formation of frozen glass surfaces on the melt pool. During Tests 3, 4, and 5, the vertical temperature gradient in the melt pool spanned less than $40^{\circ} \mathrm{C}$ with the hotter regions often being closer to the melt surface. Glass temperatures in the airlift and various locations in the glass pool approximated or were below the target idling glass upper limit temperature of $950^{\circ} \mathrm{C}$. The lower sampling boat was positioned between the thermocouple five inches from the melter floor and the bottom electrode and therefore the temperature in the sampling boat was between these two temperatures (bottom electrode averaged 722 to $822^{\circ} \mathrm{C}$ and melt pool five inches from the bottom 938 to $1020^{\circ} \mathrm{C}$ ) thus the temperature of the glass in the lower boat was about $900^{\circ} \mathrm{C}$ during idling. The upper sampling boat was positioned between the thermocouples ten and sixteen inches from the melter floor electrode and therefore the temperature in the sampling boat was between these two temperatures (melt pool ten inches from the bottom averages 941 to $1038^{\circ} \mathrm{C}$ and melt pool sixteen inches from the bottom 963 to $991^{\circ} \mathrm{C}$ ) thus the temperature of the glass in the upper boat was about $950^{\circ} \mathrm{C}$. Glass temperatures at each monitored location were relatively constant during each test once temperatures in the melt pool stabilized. Plenum temperatures reflect the use of plenum heaters and the tendency of glass compositions in Tests 1 and 2 to form frozen glass at the melt surface. Side electrode temperatures were about $50-100^{\circ} \mathrm{C}$ below those in the center of the glass pool; the bottom electrode temperature was about $200-250^{\circ} \mathrm{C}$ below those in the center of the glass pool. Power supplied to the electrodes was relatively constant during each idling period after thermal stabilization and ranged between 6 and $8 \mathrm{~kW}$ over the five idling periods.

Samples were obtained throughout and at the end of the idling period for determination of crystal content. During the idling period, simultaneous dip and glass discharge samples were taken for analysis (see Section 4.2). The sampling boats were removed at the conclusion of feeding and idling periods to retrieve glass for analysis. Examples of the sampling boats removed after testing are given in Figures 3.11-3.15. These pictures illustrate some of the features observed on the extracted sampling apparatus, including secondary sulfur phases on samples from Tests 1 and 2 as well as holes in the bottom of boats that were positioned near the bottom of the melter. Unfortunately, the boats from the feeding periods during Tests 3-5 were missing from the sampling lances upon retrieval; either the Inconel lance corroded through above the boat or the weld between the boat and the lance failed. The sampling boats that were retrieved were cut from the lance then cross-sectioned for SEM analysis. 


\section{SECTION 4.0 \\ FEED SAMPLE AND GLASS PRODUCT ANALYSIS}

\subsection{Analysis of Feed Samples}

\subsubsection{General Properties}

Feed samples from each test were analyzed to confirm physical properties and chemical composition. Samples were taken during melter testing from an inline sampling port. Sample names, sampling dates, and measured properties are given in Table 4.1. All samples were measured for density, $\mathrm{pH}$, water content, glass conversion ratio, and oxide composition by XRF. The measured glass conversion ratios for all feed samples were within 6.1 percent of the target on a weight per weight basis, validating the use of the target conversion ratio for calculating glass production rates. The water content, density, and glass yield varied within a narrow range for all the feed samples. The $\mathrm{pH}$ measured for samples from Tests 1 and 2 were higher than those from Tests 3-5.

\subsubsection{Chemical Composition}

The methods used for analysis of feed sample chemical composition are described in Section 1.5. The boron, fluorine, and lithium target values were used for normalizing the XRF data since their concentrations were not determined by XRF. These results, compared to the target composition in Table 4.2, generally corroborate the consistency of the feed composition and show good agreement with the target composition for the major elements. All oxides with target compositions greater than one percent deviated less than $10 \%$ from target for all feed samples. Nickel oxide is targeted at 0.71 and 0.76 weight percent oxide but was measured at only 0.58 and 0.47 weight percent in Tests 1 and 2, respectively. Although nickel is a minor component that is not expected to have an effect on most glass properties, the deviations are noteworthy since nickel is commonly incorporated in spinels. The composition of these feeds is further corroborated by comparison to the product glasses (see Section 4.2.1), which show most oxides with concentrations greater than $1 \mathrm{wt} \%$ in the target composition within $10 \%$ of the target. Low concentrations of titanium were measured in all feeds even though it was not included in the target compositions. Similarly, low sulfur concentrations were measured in samples from two formulations in which sulfur was not included and above-target values were found in the other three glass formulations in which sulfur is targeted at low concentrations. These measured sulfur concentrations are low estimates of the actual concentration of sulfur in the feed since sulfur is typically volatilized during sample preparation, which involves crucible melting of the feed samples to produce a homogenous glass for XRF analysis.

Corroborative analysis using DCP on solutions of acid dissolved glass was performed on select glasses produced from each test; the results are compared to the XRF analysis in Table 4.3. Values for most of the major oxides compare favorably with the XRF analysis and target 
composition except for the alkali metals sodium and potassium, which often exhibit low bias using this procedure [13]. Also, chromium in Tests 3-5, nickel in Test 3, and zinc in Test 5 samples were significantly below their target and XRF values due to formation of crystal phases during crucible melting, which are not fully dissolved in the DCP sample preparation procedure. The XRF measured concentrations for cesium are above target whereas the AA values are below target; the latter are to be preferred due to a previously noted high bias for cesium by XRF [7]. Most of the DCP boron and lithium analysis are close to the target values (deviations less than $10 \%$ ) validating the use of the target boron and lithium concentrations for normalizing the XRF data. Higher boron deviations were measured on feed samples from Test 1 and 2, at about -11 and $-18 \%$, respectively.

\subsection{Analysis of Glass Samples}

Over two and a half metric tons of glass was produced in these tests. The glass was discharged from the melter periodically into 5-gallon carbon steel pails using an airlift system. The discharged product glass was sampled at the end of each test by removing sufficient glass from the top of the cans for total inorganic analysis. Product glass masses, discharge date, and analyses performed are listed in Table 4.4. Glass samples were also obtained from sampling boats installed during feed processing and idling periods (see Section 3.3). Sampling boat data was augmented with suction samples taken from the melt pool through a port in the lid of the melter using a previously employed method [17] which involves lowering a stainless steel pipe attached three-way valve that allows an application of either suction or pressure. During introduction into the melt, sufficient pressure was applied to prevent melt from entering the pipe. The distance of the lower end of the metal tube from the bottom of the melter was estimated and, when the desired position was reached, suction was applied drawing glass to a level above the melt pool surface inside the melter where it froze. The metal tube was then withdrawn and cooled to room temperature. Samples from the melter floor were collected in this manner. Glass samples were also obtained by dipping a rod into the glass pool. Samples of cold cap material were taken using a similar method but using a rod that had a cup installed on the bottom. A complete listing of these samples and a summary of the analyses is provided in Tables 4.5 and 4.6. All dip, suction, boat, and select discharge samples underwent visual examinations to detect the presence of a separate sulfate or crystalline phases on the glass surface as well as examination by SEM-EDS to determine the composition and morphology of secondary phases.

\subsubsection{Compositional Analysis of Discharge Glasses}

All discharge glass samples were crushed and analyzed directly by XRF. The target values for boron and lithium, which are not determined by XRF, were used for normalizing the XRF data to $100 \mathrm{wt} \%$. Fluorine concentrations were determined on select samples; fluorine concentrations were then interpolated for the other samples. The XRF analyzed compositions of discharged glass samples are provided in Table 4.7. The vast majority of the XRF analysis results compared very favorably to their corresponding target values and feed sample analysis (see Section 4.1.2). Most oxides with a target concentration greater than $1 \mathrm{wt} \%$ showed less than ten percent deviation from target values and all had deviations less than twelve and a half 
percent. The exceptions are deficits of potassium in the glasses at the end of Test 1 and bismuth in the glasses at the end of Test 3. These deviations were less than twelve and quarter percent, resulted from large changes in potassium and bismuth over the course of the respective test, and are not deemed to have a discernable effect on the properties of glass melt or product. Nickel concentrations for glass from Tests 1 and 2 were 38 and 51 percent below target, both of which are significantly lower than that measured in feed samples, suggesting that nickel was retained in the melter as a precipitated secondary phase. The same trend was observed in glass from Test 3 , although to a much lesser degree. Similar to feed sample analysis, titanium and sulfur, which are not in all target compositions, were measured at low concentrations in the product glasses. Sulfur is below target for almost all glasses due to volatilization from the glass pool and cold cap. Measured fluorine concentrations in glasses from Tests 3-5 were 30 to $40 \%$ below target as a result of volatilization.

Compositional trends for selected oxides shown in Figures 4.1.a - 4.2.d illustrate the closeness to targets at the end of tests with each composition. Exceptions include the volatile constituent, fluorine, which remains significantly below its target concentration as a result of significant release to the melter exhaust; and nickel, which is below target and measured feed concentrations in the first three tests as a result of precipitation from the melt pool. During the first test, iron, potassium, manganese, lanthanum, neodymium, and zirconium, increase in concentration at the expense of aluminum, chromium, lithium, phosphorus, and calcium as the glass pool transitions from the aluminum-limited composition [34] which was in the melter prior to the start of the present tests. Subsequently, silicon, bismuth, phosphorus, fluorine, calcium, and chromium increased in concentration at the expense of iron and zirconium during Test 3. Other expected and observed transitions include increases in iron and aluminum concentrations during Test 2, decreases in aluminum, manganese, and nickel concentrations during Test 4, and increases in zinc concentrations during Test 5. The last three or four glass discharges for each composition occurred after the idling period and therefore any changes to the glass composition were the result of precipitation in the melt pool or dissolution of precipitated elements and melter components. At the ends of each of Tests 1 and 2, iron and nickel concentrations decrease as manganese concentrations increase, suggesting the precipitation of iron and nickel spinels as well as the replacement of manganese in a phase precipitated during feeding periods. Other less pronounced concentration changes in response to idling were observed after Test 1 as increases in aluminum, calcium, and chromium with decreases in potassium. Common elements that are present in some target compositions at low concentrations, such as phosphorus, magnesium, barium, zinc, and calcium, are observed at above target concentrations in the discharged glass, presumably due to contaminants in the glass forming chemicals. Nickel is observed at diminishing concentrations through Tests 4 and 5 as a residue from the previous tests and corrosion product of melter components.

\subsubsection{Chemical Durability of Discharge Glasses}

Glass discharge samples from the end of feeding for each test were evaluated for chemical durability using the PCT and TCLP methods. The PCT results are compared to those for the benchmark DWPF-EA glass in Table 4.8 and the TCLP results are compared to the WTP delisting limits $[35,36]$ and Universal Treatment Standard (UTS) limits in Table 4.9. The 
chemical durability determined by both of these methods is excellent. All measured PCT concentrations and normalized leach rates on discharge glass samples are at least eighty times lower than the corresponding values for the DWPF-EA glass. All regulated TCLP leachate concentrations are less than about one third of a $\mathrm{mg} / \mathrm{l}$ and more than an order of magnitude less than WTP delisting limits. All measured concentrations are also well below the UTS limits. The highest TCLP leachate concentrations were for bismuth which was less than $0.9 \mathrm{mg} / \mathrm{l}$. The chemical durability of these glasses is similar to that of glasses produced from wastes limited by bismuth, chromium, aluminum, and aluminum plus sodium [1] and iron [2]. These results confirm that glasses can be formulated with higher crystalline contents without compromising the quality of the vitrified product.

\subsection{Crystal Content in Glass Samples}

In the present tests, waste and glass formulations were tested that deliberately exceeded the current upper limit for glass crystal content for the WTP (less than $1 \mathrm{vol} \%$ at $950^{\circ} \mathrm{C}$ ) in order to evaluate the effects on processing, product quality, and potential effects on melter lifetime; increasing this limit could result in increased waste loadings for many waste compositions. For this purpose, a variety of samples were collected and analyzed during the melter tests and during subsequent extended idling periods. The results are discussed in this section.

\subsubsection{Background}

In addition to the platinoids, spinel plays an important role in waste vitrification. Spinels are intermediate or final products of chemical reactions in the cold cap [37] and they are often the first species crystallizing from the glass melt $[28,37]$. In natural systems, spinel phases have long been known as concentrators for platinum group elements. In nuclear waste glass melting processes, ruthenium [37] and rhodium [38, 39, 40] participate in spinel formation either as a constituent of a spinel or as nucleating agents [38, 41, 42]. Previous work at VSL revealed that Ru-Rh-spinel formed in the cold cap, but dissolved upon entering the melt during DM1200 melter tests, while ruthenium recrystallized as $\mathrm{RuO}_{2}$ in the melt. Rhodium, however, partitioned between $\mathrm{RuO}_{2}$, the melt, and a new spinel, whose liquidus temperature was high enough for the spinel to coexist with the melt at $1150^{\circ} \mathrm{C}$. The relatively small concentration of $\mathrm{Rh}_{2} \mathrm{O}_{3}$ in defense waste limits the mass of rhodium-containing spinel in the melt pool such that settling of this spinel alone would not affect the operation of a melter.

Frequently, spinel crystals dissolve when they enter the melt from the cold cap, because their liquidus temperature is lower than the temperature of the melt $[43,44]$. Small amounts of chromium and nickel are known to increase liquidus temperatures drastically. Vienna et al. [45] measured liquidus temperatures of a large number of spinels and modeled the liquidus temperature-composition relationship of $\mathrm{Fe}-\mathrm{Cr}-\mathrm{Ni}-\mathrm{Mn}$-spinels in $\mathrm{HLW}$ glasses. Liquidus temperatures ranged between about $880^{\circ} \mathrm{C}$ and $1366^{\circ} \mathrm{C}$. Spinel may form in cooler parts of the melt $[46,47]$ and spinel crystals are frequently found on the floor of melters [38, 48]. Schill et al. [49] developed a mathematical model and calculated accumulation rates of spinel on the floor of a HLW melter. As with modeling the behavior of plationoids ( $\mathrm{Ru}, \mathrm{Rh}, \mathrm{Pd}$ ) in HLW glasses [50, 
51], one must know the fraction of space spinel occupies in a given volume of melt in the settled sludge layer in order to calculate the rate at which a layer of spinel grows. Schill et al. [49] used a value of 12 volume percent. Spinel-platinoid interactions [40] were also evident in tests on the DM1200 melter system where the spinel contained ruthenium and rhodium and contributed to the mass of sludge [38].

In the present work, the extent of settling of spinel and eskolaite crystals was investigated at different volume fractions of crystals, both during feed processing and during subsequent idling of the melter. The results are compared with expectations based on crucible melt data.

\subsubsection{Glass Samples}

The following types of samples were collected during the melter tests and idling periods:

- Dip Samples: Samples taken by dipping a threaded rod into the melt (pool or discharge riser), all the way to the bottom. The sample collected in this way may contain material from various regions of the melt pool, e.g., near the surface, from the bulk of the melt, and from the bottom.

- Discharged Glass: Glass collected from the outlet of the airlift discharge.

- Boat Samples: Samples collected in "boats" (small crucibles) that were installed at two elevations in the melt pool. One set was installed prior to the start of each test and removed at the end. Another set was installed at the start of the subsequent idling period and removed at the end. Crystals found in the boat may have accumulated by settling over time. Layering of different crystal species may be observed if crystals settle at different rates and or at different times. Issues observed with these samples were corrosion of the boat materials over their extended exposure to the molten glass, which resulted in loss of the boats in some instances. In addition, corrosion of the boat material may affect locally the yield, type, and composition of crystals observed.

- Suction Samples: These samples consist of glass and entrained crystals that are suctioned from a specific location within the melter pool at a particular instant in time. These samples were added to the test protocol in response to the observed failures in some of the boat materials. Consequently, such samples were not collected for Tests 1 , 2 , and 3. It should be noted, however, that material suctioned from the melter floor in any given test will also include material that accumulated during previous tests since it was not practical to remove such material between tests.

- Cold Cap Samples: Samples of material removed from the cold cap during normal melter operations. Such samples were limited to tests showing particularly poor cold cap behavior (Tests 1 and 2).

Tables 4.5 and 4.6 provide listings of all of the samples taken during Tests 1 to 5 . Table 
4.5 lists all dip samples and samples from discharged glass together with results from SEM/EDS analyses. Table 4.6 lists all boat, suction, and cold cap samples and associated observations from SEM/EDS analysis. Table 4.10 summarizes typical compositions of major crystalline phases found in the dip samples.

\subsubsection{SEM Analysis of Glass Samples}

A number of glass samples were examined by SEM to study the crystallization characteristics. SEM images of the discharge and dip samples from all five tests are given in Figures $4.3 \mathrm{a}-4.12 \mathrm{~b}$. SEM images of the boat, suction, and cold-cap samples are given in Figures $4.13 \mathrm{a}-4.27 \mathrm{~b}$. References to figures associated with the SEM observations are included in Tables 4.5 and 4.6 along with the sample identifications. In all of the dip and discharge glass samples obtained from the five tests, crystallinity ranges mostly from 2 to $5 \mathrm{vol} \%$, except for Test 2 (Table 4.5). The most important crystalline phases include: 1) spinel; 2) $\mathrm{Fe}_{2} \mathrm{O}_{3}$, as hematite platelets; and 3) eskolaite $\left(\mathrm{Cr}_{2} \mathrm{O}_{3}\right)$ platelets. Other trace phases detected are zirconia, zircon, apatite, and sodalite. Sodalite is only found in boat sample BLZ-O-131A in Test 1 (Figure 4.15b). The relative abundances of the three major crystalline phases depend on the glass compositions, and especially on the concentrations of the spinel-forming components $\mathrm{Fe}_{2} \mathrm{O}_{3}$, $\mathrm{Cr}_{2} \mathrm{O}_{3}, \mathrm{MnO}, \mathrm{NiO}$, and $\mathrm{ZnO}$. The glasses for Tests 1 and 2 (HLW-E-SP-06 and HLW-E-SP-05) contain $\sim 20 \mathrm{wt} \% \mathrm{Fe}_{2} \mathrm{O}_{3}, \sim 0.7 \mathrm{wt} \% \mathrm{NiO}, \sim 0.6 \mathrm{wt} \% \mathrm{MnO}$, and only $0.15 \mathrm{wt} \% \mathrm{Cr}_{2} \mathrm{O}_{3}$ (Table 4.2). Therefore, spinel in the solid solutions of magnetite $\left(\mathrm{Fe}_{3} \mathrm{O}_{4}\right)$, trevorite $\left(\mathrm{NiFe}_{2} \mathrm{O}_{4}\right)$, and hematite dominate the crystallinity of all dip and discharge glass samples (Figures 4.3a, b; 4.4a, b; 4.5a., b; and 4.6a, b). In contrast, the glasses for Tests 3, 4, and 5 (glasses HLW-E-M-03, HLW-E-ES05 , and HLW-M-09) have relatively lower $\mathrm{Fe}_{2} \mathrm{O}_{3}$ contents $(\sim 6.3 \mathrm{wt} \%)$ and very high contents of $\mathrm{Cr}_{2} \mathrm{O}_{3}(3 \mathrm{wt} \%)$, as shown in Table 4.2. Spinel in the solid solutions of chromite, magnetite, and/or eskolaite dominates the crystallinity (figures $4.7 \mathrm{a}-4.12 \mathrm{~b}$ ). Test 4 used a glass formulation that did not contain $\mathrm{NiO}$ and $\mathrm{MnO}$ and, as intended, significant crystallization of eskolaite was observed in all samples (Table 4.5, Figures 4.9a, b; 4.10a, b). Test 5 used a glass formulation containing $1.5 \mathrm{wt} \% \mathrm{ZnO}$ (HLW-E-M-09, see Table 4.2). ZnO was preferentially partitioned into the chromite-magnetite spinel structure and no eskoalite crystallization was observed (Figures 4.11a, b; 4.12a, b). Typical compositions of spinel, hematite, and eskolaite are included in Table 4.10.

It is interesting to note the unexpected prevalence of hematite in samples from Tests 1 and 2 (Table 4.5). Near the end of Test 2, a discharged glass sample had a vol\% crystallinity of 3.7 (ABL-G-54A). In comparison, glass samples discharged after idling for 230 hours had up to 11.5 vol\% crystals with hematite as the dominant crystalline phase (ABL-G-71A, ABL-G-71B and ABL-G-71C). Representative SEM images are shown in Figures 4.6a and 4.6b. Crystal settling data from the suction and boat samples show that the settling rate for isometric crystals of spinel and platelets of hematite and eskolaite are quite different. Spinel settling is much quicker than settling of platelets of hematite or eskolaite. This is evidenced from some of the boat samples obtained after idling shown in Figures 4.13b, 4.16c, and 4.17b (hematite) and Figures $4.20 \mathrm{a}$, b (eskolaite). Highly concentrated platelets of hematite "float" above the densely settled spinel sludge. This layer of glass melt highly concentrated in hematite platelets was discharged first. ABL-G-71B was discharged immediately after ABL-G-71A after idling for 230 
hours. The crystal content decreased from 11.5 vol\% (ABL-G-71A) to 6.9\% (ABL-G-71B) as the glass melt became relatively depleted in hematite crystals after approximately $24.42 \mathrm{~kg}$ glass was discharged.

Representative compositions of primary crystalline phases found in all the dip and discharge glass samples are presented in Table 4.10. About $1-2 \%$ of $\mathrm{Fe}^{3+}$ was found to be replaced by $\mathrm{Cr}^{3+}$ in the hematite structure and up to $20 \%$ of $\mathrm{Cr}^{3+}$ was replaced by $\mathrm{Fe}^{3+}$ in the eskolaite structure. Chemical zoning of spinel is common, particularly in large spinel crystals. A good example is shown in Figure 4.7a; corresponding representative EDS results are shown in Table 4.10. In Test 3, typically, the core of a spinel crystal is richer in iron and the outer layer is richer in chromium. The coexistent spinel crystals with smaller sizes $(5-10 \mu \mathrm{m})$ generally have uniform chromium compositions. We believe that these large crystals ( 25 to $50 \mu \mathrm{m}$ in size) may have grown from the spinel crystals formed during the previous test (Test 2). The spinel formed during Test 2 is rich in the magnetite and trevorite components.

\subsubsection{Discussion of Glass Sample Results}

\subsubsection{Test 1}

The composition of the glass formulation used for Test 1 (Table 4.2) was designed such that Fe-Ni-Mn-Cr-spinel was the dominant phase crystallizing from the melt. Crystal yields derived from crucible tests are listed in Table 2.5; the crystal yield is expected to be $2.2 \mathrm{vol} \%$ at $950^{\circ} \mathrm{C}$.

Figure 4.28 shows crystal yields and the kind of crystals found in dip samples and in samples from discharged glass (Samples 1 to 6) taken at the end of the test and during subsequent melter idling. Sample 7 shows the crystal yield ( $2.2 \mathrm{vol} \%$, bold line) observed in crucible tests at $950^{\circ} \mathrm{C}$. In all subsequent figures in this section, the bold horizontal line marks the crystal yield expected on the basis of crucible tests. The experimental error of this yield is about $\pm 20 \%$, i.e. \pm 0.44 vol\%. Sample 7 indicates that Fe-Ni-Cr-Mn-spinel is the dominant phase, as intended. In rare cases, traces of hematite were seen in crucible samples. A comparison of these results with those found for samples collected from the DM100 melter shows the following:

- Fe-Ni-Cr-Mn-spinel is seen in all samples (Figures 4.3a, b and 4.4a, b).

- All samples contain hematite $\left(\mathrm{Fe}_{2} \mathrm{O}_{3}\right)$ in addition to spinel.

- In Samples 1, 4, and 6, crystal yields are significantly higher than the yield observed in crucible tests.

- Results from boat samples suggest that spinel settling is much faster than settling of hematite.

Figure 4.29 shows volume fractions and the types of crystals found in boat samples ( 8 and 9) taken at the end of the test and during subsequent melter idling (Figures 4.13a - 4.15b). Included in Figure 4.29 are the results from Figure 4.28 (Samples 1 to 6) as well as the crucible 
data, i.e., Sample 7 (2.2 vol\% spinel). The fractions of crystals in the glass retrieved from boat samples 8 and 9 are 3 to 10 times higher than in the other samples. The crystals accumulated in the boats in the melt pool (13" above the bottom) and near the bottom (1" above) suggest that settling of crystals is significant. It is noteworthy that hematite was not found in the boats, whereas it was seen in all other samples.

As described in Section 3, the cold cap during Tests 1 and 2 was hard and produced extensive bridging that required interruptions for manual dislodging. Sample BLZ-O-130B (Table 4.6) was collected from the frozen glass surface during such an event. The sample contained around 6 vol\% of $\mathrm{Cr}-\mathrm{Ni}-\mathrm{Fe}$ spinels and no unusual features.

\subsubsection{Test 2}

The target glass composition used in this test contains more iron than that in Test \#1 (Table 4.2). As for the glass used in Test 2, the only phase seen in crucible tests was an Fe-Ni-Cr-Mn-spinel but the yield of spinel increased from $(2.2 \pm 0.44)$ vol\% to $(4.2 \pm 0.84)$ vol\% at $950^{\circ} \mathrm{C}$. Figure 4.30 shows the yields and types of crystals found in dip and discharge glass samples 1 to 8; the crucible data (Sample 9) are shown as well. SEM/EDS analyses of the melter samples showed that hematite was the dominant phase (Figures 4.5a,b and 4.6a,b) in three out of eight samples, with relative yields of $90 \%$ (Samples 5, 6, 7) or higher (Sample 1); thus, spinel constituted only $10 \%$ or less of the crystals in these samples. Although the crystal content was similar to that found in the crucible glass in several cases (Samples 1,2, and 8), hematite was the dominant phase instead of spinel.

Figure 4.31 shows volume fractions and the types of crystals found in boat samples (10 to 12) taken during the test and during subsequent melter idling. Included in Figure 4.31 are the results from Figure 4.30 (Samples 1 to 8), as well as the crucible data (Sample 9), which shows the expected yield (4.2 vol\% bold line) and the type of crystals (spinel). The fractions of crystals in the glass retrieved from boat Samples 10 to 12 are about 2 to 5 times higher than in the other samples. The crystals accumulated in the boats in the middle of the melt pool (13" above the bottom, Figures 4.17a, b) and near the bottom (1" above) (Figures 4.16a, b, c), suggest that settling of crystals is significant.

As described in Section 3, the cold cap during Tests 1 and 2 was hard and produced extensive bridging that required interruptions for manual dislodging. Sample ABL-O-55A (Table 4.6) was collected from the cold cap during such an event. The sample contained around $10-15$ vol\% of Cr-Ni-Mn-Fe spinels and no unusual features. The sample shows that formation of spinel takes place in the cold cap. However, their composition likely evolves once they enter the melt.

\subsubsection{Test 3}

The target glass composition used in Test 3 (Table 4.2) was designed to yield a high-chromium spinel (Cr-Fe-Ni-Mn-spinel) and $\mathrm{Cr}_{2} \mathrm{O}_{3}$ (eskolaite). The crystal yield at $950^{\circ} \mathrm{C}$ 
was determined to be $(2.5 \pm 0.5)$ vol\% from crucible tests. Figure 4.32 shows the yields and types of crystals found in samples taken from the DM100 melter at the end of the test and at various times during idling. The figure shows that all samples, with the possible exception of Sample 5, are in fair agreement with the total crystal yield determined in crucible tests. However, the expected chromium-rich spinel (Figures 4.7a, b and 4.8a, b) is the dominant crystal species in the melter samples, and if eskolaite is present, the crystal fraction must be small since hardly any was seen on SEM micrographs from dip samples and discharge glass. Eskolaite was found in boat samples (Table 4.6) but is not clear whether it formed in-situ with the help of Cr coming from corrosion of the boat, or whether it was captured from the melt (Figure 4.18). In Sample 6, which is glass discharged after 231 hours of melter idling, the chromium-rich spinel contained very little manganese, whereas the spinel in a dip sample from the bottom of the melt pool, taken at essentially the same time, does contain some manganese. As given in Table 4.6, the boat recovered from the high and low locations in the melter after idling both showed the presence of chromium oxide as the dominant phase with evidence of settling. However, the findings may have been affected by the rather severe corrosion of the boats. Corrosion may have also been the cause for the appearance of crystals other than spinel (Figure 4.18). The appearance of sulfides in these and other boat samples is somewhat surprising in view of the low sulfur concentrations, and may well have contributed to the metal corrosion. Settling of spinel is evident from Figures $4.19 \mathrm{a}, \mathrm{b}$ and crystal fractions up to $12 \mathrm{vol} \%$ were observed in the boat sample after idling.

\subsubsection{Test 4}

The glass composition for Test 4 (Table 4.2) was designed such that spinel would not form by removing all divalent spinel-forming elements from the composition. This, in combination with the high chromium content led to the crystallization of chromium as $\mathrm{Cr}_{2} \mathrm{O}_{3}$ (eskolaite), as intended. The yield of eskolaite was measured to be $(2.0 \pm 0.4) \mathrm{vol} \%$ in crucible tests.

Figure 4.33 shows the yields and types of crystals found in samples taken from the DM100 at the end of the test and at various times during idling (Figures 4.9a, b and 4.10a, b). There is fair agreement between the crystal yield from crucible tests and those found in the DM100 samples, except perhaps for dip Sample 7 from the melt pool after extended idling. Eskolaite was the only crystalline species in Samples 1, 2, and 5, and Sample 7 with a yield of $98 \mathrm{vol} \%$ eskolaite may be included in this group. There are three samples that contain $\mathrm{Cr}-\mathrm{Fe}-\mathrm{Ni}$-spinel which is likely carried over from the preceding Test 3 , which was designed to produce chromium-rich spinel.

Figure 4.34 compares the results obtained from suction Samples 9 and 10, taken at the end of Test 4, and suction Samples 11 and 12, taken after 404 hours of melter idling, with the results shown in Figure 4.33. The following observations are made:

- Crystal yields are 5 to 6 times higher in Samples 10 and 12, collected very close to the bottom of the melt pool (Figures 4.22a, b), than in the samples shown in Figure 4.33. However, there is a predominance of spinel over eskolaite in these samples, which is likely due to the presence of spinel that accumulated in the previous tests. 
- The fact that suction Samples 9 and 11 contain mostly eskolaite supports the hypothesis that the spinel accumulated in previous tests. Samples 9 and 11 were collected at some distance (2" and 1", respectively) above the bottom and showed similar crystal contents to the discharge and dip samples. Thus, while there is clear evidence of a settled spinel layer (probably from prior tests) with eskolaite above it (Figure 4.21), there is little indication of enrichment of eskolaite near the bottom of the melter; however, any eskolaite that did settle collected on top of the Cr-Ni-Fe-spinel.

- Idling did not increase the concentration of eskolaite, as seen when comparing Samples 9 and 11. The small apparent increase in spinel in Sample 12 after idling versus Sample 10 may not be significant in view of the sampling and analysis uncertainties.

Two boat samples were recovered from Test 4 after idling (Table 4.6) but one was heavily corroded and did not provide a useful sample. The content of the other boat showed a $\mathrm{Cr}-\mathrm{Fe}-\mathrm{Ni}$-spinel and traces of eskolaite and apatite. The fraction of crystals in the sample decreased from the bottom to the top of the boat, yielding between 11 and 3 vol\% crystals with an average of $6 \mathrm{vol} \%$ (Figure $4.20 \mathrm{a}, \mathrm{b}$ ). The value of $11 \mathrm{vol} \%$ is comparable to those found in suction samples 10 and 12 (Figure 4.34). The presence of Fe-Ni-Cr-spinel in the boat is difficult to explain, because the feed does not contain nickel. Possible explanations are that either the corrosion of the boat itself was the source; that the small amount of nickel in the glass persisting from the previous test was sufficient (i.e., incomplete turnover); or that spinel from the bottom of the melter was carried along in the natural convection cells in the melt (there was no bubbling during idling).

\subsubsection{Test 5}

The glass composition (Table 4.2) for this test was designed to drive chromium into a spinel phase rather than eskolaite by adding zinc as a glass forming chemical. Crucible tests showed that this approach was very effective, producing a $\mathrm{Cr}-\mathrm{Zn}$-Fe-spinel with a yield of $1.6 \mathrm{vol} \%$ at $950^{\circ} \mathrm{C}$.

Figure 4.35 shows the yields of crystals in the various samples taken from the DM100 melter. The crystal yields in the DM100 samples are generally slightly higher than that from the crucible data but still in fair agreement. In addition, the spinel found in the DM100 samples is qualitatively the same (Cr-Zn-Fe-spinel) as that found in crucible samples (Figures 4.11a, b and 4.12a, b).

Figure 4.36 compares the results from suction samples (Samples 8 to 11) with those shown in Figure 4.35. The following observations are made:

- Settling of crystals is evident. Crystal yields are 14 to 16 times higher in Samples 9 and 11 , collected very close to the bottom of the melt pool (Figures $4.27 \mathrm{a}, \mathrm{b}$ ), than in the samples shown in Figure 4.35. However, Cr-Ni-Fe-spinel is found instead of the expected $\mathrm{Cr}-\mathrm{Zn}-\mathrm{Fe}$ spinel. The same Cr-Ni-Fe spinel was found on the bottom of the melt pool in Test 4, where it appeared to have been the result of accumulation from previous tests. 
- The suction Samples 8 and 10 were each taken 1" above the bottom of the melt pool. $\mathrm{Cr}-\mathrm{Zn}$-Fe-spinel was found in these samples, indicating that it had settled on top of the preexisting $\mathrm{Cr}-\mathrm{Ni}-\mathrm{Fe}$-spinel (Figures 4.23a, $\mathrm{b}$ and 4.26). The fact that eskolaite was found together with the Cr-Zn-Fe-spinel further supports the premise that there is cross contamination between subsequent tests. Eskolaite was not found in Samples 9 and 11 . This is consistent with the observation in Test 4 that any eskolaite that did settle collected on top of the $\mathrm{Cr}-\mathrm{Ni}-\mathrm{Fe}$-spinel; eskolaite never reached the very bottom of the pool, because the floor was already covered with $\mathrm{Cr}-\mathrm{Ni}$-Fe spinel. A comparison of Samples 9 and 11 shows that even after idling there was no Cr-Zn-Fe-spinel on the bottom. However, the increase in the yield from Sample 8 to 10 may indicate that more $\mathrm{Cr}-\mathrm{Zn}-\mathrm{Fe}-$ spinel settled on top of the existing residue during the idling period.

Two boat samples were recovered after the idling period in Test 5 (Table 4.6). The boat located 1" from the bottom was corroded and the alloy was depleted with respect to chromium (Figure 4.24a, b). This may have increased the yield of $\mathrm{Cr}-\mathrm{Zn}-\mathrm{Fe}$ spinel, which was highest (18 vol\%) near the bottom of the boat. However, this value is comparable to the yields found in suction samples (Figure 4.36). The other boat located 13" from the bottom of the melt pool also was corroded and showed similar crystallization characteristics as the boat located 1" from the bottom, with slightly lower crystal content.

Finally, it is worth noting that samples from the bottom of the melter (Samples 9 and 11) show that it is possible to reach spinel crystal fractions of up to at least $\sim 25 \mathrm{vol} \%$ (Figure 4.36). This "maximum packing fraction" is a critical parameter in melter lifetime assessments that evaluate the rate of growth of a settled sludge layer that could ultimately lead to melter failure $[38,40,50,51]$. The maximum values from Test 5 are considerably higher than the value of $12 \%$ used by Schill et al. [49]. A higher value results in a slower rate of growth of the sludge layer thickness for a given crystal settling rate and, therefore, an increased melter life estimate.

\subsubsection{Appearance of Hematite in DM100 Tests}

A significant and unexpected result of this series of DM100 tests was that hematite $\left(\mathrm{Fe}_{2} \mathrm{O}_{3}\right)$ was found in substantial amounts in all samples from Tests 1 and 2 where the concentration of iron in the feed was high. In contrast, hematite did not form in any of the crucible tests with the same glass compositions. Possible reasons for this difference are discussed in this section.

Crystallization of hematite along with spinel in iron-rich glasses is a known phenomenon; for example, Kim et al. [52] reported such behavior in HLW glass compositions with more than $\sim 15 \mathrm{wt} \% \mathrm{Fe}_{2} \mathrm{O}_{3}$ based on crucible melt studies. However, for the glass compositions used in Tests 1 and 2, hematite was not found in the crucible melts but was found in the melter tests.

Major differences between the conditions prevailing in the crucible melts as compared to those in the DM100 melter tests include: 
- The presence of a cold cap on top of the melt in the DM100, whereas there is none in a crucible.

- The DM100 melt pool was bubbled with air, i.e., stirred and provided with oxygen; the melt in a crucible was not.

- The heat treatment time for the crucible samples was 70 hours. In comparison, the average residence time in the DM100 melt pool was about 25 and 54 hrs in the first and second segments of Test 1, respectively; and about 42 and $76 \mathrm{hrs}$ in the first and second segments of Test 2, respectively. However, the idling times were considerably longer, at 303 and 272 hrs for Tests 1 and 2, respectively.

- The crucible melt conditions were likely much closer to isothermal, whereas temperature gradients were present in the DM100 melter (especially during un-bubbled idling periods). In conjunction with convection (natural or forced), this could result in temperature cycling for entrained crystals.

It is possible that the formation of hematite is related to the presence of iron-rich spinel (magnetite solid solutions) in iron-rich melts. Magnetite is thermodynamically not stable in the presence of oxygen. Considerable amounts of iron-rich spinel were seen in SEM micrographs of melter samples. As temperature increases when material flows downwards through the cold cap, some of the $\mathrm{Fe}^{3+}$ (from the starting material in the feed) is reduced to $\mathrm{Fe}^{2+}$, which can be accommodated in the spinel tetrahedral site. The presence of $\mathrm{Fe}^{2+}$ was not measured directly but was suggested by stoichiometric calculations based on spinel compositions from EDS measurements. These results indicate that the iron-rich spinel contains about 85 atom percent $\mathrm{Fe}^{2+}$ in the tetrahedral site, with $\mathrm{Ni}^{2+}$ and $\mathrm{Mn}^{2+}$ providing the balance. As this spinel is carried in convection loops in the melt, $\mathrm{Fe}^{2+}$ may be oxidized to $\mathrm{Fe}^{3+}$ in the vicinity of air bubbles, causing the iron-rich spinel to decompose into hematite. Skeletons of dissolving spinel crystals were observed in samples from the melt (Figure 4.13b). Decomposition by oxidation of iron-rich spinel into hematite is a known phenomenon $[53,54]$. The abundance of hematite (up to 95\% of all crystals in the melt with only 5\% spinel (Figure 4.30, Test 2, Samples 1, 5, 6, and 7); see also Figure 4.16b), suggests that there may be continuous formation of iron-rich spinel containing $\mathrm{Fe}^{2+}$ and subsequent decomposition of this spinel by oxidation. Since the concentration of oxygen in a crucible is likely more limited, the extent of this decomposition into hematite may be similarly limited. Only miniscule amounts of hematite were seen in the crucible melt samples and then only if a nucleating agent $\left(\mathrm{RuO}_{2}\right)$ was added to the glass composition.

Another phenomenon observed in the DM100 melter, related to hematite, is that hematite was either not seen in boat samples at all (Test 1, Figure 4.29) or was less prevalent than spinel (Test 2, Figure 4.31). This may be related to the slower settling of hematite as compared to spinel or may be due to somewhat more reducing conditions in the corroding metal boats, as is also suggested by the presence of sulfides.

Further studies would be useful to help resolve this issue, particularly in view of the different settling behavior observed for hematite and spinel. 


\section{SECTION 5.0 \\ MONITORED OFF-GAS EMISSIONS}

\subsection{Particulate Sampling}

The melter exhaust was sampled for metals/particles according to 40-CFR-60 Methods 3, 5, and 29 at steady-state operating conditions during tests with each feed composition while processing at optimized bubbling. The concentrations of off-gas species that are present as particulates and gaseous species that are collected in impinger solutions were derived from laboratory data on solutions extracted from air samples (filters and various solutions) together with measurements of the volume of air sampled. Particulate collection required isokinetic sampling, which entails removing gas from the exhaust at the same velocity that the air is flowing in the duct (40-CFR-60, Methods 1-5). Typically, a sample size of 30 dscf was taken at a rate of between 0.5 and $0.75 \mathrm{dscfm}$. Total particulate loading was determined by combining gravimetric analysis of the standard particle filter and chemical analysis of probe rinse solutions. An additional impinger containing $2 \mathrm{~N} \mathrm{NaOH}$ was added to the sampling train to ensure complete scrubbing of all acid gases and, particularly, iodine. The collected materials were analyzed using direct current plasma atomic emission spectroscopy (DCP-AES) for the majority of the constituents, atomic absorption (AA) for cesium, and ion chromatography (IC) for anions. Melter emission fluxes are compared to feed fluxes in Table 5.1. Notice the distinction that is made between constituents sampled as particles and as "gas". The "gaseous" constituents are operationally defined as those species that are scrubbed in the impinger solutions after the air stream has passed through a $0.3 \mu \mathrm{m}$ heated filter. All samples but one are well within the $90-$ $110 \%$ limits for isokinetic sampling; the sample from Test 5 had an isokinetic sampling percentage of 113, a departure that is judged to have little effect on the results.

Particulate emissions from the melter constituted 1.64 to 1.81 and 0.47 to 0.6 percent of feed solids for Test 1-2 and 3-5, respectively. The high level of carry-over during Tests 1 and 2 is higher than almost all values measured previously while processing HLW simulants on the same melter [1, 5-9, 34], including feeds processed at a variety of waste types, water contents, glass processing temperatures, bubbling rates, and volatile concentrations. The higher bubbling rates contributed to the higher emissions rate; however, similar bubbling rates were used during Tests 3-5 and emissions were a third of those observed during Tests 1 and 2. A more significant cause was the poor cold cap formation and behavior during these tests which resulted in more splashing of feed and glass, which in turn increased the amount of feed entrainment into the exhaust. High carry-over of non-volatile elements such as aluminum and silicon during these tests indicate gross entrainment of solid components as opposed to volatilization from the glass melt. Solids carry-over during Tests 3-5 was similar to that found for aluminum-limited waste streams (0.53 percent) processed under the same melter conditions [34] and less than that for HLW AZ-102 (0.57 - 1.47 percent) [7] and HLW C-106/AY-102 (0.61 to 0.81 percent) [6] simulants processed at lower bubbling rates, presumably due to the higher concentration of volatiles in those feeds. Solids carry-over was greater during Tests 3-5 than for feeds with similar 
volatile contents processed on the same melter at lower bubbling rates [1, 5, 34], in keeping with the expectation that melter emissions increase with increased bubbling.

As expected, the feed elements emitted at the lowest melter DF were clearly fluorine and sulfur. Actual sulfur DF values are lower than those calculated due to the actual concentration of sulfur in the feed being higher than the target value due to contamination. Other elements exhibiting volatile behavior in some of the tests include bismuth, boron, and alkali metals. Bismuth emissions range from 1.03 to 4.77 percent of bismuth fed to the melter, which is higher than the $<0.03$ to 0.87 percent measured in previous tests [1] due to the higher bubbling rates used in the present tests. The relative volatility of barium, magnesium, zinc, and zirconium is difficult to evaluate due to the low target concentrations in some of the feeds. Emissions of chlorine were measured during all tests, even though it was not included in simulant recipes or in analyzed compositions. Similar observations were made on fluorine and sulfur in some of the tests. These volatiles have frequently been observed in melter emissions, when not present in the feed recipe or present at very low concentrations, at levels exceeding the amount in the feed recipe due to their ubiquity in raw materials, presence in tap water, and high volatility at glass melting temperatures. Boron, sulfur, and the halides were the only elements detected in the impinger solutions collected downstream of the heated particle filter in the sampling train, which constitutes the "gas" fraction of the melter emissions.

\subsection{Gases Monitored by FTIR}

Melter emissions were monitored in each test for a variety of gaseous components, most notably $\mathrm{CO}$ and nitrogen species, by Fourier Transform Infra-Red Spectroscopy (FTIR). The off-gas system temperature is maintained well above $100^{\circ} \mathrm{C}$ beyond the sampling port downstream of the HEPA filter to prevent analyte loss due to condensation prior to monitoring. A summary of average concentrations monitored during each test is provided in Table 5.2. Concentrations of two of the monitored species are plotted in Figures 5.1 - 5.5. The analytes listed in Table 5.2 are those that were thought likely to be observed during the test based on previous work; no other species were detected in the off-gas stream by FTIR. Generally, emissions were low as a result of the low concentrations of nitrogen, organic carbon, ammonia, and chlorine in the feed. The most abundant nitrogen species monitored was NO, which is in keeping with previous melter tests with both HLW and LAW feeds. Little or no nitrogen was detected as other species, except $\mathrm{NO}_{2}$ which was 10 to 30 times lower in concentration than $\mathrm{NO}$ in all but Test 3 where no $\mathrm{NO}_{2}$ was detected. Other differences between monitored concentrations during Test 3 and the other tests were NO concentrations about an order of magnitude lower, measureable ammonia, carbon monoxide concentrations higher than 2 ppmv, and the lack of measured hydrogen fluoride. The explanation for these differences is unclear given the amount and type of nitrogen oxides and organic carbon is the same in all five test feeds and that the melter was operated in the same manner during each test. During each test, the concentrations of monitored species increases in response to increases in feed rate. The variability in the NO and moisture concentrations shown in Figures 5.1 - 5.5 are attributable to the dynamic conditions in the cold cap and are in keeping with previous melter tests. The concentration of water monitored by FTIR is consistent with amount of water collected in sampling train impingers when taking into account the near two-fold dilution in between the two 
sampling points. Consistent with the gaseous chlorine and fluorine concentrations observed using the Method 5-type sampling, $\mathrm{HF}$ or $\mathrm{HCl}$ were observed by FTIR in most tests. Concentrations of sulfur dioxide emissions were low in all tests and represent only a portion of the gaseous sulfur species since species other than sulfur dioxide, such as sulfuric acid, are not monitored by the FTIR. 


\section{SECTION 6.0 SUMMARY AND CONCLUSIONS}

A series of five tests was conducted on the DM100-BL vitrification system installed at VSL. The tests employed glass formulations that were designed to evaluate the possibility of further raising the tolerance for crystalline phases in the WTP HLW vitrification process in order to achieve increased waste loadings and HLW processing rates. In particular, waste and glass formulations were tested that deliberately exceeded the current upper limit for glass crystal content for the WTP (less than $1 \mathrm{vol} \%$ at $950^{\circ} \mathrm{C}$ ) in order to evaluate the effects on processing, product quality, and potential effects on melter lifetime. For this purpose, a variety of samples were collected and analyzed during the melter tests and during subsequent extended idling periods. The new glass formulations were developed based on a series of crucible melts that were prepared and characterized. Based on these results, five glass compositions were selected for melter testing. Each feed was processed at nominal and optimized bubbling rates to determine the possible extent of rate enhancements through optimized bubbling. After each melter feed was processed, the melter was idled for extended period of time at $950^{\circ} \mathrm{C}$. Multiple glass samples were taken from various locations to assess the extent of crystal formation and settling at both feeding and idling conditions.

Glasses were formulated for melter testing with high waste loadings that exhibit crystallization of (i) spinel, (ii) chromium oxide (eskolaite), and (iii) a mixture of spinel and chromium oxide phases over a range of relatively high crystal contents ( $>1 \mathrm{vol} \%)$. The glass compositions developed for DM100 testing were as follows:

- HLW-E-SP-06 glass composition targeting 2.2 vol $\%$ spinel at $950^{\circ} \mathrm{C}$

- HLW-E-SP-05 glass composition targeting $4.2 \mathrm{vol} \%$ spinel at $950^{\circ} \mathrm{C}$

- HLW-E-M-03 glass composition targeting $4.2 \mathrm{vol} \% \mathrm{spinel} /$ eskolaite at $950^{\circ} \mathrm{C}$

- HLW-E-ES-05 glass composition targeting 2 vol $\%$ eskolaite at $950^{\circ} \mathrm{C}$

- HLW-E-M-09 glass composition targeting 1.6 vol\% $\mathrm{Zn}$-based spinel at $950^{\circ} \mathrm{C}$

Each glass was formulated to meet all product quality and melter processing requirements (except for crystal content); the formulations had waste loadings ranging from 38 to 44 percent on a waste oxide basis.

Melter testing was performed on the DM100 with each of the five selected glass formulations in 50-hour test segments at a glass pool temperature of $1150^{\circ} \mathrm{C}$, at bubbling rates of $9 \mathrm{lpm}$ and optimized flow, and $500 \mathrm{~g}$ glass per liter feed solids concentration. Over seven metric tons of feed was processed to produce more than two and half metric tons of glass. Glass production rates varied significantly with changes in waste/feed composition and glass pool bubbling optimization. The two glass compositions with target iron oxide concentrations over $20 \mathrm{wt} \%$ had low production rates of 700 and $500 \mathrm{~kg} / \mathrm{m}^{2} /$ day at constant bubbling rate due to the formation of thick, hard cold caps that bridged wall-to-wall across the melt pool surface. Production rates between 900 and $1250 \mathrm{~kg} / \mathrm{m}^{2} /$ day were obtained with the other, lower-iron 
compositions tested. Two-fold increases in glass production rates were observed once the bubbling rate was optimized. Production rates also increased with increasing boron content of the glass. Analysis was performed on discharge and glass pool samples throughout the tests for total composition and secondary phases. Despite the high crystal contents, glass was readily discharged through the airlift system throughout the tests and subsequent to each idling period.

Melter exhaust was sampled during each test for particulate and gaseous species to determine the effect of changing feed composition at optimized bubbling rate on emissions. Total particulate carry-over from the melter into the off-gas stream constituted 1.64 to 1.81 percent of the feed solids while processing two high-iron compositions that formed irregular cold caps on the melt surface and 0.47 to 0.6 percent of feed solids while processing three other compositions which formed more stable cold caps. The composition of the particulate matter from the high carryover tests indicated entrainment of the particulate from splashing feed and glass. The composition of the particulate from the other tests was characterized by the volatility of the feed constituents and was consistent with other HLW compositions processed under the same conditions. Melter DFs were determined for most elements in the feed for all five compositions tested. The most volatile species were sulfur and fluorine, which is typical. Gaseous emissions of nitrogen oxides and byproducts of incomplete combustion, such as carbon monoxide and ammonia, were very low due to the lack of nitrates and organic carbon in the feed.

Glass samples from the crucible and melter tests were subjected to leach testing using the PCT and TCLP methods in order to evaluate product quality. Despite the higher crystal contents, the glass products significantly out-performed the DWPF-EA benchmark glass on the PCT leaching procedure by factors of at least 80 and exhibited TCLP leachate concentrations that were well below the WTP delisting limits.

A series of glass samples was taken during processing as well as before and after idling periods to assess the extent of crystallization and crystal settling. Samples were obtained by using sampling boats installed during feed processing and idling periods, suction samples taken near the bottom of the melt pool, dip samples collected by dipping a rod into the glass pool or airlift riser, removing a portion of the cold cap, and discharging glass.

A significant and unexpected result of this series of DM100 tests was that hematite $\left(\mathrm{Fe}_{2} \mathrm{O}_{3}\right)$ was found in substantial amounts in all samples from Tests 1 and 2 where the concentration of iron in the feed was high. In contrast, hematite did not form in any of the crucible tests with the same glass compositions. It is possible that this is due to formation and subsequent oxidation $\left(\mathrm{Fe}^{2+}-\mathrm{Fe}^{3+}\right)$ of high-Fe spinel in the melter to form hematite. If so, this could provide a route to controlling hematite vs. spinel formation. Hematite was found to settle much more slowly than did spinel. Significantly higher crystal contents were found in many locations in the melter for Test 1 and 2 than was expected based on the crucible data; for Test 2, crystal contents increased significantly after idling. Cold cap and general processing behavior was poor for both of these feeds and cold cap samples showed high spinel contents. Despite the high crystal contents, no difficulty with discharging glass through the air-lift riser was observed.

Similar to hematite, tests with eskolaite showed that it also settled more slowly than did spinel. The platelet morphology evidently significantly favors suspension compared to compact 
spinel crystals. There was little change in the eskolaite concentrations in most locations after idling. Addition of $\mathrm{Zn}$ to the glass composition (Test 5) effectively converted eskolaite to a $\mathrm{Cr}-\mathrm{Zn}$-Fe spinel, which showed clear evidence of settling. The crystal contents in melter samples from Test 5 were close to those expected on the basis of crucible tests in most locations. Samples from the bottom of the melter showed that it is possible to reach spinel crystal fractions of up to at least $\sim 25 \mathrm{vol} \%$. This "maximum packing fraction" is a critical parameter in melter lifetime assessments that evaluate the rate of growth of a settled sludge layer that could ultimately lead to melter failure. A higher value results in a slower rate of growth of the sludge layer thickness for a given crystal settling rate and, therefore, an increased melter life estimate.

The results from melter tests show many similarities but also important differences from the results obtained with the same glass formulations in crucible scale tests of crystal settling and effects on fluid rheology [55]. The crystal sizes found in the DM100 are on average much larger (up to $600 \mu \mathrm{m}$ ) than those seen in crucible melts. While there are many differences in the conditions prevailing in the DM100 melter and the crucible melts, the reason for this difference is unclear. In addition, direct comparison between the crucible tests and the melter tests is complicated by the fact that the two spinel saturated glass melts showed crystallization of hematite $\left(\mathrm{Fe}_{2} \mathrm{O}_{3}\right)$ during the melter processing, which was notably not present in the crucible experiments involving isothermal heat treatment ( 70 hours) or in the crystal settling tests. However, the crystal contents of the glass samples collected either from the discharged glass, dip samples, or bottom suction samples are consistently near or above the target values from the 70-hour isothermal crucible experiments. Since no data are available for the crystal contents of the two glass melts in equilibrium with both spinel and hematite, it is not possible to determine, on the basis of crystal \% in glass samples, the impact of possible crystal settling during the melter operation and the subsequent long idling. However, the fact that all of the samples that were collected had crystal yields near or above the target suggest that the crystal settling at the melter idling temperature $\left(950^{\circ} \mathrm{C}\right)$ was not severe for both HLW-E-SP-06 and HLW-E-SP-05. This observation is in general agreement with the conclusion from the crystal settling experiments at $950^{\circ} \mathrm{C}$, which showed that no significant settling was evident after 24 hours [55].

The results from Test 4 with a glass melt that was oversaturated with platelet eskolaite are less complicated. All dip and discharged glass samples retained eskolaite with crystal yields between $75 \%$ to over $100 \%$ of the targeted value. The occasional occurrence of spinel phase was attributed to carryover from the previous melter run with glass melts that were oversaturated with spinel. The high crystal yields suggest that the majority of the eskolaite particles were retained in suspension in the glass melts and crystal settling was not extensive. This observation agrees with settling results for $\mathrm{HLW}-\mathrm{E}-\mathrm{ES}-02$ at $950^{\circ} \mathrm{C}$ [55]; minor to moderate settling appeared to have developed after extensive aggregation of platelet eskolaite.

On the other hand, suction samples from Test 4 (eskolaite) and Test 5 (Zn-rich spinel) displayed clear signs of settling of spinel (before Test 4) and eskolaite (before Test 5). As shown from the small scale settling experiments at $1050^{\circ} \mathrm{C}$ and especially at $1150^{\circ} \mathrm{C}$ [55], significant crystal settling occurred within hours under static conditions (e.g., HLW-E-ES-02 at $1150^{\circ} \mathrm{C}$ ). During the normal melter operation (feeding) portion of the melter tests, as compared to the idling portion, the temperature was higher $\left(1150^{\circ} \mathrm{C}\right)$ and melt pool mixing by bubbling was present. Thus, the extent to which limited settling was observed in the melter tests, whereas 
extensive settling was observed at $1150^{\circ} \mathrm{C}$ in the crucible (static) tests [55], likely reflects the effects of the melt pool mixing by bubblers on maintaining the crystal particles in suspension.

Overall, the results from the present tests have identified a number of issues associated with increases in the crystal content limit used as the processability criterion. The results are dependent on waste and glass composition and the types of crystalline phases that form. Although poor cold cap and processing behavior was observed in Tests 1 and 2, no difficulty in discharging glass was observed in any of the tests, even after extended idling, and despite high crystal contents in the riser measured from dip samples. Furthermore, the discharged glass frequently contained high concentrations of crystals, suggesting relatively effective entrainment and removal of crystals from the melt pool. However, in view of the clear evidence of crystal settling, longer-term tests would be necessary to determine the potential impact on melter lifetime.

\subsection{Implications for WTP}

This work is motivated by the potential for substantial economic benefits that can be realized if glass melters can tolerate a modest amount of crystals at the nominal operating temperature of $1150^{\circ} \mathrm{C}$ because of the associated increase in waste loading. This is because crystal formation is typically the most restrictive waste loading constraint for HLW compositions. Glasses designed for DuraMelter vitrification systems have employed a limit of $<1 \mathrm{vol} \%$ crystals at a reference temperature (typically $950^{\circ} \mathrm{C}$ ) below the operating temperature ( $\mathrm{T}_{1 \%}$ constraint) [56]. This is already a less conservative approach than the traditional liquidus temperature requirement (essentially, a 0 vol\% limit) employed at WVDP and DWPF. Based on extensive testing and demonstration, this constraint has now been formally adopted for use at the Hanford WTP in place of the traditional, more conservative, liquidus-temperature constraint. Further increasing the amount of crystals allowable in the glass would further increase waste loadings and therefore further reduce waste treatment costs. For HLW glass systems, the most common crystalline phases observed after heat treatment at $950^{\circ} \mathrm{C}$ are spinel or oxides rich in Fe, and $\mathrm{Cr}$. The presence of spinel type crystalline phases seldom affects the quality of the glass product, but it can present a significant processing concern since such phases can settle and accumulate in the melter, adversely affecting melter operations and ultimately reducing the life of the melter. Therefore, the waste loading in a glass can be increased if glasses with modest levels of crystals at $1150^{\circ} \mathrm{C}$ can be demonstrated to be processable in a typical waste glass melter. However, although it is presently expected that the actively mixed DuraMelter systems should be able to tolerate a larger amount of crystals than is the case for conventional melters, the maximum concentration of crystals such melter systems can tolerate is not yet known. This report describes results from work to support the development and testing of enhanced glass formulations to evaluate the possibility of further raising the tolerance for crystalline phases in the WTP HLW vitrification process in order to achieve increased waste loadings and HLW processing rates.

The present work was built on previous work performed at VSL for ORP to increase waste loading and processing rates for high-iron and high-chromium HLW waste streams [1, 2]. Glass formulation work involving crucible melts and characterization of crucible glasses and 
DM100 melter testing was used to investigate the effects of increased crystallinity in HLW glass formulations on melter operations, waste processing rate, and product quality. DM100 tests were performed on five glass formulations that were designed to have crystal contents that exceed the current WTP upper processing limit $\left(<1 \mathrm{vol} \%\right.$ at $\left.950^{\circ} \mathrm{C}\right)$. Two tests were performed with spinel as the primary crystalline phase $\left(2.2\right.$ and $4.2 \mathrm{vol} \%$ at $\left.950^{\circ} \mathrm{C}\right)$; one test was performed with eskolaite $\left(2 \mathrm{vol} \%\right.$ at $\left.950^{\circ} \mathrm{C}\right)$; one test with a mixture of spinel and eskolaite $\left(4.2 \mathrm{vol} \%\right.$ at $\left.950^{\circ} \mathrm{C}\right)$; and one test was performed with addition of zinc to convert eskolaite to spinel $(1.6 \mathrm{vol} \%$ at $\left.950^{\circ} \mathrm{C}\right)$.

The results from the testing performed in this work provide support for the prospects for increased waste loadings through increased crystal tolerance in the WTP HLW melter. All of the high-crystal content (and, consequently, high waste loading) formulations were processed successfully in the DM100 system, despite their increased crystal contents of up to $4.2 \mathrm{vol} \%$ (at $950^{\circ} \mathrm{C}$ ) as compared to the current WTP limit of $<1 \mathrm{vol} \%$. Although poor cold cap and processing behavior was observed in Tests 1 and 2, no difficulty in discharging glass was observed in any of the tests, even after extended idling, and despite high crystal contents in the riser measured from dip samples. Furthermore, the discharged glass frequently contained high concentrations of crystals, suggesting relatively effective entrainment and removal of crystals from the melt pool. However, in view of the clear evidence of crystal settling, longer-term tests would be necessary to determine the potential impact on melter lifetime.

The principal implications of these results for WTP are:

- Increased crystal tolerance in the HLW melter system appears to offer promise as a route to achieve further enhancements in HLW glass loadings. The first step in this direction, the incorporation of the $\mathrm{T}_{1 \%}$ constraint in place of the traditional liquidus approach, has already been incorporated into the WTP HLW baseline, which has afforded improved waste loading capability. This constraint has been demonstrated to be appropriate for melter systems with active mixing such as the WTP HLW DuraMelters. The next logical step is to assess the potential to increase beyond the present $<1 \mathrm{vol} \%$ constraint. All of the high-crystal content (and, consequently, high waste loading) formulations were processed successfully in the DM100 system, despite their increased crystal contents of up to $4.2 \mathrm{vol} \%$ (at $950^{\circ} \mathrm{C}$ ) as compared to the current WTP limit of $<1 \mathrm{vol} \%$.

- Significant differences were evident between the various types of crystal phases that were tested, in terms of their effects on cold cap quality, processing behavior and extent of settling. This suggests that different limits may be required depending on the dominant crystal phase type. However, the type of the dominant crystal can be determined from the waste type that is being processed and the supporting glass formulation information and, therefore, such a constraint could be implemented in practice.

- Cold cap behavior was significantly worse in the two high-spinel tests (Tests 1 and 2) and led to reduced production rates for these tests and particularly in the case of Test 2, which employed the highest crystal content (4.2 vol\%). Thus, potential for reduced 
processing rates must be considered against the benefits of increased loading. In addition, approaches to mitigate the processing rate reduction should be investigated.

- A significant and unexpected result of this series of DM100 tests was that hematite $\left(\mathrm{Fe}_{2} \mathrm{O}_{3}\right)$ was found in substantial amounts in all samples from Tests 1 and 2 where the concentration of iron in the feed was high. In contrast, hematite did not form in any of the crucible tests with the same glass compositions, where instead $\mathrm{Cr}-\mathrm{Ni}-\mathrm{Fe}$ spinel was the dominant crystal phase. Possible reasons for this difference are discussed in Section 4.3.5, many of which relate to differences in the conditions prevailing in the actual melter tests as compared to the crucible scale tests. However, such observations highlight the importance of melter testing under prototypic conditions in order to properly assess the potential for such enhancement approaches. Hematite showed much less settling than did spinel so that methods to favor hematite formation over spinel would be useful to further enhance increased crystal tolerance.

- The results of the present tests serve to address the potential for any acute problems that may result during melter processing as a result of the increased crystal content. With the exceptions of somewhat degraded cold cap quality and reduced processing rates in Tests 1 and 2, no processing or glass discharge issues were encountered. However, the potential for chronic effects on melter performance that could ultimately result in reduced melter lifetime are much more difficult to assess from short-term tests. The present tests showed clear evidence of crystal settling but also showed clear evidence that a large fraction of the crystals were being entrained and discharged from the melter. Longer-terms tests would be necessary to determine whether these effects lead to a stable steady state that does not significantly reduce melter lifetime.

- Samples from the bottom of the melter showed that it is possible to reach spinel crystal fractions of up to at least $\sim 25 \mathrm{vol} \%$, considerably higher than the value of $12 \%$ used by Schill et al. [49]. This "maximum packing fraction" is a critical parameter in melter lifetime assessments that evaluate the rate of growth of a settled sludge layer that could ultimately lead to melter failure. A higher value results in a slower rate of growth of the sludge layer thickness for a given crystal settling rate and, therefore, an increased melter life estimate.

\subsection{Recommendations for Future Work}

- Longer-term melter tests are needed to better assess any chronic effects of crystal settling that may not be evident in short-term tests. In particular, it is important to determine whether the combined effects of crystal settling, and entrainment and discharge lead to a stable steady state that does not significantly compromise melter life.

- The origins of the differences in the dominant crystal phases observed in small-scale and melter tests (e.g., hematite) need to be understood. 
- In view of the slower settling of hematite than spinel, methods to favor hematite formation over spinel would be useful.

- Improved methods for spatial sampling throughout the melt pool during melter testing are needed.

- Data are needed to better understand the effects of active melt pool mixing (bubbling) on crystal settling.

- Methods to improve processing rates and cold cap quality in high crystal content formulations, especially in the case of spinel, would be useful.

- Data are needed to better understand the relationship between the small-scale test results and those observed in melter testing.

- Improved small-scale test methods need to be developed to better capture the effects prevailing in melter environment.

- In view of the still rather limited set of data that is available on the effects of crystal content on glass melt rheology and settling, there is a clear need for more data on the effects of:

o Crystal type, size, and concentration

o Melt properties

o Aging time

The presently available data are not yet sufficiently extensive to separate the effects of these variables or to fully assess the interplay between them. 


\section{SECTION 7.0 REFERENCES}

[1] "High Level Waste Vitrification System Improvements," K.S. Matlack, H. Gan, W. Gong, I.L. Pegg, C.C. Chapman, and I. Joseph, VSL-07R1010-1, Rev. 0, Vitreous State Laboratory, The Catholic University of America, Washington, DC, 04/16/07.

[2] "HLW Enhancement Tests on the DuraMelter" 10 with Hanford AZ-102 Tank Waste Simulants," Final Report, K.S. Matlack, W.K. Kot, H. Gan, W. Gong and I.L. Pegg, VSL-06R6260-1, Rev. 0, Vitreous State Laboratory, The Catholic University of America, Washington, DC, 2/28/06.

[3] "HLW Glass Formulation Development and Testing," Test Plan, K.S. Matlack, W.K. Kot, H. Gan, I Joseph, and I.L. Pegg, VSL-08T1520-1, Rev. 0, Vitreous State Laboratory, The Catholic University of America, Washington, DC, 6/18/08.

[4] "Test and Evaluate High Level Waste (HLW) Vitrification System Improvements," Contract DE-AC27-07RV14884 dated 9/28/07 and Amendment A001 dated 4/23/08.

[5] "Melter Tests with AZ-101 HLW Simulant Using a DuraMelter 100 Vitrification System," K.S. Matlack, W.K. Kot, and I.L. Pegg, VSL-01R10N0-1, Rev. 1, Vitreous State Laboratory, The Catholic University of America, Washington, DC, 2/25/01.

[6] "DuraMelter 100 HLW Simulant Validation Tests with C-106/AY-102 Feeds," K.S. Matlack, W. Gong and I.L. Pegg, VSL-05R5710-1, Rev. 0, Vitreous State Laboratory, The Catholic University of America, Washington, DC, 6/2/05.

[7] "Technetium/Cesium Volatility in DM100 Tests Using HLW AZ-102 and LAW SubEnvelope A1 Simulants," K.S. Matlack, W.K. Kot, and I.L. Pegg, VSL-04R4710-1, Rev. 0, Vitreous State Laboratory, The Catholic University of America, Washington, DC, 9/28/04.

[8] "Small Scale Melter Testing of HLW Algorithm Glasses: Matrix 1 Tests," K.S. Matlack, W.K. Kot, W. Gong and I.L. Pegg, Final Report, VSL-07R1220-1, Rev. 0, Vitreous State Laboratory, The Catholic University of America, Washington, DC, 11/12/07.

[9] "Small Scale Melter Testing of HLW Algorithm Glasses: Matrix 2 Tests," K.S. Matlack, W.K. Kot, W. Gong and I.L. Pegg, Final Report, VSL-08R1220-1, Rev. 0, Vitreous State Laboratory, The Catholic University of America, Washington, DC, 6/27/08.

[10] "Integrated DM1200 Melter Testing of HLW C-106/AY-102 Composition Using Bubblers," K.S. Matlack, W. Gong, T. Bardakci, N. D’Angelo, W. Kot and I.L. Pegg, VSL-03R3800-1, Rev. 0, Vitreous State Laboratory, The Catholic University of America, Washington, DC, 9/15/03. 
[11] "Integrated DM1200 Melter Testing of HLW C-104/AY-101 Compositions Using Bubblers,” K.S. Matlack, W. Gong, T. Bardakci, N. D’Angelo, W. Kot and I.L. Pegg, VSL-03R3800-3, Rev. 0, Vitreous State Laboratory, The Catholic University of America, Washington, DC, 11/24/03.

[12] "DM1200 Tests with AZ-101 HLW Simulants," K.S. Matlack, W. Gong, T. Bardakci, N. D'Angelo, W.K. Kot, and I.L. Pegg, VSL-03R3800-4, Rev. 0, Vitreous State Laboratory, The Catholic University of America, Washington, DC, 2/17/04.

[13] "Start-Up and Commissioning Tests on the DM1200 HLW Pilot Melter System Using AZ-101 Waste Simulants," K.S. Matlack, M. Brandys, and I.L. Pegg, VSL-01R0100-2, Rev. 1, Vitreous State Laboratory, The Catholic University of America, Washington, DC, 10/31/01.

[14] "Tests on the DuraMelter 1200 HLW Pilot Melter System Using AZ-101 HLW Simulants," K.S. Matlack, W.K. Kot, T. Bardakci, T.R. Schatz, W. Gong, and I.L. Pegg, VSL-02R0100-2, Rev. 0, Vitreous State Laboratory, The Catholic University of America, Washington, DC, 6/11/02.

[15] "Integrated DM1200 Melter Testing of HLW AZ-102 Compositions Using Bubblers," K.S. Matlack, W. Gong, T. Bardakci, N. D’Angelo, W. Kot and I.L. Pegg, VSL03R3800-2, Rev. 0, Vitreous State Laboratory, The Catholic University of America, Washington, DC, 9/24/03.

[16] "Integrated DM1200 Melter Testing of Redox Effects Using HLW AZ-101 and C-106/AY-102 Simulants," K.S. Matlack, W. Gong, T. Bardakci, N. D’Angelo, W. Lutze, P. M. Bizot, R. A. Callow, M. Brandys, W.K. Kot, and I.L. Pegg, VSL04R4800-1, Rev. 0, Vitreous State Laboratory, The Catholic University of America, Washington, DC, 5/6/04.

[17] "Integrated DM1200 Melter Testing of Bubbler Configurations Using HLW AZ-101 Simulants," K.S. Matlack, W. Gong, T. Bardakci, N. D’Angelo, W. Lutze, R. A. Callow, M. Brandys, W.K. Kot, and I.L. Pegg, VSL-04R4800-4, Rev. 0, Vitreous State Laboratory, The Catholic University of America, Washington, DC, 10/5/04.

[18] "Integrated DM1200 Melter Testing Using AZ-102 and C-106/AY-102 HLW Simulants: HLW Simulant Verification,” K.S. Matlack, W. Gong, T. Bardakci, N. D’Angelo, M. Brandys, W.K. Kot, and I.L. Pegg, VSL-05R5800-1, Rev. 0, Vitreous State Laboratory, The Catholic University of America, Washington, DC, 6/27/05.

[19] "Quality Assurance Project Plan for ORP RPP-WTP Support Activities Conducted by VSL," Vitreous State Laboratory, VSL-QAPP-ORP, Rev. 0, Vitreous State Laboratory, The Catholic University of America, Washington, DC, 6/24/08.

[20] "Master List of Controlled VSL Manuals and Standard Operating Procedures in Use," QA-MLCP, Rev. 36, Vitreous State Laboratory, The Catholic University of America, Washington, DC, 2/19/09. 
[21] "Round Robin Testing of a Reference Glass for Low-Activity Waste Forms," W.L. Ebert and S.F. Wolf, Department of Energy report ANL-99/22, Argonne National Laboratory, Argonne, IL, 1999.

[22] "Time-Temperature-Transformation Diagrams for AY-102 HLW Glass," W.K. Kot and I.L. Pegg, VSL-07R1240-3, Rev. 0, Vitreous State Laboratory, The Catholic University of America, Washington, DC, 09/28/07.

[23] "Chromium Phase Behavior in a Multi-Component Borosilicate Glass Melt," P. Hrma, J.D. Vienna, B.K. Wilson, T.J. Plaisted, and S.M. Heald, Journal of Non-Crystalline Solids, Vol. 352, 2114-2122, 2006.

[24] "The Effect of Chromium Oxide on the Properties of Simulated Nuclear Waste Glasses," O. Vojtech, J. Sussmilch, Z. Urbanec, P. Novy, J. Hlavac, V. Hulinsky, M. Maryska, J. Had, V. Krestan, P. Exnar, L. Bauer, J. Rusek, P. Havel, T. Cervinka, E. Stejskalova, Z. Baloun, T. Zizka, PNNL-10986, UC-810, Pacific Northwest National Laboratory, Richland, WA, February 1996.

[25] "The Incorporation of P, S, Cr, F, Cl, I, Mn, Ti, U, and Bi into Simulated Nuclear Waste Glasses: Literature Study,” M.H. Langowski, PNNL-10980, UC-512, Pacific Northwest National Laboratory, Richland, WA, February 1996.

[26] "Increasing High-Level Waste Loading in Glass without Changing the Baseline Melter Technology," P. Hrma, J. Alton, T. Plaisted, J. Klouzek, J. Matyas, M. Mika, P. Schill, M. Trochta, and L. Nemec, Waste Management '01, University of Arizona, AZ, 2001.

[27] "Property/Composition Relationships for Hanford High-Level Waste Glasses Melting at $1150^{\circ}$ C, , P.R. Hrma, G.F. Piepel, M.J. Schweiger, D.E. Smith, D.S. Kim, P.E. Redgate, J.D. Vienna, C.A. LoPresti, D.B. Simpson, D.K. Peeler, and M.H. Langowski, PNNL10359, UC-2020, Pacific Northwest National Laboratory, Richland, WA, December 1994.

[28] "Devitrification of Defense Nuclear Waste Glasses: Role of Melt Insolubles," D.F. Bickford and C.M. Jantzen, Journal of Non-Crystalline Solids, Vol. 84, 299-307, 1986.

[29] "Cr ${ }^{3+}-\mathrm{Cr}^{6+}$ Equilibrium in Binary Alkali Silicate Glasses," P. Nath and R.W. Douglas, Phys. and Chem. of Glasses, Vol 6, 197-202, 1965.

[30] "Contribution to Basicity of Technical Glass Melts in Relation to Redox Equilibria and Gas Solubilities,” F.W. Kramer, Glastech. Ber., Vol. 64(3), 71-80, 1991.

[31] "The Vitrification of Accident Wastes from the Nuclear Power Plant A-1 in Slovaka," J. Sussmilch and A. Jouan, in Proceedings of Environmental Remediation and Environmental Issues, Vol 3, R. Baschwitz et al., Eds,. American Society of Mechanical Engineers, 1993.

[32] Chemistry of Glasses, A. Paul, Chapman and Hall, London, 1982. 
[33] "X-Ray Absorption Studies of Manganese Valence and Local Environment in Borosilicate Waste Glasses," D.A. McKeown, W.K. Kot, and I.L. Pegg, J. Non-Cryst. Solids, Vol. 328, 71-89, 2003.

[34] "Melt Rate Enhancement for High Aluminum HLW Glass Formulations," K.S. Matlack, H. Gan, M. Chaudhuri, W. Gong, T. Bardakci, I.L. Pegg, and I. Joseph, VSL-08R1360-1, Rev. 0, Vitreous State Laboratory, The Catholic University of America, Washington, DC, $12 / 19 / 08$.

[35] "New Delisting Limits for Arsenic and Chrome," D. Blumenkranz, e-mail message to J. Westsik, CCN 069211, River Protection Project, Waste Treatment Plant, Richland, WA. September 15, 2003.

[36] "Data Quality Objectives Process in Support of LDR/Delisting at the WTP," J. Cook, and D. Blumenkranz, 24590-WTP-RPT-ENV-01-012, Rev. 2, River Protection Project, Waste Treatment Plant, Richland, WA, March 26, 2003.

[37] "Effect of Feed Melting, Temperature History, and Minor Component Addition on Spinel Crystallization in High-Level Waste Glass," P. Izak, P. Hrma, B.W. Arey, and T.J. Plaisted, J. Non-Cryst. Solids, 2001, 289, 17.

[38] "Testing and Modeling the Behavior of Platinoids during Vitrification of High Level Radioactive Waste," W. Lutze, W. Gong, F.P. Cardenas, K.S. Matlack, I.L. Pegg, and P. Schill, Part 1. Glass Technol: Eur. J. Glass Sci. Technol. A, 2007, 48, 263.

[39] "Crystallization in HLW Glass Melts: Composition, Cation Exchange Systematic and the Role of $\mathrm{Rh}_{2} \mathrm{O}_{3}$ in Spinel Formation," S. Annamalai, H. Gan, M. Chaudhuri, W.K. Kot, and I.L. Pegg, Ceramic Transactions, 2004, 155, 279.

[40] "Testing and Modeling the Behavior of Platinoids during Vitrification of High-Level Radioactive Waste; Part 4: Effect of Spinel, W. Gong, W. Lutze, and I. L. Pegg, European Journal of Glass Science and Technology, Part A, 2009, submitted.

[41] "Kinetics of Growth of Spinel Crystals in a Borosilicate Glass," J. Alton, T.J. Plaisted, and P. Hrma, Chemical Engineering Science 2002, 57, 2503.

[42] "Dissolution and Growth of Spinel Crystals in a Borosilicate Glass," J. Alton, T.J. Plaisted, and P.J. Hrma, J. Non-Cryst. Solids, 2002, 311, 24.

[43] "Liquidus Temperature of Spinel Precipitating High-Level Waste Glasses," M. Mika, M.J. Schweiger, J.D. Vienna, and P. Hrma, P. Mat. Res. Soc. Symp. Proc., 1997, Vol. $465,71$.

[44] "Liquidus Temperature of High-Level Borosilicate Glasses with Spinel Primary Phase," P. Hrma, J. Vienna, J. Crum, G. Piepel, and M. Mika, Mat. Res. Soc. Symp. Proc., 2000, 608, 671. 
[45] "Liquidus Temperature-Composition Model for Multi-Component Glasses in the $\mathrm{Fe}, \mathrm{Cr}$, Ni, and Mn Spinel Primary Phase Field. J. D. Vienna, P. Hrma, J. V. Crum, and M. Mika, J. Non-Cryst. Solids, 292 (2001) 1-24.

[46] "Rheology of Spinel Sludge in Molten Glass," M. Mika, P. Hrma, and M.J. Schweiger, J. Ceramics Silicaty, 1999, 44, 86.

[47] "Crucible Study of Spinel Settling in a Molten High-Level Waste Glass," J. Klouzek, J. Alton, P. Hrma and T. Plaisted, Ceramic Transactions, 2001, 119, 301.

[48] "Noble Metal and Spinel Deposition on the Floor of a Joule-Heated Ceramic Melter," V. Jain, S.M. Barnes, T.K. Vethanayagan, and L.D. Pye, J. Am. Ceram. Soc., 1991, 74, 1559.

[49] "Mathematical Model of Spinel Settling in a Real Waste Glass Melter," P. Schill, M. Trochta, J. Matyas, L. Nemec, and P. Hrma, Proceedings of Waste Management Conference, 2001, Feb. 25 - Mar. 1.

[50] "Testing and Modeling the Behavior of Platinoids during Vitrification of High Level Radioactive Waste. Part 2," P. Schill, W. Lutze, W. Gong, and I.L. Pegg, Glass Technol: Eur. J. Glass Sci. Technol. A, 2007, 48, 276.

[51] "Testing and Modeling the Behavior of Platinoids during Vitrification of High Level Radioactive Waste. Part 3," W. Gong, W. Lutze, K.S. Mattlack, and I.L. Pegg, Glass Technol.: Eur. J. Glass Sci. Technol. A, 2009, accepted.

[52] "Crystallization in Simulated Glasses from Hanford High-Level Nuclear Waste Composition Range," D. Kim, D. E. Smith, P. Hrma, and M. J. Schweiger, Report PNLSA-22303, Pacific Northwest Laboratory, Richland, WA, (1993).

[53] "Kinetic Studies on the Precipitation of Hematite from Iron-Rich Spinel Solid Solutions," T. Yamaguchi and T. Kimura, J. Amer. Ceram. Soc., 59, 333-335 (1976).

[54] "Crystallization Phenomena in Iron-Rich Glasses," A. Karamanov and M. Pelino, J. NonCryst. Solids, 281, 139-151 (2001).

[55] "Crystal Settling, Redox, and High Temperature Properties of ORP HLW and LAW Glasses," H. Gan, I.S. Muller, D.A. McKeown, M. Chaudhuri, Z. Feng, C. Viragh, C. Wang, R. Cecil, W. Zhao, W.K. Kot, I. Joseph, and I.L. Pegg, VSL-09R1510-1, Rev. 0, Vitreous State Laboratory, The Catholic University of America, Washington, DC, 6/18/09.

[56] "Glass Formulation to Support Melter Runs with HLW Simulants," W.K. Kot, K. Klatt, and I.L. Pegg, VSL-03R3760-2, Rev. 0, Vitreous State Laboratory, The Catholic University of America, Washington, DC, 9/30/03. 
The Catholic University of America Vitreous State Laboratory
ORP-56294 Rev. 0

Effects of High Crystal Content in HLW DM100 Melter Tests

Final Report, VSL-09R1520-1, Rev. 0

Table 2.1. Oxide Composition (wt\%) of Waste Streams Used in Development of HLW Glass Formulations.

\begin{tabular}{|c|c|c|c|}
\hline $\begin{array}{c}\text { Waste } \\
\text { Component }\end{array}$ & Al Limited Waste & $\begin{array}{l}\text { Fe Limited Waste } \\
\text { (Hanford AZ-102) }\end{array}$ & Cr Limited Waste \\
\hline $\mathrm{Al}_{2} \mathrm{O}_{3}$ & $49.21 \%$ & $23.02 \%$ & $25.53 \%$ \\
\hline $\mathrm{B}_{2} \mathrm{O}_{3}$ & $0.39 \%$ & $2.12 \%$ & $0.53 \%$ \\
\hline $\mathrm{BaO}$ & $0.11 \%$ & $0.00 \%$ & $0.03 \%$ \\
\hline $\mathrm{Bi}_{2} \mathrm{O}_{3}$ & $2.35 \%$ & $0.00 \%$ & $7.29 \%$ \\
\hline $\mathrm{CaO}$ & $2.21 \%$ & $0.96 \%$ & $2.47 \%$ \\
\hline $\mathrm{CdO}$ & $0.05 \%$ & $0.47 \%$ & $0.01 \%$ \\
\hline $\mathrm{Cr}_{2} \mathrm{O}_{3}$ & $1.07 \%$ & $0.37 \%$ & $3.07 \%$ \\
\hline $\mathrm{Cs}_{2} \mathrm{O}$ & $0.00 \%$ & $0.21 \%$ & $0.00 \%$ \\
\hline $\mathrm{F}$ & $1.37 \%$ & $0.00 \%$ & $2.00 \%$ \\
\hline $\mathrm{Fe}_{2} \mathrm{O}_{3}$ & $12.11 \%$ & $51.60 \%$ & $13.13 \%$ \\
\hline $\mathrm{K}_{2} \mathrm{O}$ & $0.29 \%$ & $0.24 \%$ & $0.37 \%$ \\
\hline $\mathrm{La}_{2} \mathrm{O}_{3}$ & $0.00 \%$ & $1.55 \%$ & $0.00 \%$ \\
\hline $\mathrm{Li}_{2} \mathrm{O}$ & $0.35 \%$ & $0.03 \%$ & $0.36 \%$ \\
\hline $\mathrm{MgO}$ & $0.24 \%$ & $0.30 \%$ & $0.16 \%$ \\
\hline $\mathrm{MnO}$ & $0.00 \%$ & $1.47 \%$ & $0.00 \%$ \\
\hline $\mathrm{Na}_{2} \mathrm{O}$ & $7.35 \%$ & $3.08 \%$ & $20.09 \%$ \\
\hline $\mathrm{Nd}_{2} \mathrm{O}_{3}$ & $0.00 \%$ & $0.68 \%$ & $0.00 \%$ \\
\hline $\mathrm{NiO}$ & $0.82 \%$ & $1.84 \%$ & $1.06 \%$ \\
\hline $\mathrm{P}_{2} \mathrm{O}_{5}$ & $2.16 \%$ & $0.10 \%$ & $3.34 \%$ \\
\hline $\mathrm{PbO}$ & $0.84 \%$ & $0.29 \%$ & $0.48 \%$ \\
\hline $\mathrm{SO}_{3}$ & $0.41 \%$ & $0.17 \%$ & $1.52 \%$ \\
\hline $\mathrm{SiO}_{2}$ & $10.05 \%$ & $4.17 \%$ & $10.56 \%$ \\
\hline $\mathrm{ThO}_{2}$ & $0.37 \%$ & $0.00 \%$ & $0.04 \%$ \\
\hline $\mathrm{TiO}_{2}$ & $0.02 \%$ & $0.00 \%$ & $0.01 \%$ \\
\hline $\mathrm{U}_{3} \mathrm{O}_{8}$ & $7.25 \%$ & $0.00 \%$ & $7.59 \%$ \\
\hline $\mathrm{ZnO}$ & $0.17 \%$ & $0.04 \%$ & $0.25 \%$ \\
\hline $\mathrm{ZrO}_{2}$ & $0.81 \%$ & $7.29 \%$ & $0.11 \%$ \\
\hline Total & $100.0 \%$ & $100.0 \%$ & $100.0 \%$ \\
\hline
\end{tabular}


Table 2.2. Reference Starting HLW Glass Compositions.

\begin{tabular}{|c|c|c|c|c|}
\hline \multirow{2}{*}{\multicolumn{2}{|c|}{ Reference Waste/Glass }} & Al-Limited Waste & Fe-Limited Waste & Cr-Limited Waste \\
\hline & & HLW-E-Al-27 & INEL-HLW-B10 & HLW-E-Cr-10 \\
\hline \multicolumn{2}{|c|}{$\mathrm{Al}_{2} \mathrm{O}_{3}$} & 23.97 & 8.92 & 11.06 \\
\hline \multicolumn{2}{|c|}{$\mathrm{B}_{2} \mathrm{O}_{3}$} & 15.19 & 12.03 & 14.44 \\
\hline \multicolumn{2}{|r|}{$\mathrm{BaO}$} & 0.05 & - & 0.01 \\
\hline \multicolumn{2}{|r|}{$\mathrm{Bi}_{2} \mathrm{O}_{3}$} & 1.14 & - & 3.16 \\
\hline \multicolumn{2}{|r|}{$\mathrm{CaO}$} & 6.08 & 0.37 & 1.07 \\
\hline \multicolumn{2}{|r|}{$\mathrm{CdO}$} & 0.02 & 0.18 & - \\
\hline \multicolumn{2}{|r|}{$\mathrm{Cr}_{2} \mathrm{O}_{3}$} & 0.52 & 0.15 & 1.33 \\
\hline \multicolumn{2}{|r|}{$\mathrm{Cs}_{2} \mathrm{O}$} & - $^{\text {(a) }}$ & 0.08 & - \\
\hline \multicolumn{2}{|r|}{$\mathrm{F}$} & 0.67 & - & 0.87 \\
\hline \multicolumn{2}{|r|}{$\mathrm{Fe}_{2} \mathrm{O}_{3}$} & 5.90 & 20.01 & 5.69 \\
\hline \multicolumn{2}{|r|}{$\mathrm{K}_{2} \mathrm{O}$} & 0.14 & 7.00 & 5.42 \\
\hline \multicolumn{2}{|r|}{$\mathrm{La}_{2} \mathrm{O}_{3}$} & - & 0.60 & - \\
\hline \multicolumn{2}{|r|}{$\mathrm{Li}_{2} \mathrm{O}$} & 3.57 & 1.10 & 3.31 \\
\hline \multicolumn{2}{|r|}{$\mathrm{MgO}$} & 0.12 & 0.11 & 0.07 \\
\hline \multicolumn{2}{|r|}{$\mathrm{MnO}$} & - & 0.57 & - \\
\hline \multicolumn{2}{|r|}{$\mathrm{Na}_{2} \mathrm{O}$} & 9.58 & 8.99 & 8.70 \\
\hline \multicolumn{2}{|r|}{$\mathrm{Nd}_{2} \mathrm{O}_{3}$} & - & 0.26 & - \\
\hline \multicolumn{2}{|r|}{$\mathrm{NiO}$} & 0.40 & 0.71 & 0.46 \\
\hline \multicolumn{2}{|r|}{$\mathrm{P}_{2} \mathrm{O}_{5}$} & 1.05 & 0.04 & 1.45 \\
\hline \multicolumn{2}{|r|}{$\mathrm{PbO}$} & 0.41 & 0.11 & 0.21 \\
\hline \multicolumn{2}{|r|}{$\mathrm{SO}_{3}$} & 0.20 & 0.07 & 0.66 \\
\hline \multicolumn{2}{|r|}{$\mathrm{SiO}_{2}$} & 30.50 & 35.85 & 41.94 \\
\hline \multicolumn{2}{|r|}{$\mathrm{TiO}_{2}$} & 0.01 & - & - \\
\hline \multicolumn{2}{|r|}{$\mathrm{ZnO}$} & 0.08 & 0.02 & 0.11 \\
\hline \multicolumn{2}{|r|}{$\mathrm{ZrO}_{2}$} & 0.39 & 2.83 & 0.05 \\
\hline \multicolumn{2}{|r|}{ Waste Loading } & $45 \mathrm{wt} \%$ & $38.73 \mathrm{wt} \%$ & $40 \mathrm{wt} \%$ \\
\hline \multirow{6}{*}{ 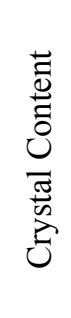 } & As-Melted Glass (vol\%) & Trace & 0.6 & NA \\
\hline & After HT at $1000^{\circ} \mathrm{C}(\mathrm{vol} \%)$ & $\mathrm{NA}^{(\mathrm{b})}$ & 2.5 & NA \\
\hline & After $\mathrm{HT}$ at $950^{\circ} \mathrm{C}(\mathrm{vol} \%)$ & 1.0 & NA & 0.6 \\
\hline & After $\mathrm{HT}$ at $900^{\circ} \mathrm{C}(\mathrm{vol} \%)$ & 3.8 & 4.6 & 0.8 \\
\hline & After HT at $850^{\circ} \mathrm{C}(\mathrm{vol} \%)$ & 3.4 & NA & 0.8 \\
\hline & After HT at $800^{\circ} \mathrm{C}$ (vol\%) & 7.2 & NA & 2.0 \\
\hline \multicolumn{2}{|r|}{ Viscosity at $1150^{\circ} \mathrm{C}(\mathrm{P})$} & 45.6 & 84.9 & 59.5 \\
\hline Electri & conductivity at $1250^{\circ} \mathrm{C}(\mathrm{S} / \mathrm{cm})$ & 0.35 & 0.17 & 0.37 \\
\hline
\end{tabular}

(a) - Empty data field (components not present in glass).

(b) NA = Not Analyzed. 
The Catholic University of America Vitreous State Laboratory
ORP-56294 Rev. 0

Effects of High Crystal Content in HLW DM100 Melter Tests

Final Report, VSL-09R1520-1, Rev. 0

Table 2.3. Target Compositions of HLW Glasses (HLW-E-SP) Formulated to Study Crystallization of Spinel Phase.

\begin{tabular}{|c|c|c|c|c|c|}
\hline Oxide & HLW-E-SP-01 & HLW-E-SP-02 & HLW-E-SP-03 & HLW-E-SP-04 & HLW-E-SP-05 \\
\hline $\mathrm{Al}_{2} \mathrm{O}_{3}$ & $25.57 \%$ & $27.17 \%$ & $28.77 \%$ & $8.22 \%$ & $9.49 \%$ \\
\hline $\mathrm{B}_{2} \mathrm{O}_{3}$ & $14.38 \%$ & $13.58 \%$ & $12.77 \%$ & $13.57 \%$ & $12.08 \%$ \\
\hline $\mathrm{BaO}$ & $0.06 \%$ & $0.06 \%$ & $0.06 \%$ & $-^{(\mathrm{a})}$ & - \\
\hline $\mathrm{Bi}_{2} \mathrm{O}_{3}$ & $1.22 \%$ & $1.30 \%$ & $1.37 \%$ & - & - \\
\hline $\mathrm{CaO}$ & $5.88 \%$ & $5.67 \%$ & $5.47 \%$ & $0.34 \%$ & $0.40 \%$ \\
\hline $\mathrm{CdO}$ & $0.03 \%$ & $0.03 \%$ & $0.03 \%$ & $0.17 \%$ & $0.19 \%$ \\
\hline $\mathrm{Cr}_{2} \mathrm{O}_{3}$ & $0.56 \%$ & $0.59 \%$ & $0.63 \%$ & $0.13 \%$ & $0.15 \%$ \\
\hline $\mathrm{Cs}_{2} \mathrm{O}$ & - & - & - & $0.07 \%$ & $0.08 \%$ \\
\hline $\mathrm{F}$ & $0.71 \%$ & $0.76 \%$ & $0.80 \%$ & - & - \\
\hline $\mathrm{Fe}_{2} \mathrm{O}_{3}$ & $6.29 \%$ & $6.69 \%$ & $7.08 \%$ & $18.46 \%$ & $21.30 \%$ \\
\hline $\mathrm{K}_{2} \mathrm{O}$ & $0.15 \%$ & $0.16 \%$ & $0.17 \%$ & $7.33 \%$ & $7.01 \%$ \\
\hline $\mathrm{La}_{2} \mathrm{O}_{3}$ & - & - & - & $0.55 \%$ & $0.64 \%$ \\
\hline $\mathrm{Li}_{2} \mathrm{O}$ & $3.40 \%$ & $3.22 \%$ & $3.05 \%$ & $1.16 \%$ & $1.10 \%$ \\
\hline $\mathrm{MgO}$ & $0.12 \%$ & $0.13 \%$ & $0.14 \%$ & $0.11 \%$ & $0.12 \%$ \\
\hline $\mathrm{MnO}$ & - & - & - & $0.52 \%$ & $0.61 \%$ \\
\hline $\mathrm{Na}_{2} \mathrm{O}$ & $9.49 \%$ & $9.40 \%$ & $9.31 \%$ & $10.33 \%$ & $9.07 \%$ \\
\hline $\mathrm{Nd}_{2} \mathrm{O}_{3}$ & - & - & - & $0.24 \%$ & $0.28 \%$ \\
\hline $\mathrm{NiO}$ & $0.43 \%$ & $0.45 \%$ & $0.48 \%$ & $0.66 \%$ & $0.76 \%$ \\
\hline $\mathrm{P}_{2} \mathrm{O}_{5}$ & $1.12 \%$ & $1.19 \%$ & $1.26 \%$ & $0.04 \%$ & $0.04 \%$ \\
\hline $\mathrm{PbO}$ & $0.44 \%$ & $0.46 \%$ & $0.49 \%$ & $0.10 \%$ & $0.12 \%$ \\
\hline $\mathrm{SO}_{3}$ & $0.21 \%$ & $0.23 \%$ & $0.24 \%$ & $0.06 \%$ & $0.07 \%$ \\
\hline $\mathrm{SiO}_{2}$ & $29.43 \%$ & $28.36 \%$ & $27.29 \%$ & $35.31 \%$ & $33.46 \%$ \\
\hline $\mathrm{TiO}_{2}$ & $0.01 \%$ & $0.01 \%$ & $0.01 \%$ & - & - \\
\hline $\mathrm{ZnO}$ & $0.09 \%$ & $0.09 \%$ & $0.10 \%$ & $0.01 \%$ & $0.02 \%$ \\
\hline $\mathrm{ZrO}_{2}$ & $0.42 \%$ & $0.45 \%$ & $0.47 \%$ & $2.61 \%$ & $3.01 \%$ \\
\hline TOTAL & $100.0 \%$ & $100.0 \%$ & $100.0 \%$ & $100.0 \%$ & $100.0 \%$ \\
\hline
\end{tabular}

(a) - Empty data field (components not present in glass). 
Table 2.3. Target Compositions of HLW Glasses (HLW-E-SP) Formulated to Study Crystallization of Spinel Phase (continued).

\begin{tabular}{|c|c|c|c|c|c|}
\hline Oxide & HLW-E-SP-06 & HLW-E-SP-07 & HLW-E-SP-08 & HLW-E-SP-09 & HLW-E-SP-10 \\
\hline $\mathrm{Al}_{2} \mathrm{O}_{3}$ & $8.91 \%$ & $7.53 \%$ & $6.15 \%$ & $8.906 \%{ }^{(b)}$ & $9.481 \%^{(b)}$ \\
\hline $\mathrm{B}_{2} \mathrm{O}_{3}$ & $13.30 \%$ & $13.01 \%$ & $13.38 \%$ & $13.288 \%$ & $12.071 \%$ \\
\hline $\mathrm{BaO}$ & - $^{\text {(a) }}$ & - & - & - & - \\
\hline $\mathrm{Bi}_{2} \mathrm{O}_{3}$ & - & - & - & - & - \\
\hline $\mathrm{CaO}$ & $0.37 \%$ & $0.31 \%$ & $0.26 \%$ & $0.372 \%$ & $0.396 \%$ \\
\hline $\mathrm{CdO}$ & $0.18 \%$ & $0.15 \%$ & $0.12 \%$ & $0.180 \%$ & $0.192 \%$ \\
\hline $\mathrm{Cr}_{2} \mathrm{O}_{3}$ & $0.15 \%$ & $0.12 \%$ & $0.10 \%$ & $0.145 \%$ & $0.154 \%$ \\
\hline $\mathrm{Cs}_{2} \mathrm{O}$ & $0.08 \%$ & $0.07 \%$ & $0.06 \%$ & $0.080 \%$ & $0.085 \%$ \\
\hline $\mathrm{F}$ & - & - & - & - & - \\
\hline $\mathrm{Fe}_{2} \mathrm{O}_{3}$ & $20.01 \%$ & $16.91 \%$ & $13.81 \%$ & $19.991 \%$ & $21.281 \%$ \\
\hline $\mathrm{K}_{2} \mathrm{O}$ & $7.00 \%$ & $7.67 \%$ & $4.65 \%$ & $6.998 \%$ & $7.004 \%$ \\
\hline $\mathrm{La}_{2} \mathrm{O}_{3}$ & $0.60 \%$ & $0.51 \%$ & $0.41 \%$ & $0.599 \%$ & $0.637 \%$ \\
\hline $\mathrm{Li}_{2} \mathrm{O}$ & $1.17 \%$ & $1.21 \%$ & $1.46 \%$ & $1.172 \%$ & $1.103 \%$ \\
\hline $\mathrm{MgO}$ & $0.11 \%$ & $0.10 \%$ & $0.08 \%$ & $0.114 \%$ & $0.122 \%$ \\
\hline $\mathrm{MnO}$ & $0.57 \%$ & $0.48 \%$ & $0.39 \%$ & $0.568 \%$ & $0.605 \%$ \\
\hline $\mathrm{Na}_{2} \mathrm{O}$ & $10.19 \%$ & $11.07 \%$ & $13.38 \%$ & $10.184 \%$ & $9.062 \%$ \\
\hline $\mathrm{Nd}_{2} \mathrm{O}_{3}$ & $0.26 \%$ & $0.22 \%$ & $0.18 \%$ & $0.263 \%$ & $0.280 \%$ \\
\hline $\mathrm{NiO}$ & $0.71 \%$ & $0.60 \%$ & $0.49 \%$ & $0.712 \%$ & $0.758 \%$ \\
\hline $\mathrm{P}_{2} \mathrm{O}_{5}$ & $0.04 \%$ & $0.03 \%$ & $0.03 \%$ & $0.040 \%$ & $0.043 \%$ \\
\hline $\mathrm{PbO}$ & $0.11 \%$ & $0.10 \%$ & $0.08 \%$ & $0.113 \%$ & $0.121 \%$ \\
\hline $\mathrm{PdO}$ & - & - & - & $0.002 \%$ & $0.002 \%$ \\
\hline $\mathrm{Rh}_{2} \mathrm{O}_{3}$ & - & - & - & $0.005 \%$ & $0.005 \%$ \\
\hline $\mathrm{RuO}_{2}$ & - & - & - & $0.077 \%$ & $0.077 \%$ \\
\hline $\mathrm{SO}_{3}$ & $0.07 \%$ & $0.06 \%$ & $0.05 \%$ & $0.066 \%$ & $0.070 \%$ \\
\hline $\mathrm{SiO}_{2}$ & $33.31 \%$ & $37.45 \%$ & $42.95 \%$ & $33.287 \%$ & $33.431 \%$ \\
\hline $\mathrm{TiO}_{2}$ & - & - & - & - & - \\
\hline $\mathrm{ZnO}$ & $0.02 \%$ & $0.01 \%$ & $0.01 \%$ & $0.016 \%$ & $0.017 \%$ \\
\hline $\mathrm{ZrO}_{2}$ & $2.83 \%$ & $2.39 \%$ & $1.95 \%$ & $2.823 \%$ & $3.005 \%$ \\
\hline TOTAL & $100.0 \%$ & $100.0 \%$ & $100.0 \%$ & $100.0 \%$ & $100.0 \%$ \\
\hline
\end{tabular}

(a) - Empty data field (components not present in glass).

(b) Compositions of HLW-E-SP-09 and -10 expanded to 3 decimal places to show concentrations of noble metals. 
ORP-56294 Rev. 0

The Catholic University of America Vitreous State Laboratory

Effects of High Crystal Content in HLW DM100 Melter Tests

Final Report, VSL-09R1520-1, Rev. 0

Table 2.4. Analyzed (XRF) Compositions of the HLW-E-SP Glasses.

\begin{tabular}{|c|c|c|c|c|c|}
\hline Oxide & HLW-E-SP-01 & HLW-E-SP-02 & HLW-E-SP-03 & HLW-E-SP-04 & HLW-E-SP-05 \\
\hline $\mathrm{Al}_{2} \mathrm{O}_{3}$ & $25.09 \%$ & $26.40 \%$ & $28.13 \%$ & $8.34 \%$ & $9.57 \%$ \\
\hline $\mathrm{B}_{2} \mathrm{O}_{3}{ }^{(a)}$ & $14.38 \%$ & $13.58 \%$ & $12.77 \%$ & $13.57 \%$ & $12.08 \%$ \\
\hline $\mathrm{BaO}$ & $0.08 \%$ & $0.06 \%$ & $0.05 \%$ & — $^{\text {(b) }}$ & - \\
\hline $\mathrm{Bi}_{2} \mathrm{O}_{3}$ & $1.38 \%$ & $1.48 \%$ & $1.47 \%$ & - & - \\
\hline $\mathrm{CaO}$ & $6.34 \%$ & $6.15 \%$ & $5.74 \%$ & $0.37 \%$ & $0.43 \%$ \\
\hline $\mathrm{CdO}$ & - & - & - & $0.17 \%$ & $0.19 \%$ \\
\hline $\mathrm{Ce}_{2} \mathrm{O}_{3}$ & $0.01 \%$ & $0.01 \%$ & $0.01 \%$ & - & - \\
\hline $\mathrm{CoO}$ & - & - & $0.00 \%$ & $0.01 \%$ & $0.01 \%$ \\
\hline $\mathrm{Cr}_{2} \mathrm{O}_{3}$ & $0.69 \%$ & $0.76 \%$ & $0.79 \%$ & $0.17 \%$ & $0.19 \%$ \\
\hline $\mathrm{Cs}_{2} \mathrm{O}$ & - & - & - & $0.09 \%$ & $0.10 \%$ \\
\hline $\mathrm{Er}_{2} \mathrm{O}_{3}$ & $0.02 \%$ & $0.01 \%$ & $0.01 \%$ & $0.02 \%$ & $0.02 \%$ \\
\hline $\mathrm{Fe}_{2} \mathrm{O}_{3}$ & $6.43 \%$ & $6.97 \%$ & $7.04 \%$ & $17.33 \%$ & $20.42 \%$ \\
\hline $\mathrm{HfO}_{2}$ & - & $0.01 \%$ & - & $0.06 \%$ & $0.08 \%$ \\
\hline $\mathrm{K}_{2} \mathrm{O}$ & $0.19 \%$ & $0.21 \%$ & $0.20 \%$ & $7.10 \%$ & $6.92 \%$ \\
\hline $\mathrm{La}_{2} \mathrm{O}_{3}$ & - & - & - & $0.50 \%$ & $0.59 \%$ \\
\hline $\mathrm{Li}_{2} \mathrm{O}^{(\mathrm{a})}$ & $3.40 \%$ & $3.22 \%$ & $3.05 \%$ & $1.16 \%$ & $1.10 \%$ \\
\hline $\mathrm{MgO}$ & $0.07 \%$ & $0.08 \%$ & $0.08 \%$ & $0.00 \%$ & $0.09 \%$ \\
\hline $\mathrm{MnO}$ & - & - & - & $0.52 \%$ & $0.62 \%$ \\
\hline $\mathrm{Na}_{2} \mathrm{O}$ & $9.67 \%$ & $9.76 \%$ & $10.31 \%$ & $11.00 \%$ & $9.21 \%$ \\
\hline $\mathrm{Nd}_{2} \mathrm{O}_{3}$ & $0.00 \%$ & $0.00 \%$ & $0.00 \%$ & $0.29 \%$ & $0.32 \%$ \\
\hline $\mathrm{NiO}$ & $0.43 \%$ & $0.46 \%$ & $0.46 \%$ & $0.62 \%$ & $0.64 \%$ \\
\hline $\mathrm{P}_{2} \mathrm{O}_{5}$ & $1.29 \%$ & $1.39 \%$ & $1.45 \%$ & $0.07 \%$ & $0.07 \%$ \\
\hline $\mathrm{PbO}$ & $0.44 \%$ & $0.46 \%$ & $0.46 \%$ & $0.10 \%$ & $0.11 \%$ \\
\hline $\mathrm{Rh}_{2} \mathrm{O}_{3}$ & - & - & - & - & - \\
\hline $\mathrm{RuO}_{2}$ & - & - & - & - & - \\
\hline $\mathrm{SO}_{3}$ & $0.23 \%$ & $0.30 \%$ & $0.29 \%$ & $0.28 \%$ & $0.32 \%$ \\
\hline $\mathrm{SiO}_{2}$ & $29.24 \%$ & $28.06 \%$ & $27.02 \%$ & $35.64 \%$ & $33.87 \%$ \\
\hline $\mathrm{SnO}_{2}$ & $0.02 \%$ & $0.02 \%$ & $0.01 \%$ & $0.03 \%$ & $0.03 \%$ \\
\hline $\mathrm{SrO}$ & $0.01 \%$ & $0.01 \%$ & $0.01 \%$ & $0.01 \%$ & $0.01 \%$ \\
\hline $\mathrm{TiO}_{2}$ & $0.03 \%$ & $0.03 \%$ & $0.04 \%$ & $0.02 \%$ & $0.02 \%$ \\
\hline $\mathrm{ZnO}$ & $0.12 \%$ & $0.12 \%$ & $0.12 \%$ & $0.06 \%$ & $0.07 \%$ \\
\hline $\mathrm{ZrO}_{2}$ & $0.44 \%$ & $0.45 \%$ & $0.44 \%$ & $2.40 \%$ & $2.85 \%$ \\
\hline TOTAL & $100 \%$ & $100 \%$ & $100 \%$ & $100 \%$ & $100 \%$ \\
\hline
\end{tabular}

(a) Target values (boldface) are used for $\mathrm{B}_{2} \mathrm{O}_{3}$ and $\mathrm{Li}_{2} \mathrm{O}$.

(b) - Empty data field (components not present in glass). 
ORP-56294 Rev. 0

The Catholic University of America Vitreous State Laboratory

Effects of High Crystal Content in HLW DM100 Melter Tests

Final Report, VSL-09R1520-1, Rev. 0

Table 2.4. Analyzed (XRF) Compositions of the HLW-E-SP Glasses (continued).

\begin{tabular}{|c|c|c|c|c|c|}
\hline Oxide & HLW-E-SP-06 & HLW-E-SP-07 & HLW-E-SP-08 & HLW-E-SP-09 & HLW-E-SP-10 \\
\hline $\mathrm{Al}_{2} \mathrm{O}_{3}$ & $8.67 \%$ & $7.49 \%$ & $6.30 \%$ & $9.01 \%$ & $9.56 \%$ \\
\hline $\mathrm{B}_{2} \mathrm{O}_{3}{ }^{(\mathrm{a})}$ & $13.30 \%$ & $13.01 \%$ & $13.38 \%$ & $13.29 \%$ & $12.07 \%$ \\
\hline $\mathrm{BaO}$ & - $^{\text {(b) }}$ & - & - & - & - \\
\hline $\mathrm{Bi}_{2} \mathrm{O}_{3}$ & - & - & - & - & - \\
\hline $\mathrm{CaO}$ & $0.41 \%$ & $0.35 \%$ & $0.29 \%$ & $0.40 \%$ & $0.44 \%$ \\
\hline $\mathrm{CdO}$ & $0.19 \%$ & $0.16 \%$ & $0.14 \%$ & $0.19 \%$ & $0.19 \%$ \\
\hline $\mathrm{Ce}_{2} \mathrm{O}_{3}$ & - & $0.01 \%$ & - & $0.01 \%$ & - \\
\hline $\mathrm{CoO}$ & $0.01 \%$ & $0.01 \%$ & $0.01 \%$ & $0.01 \%$ & $0.01 \%$ \\
\hline $\mathrm{Cr}_{2} \mathrm{O}_{3}$ & $0.19 \%$ & $0.16 \%$ & $0.13 \%$ & $0.17 \%$ & $0.18 \%$ \\
\hline $\mathrm{Cs}_{2} \mathrm{O}$ & $0.10 \%$ & $0.08 \%$ & $0.08 \%$ & $0.11 \%$ & $0.12 \%$ \\
\hline $\mathrm{Er}_{2} \mathrm{O}_{3}$ & $0.04 \%$ & $0.02 \%$ & $0.02 \%$ & $0.02 \%$ & $0.03 \%$ \\
\hline $\mathrm{Fe}_{2} \mathrm{O}_{3}$ & $20.03 \%$ & $16.60 \%$ & $13.37 \%$ & $19.02 \%$ & $20.24 \%$ \\
\hline $\mathrm{HfO}_{2}$ & $0.08 \%$ & $0.06 \%$ & - & $0.07 \%$ & $0.07 \%$ \\
\hline $\mathrm{K}_{2} \mathrm{O}$ & $7.11 \%$ & $7.75 \%$ & $4.72 \%$ & $6.73 \%$ & $7.12 \%$ \\
\hline $\mathrm{La}_{2} \mathrm{O}_{3}$ & $0.60 \%$ & $0.46 \%$ & $0.37 \%$ & $0.54 \%$ & $0.61 \%$ \\
\hline $\mathrm{Li}_{2} \mathrm{O}^{(\mathrm{a})}$ & $1.17 \%$ & $1.21 \%$ & $1.46 \%$ & $1.17 \%$ & $1.10 \%$ \\
\hline $\mathrm{MgO}$ & $0.08 \%$ & $0.09 \%$ & $0.08 \%$ & $0.08 \%$ & $0.06 \%$ \\
\hline $\mathrm{MnO}$ & $0.61 \%$ & $0.51 \%$ & $0.41 \%$ & $0.57 \%$ & $0.59 \%$ \\
\hline $\mathrm{Na}_{2} \mathrm{O}$ & $10.35 \%$ & $11.62 \%$ & $13.70 \%$ & $10.95 \%$ & $9.76 \%$ \\
\hline $\mathrm{Nd}_{2} \mathrm{O}_{3}$ & $0.33 \%$ & $0.27 \%$ & $0.21 \%$ & $0.30 \%$ & $0.29 \%$ \\
\hline $\mathrm{NiO}$ & $0.70 \%$ & $0.59 \%$ & $0.48 \%$ & $0.62 \%$ & $0.61 \%$ \\
\hline $\mathrm{P}_{2} \mathrm{O}_{5}$ & $0.08 \%$ & $0.07 \%$ & $0.06 \%$ & $0.07 \%$ & $0.07 \%$ \\
\hline $\mathrm{PbO}$ & $0.11 \%$ & $0.10 \%$ & $0.07 \%$ & $0.11 \%$ & $0.11 \%$ \\
\hline $\mathrm{Rh}_{2} \mathrm{O}_{3}$ & - & $0.00 \%$ & - & $0.01 \%$ & $0.01 \%$ \\
\hline $\mathrm{RuO}_{2}$ & - & - & $0.21 \%$ & $0.08 \%$ & $0.08 \%$ \\
\hline $\mathrm{SO}_{3}$ & $0.28 \%$ & $0.26 \%$ & - & $0.28 \%$ & $0.29 \%$ \\
\hline $\mathrm{SiO}_{2}$ & $32.54 \%$ & $36.67 \%$ & $42.45 \%$ & $33.32 \%$ & $33.44 \%$ \\
\hline $\mathrm{SnO}_{2}$ & $0.04 \%$ & $0.02 \%$ & $0.03 \%$ & $0.03 \%$ & $0.02 \%$ \\
\hline $\mathrm{SrO}$ & $0.01 \%$ & $0.01 \%$ & - & $0.01 \%$ & $0.01 \%$ \\
\hline $\mathrm{TiO}_{2}$ & $0.01 \%$ & $0.02 \%$ & $0.02 \%$ & $0.01 \%$ & $0.02 \%$ \\
\hline $\mathrm{ZnO}$ & $0.08 \%$ & $0.06 \%$ & $0.05 \%$ & $0.07 \%$ & $0.05 \%$ \\
\hline $\mathrm{ZrO}_{2}$ & $2.85 \%$ & $2.32 \%$ & $1.90 \%$ & $2.68 \%$ & $2.79 \%$ \\
\hline TOTAL & $100 \%$ & $100 \%$ & $100 \%$ & $100 \%$ & $100 \%$ \\
\hline
\end{tabular}

(a) Target values (boldface) are used for $\mathrm{B}_{2} \mathrm{O}_{3}$ and $\mathrm{Li}_{2} \mathrm{O}$.

(b) - Empty data field (components not present in glass). 
The Catholic University of America Vitreous State Laboratory
ORP-56294 Rev. 0

Effects of High Crystal Content in HLW DM100 Melter Tests

Final Report, VSL-09R1520-1, Rev. 0

Table 2.5. Characterization Data for the HLW-E-SP Series of Glasses.

\begin{tabular}{|c|c|c|c|c|c|}
\hline & Property & HLW-E-SP-01 & HLW-E-SP-02 & HLW-E-SP-03 & HLW-E-SP-04 \\
\hline & Waste Loading & $48.00 \%$ & $51.00 \%$ & $54.00 \%$ & $35.73 \%$ \\
\hline & As-Melted at $1200^{\circ} \mathrm{C}(\mathrm{vol} \%)$ & $1.0(\mathrm{Sp})$ & $1.6(\mathrm{Sp})$ & $2.5(\mathrm{Sp})$ & 0.0 \\
\hline & After HT at $1150^{\circ} \mathrm{C}(\mathrm{vol} \%)$ & $0.8(\mathrm{Sp})$ & $1.0(\mathrm{Sp})$ & $1.6(\mathrm{Sp})$ & $1.0(\mathrm{Sp})$ \\
\hline$\stackrel{\text { ङ }}{\rightleftarrows}$ & After HT at $1050^{\circ} \mathrm{C}$ (vol\%) & $2.9(\mathrm{Sp})$ & $3.3(\mathrm{Sp})$ & $4.1(\mathrm{Sp})$ & $1.3(\mathrm{Sp})^{(\mathrm{b})}$ \\
\hline$\frac{\tilde{0}}{\pi}$ & After $\mathrm{HT}$ at $950^{\circ} \mathrm{C}(\mathrm{vol} \%)$ & $2.4(\mathrm{Sp}, \mathrm{CP})$ & $3.9(\mathrm{Sp}, \mathrm{CP})$ & $4.7(\mathrm{Sp}, \mathrm{CP})$ & $\begin{array}{c}2.6(\mathrm{Sp}, \\
\text { Trace Fe) }\end{array}$ \\
\hline 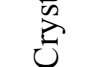 & After HT at $850^{\circ} \mathrm{C}(\mathrm{vol} \%)$ & $5.2(\mathrm{Sp}, \mathrm{CP})$ & $6.8(\mathrm{Sp}, \mathrm{CP})$ & $7.8(\mathrm{Sp}, \mathrm{CP})$ & $-^{(\mathrm{c})}$ \\
\hline & After $\mathrm{HT}$ at $750^{\circ} \mathrm{C}(\mathrm{vol} \%)$ & $10.3(\mathrm{Sp}, \mathrm{CP})$ & $12.4(\mathrm{Sp}, \mathrm{CP}, \mathrm{Si})$ & $20.6(\mathrm{Sp}, \mathrm{CP}, \mathrm{Si})$ & - \\
\hline & $\begin{array}{l}\text { Approximate Average } \\
\text { Particle Size }\end{array}$ & $4 \mu \mathrm{m}$ & $3 \mu \mathrm{m}$ & $3 \mu \mathrm{m}$ & $40 \mu \mathrm{m}$ \\
\hline & $950^{\circ} \mathrm{C}$ & - & - & - & - \\
\hline 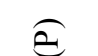 & $1000^{\circ} \mathrm{C}$ & - & - & - & - \\
\hline$\stackrel{5}{0}$ & $1050^{\circ} \mathrm{C}$ & - & - & - & - \\
\hline$>$ & $1100^{\circ} \mathrm{C}$ & - & - & - & - \\
\hline & $1150^{\circ} \mathrm{C}$ & - & - & - & - \\
\hline & $950^{\circ} \mathrm{C}$ & - & - & - & - \\
\hline 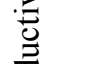 & $1000^{\circ} \mathrm{C}$ & - & - & - & - \\
\hline ठ & $1050^{\circ} \mathrm{C}$ & - & - & - & - \\
\hline$\stackrel{\Xi}{\Xi}$ & $1100^{\circ} \mathrm{C}$ & - & - & - & - \\
\hline & $1150^{\circ} \mathrm{C}$ & - & - & - & - \\
\hline & B (g/l) & - & - & - & - \\
\hline 气 & $\operatorname{Li}(\mathrm{g} / \mathrm{l})$ & - & - & - & - \\
\hline$z_{2}$ & $\mathrm{Na}(\mathrm{g} / \mathrm{l})$ & - & - & - & - \\
\hline
\end{tabular}

(a) Glass melting time $=2$ hours, Heat treatment time $=70$ hours, $\mathrm{Sp}=\mathrm{Spinel}, \mathrm{CP}=$ Calcium Phosphate, $\mathrm{Si}=\mathrm{Silicate}$ with $\mathrm{Na}, \mathrm{Ca}$, and $\mathrm{Al} ; \mathrm{Fe}=$ Iron Oxide.

(b) Heat treated at $1100^{\circ} \mathrm{C}$

(c) - Empty data field (Not Analyzed). 
Table 2.5. Characterization Data for the HLW-E-SP Series of Glasses (continued).

\begin{tabular}{|c|c|c|c|c|c|}
\hline & Property & HLW-E-SP-05 & HLW-E-SP-06 & HLW-E-SP-07 & HLW-E-SP-08 \\
\hline & Waste Loading & $41.23 \%$ & $38.73 \%$ & $32.73 \%$ & $26.73 \%$ \\
\hline & As-Melted at $1200^{\circ} \mathrm{C}(\mathrm{vol} \%)$ & $1.5(\mathrm{Sp})$ & $0.4(\mathrm{Sp})$ & 0 & 0 \\
\hline & After $\mathrm{HT}$ at $1150^{\circ} \mathrm{C}(\mathrm{vol} \%)$ & $2.9(\mathrm{Sp})$ & $1.3(\mathrm{Sp})$ & 0 & 0 \\
\hline 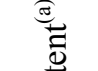 & After $\mathrm{HT}$ at $1100^{\circ} \mathrm{C}(\mathrm{vol} \%)$ & $4.0(\mathrm{Sp})$ & $1.0(\mathrm{Sp})$ & 0 & 0 \\
\hline$\overline{0}$ & After $\mathrm{HT}$ at $1000^{\circ} \mathrm{C}(\mathrm{vol} \%)$ & $4.0(\mathrm{Sp}, \mathrm{Fe})$ & $1.4(\mathrm{Sp})$ & $1.0(\mathrm{Sp})$ & 0 \\
\hline$\overbrace{\vec{\theta}}^{\infty}$ & After $\mathrm{HT}$ at $950^{\circ} \mathrm{C}(\mathrm{vol} \%)$ & $4.2(\mathrm{Sp})$ & $2.2(\mathrm{Sp})$ & $1.9(\mathrm{Sp})$ & 0 \\
\hline & After $\mathrm{HT}$ at $900^{\circ} \mathrm{C}(\mathrm{vol} \%)$ & $5.2(\mathrm{Sp})$ & $2.9(\mathrm{Sp})$ & $3.0(\mathrm{Sp})$ & 0 \\
\hline & $\begin{array}{c}\text { Approximate Average } \\
\text { Particle Size }\end{array}$ & $5 \mu \mathrm{m}$ & $10 \mu \mathrm{m}$ & $50 \mu \mathrm{m}$ & Not Applicable \\
\hline & $950^{\circ} \mathrm{C}$ & $3250.9\left(960^{\circ} \mathrm{C}\right)^{(b)}$ & $323.1\left(963^{\circ} \mathrm{C}\right)^{(b)}$ & 376.3 & - $^{(\mathrm{c})}$ \\
\hline$\overparen{\theta}$ & $1000^{\circ} \mathrm{C}$ & $222.1\left(1060^{\circ} \mathrm{C}\right)$ & $107.7\left(1062^{\circ} \mathrm{C}\right)$ & 195.5 & - \\
\hline$\stackrel{5}{0}$ & $1050^{\circ} \mathrm{C}$ & $60.6\left(1162^{\circ} \mathrm{C}\right)$ & $40.4\left(1161^{\circ} \mathrm{C}\right)$ & 111.5 & - \\
\hline$>$ & $1100^{\circ} \mathrm{C}$ & $33.7\left(1263^{\circ} \mathrm{C}\right)$ & - & 68.3 & - \\
\hline & $1150^{\circ} \mathrm{C}$ & - & - & 44.5 & - \\
\hline & $950^{\circ} \mathrm{C}$ & 0.076 & 0.078 & - & - \\
\hline 苞 & $1000^{\circ} \mathrm{C}$ & 0.096 & 0.105 & - & - \\
\hline ठํ & $1050^{\circ} \mathrm{C}$ & 0.119 & 0.137 & - & - \\
\hline & $1100^{\circ} \mathrm{C}$ & 0.145 & 0.175 & - & - \\
\hline & $1150^{\circ} \mathrm{C}$ & 0.175 & 0.218 & - & - \\
\hline ] $\widehat{d}$ & $\mathrm{~B}(\mathrm{~g} / \mathrm{l})$ & 1.229 & 0.521 & - & - \\
\hline $\bar{\Xi}$ & $\mathrm{Li}(\mathrm{g} / \mathrm{l})$ & 1.036 & 0.227 & - & - \\
\hline$z_{2}$ & $\mathrm{Na}(\mathrm{g} / \mathrm{l})$ & 0.955 & 0.568 & - & - \\
\hline
\end{tabular}

(a) Glass melting time $=2$ hours, Heat treatment time $=70$ hours, $\mathrm{Sp}=$ Spinel, $\mathrm{Fe}=$ Iron Oxide.

(b) Fitting of viscosity data was not performed for HLW-E-SP-05 and -06 because non-Newtonian behavior observed. Apparent viscosity data at selected shear rate $(1.51 / \mathrm{s})$ and temperatures are reported for these two glasses.

(c) - Empty data field (Not Analyzed). 
Table 2.5. Characterization Data for the HLW-E-SP Series of Glasses (continued).

\begin{tabular}{|c|c|c|c|}
\hline & Property & HLW-E-SP-09 & HLW-E-SP-10 \\
\hline & Waste Loading & $38.73 \%$ & $41.23 \%$ \\
\hline & As-Melted at $1200^{\circ} \mathrm{C}(\mathrm{vol} \%)$ & - $^{\text {(b) }}$ & $2.3(\mathrm{Sp})$ \\
\hline & After $\mathrm{HT}$ at $1150^{\circ} \mathrm{C}(\mathrm{vol} \%)$ & $2.1(\mathrm{Sp})$ & $3.1(\mathrm{Sp})$ \\
\hline 苛 & After $\mathrm{HT}$ at $1100^{\circ} \mathrm{C}(\mathrm{vol} \%)$ & $2.4(\mathrm{Sp})$ & $2.7(\mathrm{Sp})$ \\
\hline$\stackrel{0}{3}$ & After $\mathrm{HT}$ at $1000^{\circ} \mathrm{C}(\mathrm{vol} \%)$ & $2.9(\mathrm{Sp}, \mathrm{Fe})$ & $4.4(\mathrm{Sp})$ \\
\hline$\sum_{i}^{\infty}$ & After $\mathrm{HT}$ at $950^{\circ} \mathrm{C}(\mathrm{vol} \%)$ & $3.8(\mathrm{Sp})$ & $5.1(\mathrm{Sp})$ \\
\hline & After HT at $900^{\circ} \mathrm{C}(\mathrm{vol} \%)$ & $4.1(\mathrm{Sp})$ & $5.3(\mathrm{Sp})$ \\
\hline & $\begin{array}{l}\text { Approximate Average } \\
\text { Particle Size }\end{array}$ & $5 \mu \mathrm{m}$ & $5 \mu \mathrm{m}$ \\
\hline & $950^{\circ} \mathrm{C}$ & - & - \\
\hline E & $1000^{\circ} \mathrm{C}$ & - & - \\
\hline$\stackrel{\substack{0 \\
0}}{0}$ & $1050^{\circ} \mathrm{C}$ & - & - \\
\hline$>$ & $1100^{\circ} \mathrm{C}$ & - & - \\
\hline & $1150^{\circ} \mathrm{C}$ & - & - \\
\hline & $950^{\circ} \mathrm{C}$ & - & - \\
\hline 总 & $1000^{\circ} \mathrm{C}$ & - & - \\
\hline نं $\frac{\tilde{0}}{0}$ & $1050^{\circ} \mathrm{C}$ & - & - \\
\hline$\stackrel{\stackrel{\mathscr{E}}{\mathrm{E}}}{\mathrm{U}}$ & $1100^{\circ} \mathrm{C}$ & - & - \\
\hline & $1150^{\circ} \mathrm{C}$ & - & - \\
\hline 엉 & $\mathrm{B}(\mathrm{g} / \mathrm{l})$ & - & - \\
\hline 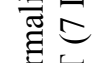 & $\operatorname{Li}(g / 1)$ & - & - \\
\hline$z_{2}$ & $\mathrm{Na}(\mathrm{g} / \mathrm{l})$ & - & - \\
\hline
\end{tabular}

(a) Glass melting time $=2$ hours, Heat treatment time $=70$ hours, $\mathrm{Sp}=$ Spinel, $\mathrm{Fe}=$ Iron Oxide. (b) - Empty data field (Not Analyzed). 
Table 2.6. Target Compositions of HLW Glasses (HLW-E-ES) Formulated to Study Crystallization of Chromium Oxide (Eskolaite) Phase.

\begin{tabular}{|c|c|c|c|c|c|}
\hline Oxide & HLW-E-ES-01 & HLW-E-ES-02 & HLW-E-ES-03 & HLW-E-ES-04 & HLW-E-ES-05 \\
\hline $\mathrm{Al}_{2} \mathrm{O}_{3}$ & $12.55 \%$ & $12.36 \%$ & $12.17 \%$ & $11.98 \%$ & $10.86 \%$ \\
\hline $\mathrm{B}_{2} \mathrm{O}_{3}$ & $13.76 \%$ & $13.55 \%$ & $13.34 \%$ & $13.13 \%$ & $14.80 \%$ \\
\hline $\mathrm{BaO}$ & $0.01 \%$ & $0.01 \%$ & $0.01 \%$ & $0.01 \%$ & $0.01 \%$ \\
\hline $\mathrm{Bi}_{2} \mathrm{O}_{3}$ & $3.58 \%$ & $3.53 \%$ & $3.47 \%$ & $3.42 \%$ & $3.53 \%$ \\
\hline $\mathrm{CaO}$ & $1.21 \%$ & $1.20 \%$ & $1.18 \%$ & $1.16 \%$ & $1.20 \%$ \\
\hline $\mathrm{Cr}_{2} \mathrm{O}_{3}$ & $1.51 \%$ & $3.00 \%$ & $4.50 \%$ & $6.00 \%$ & $3.00 \%$ \\
\hline $\mathrm{Cs}_{2} \mathrm{O}$ & - $^{\text {(a) }}$ & - & - & - & - \\
\hline $\mathrm{F}$ & $0.98 \%$ & $0.97 \%$ & $0.95 \%$ & $0.94 \%$ & $0.97 \%$ \\
\hline $\mathrm{Fe}_{2} \mathrm{O}_{3}$ & $6.45 \%$ & $6.36 \%$ & $6.26 \%$ & $6.16 \%$ & $6.36 \%$ \\
\hline $\mathrm{K}_{2} \mathrm{O}$ & $4.68 \%$ & $4.61 \%$ & $4.54 \%$ & $4.47 \%$ & $5.61 \%$ \\
\hline $\mathrm{Li}_{2} \mathrm{O}$ & $2.68 \%$ & $2.64 \%$ & $2.60 \%$ & $2.55 \%$ & $3.14 \%$ \\
\hline $\mathrm{MgO}$ & $0.08 \%$ & $0.08 \%$ & $0.08 \%$ & $0.08 \%$ & $0.08 \%$ \\
\hline $\mathrm{MnO}$ & - & - & - & - & - \\
\hline $\mathrm{Na}_{2} \mathrm{O}$ & $9.87 \%$ & $9.72 \%$ & $9.57 \%$ & $9.42 \%$ & $9.72 \%$ \\
\hline $\mathrm{NiO}$ & - & - & - & - & - \\
\hline $\mathrm{P}_{2} \mathrm{O}_{5}$ & $1.64 \%$ & $1.62 \%$ & $1.59 \%$ & $1.57 \%$ & $1.62 \%$ \\
\hline $\mathrm{PbO}$ & $0.24 \%$ & $0.23 \%$ & $0.23 \%$ & $0.23 \%$ & $0.23 \%$ \\
\hline $\mathrm{SO}_{3}$ & - & - & - & - & - \\
\hline $\mathrm{SiO}_{2}$ & $40.69 \%$ & $40.07 \%$ & $39.45 \%$ & $38.83 \%$ & $38.82 \%$ \\
\hline $\mathrm{TiO}_{2}$ & - & - & - & - & - \\
\hline $\mathrm{ZnO}$ & - & - & - & - & - \\
\hline $\mathrm{ZrO}_{2}$ & $0.05 \%$ & $0.05 \%$ & $0.05 \%$ & $0.05 \%$ & $0.05 \%$ \\
\hline TOTAL & $100.0 \%$ & $100.0 \%$ & $100.0 \%$ & $100.0 \%$ & $100.0 \%$ \\
\hline
\end{tabular}

(a) _ Empty data field (components not present in glass). 
Table 2.6. Target Compositions of HLW Glasses (HLW-E-ES) Formulated to Study Crystallization of Chromium Oxide (Eskolaite) Phase (continued).

\begin{tabular}{|c|c|c|c|c|c|}
\hline Oxide & HLW-E-ES-06 & HLW-E-ES-07 & HLW-E-ES-C16 & HLW-E-ES-08 & HLW-E-ES-09 \\
\hline $\mathrm{Al}_{2} \mathrm{O}_{3}$ & $11.01 \%$ & $11.48 \%$ & $4.50 \%$ & $4.41 \%$ & $11.06 \%$ \\
\hline $\mathrm{B}_{2} \mathrm{O}_{3}$ & $14.37 \%$ & $13.77 \%$ & $14.40 \%$ & $14.10 \%$ & $14.45 \%$ \\
\hline $\mathrm{BaO}$ & $0.01 \%$ & $0.01 \%$ & - $^{\text {(a) }}$ & - & $0.01 \%$ \\
\hline $\mathrm{Bi}_{2} \mathrm{O}_{3}$ & $3.15 \%$ & $3.28 \%$ & - & - & $3.16 \%$ \\
\hline $\mathrm{CaO}$ & $1.07 \%$ & $1.11 \%$ & - & - & $1.07 \%$ \\
\hline $\mathrm{Cr}_{2} \mathrm{O}_{3}$ & $3.00 \%$ & $3.00 \%$ & $2.85 \%$ & $2.85 \%$ & $1.33 \%$ \\
\hline $\mathrm{Cs}_{2} \mathrm{O}$ & - & - & - & - & - \\
\hline $\mathrm{F}$ & $0.87 \%$ & $0.90 \%$ & - & & $0.87 \%$ \\
\hline $\mathrm{Fe}_{2} \mathrm{O}_{3}$ & $5.66 \%$ & $5.90 \%$ & $4.50 \%$ & $4.41 \%$ & $5.69 \%$ \\
\hline $\mathrm{K}_{2} \mathrm{O}$ & $5.39 \%$ & $10.25 \%$ & $3.84 \%$ & $3.76 \%$ & $0.16 \%$ \\
\hline $\mathrm{Li}_{2} \mathrm{O}$ & $3.29 \%$ & $0.16 \%$ & $3.15 \%$ & $3.09 \%$ & $3.31 \%$ \\
\hline $\mathrm{MgO}$ & $0.07 \%$ & $0.07 \%$ & $0.36 \%$ & $0.35 \%$ & $0.07 \%$ \\
\hline $\mathrm{MnO}$ & - & - & - & $1.00 \%$ & - \\
\hline $\mathrm{Na}_{2} \mathrm{O}$ & $8.66 \%$ & $9.03 \%$ & $8.00 \%$ & $7.84 \%$ & $8.70 \%$ \\
\hline $\mathrm{NiO}$ & - & $0.48 \%$ & - & $1.00 \%$ & $0.46 \%$ \\
\hline $\mathrm{P}_{2} \mathrm{O}_{5}$ & $1.44 \%$ & $1.50 \%$ & - & - & $1.45 \%$ \\
\hline $\mathrm{PbO}$ & $0.21 \%$ & $0.22 \%$ & - & - & $0.21 \%$ \\
\hline $\mathrm{SO}_{3}$ & - & - & - & - & $0.66 \%$ \\
\hline $\mathrm{SiO}_{2}$ & $41.75 \%$ & $38.69 \%$ & $53.15 \%$ & $52.06 \%$ & $41.95 \%$ \\
\hline $\mathrm{TiO}_{2}$ & - & - & $5.25 \%$ & $5.14 \%$ & $5.25 \%$ \\
\hline $\mathrm{ZnO}$ & - & $0.11 \%$ & - & - & $0.11 \%$ \\
\hline $\mathrm{ZrO}_{2}$ & $0.05 \%$ & $0.05 \%$ & - & - & $0.05 \%$ \\
\hline TOTAL & $100.0 \%$ & $100.0 \%$ & $100.0 \%$ & $100.0 \%$ & $100.0 \%$ \\
\hline
\end{tabular}

(a) - Empty data field (components not present in glass). 
The Catholic University of America Vitreous State Laboratory
ORP-56294 Rev. 0

Effects of High Crystal Content in HLW DM100 Melter Tests

Final Report, VSL-09R1520-1, Rev. 0

Table 2.6. Target Compositions of HLW Glasses (HLW-E-ES) Formulated to Study Crystallization of Chromium Oxide (Eskolaite) Phase (continued).

\begin{tabular}{|c|c|c|c|c|c|}
\hline Oxide & HLW-E-ES-10 & HLW-E-ES-11 & HLW-E-ES-12 & HLW-E-ES-13 & HLW-E-ES-14 \\
\hline $\mathrm{Al}_{2} \mathrm{O}_{3}$ & $11.48 \%$ & $11.48 \%$ & $11.48 \%$ & $11.06 \%$ & $10.849 \%^{(\mathrm{b})}$ \\
\hline $\mathrm{B}_{2} \mathrm{O}_{3}$ & $9.77 \%$ & $13.77 \%$ & $12.52 \%$ & $14.45 \%$ & $14.790 \%$ \\
\hline $\mathrm{BaO}$ & $0.01 \%$ & $0.01 \%$ & $0.01 \%$ & $0.01 \%$ & $0.015 \%$ \\
\hline $\mathrm{Bi}_{2} \mathrm{O}_{3}$ & $3.28 \%$ & $3.28 \%$ & $3.28 \%$ & $3.16 \%$ & $3.526 \%$ \\
\hline $\mathrm{CaO}$ & $1.11 \%$ & $1.11 \%$ & $1.11 \%$ & $1.07 \%$ & $1.195 \%$ \\
\hline $\mathrm{Cr}_{2} \mathrm{O}_{3}$ & $3.00 \%$ & $3.00 \%$ & $3.00 \%$ & $1.99 \%$ & $2.997 \%$ \\
\hline $\mathrm{Cs}_{2} \mathrm{O}$ & - $^{\text {(a) }}$ & - & - & - & - \\
\hline $\mathrm{F}$ & $0.90 \%$ & $0.90 \%$ & $0.90 \%$ & $0.87 \%$ & $0.967 \%$ \\
\hline $\mathrm{Fe}_{2} \mathrm{O}_{3}$ & $5.90 \%$ & $5.90 \%$ & $5.90 \%$ & $5.69 \%$ & $6.351 \%$ \\
\hline $\mathrm{K}_{2} \mathrm{O}$ & $15.25 \%$ & $5.25 \%$ & $10.25 \%$ & $10.44 \%$ & $5.606 \%$ \\
\hline $\mathrm{Li}_{2} \mathrm{O}$ & $0.16 \%$ & $0.16 \%$ & $0.16 \%$ & $0.16 \%$ & $3.134 \%$ \\
\hline $\mathrm{MgO}$ & $0.07 \%$ & $0.07 \%$ & $0.07 \%$ & $0.07 \%$ & $0.077 \%$ \\
\hline $\mathrm{MnO}$ & - & - & - & - & - \\
\hline $\mathrm{Na}_{2} \mathrm{O}$ & $7.03 \%$ & $9.03 \%$ & $9.03 \%$ & $8.70 \%$ & $9.717 \%$ \\
\hline $\mathrm{NiO}$ & $0.48 \%$ & $0.48 \%$ & $0.48 \%$ & $0.46 \%$ & \\
\hline $\mathrm{P}_{2} \mathrm{O}_{5}$ & $1.50 \%$ & $1.50 \%$ & $1.50 \%$ & $1.45 \%$ & $1.615 \%$ \\
\hline $\mathrm{PbO}$ & $0.22 \%$ & $0.22 \%$ & $0.22 \%$ & $0.21 \%$ & $0.232 \%$ \\
\hline $\mathrm{PdO}$ & - & - & - & - & $0.002 \%$ \\
\hline $\mathrm{Rh}_{2} \mathrm{O}_{3}$ & - & - & - & - & $0.005 \%$ \\
\hline $\mathrm{RuO}_{2}$ & - & - & - & - & $0.077 \%$ \\
\hline $\mathrm{SO}_{3}$ & - & - & - & - & - \\
\hline $\mathrm{SiO}_{2}$ & $39.69 \%$ & $38.44 \%$ & $34.69 \%$ & $40.07 \%$ & $38.792 \%$ \\
\hline $\mathrm{TiO}_{2}$ & - & $5.25 \%$ & $5.25 \%$ & - & - \\
\hline $\mathrm{ZnO}$ & $0.11 \%$ & $0.11 \%$ & $0.11 \%$ & $0.11 \%$ & - \\
\hline $\mathrm{ZrO}_{2}$ & $0.05 \%$ & $0.05 \%$ & $0.05 \%$ & $0.05 \%$ & $0.053 \%$ \\
\hline TOTAL & $100.0 \%$ & $100.0 \%$ & $100.0 \%$ & $100.0 \%$ & $100.0 \%$ \\
\hline
\end{tabular}

(a) - Empty data field (components not present in glass).

(b) Composition of HLW-E-ES-14 given in 3 decimal places to show concentrations of noble metals. 
Table 2.6. Target Compositions of HLW Glasses (HLW-E-ES) Formulated to Study Crystallization of Chromium Oxide (Eskolaite) Phase (continued).

\begin{tabular}{|c|c|c|}
\hline Oxide & HLW-E-ES-15 & HLW-E-ES-16 \\
\hline $\mathrm{Al}_{2} \mathrm{O}_{3}$ & $11.06 \%$ & $11.06 \%$ \\
\hline $\mathrm{B}_{2} \mathrm{O}_{3}$ & $13.98 \%$ & $12.48 \%$ \\
\hline $\mathrm{BaO}$ & $0.01 \%$ & $0.01 \%$ \\
\hline $\mathrm{Bi}_{2} \mathrm{O}_{3}$ & $3.16 \%$ & $3.16 \%$ \\
\hline $\mathrm{CaO}$ & $7.07 \%$ & $5.32 \%$ \\
\hline $\mathrm{Cr}_{2} \mathrm{O}_{3}$ & $1.33 \%$ & $1.33 \%$ \\
\hline $\mathrm{Cs}_{2} \mathrm{O}$ & $-^{\text {(a) }}$ & - \\
\hline $\mathrm{F}$ & $0.87 \%$ & $0.87 \%$ \\
\hline $\mathrm{Fe}_{2} \mathrm{O}_{3}$ & $5.69 \%$ & $5.69 \%$ \\
\hline $\mathrm{K}_{2} \mathrm{O}$ & $5.16 \%$ & $4.41 \%$ \\
\hline $\mathrm{Li}_{2} \mathrm{O}$ & $0.16 \%$ & $0.16 \%$ \\
\hline $\mathrm{MgO}$ & $0.07 \%$ & $0.07 \%$ \\
\hline $\mathrm{MnO}$ & - & - \\
\hline $\mathrm{Na}_{2} \mathrm{O}$ & $8.70 \%$ & $8.70 \%$ \\
\hline $\mathrm{NiO}$ & $0.46 \%$ & $0.46 \%$ \\
\hline $\mathrm{P}_{2} \mathrm{O}_{5}$ & $1.45 \%$ & $1.45 \%$ \\
\hline $\mathrm{PbO}$ & $0.21 \%$ & $0.21 \%$ \\
\hline $\mathrm{SO}_{3}$ & $0.66 \%$ & $0.66 \%$ \\
\hline $\mathrm{SiO}_{2}$ & $39.82 \%$ & $39.57 \%$ \\
\hline $\mathrm{TiO}_{2}$ & - & $4.25 \%$ \\
\hline $\mathrm{ZnO}$ & $0.11 \%$ & $0.11 \%$ \\
\hline $\mathrm{ZrO}_{2}$ & $0.05 \%$ & $0.05 \%$ \\
\hline TOTAL & $100.0 \%$ & $100.0 \%$ \\
\hline
\end{tabular}

(a) _ Empty data field (components not present in glass). 
The Catholic University of America Vitreous State Laboratory
ORP-56294 Rev. 0

Effects of High Crystal Content in HLW DM100 Melter Tests

Final Report, VSL-09R1520-1, Rev. 0

Table 2.7. Analyzed (XRF) Compositions of the HLW-E-ES Glasses.

\begin{tabular}{|c|c|c|c|c|c|}
\hline Oxide & HLW-E-ES-01 & HLW-E-ES-02 & HLW-E-ES-03 & HLW-E-ES-04 & HLW-E-ES-05 \\
\hline $\mathrm{Al}_{2} \mathrm{O}_{3}$ & $12.28 \%$ & $11.98 \%$ & $12.16 \%$ & $11.97 \%$ & $10.90 \%$ \\
\hline $\mathrm{B}_{2} \mathrm{O}_{3}^{(\mathrm{a})}$ & $13.76 \%$ & $13.55 \%$ & $13.34 \%$ & $13.13 \%$ & $14.80 \%$ \\
\hline $\mathrm{BaO}$ & $0.01 \%$ & $0.03 \%$ & $0.03 \%$ & $0.02 \%$ & $0.01 \%$ \\
\hline $\mathrm{Bi}_{2} \mathrm{O}_{3}$ & $3.68 \%$ & $3.75 \%$ & $3.66 \%$ & $3.58 \%$ & $3.68 \%$ \\
\hline $\mathrm{CaO}$ & $1.26 \%$ & $1.26 \%$ & $1.19 \%$ & $1.21 \%$ & $1.28 \%$ \\
\hline $\mathrm{CdO}$ & $--^{(b)}$ & - & - & - & - \\
\hline $\mathrm{Ce}_{2} \mathrm{O}_{3}$ & - & - & - & - & - \\
\hline $\mathrm{CoO}$ & $0.00 \%$ & - & $0.01 \%$ & $0.00 \%$ & $0.00 \%$ \\
\hline $\mathrm{Cr}_{2} \mathrm{O}_{3}$ & $1.90 \%$ & $3.66 \%$ & $5.00 \%$ & $6.84 \%$ & $3.64 \%$ \\
\hline $\mathrm{Cs}_{2} \mathrm{O}$ & - & - & - & - & - \\
\hline $\mathrm{Er}_{2} \mathrm{O}_{3}$ & $0.01 \%$ & - & $0.01 \%$ & $0.01 \%$ & $0.01 \%$ \\
\hline $\mathrm{Fe}_{2} \mathrm{O}_{3}$ & $6.19 \%$ & $6.28 \%$ & $6.05 \%$ & $6.04 \%$ & $6.32 \%$ \\
\hline $\mathrm{HfO}_{2}$ & - & - & - & - & - \\
\hline $\mathrm{K}_{2} \mathrm{O}$ & $4.35 \%$ & $4.46 \%$ & $4.16 \%$ & $4.35 \%$ & $5.19 \%$ \\
\hline $\mathrm{La}_{2} \mathrm{O}_{3}$ & - & - & $0.01 \%$ & - & - \\
\hline $\mathrm{Li}_{2} \mathrm{O}^{(\mathrm{a})}$ & $2.68 \%$ & $2.64 \%$ & $2.60 \%$ & $2.55 \%$ & $3.14 \%$ \\
\hline $\mathrm{MgO}$ & - & - & $0.10 \%$ & $0.09 \%$ & - \\
\hline $\mathrm{MnO}$ & - & - & - & - & - \\
\hline $\mathrm{Na}_{2} \mathrm{O}$ & $11.74 \%$ & $11.11 \%$ & $10.23 \%$ & $9.57 \%$ & $9.80 \%$ \\
\hline $\mathrm{Nd}_{2} \mathrm{O}_{3}$ & - & $0.01 \%$ & - & - & - \\
\hline $\mathrm{NiO}$ & - & - & - & - & - \\
\hline $\mathrm{P}_{2} \mathrm{O}_{5}$ & $1.88 \%$ & $1.86 \%$ & $1.82 \%$ & $1.81 \%$ & $1.87 \%$ \\
\hline $\mathrm{PbO}$ & $0.22 \%$ & $0.22 \%$ & $0.21 \%$ & $0.21 \%$ & $0.22 \%$ \\
\hline $\mathrm{Rh}_{2} \mathrm{O}_{3}$ & - & - & - & - & - \\
\hline $\mathrm{RuO}_{2}$ & - & - & - & - & - \\
\hline $\mathrm{SO}_{3}$ & $0.07 \%$ & $0.06 \%$ & $0.07 \%$ & $0.07 \%$ & $0.08 \%$ \\
\hline $\mathrm{SiO}_{2}$ & $39.78 \%$ & $38.99 \%$ & $39.21 \%$ & $38.41 \%$ & $38.88 \%$ \\
\hline $\mathrm{SnO}_{2}$ & $0.02 \%$ & $0.02 \%$ & $0.02 \%$ & $0.02 \%$ & $0.01 \%$ \\
\hline $\mathrm{SrO}$ & $0.01 \%$ & $0.01 \%$ & $0.01 \%$ & $0.01 \%$ & $0.01 \%$ \\
\hline $\mathrm{TiO}_{2}$ & $0.02 \%$ & $0.01 \%$ & $0.02 \%$ & $0.02 \%$ & $0.01 \%$ \\
\hline $\mathrm{ZnO}$ & $0.02 \%$ & $0.02 \%$ & $0.02 \%$ & $0.02 \%$ & $0.02 \%$ \\
\hline $\mathrm{ZrO}_{2}$ & $0.06 \%$ & $0.05 \%$ & $0.05 \%$ & $0.05 \%$ & $0.06 \%$ \\
\hline TOTAL & $100 \%$ & $100 \%$ & $100 \%$ & $100 \%$ & $100 \%$ \\
\hline
\end{tabular}

(a) Target values (boldface) are used for $\mathrm{B}_{2} \mathrm{O}_{3}$ and $\mathrm{Li}_{2} \mathrm{O}$.

(b) - Empty data field (components not present in glass). 
The Catholic University of America Vitreous State Laboratory
ORP-56294 Rev. 0

Effects of High Crystal Content in HLW DM100 Melter Tests

Final Report, VSL-09R1520-1, Rev. 0

Table 2.7. Analyzed (XRF) Compositions of the HLW-E-ES Glasses (continued).

\begin{tabular}{|c|c|c|c|c|c|}
\hline Oxide & HLW-E-ES-06 & HLW-E-ES-07 & HLW-E-ES-C16 & HLW-E-ES-08 & HLW-E-ES-09 \\
\hline $\mathrm{Al}_{2} \mathrm{O}_{3}$ & $11.15 \%$ & $11.56 \%$ & $4.74 \%$ & $4.66 \%$ & $11.04 \%$ \\
\hline $\mathrm{B}_{2} \mathrm{O}_{3}{ }^{(\mathrm{a})}$ & $14.37 \%$ & $13.77 \%$ & $14.40 \%$ & $14.10 \%$ & $14.45 \%$ \\
\hline $\mathrm{BaO}$ & $0.01 \%$ & $0.01 \%$ & - & - & $0.01 \%$ \\
\hline $\mathrm{Bi}_{2} \mathrm{O}_{3}$ & $3.35 \%$ & $3.33 \%$ & $0.00 \%$ & - & $3.39 \%$ \\
\hline $\mathrm{CaO}$ & $1.14 \%$ & $1.14 \%$ & $0.03 \%$ & $0.03 \%$ & $1.16 \%$ \\
\hline $\mathrm{CdO}$ & $-{ }^{(\mathrm{b})}$ & - & - & - & - \\
\hline $\mathrm{Ce}_{2} \mathrm{O}_{3}$ & - & - & - & - & - \\
\hline $\mathrm{CoO}$ & $0.00 \%$ & $0.00 \%$ & - & - & - \\
\hline $\mathrm{Cr}_{2} \mathrm{O}_{3}$ & $3.55 \%$ & $3.48 \%$ & $3.25 \%$ & $3.26 \%$ & $1.53 \%$ \\
\hline $\mathrm{Cs}_{2} \mathrm{O}$ & - & - & - & - & - \\
\hline $\mathrm{Er}_{2} \mathrm{O}_{3}$ & - & $0.01 \%$ & - & - & $0.01 \%$ \\
\hline $\mathrm{Fe}_{2} \mathrm{O}_{3}$ & $5.66 \%$ & $5.73 \%$ & $4.48 \%$ & $4.33 \%$ & $5.71 \%$ \\
\hline $\mathrm{HfO}_{2}$ & - & - & - & - & - \\
\hline $\mathrm{K}_{2} \mathrm{O}$ & $4.79 \%$ & $9.89 \%$ & $3.88 \%$ & $3.76 \%$ & $0.21 \%$ \\
\hline $\mathrm{La}_{2} \mathrm{O}_{3}$ & - & $0.01 \%$ & - & - & - \\
\hline $\mathrm{Li}_{2} \mathrm{O}^{(\mathrm{a})}$ & $3.29 \%$ & $0.16 \%$ & $3.15 \%$ & $3.09 \%$ & $3.31 \%$ \\
\hline $\mathrm{MgO}$ & - & $0.05 \%$ & $0.35 \%$ & $0.29 \%$ & - \\
\hline $\mathrm{MnO}$ & - & - & - & $1.02 \%$ & - \\
\hline $\mathrm{Na}_{2} \mathrm{O}$ & $8.76 \%$ & $9.33 \%$ & $8.22 \%$ & $7.68 \%$ & $9.10 \%$ \\
\hline $\mathrm{Nd}_{2} \mathrm{O}_{3}$ & - & - & - & - & - \\
\hline $\mathrm{NiO}$ & - & $0.46 \%$ & - & $0.99 \%$ & $0.46 \%$ \\
\hline $\mathrm{P}_{2} \mathrm{O}_{5}$ & $1.65 \%$ & $1.73 \%$ & $0.04 \%$ & $0.04 \%$ & $1.61 \%$ \\
\hline $\mathrm{PbO}$ & $0.20 \%$ & $0.20 \%$ & $0.00 \%$ & $0.00 \%$ & $0.20 \%$ \\
\hline $\mathrm{Rh}_{2} \mathrm{O}_{3}$ & - & - & - & - & - \\
\hline $\mathrm{RuO}_{2}$ & - & - & - & - & $0.00 \%$ \\
\hline $\mathrm{SO}_{3}$ & $0.06 \%$ & $0.06 \%$ & $0.03 \%$ & $0.05 \%$ & $0.42 \%$ \\
\hline $\mathrm{SiO}_{2}$ & $41.85 \%$ & $38.85 \%$ & $52.01 \%$ & $51.34 \%$ & $41.53 \%$ \\
\hline $\mathrm{SnO}_{2}$ & $0.01 \%$ & - & - & $0.01 \%$ & $0.01 \%$ \\
\hline $\mathrm{SrO}$ & $0.01 \%$ & - & $0.01 \%$ & $0.01 \%$ & $0.01 \%$ \\
\hline $\mathrm{TiO}_{2}$ & $0.02 \%$ & $0.02 \%$ & $5.35 \%$ & $5.30 \%$ & $5.59 \%$ \\
\hline $\mathrm{ZnO}$ & $0.02 \%$ & $0.13 \%$ & - & $0.01 \%$ & $0.13 \%$ \\
\hline $\mathrm{ZrO}_{2}$ & $0.05 \%$ & $0.05 \%$ & $0.00 \%$ & $0.00 \%$ & $0.05 \%$ \\
\hline TOTAL & $100 \%$ & $100 \%$ & $100 \%$ & $100 \%$ & $100 \%$ \\
\hline
\end{tabular}

(a) Target values (boldface) are used for $\mathrm{B}_{2} \mathrm{O}_{3}$ and $\mathrm{Li}_{2} \mathrm{O}$.

(b) - Empty data field (components not present in glass). 
The Catholic University of America Vitreous State Laboratory
ORP-56294 Rev. 0

Effects of High Crystal Content in HLW DM100 Melter Tests

Final Report, VSL-09R1520-1, Rev. 0

Table 2.7. Analyzed (XRF) Compositions of the HLW-E-ES Glasses (continued).

\begin{tabular}{|c|c|c|c|c|c|}
\hline Oxide & HLW-E-ES-10 & HLW-E-ES-11 & HLW-E-ES-12 & HLW-E-ES-13 & HLW-E-ES-14 \\
\hline $\mathrm{Al}_{2} \mathrm{O}_{3}$ & $111.70 \%$ & $11.48 \%$ & $11.42 \%$ & $11.11 \%$ & $10.91 \%$ \\
\hline $\mathrm{B}_{2} \mathrm{O}_{3}^{(\mathrm{a})}$ & $9.77 \%$ & $13.77 \%$ & $12.52 \%$ & $14.45 \%$ & $14.79 \%$ \\
\hline $\mathrm{BaO}$ & $0.03 \%$ & $0.02 \%$ & $0.01 \%$ & $0.01 \%$ & $0.03 \%$ \\
\hline $\mathrm{Bi}_{2} \mathrm{O}_{3}$ & $3.58 \%$ & $3.34 \%$ & $3.38 \%$ & $3.25 \%$ & $3.52 \%$ \\
\hline $\mathrm{CaO}$ & $1.18 \%$ & $1.15 \%$ & $1.15 \%$ & $1.10 \%$ & $1.21 \%$ \\
\hline $\mathrm{CdO}$ & $--^{(b)}$ & - & - & - & - \\
\hline $\mathrm{Ce}_{2} \mathrm{O}_{3}$ & - & - & - & - & - \\
\hline $\mathrm{CoO}$ & $0.00 \%$ & $0.00 \%$ & $0.00 \%$ & $0.00 \%$ & - \\
\hline $\mathrm{Cr}_{2} \mathrm{O}_{3}$ & $2.15 \%$ & $3.35 \%$ & $3.45 \%$ & $2.32 \%$ & $3.36 \%$ \\
\hline $\mathrm{Cs}_{2} \mathrm{O}$ & $0.01 \%$ & - & - & - & - \\
\hline $\mathrm{Er}_{2} \mathrm{O}_{3}$ & $0.01 \%$ & - & $0.01 \%$ & $0.01 \%$ & $0.01 \%$ \\
\hline $\mathrm{Fe}_{2} \mathrm{O}_{3}$ & $6.13 \%$ & $5.65 \%$ & $5.73 \%$ & $5.60 \%$ & $6.00 \%$ \\
\hline $\mathrm{HfO}_{2}$ & - & - & - & - & - \\
\hline $\mathrm{K}_{2} \mathrm{O}$ & $14.65 \%$ & $5.20 \%$ & $10.03 \%$ & $10.16 \%$ & $5.46 \%$ \\
\hline $\mathrm{La}_{2} \mathrm{O}_{3}$ & - & - & - & - & - \\
\hline $\mathrm{Li}_{2} \mathrm{O}^{(\mathrm{a})}$ & $0.16 \%$ & $0.16 \%$ & $0.16 \%$ & $0.16 \%$ & $3.13 \%$ \\
\hline $\mathrm{MgO}$ & $0.07 \%$ & - & $0.05 \%$ & $0.05 \%$ & $0.06 \%$ \\
\hline $\mathrm{MnO}$ & - & - & - & - & - \\
\hline $\mathrm{Na}_{2} \mathrm{O}$ & $6.77 \%$ & $9.41 \%$ & $9.20 \%$ & $9.05 \%$ & $10.25 \%$ \\
\hline $\mathrm{Nd}_{2} \mathrm{O}_{3}$ & - & - & - & - & - \\
\hline $\mathrm{NiO}$ & $0.49 \%$ & $0.44 \%$ & $0.46 \%$ & $0.45 \%$ & - \\
\hline $\mathrm{P}_{2} \mathrm{O}_{5}$ & $1.66 \%$ & $1.71 \%$ & $1.69 \%$ & $1.62 \%$ & $1.83 \%$ \\
\hline $\mathrm{PbO}$ & $0.21 \%$ & $0.21 \%$ & $0.21 \%$ & $0.20 \%$ & $0.21 \%$ \\
\hline $\mathrm{Rh}_{2} \mathrm{O}_{3}$ & - & - & - & - & - \\
\hline $\mathrm{RuO}_{2}$ & - & - & - & - & $0.08 \%$ \\
\hline $\mathrm{SO}_{3}$ & $0.05 \%$ & $0.07 \%$ & $0.06 \%$ & $0.06 \%$ & $0.06 \%$ \\
\hline $\mathrm{SiO}_{2}$ & $41.15 \%$ & $38.41 \%$ & $34.78 \%$ & $40.19 \%$ & $39.00 \%$ \\
\hline $\mathrm{SnO}_{2}$ & $0.01 \%$ & - & $0.01 \%$ & $0.01 \%$ & $0.01 \%$ \\
\hline $\mathrm{SrO}$ & $0.01 \%$ & $0.01 \%$ & - & $0.01 \%$ & - \\
\hline $\mathrm{TiO}_{2}$ & $0.02 \%$ & $5.42 \%$ & $5.44 \%$ & $0.02 \%$ & $0.02 \%$ \\
\hline $\mathrm{ZnO}$ & $0.13 \%$ & $0.12 \%$ & $0.13 \%$ & $0.11 \%$ & $0.01 \%$ \\
\hline $\mathrm{ZrO}_{2}$ & $0.05 \%$ & $0.05 \%$ & $0.05 \%$ & $0.05 \%$ & $0.05 \%$ \\
\hline TOTAL & $100 \%$ & $100 \%$ & $100 \%$ & $100 \%$ & $100 \%$ \\
\hline
\end{tabular}

(a) Target values (boldface) are used for $\mathrm{B}_{2} \mathrm{O}_{3}$ and $\mathrm{Li}_{2} \mathrm{O}$.

(b) - Empty data field (components not present in glass). 
Table 2.7. Analyzed (XRF) Compositions of the HLW-E-ES Glasses (continued).

\begin{tabular}{|c|c|c|}
\hline Oxide & HLW-E-ES-15 & HLW-E-ES-16 \\
\hline $\mathrm{Al}_{2} \mathrm{O}_{3}$ & $11.01 \%$ & $11.15 \%$ \\
\hline $\mathrm{B}_{2} \mathrm{O}_{3}{ }^{(\mathrm{a})}$ & $13.98 \%$ & $12.48 \%$ \\
\hline $\mathrm{BaO}$ & $-^{(\mathrm{b})}$ & $0.02 \%$ \\
\hline $\mathrm{Bi}_{2} \mathrm{O}_{3}$ & $3.32 \%$ & $3.27 \%$ \\
\hline $\mathrm{CaO}$ & $7.21 \%$ & $5.27 \%$ \\
\hline $\mathrm{CdO}$ & - & - \\
\hline $\mathrm{Ce}_{2} \mathrm{O}_{3}$ & - & - \\
\hline $\mathrm{CoO}$ & $0.00 \%$ & $0.00 \%$ \\
\hline $\mathrm{Cr}_{2} \mathrm{O}_{3}$ & $1.58 \%$ & $1.40 \%$ \\
\hline $\mathrm{Cs}_{2} \mathrm{O}$ & - & - \\
\hline $\mathrm{Er}_{2} \mathrm{O}_{3}$ & $0.01 \%$ & $0.01 \%$ \\
\hline $\mathrm{Fe}_{2} \mathrm{O}_{3}$ & $5.57 \%$ & $5.48 \%$ \\
\hline $\mathrm{HfO}_{2}$ & - & - \\
\hline $\mathrm{K}_{2} \mathrm{O}$ & $5.25 \%$ & $4.39 \%$ \\
\hline $\mathrm{La}_{2} \mathrm{O}_{3}$ & $0.01 \%$ & - \\
\hline $\mathrm{Li}_{2} \mathrm{O}^{(\mathrm{a})}$ & $0.16 \%$ & $0.16 \%$ \\
\hline $\mathrm{MgO}$ & - & - \\
\hline $\mathrm{MnO}$ & - & - \\
\hline $\mathrm{Na}_{2} \mathrm{O}$ & $9.21 \%$ & $9.24 \%$ \\
\hline $\mathrm{Nd}_{2} \mathrm{O}_{3}$ & - & - \\
\hline $\mathrm{NiO}$ & $0.45 \%$ & $0.44 \%$ \\
\hline $\mathrm{P}_{2} \mathrm{O}_{5}$ & $1.60 \%$ & $1.50 \%$ \\
\hline $\mathrm{PbO}$ & $0.19 \%$ & $0.20 \%$ \\
\hline $\mathrm{Rh}_{2} \mathrm{O}_{3}$ & - & - \\
\hline $\mathrm{RuO}_{2}$ & - & - \\
\hline $\mathrm{SO}_{3}$ & $0.56 \%$ & $0.51 \%$ \\
\hline $\mathrm{SiO}_{2}$ & $39.60 \%$ & $39.88 \%$ \\
\hline $\mathrm{SnO}_{2}$ & $0.01 \%$ & $0.01 \%$ \\
\hline $\mathrm{SrO}$ & $0.01 \%$ & - \\
\hline $\mathrm{TiO}_{2}$ & $0.02 \%$ & $4.39 \%$ \\
\hline $\mathrm{ZnO}$ & $0.12 \%$ & $0.11 \%$ \\
\hline $\mathrm{ZrO}_{2}$ & $0.05 \%$ & $0.05 \%$ \\
\hline TOTAL & $100 \%$ & $100 \%$ \\
\hline
\end{tabular}

(a) Target values (boldface) are used for $\mathrm{B}_{2} \mathrm{O}_{3}$ and $\mathrm{Li}_{2} \mathrm{O}$.

(b) - Empty data field (components not present in glass). 
Table 2.8. Characterization Data for the HLW-E-ES Series of Glasses.

\begin{tabular}{|c|c|c|c|c|c|}
\hline & Property & HLW-E-ES-01 & HLW-E-ES-02 & HLW-E-ES-03 & HLW-E-ES-04 \\
\hline & Formulation Basis & $\begin{array}{l}\text { Remove } \mathrm{S}, \mathrm{Ni} \text { and } \\
\mathrm{Zn} \text { from Cr-waste }\end{array}$ & $\begin{array}{c}\text { Increase } \mathrm{Cr}_{2} \mathrm{O}_{3} \text { to } \\
3 \mathrm{wt} \% \text { in } \mathrm{ES}-01\end{array}$ & $\begin{array}{l}\text { Increase } \mathrm{Cr}_{2} \mathrm{O}_{3} \text { to } \\
4.5 \mathrm{wt} \% \text { in } \mathrm{ES}-01\end{array}$ & $\begin{array}{c}\text { Increase } \mathrm{Cr}_{2} \mathrm{O}_{3} \text { to } \\
6 \mathrm{wt} \% \text { in ES- } 01\end{array}$ \\
\hline & As-Melted at $1200^{\circ} \mathrm{C}(\mathrm{vol} \%)$ & $0.3(\mathrm{ES})$ & $1.8(\mathrm{ES})$ & $3.5(\mathrm{ES})$ & $5.1(\mathrm{ES})$ \\
\hline & After HT at $1150^{\circ} \mathrm{C}(\mathrm{vol} \%)$ & $0.5(\mathrm{ES})$ & $1.6(\mathrm{ES})$ & $2.2(\mathrm{ES})$ & $4.3(\mathrm{ES})$ \\
\hline$\stackrel{0}{\square}$ & After HT at $1100^{\circ} \mathrm{C}(\mathrm{vol} \%)$ & 0.7 (ES) & $1.3(\mathrm{ES})$ & $2.6(\mathrm{ES})$ & $3.6(\mathrm{ES})$ \\
\hline $\bar{u}$ & After $\mathrm{HT}$ at $1000^{\circ} \mathrm{C}(\mathrm{vol} \%)$ & $0.6(\mathrm{ES})$ & $2.0(\mathrm{ES})$ & $2.7(\mathrm{ES})$ & $3.7(\mathrm{ES})$ \\
\hline$\sum_{i}^{\infty}$ & After $\mathrm{HT}$ at $950^{\circ} \mathrm{C}(\mathrm{vol} \%)$ & $0.6(\mathrm{ES})$ & $2.0(\mathrm{ES})$ & 2.7 (ES) & $3.6(\mathrm{ES})$ \\
\hline & After $\mathrm{HT}$ at $900^{\circ} \mathrm{C}(\mathrm{vol} \%)$ & 0.7 (ES) & $1.7(\mathrm{ES})$ & $3.0(\mathrm{ES})$ & $4.1(\mathrm{ES})$ \\
\hline & $\begin{array}{l}\text { Approximate Average } \\
\text { Particle Size }\end{array}$ & $20 \mu \mathrm{m}$ & $22 \mu \mathrm{m}$ & $18 \mu \mathrm{m}$ & $16 \mu \mathrm{m}$ \\
\hline & $950^{\circ} \mathrm{C}$ & - $^{(\mathrm{b})}$ & $807.7\left(961^{\circ} \mathrm{C}\right)^{(\mathrm{c})}$ & - & - \\
\hline$\gtrsim$ & $1050^{\circ} \mathrm{C}$ & - & $336.5\left(1062^{\circ} \mathrm{C}\right)$ & - & - \\
\hline $\begin{array}{l}0 \\
0 \\
0\end{array}$ & $1150^{\circ} \mathrm{C}$ & - & $141.3\left(1164^{\circ} \mathrm{C}\right)$ & - & - \\
\hline & $1200^{\circ} \mathrm{C}$ & - & $80.8\left(1265^{\circ} \mathrm{C}\right)$ & - & - \\
\hline & $950^{\circ} \mathrm{C}$ & - & - & - & - \\
\hline 总 & $1000^{\circ} \mathrm{C}$ & - & - & - & - \\
\hline نं & $1050^{\circ} \mathrm{C}$ & - & - & - & - \\
\hline$\Xi_{0}^{0}$ & $1100^{\circ} \mathrm{C}$ & - & - & - & - \\
\hline & $1150^{\circ} \mathrm{C}$ & - & - & - & - \\
\hline & B (g/l) & - & 1.303 & - & - \\
\hline$\overline{\Xi ే \Xi}$ & $\mathrm{Li}(\mathrm{g} / \mathrm{l})$ & - & 1.044 & - & - \\
\hline 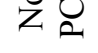 & $\mathrm{Na}(\mathrm{g} / \mathrm{l})$ & - & 0.828 & - & - \\
\hline
\end{tabular}

(a) Glass melting time $=2$ hours, Heat treatment time $=70$ hours, ES $=$ Eskolaite (with minor amounts of iron incorporated).

(b) - Empty data field (Not Analyzed).

(c) Fitting of viscosity data not performed because of non-Newtonian behavior observed. Apparent viscosity data measured at selected shear rate $(1.51 / \mathrm{s})$ and temperatures are reported. 
ORP-56294 Rev. 0

The Catholic University of America Vitreous State Laboratory

Table 2.8. Characterization Data for the HLW-E-ES Series of Glasses (continued).

\begin{tabular}{|c|c|c|c|c|c|}
\hline & Property & HLW-E-ES-05 & HLW-E-ES-06 & HLW-E-ES-07 & HLW-E-ES-C16 \\
\hline & Formulation Basis & $\begin{array}{l}\text { ES-02 with } \\
\text { changes to }\end{array}$ & $\begin{array}{l}\text { Increase } \mathrm{Cr}_{2} \mathrm{O}_{3} \text { to } \\
3 \% \text { in reference }\end{array}$ & $\begin{array}{l}\text { Increase } \mathrm{K}_{2} \mathrm{O} \text { in } \\
\text { order to increase }\end{array}$ & $\begin{array}{c}\text { C-16 high- } \\
\text { chromium glass }\end{array}$ \\
\hline & As-Melted at $1200^{\circ} \mathrm{C}(\mathrm{vol} \%)$ & $1.5(\mathrm{ES})$ & $1.4(\mathrm{ES})$ & $0.8(\mathrm{ES})$ & $1.1(\mathrm{ES})$ \\
\hline & After HT at $1150^{\circ} \mathrm{C}(\mathrm{vol} \%)$ & $1.4(\mathrm{ES})$ & $1.7(\mathrm{ES})$ & $1.2(\mathrm{ES})$ & $1.7(\mathrm{ES})$ \\
\hline$\stackrel{5}{\square}$ & After HT at $1100^{\circ} \mathrm{C}(\mathrm{vol} \%)$ & $1.1(\mathrm{ES})$ & $1.1(\mathrm{ES})$ & $0.9(\mathrm{ES})$ & $1.4(\mathrm{ES})^{(\mathrm{d})}$ \\
\hline$\bigcup_{0}^{0}$ & After $\mathrm{HT}$ at $1000^{\circ} \mathrm{C}(\mathrm{vol} \%)$ & $1.4(\mathrm{ES})$ & $1.3(\mathrm{ES})$ & $\begin{array}{l}1.4 \text { (ES, Trace } \\
\text { CP and Sp) }\end{array}$ & $1.1(\mathrm{ES})$ \\
\hline 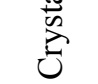 & After $\mathrm{HT}$ at $950^{\circ} \mathrm{C}(\mathrm{vol} \%)$ & $2.0(\mathrm{ES})$ & $1.3(\mathrm{ES})$ & $\begin{array}{c}1.9(35 \% \mathrm{ES}, \\
50 \% \mathrm{CP}, 15 \% \mathrm{Sp})\end{array}$ & $1.5(\mathrm{ES})$ \\
\hline & After $\mathrm{HT}$ at $900^{\circ} \mathrm{C}(\mathrm{vol} \%)$ & $1.7(\mathrm{ES})$ & $1.4(\mathrm{ES})$ & $\begin{array}{c}1.9(15 \% \mathrm{ES} \\
50 \% \mathrm{CP}, 35 \% \mathrm{Sp})\end{array}$ & $1.2(\mathrm{ES})$ \\
\hline & $\begin{array}{c}\text { Approximate Average } \\
\text { Particle Size }\end{array}$ & $22 \mu \mathrm{m}$ & $17 \mu \mathrm{m}$ & $17 \mu \mathrm{m}(\mathrm{ES})$ & $9 \mu \mathrm{m}$ \\
\hline & $950^{\circ} \mathrm{C}$ & $329.79\left(972^{\circ} \mathrm{C}\right)^{(\mathrm{b})}$ & $581.6\left(960^{\circ} \mathrm{C}\right)^{(\mathrm{b})}$ & - $^{(\mathrm{c})}$ & - \\
\hline$\stackrel{2}{2}$ & $1050^{\circ} \mathrm{C}$ & $133.79\left(1063^{\circ} \mathrm{C}\right)$ & $218.0\left(1062^{\circ} \mathrm{C}\right)$ & - & - \\
\hline $\begin{array}{l}0 \\
0 \\
.02\end{array}$ & $1150^{\circ} \mathrm{C}$ & $68.79\left(1164^{\circ} \mathrm{C}\right)$ & $132.8\left(1164^{\circ} \mathrm{C}\right)$ & - & - \\
\hline & $1200^{\circ} \mathrm{C}$ & $32.19\left(1265^{\circ} \mathrm{C}\right)$ & $60.5\left(1266^{\circ} \mathrm{C}\right)$ & - & - \\
\hline & $950^{\circ} \mathrm{C}$ & 0.103 & 0.080 & - & - \\
\hline 䁬 & $1000^{\circ} \mathrm{C}$ & 0.136 & 0.109 & - & - \\
\hline نे & $1050^{\circ} \mathrm{C}$ & 0.173 & 0.143 & - & - \\
\hline 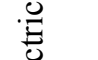 & $1100^{\circ} \mathrm{C}$ & 0.214 & 0.181 & - & - \\
\hline & $1150^{\circ} \mathrm{C}$ & 0.259 & 0.222 & - & - \\
\hline & B (g/l) & - & - & - & - \\
\hline こ & $\mathrm{Li}(\mathrm{g} / \mathrm{l})$ & - & - & - & - \\
\hline$z 2$ & $\mathrm{Na}(\mathrm{g} / \mathrm{l})$ & - & - & - & - \\
\hline
\end{tabular}

(a) Glass melting time $=2$ hours, Heat treatment time $=70$ hours, ES $=$ Eskolaite (with minor amounts of iron incorporated), $\mathrm{Sp}=$ Spinel, CP = Calcium Phosphate.

(b) Fitting of viscosity data not performed because of non-Newtonian behavior observed. Apparent viscosity data measured at selected shear rate $(1.51 / \mathrm{s})$ and temperatures are reported.

(c) - Empty data field (Not Analyzed).

(d) Small amounts of Ti incorporated in eskolaite phase. 
Table 2.8. Characterization Data for the HLW-E-ES Series of Glasses (continued).

\begin{tabular}{|c|c|c|c|c|c|}
\hline & Property & HLW-E-ES-08 & HLW-E-ES-09 & HLW-E-ES-10 & HLW-E-ES-11 \\
\hline & Formulation Basis & $\begin{array}{l}\text { Add divalent to } \\
\text { C16 }\end{array}$ & $\begin{array}{c}\text { Substitute Ti for K } \\
\text { in reference glass } \\
\text { HLW-E-Cr-10 }\end{array}$ & $\begin{array}{l}\text { Further increase } \\
\mathrm{K}_{2} \mathrm{O} \text { in glass } \\
\mathrm{HLW} \text {-E-ES-07 }\end{array}$ & $\begin{array}{c}\text { Substitute Ti for K } \\
\text { partially in glass } \\
\text { HLW-E-ES-07 }\end{array}$ \\
\hline & As-Melted at $1200^{\circ} \mathrm{C}(\mathrm{vol} \%)$ & $1.2(\mathrm{ES})$ & $0.8(\mathrm{ES})$ & Chromate Layer & $2.2(\mathrm{ES})^{(\mathrm{c})}$ \\
\hline & After HT at $1150^{\circ} \mathrm{C}(\mathrm{vol} \%)$ & $-^{(\mathrm{b})}$ & - & - & - \\
\hline$\stackrel{0}{\square}$ & After HT at $1100^{\circ} \mathrm{C}(\mathrm{vol} \%)$ & $2.2(\mathrm{ES})$ & $1.5(\mathrm{Sp})$ & $0.1(\mathrm{ES}, \mathrm{Sp})$ & $2.5(\mathrm{ES})$ \\
\hline $\bar{e}$ & After HT at $1000^{\circ} \mathrm{C}(\mathrm{vol} \%)$ & NA & NA & NA & NA \\
\hline$\sum_{\tilde{U}}^{\frac{\pi}{\omega}}$ & After $\mathrm{HT}$ at $950^{\circ} \mathrm{C}(\mathrm{vol} \%)$ & 1.7 (ES) & $2.0(\mathrm{Sp})$ & $\begin{array}{c}3.2(\mathrm{KAS}, \mathrm{ES}, \\
\mathrm{Sp})\end{array}$ & $4.5(\mathrm{Sp}, \mathrm{CP})$ \\
\hline & After HT at $900^{\circ} \mathrm{C}(\mathrm{vol} \%)$ & - & - & - & - \\
\hline & $\begin{array}{c}\text { Approximate Average } \\
\text { Particle Size }\end{array}$ & $10 \mu \mathrm{m}$ & $5 \mu \mathrm{m}(\mathrm{Sp})$ & NA & NA \\
\hline & $950^{\circ} \mathrm{C}$ & - & - & - & - \\
\hline$\Theta$ & $1000^{\circ} \mathrm{C}$ & - & - & - & - \\
\hline 㿿 & $1050^{\circ} \mathrm{C}$ & - & - & - & - \\
\hline 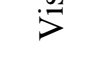 & $1100^{\circ} \mathrm{C}$ & - & - & - & - \\
\hline & $1150^{\circ} \mathrm{C}$ & - & - & - & - \\
\hline & $950^{\circ} \mathrm{C}$ & - & - & - & - \\
\hline 焉 & $1000^{\circ} \mathrm{C}$ & - & - & - & - \\
\hline లँ है & $1050^{\circ} \mathrm{C}$ & - & - & - & - \\
\hline$\stackrel{\mathscr{E}}{E}$ & $1100^{\circ} \mathrm{C}$ & - & - & - & - \\
\hline & $1150^{\circ} \mathrm{C}$ & - & - & 一 & - \\
\hline & $\mathrm{B}(\mathrm{g} / \mathrm{l})$ & - & - & 0.771 & - \\
\hline ह & $\operatorname{Li}(\mathrm{g} / \mathrm{l})$ & - & - & 0.845 & - \\
\hline $\mathrm{Z} 2$ & $\mathrm{Na}(\mathrm{g} / \mathrm{l})$ & - & - & 0.594 & - \\
\hline
\end{tabular}

(a) Glass melting time $=2$ hours, Heat treatment time $=70$ hours, $\mathrm{ES}=$ Eskolaite (with minor amounts of iron incorporated), $\mathrm{Sp}=$ Spinel (rich in chromium), KAS = Potassium Aluminum Silicate, $\mathrm{CP}=$ Calcium Phosphate (with fluorine incorporated).

(b) - Empty data field (Not Analyzed).

${ }^{(\mathrm{c})}$ Extensive crystallization $(\approx 10 \mathrm{vol} \%)$ of an unidentified ultra-fine phase also observed. 
Table 2.8. Characterization Data for the HLW-E-ES Series of Glasses (continued).

\begin{tabular}{|c|c|c|c|c|c|}
\hline & Property & HLW-E-ES-12 & HLW-E-ES-13 & HLW-E-ES-14 & HLW-E-ES-15 \\
\hline & Formulation Basis & $\begin{array}{l}\text { Add Ti to glass } \\
\text { HLW-E-ES-07 } \\
\text { (High K and Ti) }\end{array}$ & $\begin{array}{l}\text { Remove } S \text { and } \\
\text { increase } \mathrm{Cr} \text { in } \\
\text { HLW-E-Cr-10 }\end{array}$ & $\begin{array}{l}\text { Add noble metals } \\
\text { to HLW-E-ES-05 }\end{array}$ & $\begin{array}{l}\text { Add } \mathrm{Ca} \text { in } \\
\text { reference glass } \\
\text { HLW-E-Cr-10 }\end{array}$ \\
\hline & As-Melted at $1200^{\circ} \mathrm{C}(\mathrm{vol} \%)$ & $0.8(\mathrm{ES}, \mathrm{U})$ & $0.1(\mathrm{ES})$ & $0.6(\mathrm{ES}, \mathrm{Ru})$ & $0.6(\mathrm{ES}, \mathrm{CP})$ \\
\hline & After $\mathrm{HT}$ at $1150^{\circ} \mathrm{C}(\mathrm{vol} \%)$ & - $^{(\mathrm{b})}$ & - & - & - \\
\hline 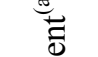 & After $\mathrm{HT}$ at $1100^{\circ} \mathrm{C}(\mathrm{vol} \%)$ & $1.6(\mathrm{ES})$ & $0.8(\mathrm{ES})$ & $1.4(\mathrm{ES}, \mathrm{Ru})$ & $2.2(\mathrm{ES}, \mathrm{CP})$ \\
\hline ن & After $\mathrm{HT}$ at $1000^{\circ} \mathrm{C}(\mathrm{vol} \%)$ & - & - & - & - \\
\hline$\sum_{i}^{\infty}$ & After $\mathrm{HT}$ at $950^{\circ} \mathrm{C}(\mathrm{vol} \%)$ & $1.9(\mathrm{ES})$ & 1.1 (Sp, ES, CP) & 1.1 (ES, Sp, CP) & $3.1(\mathrm{ES}, \mathrm{Sp}, \mathrm{CP})$ \\
\hline & After $\mathrm{HT}$ at $900^{\circ} \mathrm{C}(\mathrm{vol} \%)$ & NA & NA & $1.4(\mathrm{ES})$ & 3.7 (ES, Sp, CP) \\
\hline & $\begin{array}{l}\text { Approximate Average } \\
\text { Particle Size }\end{array}$ & $18 \mu \mathrm{m}$ & $18 \mu \mathrm{m}(\mathrm{ES})$ & $22 \mu \mathrm{m}(\mathrm{ES})$ & $12 \mu \mathrm{m}(\mathrm{ES})$ \\
\hline & $950^{\circ} \mathrm{C}$ & - & - & - & - \\
\hline 2 & $1000^{\circ} \mathrm{C}$ & - & - & - & - \\
\hline 至 & $1050^{\circ} \mathrm{C}$ & - & - & - & - \\
\hline$>$ & $1100^{\circ} \mathrm{C}$ & - & - & - & - \\
\hline & $1150^{\circ} \mathrm{C}$ & - & - & - & - \\
\hline & $950^{\circ} \mathrm{C}$ & - & - & - & - \\
\hline & $1000^{\circ} \mathrm{C}$ & - & - & - & - \\
\hline 0 & $1050^{\circ} \mathrm{C}$ & - & - & - & - \\
\hline & $1100^{\circ} \mathrm{C}$ & - & - & - & - \\
\hline & $1150^{\circ} \mathrm{C}$ & - & - & - & - \\
\hline & $\mathrm{B}(\mathrm{g} / \mathrm{l})$ & - & - & - & - \\
\hline $\bar{\Xi} \bar{\Xi}$ & $\mathrm{Li}(\mathrm{g} / \mathrm{l})$ & - & - & - & - \\
\hline & $\mathrm{Na}(g / 1)$ & - & - & - & - \\
\hline
\end{tabular}

(a) Glass melting time $=2$ hours, Heat treatment time $=70$ hours, $\mathrm{ES}=$ Eskolaite (with minor amounts of iron incorporated), $\mathrm{U}=$ Unidentified ultra-fine phase, $\mathrm{Sp}=$ Spinel, $\mathrm{CP}=$ Calcium Phosphate, $\mathrm{Ru}=$ Ruthenium Particle.

(b) — Empty data field (Not Analyzed). 


\section{Table 2.8. Characterization Data for the HLW-E-ES Series of Glasses (continued).}

\begin{tabular}{|c|c|c|}
\hline & Property & HLW-E-ES-16 \\
\hline & Formulation Basis & $\begin{array}{l}\text { Add } \mathrm{Ca} \text { and } \mathrm{Ti} \text { in } \\
\text { reference glass } \\
\text { HLW-E-Cr-10 }\end{array}$ \\
\hline & As-Melted at $1200^{\circ} \mathrm{C}(\mathrm{vol} \%)$ & 0.7 (ES, CP) \\
\hline & After HT at $1150^{\circ} \mathrm{C}(\mathrm{vol} \%)$ & - $^{\text {(b) }}$ \\
\hline$\stackrel{5}{\square}$ & After $\mathrm{HT}$ at $1100^{\circ} \mathrm{C}(\mathrm{vol} \%)$ & $1.8(\mathrm{ES}, \mathrm{CP})$ \\
\hline e & After $\mathrm{HT}$ at $1000^{\circ} \mathrm{C}(\mathrm{vol} \%)$ & NA \\
\hline$\sum_{i}^{\infty}$ & After $\mathrm{HT}$ at $950^{\circ} \mathrm{C}(\mathrm{vol} \%)$ & $3.0(\mathrm{CP}, \mathrm{Sp}, \mathrm{ES})$ \\
\hline & After $\mathrm{HT}$ at $900^{\circ} \mathrm{C}(\mathrm{vol} \%)$ & $\begin{array}{c}5.0 \text { (CS, CP } \\
\text { Sp, ES) }\end{array}$ \\
\hline & $\begin{array}{l}\text { Approximate Average } \\
\text { Particle Size }\end{array}$ & $9 \mu \mathrm{m}(\mathrm{ES})$ \\
\hline & $950^{\circ} \mathrm{C}$ & - \\
\hline I & $1000^{\circ} \mathrm{C}$ & - \\
\hline$\cdot \frac{\vec{n}}{5}$ & $1050^{\circ} \mathrm{C}$ & - \\
\hline$>$ & $1100^{\circ} \mathrm{C}$ & - \\
\hline & $1150^{\circ} \mathrm{C}$ & - \\
\hline & $950^{\circ} \mathrm{C}$ & - \\
\hline 曾 & $1000^{\circ} \mathrm{C}$ & - \\
\hline ठี है & $1050^{\circ} \mathrm{C}$ & - \\
\hline : & $1100^{\circ} \mathrm{C}$ & - \\
\hline & $1150^{\circ} \mathrm{C}$ & - \\
\hline & B (g/l) & - \\
\hline$\overline{\Xi \Xi}$ & $\operatorname{Li}(g / l)$ & - \\
\hline$z$ & $\mathrm{Na}(g / 1)$ & - \\
\hline
\end{tabular}

(a) Glass melting time $=2$ hours, Heat treatment time $=70$ hours, $\mathrm{ES}=$ Eskolaite (with minor amounts of iron incorporated), $\mathrm{Sp}=$ Spinel, CP = Calcium Phosphate, $\mathrm{CS}=$ Calcium Silicate .

(b) - Empty data field (Not Analyzed). 
The Catholic University of America Vitreous State Laboratory
ORP-56294 Rev. 0

Effects of High Crystal Content in HLW DM100 Melter Tests

Final Report, VSL-09R1520-1, Rev. 0

Table 2.9. Target Compositions of HLW Glasses (HLW-E-M) Formulated to Study Crystallization of Spinel and Chromium Oxide (Eskolaite) Phases.

\begin{tabular}{|c|c|c|c|c|c|}
\hline Oxide & HLW-E-M-01 & HLW-E-M-02 & HLW-E-M-03 & HLW-E-M-04 & HLW-E-M-05 \\
\hline $\mathrm{Al}_{2} \mathrm{O}_{3}$ & $12.23 \%$ & $11.86 \%$ & $12.17 \%$ & $11.98 \%$ & $12.42 \%$ \\
\hline $\mathrm{B}_{2} \mathrm{O}_{3}$ & $13.41 \%$ & $13.01 \%$ & $13.34 \%$ & $13.13 \%$ & $13.62 \%$ \\
\hline $\mathrm{BaO}$ & $0.01 \%$ & $0.01 \%$ & $0.01 \%$ & $0.01 \%$ & $0.01 \%$ \\
\hline $\mathrm{Bi}_{2} \mathrm{O}_{3}$ & $3.49 \%$ & $3.39 \%$ & $3.47 \%$ & $3.42 \%$ & $3.55 \%$ \\
\hline $\mathrm{CaO}$ & $1.18 \%$ & $1.15 \%$ & $1.18 \%$ & $1.16 \%$ & $1.20 \%$ \\
\hline $\mathrm{Cr}_{2} \mathrm{O}_{3}$ & $3.00 \%$ & $4.50 \%$ & $3.00 \%$ & $4.50 \%$ & $1.51 \%$ \\
\hline $\mathrm{F}$ & $0.96 \%$ & $0.93 \%$ & $0.95 \%$ & $0.94 \%$ & $0.97 \%$ \\
\hline $\mathrm{Fe}_{2} \mathrm{O}_{3}$ & $6.29 \%$ & $6.10 \%$ & $6.26 \%$ & $6.16 \%$ & $6.39 \%$ \\
\hline $\mathrm{K}_{2} \mathrm{O}$ & $4.56 \%$ & $4.43 \%$ & $4.54 \%$ & $4.47 \%$ & $4.63 \%$ \\
\hline $\mathrm{Li}_{2} \mathrm{O}$ & $2.61 \%$ & $2.53 \%$ & $2.60 \%$ & $2.55 \%$ & $2.65 \%$ \\
\hline $\mathrm{MgO}$ & $0.08 \%$ & $0.07 \%$ & $0.08 \%$ & $0.08 \%$ & $0.08 \%$ \\
\hline $\mathrm{MnO}$ & $0.50 \%$ & $1.20 \%$ & $0.75 \%$ & $0.75 \%$ & $0.50 \%$ \\
\hline $\mathrm{Na}_{2} \mathrm{O}$ & $9.62 \%$ & $9.33 \%$ & $9.57 \%$ & $9.42 \%$ & $9.77 \%$ \\
\hline $\mathrm{NiO}$ & $0.50 \%$ & $1.20 \%$ & $0.75 \%$ & $0.75 \%$ & $0.50 \%$ \\
\hline $\mathrm{P}_{2} \mathrm{O}_{5}$ & $1.60 \%$ & $1.55 \%$ & $1.59 \%$ & $1.57 \%$ & $1.62 \%$ \\
\hline $\mathrm{PbO}$ & $0.23 \%$ & $0.22 \%$ & $0.23 \%$ & $0.23 \%$ & $0.23 \%$ \\
\hline $\mathrm{SiO}_{2}$ & $39.66 \%$ & $38.46 \%$ & $39.45 \%$ & $38.83 \%$ & $40.28 \%$ \\
\hline $\mathrm{ZnO}$ & - & - & - & - & - \\
\hline $\mathrm{ZrO}_{2}$ & $0.05 \%$ & $0.05 \%$ & $0.05 \%$ & $0.05 \%$ & $0.05 \%$ \\
\hline TOTAL & $100.0 \%$ & $100.0 \%$ & $100.0 \%$ & $100.0 \%$ & $100.0 \%$ \\
\hline
\end{tabular}

(a) - Empty data field (components not present in glass). 
The Catholic University of America Vitreous State Laboratory
ORP-56294 Rev. 0

Effects of High Crystal Content in HLW DM100 Melter Tests

Final Report, VSL-09R1520-1, Rev. 0

Table 2.9. Target Compositions of HLW Glasses (HLW-E-M) Formulated to Study Crystallization of Spinel and Chromium Oxide (Eskolaite) Phases (continued).

\begin{tabular}{|c|c|c|c|c|c|}
\hline Oxide & HLW-E-M-06 & HLW-E-M-07 & HLW-E-M-08 & HLW-E-M-09 & HLW-E-M-10 \\
\hline $\mathrm{Al}_{2} \mathrm{O}_{3}$ & $12.04 \%$ & $10.84 \%$ & $10.84 \%$ & $10.69 \%$ & $10.52 \%$ \\
\hline $\mathrm{B}_{2} \mathrm{O}_{3}$ & $13.20 \%$ & $14.15 \%$ & $14.15 \%$ & $14.57 \%$ & $14.34 \%$ \\
\hline $\mathrm{BaO}$ & $0.01 \%$ & $0.01 \%$ & $0.01 \%$ & $0.01 \%$ & $0.01 \%$ \\
\hline $\mathrm{Bi}_{2} \mathrm{O}_{3}$ & $3.44 \%$ & $3.10 \%$ & $3.10 \%$ & $3.47 \%$ & $3.42 \%$ \\
\hline $\mathrm{CaO}$ & $1.16 \%$ & $1.05 \%$ & $1.05 \%$ & $1.18 \%$ & $1.16 \%$ \\
\hline $\mathrm{Cr}_{2} \mathrm{O}_{3}$ & $4.50 \%$ & $3.00 \%$ & $3.00 \%$ & $3.00 \%$ & $3.00 \%$ \\
\hline $\mathrm{F}$ & $0.94 \%$ & $0.85 \%$ & $0.85 \%$ & $0.95 \%$ & $0.94 \%$ \\
\hline $\mathrm{Fe}_{2} \mathrm{O}_{3}$ & $6.19 \%$ & $5.58 \%$ & $5.58 \%$ & $6.26 \%$ & $6.16 \%$ \\
\hline $\mathrm{K}_{2} \mathrm{O}$ & $4.49 \%$ & $5.31 \%$ & $5.31 \%$ & $5.52 \%$ & $5.44 \%$ \\
\hline $\mathrm{Li}_{2} \mathrm{O}$ & $2.57 \%$ & $3.24 \%$ & $3.24 \%$ & $3.09 \%$ & $3.04 \%$ \\
\hline $\mathrm{MgO}$ & $0.08 \%$ & $0.07 \%$ & $0.07 \%$ & $0.08 \%$ & $0.08 \%$ \\
\hline $\mathrm{MnO}$ & $0.50 \%$ & $0.75 \%$ & - & - & $0.75 \%$ \\
\hline $\mathrm{Na}_{2} \mathrm{O}$ & $9.47 \%$ & $8.53 \%$ & $8.53 \%$ & $9.57 \%$ & $9.42 \%$ \\
\hline $\mathrm{NiO}$ & $0.50 \%$ & $0.75 \%$ & - & - & $0.75 \%$ \\
\hline $\mathrm{P}_{2} \mathrm{O}_{5}$ & $1.58 \%$ & $1.42 \%$ & $1.42 \%$ & $1.59 \%$ & $1.57 \%$ \\
\hline $\mathrm{PbO}$ & $0.23 \%$ & $0.21 \%$ & $0.21 \%$ & $0.23 \%$ & $0.23 \%$ \\
\hline $\mathrm{SiO}_{2}$ & $39.04 \%$ & $41.10 \%$ & $41.10 \%$ & $38.22 \%$ & $37.62 \%$ \\
\hline $\mathrm{ZnO}$ & - & - & $1.50 \%$ & $1.50 \%$ & $1.50 \%$ \\
\hline $\mathrm{ZrO}_{2}$ & $0.05 \%$ & $0.05 \%$ & $0.05 \%$ & $0.05 \%$ & $0.05 \%$ \\
\hline TOTAL & $100.0 \%$ & $100.0 \%$ & $100.0 \%$ & $100.0 \%$ & $100.0 \%$ \\
\hline
\end{tabular}

(a) - Empty data field (components not present in glass). 
Table 2.9. Target Compositions of HLW Glasses (HLW-E-M) Formulated to Study Crystallization of Spinel and Chromium Oxide (Eskolaite) Phases (continued).

\begin{tabular}{|c|c|c|c|}
\hline Oxide & HLW-E-M-11 & HLW-E-M-12 & HLW-E-M-13 \\
\hline $\mathrm{Al}_{2} \mathrm{O}_{3}$ & $12.17 \%$ & $10.41 \%$ & $10.19 \%$ \\
\hline $\mathrm{B}_{2} \mathrm{O}_{3}$ & $13.34 \%$ & $14.19 \%$ & $13.89 \%$ \\
\hline $\mathrm{BaO}$ & $0.01 \%$ & $0.01 \%$ & $0.01 \%$ \\
\hline $\mathrm{Bi}_{2} \mathrm{O}_{3}$ & $3.47 \%$ & $3.38 \%$ & $3.31 \%$ \\
\hline $\mathrm{CaO}$ & $1.18 \%$ & $1.15 \%$ & $1.12 \%$ \\
\hline $\mathrm{Cr}_{2} \mathrm{O}_{3}$ & $3.00 \%$ & $3.00 \%$ & $4.50 \%$ \\
\hline $\mathrm{F}$ & $0.95 \%$ & $0.93 \%$ & $0.91 \%$ \\
\hline $\mathrm{Fe}_{2} \mathrm{O}_{3}$ & $6.26 \%$ & $6.09 \%$ & $5.96 \%$ \\
\hline $\mathrm{K}_{2} \mathrm{O}$ & $4.54 \%$ & $5.38 \%$ & $5.26 \%$ \\
\hline $\mathrm{Li}_{2} \mathrm{O}$ & $2.60 \%$ & $3.01 \%$ & $2.94 \%$ \\
\hline $\mathrm{MgO}$ & $0.08 \%$ & $0.07 \%$ & $0.07 \%$ \\
\hline $\mathrm{MnO}$ & - & - & - \\
\hline $\mathrm{Na}_{2} \mathrm{O}$ & $9.57 \%$ & $9.32 \%$ & $9.12 \%$ \\
\hline $\mathrm{NiO}$ & - & - & - \\
\hline $\mathrm{P}_{2} \mathrm{O}_{5}$ & $1.59 \%$ & $1.55 \%$ & $1.52 \%$ \\
\hline $\mathrm{PbO}$ & $0.23 \%$ & $0.22 \%$ & $0.22 \%$ \\
\hline $\mathrm{SiO}_{2}$ & $39.45 \%$ & $37.22 \%$ & $36.42 \%$ \\
\hline $\mathrm{ZnO}$ & $1.50 \%$ & $4.00 \%$ & $4.50 \%$ \\
\hline $\mathrm{ZrO}_{2}$ & $0.05 \%$ & $0.05 \%$ & $0.05 \%$ \\
\hline TOTAL & $100.0 \%$ & $100.0 \%$ & $100.0 \%$ \\
\hline
\end{tabular}

(a) - Empty data field (components not present in glass). 
ORP-56294 Rev. 0

The Catholic University of America Vitreous State Laboratory

Effects of High Crystal Content in HLW DM100 Melter Tests

Final Report, VSL-09R1520-1, Rev. 0

Table 2.10. Analyzed (XRF) Compositions of the HLW-E-M Glasses.

\begin{tabular}{|c|c|c|c|c|c|}
\hline Oxide & HLW-E-M-01 & HLW-E-M-02 & HLW-E-M-03 & HLW-E-M-04 & HLW-E-M-05 \\
\hline $\mathrm{Al}_{2} \mathrm{O}_{3}$ & $12.18 \%$ & $11.84 \%$ & $12.18 \%$ & $11.89 \%$ & $12.19 \%$ \\
\hline $\mathrm{B}_{2} \mathrm{O}_{3}{ }^{(\mathrm{a})}$ & $13.41 \%$ & $13.01 \%$ & $13.34 \%$ & $13.13 \%$ & $13.62 \%$ \\
\hline $\mathrm{BaO}$ & $0.02 \%$ & $0.01 \%$ & $0.02 \%$ & $0.01 \%$ & $0.02 \%$ \\
\hline $\mathrm{Bi}_{2} \mathrm{O}_{3}$ & $3.63 \%$ & $3.60 \%$ & $3.67 \%$ & $3.66 \%$ & $3.98 \%$ \\
\hline $\mathrm{CaO}$ & $1.21 \%$ & $1.15 \%$ & $1.25 \%$ & $1.22 \%$ & $1.29 \%$ \\
\hline $\mathrm{CdO}$ & - $^{(\mathrm{b})}$ & - & - & - & - \\
\hline $\mathrm{Ce}_{2} \mathrm{O}_{3}$ & - & - & - & - & - \\
\hline $\mathrm{CoO}$ & - & $0.00 \%$ & $0.00 \%$ & - & $0.00 \%$ \\
\hline $\mathrm{Cr}_{2} \mathrm{O}_{3}$ & $3.53 \%$ & $5.29 \%$ & $3.50 \%$ & $5.36 \%$ & $1.93 \%$ \\
\hline $\mathrm{Cs}_{2} \mathrm{O}$ & - & - & - & - & - \\
\hline $\mathrm{Er}_{2} \mathrm{O}_{3}$ & $0.01 \%$ & - & - & $0.01 \%$ & - \\
\hline $\mathrm{Fe}_{2} \mathrm{O}_{3}$ & $6.11 \%$ & $6.00 \%$ & $6.13 \%$ & $6.18 \%$ & $6.64 \%$ \\
\hline $\mathrm{HfO}_{2}$ & - & - & - & - & - \\
\hline $\mathrm{K}_{2} \mathrm{O}$ & $4.55 \%$ & $4.34 \%$ & $4.34 \%$ & $4.35 \%$ & $4.65 \%$ \\
\hline $\mathrm{La}_{2} \mathrm{O}_{3}$ & $0.01 \%$ & $0.01 \%$ & $0.01 \%$ & - & - \\
\hline $\mathrm{Li}_{2} \mathrm{O}^{(\mathrm{a})}$ & $2.61 \%$ & $2.53 \%$ & $2.60 \%$ & $2.55 \%$ & $2.65 \%$ \\
\hline $\mathrm{MgO}$ & $0.07 \%$ & - & $0.07 \%$ & $0.07 \%$ & $0.07 \%$ \\
\hline $\mathrm{MnO}$ & $0.52 \%$ & $1.23 \%$ & $0.77 \%$ & $0.79 \%$ & $0.54 \%$ \\
\hline $\mathrm{Na}_{2} \mathrm{O}$ & $9.92 \%$ & $9.80 \%$ & $9.86 \%$ & $9.63 \%$ & $9.96 \%$ \\
\hline $\mathrm{Nd}_{2} \mathrm{O}_{3}$ & - & - & - & - & - \\
\hline $\mathrm{NiO}$ & $0.50 \%$ & $1.15 \%$ & $0.73 \%$ & $0.76 \%$ & $0.52 \%$ \\
\hline $\mathrm{P}_{2} \mathrm{O}_{5}$ & $1.87 \%$ & $1.77 \%$ & $1.86 \%$ & $1.78 \%$ & $1.88 \%$ \\
\hline $\mathrm{PbO}$ & $0.21 \%$ & $0.21 \%$ & $0.21 \%$ & $0.21 \%$ & $0.24 \%$ \\
\hline $\mathrm{Rh}_{2} \mathrm{O}_{3}$ & - & - & - & - & - \\
\hline $\mathrm{RuO}_{2}$ & - & - & - & - & - \\
\hline $\mathrm{SO}_{3}$ & $0.08 \%$ & $0.09 \%$ & $0.07 \%$ & $0.08 \%$ & $0.08 \%$ \\
\hline $\mathrm{SiO}_{2}$ & $39.46 \%$ & $37.80 \%$ & $39.28 \%$ & $38.18 \%$ & $39.61 \%$ \\
\hline $\mathrm{SnO}_{2}$ & $0.01 \%$ & $0.01 \%$ & $0.01 \%$ & $0.01 \%$ & $0.01 \%$ \\
\hline $\mathrm{SrO}$ & $0.01 \%$ & $0.01 \%$ & $0.01 \%$ & $0.01 \%$ & $0.01 \%$ \\
\hline $\mathrm{TiO}_{2}$ & $0.02 \%$ & $0.02 \%$ & $0.02 \%$ & $0.01 \%$ & $0.02 \%$ \\
\hline $\mathrm{ZnO}$ & $0.02 \%$ & $0.02 \%$ & $0.02 \%$ & $0.02 \%$ & $0.02 \%$ \\
\hline $\mathrm{ZrO}_{2}$ & $0.05 \%$ & $0.05 \%$ & $0.05 \%$ & $0.05 \%$ & $0.06 \%$ \\
\hline TOTAL & $100 \%$ & $100 \%$ & $100 \%$ & $100 \%$ & $100 \%$ \\
\hline
\end{tabular}

(a) Target values (boldface) are used for $\mathrm{B}_{2} \mathrm{O}_{3}$ and $\mathrm{Li}_{2} \mathrm{O}$.

(b) - Empty data field (components not present in glass). 
The Catholic University of America Vitreous State Laboratory
ORP-56294 Rev. 0

Effects of High Crystal Content in HLW DM100 Melter Tests

Final Report, VSL-09R1520-1, Rev. 0

Table 2.10. Analyzed (XRF) Compositions of the HLW-E-M Glasses (continued).

\begin{tabular}{|c|c|c|c|c|c|}
\hline Oxide & HLW-E-M-06 & HLW-E-M-07 & HLW-E-M-08 & HLW-E-M-09 & HLW-E-M-10 \\
\hline $\mathrm{Al}_{2} \mathrm{O}_{3}$ & $12.07 \%$ & $10.92 \%$ & $10.95 \%$ & $10.59 \%$ & $10.66 \%$ \\
\hline $\mathrm{B}_{2} \mathrm{O}_{3}{ }^{(\mathrm{a})}$ & $13.20 \%$ & $14.15 \%$ & $14.15 \%$ & $14.57 \%$ & $14.34 \%$ \\
\hline $\mathrm{BaO}$ & $0.02 \%$ & $0.01 \%$ & $0.02 \%$ & $0.02 \%$ & $0.02 \%$ \\
\hline $\mathrm{Bi}_{2} \mathrm{O}_{3}$ & $3.59 \%$ & $3.18 \%$ & $3.22 \%$ & $3.68 \%$ & $3.40 \%$ \\
\hline $\mathrm{CaO}$ & $1.21 \%$ & $1.10 \%$ & $1.09 \%$ & $1.25 \%$ & $1.19 \%$ \\
\hline $\mathrm{CdO}$ & $-{ }^{(\mathrm{b})}$ & - & - & - & - \\
\hline $\mathrm{Ce}_{2} \mathrm{O}_{3}$ & - & - & - & - & - \\
\hline $\mathrm{CoO}$ & $0.00 \%$ & $0.00 \%$ & $0.01 \%$ & - & $0.00 \%$ \\
\hline $\mathrm{Cr}_{2} \mathrm{O}_{3}$ & $5.05 \%$ & $3.51 \%$ & $3.40 \%$ & $3.51 \%$ & $3.37 \%$ \\
\hline $\mathrm{Cs}_{2} \mathrm{O}$ & - & - & - & - & - \\
\hline $\mathrm{Er}_{2} \mathrm{O}_{3}$ & - & $0.01 \%$ & $0.00 \%$ & $0.01 \%$ & - \\
\hline $\mathrm{Fe}_{2} \mathrm{O}_{3}$ & $6.06 \%$ & $5.43 \%$ & $5.48 \%$ & $6.50 \%$ & $6.04 \%$ \\
\hline $\mathrm{HfO}_{2}$ & - & - & - & - & - \\
\hline $\mathrm{K}_{2} \mathrm{O}$ & $4.25 \%$ & $4.65 \%$ & $5.04 \%$ & $5.49 \%$ & $5.21 \%$ \\
\hline $\mathrm{La}_{2} \mathrm{O}_{3}$ & $0.01 \%$ & - & $0.01 \%$ & - & - \\
\hline $\mathrm{Li}_{2} \mathrm{O}^{(\mathrm{a})}$ & $2.57 \%$ & $3.24 \%$ & $3.24 \%$ & $3.09 \%$ & $3.04 \%$ \\
\hline $\mathrm{MgO}$ & $0.09 \%$ & $0.07 \%$ & - & $0.06 \%$ & $0.06 \%$ \\
\hline $\mathrm{MnO}$ & $0.51 \%$ & $0.77 \%$ & - & - & $0.75 \%$ \\
\hline $\mathrm{Na}_{2} \mathrm{O}$ & $10.24 \%$ & $9.24 \%$ & $8.90 \%$ & $9.72 \%$ & $10.09 \%$ \\
\hline $\mathrm{Nd}_{2} \mathrm{O}_{3}$ & - & - & - & - & - \\
\hline $\mathrm{NiO}$ & $0.49 \%$ & $0.73 \%$ & - & - & $0.68 \%$ \\
\hline $\mathrm{P}_{2} \mathrm{O}_{5}$ & $1.79 \%$ & $1.61 \%$ & $1.61 \%$ & $1.84 \%$ & $1.80 \%$ \\
\hline $\mathrm{PbO}$ & $0.22 \%$ & $0.19 \%$ & $0.20 \%$ & $0.21 \%$ & $0.19 \%$ \\
\hline $\mathrm{Rh}_{2} \mathrm{O}_{3}$ & - & - & - & - & $0.00 \%$ \\
\hline $\mathrm{RuO}_{2}$ & - & - & - & - & - \\
\hline $\mathrm{SO}_{3}$ & $0.06 \%$ & $0.07 \%$ & $0.07 \%$ & - & - \\
\hline $\mathrm{SiO}_{2}$ & $38.46 \%$ & $40.98 \%$ & $41.00 \%$ & $37.87 \%$ & $37.67 \%$ \\
\hline $\mathrm{SnO}_{2}$ & $0.01 \%$ & $0.01 \%$ & $0.01 \%$ & $0.00 \%$ & $0.01 \%$ \\
\hline $\mathrm{SrO}$ & $0.01 \%$ & $0.01 \%$ & $0.01 \%$ & $0.01 \%$ & $0.01 \%$ \\
\hline $\mathrm{TiO}_{2}$ & $0.02 \%$ & $0.01 \%$ & $0.02 \%$ & $0.02 \%$ & $0.01 \%$ \\
\hline $\mathrm{ZnO}$ & $0.02 \%$ & $0.01 \%$ & $1.47 \%$ & $1.48 \%$ & $1.39 \%$ \\
\hline $\mathrm{ZrO}_{2}$ & $0.05 \%$ & $0.04 \%$ & $0.05 \%$ & $0.06 \%$ & $0.05 \%$ \\
\hline TOTAL & $100 \%$ & $100 \%$ & $100 \%$ & $100 \%$ & $100 \%$ \\
\hline
\end{tabular}

(a) Target values (boldface) are used for $\mathrm{B}_{2} \mathrm{O}_{3}$ and $\mathrm{Li}_{2} \mathrm{O}$.

(b) - Empty data field (components not present in glass). 
The Catholic University of America Vitreous State Laboratory
ORP-56294 Rev. 0

Effects of High Crystal Content in HLW DM100 Melter Tests

Final Report, VSL-09R1520-1, Rev. 0

Table 2.10. Analyzed (XRF) Compositions of the HLW-E-M Glasses (continued).

\begin{tabular}{|c|c|c|c|}
\hline Oxide & HLW-E-M-11 & HLW-E-M-12 & HLW-E-M-13 \\
\hline $\mathrm{Al}_{2} \mathrm{O}_{3}$ & $12.11 \%$ & $10.25 \%$ & $10.12 \%$ \\
\hline $\mathrm{B}_{2} \mathrm{O}_{3}{ }^{(\mathrm{a})}$ & $13.34 \%$ & $14.19 \%$ & $13.89 \%$ \\
\hline $\mathrm{BaO}$ & $0.02 \%$ & $0.01 \%$ & $0.01 \%$ \\
\hline $\mathrm{Bi}_{2} \mathrm{O}_{3}$ & $3.55 \%$ & $3.64 \%$ & $3.38 \%$ \\
\hline $\mathrm{CaO}$ & $1.22 \%$ & $1.21 \%$ & $1.17 \%$ \\
\hline $\mathrm{CdO}$ & - & - & - \\
\hline $\mathrm{Ce}_{2} \mathrm{O}_{3}$ & - & - & - \\
\hline $\mathrm{CoO}$ & $0.00 \%$ & $0.01 \%$ & $0.00 \%$ \\
\hline $\mathrm{Cr}_{2} \mathrm{O}_{3}$ & $3.52 \%$ & $3.57 \%$ & $5.11 \%$ \\
\hline $\mathrm{Cs}_{2} \mathrm{O}$ & - & - & - \\
\hline $\mathrm{Er}_{2} \mathrm{O}_{3}$ & $0.01 \%$ & $0.02 \%$ & $0.01 \%$ \\
\hline $\mathrm{Fe}_{2} \mathrm{O}_{3}$ & $6.26 \%$ & $6.30 \%$ & $6.05 \%$ \\
\hline $\mathrm{HfO}_{2}$ & - & - & - \\
\hline $\mathrm{K}_{2} \mathrm{O}$ & $4.43 \%$ & $5.28 \%$ & $5.12 \%$ \\
\hline $\mathrm{La}_{2} \mathrm{O}_{3}$ & - & - & - \\
\hline $\mathrm{Li}_{2} \mathrm{O}^{(\mathrm{a})}$ & $2.60 \%$ & $3.01 \%$ & $2.94 \%$ \\
\hline $\mathrm{MgO}$ & - & - & - \\
\hline $\mathrm{MnO}$ & - & - & - \\
\hline $\mathrm{Na}_{2} \mathrm{O}$ & $10.09 \%$ & $9.69 \%$ & $9.27 \%$ \\
\hline $\mathrm{Nd}_{2} \mathrm{O}_{3}$ & - & - & - \\
\hline $\mathrm{NiO}$ & - & $0.00 \%$ & - \\
\hline $\mathrm{P}_{2} \mathrm{O}_{5}$ & $1.80 \%$ & $1.72 \%$ & $1.70 \%$ \\
\hline $\mathrm{PbO}$ & $0.21 \%$ & $0.21 \%$ & $0.21 \%$ \\
\hline $\mathrm{Rh}_{2} \mathrm{O}_{3}$ & - & - & - \\
\hline $\mathrm{RuO}_{2}$ & - & - & - \\
\hline $\mathrm{SO}_{3}$ & $0.01 \%$ & - & $0.01 \%$ \\
\hline $\mathrm{SiO}_{2}$ & $39.26 \%$ & $36.67 \%$ & $36.47 \%$ \\
\hline $\mathrm{SnO}_{2}$ & - & $0.01 \%$ & $0.01 \%$ \\
\hline $\mathrm{SrO}$ & $0.01 \%$ & $0.01 \%$ & $0.01 \%$ \\
\hline $\mathrm{TiO}_{2}$ & $0.02 \%$ & $0.02 \%$ & $0.02 \%$ \\
\hline $\mathrm{ZnO}$ & $1.45 \%$ & $4.03 \%$ & $4.41 \%$ \\
\hline $\mathrm{ZrO}_{2}$ & $0.05 \%$ & $0.05 \%$ & $0.05 \%$ \\
\hline TOTAL & $100 \%$ & $100 \%$ & $100 \%$ \\
\hline
\end{tabular}

(a) Target values (boldface) are used for $\mathrm{B}_{2} \mathrm{O}_{3}$ and $\mathrm{Li}_{2} \mathrm{O}$.

(b) - Empty data field (components not present in glass). 
Table 2.11. Characterization Data for the HLW-E-M Series of Glasses.

\begin{tabular}{|c|c|c|c|c|c|}
\hline & Property & HLW-E-M-01 & HLW-E-M-02 & HLW-E-M-03 & HLW-E-M-04 \\
\hline & Formulation Basis & $\begin{array}{c}\text { Add divalent } \\
\text { metals (Mn \& Ni) } \\
\text { to HLW-E-ES-02 }\end{array}$ & $\begin{array}{c}\text { Add divalent } \\
\text { metals (Mn \& Ni) } \\
\text { to HLW-E-ES-03 }\end{array}$ & $\begin{array}{l}\text { Increase divalent } \\
\text { metals conc. in } \\
\text { HLW-E-M-01 }\end{array}$ & $\begin{array}{l}\text { Decrease divalent } \\
\text { metals conc. in } \\
\text { HLW-E-M-02 }\end{array}$ \\
\hline & As-Melted at $1200^{\circ} \mathrm{C}(\mathrm{vol} \%)$ & $2.3(\mathrm{ES})$ & $\begin{array}{c}4.5(95 \% \mathrm{Sp} \\
5 \% \mathrm{ES})\end{array}$ & $\begin{array}{c}1.9(85 \% \mathrm{ES} \\
15 \% \mathrm{SP})\end{array}$ & $\begin{array}{c}3.2(95 \% \mathrm{ES} \\
5 \% \mathrm{SP})\end{array}$ \\
\hline & After $\mathrm{HT}$ at $1150^{\circ} \mathrm{C}(\mathrm{vol} \%)$ & $1.8(\mathrm{ES})$ & $3.5(\mathrm{Sp})$ & $\begin{array}{c}2.2(15 \% \mathrm{ES}, \\
85 \% \mathrm{Sp})\end{array}$ & $\begin{array}{c}2.6(50 \% \mathrm{ES}, \\
50 \% \mathrm{SP})\end{array}$ \\
\hline$\stackrel{\Xi}{\mathbb{E}}$ & After $\mathrm{HT}$ at $1100^{\circ} \mathrm{C}(\mathrm{vol} \%)$ & $\begin{array}{c}1.8(95 \% \mathrm{ES}, \\
5 \% \mathrm{Sp})\end{array}$ & $4.0(\mathrm{Sp})$ & $2.1(\mathrm{Sp})$ & $\begin{array}{c}3.2(40 \% \mathrm{ES}, \\
60 \% \mathrm{SP})\end{array}$ \\
\hline$\overbrace{0}^{\tilde{0}}$ & After $\mathrm{HT}$ at $1000^{\circ} \mathrm{C}(\mathrm{vol} \%)$ & $\begin{array}{c}2.8(30 \% \mathrm{ES}, \\
70 \% \mathrm{Sp})\end{array}$ & $3.2(\mathrm{Sp})$ & $\begin{array}{l}2.4(\mathrm{Sp}, \\
\text { Trace ES) }\end{array}$ & $\begin{array}{c}4.0(\mathrm{Sp}, \\
\text { Trace ES) }\end{array}$ \\
\hline 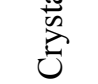 & After $\mathrm{HT}$ at $950^{\circ} \mathrm{C}(\mathrm{vol} \%)$ & $\begin{array}{c}2.8 \text { (Sp, } \\
\text { Trace ES) }\end{array}$ & $3.8(\mathrm{Sp})$ & $2.5(\mathrm{Sp})$ & $4.3(\mathrm{Sp})$ \\
\hline & After $\mathrm{HT}$ at $900^{\circ} \mathrm{C}(\mathrm{vol} \%)$ & $2.5(\mathrm{SP})$ & $3.9(\mathrm{Sp})$ & $2.2(\mathrm{Sp})$ & $3.6(\mathrm{Sp}, \mathrm{CP})$ \\
\hline & $\begin{array}{c}\text { Approximate Average } \\
\text { Particle Size }\end{array}$ & $\begin{array}{l}28 \mu \mathrm{m}(\mathrm{Sp}) \\
18 \mu \mathrm{m}(\mathrm{ES})\end{array}$ & $\begin{array}{l}5 \mu \mathrm{m}(\mathrm{Sp}) \\
17 \mu \mathrm{m}(\mathrm{ES})\end{array}$ & $\begin{array}{l}4 \mu \mathrm{m}(\mathrm{Sp}) \\
15 \mu \mathrm{m}(\mathrm{ES})\end{array}$ & $\begin{array}{l}7 \mu \mathrm{m}(\mathrm{Sp}) \\
25 \mu \mathrm{m}(\mathrm{ES})\end{array}$ \\
\hline & $950^{\circ} \mathrm{C}$ & $-^{(\mathrm{b})}$ & - & $610.9\left(963^{\circ} \mathrm{C}\right)^{(\mathrm{c})}$ & - \\
\hline${ }_{\lambda}^{2}$ & $1050^{\circ} \mathrm{C}$ & - & - & $311.4\left(1064^{\circ} \mathrm{C}\right)$ & - \\
\hline $\begin{array}{l}0 \\
0 \\
0\end{array}$ & $1150^{\circ} \mathrm{C}$ & - & - & $170.4\left(1166^{\circ} \mathrm{C}\right)$ & - \\
\hline & $1200^{\circ} \mathrm{C}$ & - & - & $82.4\left(1267^{\circ} \mathrm{C}\right)$ & - \\
\hline & $950^{\circ} \mathrm{C}$ & - & - & 0.106 & - \\
\hline 芑 & $1000^{\circ} \mathrm{C}$ & - & - & 0.132 & - \\
\hline نे & $1050^{\circ} \mathrm{C}$ & - & - & 0.161 & - \\
\hline 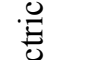 & $1100^{\circ} \mathrm{C}$ & - & - & 0.193 & - \\
\hline & $1150^{\circ} \mathrm{C}$ & - & - & 0.229 & - \\
\hline & B (g/l) & - & - & 0.901 & 0.915 \\
\hline ฮี & $\mathrm{Li}(\mathrm{g} / \mathrm{l})$ & - & - & 0.703 & 0.766 \\
\hline & $\mathrm{Na}(\mathrm{g} / \mathrm{l})$ & - & - & 0.679 & 0.704 \\
\hline
\end{tabular}

(a) Glass melting time $=2$ hours, Heat treatment time $=70$ hours, $\mathrm{Sp}=$ Spinel, $\mathrm{ES}=$ Eskolaite, $\mathrm{CP}=\mathrm{Calcium}$ Phosphate

(b) - Empty data field (Not Analyzed).

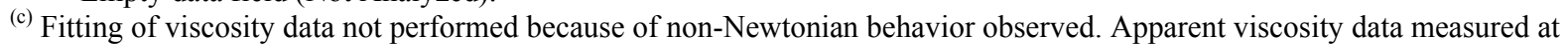
selected shear rate $(1.51 / \mathrm{s})$ and temperatures are reported. 
ORP-56294 Rev. 0

The Catholic University of America Vitreous State Laboratory

Table 2.11. Characterization Data for the HLW-E-M Series of Glasses (continued).

\begin{tabular}{|c|c|c|c|c|c|}
\hline & Property & HLW-E-M-05 & HLW-E-M-06 & HLW-E-M-07 & HLW-E-M-08 \\
\hline & Formulation Basis & $\begin{array}{c}\text { Add divalent } \\
\text { metals to HLW-E- } \\
\text { ES-01 (lower Cr } \\
\text { than ES-02) }\end{array}$ & $\begin{array}{l}\text { Decrease divalent } \\
\text { metals conc. in } \\
\text { HLW-E-M-02 }\end{array}$ & $\begin{array}{c}\text { Add divalent } \\
\text { metals (Mn \& Ni) } \\
\text { to HLW-E-ES-06 }\end{array}$ & $\begin{array}{l}\text { Add } \mathrm{ZnO} \text { to } \\
\text { HLW-E-ES-06 }\end{array}$ \\
\hline & As-Melted at $1200^{\circ} \mathrm{C}(\mathrm{vol} \%)$ & $0.2(\mathrm{ES})$ & $3.7(\mathrm{ES})$ & $1.8(\mathrm{ES})$ & $1.6(\mathrm{Sp})$ \\
\hline & After HT at $1150^{\circ} \mathrm{C}(\mathrm{vol} \%)$ & $1.0(\mathrm{ES})$ & $3.8(\mathrm{ES})$ & $\begin{array}{c}1.8(75 \% \mathrm{ES} \\
25 \% \mathrm{Sp})\end{array}$ & $2.4(\mathrm{Sp})$ \\
\hline 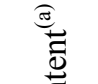 & After HT at $1100^{\circ} \mathrm{C}(\mathrm{vol} \%)$ & $\begin{array}{c}0.8(65 \% \mathrm{ES}, \\
35 \% \mathrm{Sp})\end{array}$ & $\begin{array}{c}3.5(90 \% \mathrm{ES}, \\
10 \% \mathrm{Sp})\end{array}$ & $\begin{array}{c}2.5(50 \% \mathrm{ES}, \\
50 \% \mathrm{Sp})\end{array}$ & $1.9(\mathrm{Sp})$ \\
\hline$\bigcup_{\tilde{\sigma}}^{\tilde{0}}$ & After $\mathrm{HT}$ at $1000^{\circ} \mathrm{C}(\mathrm{vol} \%)$ & $1.1(\mathrm{Sp})$ & $\begin{array}{c}3.0(55 \% \mathrm{ES}, \\
45 \% \mathrm{Sp})\end{array}$ & $\begin{array}{c}2.9(5 \% \mathrm{ES} \\
9 \% \mathrm{Sp})\end{array}$ & $2.1(\mathrm{Sp})$ \\
\hline 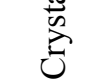 & After $\mathrm{HT}$ at $950^{\circ} \mathrm{C}(\mathrm{vol} \%)$ & $\begin{array}{l}1.0 \text { (Sp, Trace } \\
\text { ES) }\end{array}$ & $\begin{array}{c}2.8(20 \% \mathrm{ES}, \\
80 \% \mathrm{Sp})\end{array}$ & $2.4(\mathrm{Sp})$ & $1.8(\mathrm{Sp})$ \\
\hline & After $\mathrm{HT}$ at $900^{\circ} \mathrm{C}(\mathrm{vol} \%)$ & $1.2(\mathrm{Sp})$ & $\begin{array}{c}3.1(5 \% \mathrm{ES} \\
95 \% \mathrm{Sp}) \\
\end{array}$ & $2.7(\mathrm{Sp})$ & $1.8(\mathrm{Sp})$ \\
\hline & $\begin{array}{c}\text { Approximate Average } \\
\text { Particle Size }\end{array}$ & $\begin{array}{l}20 \mu \mathrm{m} \text { (Sp), } \\
25 \mu \mathrm{m} \text { (ES) }\end{array}$ & $\begin{array}{l}22 \mu \mathrm{m} \text { (Sp), } \\
22 \mu \mathrm{m} \text { (ES) }\end{array}$ & $\begin{array}{l}26 \mu \mathrm{m}(\mathrm{Sp}) \\
20 \mu \mathrm{m}(\mathrm{ES})\end{array}$ & $2 \mu \mathrm{m}$ \\
\hline & $950^{\circ} \mathrm{C}$ & - $^{(\mathrm{b})}$ & - & - & 415.1 \\
\hline 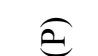 & $1000^{\circ} \mathrm{C}$ & - & - & - & 232.4 \\
\hline$\stackrel{\substack{n \\
0}}{0}$ & $1050^{\circ} \mathrm{C}$ & - & - & - & 138.8 \\
\hline 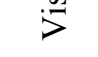 & $1100^{\circ} \mathrm{C}$ & - & - & - & 87.5 \\
\hline & $1150^{\circ} \mathrm{C}$ & - & - & - & 57.8 \\
\hline & $950^{\circ} \mathrm{C}$ & - & - & - & 0.092 \\
\hline 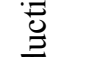 & $1000^{\circ} \mathrm{C}$ & - & - & - & 0.117 \\
\hline$e^{\overline{0}} \frac{\overline{0}}{\infty}$ & $1050^{\circ} \mathrm{C}$ & - & - & - & 0.147 \\
\hline & $1100^{\circ} \mathrm{C}$ & - & - & - & 0.181 \\
\hline & $1150^{\circ} \mathrm{C}$ & - & - & - & 0.220 \\
\hline & $\mathrm{B}(\mathrm{g} / \mathrm{l})$ & - & - & - & - \\
\hline$\overline{\Xi ี \Xi}$ & $\mathrm{Li}(\mathrm{g} / \mathrm{l})$ & - & - & - & - \\
\hline$Z_{2}$ & $\mathrm{Na}(\mathrm{g} / \mathrm{l})$ & - & - & - & - \\
\hline
\end{tabular}

(a) Glass melting time $=2$ hours, Heat treatment time $=70$ hours, $\mathrm{ES}=$ Eskolaite (with minor amounts of iron incorporated), $\mathrm{Sp}=$ Spinel.

(b) - Empty data field (Not Analyzed). 
Table 2.11. Characterization Data for the HLW-E-M Series of Glasses (continued).

\begin{tabular}{|c|c|c|c|c|c|}
\hline & Property & HLW-E-M-09 & HLW-E-M-10 & HLW-E-M-11 & HLW-E-M-12 \\
\hline & Formulation Basis & $\begin{array}{l}\text { Add } \mathrm{ZnO} \text { to } \\
\text { HLW-E-ES-05 }\end{array}$ & $\begin{array}{l}\text { Add } \mathrm{Mn}, \mathrm{Ni} \text { and } \\
\mathrm{ZnO} \text { to HLW-E- }\end{array}$ & $\begin{array}{l}\text { Substitute } \mathrm{ZnO} \text { for } \\
\mathrm{MnO} \text { and } \mathrm{NiO} \text { in }\end{array}$ & $\begin{array}{c}\text { Increase } \mathrm{ZnO} \text { in } \\
\text { HLW-E-M-09 }\end{array}$ \\
\hline & As-Melted at $1200^{\circ} \mathrm{C}$ (vol\%) & $1.5(\mathrm{Sp})$ & $2.0(\mathrm{Sp})$ & $2.5(\mathrm{Sp})$ & $2.7(\mathrm{Sp})$ \\
\hline & After $\mathrm{HT}$ at $1150^{\circ} \mathrm{C}(\mathrm{vol} \%)$ & $2.5(\mathrm{Sp})$ & $2.8(\mathrm{Sp})$ & $2.5(\mathrm{Sp})$ & $2.8(\mathrm{Sp})$ \\
\hline$\stackrel{0}{\overrightarrow{0}}$ & After $\mathrm{HT}$ at $1100^{\circ} \mathrm{C}(\mathrm{vol} \%)$ & $2.4(\mathrm{Sp})$ & $2.3(\mathrm{Sp})$ & $2.5(\mathrm{Sp})$ & $2.6(\mathrm{Sp})$ \\
\hline ē & After $\mathrm{HT}$ at $1000^{\circ} \mathrm{C}(\mathrm{vol} \%)$ & $1.8(\mathrm{Sp})$ & $2.4(\mathrm{Sp})$ & $2.3(\mathrm{Sp})$ & $4.0(\mathrm{Sp})$ \\
\hline$\sum_{i}^{\infty}$ & After $\mathrm{HT}$ at $950^{\circ} \mathrm{C}(\mathrm{vol} \%)$ & $1.6(\mathrm{Sp})$ & $2.5(\mathrm{Sp})$ & $2.3(\mathrm{Sp})$ & $2.2(\mathrm{Sp})$ \\
\hline & After $\mathrm{HT}$ at $900^{\circ} \mathrm{C}(\mathrm{vol} \%)$ & $2.0(\mathrm{Sp})$ & $2.2(\mathrm{Sp})$ & $2.6(\mathrm{Sp})$ & $2.4(\mathrm{Sp})$ \\
\hline & $\begin{array}{c}\text { Approximate Average } \\
\text { Particle Size }\end{array}$ & $2 \mu \mathrm{m}$ & $3 \mu \mathrm{m}$ & $2 \mu \mathrm{m}$ & $1 \mu \mathrm{m}$ \\
\hline & $950^{\circ} \mathrm{C}$ & 253.8 & $-^{(\mathrm{b})}$ & - & - \\
\hline$\overparen{E}$ & $1000^{\circ} \mathrm{C}$ & 147.3 & - & - & - \\
\hline 㺃 & $1050^{\circ} \mathrm{C}$ & 89.8 & - & - & - \\
\hline$i^{2}$ & $1100^{\circ} \mathrm{C}$ & 57.2 & - & - & - \\
\hline & $1150^{\circ} \mathrm{C}$ & 37.8 & - & - & - \\
\hline & $950^{\circ} \mathrm{C}$ & 0.152 & - & - & - \\
\hline 苞 & $1000^{\circ} \mathrm{C}$ & 0.196 & - & - & - \\
\hline రี $\frac{\tilde{0}}{\infty}$ & $1050^{\circ} \mathrm{C}$ & 0.245 & - & - & - \\
\hline & $1100^{\circ} \mathrm{C}$ & 0.300 & - & - & - \\
\hline & $1150^{\circ} \mathrm{C}$ & 0.360 & - & - & - \\
\hline & $\mathrm{B}(\mathrm{g} / \mathrm{l})$ & 4.682 & - & - & - \\
\hline 气 & $\mathrm{Li}(\mathrm{g} / \mathrm{l})$ & 3.716 & - & - & - \\
\hline$Z_{2}$ & $\mathrm{Na}(\mathrm{g} / \mathrm{l})$ & 2.766 & - & - & - \\
\hline
\end{tabular}

(a) Glass melting time $=2$ hours, Heat treatment time $=70$ hours, $\mathrm{Sp}=$ Spinel.

(b) - Empty data field (Not Analyzed). 
Table 2.11. Characterization Data for the HLW-E-M Series of Glasses (continued).

\begin{tabular}{|c|c|c|}
\hline & Property & HLW-E-M-13 \\
\hline & Formulation Basis & $\begin{array}{l}\text { Increase both Cr } \\
\text { and } \mathrm{Zn} \text { in HLW- } \\
\text { E-M-09 }\end{array}$ \\
\hline & As-Melted at $1200^{\circ} \mathrm{C}$ (vol\%) & $4.2(\mathrm{Sp})$ \\
\hline & After $\mathrm{HT}$ at $1150^{\circ} \mathrm{C}(\mathrm{vol} \%)$ & - (b) $^{(12}$ \\
\hline$\stackrel{0}{=}$ & After $\mathrm{HT}$ at $1100^{\circ} \mathrm{C}(\mathrm{vol} \%)$ & $2.6(\mathrm{Sp})$ \\
\hline i & After $\mathrm{HT}$ at $1000^{\circ} \mathrm{C}(\mathrm{vol} \%)$ & NA \\
\hline$\sum_{i}^{\infty}$ & After $\mathrm{HT}$ at $950^{\circ} \mathrm{C}(\mathrm{vol} \%)$ & $3.1(\mathrm{Sp})$ \\
\hline & After $\mathrm{HT}$ at $900^{\circ} \mathrm{C}(\mathrm{vol} \%)$ & NA \\
\hline & $\begin{array}{c}\text { Approximate Average } \\
\text { Particle Size }\end{array}$ & $1 \mu \mathrm{m}$ \\
\hline & $950^{\circ} \mathrm{C}$ & - \\
\hline (2) & $1000^{\circ} \mathrm{C}$ & - \\
\hline$=$ & $1050^{\circ} \mathrm{C}$ & - \\
\hline$j$ & $1100^{\circ} \mathrm{C}$ & - \\
\hline & $1150^{\circ} \mathrm{C}$ & - \\
\hline & $950^{\circ} \mathrm{C}$ & - \\
\hline$\stackrel{\vec{\sigma}}{z}$ & $1000^{\circ} \mathrm{C}$ & - \\
\hline نं & $1050^{\circ} \mathrm{C}$ & - \\
\hline$\stackrel{\Xi}{ \pm}$ & $1100^{\circ} \mathrm{C}$ & - \\
\hline & $1150^{\circ} \mathrm{C}$ & - \\
\hline & $\mathrm{B}(\mathrm{g} / \mathrm{l})$ & 4.225 \\
\hline $\bar{\Xi}$ & $\mathrm{Li}(\mathrm{g} / \mathrm{l})$ & 3.253 \\
\hline Z & $\mathrm{Na}(\mathrm{g} / \mathrm{l})$ & 2.507 \\
\hline
\end{tabular}

(a) Glass melting time $=2$ hours, Heat treatment time $=70$ hours, $\mathrm{Sp}=$ Spinel. (b) - Empty data field (Not Analyzed). 
The Catholic University of America Vitreous State Laboratory
ORP-56294 Rev. 0

Effects of High Crystal Content in HLW DM100 Melter Tests

Final Report, VSL-09R1520-1, Rev. 0

Table 2.12. Summary of Target Compositions of HLW Glasses Selected for Melter Tests.

\begin{tabular}{|c|c|c|c|c|c|}
\hline Test & Test 1 & Test 2 & Test 3 & Test 4 & Test 5 \\
\hline Target Glass & HLW-E-SP-06 & HLW-E-SP-05 & HLW-E-M-03 & HLW-E-ES-05 & HLW-E-M-09 \\
\hline $\mathrm{Al}_{2} \mathrm{O}_{3}$ & $8.91 \%$ & $9.49 \%$ & $12.17 \%$ & $10.86 \%$ & $10.69 \%$ \\
\hline $\mathrm{B}_{2} \mathrm{O}_{3}$ & $13.30 \%$ & $12.08 \%$ & $13.34 \%$ & $14.80 \%$ & $14.57 \%$ \\
\hline $\mathrm{BaO}$ & - $^{\text {(a) }}$ & - & $0.01 \%$ & $0.01 \%$ & $0.01 \%$ \\
\hline $\mathrm{Bi}_{2} \mathrm{O}_{3}$ & - & - & $3.47 \%$ & $3.53 \%$ & $3.47 \%$ \\
\hline $\mathrm{CaO}$ & $0.37 \%$ & $0.40 \%$ & $1.18 \%$ & $1.20 \%$ & $1.18 \%$ \\
\hline $\mathrm{CdO}$ & $0.18 \%$ & $0.19 \%$ & - & - & - \\
\hline $\mathrm{Cr}_{2} \mathrm{O}_{3}$ & $0.15 \%$ & $0.15 \%$ & $3.00 \%$ & $3.00 \%$ & $3.00 \%$ \\
\hline $\mathrm{Cs}_{2} \mathrm{O}$ & $0.08 \%$ & $0.08 \%$ & - & - & - \\
\hline $\mathrm{F}$ & - & - & $0.95 \%$ & $0.97 \%$ & $0.95 \%$ \\
\hline $\mathrm{Fe}_{2} \mathrm{O}_{3}$ & $20.01 \%$ & $21.30 \%$ & $6.26 \%$ & $6.36 \%$ & $6.26 \%$ \\
\hline $\mathrm{K}_{2} \mathrm{O}$ & $7.00 \%$ & $7.01 \%$ & $4.54 \%$ & $5.61 \%$ & $5.52 \%$ \\
\hline $\mathrm{La}_{2} \mathrm{O}_{3}$ & $0.60 \%$ & $0.64 \%$ & - & - & - \\
\hline $\mathrm{Li}_{2} \mathrm{O}$ & $1.17 \%$ & $1.10 \%$ & $2.60 \%$ & $3.14 \%$ & $3.09 \%$ \\
\hline $\mathrm{MgO}$ & $0.11 \%$ & $0.12 \%$ & $0.08 \%$ & $0.08 \%$ & $0.08 \%$ \\
\hline $\mathrm{MnO}$ & $0.57 \%$ & $0.61 \%$ & $0.75 \%$ & - & - \\
\hline $\mathrm{Na}_{2} \mathrm{O}$ & $10.19 \%$ & $9.07 \%$ & $9.57 \%$ & $9.72 \%$ & $9.57 \%$ \\
\hline $\mathrm{Nd}_{2} \mathrm{O}_{3}$ & $0.26 \%$ & $0.28 \%$ & - & - & - \\
\hline $\mathrm{NiO}$ & $0.71 \%$ & $0.76 \%$ & $0.75 \%$ & - & - \\
\hline $\mathrm{P}_{2} \mathrm{O}_{5}$ & $0.04 \%$ & $0.04 \%$ & $1.59 \%$ & $1.62 \%$ & $1.59 \%$ \\
\hline $\mathrm{PbO}$ & $0.11 \%$ & $0.12 \%$ & $0.23 \%$ & $0.23 \%$ & $0.23 \%$ \\
\hline $\mathrm{SO}_{3}$ & $0.07 \%$ & $0.07 \%$ & - & - & - \\
\hline $\mathrm{SiO}_{2}$ & $33.31 \%$ & $33.46 \%$ & $39.45 \%$ & $38.82 \%$ & $38.22 \%$ \\
\hline $\mathrm{ZnO}$ & $0.02 \%$ & $0.02 \%$ & - & - & $1.50 \%$ \\
\hline $\mathrm{ZrO}_{2}$ & $2.83 \%$ & $3.01 \%$ & $0.05 \%$ & $0.05 \%$ & $0.05 \%$ \\
\hline TOTAL & $100.0 \%$ & $100.0 \%$ & $100.0 \%$ & $100.0 \%$ & $100.0 \%$ \\
\hline
\end{tabular}

(a) — indicates empty data field. 
Table 2.13. Compositional Summary of the HLW Simulant, Glass Formers and Target Glass (HLW-E-SP-06) for Melter Test 1.

\begin{tabular}{|c|c|c|c|}
\hline Oxide & $\begin{array}{c}\text { Test } 1 \\
\text { HLW Simulant }\end{array}$ & $\begin{array}{c}\text { Test } 1 \\
\text { Glass Formers } \\
\text { (as wt \% of Glass) }\end{array}$ & $\begin{array}{c}\text { Test } 1 \\
\text { Target Glass } \\
\text { (HLW-E-SP-06) }\end{array}$ \\
\hline $\mathrm{Al}_{2} \mathrm{O}_{3}$ & $23.02 \%$ & - $^{\text {(a) }}$ & $8.91 \%$ \\
\hline $\mathrm{B}_{2} \mathrm{O}_{3}$ & $2.06 \%$ & $12.50 \%$ & $13.30 \%$ \\
\hline $\mathrm{CaO}$ & $0.96 \%$ & - & $0.37 \%$ \\
\hline $\mathrm{CdO}$ & $0.47 \%$ & - & $0.18 \%$ \\
\hline $\mathrm{Cr}_{2} \mathrm{O}_{3}$ & $0.37 \%$ & - & $0.15 \%$ \\
\hline $\mathrm{Cs}_{2} \mathrm{O}$ & $0.21 \%$ & - & $0.08 \%$ \\
\hline $\mathrm{Fe}_{2} \mathrm{O}_{3}$ & $51.66 \%$ & - & $20.01 \%$ \\
\hline $\mathrm{K}_{2} \mathrm{O}$ & $0.24 \%$ & $6.91 \%$ & $7.00 \%$ \\
\hline $\mathrm{La}_{2} \mathrm{O}_{3}$ & $1.55 \%$ & - & $0.60 \%$ \\
\hline $\mathrm{Li}_{2} \mathrm{O}$ & $0.03 \%$ & $1.16 \%$ & $1.17 \%$ \\
\hline $\mathrm{MgO}$ & $0.30 \%$ & - & $0.11 \%$ \\
\hline $\mathrm{MnO}$ & $1.47 \%$ & - & $0.57 \%$ \\
\hline $\mathrm{Na}_{2} \mathrm{O}$ & $3.08 \%$ & $9.00 \%$ & $10.19 \%$ \\
\hline $\mathrm{Nd}_{2} \mathrm{O}_{3}$ & $0.68 \%$ & - & $0.26 \%$ \\
\hline $\mathrm{NiO}$ & $1.84 \%$ & - & $0.71 \%$ \\
\hline $\mathrm{P}_{2} \mathrm{O}_{5}$ & $0.10 \%$ & - & $0.04 \%$ \\
\hline $\mathrm{PbO}$ & $0.29 \%$ & - & $0.11 \%$ \\
\hline $\mathrm{SO}_{3}$ & $0.17 \%$ & - & $0.07 \%$ \\
\hline $\mathrm{SiO}_{2}$ & $4.17 \%$ & $31.70 \%$ & $33.31 \%$ \\
\hline $\mathrm{ZnO}$ & $0.04 \%$ & - & $0.02 \%$ \\
\hline $\mathrm{ZrO}_{2}$ & $7.29 \%$ & - & $2.83 \%$ \\
\hline TOTAL & $100.0 \%$ & $61.27 \%$ & $100.0 \%$ \\
\hline \multicolumn{4}{|c|}{ Volatiles (g/100 g of waste oxide) } \\
\hline Carbonate & $1.145 \mathrm{E}+00$ & - & - \\
\hline Nitrite & $0.407 \mathrm{E}-01$ & - & - \\
\hline Nitrate & $1.883 \mathrm{E}+00$ & - & - \\
\hline Total Organic Carbon & 4.959E-02 & - & - \\
\hline
\end{tabular}

(a) - Empty data field. 
Table 2.14. Compositions of the HLW Melter Feed (Simulant and Glass Forming Additives) to Produce $600 \mathrm{~kg}$ of Target Glass for Test 1.

\begin{tabular}{|c|c|c|c|}
\hline \multicolumn{2}{|c|}{ Test 1 HLW Simulant } & \multicolumn{2}{|c|}{ Test 1 Glass Forming Additives } \\
\hline Starting Materials & Target Weight (kg) $)^{(a)}$ & Starting Materials & Target Weight (kg) $)^{(\mathbf{a})}$ \\
\hline $\mathrm{Al}(\mathrm{OH})_{3}$ & 82.67 & - $^{\text {(a) }}$ & - \\
\hline $\mathrm{H}_{3} \mathrm{BO}_{3}$ & 8.61 & $\mathrm{Na}_{2} \mathrm{~B}_{4} \mathrm{O}_{7} \cdot 10 \mathrm{H}_{2} \mathrm{O}$ & 207.50 \\
\hline $\mathrm{CaO}$ & 2.26 & - & - \\
\hline $\mathrm{CdO}$ & 1.08 & - & - \\
\hline $\mathrm{Cr}_{2} \mathrm{O}_{3}$ & 0.88 & - & - \\
\hline $\mathrm{CsOH}(50 \%$ Solution $)$ & 1.02 & - & - \\
\hline $\mathrm{Fe}(\mathrm{OH})_{3}(13 \%$ slurry $)$ & 804.48 & - & - \\
\hline $\mathrm{K}_{2} \mathrm{CO}_{3}$ & 0.83 & $\mathrm{~K}_{2} \mathrm{CO}_{3}$ & 61.45 \\
\hline $\mathrm{La}_{2} \mathrm{O}_{3}$ & 3.63 & - & - \\
\hline $\mathrm{Li}_{2} \mathrm{CO}_{3}$ & 0.19 & $\mathrm{Li}_{2} \mathrm{CO}_{3}$ & 17.66 \\
\hline $\mathrm{MgO}$ & 0.70 & - & - \\
\hline $\mathrm{MnO}_{2}$ & 4.22 & - & - \\
\hline $\mathrm{Na}_{2} \mathrm{CO}_{3}$ & 6.58 & $\mathrm{Na}_{2} \mathrm{CO}_{3}$ & 35.61 \\
\hline $\mathrm{Nd}_{2} \mathrm{O}_{3}$ & 1.59 & - & - \\
\hline $\mathrm{Ni}(\mathrm{OH})_{2}$ & 5.33 & - & - \\
\hline $\mathrm{Na}_{2} \mathrm{HPO}_{4}$ & 0.49 & - & - \\
\hline $\mathrm{PbO}$ & 0.68 & - & - \\
\hline $\mathrm{Na}_{2} \mathrm{SO}_{4}$ & 0.71 & - & - \\
\hline $\mathrm{SiO}_{2}$ & 9.79 & $\mathrm{SiO}_{2}$ & 191.12 \\
\hline $\mathrm{ZnO}$ & 0.10 & - & - \\
\hline $\mathrm{Zr}(\mathrm{OH})_{4} \cdot x \mathrm{H}_{2} \mathrm{O}(50 \%)$ & 39.22 & - & - \\
\hline $\mathrm{Fe}_{2} \mathrm{O}_{3}$ & 42.32 & - & - \\
\hline $\mathrm{NaNO}_{2}$ & 1.43 & - & - \\
\hline $\mathrm{NaNO}_{3}$ & 6.03 & - & - \\
\hline $\mathrm{H}_{2} \mathrm{C}_{2} \mathrm{O}_{4} \cdot 2 \mathrm{H}_{2} \mathrm{O}$ & 0.61 & - & - \\
\hline Water & 152.54 & - & - \\
\hline Simulant Subtotal & 1178.0 & Glass Formers Subtotal & 514.3 \\
\hline- & - & Feed Total & 1691.3 \\
\hline
\end{tabular}

(a) - Empty data field. 
ORP-56294 Rev. 0

The Catholic University of America Vitreous State Laboratory

Table 2.15. Compositional Summary of the HLW Simulant, Glass Formers and Target Glass (HLW-E-SP-05) for Melter Test 2.

\begin{tabular}{|c|c|c|c|}
\hline Oxide & $\begin{array}{c}\text { Test } 2 \\
\text { HLW Simulant }\end{array}$ & $\begin{array}{c}\text { Test } 2 \\
\text { Glass Former } \\
\text { (as wt \% of Glass) }\end{array}$ & $\begin{array}{c}\text { Test } 2 \\
\text { Target Glass } \\
\text { (HLW-E-SP-05) } \\
\end{array}$ \\
\hline $\mathrm{Al}_{2} \mathrm{O}_{3}$ & $23.02 \%$ & - $^{\text {(a) }}$ & $9.49 \%$ \\
\hline $\mathrm{B}_{2} \mathrm{O}_{3}$ & $2.06 \%$ & $11.23 \%$ & $12.08 \%$ \\
\hline $\mathrm{CaO}$ & $0.96 \%$ & - & $0.40 \%$ \\
\hline $\mathrm{CdO}$ & $0.47 \%$ & - & $0.19 \%$ \\
\hline $\mathrm{Cr}_{2} \mathrm{O}_{3}$ & $0.37 \%$ & - & $0.15 \%$ \\
\hline $\mathrm{Cs}_{2} \mathrm{O}$ & $0.21 \%$ & - & $0.08 \%$ \\
\hline $\mathrm{Fe}_{2} \mathrm{O}_{3}$ & $51.66 \%$ & - & $21.30 \%$ \\
\hline $\mathrm{K}_{2} \mathrm{O}$ & $0.24 \%$ & $6.91 \%$ & $7.01 \%$ \\
\hline $\mathrm{La}_{2} \mathrm{O}_{3}$ & $1.55 \%$ & - & $0.64 \%$ \\
\hline $\mathrm{Li}_{2} \mathrm{O}$ & $0.03 \%$ & $1.09 \%$ & $1.10 \%$ \\
\hline $\mathrm{MgO}$ & $0.30 \%$ & - & $0.12 \%$ \\
\hline $\mathrm{MnO}$ & $1.47 \%$ & - & $0.61 \%$ \\
\hline $\mathrm{Na}_{2} \mathrm{O}$ & $3.08 \%$ & $7.80 \%$ & $9.07 \%$ \\
\hline $\mathrm{Nd}_{2} \mathrm{O}_{3}$ & $0.68 \%$ & - & $0.28 \%$ \\
\hline $\mathrm{NiO}$ & $1.84 \%$ & - & $0.76 \%$ \\
\hline $\mathrm{P}_{2} \mathrm{O}_{5}$ & $0.10 \%$ & - & $0.04 \%$ \\
\hline $\mathrm{PbO}$ & $0.29 \%$ & - & $0.12 \%$ \\
\hline $\mathrm{SO}_{3}$ & $0.17 \%$ & - & $0.07 \%$ \\
\hline $\mathrm{SiO}_{2}$ & $4.17 \%$ & $31.74 \%$ & $33.46 \%$ \\
\hline $\mathrm{ZnO}$ & $0.04 \%$ & - & $0.02 \%$ \\
\hline $\mathrm{ZrO}_{2}$ & $7.29 \%$ & - & $3.01 \%$ \\
\hline TOTAL & $100.0 \%$ & $58.77 \%$ & $100.0 \%$ \\
\hline \multicolumn{4}{|c|}{ Volatiles ( $\mathrm{g} / \mathbf{1 0 0} \mathrm{g}$ of waste oxide) } \\
\hline Carbonate & $1.145 \mathrm{E}+00$ & - & - \\
\hline Nitrite & $0.407 \mathrm{E}-01$ & - & - \\
\hline Nitrate & $1.883 \mathrm{E}+00$ & - & - \\
\hline Total Organic Carbon & $4.959 \mathrm{E}-02$ & - & - \\
\hline
\end{tabular}

(a) - Empty data field. 
Table 2.16. Compositions of the HLW Melter Feed (Simulant and Glass Forming Additives) to Produce $600 \mathrm{~kg}$ of Target Glass for Test 2.

\begin{tabular}{|c|c|c|c|}
\hline \multicolumn{2}{|c|}{ Test 2 HLW Simulant } & \multicolumn{2}{|c|}{ Test 2 Glass Forming Additives } \\
\hline Starting Materials & Target Weight (kg) $)^{(a)}$ & Starting Materials & Target Weight (kg) $)^{(\mathbf{a})}$ \\
\hline $\mathrm{Al}(\mathrm{OH})_{3}$ & 88.01 & - $^{\text {(a) }}$ & - \\
\hline $\mathrm{H}_{3} \mathrm{BO}_{3}$ & 9.16 & $\mathrm{Na}_{2} \mathrm{~B}_{4} \mathrm{O}_{7} \cdot 10 \mathrm{H}_{2} \mathrm{O}$ & 186.41 \\
\hline $\mathrm{CaO}$ & 2.40 & - & - \\
\hline $\mathrm{CdO}$ & 1.15 & - & - \\
\hline $\mathrm{Cr}_{2} \mathrm{O}_{3}$ & 0.94 & - & - \\
\hline $\mathrm{CsOH}(50 \%$ Solution $)$ & 1.08 & - & - \\
\hline $\mathrm{Fe}(\mathrm{OH})_{3}(13 \%$ slurry $)$ & 881.40 & - & - \\
\hline $\mathrm{K}_{2} \mathrm{CO}_{3}$ & 0.89 & $\mathrm{~K}_{2} \mathrm{CO}_{3}$ & 61.45 \\
\hline $\mathrm{La}_{2} \mathrm{O}_{3}$ & 3.86 & - & - \\
\hline $\mathrm{Li}_{2} \mathrm{CO}_{3}$ & 0.20 & $\mathrm{Li}_{2} \mathrm{CO}_{3}$ & 16.59 \\
\hline $\mathrm{MgO}$ & 0.74 & - & - \\
\hline $\mathrm{MnO}_{2}$ & 4.49 & - & - \\
\hline $\mathrm{Na}_{2} \mathrm{CO}_{3}$ & 7.01 & $\mathrm{Na}_{2} \mathrm{CO}_{3}$ & 29.03 \\
\hline $\mathrm{Nd}_{2} \mathrm{O}_{3}$ & 1.69 & - & - \\
\hline $\mathrm{Ni}(\mathrm{OH})_{2}$ & 5.68 & - & - \\
\hline $\mathrm{Na}_{2} \mathrm{HPO}_{4}$ & 0.52 & - & 一 \\
\hline $\mathrm{PbO}$ & 0.73 & - & - \\
\hline $\mathrm{Na}_{2} \mathrm{SO}_{4}$ & 0.75 & - & - \\
\hline $\mathrm{SiO}_{2}$ & 10.42 & $\mathrm{SiO}_{2}$ & 192.36 \\
\hline $\mathrm{ZnO}$ & 0.10 & - & - \\
\hline $\mathrm{Zr}(\mathrm{OH})_{4} \cdot x \mathrm{H}_{2} \mathrm{O}(50 \%)$ & 41.75 & - & - \\
\hline $\mathrm{Fe}_{2} \mathrm{OH}_{3}$ & 42.60 & & \\
\hline $\mathrm{NaNO}_{2}$ & 1.52 & - & - \\
\hline $\mathrm{NaNO}_{3}$ & 6.42 & - & - \\
\hline $\mathrm{H}_{2} \mathrm{C}_{2} \mathrm{O}_{4} \cdot 2 \mathrm{H}_{2} \mathrm{O}$ & 0.65 & - & - \\
\hline Water & 81.11 & - & - \\
\hline Simulant Subtotal & 1195.3 & Glass Formers Subtotal & 485.8 \\
\hline- & - & Feed Total & 1681.1 \\
\hline
\end{tabular}

(a) - Empty data field. 
The Catholic University of America Vitreous State Laboratory
ORP-56294 Rev. 0

Effects of High Crystal Content in HLW DM100 Melter Tests

Final Report, VSL-09R1520-1, Rev. 0

Table 2.17. Compositional Summary of the HLW Simulant, Glass Formers and Target Glass (HLW-E-M-03) for Melter Test 3.

\begin{tabular}{|c|c|c|c|}
\hline Oxide & $\begin{array}{c}\text { Test } 3 \\
\text { HLW Simulant }\end{array}$ & $\begin{array}{c}\text { Test } 3 \\
\text { Glass Former } \\
\text { (as wt \% of Glass) }\end{array}$ & $\begin{array}{c}\text { Test } 3 \\
\text { Target Glass } \\
(\text { HLW-E-M-03) }\end{array}$ \\
\hline $\mathrm{Al}_{2} \mathrm{O}_{3}$ & $26.62 \%$ & - $^{\text {(a) }}$ & $12.17 \%$ \\
\hline $\mathrm{B}_{2} \mathrm{O}_{3}$ & $0.55 \%$ & $13.09 \%$ & $13.34 \%$ \\
\hline $\mathrm{BaO}$ & $0.03 \%$ & - & $0.01 \%$ \\
\hline $\mathrm{Bi}_{2} \mathrm{O}_{3}$ & $7.60 \%$ & - & $3.47 \%$ \\
\hline $\mathrm{CaO}$ & $2.58 \%$ & - & $1.18 \%$ \\
\hline $\mathrm{Cr}_{2} \mathrm{O}_{3}$ & $6.56 \%$ & - & $3.00 \%$ \\
\hline $\mathrm{F}$ & $2.09 \%$ & - & $0.95 \%$ \\
\hline $\mathrm{Fe}_{2} \mathrm{O}_{3}$ & $13.69 \%$ & - & $6.26 \%$ \\
\hline $\mathrm{K}_{2} \mathrm{O}$ & $0.39 \%$ & $4.36 \%$ & $4.54 \%$ \\
\hline $\mathrm{Li}_{2} \mathrm{O}$ & $0.38 \%$ & $2.42 \%$ & $2.60 \%$ \\
\hline $\mathrm{MgO}$ & $0.17 \%$ & - & $0.08 \%$ \\
\hline $\mathrm{MnO}$ & $1.64 \%$ & - & $0.75 \%$ \\
\hline $\mathrm{Na}_{2} \mathrm{O}$ & $20.95 \%$ & - & $9.57 \%$ \\
\hline $\mathrm{NiO}$ & $1.64 \%$ & - & $0.75 \%$ \\
\hline $\mathrm{P}_{2} \mathrm{O}_{5}$ & $3.48 \%$ & - & $1.59 \%$ \\
\hline $\mathrm{PbO}$ & $0.50 \%$ & - & $0.23 \%$ \\
\hline $\mathrm{SiO}_{2}$ & $11.01 \%$ & $34.42 \%$ & $39.45 \%$ \\
\hline $\mathrm{ZrO}_{2}$ & $0.11 \%$ & - & $0.05 \%$ \\
\hline TOTAL & $100.0 \%$ & $54.3 \%$ & $100.0 \%$ \\
\hline \multicolumn{4}{|c|}{ Volatiles (g/100 g of waste oxide) } \\
\hline Carbonate & $1.145 \mathrm{E}+00$ & - & - \\
\hline Nitrite & $0.407 \mathrm{E}-01$ & - & - \\
\hline Nitrate & $1.883 \mathrm{E}+00$ & - & - \\
\hline Total Organic Carbon & 4.959E-02 & - & - \\
\hline
\end{tabular}

(a) - Empty data field. 
Table 2.18. Compositions of the HLW Melter Feed (Simulant and Glass Forming Additives) to Produce $600 \mathrm{~kg}$ of Target Glass for Test 3.

\begin{tabular}{|c|c|c|c|}
\hline \multicolumn{2}{|c|}{ Test 3 HLW Simulant } & \multicolumn{2}{|c|}{ Test 3 Glass Forming Additives } \\
\hline Starting Materials & Target Weight (kg) $)^{(a)}$ & Starting Materials & Target Weight (kg) ${ }^{(\mathrm{a})}$ \\
\hline $\mathrm{Al}(\mathrm{OH})_{3}$ & 112.85 & - $^{\text {(a) }}$ & - \\
\hline $\mathrm{H}_{3} \mathrm{BO}_{3}$ & 2.72 & $\mathrm{HB}_{3} \mathrm{O}_{3}$ & 140.91 \\
\hline $\mathrm{BaCO}_{3}$ & 0.11 & - & - \\
\hline $\mathrm{Bi}_{2} \mathrm{O}_{3}$ & 21.06 & - & - \\
\hline $\mathrm{CaO}$ & 7.13 & & \\
\hline $\mathrm{Cr}_{2} \mathrm{O}_{3}$ & 18.18 & - & - \\
\hline $\mathrm{NaF}$ & 12.70 & - & - \\
\hline $\mathrm{Fe}(\mathrm{OH})_{3}(13 \%$ slurry $)$ & 386.49 & - & - \\
\hline $\mathrm{K}_{2} \mathrm{CO}_{3}$ & 1.57 & $\mathrm{~K}_{2} \mathrm{CO}_{3}$ & 38.80 \\
\hline $\mathrm{Li}_{2} \mathrm{CO}_{3}$ & 2.57 & $\mathrm{Li}_{2} \mathrm{CO}_{3}$ & 36.89 \\
\hline $\mathrm{MgO}$ & 0.47 & - & - \\
\hline $\mathrm{MnO}_{2}$ & 5.57 & & \\
\hline $\mathrm{Na}_{2} \mathrm{CO}_{3}$ & 62.95 & - & - \\
\hline $\mathrm{Ni}(\mathrm{OH})_{2}$ & 5.61 & & \\
\hline $\mathrm{Na}_{2} \mathrm{HPO}_{4}$ & 19.30 & - & - \\
\hline $\mathrm{PbO}$ & 1.37 & - & - \\
\hline $\mathrm{SiO}_{2}$ & 30.50 & $\mathrm{SiO}_{2}$ & 208.62 \\
\hline $\mathrm{Zr}(\mathrm{OH})_{4} \cdot x \mathrm{H}_{2} \mathrm{O}(50 \%)$ & 0.72 & - & - \\
\hline $\mathrm{NaNO}_{2}$ & 1.68 & - & - \\
\hline $\mathrm{NaNO}_{3}$ & 7.11 & - & - \\
\hline $\mathrm{H}_{2} \mathrm{C}_{2} \mathrm{O}_{4} \cdot 2 \mathrm{H}_{2} \mathrm{O}$ & 0.72 & - & - \\
\hline Water & 547.62 & - & - \\
\hline Simulant Subtotal & 1249.0 & Glass Formers Subtotal & 425.2 \\
\hline - & - & Feed Total & 1674.2 \\
\hline
\end{tabular}

(a) - Empty data field. 
The Catholic University of America Vitreous State Laboratory
ORP-56294 Rev. 0

Effects of High Crystal Content in HLW DM100 Melter Tests

Final Report, VSL-09R1520-1, Rev. 0

Table 2.19. Compositional Summary of the HLW Simulant, Glass Formers and Target Glass (HLW-E-ES-05) for Melter Test 4.

\begin{tabular}{|c|c|c|c|}
\hline Oxide & $\begin{array}{c}\text { Test } 4 \\
\text { HLW Simulant }\end{array}$ & $\begin{array}{c}\text { Test } 4 \\
\text { Glass Former } \\
\text { (as wt \% of Glass) }\end{array}$ & $\begin{array}{c}\text { Test } 4 \\
\text { Target Glass } \\
\text { (HLW-E-ES-05) }\end{array}$ \\
\hline $\mathrm{Al}_{2} \mathrm{O}_{3}$ & $25.05 \%$ & - $^{\text {(a) }}$ & $10.86 \%$ \\
\hline $\mathrm{B}_{2} \mathrm{O}_{3}$ & $0.59 \%$ & $14.55 \%$ & $14.80 \%$ \\
\hline $\mathrm{BaO}$ & $0.03 \%$ & - & $0.01 \%$ \\
\hline $\mathrm{Bi}_{2} \mathrm{O}_{3}$ & $8.14 \%$ & - & $3.53 \%$ \\
\hline $\mathrm{CaO}$ & $2.76 \%$ & - & $1.20 \%$ \\
\hline $\mathrm{Cr}_{2} \mathrm{O}_{3}$ & $6.92 \%$ & - & $3.00 \%$ \\
\hline $\mathrm{F}$ & $2.23 \%$ & - & $0.97 \%$ \\
\hline $\mathrm{Fe}_{2} \mathrm{O}_{3}$ & $14.66 \%$ & - & $6.36 \%$ \\
\hline $\mathrm{K}_{2} \mathrm{O}$ & $0.41 \%$ & $5.43 \%$ & $5.61 \%$ \\
\hline $\mathrm{Li}_{2} \mathrm{O}$ & $0.40 \%$ & $2.96 \%$ & $3.14 \%$ \\
\hline $\mathrm{MgO}$ & $0.18 \%$ & - & $0.08 \%$ \\
\hline $\mathrm{Na}_{2} \mathrm{O}$ & $22.43 \%$ & - & $9.72 \%$ \\
\hline $\mathrm{P}_{2} \mathrm{O}_{5}$ & $3.73 \%$ & - & $1.62 \%$ \\
\hline $\mathrm{PbO}$ & $0.54 \%$ & - & $0.23 \%$ \\
\hline $\mathrm{SiO}_{2}$ & $11.79 \%$ & $33.71 \%$ & $38.82 \%$ \\
\hline $\mathrm{ZrO}_{2}$ & $0.12 \%$ & - & $0.05 \%$ \\
\hline TOTAL & $100.0 \%$ & $56.65 \%$ & $100.0 \%$ \\
\hline \multicolumn{4}{|c|}{ Volatiles (g/100 $\mathrm{g}$ of waste oxide) } \\
\hline Carbonate & $1.145 \mathrm{E}+00$ & - & - \\
\hline Nitrite & $0.407 \mathrm{E}-01$ & - & - \\
\hline Nitrate & $1.883 \mathrm{E}+00$ & - & - \\
\hline Total Organic Carbon & $4.959 \mathrm{E}-02$ & - & - \\
\hline
\end{tabular}

(a) - Empty data field. 
Table 2.20. Compositions of the HLW Melter Feed (Simulant and Glass Forming Additives) to Produce $600 \mathrm{~kg}$ of Target Glass for Test 4.

\begin{tabular}{|c|c|c|c|}
\hline \multicolumn{2}{|c|}{ Test 4 HLW Simulant } & \multicolumn{2}{|c|}{ Test 4 Glass Forming Additives } \\
\hline Starting Materials & Target Weight (kg) ${ }^{(a)}$ & Starting Materials & Target Weight (kg) ${ }^{(\mathrm{a})}$ \\
\hline $\mathrm{Al}(\mathrm{OH})_{3}$ & 100.71 & - $^{\text {(a) }}$ & - \\
\hline $\mathrm{H}_{3} \mathrm{BO}_{3}$ & 2.76 & $\mathrm{HB}_{3} \mathrm{O}_{3}$ & 156.58 \\
\hline $\mathrm{BaO}$ & 0.11 & - & - \\
\hline $\mathrm{Bi}_{2} \mathrm{O}_{3}$ & 21.39 & - & - \\
\hline $\mathrm{CaO}$ & 7.25 & - & - \\
\hline $\mathrm{Cr}_{2} \mathrm{O}_{3}$ & 18.18 & - & - \\
\hline $\mathrm{NaF}$ & 12.90 & - & - \\
\hline $\mathrm{Fe}(\mathrm{OH})_{3}(13 \%$ slurry $)$ & 392.56 & - & - \\
\hline $\mathrm{K}_{2} \mathrm{CO}_{3}$ & 1.59 & $\mathrm{~K}_{2} \mathrm{CO}_{3}$ & 48.30 \\
\hline $\mathrm{Li}_{2} \mathrm{CO}_{3}$ & 2.61 & $\mathrm{Li}_{2} \mathrm{CO}_{3}$ & 45.08 \\
\hline $\mathrm{MgO}$ & 0.47 & - & - \\
\hline $\mathrm{Na}_{2} \mathrm{CO}_{3}$ & 64.33 & - & - \\
\hline $\mathrm{Na}_{2} \mathrm{HPO}_{4}$ & 19.60 & - & - \\
\hline $\mathrm{PbO}$ & 1.40 & - & - \\
\hline $\mathrm{SiO}_{2}$ & 30.98 & $\mathrm{SiO}_{2}$ & 204.32 \\
\hline $\mathrm{Zr}(\mathrm{OH})_{4} \cdot \mathrm{xH}_{2} \mathrm{O}(50 \%)$ & 0.74 & - & - \\
\hline $\mathrm{NaNO}_{2}$ & 1.60 & 一 & - \\
\hline $\mathrm{NaNO}_{3}$ & 6.75 & - & - \\
\hline $\mathrm{H}_{2} \mathrm{C}_{2} \mathrm{O}_{4} \cdot 2 \mathrm{H}_{2} \mathrm{O}$ & 0.68 & - & - \\
\hline Water & 499.10 & - & - \\
\hline Simulant Subtotal & 1185.7 & Glass Formers Subtotal & 454.3 \\
\hline - & - & Feed Total & 1640.0 \\
\hline
\end{tabular}

(a) - Empty data field. 
The Catholic University of America Vitreous State Laboratory
ORP-56294 Rev. 0

Effects of High Crystal Content in HLW DM100 Melter Tests

Final Report, VSL-09R1520-1, Rev. 0

Table 2.21. Compositional Summary of the HLW Simulant, Glass Formers and Target Glass (HLW-E-M-09) for Melter Test 5.

\begin{tabular}{|c|c|c|c|}
\hline Oxide & $\begin{array}{c}\text { Test } 5 \\
\text { HLW Simulant }\end{array}$ & $\begin{array}{c}\text { Test } 5 \\
\text { Glass Former } \\
\text { (as wt \% of Glass) }\end{array}$ & $\begin{array}{c}\text { Test } 5 \\
\text { Target Glass } \\
\text { (HLW-E-M-09) }\end{array}$ \\
\hline $\mathrm{Al}_{2} \mathrm{O}_{3}$ & $24.17 \%$ & - $^{\text {(a) }}$ & $10.69 \%$ \\
\hline $\mathrm{B}_{2} \mathrm{O}_{3}$ & $0.57 \%$ & $14.32 \%$ & $14.57 \%$ \\
\hline $\mathrm{BaO}$ & $0.03 \%$ & - & $0.01 \%$ \\
\hline $\mathrm{Bi}_{2} \mathrm{O}_{3}$ & $7.86 \%$ & - & $3.47 \%$ \\
\hline $\mathrm{CaO}$ & $2.66 \%$ & - & $1.18 \%$ \\
\hline $\mathrm{Cr}_{2} \mathrm{O}_{3}$ & $6.78 \%$ & - & $3.00 \%$ \\
\hline $\mathrm{F}$ & $2.16 \%$ & - & $0.95 \%$ \\
\hline $\mathrm{Fe}_{2} \mathrm{O}_{3}$ & $14.15 \%$ & - & $6.26 \%$ \\
\hline $\mathrm{K}_{2} \mathrm{O}$ & $0.40 \%$ & $5.35 \%$ & $5.52 \%$ \\
\hline $\mathrm{Li}_{2} \mathrm{O}$ & $0.39 \%$ & $2.92 \%$ & $3.09 \%$ \\
\hline $\mathrm{MgO}$ & $0.17 \%$ & - & $0.08 \%$ \\
\hline $\mathrm{Na}_{2} \mathrm{O}$ & $21.65 \%$ & - & $9.57 \%$ \\
\hline $\mathrm{P}_{2} \mathrm{O}_{5}$ & $3.60 \%$ & - & $1.59 \%$ \\
\hline $\mathrm{PbO}$ & $0.52 \%$ & - & $0.23 \%$ \\
\hline $\mathrm{SiO}_{2}$ & $11.38 \%$ & $33.19 \%$ & $38.22 \%$ \\
\hline $\mathrm{ZnO}$ & $3.39 \%$ & - & $1.50 \%$ \\
\hline $\mathrm{ZrO}_{2}$ & $0.12 \%$ & - & $0.05 \%$ \\
\hline TOTAL & $100.0 \%$ & $55.8 \%$ & $100.0 \%$ \\
\hline \multicolumn{4}{|c|}{ Volatiles ( $\mathrm{g} / \mathbf{1 0 0} \mathrm{g}$ of waste oxide) } \\
\hline Carbonate & $1.145 \mathrm{E}+00$ & - & - \\
\hline Nitrite & $0.407 \mathrm{E}-01$ & - & - \\
\hline Nitrate & $1.883 \mathrm{E}+00$ & - & - \\
\hline Total Organic Carbon & 4.959E-02 & - & - \\
\hline
\end{tabular}

(a) - Empty data field. 
Table 2.22. Compositions of the HLW Melter Feed (Simulant and Glass Forming Additives) to Produce $600 \mathrm{~kg}$ of Target Glass for Test 5.

\begin{tabular}{|c|c|c|c|}
\hline \multicolumn{2}{|c|}{ Test 5 HLW Simulant } & \multicolumn{2}{|c|}{ Test 5 Glass Forming Additives } \\
\hline Starting Materials & Target Weight (kg) $)^{(\mathbf{a})}$ & Starting Materials & Target Weight (kg) ${ }^{(\mathbf{a})}$ \\
\hline $\mathrm{Al}(\mathrm{OH})_{3}$ & 99.15 & - $^{\text {(a) }}$ & - \\
\hline $\mathrm{H}_{3} \mathrm{BO}_{3}$ & 2.72 & $\mathrm{HB}_{3} \mathrm{O}_{3}$ & 154.16 \\
\hline $\mathrm{BaCO}_{3}$ & 0.11 & - & - \\
\hline $\mathrm{Bi}_{2} \mathrm{O}_{3}$ & 21.06 & - & - \\
\hline $\mathrm{CaO}$ & 7.13 & & \\
\hline $\mathrm{Cr}_{2} \mathrm{O}_{3}$ & 18.18 & - & - \\
\hline $\mathrm{NaF}$ & 12.70 & - & - \\
\hline $\mathrm{Fe}(\mathrm{OH})_{3}(13 \%$ slurry $)$ & 386.49 & - & - \\
\hline $\mathrm{K}_{2} \mathrm{CO}_{3}$ & 1.57 & $\mathrm{~K}_{2} \mathrm{CO}_{3}$ & 47.56 \\
\hline $\mathrm{Li}_{2} \mathrm{CO}_{3}$ & 2.57 & $\mathrm{Li}_{2} \mathrm{CO}_{3}$ & 44.39 \\
\hline $\mathrm{MgO}$ & 0.47 & - & - \\
\hline $\mathrm{Na}_{2} \mathrm{CO}_{3}$ & 63.14 & - & - \\
\hline $\mathrm{Na}_{2} \mathrm{HPO}_{4}$ & 19.30 & - & - \\
\hline $\mathrm{PbO}$ & 1.37 & - & - \\
\hline $\mathrm{SiO}_{2}$ & 30.50 & $\mathrm{SiO}_{2}$ & 201.16 \\
\hline $\mathrm{ZnO}$ & 9.09 & & \\
\hline $\mathrm{Zr}(\mathrm{OH})_{4} \cdot x \mathrm{H}_{2} \mathrm{O}(50 \%)$ & 0.73 & - & - \\
\hline $\mathrm{NaNO}_{2}$ & 1.63 & - & - \\
\hline $\mathrm{NaNO}_{3}$ & 6.88 & - & - \\
\hline $\mathrm{H}_{2} \mathrm{C}_{2} \mathrm{O}_{4} \cdot 2 \mathrm{H}_{2} \mathrm{O}$ & 0.69 & - & - \\
\hline Water & 550.34 & - & - \\
\hline Simulant Subtotal & 1235.8 & Glass Formers Subtotal & 447.3 \\
\hline - & - & Feed Total & 1683.1 \\
\hline
\end{tabular}

(a) - Empty data field. 
Table 3.1. Summary of Results from DM100 Tests.

\begin{tabular}{|c|c|c|c|c|c|}
\hline \multicolumn{2}{|r|}{ Test } & $1 \mathrm{~A}$ & 1B & $2 \mathrm{~A}$ & $2 \mathrm{~B}$ \\
\hline \multirow{3}{*}{ Time } & Feed Start & 9/15/08 11:10 & 9/17/08 16:00 & $10 / 6 / 0810: 45$ & 10/8/08 11:30 \\
\hline & Feed End & 9/17/08 15:30 & 9/19/08 18:00 & 10/8/08 11:00 & 10/10/08 17:00 \\
\hline & Interval & $52.3 \mathrm{hr}$ & $50.0 \mathrm{hr}$ & $48.25 \mathrm{hr}$ & 53.5 \\
\hline \multicolumn{2}{|c|}{ Water Feeding for Cold Cap } & $62 \mathrm{~min}$ & 0 & 0 & 0 \\
\hline \multicolumn{2}{|c|}{ Slurry Feeding } & $51.3 \mathrm{hr}$ & $50.0 \mathrm{hr}$ & $48.25 \mathrm{hr}$ & $53.5 \mathrm{hr}$ \\
\hline \multicolumn{2}{|c|}{ Feeding Interruptions } & $20 \mathrm{~min}$ & $26 \mathrm{~min}$ & $26 \mathrm{~min}$ & $44 \mathrm{~min}$ \\
\hline \multicolumn{2}{|c|}{ Cold Cap Burn Duration } & NA & $9 \mathrm{hr}$ & NA & $9 \mathrm{hr}$ \\
\hline \multicolumn{2}{|c|}{ Average Bubbling Rate } & $9.0 \mathrm{lpm}$ & $23.3 \mathrm{lpm}$ & $9.0 \mathrm{lpm}$ & $17.0 \mathrm{lpm}$ \\
\hline \multirow{6}{*}{ Feed } & Target Glass & HLW-E-SP-06 & HLW-E-SP-06 & HLW-E-SP-05 & HLW-E-SP-05 \\
\hline & $\begin{array}{l}\text { Crystal Content } \\
\text { Target @ } 950^{\circ} \mathrm{C}\end{array}$ & $2.2 \%$ Spinel & $2.2 \%$ Spinel & $4.2 \%$ Spinel & $4.2 \%$ Spinel \\
\hline & Used & $615 \mathrm{~kg}$ & $945 \mathrm{~kg}$ & $350 \mathrm{~kg}$ & $621 \mathrm{~kg}$ \\
\hline & \multirow{2}{*}{ Target Glass yield } & $500 \mathrm{~g} / 1$ & $500 \mathrm{~g} / 1$ & $500 \mathrm{~g} / 1$ & $500 \mathrm{~g} / 1$ \\
\hline & & $0.359 \mathrm{~kg} / \mathrm{kg}$ & $0.359 \mathrm{~kg} / \mathrm{kg}$ & $0.356 \mathrm{~kg} / \mathrm{kg}$ & $0.356 \mathrm{~kg} / \mathrm{kg}$ \\
\hline & Average Feed Rate & $12.0 \mathrm{~kg} / \mathrm{hr}$ & $18.9 \mathrm{~kg} / \mathrm{hr}$ & $7.3 \mathrm{~kg} / \mathrm{hr}$ & $11.6 \mathrm{~kg} / \mathrm{hr}$ \\
\hline \multirow{4}{*}{$\begin{array}{c}\text { Glass } \\
\text { Produced }\end{array}$} & Average Rate ${ }^{*}$ & $957 \mathrm{~kg} / \mathrm{m}^{2} /$ day & $1508 \mathrm{~kg} / \mathrm{m}^{2} /$ day & $574 \mathrm{~kg} / \mathrm{m}^{2} /$ day & $918 \mathrm{~kg} / \mathrm{m}^{2} /$ day \\
\hline & Steady State Rate ${ }^{*}$ & $700 \mathrm{~kg} / \mathrm{m}^{2} /$ day & $1500 \mathrm{~kg} / \mathrm{m}^{2} /$ day & $500 \mathrm{~kg} / \mathrm{m}^{2} /$ day & $900 \mathrm{~kg} / \mathrm{m}^{2} /$ day \\
\hline & Average Power Use & $\begin{array}{l}4.6 \mathrm{~kW} \mathrm{hr} / \mathrm{kg} \\
\text { glass }\end{array}$ & $\begin{array}{l}3.7 \mathrm{~kW} \mathrm{hr} / \mathrm{kg} \\
\text { glass }\end{array}$ & $\begin{array}{l}5.6 \mathrm{~kW} \mathrm{hr} / \mathrm{kg} \\
\text { glass }\end{array}$ & $\begin{array}{c}4.4 \mathrm{~kW} \mathrm{hr} / \mathrm{kg} \\
\text { glass }\end{array}$ \\
\hline & Poured & \multicolumn{2}{|c|}{$539 \mathrm{~kg}$} & \multicolumn{2}{|c|}{$339 \mathrm{~kg}$} \\
\hline
\end{tabular}

*- Rates calculated from feed data.

Note: Rates do not take into account the time for water feeding and cold cap burn-off 
Table 3.1. Summary of Results from DM100 Tests (continued).

\begin{tabular}{|c|c|c|c|c|c|}
\hline \multicolumn{2}{|r|}{ Test } & $3 \mathrm{~A}$ & $3 B$ & $4 \mathrm{~A}$ & $4 \mathrm{~B}$ \\
\hline \multirow{3}{*}{ Time } & Feed Start & $10 / 27 / 089: 35$ & 10/29/08 14:49 & 11/10/08 12:47 & 11/12/08 16:00 \\
\hline & Feed End & 10/29/08 13:30 & 10/31/08 15:30 & 11/12/08 16:00 & $11 / 14 / 0810: 40$ \\
\hline & Interval & $50.4 \mathrm{hr}$ & $48.7 \mathrm{hr}$ & $51.2 \mathrm{hr}$ & 42.7 \\
\hline \multicolumn{2}{|c|}{ Water Feeding for Cold Cap } & $27 \mathrm{~min}$ & 0 & $28 \mathrm{~min}$ & NA \\
\hline \multicolumn{2}{|c|}{ Slurry Feeding } & $50.0 \mathrm{hr}$ & $48.7 \mathrm{hr}$ & $49.9 \mathrm{hr}$ & $42.7 \mathrm{hr}$ \\
\hline \multicolumn{2}{|c|}{ Feeding Interruptions } & $12 \mathrm{~min}$ & $13 \mathrm{~min}$ & $6 \mathrm{~min}$ & $17 \mathrm{~min}$ \\
\hline \multicolumn{2}{|c|}{ Cold Cap Burn Duration } & NA & $4 \mathrm{hr}$ & NA & $2.5 \mathrm{hr}$ \\
\hline \multicolumn{2}{|c|}{ Average Bubbling Rate } & $8.8 \mathrm{lpm}$ & $15.0 \mathrm{lpm}$ & $8.91 \mathrm{pm}$ & $14.9 \mathrm{lpm}$ \\
\hline \multirow{6}{*}{ Feed } & Target Glass & HLW-E-M-03 & HLW-E-M-03 & HLW-E-ES-05 & HLW-E-ES-05 \\
\hline & $\begin{array}{l}\text { Crystal Content } \\
\text { Target } @ 950^{\circ} \mathrm{C}\end{array}$ & $\begin{array}{c}2.5 \% \text { Spinel } \\
\text { (Eskolaite } \\
\text { at high T) }\end{array}$ & $\begin{array}{c}2.5 \% \text { Spinel } \\
\text { (Eskolaite } \\
\text { at high T) }\end{array}$ & $2 \%$ Eskolaite & 2\% Eskolaite \\
\hline & Used & $577 \mathrm{~kg}$ & $972 \mathrm{~kg}$ & $667 \mathrm{~kg}$ & $949 \mathrm{~kg}$ \\
\hline & \multirow{2}{*}{ Target Glass yield } & $500 \mathrm{~g} / 1$ & $500 \mathrm{~g} / 1$ & $500 \mathrm{~g} / 1$ & $500 \mathrm{~g} / 1$ \\
\hline & & $0.358 \mathrm{~kg} / \mathrm{kg}$ & $0.358 \mathrm{~kg} / \mathrm{kg}$ & $0.358 \mathrm{~kg} / \mathrm{kg}$ & $0.358 \mathrm{~kg} / \mathrm{kg}$ \\
\hline & Average Feed Rate & $11.5 \mathrm{~kg} / \mathrm{hr}$ & $20.0 \mathrm{~kg} / \mathrm{hr}$ & $13.4 \mathrm{~kg} / \mathrm{hr}$ & $22.2 \mathrm{~kg} / \mathrm{hr}$ \\
\hline \multirow{4}{*}{$\begin{array}{c}\text { Glass } \\
\text { Produced }\end{array}$} & Average Rate & $918 \mathrm{~kg} / \mathrm{m}^{2} /$ day & $1588 \mathrm{~kg} / \mathrm{m}^{2} /$ day & $1064 \mathrm{~kg} / \mathrm{m}^{2} /$ day & $1768 \mathrm{~kg} / \mathrm{m}^{2} /$ day \\
\hline & Steady State Rate & $900 \mathrm{~kg} / \mathrm{m}^{2} /$ day & $1600 \mathrm{~kg} / \mathrm{m}^{2} /$ day & $1050 \mathrm{~kg} / \mathrm{m}^{2} /$ day & $1800 \mathrm{~kg} / \mathrm{m}^{2} /$ day \\
\hline & $\begin{array}{l}\text { Average Power } \\
\text { Use }\end{array}$ & $\begin{array}{l}4.3 \mathrm{~kW} \mathrm{hr} / \mathrm{kg} \\
\text { glass }\end{array}$ & $\begin{array}{c}3.5 \mathrm{~kW} \mathrm{hr} / \mathrm{kg} \\
\text { glass }\end{array}$ & $\begin{array}{l}4.2 \mathrm{~kW} \mathrm{hr} / \mathrm{kg} \\
\text { glass }\end{array}$ & $\begin{array}{c}3.6 \mathrm{~kW} \mathrm{hr} / \mathrm{kg} \\
\text { glass }\end{array}$ \\
\hline & Poured & \multicolumn{2}{|c|}{$566 \mathrm{~kg}$} & \multicolumn{2}{|c|}{$594 \mathrm{~kg}$} \\
\hline
\end{tabular}

*- Rates calculated from feed data.

Note: Rates do not take into account the time for water feeding and cold cap burn-off. 
Table 3.1. Summary of Results from DM100 Tests (continued).

\begin{tabular}{|c|c|c|c|}
\hline \multicolumn{2}{|r|}{ Test } & $5 \mathrm{~A}$ & $5 \mathrm{~B}$ \\
\hline \multirow{3}{*}{ Time } & Feed Start & $12 / 8 / 088: 50$ & 12/10/08 11:51 \\
\hline & Feed End & 12/10/08 11:42 & $12 / 11 / 0822: 00$ \\
\hline & Interval & $50.9 \mathrm{hr}$ & 34.2 \\
\hline \multicolumn{2}{|c|}{ Water Feeding for Cold Cap } & $52 \mathrm{~min}$ & NA \\
\hline \multicolumn{2}{|c|}{ Slurry Feeding } & $50.0 \mathrm{hr}$ & $34.2 \mathrm{hr}$ \\
\hline \multicolumn{2}{|c|}{ Feeding Interruptions } & $11 \mathrm{~min}$ & $15 \min$ \\
\hline \multicolumn{2}{|c|}{ Cold Cap Burn Duration } & NA & $2.5 \mathrm{hr}$ \\
\hline \multicolumn{2}{|c|}{ Average Bubbling Rate } & $9.0 \mathrm{lpm}$ & $14.5 \mathrm{lpm}$ \\
\hline \multirow{6}{*}{ Feed } & Target Glass & HLW-E-M-09 & HLW-E-M-09 \\
\hline & $\begin{array}{l}\text { Crystal Content } \\
\text { Target } @ 950^{\circ} \mathrm{C}\end{array}$ & $\begin{array}{l}\text { 1.6\% Spinel } \\
\text { (Zn-based) }\end{array}$ & $\begin{array}{l}\text { 1.6\% Spinel } \\
\text { (Zn-based) }\end{array}$ \\
\hline & Used & $773 \mathrm{~kg}$ & $813 \mathrm{~kg}$ \\
\hline & \multirow{2}{*}{ Target Glass yield } & $500 \mathrm{~g} / 1$ & $500 \mathrm{~g} / 1$ \\
\hline & & $0.356 \mathrm{~kg} / \mathrm{kg}$ & $0.356 \mathrm{~kg} / \mathrm{kg}$ \\
\hline & Average Feed Rate & $15.5 \mathrm{~kg} / \mathrm{hr}$ & $23.8 \mathrm{~kg} / \mathrm{hr}$ \\
\hline \multirow{4}{*}{$\begin{array}{c}\text { Glass } \\
\text { Produced }\end{array}$} & Average Rate ${ }^{*}$ & $1223 \mathrm{~kg} / \mathrm{m}^{2} /$ day & $1881 \mathrm{~kg} / \mathrm{m}^{2} /$ day \\
\hline & Steady State Rate & $1250 \mathrm{~kg} / \mathrm{m}^{2} /$ day & $1800 \mathrm{~kg} / \mathrm{m}^{2} /$ day \\
\hline & $\begin{array}{c}\text { Average Power } \\
\text { Use }\end{array}$ & $\begin{array}{l}3.9 \mathrm{~kW} \mathrm{hr} / \mathrm{kg} \\
\text { glass }\end{array}$ & $\begin{array}{c}3.6 \mathrm{~kW} \mathrm{hr} / \mathrm{kg} \\
\text { glass }\end{array}$ \\
\hline & Poured & \multicolumn{2}{|c|}{$567 \mathrm{~kg}$} \\
\hline
\end{tabular}

*- Rates calculated from feed data.

Note: Rates do not take into account the time for water feeding and cold cap burn-off. 
The Catholic University of America

ORP-56294 Rev. 0

Vitreous State Laboratory

Effects of High Crystal Content in HLW DM100 Melter Tests

Final Report, VSL-09R1520-1, Rev. 0

Table 3.2. Steady-State Production Rates Achieved on the DM100 with HLW Compositions at a Glass Temperature of $1150^{\circ} \mathrm{C}$ and Solids Content near 500 g glass/liter.

\begin{tabular}{|c|c|c|c|}
\hline HLW Waste & $\begin{array}{l}\text { Bubbling } \\
\text { Rate (lpm) }\end{array}$ & $\begin{array}{c}\text { Glass Yield } \\
(\mathrm{g} / \mathrm{L})\end{array}$ & $\begin{array}{l}\text { Production Rate } \\
\left(\mathrm{kg} / \mathrm{m}^{2} / \text { day }\right)\end{array}$ \\
\hline \multirow{2}{*}{ Test 1 (HLW-E-SP-06) } & 9 & 500 & 700 \\
\hline & Optimized & 500 & 1500 \\
\hline \multirow{2}{*}{ Test 2 (HLW-E-SP-05) } & 9 & 500 & 500 \\
\hline & Optimized & 500 & 900 \\
\hline \multirow{2}{*}{ Test 3 (HLW-E-M-03) } & 9 & 500 & 900 \\
\hline & Optimized & 500 & 1600 \\
\hline \multirow{2}{*}{ Test 4 (HLW-E-ES-05) } & 9 & 500 & 1050 \\
\hline & Optimized & 500 & 1800 \\
\hline \multirow{2}{*}{ Test 5 (HLW-E-M-09) } & 9 & 500 & 1250 \\
\hline & Optimized & 500 & 1800 \\
\hline Bismuth Limited [1] & 9 & 500 & 830 \\
\hline Chromium Limited [1] & 9 & 500 & 1150 \\
\hline \multirow{2}{*}{$\begin{array}{c}\text { Aluminum Limited } \\
\text { (HLW-E-Al-27, Al oxide) [1] }\end{array}$} & 9 & 500 & 550 \\
\hline & Optimized & 500 & 1000 \\
\hline \multirow{2}{*}{ Aluminum and Sodium Limited [1] } & 9 & 500 & 400 \\
\hline & Optimized & 500 & 1250 \\
\hline Aluminum Limited (HLW-E-Al-27, Al hydroxide) [34] & 9 & 500 & 700 \\
\hline Aluminum Limited (HWI-Al-16, Al hydroxide) [34] & 9 & 500 & 950 \\
\hline Aluminum Limited (HWI-Al-16, Al oxide) [34] & 9 & 500 & 700 \\
\hline Aluminum Limited (HWI-Al-19, Al hydroxide) [34] & 9 & 500 & 950 \\
\hline AZ-101 [5] & 9 & 530 & 1300 \\
\hline AZ-102, Nominal Rheology [18] & 9 & 550 & 1200 \\
\hline AZ-102, Adjusted Rheology [18] & 9 & 550 & 1400 \\
\hline C-106/AY-102, High Waste Loading [18] & Optimized & 420 & 1350 \\
\hline C-106/AY-102, Nominal Rheology [6] & 9 & 435 & 1100 \\
\hline C-106/AY-102, Adjusted Rheology [6] & 9 & 435 & 1150 \\
\hline C-106/AY-102, SIPP [6] & 9 & 470 & 1180 \\
\hline HLW02-24, High Viscosity [8] & 9 & 500 & 900 \\
\hline HLW-ALG-17, Low Viscosity [8] & 9 & 500 & 1600 \\
\hline HLW-ALG-16, High Conductivity [8] & 9 & 500 & 1200 \\
\hline HLW02-46, Low Conductivity [8] & 9 & 500 & 900 \\
\hline C-106/AY-102 [8] & 9 & 500 & 1000 \\
\hline C-106/AY-102 + 15\% GFCs [8] & 9 & 500 & 1000 \\
\hline C-106/AY-102-15\% GFCs [8] & 9 & 500 & 1050 \\
\hline C-106/AY-102 replacing borax with boric acid and soda ash [8] & 9 & 500 & 1050 \\
\hline $\mathrm{C}-106 / \mathrm{AY}-102, \mathrm{SiO}_{2}=33 \%[9]$ & 9 & 500 & 2000 \\
\hline $\mathrm{C}-106 / \mathrm{AY}-102, \mathrm{SiO}_{2}=53.1 \%[9]$ & 9 & 500 & 700 \\
\hline $\mathrm{C}-106 / \mathrm{AY}-102, \mathrm{MnO}=8 \%[9]$ & 9 & 500 & 750 \\
\hline $\mathrm{C}-106 / \mathrm{AY}-102, \mathrm{Na}_{2} \mathrm{O}=20.0 \%[9]$ & 9 & 500 & 2150 \\
\hline $\begin{array}{c}\text { C-106/AY-102, } \mathrm{K}_{2} \mathrm{O}=2.5 \%, \mathrm{Cr}_{2} \mathrm{O}_{3}=0.6 \%, \mathrm{La}_{2} \mathrm{O}_{3}=1.2 \%, \\
\mathrm{TiO}_{2}=1 \%, \mathrm{ZnO}=4 \%[9]\end{array}$ & 9 & 500 & 1700 \\
\hline C-106/AY-102, $\mathrm{B}_{2} \mathrm{O}_{3}=4.3 \%[9]$ & 9 & 500 & 900 \\
\hline $\mathrm{C}-106 / \mathrm{AY}-102, \mathrm{~B}_{2} \mathrm{O}_{3}=15 \%[9]$ & 9 & 500 & 1550 \\
\hline $\mathrm{C}-106 / \mathrm{AY}-102, \mathrm{Al}_{2} \mathrm{O}_{3}=13 \%[9]$ & 9 & 500 & 900 \\
\hline $\mathrm{C}-106 / \mathrm{AY}-102, \mathrm{Li}_{2} \mathrm{O}=0 \%[9]$ & 9 & 1150 & 450 \\
\hline Algorithm Generated, $\mathrm{ZrO}_{2}=10.65 \%[9]$ & 9 & 1150 & 850 \\
\hline Algorithm Generated, $\mathrm{SrO}=9.27 \%[9]$ & 9 & 1150 & 650 \\
\hline
\end{tabular}


The Catholic University of America Vitreous State Laboratory
ORP-56294 Rev. 0

Effects of High Crystal Content in HLW DM100 Melter Tests

Final Report, VSL-09R1520-1, Rev. 0

Table 3.3. Summary of Measured DM100 Parameters.

\begin{tabular}{|c|c|c|c|c|c|c|c|c|c|c|c|c|c|c|}
\hline \multirow{3}{*}{\multicolumn{3}{|c|}{ Test }} & \multicolumn{6}{|c|}{1 (HLW-E-SP-06 composition) } & \multicolumn{6}{|c|}{2 (HLW-E-SP-05 composition) } \\
\hline & & & \multicolumn{3}{|c|}{$\mathrm{A}$} & \multicolumn{3}{|c|}{$\mathrm{B}$} & \multicolumn{3}{|c|}{$\mathrm{A}$} & \multicolumn{3}{|c|}{$\mathrm{B}$} \\
\hline & & & AVG & MIN & MAX & AVG & MIN & MAX & AVG & MIN & MAX & AVG & MIN & MAX \\
\hline \multirow{14}{*}{$\begin{array}{c}\mathrm{T} \\
\mathrm{E} \\
\mathrm{M} \\
\mathrm{P} \\
\mathrm{E} \\
\mathrm{R} \\
\mathrm{A} \\
\mathrm{T} \\
\mathrm{U} \\
\mathrm{R} \\
\mathrm{E} \\
\left({ }^{\circ} \mathrm{C}\right)\end{array}$} & \multirow{4}{*}{ Electrode } & East Upper & 1006 & 596 & 1092 & 1060 & 1003 & 1085 & 868 & 585 & 1025 & 998 & 949 & 1031 \\
\hline & & West Upper & 1028 & 676 & 1086 & 1079 & 1040 & 1104 & 909 & 670 & 1030 & 1042 & 1008 & 1073 \\
\hline & & $\begin{array}{c}\text { West } \\
\text { Lower }\end{array}$ & 1066 & 1033 & 1135 & 1066 & 1028 & 1095 & 1009 & 994 & 1026 & 1024 & 990 & 1039 \\
\hline & & Bottom & 726 & 693 & 773 & 741 & 692 & 781 & 652 & 629 & 660 & 681 & 650 & 692 \\
\hline & \multirow{4}{*}{ Glass } & $\begin{array}{l}27 " \text { from } \\
\text { bottom }\end{array}$ & 1039 & 355 & 1168 & 1122 & 1008 & 1186 & 930 & 408 & 1152 & 1081 & 947 & 1169 \\
\hline & & $\begin{array}{c}16 " \text { from } \\
\text { bottom }\end{array}$ & 1104 & 605 & 1171 & 1140 & 1067 & 1186 & 1101 & 572 & 1184 & 1148 & 1069 & 1182 \\
\hline & & $\begin{array}{c}10 " \text { from } \\
\text { bottom }\end{array}$ & 1146 & 1086 & 1172 & 1150 & 1119 & 1186 & 1171 & 1142 & 1199 & 1172 & 1134 & 1200 \\
\hline & & $\begin{array}{l}5 " \text { from } \\
\text { bottom }\end{array}$ & 1157 & 1108 & 1179 & 1153 & 1106 & 1192 & 1144 & 1107 & 1185 & 1147 & 1104 & 1174 \\
\hline & \multirow{2}{*}{ Plenum } & Exposed & 439 & 272 & 646 & 469 & 313 & 538 & 403 & 127 & 563 & 430 & 217 & 516 \\
\hline & & Thermowell & 387 & 287 & 632 & 436 & 263 & 558 & 369 & 295 & 536 & 364 & 256 & 441 \\
\hline & \multirow{2}{*}{ Discharge } & Chamber & 1035 & 779 & 1095 & 1062 & 1021 & 1078 & 1056 & 997 & 1097 & 1092 & 1029 & 1109 \\
\hline & & Air Lift & 1024 & 809 & 1148 & 1064 & 1009 & 1134 & 1009 & 296 & 1156 & 1082 & 1060 & 1161 \\
\hline & \multicolumn{2}{|c|}{ Film Cooler Outlet } & 275 & 255 & 307 & 288 & 274 & 295 & 276 & 257 & 302 & 284 & 246 & 297 \\
\hline & \multicolumn{2}{|c|}{ Transition Line Outlet } & 262 & 246 & 289 & 272 & 210 & 282 & 263 & 253 & 286 & 270 & 241 & 280 \\
\hline \multicolumn{3}{|c|}{ Lance Bubbling (lpm) } & 9.0 & 2.0 & 9.1 & 23.3 & 15.0 & 30.1 & 8.9 & 8.5 & 9.5 & 17.0 & 8.9 & 30.2 \\
\hline \multicolumn{3}{|c|}{ Melter Pressure (inches water) } & -0.95 & -4.20 & 2.24 & -0.89 & -3.57 & 2.89 & -1.00 & -4.07 & 0.83 & -0.87 & -5.22 & 1.30 \\
\hline \multicolumn{3}{|c|}{ Total Electrode Voltage (V) } & 45.5 & 1.0 & 56.7 & 57.5 & 46.5 & 64.2 & 46.6 & 0.9 & 56.9 & 50.1 & 41.8 & 55.7 \\
\hline \multicolumn{3}{|c|}{ Total Power $(\mathrm{kW})$} & 18.2 & 0.0 & 25.8 & 25.4 & 17.0 & 30.6 & 14.5 & 0.0 & 16.8 & 18.2 & 14.0 & 20.8 \\
\hline \multicolumn{3}{|c|}{ Glass Resistance (ohms) } & 0.115 & 0.104 & 0.127 & 0.130 & 0.115 & 0.148 & 0.150 & 0.129 & 0.209 & 0.138 & 0.114 & 0.154 \\
\hline
\end{tabular}


The Catholic University of America Vitreous State Laboratory
ORP-56294 Rev. 0

Effects of High Crystal Content in HLW DM100 Melter Tests

Final Report, VSL-09R1520-1, Rev. 0

Table 3.3. Summary of Measured DM100 Parameters (continued).

\begin{tabular}{|c|c|c|c|c|c|c|c|c|c|c|c|c|c|c|}
\hline \multirow{3}{*}{\multicolumn{3}{|c|}{ Test }} & \multicolumn{6}{|c|}{3 (HLW-E-M-03 composition) } & \multicolumn{6}{|c|}{4 (HLW-E-ES-05 composition) } \\
\hline & & & \multicolumn{3}{|c|}{ A } & \multicolumn{3}{|c|}{$\mathrm{B}$} & \multicolumn{3}{|c|}{ A } & \multicolumn{3}{|c|}{ B } \\
\hline & & & AVG & MIN & MAX & AVG & MIN & MAX & AVG & MIN & MAX & AVG & MIN & MAX \\
\hline \multirow{14}{*}{$\begin{array}{c}\mathrm{T} \\
\mathrm{E} \\
\mathrm{M} \\
\mathrm{P} \\
\mathrm{E} \\
\mathrm{R} \\
\mathrm{A} \\
\mathrm{T} \\
\mathrm{U} \\
\mathrm{R} \\
\mathrm{E} \\
\left({ }^{\circ} \mathrm{C}\right)\end{array}$} & \multirow{4}{*}{ Electrode } & East Upper & 987 & 688 & 1077 & 1054 & 1020 & 1069 & 999 & 729 & 1072 & 1097 & 1056 & 1113 \\
\hline & & West Upper & 985 & 743 & 1053 & 1067 & 1034 & 1090 & 1015 & 730 & 1074 & 1078 & 1056 & 1095 \\
\hline & & $\begin{array}{c}\text { West } \\
\text { Lower }\end{array}$ & 1009 & 994 & 1041 & 1042 & 1004 & 1059 & 1018 & 986 & 1038 & 1058 & 1023 & 1071 \\
\hline & & Bottom & 692 & 664 & 752 & 709 & 665 & 722 & 668 & 663 & 727 & 704 & 667 & 719 \\
\hline & \multirow{4}{*}{ Glass } & $\begin{array}{l}27 \text { " from } \\
\text { bottom }\end{array}$ & 1042 & 455 & 1151 & 1143 & 928 & 1164 & 1072 & 619 & 1156 & 1124 & 1049 & 1157 \\
\hline & & $\begin{array}{c}16 " \text { from } \\
\text { bottom }\end{array}$ & 1109 & 448 & 1161 & 1150 & 1113 & 1165 & 1130 & 468 & 1163 & 1135 & 1097 & 1160 \\
\hline & & $\begin{array}{l}10 " \text { from } \\
\text { bottom }\end{array}$ & 1159 & 1127 & 1180 & 1157 & 1133 & 1173 & 1158 & 1139 & 1185 & 1155 & 1115 & 1177 \\
\hline & & $\begin{array}{l}5 " \text { from } \\
\text { bottom }\end{array}$ & 1119 & 1083 & 1135 & 1147 & 1122 & 1162 & 1141 & 1101 & 1164 & 1150 & 1128 & 1173 \\
\hline & \multirow{2}{*}{ Plenum } & Exposed & 461 & 244 & 688 & 464 & 225 & 514 & 457 & 340 & 704 & 465 & 375 & 566 \\
\hline & & Thermowell & 420 & 325 & 682 & 415 & 327 & 488 & 421 & 340 & 698 & 411 & 285 & 480 \\
\hline & \multirow{2}{*}{ Discharge } & Chamber & 1084 & 1042 & 1104 & 1089 & 1054 & 1109 & 987 & 638 & 1054 & 1029 & 1004 & 1047 \\
\hline & & Air Lift & 1050 & 973 & 1109 & 1070 & 1043 & 1121 & 991 & 848 & 1085 & 1043 & 1005 & 1105 \\
\hline & \multicolumn{2}{|c|}{ Film Cooler Outlet } & 292 & 278 & 310 & 293 & 274 & 299 & 275 & 136 & 297 & 275 & 257 & 284 \\
\hline & \multicolumn{2}{|c|}{ Transition Line Outlet } & 272 & 263 & 285 & 273 & 215 & 283 & 264 & 136 & 286 & 264 & 213 & 271 \\
\hline \multicolumn{3}{|c|}{ Lance Bubbling (lpm) } & 8.8 & 2.5 & 12.4 & 15.0 & 9.9 & 24.8 & 8.9 & 1.3 & 15.0 & 14.9 & 13.0 & 20.1 \\
\hline \multicolumn{3}{|c|}{ Melter Pressure (inches water) } & -0.84 & -2.84 & 0.27 & -0.78 & -3.61 & 0.33 & -0.83 & -3.28 & 0.28 & -0.69 & -3.35 & 0.47 \\
\hline \multicolumn{3}{|c|}{ Total Electrode Voltage $(\mathrm{V})$} & 44.7 & 1.1 & 51.4 & 51.2 & 42.8 & 58.7 & 44.9 & 1.0 & 54.7 & 49.1 & 43.1 & 53.7 \\
\hline \multicolumn{3}{|c|}{ Total Power $(\mathrm{kW})$} & 17.7 & 0.0 & 19.3 & 25.2 & 17.4 & 28.4 & 20.1 & 10.2 & 22.9 & 28.3 & 21.2 & 30.8 \\
\hline \multicolumn{3}{|c|}{ Glass Resistance (ohms) } & 0.114 & 0.093 & 0.149 & 0.104 & 0.095 & 0.125 & 0.101 & 0.080 & 0.148 & 0.085 & 0.078 & 0.095 \\
\hline
\end{tabular}


Table 3.3. Summary of Measured DM100 Parameters (continued).

\begin{tabular}{|c|c|c|c|c|c|c|c|c|}
\hline \multirow{3}{*}{\multicolumn{3}{|c|}{ Test }} & \multicolumn{6}{|c|}{5 (HLW-E-M-09 composition) } \\
\hline & & & \multicolumn{3}{|c|}{ A } & \multicolumn{3}{|c|}{$\mathrm{B}$} \\
\hline & & & AVG & MIN & MAX & AVG & MIN & MAX \\
\hline \multirow{14}{*}{$\begin{array}{c}\mathrm{T} \\
\mathrm{E} \\
\mathrm{M} \\
\mathrm{P} \\
\mathrm{E} \\
\mathrm{R} \\
\mathrm{A} \\
\mathrm{T} \\
\mathrm{U} \\
\mathrm{R} \\
\mathrm{E} \\
\left({ }^{\circ} \mathrm{C}\right)\end{array}$} & \multirow{4}{*}{ Electrode } & East Upper & 1000 & 675 & 1086 & 1107 & 1062 & 1126 \\
\hline & & West Upper & 1043 & 679 & 1104 & 1087 & 1060 & 1104 \\
\hline & & West Lower & 1047 & 1030 & 1068 & 1067 & 1037 & 1080 \\
\hline & & Bottom & 704 & 693 & 758 & 723 & 694 & 732 \\
\hline & \multirow{4}{*}{ Glass } & 27 " from bottom & 1059 & 540 & 1162 & 1134 & 1033 & 1162 \\
\hline & & 16" from bottom & 1124 & 730 & 1168 & 1143 & 1095 & 1171 \\
\hline & & 10 " from bottom & 1156 & 1130 & 1177 & 1156 & 1117 & 1177 \\
\hline & & 5" from bottom & 1152 & 1134 & 1173 & 1155 & 1117 & 1174 \\
\hline & \multirow{2}{*}{ Plenum } & Exposed & 456 & 288 & 683 & 502 & 402 & 558 \\
\hline & & Thermowell & 416 & 331 & 654 & 445 & 352 & 505 \\
\hline & \multirow{2}{*}{ Discharge } & Chamber & 1032 & 960 & 1061 & 1063 & 1040 & 1076 \\
\hline & & Air Lift & 1018 & 933 & 1081 & 1067 & 1030 & 1218 \\
\hline & \multicolumn{2}{|c|}{ Film Cooler Outlet } & 288 & 266 & 301 & 295 & 224 & 302 \\
\hline & \multicolumn{2}{|c|}{ Transition Line Outlet } & 276 & 259 & 291 & 285 & 219 & 295 \\
\hline \multicolumn{3}{|c|}{ Lance Bubbling (lpm) } & 9.0 & 1.3 & 9.1 & 14.5 & 9.1 & 18.2 \\
\hline \multicolumn{3}{|c|}{ Melter Pressure (inches water) } & -0.76 & -2.40 & 0.55 & -0.73 & -2.52 & 0.69 \\
\hline \multicolumn{3}{|c|}{ Total Electrode Voltage (V) } & 45.3 & 1.1 & 52.5 & 52.1 & 43.9 & 57.6 \\
\hline \multicolumn{3}{|c|}{ Total Power $(\mathrm{kW})$} & 21.8 & 19.7 & 24.8 & 30.4 & 22.2 & 35.3 \\
\hline \multicolumn{3}{|c|}{ Glass Resistance (ohms) } & 0.095 & 0.085 & 0.134 & 0.089 & 0.083 & 0.102 \\
\hline
\end{tabular}


Table 3.4. Summary of Idling Periods after DM100 Tests.

\begin{tabular}{|c|c|c|c|c|c|c|}
\hline \multicolumn{2}{|r|}{ Test } & 1 & 2 & 3 & 4 & 5 \\
\hline \multirow{3}{*}{ Time* } & Start & $\begin{array}{c}9 / 20 / 08 \\
2: 59\end{array}$ & $\begin{array}{c}10 / 11 / 08 \\
2: 19\end{array}$ & $\begin{array}{c}10 / 31 / 08 \\
20: 59\end{array}$ & 11/14/08 15:07 & $12 / 12 / 0800: 53$ \\
\hline & End & $\begin{array}{c}10 / 2 / 08 \\
14: 05\end{array}$ & $\begin{array}{c}10 / 22 / 08 \\
10: 30\end{array}$ & $\begin{array}{c}11 / 10 / 08 \\
7: 00\end{array}$ & $11 / 24 / 08$ 13:41 & $12 / 19 / 0814: 03$ \\
\hline & Duration & $299 \mathrm{hr}$ & $272 \mathrm{hr}$ & $226 \mathrm{hr}$ & $248 \mathrm{hr}$ & $181 \mathrm{hr}$ \\
\hline \multirow{12}{*}{$\begin{array}{c}\text { Avg. } \\
\text { Temps } \\
\text { during } \\
\text { idling } \\
\text { periods } \\
\left({ }^{\circ} \mathrm{C}\right)\end{array}$} & East Upper Electrode & 814 & 847 & 873 & 894 & 899 \\
\hline & West Upper Electrode & 820 & 827 & 871 & 891 & 897 \\
\hline & West Lower Electrode & 945 & 898 & 829 & 792 & 805 \\
\hline & Bottom Electrode & 822 & 720 & 746 & 724 & 746 \\
\hline & Glass 27 " from bottom & 839 & 873 & 973 & 988 & 958 \\
\hline & Glass 16 " from bottom & 974 & 964 & 991 & 988 & 963 \\
\hline & Glass 10 " from bottom & 1036 & 1038 & 969 & 950 & 941 \\
\hline & Glass $5 "$ from bottom & 1020 & 981 & 1002 & 963 & 938 \\
\hline & Plenum Exposed & 414 & 694 & 800 & 842 & 846 \\
\hline & Plenum Thermowell & 419 & 696 & 797 & 840 & 838 \\
\hline & Discharge Chamber & 969 & 938 & 982 & 953 & 953 \\
\hline & Air Lift & 941 & 928 & 912 & 897 & 905 \\
\hline
\end{tabular}

* - idling time is defined by the times of installation and removal double boat sampling probe. 
The Catholic University of America Vitreous State Laboratory
ORP-56294 Rev. 0

Effects of High Crystal Content in HLW DM100 Melter Tests

Final Report, VSL-09R1520-1, Rev. 0

Table 4.1. Characteristics of Melter Feed Samples from DM100 Tests.

\begin{tabular}{|c|c|c|c|c|c|c|c|c|c|c|}
\hline \multirow{3}{*}{ Test } & \multirow{3}{*}{ Composition } & \multirow{3}{*}{ Date } & \multirow{3}{*}{ Name } & \multirow{3}{*}{$\begin{array}{c}\% \\
\text { Water }\end{array}$} & \multirow{3}{*}{ pH } & \multirow{3}{*}{$\begin{array}{c}\text { Density } \\
(\mathrm{g} / \mathrm{ml})\end{array}$} & \multicolumn{4}{|c|}{ Glass Yield } \\
\hline & & & & & & & $(\alpha / l)$ & Measured & Target & \%Dev \\
\hline & & & & & & & $(g / I)$ & (kg/kg) & (kg/kg) & \%Dev. \\
\hline \multirow{3}{*}{1} & \multirow{3}{*}{ HLW-E-SP-06 } & 9/15/08 & BLZ-F-47B & 57.09 & 10.49 & 1.42 & 528 & 0.372 & 0.359 & 3.51 \\
\hline & & $9 / 18 / 08$ & BLZ-F-108A & 56.25 & 10.41 & 1.43 & 541 & 0.378 & 0.359 & 5.38 \\
\hline & & $9 / 22 / 08$ & BLZ-F-130A & 55.82 & 10.60 & 1.41 & 537 & 0.381 & 0.359 & 6.07 \\
\hline \multirow{2}{*}{2} & \multirow{2}{*}{ HLW-E-SP-05 } & $10 / 6 / 08$ & BLZ-F-139A & 58.25 & 10.66 & 1.38 & 499 & 0.362 & 0.356 & 1.63 \\
\hline & & $10 / 10 / 08$ & ABL-F-55A & 57.08 & 10.48 & 1.40 & 519 & 0.370 & 0.356 & 4.04 \\
\hline \multirow{2}{*}{3} & \multirow{2}{*}{ HLW-E-M-03 } & $10 / 17 / 08$ & ABL-F-63B & 57.76 & 8.69 & 1.40 & 502 & 0.359 & 0.358 & 0.20 \\
\hline & & $10 / 31 / 08$ & ABL-F-132A & 57.50 & 9.28 & 1.38 & 499 & 0.362 & 0.358 & 1.06 \\
\hline \multirow{4}{*}{4} & \multirow{4}{*}{ HLW-E-ES05 } & $11 / 10 / 08$ & ABL-F-141A & 57.48 & 9.17 & 1.41 & 511 & 0.363 & 0.358 & 1.28 \\
\hline & & $11 / 11 / 08$ & BBL-F-12A & 56.18 & 9.17 & 1.40 & 523 & 0.373 & 0.358 & 4.30 \\
\hline & & $11 / 12 / 08$ & BBL-F-29A & 56.52 & 9.14 & 1.41 & 520 & 0.369 & 0.358 & 2.99 \\
\hline & & $11 / 13 / 08$ & BBL-F-42A & 56.40 & 9.07 & 1.41 & 522 & 0.370 & 0.358 & 3.38 \\
\hline \multirow{3}{*}{5} & \multirow{3}{*}{ HLW-E-M-09 } & $12 / 8 / 08$ & BBL-F-73A & 57.79 & 9.34 & 1.39 & 497 & 0.358 & 0.356 & 0.45 \\
\hline & & $12 / 10 / 08$ & BBL-F-103A & 57.02 & 9.37 & 1.40 & 510 & 0.364 & 0.356 & 2.30 \\
\hline & & $12 / 11 / 08$ & BBL-F-121A & 57.20 & 9.56 & 1.39 & 504 & 0.362 & 0.356 & 1.77 \\
\hline
\end{tabular}


Table 4.2. XRF Analyzed Compositions of Vitrified Melter Feed Samples (wt\%).

\begin{tabular}{|c|c|c|c|c|c|c|c|c|c|c|c|c|c|c|c|}
\hline Test & \multicolumn{5}{|c|}{1 (HLW-E-SP-06) } & \multicolumn{5}{|c|}{2 (HLW-E-SP-05) } & \multicolumn{5}{|c|}{3 (HLW-E-M-03) } \\
\hline Constituent & Target & $\begin{array}{c}\text { BLZ-F- } \\
47 \mathrm{~B}\end{array}$ & $\begin{array}{c}\text { BLZ-F- } \\
108 \mathrm{~A}\end{array}$ & Average & $\%$ Dev. & Target & $\begin{array}{c}\text { BLZ-F- } \\
139 A\end{array}$ & $\begin{array}{c}\text { ABL-F- } \\
55 \mathrm{~A} \\
\end{array}$ & Average & $\%$ Dev. & Target & $\begin{array}{c}\text { ABL-F- } \\
63 \mathrm{~B} \\
\end{array}$ & $\begin{array}{c}\text { ABL-F- } \\
132 \mathrm{~A}\end{array}$ & Average & $\%$ Dev. \\
\hline $\mathrm{Al}_{2} \mathrm{O}_{3}$ & 8.91 & 8.87 & 8.92 & 8.89 & -0.21 & 9.49 & 9.41 & 9.42 & 9.41 & -0.81 & 12.17 & 11.71 & 11.77 & 11.74 & -3.49 \\
\hline $\mathrm{B}_{2} \mathrm{O}_{3} *$ & 13.30 & 13.30 & 13.30 & 13.30 & $\mathrm{NC}$ & 12.08 & 12.08 & 12.08 & 12.08 & $\mathrm{NC}$ & 13.34 & 13.34 & 13.34 & 13.34 & $\mathrm{NC}$ \\
\hline $\mathrm{BaO}$ & $\S$ & $<0.01$ & $<0.01$ & $<0.01$ & $\mathrm{NC}$ & $\S$ & $<0.01$ & 0.01 & $<0.01$ & $\mathrm{NC}$ & 0.01 & 0.02 & 0.02 & 0.02 & $\mathrm{NC}$ \\
\hline $\mathrm{Bi}_{2} \mathrm{O}_{3}$ & $\S$ & $<0.01$ & $<0.01$ & $<0.01$ & $\mathrm{NC}$ & $\S$ & $<0.01$ & $<0.01$ & $<0.01$ & $\mathrm{NC}$ & 3.47 & 3.40 & 3.40 & 3.40 & -2.08 \\
\hline $\mathrm{CaO}$ & 0.37 & 0.47 & 0.44 & 0.45 & $\mathrm{NC}$ & 0.40 & 0.42 & 0.43 & 0.42 & $\mathrm{NC}$ & 1.18 & 1.15 & 1.16 & 1.16 & -1.82 \\
\hline $\mathrm{CdO}$ & 0.18 & 0.17 & 0.17 & 0.17 & $\mathrm{NC}$ & 0.19 & 0.17 & 0.14 & 0.16 & $\mathrm{NC}$ & $\S$ & $<0.01$ & $<0.01$ & $<0.01$ & $\mathrm{NC}$ \\
\hline $\mathrm{Cr}_{2} \mathrm{O}_{3}$ & 0.15 & 0.17 & 0.16 & 0.16 & $\mathrm{NC}$ & 0.15 & 0.18 & 0.17 & 0.17 & $\mathrm{NC}$ & 3.00 & 3.15 & 3.17 & 3.16 & 5.40 \\
\hline $\mathrm{Cs}_{2} \mathrm{O}$ & 0.08 & 0.09 & 0.08 & 0.09 & $\mathrm{NC}$ & 0.08 & 0.09 & 0.09 & 0.09 & $\mathrm{NC}$ & $\S$ & $<0.01$ & $<0.01$ & $<0.01$ & $\mathrm{NC}$ \\
\hline $\mathrm{F}^{*}$ & $\S$ & $<0.01$ & $<0.01$ & $\mathrm{NC}$ & $\mathrm{NC}$ & $\S$ & $<0.01$ & $<0.01$ & $\mathrm{NC}$ & $\mathrm{NC}$ & 0.95 & 0.95 & 0.95 & 0.95 & $\mathrm{NC}$ \\
\hline $\mathrm{Fe}_{2} \mathrm{O}_{3}$ & 20.01 & 19.79 & 19.66 & 19.73 & -1.39 & 21.30 & 21.28 & 21.17 & 21.22 & -0.35 & 6.26 & 6.26 & 6.26 & 6.26 & 0.02 \\
\hline $\mathrm{K}_{2} \mathrm{O}$ & 7.00 & 6.35 & 6.45 & 6.40 & -8.56 & 7.01 & 6.55 & 6.58 & 6.57 & -6.31 & 4.54 & 4.36 & 4.25 & 4.31 & -5.11 \\
\hline $\mathrm{La}_{2} \mathrm{O}_{3}$ & 0.60 & 0.58 & 0.57 & 0.57 & $\mathrm{NC}$ & 0.64 & 0.36 & 0.34 & 0.35 & $\mathrm{NC}$ & $\S$ & $<0.01$ & $<0.01$ & $<0.01$ & $\mathrm{NC}$ \\
\hline $\mathrm{Li}_{2} \mathrm{O}^{*}$ & 1.17 & 1.17 & 1.17 & 1.17 & $\mathrm{NC}$ & 1.10 & 1.10 & 1.10 & 1.10 & $\mathrm{NC}$ & 2.60 & 2.60 & 2.60 & 2.60 & $\mathrm{NC}$ \\
\hline $\mathrm{MgO}$ & 0.11 & 0.18 & 0.20 & 0.19 & $\mathrm{NC}$ & 0.12 & 0.08 & 0.08 & 0.08 & $\mathrm{NC}$ & 0.08 & 0.10 & 0.09 & 0.10 & $\mathrm{NC}$ \\
\hline $\mathrm{MnO}$ & 0.57 & 0.56 & 0.55 & 0.55 & $\mathrm{NC}$ & 0.61 & 0.54 & 0.53 & 0.54 & $\mathrm{NC}$ & 0.75 & 0.72 & 0.70 & 0.71 & $\mathrm{NC}$ \\
\hline $\mathrm{Na}_{2} \mathrm{O}$ & 10.19 & 9.68 & 9.65 & 9.67 & -5.16 & 9.07 & 9.33 & 9.28 & 9.30 & 2.57 & 9.57 & 9.68 & 9.85 & 9.77 & 2.00 \\
\hline $\mathrm{Nd}_{2} \mathrm{O}_{3}$ & 0.26 & 0.29 & 0.29 & 0.29 & $\mathrm{NC}$ & 0.28 & 0.31 & 0.31 & 0.31 & $\mathrm{NC}$ & $\S$ & $<0.01$ & $<0.01$ & $<0.01$ & $\mathrm{NC}$ \\
\hline $\mathrm{NiO}$ & 0.71 & 0.59 & 0.57 & 0.58 & $\mathrm{NC}$ & 0.76 & 0.48 & 0.45 & 0.47 & $\mathrm{NC}$ & 0.75 & 0.70 & 0.70 & 0.70 & $\mathrm{NC}$ \\
\hline $\mathrm{P}_{2} \mathrm{O}_{5}$ & 0.04 & 0.07 & 0.07 & 0.07 & $\mathrm{NC}$ & 0.04 & 0.06 & 0.06 & 0.06 & $\mathrm{NC}$ & 1.59 & 1.61 & 1.61 & 1.61 & 1.21 \\
\hline $\mathrm{PbO}$ & 0.11 & 0.09 & 0.08 & 0.08 & $\mathrm{NC}$ & 0.12 & 0.09 & 0.09 & 0.09 & $\mathrm{NC}$ & 0.23 & 0.20 & 0.19 & 0.19 & $\mathrm{NC}$ \\
\hline $\mathrm{SiO}_{2}$ & 33.31 & 34.52 & 34.69 & 34.60 & 3.87 & 33.46 & 34.42 & 34.63 & 34.52 & 3.19 & 39.45 & 39.82 & 39.74 & 39.78 & 0.82 \\
\hline $\mathrm{SO}_{3}$ & 0.07 & 0.18 & 0.18 & 0.18 & $\mathrm{NC}$ & 0.07 & 0.20 & 0.19 & 0.19 & $\mathrm{NC}$ & $\S$ & 0.09 & 0.10 & 0.10 & $\mathrm{NC}$ \\
\hline $\mathrm{TiO}_{2}$ & $\S$ & 0.09 & 0.08 & 0.08 & $\mathrm{NC}$ & $\S$ & 0.08 & 0.08 & 0.08 & $\mathrm{NC}$ & $\S$ & 0.04 & 0.04 & 0.04 & $\mathrm{NC}$ \\
\hline $\mathrm{ZnO}$ & 0.02 & 0.04 & 0.04 & 0.04 & $\mathrm{NC}$ & 0.02 & 0.03 & 0.03 & 0.03 & $\mathrm{NC}$ & $\S$ & 0.01 & $<0.01$ & $<0.01$ & $\mathrm{NC}$ \\
\hline $\mathrm{ZrO}_{2}$ & 2.83 & 2.76 & 2.67 & 2.71 & -4.03 & 3.01 & 2.74 & 2.75 & 2.74 & -8.89 & 0.05 & 0.07 & 0.06 & 0.06 & $\mathrm{NC}$ \\
\hline Sum & 100.00 & 100.00 & 100.00 & 100.00 & $\mathrm{NC}$ & 100.00 & 100.00 & 100.00 & 100.00 & $\mathrm{NC}$ & 100.00 & 100.00 & 100.00 & 100.00 & $\mathrm{NC}$ \\
\hline
\end{tabular}

$\S$ - Not a target constituent

* Target values

$\mathrm{NC}-$ Not calculated 
Table 4.2. XRF Analyzed Compositions of Vitrified Melter Feed Samples (wt\%) (continued).

\begin{tabular}{|c|c|c|c|c|c|c|c|c|c|c|c|c|c|}
\hline \multirow{2}{*}{$\begin{array}{c}\text { Test } \\
\text { Sample ID }\end{array}$} & \multicolumn{7}{|c|}{4 (HLW-E-ES-05) } & \multicolumn{6}{|c|}{5 (HLW-E-M-09) } \\
\hline & Target & $\begin{array}{c}\text { ABL-F- } \\
141 \mathrm{~A}\end{array}$ & $\begin{array}{c}\text { BBL-F- } \\
12 \mathrm{~A}\end{array}$ & $\begin{array}{c}\text { BBL-F- } \\
29 \mathrm{~A}\end{array}$ & $\begin{array}{c}\text { BBL-F- } \\
42 \mathrm{~A}\end{array}$ & Average & \% Dev. & Target & $\begin{array}{c}\text { BBL-F- } \\
73 \mathrm{~A}\end{array}$ & $\begin{array}{c}\text { BBL-F- } \\
103 \mathrm{~A}\end{array}$ & $\begin{array}{c}\text { BBL-F- } \\
121 \mathrm{~A}\end{array}$ & Average & $\%$ Dev. \\
\hline $\mathrm{Al}_{2} \mathrm{O}_{3}$ & 10.86 & 10.60 & 10.73 & 10.55 & 10.64 & 10.63 & -2.13 & 10.69 & 10.54 & 10.49 & 10.65 & 10.56 & -1.20 \\
\hline $\mathrm{B}_{2} \mathrm{O}_{3} *$ & 14.80 & 14.80 & 14.80 & 14.80 & 14.80 & 14.80 & $\mathrm{NC}$ & 14.57 & 14.57 & 14.57 & 14.57 & 14.57 & $\mathrm{NC}$ \\
\hline $\mathrm{BaO}$ & 0.01 & 0.02 & 0.01 & 0.02 & 0.02 & 0.02 & $\mathrm{NC}$ & 0.01 & 0.02 & 0.02 & 0.02 & 0.02 & $\mathrm{NC}$ \\
\hline $\mathrm{Bi}_{2} \mathrm{O}_{3}$ & 3.53 & 3.39 & 3.35 & 3.53 & 3.25 & 3.38 & -4.16 & 3.47 & 3.23 & 3.44 & 3.28 & 3.32 & -4.49 \\
\hline $\mathrm{CaO}$ & 1.20 & 1.17 & 1.15 & 1.23 & 1.06 & 1.15 & -3.55 & 1.18 & 1.15 & 1.11 & 1.12 & 1.13 & -4.24 \\
\hline $\mathrm{CdO}$ & $\S$ & $<0.01$ & $<0.01$ & $<0.01$ & $<0.01$ & $<0.01$ & $\mathrm{NC}$ & $\S$ & $<0.01$ & $<0.01$ & $<0.01$ & $<0.01$ & $\mathrm{NC}$ \\
\hline $\mathrm{Cr}_{2} \mathrm{O}_{3}$ & 3.00 & 3.18 & 3.20 & 3.20 & 3.06 & 3.16 & 5.40 & 3.00 & 3.19 & 3.27 & 3.18 & 3.21 & 7.16 \\
\hline $\mathrm{Cs}_{2} \mathrm{O}$ & $\S$ & $<0.01$ & $<0.01$ & $<0.01$ & $<0.01$ & $<0.01$ & $\mathrm{NC}$ & $\S$ & $<0.01$ & $<0.01$ & $<0.01$ & $<0.01$ & $\mathrm{NC}$ \\
\hline $\mathrm{F}^{*}$ & 0.97 & 0.97 & 0.97 & 0.97 & 0.97 & 0.97 & $\mathrm{NC}$ & 0.95 & 0.95 & 0.95 & 0.95 & 0.95 & $\mathrm{NC}$ \\
\hline $\mathrm{Fe}_{2} \mathrm{O}_{3}$ & 6.36 & 6.25 & 6.24 & 6.41 & 6.05 & 6.24 & -1.80 & 6.26 & 5.94 & 6.20 & 5.79 & 5.98 & -4.44 \\
\hline $\mathrm{K}_{2} \mathrm{O}$ & 5.61 & 5.35 & 5.19 & 5.27 & 5.11 & 5.23 & -6.73 & 5.52 & 5.10 & 5.10 & 5.11 & 5.11 & -7.57 \\
\hline $\mathrm{La}_{2} \mathrm{O}_{3}$ & $\S$ & 0.01 & $<0.01$ & 0.01 & $<0.01$ & $<0.01$ & $\mathrm{NC}$ & $\S$ & $<0.01$ & $<0.01$ & 0.01 & $<0.01$ & $\mathrm{NC}$ \\
\hline $\mathrm{Li}_{2} \mathrm{O}^{*}$ & 3.14 & 3.14 & 3.14 & 3.14 & 3.14 & 3.14 & $\mathrm{NC}$ & 3.09 & 3.09 & 3.09 & 3.09 & 3.09 & $\mathrm{NC}$ \\
\hline $\mathrm{MgO}$ & 0.08 & 0.13 & 0.14 & 0.13 & 0.13 & 0.13 & $\mathrm{NC}$ & 0.08 & 0.13 & 0.11 & 0.13 & 0.12 & $\mathrm{NC}$ \\
\hline $\mathrm{MnO}$ & $\S$ & 0.02 & 0.01 & 0.01 & 0.01 & 0.01 & $\mathrm{NC}$ & $\S$ & 0.01 & $<0.01$ & $<0.01$ & $<0.01$ & $\mathrm{NC}$ \\
\hline $\mathrm{Na}_{2} \mathrm{O}$ & 9.72 & 9.44 & 9.30 & 9.15 & 10.09 & 9.49 & -2.40 & 9.57 & 9.04 & 9.31 & 9.06 & 9.14 & -4.56 \\
\hline $\mathrm{Nd}_{2} \mathrm{O}_{3}$ & $\S$ & $<0.01$ & 0.01 & 0.01 & $<0.01$ & $<0.01$ & $\mathrm{NC}$ & $\S$ & $<0.01$ & $<0.01$ & $<0.01$ & $<0.01$ & $\mathrm{NC}$ \\
\hline $\mathrm{NiO}$ & $\S$ & 0.01 & $<0.01$ & $<0.01$ & $<0.01$ & $<0.01$ & $\mathrm{NC}$ & $\S$ & $<0.01$ & $<0.01$ & $<0.01$ & $<0.01$ & $\mathrm{NC}$ \\
\hline $\mathrm{P}_{2} \mathrm{O}_{5}$ & 1.62 & 1.71 & 1.72 & 1.67 & 1.66 & 1.69 & 4.60 & 1.59 & 1.67 & 1.62 & 1.66 & 1.65 & 3.71 \\
\hline $\mathrm{PbO}$ & 0.23 & 0.19 & 0.18 & 0.19 & 0.17 & 0.18 & $\mathrm{NC}$ & 0.23 & 0.17 & 0.16 & 0.16 & 0.16 & $\mathrm{NC}$ \\
\hline $\mathrm{SiO}_{2}$ & 38.82 & 39.45 & 39.69 & 39.54 & 39.67 & 39.59 & 1.97 & 38.22 & 39.62 & 38.86 & 39.60 & 39.36 & 2.97 \\
\hline $\mathrm{SO}_{3}$ & $\S$ & 0.07 & 0.06 & 0.06 & 0.06 & 0.06 & $\mathrm{NC}$ & $\S$ & 0.03 & 0.03 & 0.03 & 0.03 & $\mathrm{NC}$ \\
\hline $\mathrm{TiO}_{2}$ & $\S$ & 0.04 & 0.04 & 0.04 & 0.04 & 0.04 & $\mathrm{NC}$ & $\S$ & 0.01 & 0.02 & 0.02 & 0.01 & $\mathrm{NC}$ \\
\hline $\mathrm{ZnO}$ & $\S$ & $<0.01$ & $<0.01$ & $<0.01$ & $<0.01$ & $<0.01$ & $\mathrm{NC}$ & 1.50 & 1.48 & 1.58 & 1.51 & 1.52 & 1.60 \\
\hline $\mathrm{ZrO}_{2}$ & 0.05 & 0.07 & 0.06 & 0.07 & 0.07 & 0.07 & $\mathrm{NC}$ & 0.05 & 0.05 & 0.05 & 0.05 & 0.05 & $\mathrm{NC}$ \\
\hline Sum & 100.00 & 100.00 & 100.00 & 100.00 & 100.00 & 100.00 & $\mathrm{NC}$ & 100.00 & 100.00 & 100.00 & 100.00 & 100.00 & $\mathrm{NC}$ \\
\hline
\end{tabular}

$\S$ - Not a target constituent

* Target values

$\mathrm{NC}-$ Not calculated 
The Catholic University of America Vitreous State Laboratory
ORP-56294 Rev. 0

Effects of High Crystal Content in HLW DM100 Melter Tests

Final Report, VSL-09R1520-1, Rev. 0

Table 4.3. XRF and DCP Analyzed Compositions of Selected Vitrified Melter Feed Samples during DM100 Tests (wt\%).

\begin{tabular}{|c|c|c|c|c|c|c|c|c|c|c|}
\hline \multirow{3}{*}{$\begin{array}{c}\text { Test } \\
\text { Sample I.D. } \\
\text { Constituent }\end{array}$} & \multicolumn{5}{|c|}{1 (HLW-E-SP-06) } & \multicolumn{5}{|c|}{2 (HLW-E-SP-05) } \\
\hline & \multirow{2}{*}{ Target } & \multicolumn{2}{|c|}{ BLZ-F-47B } & \multicolumn{2}{|c|}{ BLZ-F-108A } & \multirow[b]{2}{*}{ Target } & \multicolumn{2}{|c|}{ ABL-F-55A } & \multicolumn{2}{|c|}{ BLZ-F-139A } \\
\hline & & XRF & DCP & XRF & DCP & & XRF & DCP & XRF & DCP \\
\hline $\mathrm{Al}_{2} \mathrm{O}_{3}$ & 8.91 & 8.87 & 8.47 & 8.92 & 9.28 & 9.49 & 9.42 & 8.57 & 9.41 & 8.46 \\
\hline $\mathrm{B}_{2} \mathrm{O}_{3}$ & 13.30 & $13.30 *$ & 11.85 & $13.30 *$ & 11.37 & 12.08 & $12.08^{*}$ & 10.36 & 12.08 & 9.98 \\
\hline $\mathrm{BaO}$ & $\S$ & $<0.01$ & $<0.01$ & $<0.01$ & $<0.01$ & $\S$ & 0.01 & $<0.01$ & $<0.01$ & $<0.01$ \\
\hline $\mathrm{Bi}_{2} \mathrm{O}_{3}$ & $\S$ & $<0.01$ & 0.07 & $<0.01$ & 0.06 & $\S$ & $<0.01$ & 0.03 & $<0.01$ & 0.08 \\
\hline $\mathrm{CaO}$ & 0.37 & 0.47 & 0.50 & 0.44 & 0.48 & 0.40 & 0.43 & 0.49 & 0.42 & 0.44 \\
\hline $\mathrm{CdO}$ & 0.18 & 0.17 & 0.16 & 0.17 & 0.17 & 0.19 & 0.14 & 0.15 & 0.17 & 0.16 \\
\hline $\mathrm{Cr}_{2} \mathrm{O}_{3}$ & 0.15 & 0.17 & 0.15 & 0.16 & 0.15 & 0.15 & 0.17 & 0.16 & 0.18 & 0.16 \\
\hline $\mathrm{Cs}_{2} \mathrm{O}$ & 0.08 & 0.09 & 0.06 & 0.08 & 0.06 & 0.08 & 0.09 & 0.05 & 0.09 & 0.05 \\
\hline $\mathrm{F}$ & $\S$ & NA & NA & NA & NA & $\S$ & NA & NA & NA & NA \\
\hline $\mathrm{Fe}_{2} \mathrm{O}_{3}$ & 20.01 & 19.79 & 19.64 & 19.66 & 20.12 & 21.30 & 21.17 & 22.41 & 21.28 & 22.47 \\
\hline $\mathrm{K}_{2} \mathrm{O}$ & 7.00 & 6.35 & 5.79 & 6.45 & 5.80 & 7.01 & 6.58 & 6.06 & 6.55 & 5.89 \\
\hline $\mathrm{La}_{2} \mathrm{O}_{3}$ & 0.60 & 0.58 & NA & 0.57 & NA & 0.64 & 0.34 & NA & 0.36 & NA \\
\hline $\mathrm{Li}_{2} \mathrm{O}$ & 1.17 & $1.17^{*}$ & 1.20 & $1.17^{*}$ & 1.16 & 1.10 & $1.10^{*}$ & 1.23 & 1.10 & 1.06 \\
\hline $\mathrm{MgO}$ & 0.11 & 0.18 & 0.25 & 0.20 & 0.20 & 0.12 & 0.08 & 0.13 & 0.08 & 0.12 \\
\hline $\mathrm{MnO}$ & 0.57 & 0.56 & 0.61 & 0.55 & 0.60 & 0.61 & 0.53 & 0.61 & 0.54 & 0.61 \\
\hline $\mathrm{Na}_{2} \mathrm{O}$ & 10.19 & 9.68 & 8.90 & 9.65 & 8.75 & 9.07 & 9.28 & 8.29 & 9.33 & 7.84 \\
\hline $\mathrm{Nd}_{2} \mathrm{O}_{3}$ & 0.26 & 0.29 & NA & 0.29 & NA & 0.28 & 0.31 & NA & 0.31 & NA \\
\hline $\mathrm{NiO}$ & 0.71 & 0.59 & 0.65 & 0.57 & 0.64 & 0.76 & 0.45 & 0.54 & 0.48 & 0.56 \\
\hline $\mathrm{P}_{2} \mathrm{O} 5$ & 0.04 & 0.07 & $<0.01$ & 0.07 & $<0.01$ & 0.04 & 0.06 & 0.07 & 0.06 & 0.10 \\
\hline $\mathrm{PbO}$ & 0.11 & 0.09 & 0.10 & 0.08 & 0.07 & 0.12 & 0.09 & 0.13 & 0.09 & 0.11 \\
\hline $\mathrm{SiO}_{2}$ & 33.31 & 34.52 & 35.32 & 34.69 & 35.51 & 33.46 & 34.63 & 34.22 & 34.42 & 34.29 \\
\hline $\mathrm{SO} 3$ & 0.07 & 0.18 & NA & 0.18 & NA & 0.07 & 0.19 & NA & 0.20 & NA \\
\hline $\mathrm{TiO}_{2}$ & $\S$ & 0.09 & 0.09 & 0.08 & 0.09 & $\S$ & 0.08 & 0.08 & 0.08 & 0.08 \\
\hline $\mathrm{ZnO}$ & 0.02 & 0.04 & 0.04 & 0.04 & 0.04 & 0.02 & 0.03 & 0.03 & 0.03 & 0.03 \\
\hline $\mathrm{ZrO}_{2}$ & 2.83 & 2.76 & 2.76 & 2.67 & 2.70 & 3.01 & 2.75 & 2.77 & 2.74 & 3.00 \\
\hline Sum & 100.00 & 100.00 & 96.55 & 100.00 & 97.19 & 100.00 & 100.00 & 96.33 & 100.00 & 95.44 \\
\hline
\end{tabular}

$\S$ - Not a target constituent;

NA - Not analyzed

* - Target values used for XRF-analyzed compositions 
Table 4.3. XRF and DCP Analyzed Compositions on Selected Vitrified Melter Feed Samples during DM100 Melter Tests (wt\%) (continued).

\begin{tabular}{|c|c|c|c|c|c|c|c|c|c|}
\hline \multirow{3}{*}{$\begin{array}{c}\text { Test } \\
\text { Sample I.D. } \\
\text { Constituent }\end{array}$} & \multicolumn{6}{|c|}{3 (HLW-E-M-03) } & \multirow{2}{*}{\multicolumn{3}{|c|}{$\frac{4 \text { (HLW-E-ES-05) }}{\text { BBL-F-12A }}$}} \\
\hline & \multirow{2}{*}{ Target } & \multicolumn{2}{|c|}{ ABL-F-63B } & \multicolumn{3}{|c|}{ ABL-F-132A } & & & \\
\hline & & XRF & DCP & Target & XRF & DCP & Target & XRF & DCP \\
\hline $\mathrm{Al}_{2} \mathrm{O}_{3}$ & 12.17 & 11.71 & 11.19 & 12.17 & 11.77 & 10.89 & 10.86 & 10.73 & 10.07 \\
\hline $\mathrm{B}_{2} \mathrm{O}_{3}$ & 13.34 & 13.34* & 12.27 & 13.34 & 13.34* & 12.33 & 14.80 & $14.80^{*}$ & 13.79 \\
\hline $\mathrm{BaO}$ & 0.01 & 0.02 & 0.02 & 0.01 & 0.02 & 0.02 & 0.01 & 0.01 & 0.02 \\
\hline$\overline{\mathrm{Bi}_{2} \mathrm{O}_{3}}$ & 3.47 & 3.40 & 3.27 & 3.47 & 3.40 & 3.68 & 3.53 & 3.35 & 3.23 \\
\hline $\mathrm{CaO}$ & 1.18 & 1.15 & 1.30 & 1.18 & 1.16 & 1.27 & 1.20 & 1.15 & 1.31 \\
\hline $\mathrm{CdO}$ & $\S$ & $<0.01$ & 0.05 & $\S$ & $<0.01$ & $<0.01$ & $\S$ & $<0.01$ & 0.01 \\
\hline $\mathrm{Cr}_{2} \mathrm{O}_{3}$ & 3.00 & 3.15 & 0.76 & 3.00 & 3.17 & 0.37 & 3.00 & 3.20 & 0.93 \\
\hline $\mathrm{Cs}_{2} \mathrm{O}$ & $\S$ & $<0.01$ & NA & $\S$ & $<0.01$ & NA & $\S$ & $<0.01$ & NA \\
\hline $\mathrm{F}$ & 0.95 & $0.95 *$ & NA & 0.95 & $0.95^{*}$ & NA & 0.97 & $0.97 *$ & NA \\
\hline $\mathrm{Fe}_{2} \mathrm{O}_{3}$ & 6.26 & 6.26 & 5.31 & 6.26 & 6.26 & 5.12 & 6.36 & 6.24 & 5.76 \\
\hline $\mathrm{K}_{2} \mathrm{O}$ & 4.54 & 4.36 & 4.13 & 4.54 & 4.25 & 3.91 & 5.61 & 5.19 & 5.03 \\
\hline $\mathrm{La}_{2} \mathrm{O}_{3}$ & $\S$ & $<0.01$ & NA & $\S$ & $<0.01$ & NA & $\S$ & $<0.01$ & NA \\
\hline $\mathrm{Li}_{2} \mathrm{O}$ & 2.60 & $2.60 *$ & 2.45 & 2.60 & $2.60 *$ & 2.53 & 3.14 & $3.14 *$ & 3.05 \\
\hline $\mathrm{MgO}$ & 0.08 & 0.10 & 0.16 & 0.08 & 0.09 & 0.13 & 0.08 & 0.14 & 0.18 \\
\hline $\mathrm{MnO}$ & 0.75 & 0.72 & 0.64 & 0.75 & 0.70 & 0.56 & $\S$ & 0.01 & 0.02 \\
\hline $\mathrm{Na}_{2} \mathrm{O}$ & 9.57 & 9.68 & 8.84 & 9.57 & 9.85 & 8.40 & 9.72 & 9.30 & 8.94 \\
\hline $\mathrm{Nd}_{2} \mathrm{O}_{3}$ & $\S$ & $<0.01$ & NA & $\S$ & $<0.01$ & NA & $\S$ & 0.01 & NA \\
\hline $\mathrm{NiO}$ & 0.75 & 0.70 & 0.42 & 0.75 & 0.70 & 0.35 & $\S$ & $<0.01$ & 0.01 \\
\hline $\mathrm{P}_{2} \mathrm{O} 5$ & 1.59 & 1.61 & 1.30 & 1.59 & 1.61 & 1.41 & 1.62 & 1.72 & 1.53 \\
\hline $\mathrm{PbO}$ & 0.23 & 0.20 & 0.25 & 0.23 & 0.19 & 0.19 & 0.23 & 0.18 & 0.23 \\
\hline $\mathrm{SiO}_{2}$ & 39.45 & 39.82 & 41.44 & 39.45 & 39.74 & 38.93 & 38.82 & 39.69 & 40.16 \\
\hline SO3 & $\S$ & 0.09 & NA & $\S$ & 0.10 & NA & $\S$ & 0.06 & NA \\
\hline $\mathrm{TiO}_{2}$ & $\S$ & 0.04 & 0.04 & $\S$ & 0.04 & 0.04 & $\S$ & 0.04 & 0.04 \\
\hline $\mathrm{ZnO}$ & $\S$ & 0.01 & $<0.01$ & $\S$ & $<0.01$ & $<0.01$ & $\S$ & $<0.01$ & 0.01 \\
\hline $\mathrm{ZrO}_{2}$ & 0.05 & 0.07 & 0.11 & 0.05 & 0.06 & 0.07 & 0.05 & 0.06 & 0.09 \\
\hline Sum & 100.00 & 100.00 & 93.95 & 100.00 & 100.00 & 90.19 & 100.00 & 100.00 & 94.42 \\
\hline
\end{tabular}

$\S$ - Not a target constituent;

NA - Not analyzed

* - Target values used for XRF-analyzed compositions 
The Catholic University of America Vitreous State Laboratory
ORP-56294 Rev. 0

Effects of High Crystal Content in HLW DM100 Melter Tests

Final Report, VSL-09R1520-1, Rev. 0

Table 4.4. List of Glass Discharged, Masses, and Analysis Performed.

\begin{tabular}{|c|c|c|c|c|c|c|}
\hline Test & Composition & Date & Name & Analysis & Mass (kg) & \begin{tabular}{|c|}
$\begin{array}{c}\text { Cumulative Mass } \\
\text { (kg) }\end{array}$ \\
\end{tabular} \\
\hline \multirow{38}{*}{1} & \multirow{38}{*}{$\begin{array}{c}\text { HLW-E- } \\
\text { SP-06 }\end{array}$} & \multirow{7}{*}{$9 / 16 / 08$} & BLZ-G-65A & - & - & - \\
\hline & & & BLZ-G-67A & XRF, DCP & 22.82 & 22.82 \\
\hline & & & BLZ-G-69A & - & - & - \\
\hline & & & BLZ-G-72A & $\mathrm{XRF}$ & 19.34 & 42.16 \\
\hline & & & BLZ-G-73A & - & - & - \\
\hline & & & BLZ-G-75A & $\mathrm{XRF}$ & 28.30 & 70.46 \\
\hline & & & BLZ-G-78A & - & - & - \\
\hline & & \multirow{9}{*}{$9 / 17 / 08$} & BLZ-G-80A & XRF & 25.60 & 96.06 \\
\hline & & & BLZ-G-82A & - & - & - \\
\hline & & & BLZ-G-82B & XRF & 19.90 & 115.96 \\
\hline & & & BLZ-G-83A & - & - & - \\
\hline & & & BLZ-G-88A & $\mathrm{XRF}$ & 20.28 & 136.24 \\
\hline & & & BLZ-G-89A & - & - & - \\
\hline & & & BLZ-G-90A & $\mathrm{XRF}$ & 18.76 & 155.00 \\
\hline & & & BLZ-G-91A & - & - & - \\
\hline & & & BLZ-G-91B & $\mathrm{XRF}$ & 19.20 & 174.20 \\
\hline & & \multirow{15}{*}{$9 / 18 / 08$} & BLZ-G-95A & - & - & - \\
\hline & & & BLZ-G-97A & XRF & 22.32 & 196.52 \\
\hline & & & BLZ-G-98A & - & - & - \\
\hline & & & BLZ-G-98B & $\mathrm{XRF}$ & 19.70 & 216.22 \\
\hline & & & BLZ-G-99A & - & - & - \\
\hline & & & BLZ-G-99B & $\mathrm{XRF}$ & 26.90 & 243.12 \\
\hline & & & BLZ-G-101A & - & - & - \\
\hline & & & BLZ-G-101B & XRF & 22.90 & 266.02 \\
\hline & & & BLZ-G-104A & - & - & - \\
\hline & & & BLZ-G-104B & XRF & 19.02 & 285.04 \\
\hline & & & BLZ-G-104C & - & - & - \\
\hline & & & BLZ-G-105A & $\mathrm{XRF}$ & 26.62 & 311.66 \\
\hline & & & BLZ-G-107A & - & - & - \\
\hline & & & BLZ-G-108A & $\mathrm{XRF}$ & 24.76 & 336.42 \\
\hline & & & BLZ-G-111A & - & - & - \\
\hline & & \multirow{7}{*}{$9 / 19 / 08$} & BLZ-G-111B & $\mathrm{XRF}$ & 23.46 & 359.88 \\
\hline & & & BLZ-G-114A & - & - & - \\
\hline & & & BLZ-G-114B & $\mathrm{XRF}$ & 21.66 & 381.54 \\
\hline & & & BLZ-G-116A & - & - & - \\
\hline & & & BLZ-G-117A & XRF & 23.58 & 405.12 \\
\hline & & & BLZ-G-117B & - & - & - \\
\hline & & & BLZ-G-117C & XRF & 21.70 & 426.82 \\
\hline
\end{tabular}

"-" Empty data field 
The Catholic University of America Vitreous State Laboratory
ORP-56294 Rev. 0

Effects of High Crystal Content in HLW DM100 Melter Tests

Final Report, VSL-09R1520-1, Rev. 0

Table 4.4. List of Glass Discharged, Masses, and Analysis Performed (continued).

\begin{tabular}{|c|c|c|c|c|c|c|}
\hline Test & Composition & Date & Name & Analysis & Mass (kg) & \begin{tabular}{|c|}
$\begin{array}{c}\text { Cumulative Mass } \\
\text { (kg) }\end{array}$ \\
\end{tabular} \\
\hline \multirow{7}{*}{1} & \multirow{7}{*}{$\begin{array}{l}\text { HLW-E- } \\
\text { SP-06 }\end{array}$} & \multirow{4}{*}{$9 / 19 / 08$} & BLZ-G-120A & - & - & - \\
\hline & & & BLZ-G-120B & XRF & 23.88 & 450.70 \\
\hline & & & BLZ-G-122A & - & - & - \\
\hline & & & BLZ-G-123A & XRF,SEM,PCT,TCLP & 22.46 & 473.16 \\
\hline & & $9 / 20 / 08$ & BLZ-G-129A & XRF & 4.94 & 478.10 \\
\hline & & \multirow{2}{*}{$10 / 2 / 08$} & BLZ-G-131A & XRF, SEM & 24.12 & 502.22 \\
\hline & & & BLZ-G-131B & XRF & 37.00 & 539.22 \\
\hline \multirow{31}{*}{2} & \multirow{31}{*}{$\begin{array}{l}\text { HLW-E- } \\
\text { SP-05 }\end{array}$} & \multirow{3}{*}{$10 / 7 / 08$} & ABL-G-5A & - & - & - \\
\hline & & & ABL-G-10A & XRF & 20.46 & 559.68 \\
\hline & & & ABL-G-11A & - & - & - \\
\hline & & \multirow{8}{*}{$10 / 8 / 08$} & ABL-G-12A & $\mathrm{XRF}$ & 16.80 & 576.48 \\
\hline & & & ABL-G-17A & - & - & - \\
\hline & & & ABL-G-17B & XRF & 17.28 & 593.76 \\
\hline & & & ABL-G-21A & - & - & - \\
\hline & & & ABL-G-22A & $\mathrm{XRF}$ & 18.90 & 612.66 \\
\hline & & & ABL-G-23A & - & - & - \\
\hline & & & ABL-G-23C & $\mathrm{XRF}$ & 24.44 & 637.10 \\
\hline & & & ABL-G-26A & - & - & - \\
\hline & & \multirow{11}{*}{$10 / 9 / 08$} & ABL-G-29A & - & - & - \\
\hline & & & ABL-G-30A & $\mathrm{XRF}$ & 22.20 & 659.30 \\
\hline & & & ABL-G-33A & - & - & - \\
\hline & & & ABL-G-34A & XRF & 20.94 & 680.24 \\
\hline & & & ABL-G-38A & - & - & - \\
\hline & & & ABL-G-38B & $\mathrm{XRF}$ & 19.24 & 699.48 \\
\hline & & & ABL-G-41A & - & - & - \\
\hline & & & ABL-G-41B & - & - & - \\
\hline & & & ABL-G-42A & $\mathrm{XRF}$ & 27.70 & 727.18 \\
\hline & & & ABL-G-43A & - & - & - \\
\hline & & & ABL-G-43B & - & - & - \\
\hline & & \multirow{6}{*}{$10 / 10 / 08$} & ABL-G-47A & XRF & 26.04 & 753.22 \\
\hline & & & ABL-G-48A & - & - & - \\
\hline & & & ABL-G-49A & XRF & 17.50 & 770.72 \\
\hline & & & ABL-G-49B & - & - & - \\
\hline & & & ABL-G-50A & XRF & 19.28 & 790.00 \\
\hline & & & ABL-G-54A & XRF,PCT.TCLP & 5.72 & 795.72 \\
\hline & & \multirow{3}{*}{$10 / 20 / 08$} & ABL-G-71A & XRF, SEM & 22.42 & 818.14 \\
\hline & & & ABL-G-71B & XRF & 33.04 & 851.18 \\
\hline & & & ABL-G-71C & XRF, SEM & 32.62 & 883.80 \\
\hline
\end{tabular}

"-" Empty data field 
Table 4.4. List of Glass Discharged, Masses, and Analysis Performed (continued).

\begin{tabular}{|c|c|c|c|c|c|c|}
\hline Test & Composition & Date & Name & Analysis & Mass (kg) & \begin{tabular}{|c|}
$\begin{array}{c}\text { Cumulative Mass } \\
\text { (kg) }\end{array}$ \\
\end{tabular} \\
\hline \multirow{40}{*}{3} & \multirow{40}{*}{$\begin{array}{c}\text { HLW-E- } \\
\text { M-03 }\end{array}$} & \multirow{7}{*}{$10 / 28 / 08$} & ABL-G-84A & - & - & - \\
\hline & & & ABL-G-86A & XRF, F & 21.72 & 905.52 \\
\hline & & & ABL-G-87A & - & - & - \\
\hline & & & ABL-G-87B & $\mathrm{XRF}$ & 27.62 & 933.14 \\
\hline & & & ABL-G-91A & - & - & - \\
\hline & & & ABL-G-91B & $\mathrm{XRF}$ & 27.04 & 960.18 \\
\hline & & & ABL-G-94A & - & - & - \\
\hline & & \multirow{9}{*}{$10 / 29 / 08$} & ABL-G-95A & XRF & 27.66 & 987.84 \\
\hline & & & ABL-G-95B & - & - & - \\
\hline & & & ABL-G-97A & XRF, F & 29.98 & 1017.82 \\
\hline & & & ABL-G-99A & - & - & - \\
\hline & & & ABL-G-102A & XRF & 31.02 & 1048.84 \\
\hline & & & ABL-G-103A & - & - & - \\
\hline & & & ABL-G-105A & XRF & 25.88 & 1074.72 \\
\hline & & & ABL-G-106A & - & - & - \\
\hline & & & ABL-G-106B & XRF, F & 23.78 & 1098.50 \\
\hline & & \multirow{13}{*}{$10 / 30 / 08$} & ABL-G-110A & - & - & - \\
\hline & & & ABL-G-111A & XRF & 24.20 & 1122.70 \\
\hline & & & ABL-G-112A & - & - & - \\
\hline & & & ABL-G-112B & XRF & 23.60 & 1146.30 \\
\hline & & & ABL-G-114A & - & - & - \\
\hline & & & ABL-G-114B & XRF, F & 29.24 & 1175.54 \\
\hline & & & ABL-G-115A & - & - & - \\
\hline & & & ABL-G-115B & XRF & 26.96 & 1202.50 \\
\hline & & & ABL-G-115C & - & - & - \\
\hline & & & ABL-G-119A & XRF & 25.32 & 1227.82 \\
\hline & & & ABL-G-120A & - & - & - \\
\hline & & & ABL-G-120B & XRF & 25.78 & 1253.60 \\
\hline & & & ABL-G-123A & - & - & - \\
\hline & & \multirow{7}{*}{$10 / 31 / 08$} & ABL-G-123B & XRF, F & 24.62 & 1278.22 \\
\hline & & & ABL-G-123C & - & - & - \\
\hline & & & ABL-G-125A & $\mathrm{XRF}$ & 22.46 & 1300.68 \\
\hline & & & ABL-G-125B & - & - & - \\
\hline & & & ABL-G-126A & XRF & 23.78 & 1324.46 \\
\hline & & & ABL-G-131A & XRF, F & 25.38 & 1349.84 \\
\hline & & & ABL-G-131B & XRF,SEM,PCT,TCLP & 28.62 & 1378.46 \\
\hline & & $11 / 1 / 08$ & ABL-G-140A & XRF & 7.42 & 1385.88 \\
\hline & & \multirow{3}{*}{$11 / 10 / 08$} & ABL-G-141A & XRF, SEM & 9.78 & 1395.66 \\
\hline & & & ABL-G-141B & XRF & 29.70 & 1425.36 \\
\hline & & & ABL-G-141C & XRF & 24.80 & 1450.16 \\
\hline
\end{tabular}

"-" Empty data field 
The Catholic University of America Vitreous State Laboratory
ORP-56294 Rev. 0

Effects of High Crystal Content in HLW DM100 Melter Tests

Final Report, VSL-09R1520-1, Rev. 0

Table 4.4. List of Glass Discharged, Masses, and Analysis Performed (continued).

\begin{tabular}{|c|c|c|c|c|c|c|}
\hline Test & Composition & Date & Name & Analysis & Mass (kg) & $\begin{array}{c}\text { Cumulative Mass } \\
\text { (kg) }\end{array}$ \\
\hline \multirow{39}{*}{4} & \multirow{39}{*}{$\begin{array}{c}\text { HLW-E-ES- } \\
05\end{array}$} & \multirow{7}{*}{$11 / 11 / 08$} & BBL-G-10A & $\mathrm{XRF}$ & 25.56 & 1475.72 \\
\hline & & & BBL-G-10B & - & - & - \\
\hline & & & BBL-G-12A & $\mathrm{XRF}$ & 26.76 & 1502.48 \\
\hline & & & BBL-G-13A & - & - & - \\
\hline & & & BBL-G-13B & $\mathrm{XRF}$ & 23.68 & 1526.16 \\
\hline & & & BBL-G-17A & - & - & - \\
\hline & & & BBL-G-17B & XRF & 23.80 & 1549.96 \\
\hline & & \multirow{12}{*}{$11 / 12 / 08$} & BBL-G-20A & - & - & - \\
\hline & & & BBL-G-20B & $\mathrm{XRF}$ & 20.92 & 1570.88 \\
\hline & & & BBL-G-22A & - & - & - \\
\hline & & & BBL-G-23A & $\mathrm{XRF}$ & 22.62 & 1593.50 \\
\hline & & & BBL-G-23B & - & - & - \\
\hline & & & BBL-G-23C & $\mathrm{XRF}$ & 21.46 & 1614.96 \\
\hline & & & BBL-G-25A & - & - & - \\
\hline & & & BBL-G-25B & XRF & 21.62 & 1636.58 \\
\hline & & & BBL-G-29A & - & - & - \\
\hline & & & BBL-G-30A & $\mathrm{XRF}$ & 24.08 & 1660.66 \\
\hline & & & BBL-G-30B & - & - & - \\
\hline & & & BBL-G-30C & $\mathrm{XRF}$ & 28.20 & 1688.86 \\
\hline & & \multirow{14}{*}{$11 / 13 / 08$} & BBL-G-34A & - & - & - \\
\hline & & & BBL-G-35A & $\mathrm{XRF}$ & 23.28 & 1712.14 \\
\hline & & & BBL-G-35B & - & - & - \\
\hline & & & BBL-G-35C & $\mathrm{XRF}$ & 17.06 & 1729.20 \\
\hline & & & BBL-G-35D & - & - & - \\
\hline & & & BBL-G-38A & XRF & 27.62 & 1756.82 \\
\hline & & & BBL-G-39A & - & - & - \\
\hline & & & BBL-G-39B & $\mathrm{XRF}$ & 32.46 & 1789.28 \\
\hline & & & BBL-G-42A & - & - & - \\
\hline & & & BBL-G-42B & $\mathrm{XRF}$ & 27.02 & 1816.30 \\
\hline & & & BBL-G-43A & - & - & - \\
\hline & & & BBL-G-43B & $\mathrm{XRF}$ & 24.26 & 1840.56 \\
\hline & & & BBL-G-45A & - & - & - \\
\hline & & & BBL-G-45B & $\mathrm{XRF}$ & 26.88 & 1867.44 \\
\hline & & \multirow{6}{*}{$11 / 14 / 08$} & BBL-G-47A & - & - & - \\
\hline & & & BBL-G-47B & $\mathrm{XRF}$ & 27.68 & 1895.12 \\
\hline & & & BBL-G-51A & - & - & - \\
\hline & & & BBL-G-51B & $\mathrm{XRF}$ & 28.76 & 1923.88 \\
\hline & & & BBL-G-53A & - & - & - \\
\hline & & & BBL-G-53B & XRF & 21.88 & 1945.76 \\
\hline
\end{tabular}

"-" Empty data field 
Table 4.4. List of Glass Discharged, Masses, and Analysis Performed (continued).

\begin{tabular}{|c|c|c|c|c|c|c|}
\hline Test & Formulation & Date & Name & Analysis & Mass (kg) & $\begin{array}{c}\text { Cumulative Mass } \\
\text { (kg) }\end{array}$ \\
\hline \multirow{6}{*}{4} & \multirow{6}{*}{$\begin{array}{c}\text { HLW-E-ES- } \\
05\end{array}$} & \multirow{2}{*}{$11 / 14 / 08$} & BBL-G-57A & XRF, SEM, PCT, TCLP & 19.50 & 1965.26 \\
\hline & & & BBL-G-60A & XRF & 4.86 & 1970.12 \\
\hline & & \multirow{4}{*}{$12 / 1 / 08$} & BBL-G-60B & XRF, SEM & 2.14 & 1972.26 \\
\hline & & & BBL-G-60C & XRF & 31.64 & 2003.90 \\
\hline & & & BBL-G-61A & $\mathrm{XRF}$ & 29.16 & 2033.06 \\
\hline & & & BBL-G-61B & $\mathrm{XRF}$ & 10.66 & 2043.72 \\
\hline \multirow{32}{*}{5} & \multirow{32}{*}{$\begin{array}{c}\text { HLW-E-M- } \\
09\end{array}$} & \multirow{2}{*}{$12 / 8 / 08$} & BBL-G-77A & - & - & - \\
\hline & & & BBL-G-80A & XRF, F & 26.86 & 2070.58 \\
\hline & & \multirow{9}{*}{$12 / 9 / 08$} & BBL-G-82A & - & - & - \\
\hline & & & BBL-G-83A & XRF & 19.28 & 2089.86 \\
\hline & & & BBL-G-86A & - & - & - \\
\hline & & & BBL-G-86B & XRF, F & 23.76 & 2113.62 \\
\hline & & & BBL-G-88A & - & - & - \\
\hline & & & BBL-G-88B & XRF & 27.72 & 2141.34 \\
\hline & & & BBL-G-89A & - & - & - \\
\hline & & & BBL-G-89B & XRF & 20.42 & 2161.76 \\
\hline & & & BBL-G-93A & - & - & - \\
\hline & & \multirow{15}{*}{$12 / 10 / 08$} & BBL-G-93B & XRF, F & 22.64 & 2184.40 \\
\hline & & & BBL-G-94A & - & - & - \\
\hline & & & BBL-G-94B & $\mathrm{XRF}$ & 19.52 & 2203.92 \\
\hline & & & BBL-G-95A & - & - & - \\
\hline & & & BBL-G-95B & $\mathrm{XRF}$ & 22.82 & 2226.74 \\
\hline & & & BBL-G-99A & - & - & - \\
\hline & & & BBL-G-101A & XRF, F & 25.14 & 2251.88 \\
\hline & & & BBL-G-101B & - & - & - \\
\hline & & & BBL-G-101C & $\mathrm{XRF}$ & 25.76 & 2277.64 \\
\hline & & & BBL-G-102A & - & - & - \\
\hline & & & BBL-G-103A & - & - & - \\
\hline & & & BBL-G-103B & $\mathrm{XRF}$ & 27.74 & 2305.38 \\
\hline & & & BBL-G-105A & - & - & - \\
\hline & & & BBL-G-105B & XRF, F & 24.34 & 2329.72 \\
\hline & & & BBL-G-105C & - & - & - \\
\hline & & \multirow{6}{*}{$12 / 11 / 08$} & BBL-G-108A & - & - & - \\
\hline & & & BBL-G-109A & XRF & 28.84 & 2358.56 \\
\hline & & & BBL-G-109B & - & - & - \\
\hline & & & BBL-G-111A & XRF & 20.42 & 2378.98 \\
\hline & & & BBL-G-111B & - & - & - \\
\hline & & & BBL-G-112A & XRF & 23.44 & 2402.42 \\
\hline
\end{tabular}

"-" Empty data field 
Table 4.4. List of Glass Discharged, Masses, and Analysis Performed (continued).

\begin{tabular}{|c|c|c|c|c|c|c|}
\hline Test & Formulation & Date & Name & Analysis & Mass (kg) & $\begin{array}{c}\text { Cumulative Mass } \\
\text { (kg) }\end{array}$ \\
\hline \multirow{12}{*}{5} & \multirow{12}{*}{$\begin{array}{c}\text { HLW-E-M- } \\
09\end{array}$} & \multirow{8}{*}{$12 / 11 / 08$} & BBL-G-112B & - & - & - \\
\hline & & & BBL-G-113A & XRF, F & 27.20 & 2429.62 \\
\hline & & & BBL-G-113B & - & - & - \\
\hline & & & BBL-G-117A & XRF & 17.90 & 2447.52 \\
\hline & & & BBL-G-117B & - & - & - \\
\hline & & & BBL-G-117C & $\mathrm{XRF}$ & 28.12 & 2475.64 \\
\hline & & & BBL-G-119A & - & - & - \\
\hline & & & BBL-G-120A & $\mathrm{XRF}$ & 38.72 & 2514.36 \\
\hline & & $12 / 12 / 08$ & BBL-G-124A & XRF, F, PCT, TCLP & 16.24 & 2530.60 \\
\hline & & \multirow{3}{*}{$12 / 19 / 08$} & BBL-G-130A & XRF, SEM & 2.60 & 2533.20 \\
\hline & & & BBL-G-130B & $\mathrm{XRF}$ & 34.24 & 2567.44 \\
\hline & & & BBL-G-130C & XRF & 43.22 & 2610.66 \\
\hline
\end{tabular}

"-" Empty data field 
Table 4.5. List of Dip and Discharge Glass Samples with Secondary Phase Observations.

\begin{tabular}{|c|c|c|c|c|c|c|c|}
\hline & Test Info & $\begin{array}{l}\text { Sampling } \\
\text { Date }\end{array}$ & $\begin{array}{c}\text { Sampling } \\
\text { time }\end{array}$ & Sample I.D. & $\begin{array}{c}\text { Sample } \\
\text { Location }\end{array}$ & SEM Observations & $\begin{array}{c}\text { Vol\% } \\
\text { Crystallinity }\end{array}$ \\
\hline \multirow{7}{*}{1} & Before Test & $9 / 15 / 08$ & $07: 16$ & BLZ-D-47A & Melt Pool & $\mathrm{SiO}_{2}, \mathrm{Fe}$ oxide, $\mathrm{Ca}-\mathrm{Al}$ oxide, $\mathrm{Zr}$-rich phase, and $\mathrm{Fe}-\mathrm{Cr}$ spinel & NA \\
\hline & End of Test & $9 / 19 / 08$ & $16: 23$ & BLZ-G-123A & Discharge & $\mathrm{Fe}, \mathrm{Ni}, \mathrm{Cr}, \mathrm{Mn}$ spinel and hematite platelets & 4.8 \\
\hline & End of Test & $9 / 20 / 08$ & 02:54 & BLZ-D-129A & Melt Pool & $\mathrm{Fe}, \mathrm{Ni}, \mathrm{Cr}, \mathrm{Mn}$ spinel, hematite platelets & 2.6 \\
\hline & Idled $80 \mathrm{~h}$ & $9 / 23 / 08$ & 11:00 & BLZ-D-130A & Riser & $\mathrm{Fe}, \mathrm{Ni}, \mathrm{Cr}, \mathrm{Mn}$ spinel, hematite platelets, sulfate $(\mathrm{K}, \mathrm{Cr})$ deposits & 2.9 \\
\hline & Idled $278 \mathrm{~h}$ & $10 / 1 / 08$ & $16: 55$ & BLZ-D-130B & Riser & $\mathrm{Fe}, \mathrm{Ni}, \mathrm{Cr}, \mathrm{Mn}$ spinel, hematite platelets & 5.4 \\
\hline & Idled $302 \mathrm{~h}$ & $10 / 2 / 08$ & $17: 21$ & BLZ-G-131A & Discharge & Hematite platelets, Fe, Ni, Cr, Mn spinel (Fig. 4.3a, b) & 2.3 \\
\hline & Idled $303 \mathrm{~h}$ & $10 / 2 / 08$ & $18: 20$ & BLZ-D-131A & Melt Pool & $\begin{array}{c}\mathrm{Fe}, \mathrm{Ni}, \mathrm{Mn}, \mathrm{Cr} \text { spinel, hematite platelets, sulfate }(\mathrm{K}, \mathrm{Na}, \mathrm{Cr} \text {, } \\
\text { trace } \mathrm{Bi} \text { ) deposits (Fig. } 4.4 \mathrm{a}, \mathrm{b})\end{array}$ & 3.9 \\
\hline \multirow{10}{*}{2} & Before Test & \multirow{2}{*}{$10 / 6 / 08$} & $07: 24$ & BLZ-D-131B & Riser & $\mathrm{Fe}, \mathrm{Ni}, \mathrm{Cr}, \mathrm{Mn}$ spinel, hematite platelets & 2.2 \\
\hline & Before Test & & 09:00 & BLZ-D-131C & Melt Pool & $90 \% \mathrm{Fe}, \mathrm{Ni}, \mathrm{Cr}, \mathrm{Mn}$ spinel, hematite platelets & 2.7 \\
\hline & End of Test & $10 / 10 / 08$ & $15: 01$ & ABL-G-54A & Discharge & Hematite platelets, $<5 \% \mathrm{Fe}, \mathrm{N}, \mathrm{Cr}, \mathrm{Mn}$ spinel & 3.7 \\
\hline & End of Test & $10 / 11 / 08$ & 02:10 & ABL-D-57A & Melt Pool & $\mathrm{Fe}, \mathrm{Ni}, \mathrm{Cr}, \mathrm{Mn}$ spinel, hematite platelets & 3.9 \\
\hline & Idled $80 \mathrm{~h}$ & $10 / 14 / 08$ & 09:40 & ABL-D-63A & Riser & $85 \% \mathrm{Fe}, \mathrm{Ni}, \mathrm{Mn}, \mathrm{Cr}$ spinel, hematite platelets & 9.4 \\
\hline & Idled $222 \mathrm{~h}$ & \multirow{4}{*}{$10 / 20 / 08$} & 07:50 & ABL-D-63B & Riser & Fe, Ni, Mn, Cr spinel, hematite platelets (Fig 4.5a, b) & 8.7 \\
\hline & Idled $230 \mathrm{~h}$ & & $16: 30$ & ABL-G-71A & Discharge & $90 \%$ hematite platelets, Fe, Ni, Cr, Mn spinel, (Fig. 4.6a, b) & 11.5 \\
\hline & Idled $230 \mathrm{~h}$ & & $16: 39$ & ABL-G-71B & Discharge & 85-90\% hematite platelets, $\mathrm{Fe}, \mathrm{Ni}, \mathrm{Cr}, \mathrm{Mn}$ spinel, & 6.9 \\
\hline & Idled $232 \mathrm{~h}$ & & 18:15 & ABL-G-71C & Discharge & $85-90 \%$ hematite platelets, $\mathrm{Fe}, \mathrm{Ni}, \mathrm{Cr}$ spinel & 8.5 \\
\hline & Idled $272 \mathrm{~h}$ & $10 / 22 / 08$ & $10: 35$ & ABL-D-71A & Melt Pool & Hematite platelets, $\mathrm{Fe}, \mathrm{Ni}, \mathrm{Cr}, \mathrm{Mn}$ spinel, and a few sodalite & 4.8 \\
\hline \multirow{8}{*}{3} & Before Test & \multirow{2}{*}{$10 / 27 / 08$} & 06:34 & ABL-D-71B & Riser & $95 \%$ hematite platelets, $\mathrm{Fe}, \mathrm{Ni}, \mathrm{Cr}, \mathrm{Mn}$ spinel, & 6.0 \\
\hline & Before Test & & $06: 50$ & ABL-D-74A & Melt Pool & 70-90\% Fe, Ni, Cr, Mn spinel, hematite platelets & 1.0 \\
\hline & End of Test & \multirow{2}{*}{$10 / 31 / 08$} & $13: 45$ & ABL-G-131B & Discharge & $\mathrm{Cr}, \mathrm{Fe}, \mathrm{Ni}, \mathrm{Mn}$ spinel & 2.8 \\
\hline & End of Test & & $20: 30$ & ABL-D-134A & Melt Pool & $\mathrm{Cr}, \mathrm{Fe}, \mathrm{Ni}, \mathrm{Mn}$ spinel & 2.7 \\
\hline & Idled $60 \mathrm{~h}$ & $11 / 3 / 08$ & $07: 35$ & ABL-D-140A & Riser & $\mathrm{Cr}, \mathrm{Fe}, \mathrm{Ni}, \mathrm{Mn}$ spinel (Fig 4.7a, b) & 2.9 \\
\hline & Idled $228 \mathrm{~h}$ & \multirow{3}{*}{$11 / 10 / 08$} & $06: 45$ & ABL-D-140B & Riser & $\mathrm{Cr}, \mathrm{Fe}, \mathrm{Ni}, \mathrm{Mn}$ spinel & 3.0 \\
\hline & Idled $228 \mathrm{~h}$ & & 07:05 & ABL-D-140C & Melt Pool & $\mathrm{Cr}, \mathrm{Fe}, \mathrm{Ni}, \mathrm{Mn}$ spinel & 3.4 \\
\hline & Idled $231 \mathrm{~h}$ & & $10: 11$ & ABL-G-141B & Discharge & $\mathrm{Cr}, \mathrm{Fe}, \mathrm{Ni}$ spinel (Fig. 4.8a, b) & 2.6 \\
\hline
\end{tabular}


Table 4.5. List of Dip and Discharge Glass Samples with Secondary Phase Observations (continued).

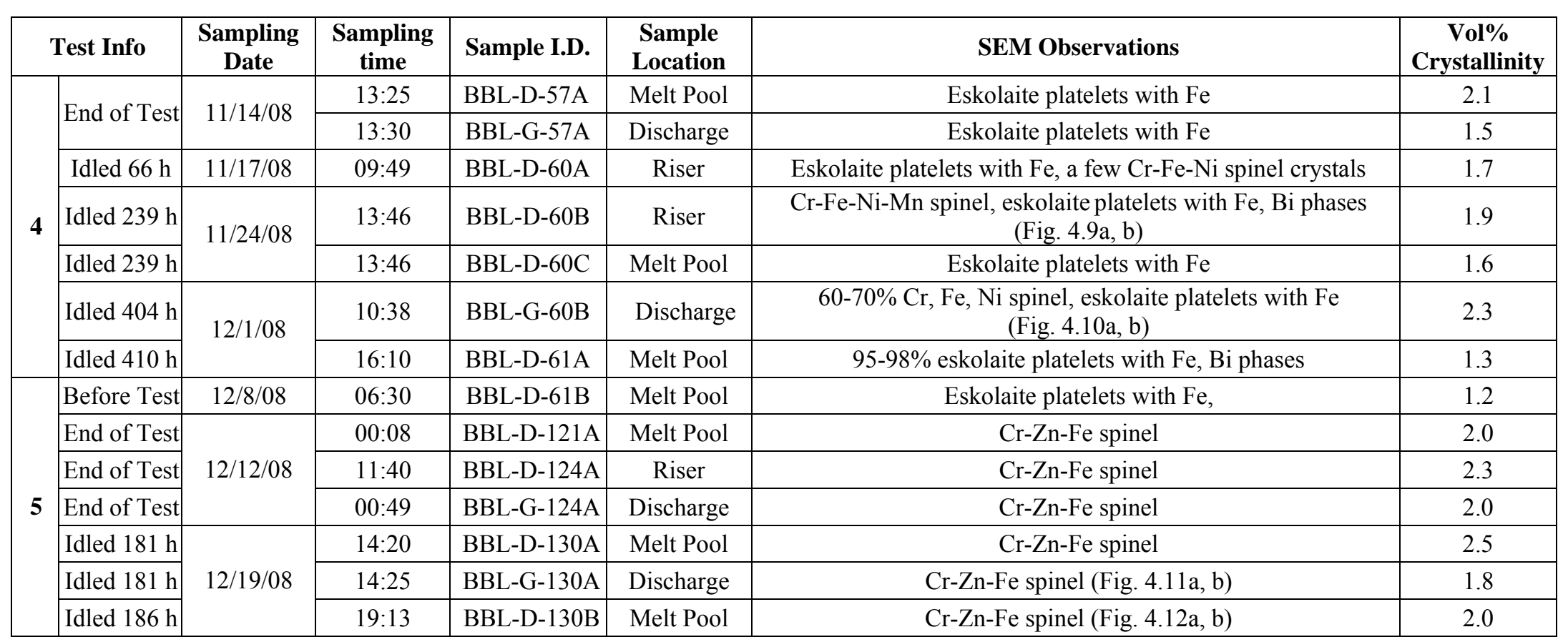


The Catholic University of America

Vitreous State Laboratory
ORP-56294 Rev. 0

Effects of High Crystal Content in HLW DM100 Melter Tests

Final Report, VSL-09R1520-1, Rev. 0

\section{Table 4.6. List of Boat, Suction and Cold Cap Glass Samples with Secondary Phase Observations.}

\begin{tabular}{|c|c|c|c|c|c|c|}
\hline \multicolumn{2}{|c|}{ Test } & $\begin{array}{l}\text { Sample Type } \\
\text { Boat 1" from } \\
\text { bottom }\end{array}$ & $\begin{array}{c}\text { Sampling } \\
\text { Date/Time } \\
\\
9 / 20 / 08 \\
2: 24\end{array}$ & $\begin{array}{l}\text { Sample I.D. } \\
\text { BLZ-O-130A }\end{array}$ & \begin{tabular}{c|} 
Visual \\
Observations \\
$\begin{array}{c}\text { External yellow } \\
\text { phase present }\end{array}$
\end{tabular} & \begin{tabular}{|c|} 
SEM Observations \\
Sample contains regions from 8 to $36 \mathrm{vol} \% \mathrm{Fe}, \mathrm{Ni}, \mathrm{Cr}$ and \\
Fe, Cr, Ni spinels. Average total crystal content about \\
$26 \mathrm{vol} \%$. Potassium sulfate external yellow phase. \\
(Fig. $4.13 \mathrm{a}, \mathrm{b})$ \\
\end{tabular} \\
\hline \multirow{3}{*}{1} & $\begin{array}{c}\text { During } \\
\text { Idling }\end{array}$ & $\begin{array}{l}\text { Sample of } \\
\text { frozen glass } \\
\text { surface }\end{array}$ & $\begin{array}{c}9 / 22 / 08 \\
14: 45\end{array}$ & BLZ-O-130B & - & $\begin{array}{c}\text { Sample contains regions from } 4 \text { to } 8 \text { vol } \% \mathrm{Fe}, \mathrm{Ni}, \mathrm{Cr} \text { and } \\
\mathrm{Fe}, \mathrm{Cr} \text {, Ni spinels. Average total crystal content about } \\
6 \text { vol } \% .\end{array}$ \\
\hline & $\begin{array}{l}\text { After } \\
\text { Idling }\end{array}$ & $\begin{array}{l}\text { Boat } 13 " \text { from } \\
\text { bottom }\end{array}$ & 10/2/08 14:05 & BLZ-O-131B & $\begin{array}{l}\text { External yellow } \\
\text { phase present }\end{array}$ & \begin{tabular}{|} 
Sample contains regions from 10 to 21 vol\% Fe, Ni, Cr \\
and $\mathrm{Fe}, \mathrm{Cr}, \mathrm{Ni}$ spinels. Average total crystal content about \\
18 vol\%. (Fig. $4.14 \mathrm{a}, \mathrm{b}, \mathrm{c}, \mathrm{d}$ )
\end{tabular} \\
\hline & $\begin{array}{l}\text { After } \\
\text { Idling }\end{array}$ & $\begin{array}{l}\text { Boat 1" from } \\
\text { bottom }\end{array}$ & 10/2/08 14:05 & BLZ-O-131A & $\begin{array}{l}\text { External yellow } \\
\text { phase present } \\
\text { Half of bottom of } \\
\text { boat gone }\end{array}$ & $\begin{array}{l}\text { Crystals in sample about half sodalite and spinels with } \\
\text { trace amounts of Fe oxide platelets, zircon, and apatite. } \\
\text { No apparent gradation of crystals in the sample. Average } \\
\text { total crystal content about } 13 \text { vol\%. (Fig. } 4.15 \mathrm{a}, \mathrm{b})\end{array}$ \\
\hline \multirow{4}{*}{2} & $\begin{array}{c}\text { During } \\
\text { Test } \\
\end{array}$ & $\begin{array}{c}\text { Cold cap } \\
\text { sample }\end{array}$ & $\begin{array}{c}10 / 10 / 08 \\
17: 45 \\
\end{array}$ & ABL-O-55A & Multiple phases & $10-15$ vol $\% \mathrm{Fe}, \mathrm{Ni}, \mathrm{Cr}, \mathrm{Mn}$ spinels. \\
\hline & $\begin{array}{c}\text { During } \\
\text { Test }\end{array}$ & $\begin{array}{l}\text { Boat 1" from } \\
\text { bottom }\end{array}$ & $\begin{array}{c}10 / 11 / 08 \\
02: 17\end{array}$ & ABL-O-57B & $\begin{array}{l}\text { External yellow } \\
\text { phase present }\end{array}$ & $\begin{array}{c}\text { Sample contains regions with } 0 \text { to } 27 \mathrm{vol} \% \mathrm{Fe}, \mathrm{Ni}, \mathrm{Cr} \\
\text { and } \mathrm{Fe}, \mathrm{Ni}, \mathrm{Cr} \text { spinels. Concentration of spinels decreases } \\
\text { with distance from the boat wall. Average total crystal } \\
\text { content about } 15 \mathrm{vol} \% \text {. }\end{array}$ \\
\hline & $\begin{array}{l}\text { After } \\
\text { Idling }\end{array}$ & $\begin{array}{l}\text { Boat 1" from } \\
\text { bottom }\end{array}$ & $\begin{array}{c}10 / 22 / 08 \\
10: 30\end{array}$ & ABL-O-71A & $\begin{array}{c}\text { External yellow } \\
\text { phase present } \\
\text { Half bottom of boat } \\
\text { gone }\end{array}$ & \begin{tabular}{|} 
Sample contains nodule-like regions with 3 to 29 vol\% \\
Fe, Ni, Cr and Fe, Ni, Cr spinels and hematite platelets. \\
Concentration of spinels decreases with distance from the \\
boat bottom. Average total crystal content about 20 vol\%. \\
(Fig. $4.16 \mathrm{a}, \mathrm{b}, \mathrm{c}$ )
\end{tabular} \\
\hline & $\begin{array}{l}\text { After } \\
\text { Idling }\end{array}$ & $\begin{array}{l}\text { Boat } 13 " \text { from } \\
\text { bottom }\end{array}$ & $\begin{array}{c}10 / 22 / 08 \\
10: 30\end{array}$ & ABL-O-71B & $\begin{array}{l}\text { External yellow } \\
\text { phase present }\end{array}$ & \begin{tabular}{|} 
Sample contains regions with 5 to 26 vol\% Fe, Ni, Cr \\
spinels with lesser zirconia and hematite platelets. \\
Concentration of spinels decreases with distance from \\
the boat bottom. Average total crystal content about \\
17 vol \%. (Fig. $4.17 \mathrm{a}, \mathrm{b}$ ) \\
\end{tabular} \\
\hline \multirow{3}{*}{3} & $\begin{array}{c}\text { During } \\
\text { Test } \\
\end{array}$ & $\begin{array}{l}\text { Boat 1" from } \\
\text { bottom }\end{array}$ & $\begin{array}{l}10 / 31 / 08 \\
20: 51 \\
\end{array}$ & - & Entire boat is gone & NA \\
\hline & $\begin{array}{l}\text { After } \\
\text { Idling }\end{array}$ & $\begin{array}{l}\text { Boat } 13 " \text { from } \\
\text { bottom }\end{array}$ & $\begin{array}{c}11 / 10 / 08 \\
7: 00\end{array}$ & ABL-O-141A & $\begin{array}{l}\text { Hole in boat } \\
\text { bottom }\end{array}$ & $\begin{array}{c}\text { Boat metal near hole depleted in Cr and Fe. Crystal } \\
\text { content of remaining glass has } 2.8 \text { to } 7.2 \text { vol\% crystals of } \\
\text { chromium oxide and spinels with lesser amounts of } \mathrm{Cr} \\
\text { sulfide. Average total crystal content about } 5 \text { vol\%. } \\
\text { (Fig. } 4.18 \text { ) }\end{array}$ \\
\hline & $\begin{array}{l}\text { After } \\
\text { Idling }\end{array}$ & $\begin{array}{l}\text { Boat 1" from } \\
\text { bottom }\end{array}$ & $\begin{array}{c}11 / 10 / 08 \\
7: 00\end{array}$ & ABL-O-141B & $\begin{array}{l}\text { Bottom of boat } \\
\text { gone }\end{array}$ & $\begin{array}{c}\text { Varies from } 12 \text { to } 3 \% \text { chromium oxide crystals from near } \\
\text { the bottom towards the top of the sampling boat. One } \\
\text { small Ni sulfide nodule. Average total crystal content } \\
\text { about } 7 \% \text {. (Fig. } 4.19 \mathrm{a}, \mathrm{b} \text { ) }\end{array}$ \\
\hline
\end{tabular}




\section{Table 4.6. List of Boat, Suction and Cold Cap Glass Samples with Secondary Phase Observations} (continued).

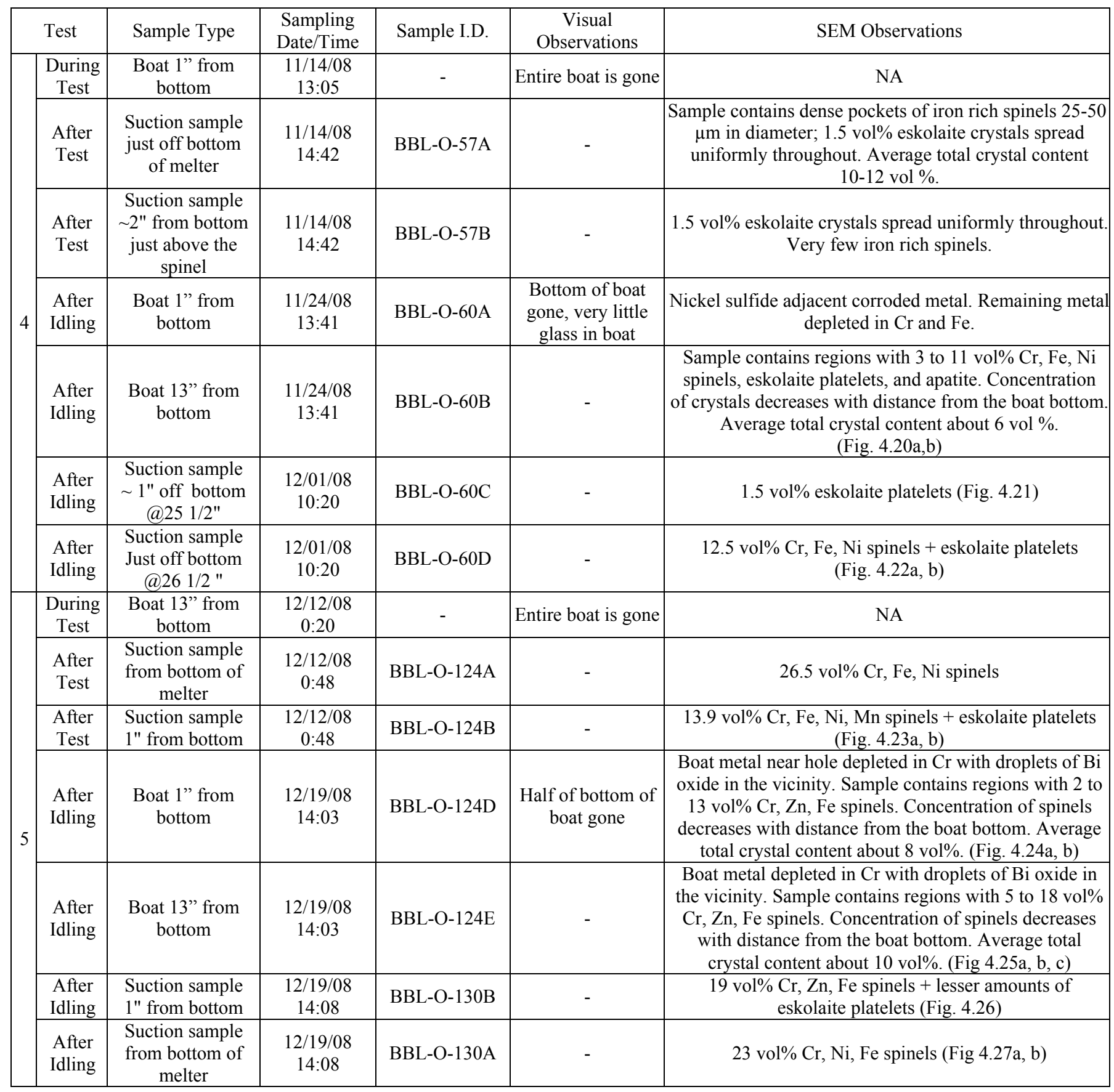


Table 4.7. XRF Analyzed Composition for Glass Discharged During DM100 Tests (wt\%).

\begin{tabular}{|c|c|c|c|c|c|c|c|c|c|c|c|c|c|c|c|c|}
\hline Test & \multicolumn{16}{|c|}{1 (HLW-E-SP-06) } \\
\hline Glass (kg) & \multirow[b]{2}{*}{ Target } & 22.82 & 42.16 & 70.46 & 96.06 & 115.96 & 136.24 & 155.00 & 174.20 & 196.52 & 216.22 & 243.12 & 266.02 & 285.04 & 311.66 & 336.42 \\
\hline Constituent & & $\begin{array}{c}\text { BLZ-G- } \\
67 \mathrm{~A}\end{array}$ & $\begin{array}{c}\text { BLZ-G- } \\
72 \mathrm{~A}\end{array}$ & $\begin{array}{c}\text { BLZ-G- } \\
75 \mathrm{~A}\end{array}$ & $\begin{array}{c}\text { BLZ-G- } \\
80 \mathrm{~A}\end{array}$ & $\begin{array}{c}\text { BLZ-G- } \\
82 B\end{array}$ & $\begin{array}{c}\text { BLZ-G- } \\
88 \mathrm{~A}\end{array}$ & $\begin{array}{c}\text { BLZ-G- } \\
90 \mathrm{~A}\end{array}$ & \begin{tabular}{|c|} 
BLZ-G- \\
$91 \mathrm{~B}$
\end{tabular} & $\begin{array}{c}\text { BLZ-G- } \\
97 \mathrm{~A}\end{array}$ & $\begin{array}{c}\text { BLZ-G- } \\
98 \mathrm{~B}\end{array}$ & $\begin{array}{c}\text { BLZ-G- } \\
\text { 99B }\end{array}$ & $\begin{array}{c}\text { BLZ-G- } \\
101 \mathrm{~B}\end{array}$ & $\begin{array}{c}\text { BLZ-G- } \\
104 B\end{array}$ & $\begin{array}{c}\text { BLZ-G- } \\
105 \mathrm{~A}\end{array}$ & $\begin{array}{c}\text { BLZ-G- } \\
108 \mathrm{~A}\end{array}$ \\
\hline $\mathrm{Al}_{2} \mathrm{O}_{3}$ & 8.91 & 16.79 & 15.79 & 14.63 & 13.94 & 13.61 & 12.90 & 12.71 & 12.25 & 11.92 & 11.72 & 11.43 & 11.15 & 11.02 & 10.60 & 10.41 \\
\hline $\mathrm{B}_{2} \mathrm{O}_{3}{ }^{*}$ & 13.30 & 14.82 & 14.50 & 14.33 & 14.19 & 14.10 & 14.01 & 13.94 & 13.88 & 13.81 & 13.76 & 13.69 & 13.65 & 13.61 & 13.57 & 13.53 \\
\hline $\mathrm{BaO}$ & $\S$ & 0.03 & 0.03 & 0.03 & 0.02 & 0.02 & 0.02 & 0.02 & 0.01 & 0.01 & 0.01 & 0.00 & 0.01 & $<.01$ & 0.01 & 0.01 \\
\hline $\mathrm{Bi}_{2} \mathrm{O}_{3}$ & $\S$ & 0.63 & 0.54 & 0.47 & 0.37 & 0.34 & 0.27 & 0.25 & 0.23 & 0.21 & 0.18 & 0.17 & 0.15 & 0.13 & 0.10 & 0.10 \\
\hline $\mathrm{CaO}$ & 0.37 & 3.26 & 2.88 & 2.51 & 2.18 & 1.99 & 1.75 & 1.64 & 1.52 & 1.39 & 1.28 & 1.22 & 1.10 & 1.06 & 0.95 & 0.91 \\
\hline $\mathrm{CdO}$ & 0.18 & 0.09 & 0.09 & 0.12 & 0.12 & 0.12 & 0.12 & 0.11 & 0.12 & 0.13 & 0.13 & 0.15 & 0.14 & 0.14 & 0.14 & 0.15 \\
\hline $\mathrm{Cr}_{2} \mathrm{O}_{3}$ & 0.15 & 0.30 & 0.27 & 0.27 & 0.22 & 0.21 & 0.20 & 0.20 & 0.19 & 0.18 & 0.18 & 0.19 & 0.21 & 0.21 & 0.20 & 0.20 \\
\hline $\mathrm{Cs}_{2} \mathrm{O}$ & 0.08 & 0.05 & 0.05 & 0.07 & 0.07 & 0.06 & 0.07 & 0.06 & 0.07 & 0.07 & 0.08 & 0.08 & 0.08 & 0.08 & 0.09 & 0.08 \\
\hline $\mathrm{Fe}_{2} \mathrm{O}_{3}$ & 20.01 & 12.09 & 13.09 & 14.38 & 14.54 & 14.62 & 15.29 & 15.41 & 15.74 & 15.98 & 16.15 & 16.49 & 16.66 & 17.07 & 17.26 & 17.75 \\
\hline $\mathrm{K}_{2} \mathrm{O}$ & 7.00 & 3.17 & 3.62 & 4.18 & 4.45 & 4.59 & 4.89 & 4.96 & 5.04 & 5.17 & 5.34 & 5.42 & 5.48 & 5.59 & 5.79 & 5.88 \\
\hline $\mathrm{La}_{2} \mathrm{O}_{3}$ & 0.60 & 0.28 & 0.31 & 0.35 & 0.36 & 0.39 & 0.43 & 0.43 & 0.44 & 0.45 & 0.44 & 0.46 & 0.48 & 0.48 & 0.50 & 0.52 \\
\hline $\mathrm{Li}_{2} \mathrm{O}^{*}$ & 1.17 & 2.44 & 2.17 & 2.03 & 1.91 & 1.84 & 1.76 & 1.71 & 1.65 & 1.60 & 1.55 & 1.50 & 1.46 & 1.43 & 1.40 & 1.37 \\
\hline $\mathrm{MgO}$ & 0.11 & 0.25 & 0.25 & 0.24 & 0.21 & 0.26 & 0.23 & 0.25 & 0.21 & 0.21 & 0.14 & 0.20 & 0.20 & 0.17 & 0.19 & 0.19 \\
\hline $\mathrm{MnO}$ & 0.57 & 0.34 & 0.35 & 0.39 & 0.40 & 0.40 & 0.42 & 0.42 & 0.43 & 0.43 & 0.44 & 0.46 & 0.45 & 0.47 & 0.47 & 0.49 \\
\hline $\mathrm{Na}_{2} \mathrm{O}$ & 10.19 & 10.18 & 10.07 & 9.17 & 10.05 & 9.79 & 9.58 & 10.05 & 10.50 & 10.68 & 10.34 & 10.27 & 10.38 & 10.24 & 10.06 & 10.03 \\
\hline $\mathrm{Nd}_{2} \mathrm{O}_{3}$ & 0.26 & 0.13 & 0.16 & 0.18 & 0.19 & 0.20 & 0.22 & 0.22 & 0.22 & 0.23 & 0.24 & 0.25 & 0.24 & 0.25 & 0.26 & 0.26 \\
\hline $\mathrm{NiO}$ & 0.71 & 0.35 & 0.35 & 0.37 & 0.35 & 0.36 & 0.36 & 0.36 & 0.37 & 0.37 & 0.37 & 0.39 & 0.40 & 0.40 & 0.40 & 0.42 \\
\hline $\mathrm{P}_{2} \mathrm{O}_{5}$ & 0.04 & 0.55 & 0.49 & 0.41 & 0.38 & 0.36 & 0.31 & 0.30 & 0.26 & 0.23 & 0.23 & 0.21 & 0.19 & 0.18 & 0.16 & 0.15 \\
\hline $\mathrm{PbO}$ & 0.11 & 0.23 & 0.21 & 0.19 & 0.16 & 0.15 & 0.15 & 0.14 & 0.13 & 0.12 & 0.12 & 0.12 & 0.11 & 0.11 & 0.11 & 0.10 \\
\hline $\mathrm{SiO}_{2}$ & 33.31 & 32.14 & 32.78 & 33.39 & 33.61 & 34.35 & 34.69 & 34.46 & 34.29 & 34.36 & 34.82 & 34.80 & 34.96 & 34.74 & 35.11 & 34.73 \\
\hline $\mathrm{SO}_{3}$ & 0.07 & 0.10 & 0.10 & 0.11 & 0.11 & 0.11 & 0.12 & 0.12 & 0.12 & 0.12 & 0.12 & 0.11 & 0.11 & 0.11 & 0.11 & 0.10 \\
\hline $\mathrm{TiO}_{2}$ & $\S$ & 0.07 & 0.07 & 0.07 & 0.07 & 0.07 & 0.07 & 0.07 & 0.07 & 0.08 & 0.07 & 0.08 & 0.08 & 0.08 & 0.07 & 0.08 \\
\hline $\mathrm{ZnO}$ & 0.02 & 0.09 & 0.08 & 0.08 & 0.06 & 0.06 & 0.06 & 0.06 & 0.06 & 0.05 & 0.05 & 0.05 & 0.05 & 0.05 & 0.05 & 0.05 \\
\hline $\mathrm{ZrO}_{2}$ & 2.83 & 1.65 & 1.76 & 2.03 & 2.02 & 2.02 & 2.09 & 2.10 & 2.18 & 2.21 & 2.24 & 2.27 & 2.28 & 2.38 & 2.40 & 2.48 \\
\hline Sum & 100.00 & 100.00 & 100.00 & 100.00 & 100.00 & 100.00 & 100.00 & 100.00 & 100.00 & 100.00 & 100.00 & 100.00 & 100.00 & 100.00 & 100.00 & 100.00 \\
\hline
\end{tabular}

$\S$ - Not a target constituent; * - Target values calculated using simple well-stirred tank model based on the DCP results of the first discharge 
ORP-56294 Rev. 0

Table 4.7. XRF Analyzed Composition for Glass Discharged During DM100 Tests (wt\%) (continued).

\begin{tabular}{|c|c|c|c|c|c|c|c|c|c|c|c|c|c|c|c|c|}
\hline Test & \multicolumn{11}{|c|}{1 (HLW-E-SP-06) } & \multicolumn{5}{|c|}{2 (HLW-E-SP-05) } \\
\hline Glass (kg) & \multirow[b]{2}{*}{ Target } & 359.88 & 381.54 & 405.12 & 426.82 & 450.70 & 473.16 & 478.10 & 502.22 & 539.22 & \multirow{2}{*}{$\begin{array}{c}\% \text { Dev } \\
\text { from } \\
\text { Target\$ }\end{array}$} & \multirow[b]{2}{*}{ Target } & 559.68 & 576.48 & 593.76 & 612.66 \\
\hline Constituent & & $\begin{array}{c}\text { BLZ-G- } \\
111 \mathrm{~B}\end{array}$ & $\begin{array}{c}\text { BLZ-G- } \\
114 \mathrm{~B}\end{array}$ & $\begin{array}{c}\text { BLZ-G- } \\
117 \mathrm{~A}\end{array}$ & $\begin{array}{c}\text { BLZ-G- } \\
117 \mathrm{C}\end{array}$ & $\begin{array}{c}\text { BLZ-G- } \\
120 \mathrm{~B}\end{array}$ & $\begin{array}{c}\text { BLZ-G- } \\
123 \mathrm{~A}\end{array}$ & $\begin{array}{c}\text { BLZ-G- } \\
129 A\end{array}$ & $\begin{array}{c}\text { BLZ-G- } \\
131 \mathrm{~A}\end{array}$ & $\begin{array}{c}\text { BLZ-G- } \\
131 \mathrm{~B}\end{array}$ & & & $\begin{array}{c}\text { ABL-G- } \\
10 \mathrm{~A}\end{array}$ & $\begin{array}{c}\text { ABL-G- } \\
12 \mathrm{~A}\end{array}$ & $\begin{array}{c}\text { ABL-G- } \\
17 \mathrm{~B}\end{array}$ & $\begin{array}{c}\text { ABL-G- } \\
22 \mathrm{~A}\end{array}$ \\
\hline $\mathrm{Al}_{2} \mathrm{O}_{3}$ & 8.91 & 10.40 & 10.16 & 10.16 & 9.95 & 9.78 & 9.56 & 9.79 & 10.26 & 10.53 & \begin{tabular}{|l|}
7.20 \\
\end{tabular} & 9.49 & 10.83 & 10.28 & 10.25 & 10.04 \\
\hline $\mathrm{B}_{2} \mathrm{O}_{3}{ }^{*}$ & 13.30 & 13.51 & 13.48 & 13.46 & 13.44 & 13.42 & 13.41 & 13.41 & 13.41 & 13.41 & 0.83 & 12.08 & 13.27 & 13.16 & 13.06 & 12.96 \\
\hline $\mathrm{BaO}$ & $\S$ & $<0.01$ & 0.01 & $<0.01$ & $<0.01$ & $<0.01$ & 0.01 & 0.01 & 0.01 & 0.01 & $\mathrm{NC}$ & $\S$ & $<0.01$ & 0.01 & 0.01 & $<0.01$ \\
\hline $\mathrm{Bi}_{2} \mathrm{O}_{3}$ & $\S$ & 0.09 & 0.08 & 0.07 & 0.06 & 0.05 & 0.05 & 0.05 & 0.09 & 0.10 & $\mathrm{NC}$ & $\S$ & 0.08 & 0.06 & 0.05 & 0.04 \\
\hline $\mathrm{CaO}$ & 0.37 & 0.87 & 0.80 & 0.78 & 0.74 & 0.69 & 0.67 & 0.70 & 0.84 & 0.86 & $\mathrm{NC}$ & 0.40 & 0.80 & 0.71 & 0.66 & 0.64 \\
\hline $\mathrm{CdO}$ & 0.18 & 0.16 & 0.16 & 0.14 & 0.16 & 0.14 & 0.16 & 0.15 & 0.15 & 0.15 & $\mathrm{NC}$ & 0.19 & 0.14 & 0.16 & 0.15 & 0.17 \\
\hline $\mathrm{Cr}_{2} \mathrm{O}_{3}$ & 0.15 & 0.20 & 0.18 & 0.18 & 0.18 & 0.18 & 0.18 & 0.16 & 0.22 & 0.21 & $\mathrm{NC}$ & 0.15 & 0.19 & 0.18 & 0.17 & 0.18 \\
\hline $\mathrm{Cs}_{2} \mathrm{O}$ & 0.08 & 0.09 & 0.10 & 0.08 & 0.09 & 0.07 & 0.09 & 0.09 & 0.08 & 0.08 & $\mathrm{NC}$ & 0.08 & 0.09 & 0.08 & 0.08 & 0.07 \\
\hline $\mathrm{Fe}_{2} \mathrm{O}_{3}$ & 20.01 & 17.51 & 17.97 & 17.60 & 18.27 & 18.22 & 18.81 & 18.20 & 17.75 & 17.17 & -5.98 & 21.30 & 16.67 & 17.94 & 18.05 & 18.64 \\
\hline $\mathrm{K}_{2} \mathrm{O}$ & 7.00 & 5.84 & 5.91 & 5.96 & 6.11 & 6.06 & 6.15 & 6.13 & 5.90 & 5.78 & -12.23 & 7.01 & 5.73 & 5.98 & 6.07 & 6.21 \\
\hline $\mathrm{La}_{2} \mathrm{O}_{3}$ & 0.60 & 0.53 & 0.50 & 0.52 & 0.54 & 0.54 & 0.55 & 0.56 & 0.54 & 0.52 & $\mathrm{NC}$ & 0.64 & 0.45 & 0.43 & 0.43 & 0.43 \\
\hline $\mathrm{Li}_{2} \mathrm{O}^{*}$ & 1.17 & 1.34 & 1.32 & 1.31 & 1.29 & 1.28 & 1.26 & 1.26 & 1.26 & 1.26 & 7.77 & 1.10 & 1.25 & 1.23 & 1.22 & 1.21 \\
\hline $\mathrm{MgO}$ & 0.11 & 0.17 & 0.22 & 0.16 & 0.22 & 0.18 & 0.18 & 0.18 & 0.21 & 0.22 & $\mathrm{NC}$ & 0.12 & 0.19 & 0.17 & 0.13 & 0.17 \\
\hline $\mathrm{MnO}$ & 0.57 & 0.48 & 0.49 & 0.48 & 0.51 & 0.50 & 0.52 & 0.52 & 0.55 & 0.54 & $\mathrm{NC}$ & 0.61 & 0.52 & 0.53 & 0.54 & 0.54 \\
\hline $\mathrm{Na}_{2} \mathrm{O}$ & 10.19 & 10.37 & 10.05 & 10.12 & 9.71 & 10.40 & 10.07 & 9.93 & 10.08 & 10.20 & -1.24 & 9.07 & 10.56 & 10.19 & 10.25 & 9.94 \\
\hline $\mathrm{Nd}_{2} \mathrm{O}_{3}$ & 0.26 & 0.26 & 0.26 & 0.28 & 0.28 & 0.27 & 0.28 & 0.28 & 0.26 & 0.26 & $\mathrm{NC}$ & 0.28 & 0.26 & 0.28 & 0.29 & 0.30 \\
\hline $\mathrm{NiO}$ & 0.71 & 0.41 & 0.42 & 0.40 & 0.43 & 0.42 & 0.44 & 0.39 & 0.39 & 0.37 & $\mathrm{NC}$ & 0.76 & 0.29 & 0.31 & 0.30 & 0.33 \\
\hline $\mathrm{P}_{2} \mathrm{O}_{5}$ & 0.04 & 0.13 & 0.12 & 0.13 & 0.12 & 0.11 & 0.10 & 0.11 & 0.14 & 0.14 & $\mathrm{NC}$ & 0.04 & 0.14 & 0.11 & 0.12 & 0.10 \\
\hline $\mathrm{PbO}$ & 0.11 & 0.10 & 0.10 & 0.10 & 0.10 & 0.09 & 0.09 & 0.09 & 0.10 & 0.11 & $\mathrm{NC}$ & 0.12 & 0.09 & 0.11 & 0.10 & 0.10 \\
\hline $\mathrm{SiO}_{2}$ & 33.31 & 34.83 & 34.87 & 35.37 & 34.96 & 34.79 & 34.55 & 35.18 & 34.95 & 35.28 & 3.69 & 33.46 & 35.77 & 35.21 & 35.19 & 35.02 \\
\hline $\mathrm{SO}_{3}$ & 0.07 & 0.10 & 0.11 & 0.11 & 0.11 & 0.11 & 0.11 & 0.13 & 0.18 & 0.17 & $\mathrm{NC}$ & 0.07 & 0.17 & 0.18 & 0.17 & 0.16 \\
\hline $\mathrm{TiO}_{2}$ & $\S$ & 0.08 & 0.08 & 0.08 & 0.08 & 0.08 & 0.08 & 0.08 & 0.08 & 0.08 & $\mathrm{NC}$ & $\S$ & 0.08 & 0.08 & 0.08 & 0.08 \\
\hline $\mathrm{ZnO}$ & 0.02 & 0.05 & 0.05 & 0.05 & 0.04 & 0.04 & 0.05 & 0.05 & 0.07 & 0.08 & $\mathrm{NC}$ & 0.02 & 0.07 & 0.07 & 0.06 & 0.06 \\
\hline $\mathrm{ZrO}_{2}$ & 2.83 & 2.47 & 2.55 & 2.47 & 2.59 & 2.54 & 2.63 & 2.54 & 2.48 & 2.47 & -6.94 & 3.01 & 2.37 & 2.54 & 2.55 & 2.61 \\
\hline Sum & 100.00 & 100.00 & 100.00 & 100.00 & 100.00 & 100.00 & 100.00 & 100.00 & 100.00 & 100.00 & 0.00 & 100.00 & 100.00 & 100.00 & 100.00 & 100.00 \\
\hline
\end{tabular}

\$ calculated on BLZ-G-123A (last discharge prior to idling); NC - Not calculated. 
ORP-56294 Rev. 0

Table 4.7. XRF Analyzed Composition for Glass Discharged During DM100 Tests (wt\%) (continued).

\begin{tabular}{|c|c|c|c|c|c|c|c|c|c|c|c|c|c|c|}
\hline Test & \multicolumn{14}{|c|}{2 (HLW-E-SP-05) } \\
\hline Glass (kg) & \multirow[b]{2}{*}{ Target } & 637.10 & 659.30 & 680.24 & 699.48 & 727.18 & 753.22 & 770.72 & 790.00 & 795.72 & 818.14 & 851.18 & 883.80 & \multirow{2}{*}{$\begin{array}{c}\text { \%Dev. } \\
\text { from } \\
\text { Target\$ }\end{array}$} \\
\hline Constituent & & $\begin{array}{c}\text { ABL-G- } \\
23 \mathrm{C}\end{array}$ & $\begin{array}{c}\text { ABL-G- } \\
30 \mathrm{~A}\end{array}$ & $\begin{array}{c}\text { ABL-G- } \\
34 \mathrm{~A}\end{array}$ & $\begin{array}{c}\text { ABL-G- } \\
\text { 38B }\end{array}$ & $\begin{array}{c}\text { ABL-G- } \\
42 \mathrm{~A}\end{array}$ & $\begin{array}{c}\text { ABL-G- } \\
47 \mathrm{~A}\end{array}$ & $\begin{array}{c}\text { ABL-G- } \\
49 \mathrm{~A}\end{array}$ & $\begin{array}{c}\text { ABL-G- } \\
50 \mathrm{~A}\end{array}$ & $\begin{array}{c}\text { ABL-G- } \\
54 \mathrm{~A}\end{array}$ & $\begin{array}{c}\text { ABL-G- } \\
71 \mathrm{~A}\end{array}$ & $\begin{array}{c}\text { ABL-G- } \\
71 \mathrm{~B}\end{array}$ & $\begin{array}{c}\text { ABL-G- } \\
71 \mathrm{C}\end{array}$ & \\
\hline $\mathrm{Al}_{2} \mathrm{O}_{3}$ & 9.49 & 10.05 & 10.00 & 9.95 & 9.92 & 10.00 & 9.81 & 9.92 & 9.80 & 9.59 & 9.92 & 9.83 & 10.07 & 1.06 \\
\hline $\mathrm{B}_{2} \mathrm{O}_{3} *$ & 12.08 & 12.85 & 12.76 & 12.69 & 12.63 & 12.55 & 12.49 & 12.45 & 12.41 & 12.49 & 12.49 & 12.49 & 12.49 & $\mathrm{NC}$ \\
\hline $\mathrm{BaO}$ & $\S$ & $<0.01$ & 0.01 & $<0.01$ & $<0.01$ & $<0.01$ & $<0.01$ & $<0.01$ & $<0.01$ & $<0.01$ & $<0.01$ & 0.01 & $<0.01$ & $\mathrm{NC}$ \\
\hline $\mathrm{Bi}_{2} \mathrm{O}_{3}$ & $\S$ & 0.04 & 0.03 & 0.03 & 0.03 & 0.02 & 0.02 & 0.02 & 0.02 & 0.01 & 0.03 & 0.03 & 0.04 & $\mathrm{NC}$ \\
\hline $\mathrm{CaO}$ & 0.40 & 0.63 & 0.58 & 0.57 & 0.55 & 0.54 & 0.53 & 0.51 & 0.51 & 0.52 & 0.57 & 0.57 & 0.57 & $\mathrm{NC}$ \\
\hline $\mathrm{CdO}$ & 0.19 & 0.15 & 0.15 & 0.14 & 0.14 & 0.14 & 0.14 & 0.14 & 0.14 & 0.16 & 0.15 & 0.15 & 0.15 & $\mathrm{NC}$ \\
\hline $\mathrm{Cr}_{2} \mathrm{O}_{3}$ & 0.15 & 0.17 & 0.18 & 0.19 & 0.17 & 0.17 & 0.18 & 0.17 & 0.17 & 0.18 & 0.19 & 0.17 & 0.16 & $\mathrm{NC}$ \\
\hline $\mathrm{Cs}_{2} \mathrm{O}$ & 0.08 & 0.08 & 0.08 & 0.08 & 0.08 & 0.08 & 0.08 & 0.07 & 0.08 & 0.09 & 0.09 & 0.09 & 0.08 & $\mathrm{NC}$ \\
\hline $\mathrm{Fe}_{2} \mathrm{O}_{3}$ & 21.30 & 18.98 & 19.11 & 18.99 & 18.85 & 19.27 & 19.65 & 18.82 & 19.57 & 20.48 & 19.34 & 19.09 & 18.67 & -3.82 \\
\hline $\mathrm{K}_{2} \mathrm{O}$ & 7.01 & 6.30 & 6.26 & 6.28 & 6.29 & 6.40 & 6.43 & 6.30 & 6.43 & 6.46 & 6.29 & 6.29 & 6.35 & -7.85 \\
\hline $\mathrm{La}_{2} \mathrm{O}_{3}$ & 0.64 & 0.42 & 0.39 & 0.40 & 0.40 & 0.38 & 0.39 & 0.36 & 0.37 & 0.37 & 0.38 & 0.37 & 0.36 & $\mathrm{NC}$ \\
\hline $\mathrm{Li}_{2} \mathrm{O}^{*}$ & 1.10 & 1.20 & 1.19 & 1.18 & 1.17 & 1.16 & 1.15 & 1.15 & 1.14 & 1.16 & 1.16 & 1.16 & 1.16 & 5.44 \\
\hline $\mathrm{MgO}$ & 0.12 & 0.11 & 0.14 & 0.13 & 0.14 & 0.13 & 0.12 & 0.10 & 0.11 & 0.10 & 0.17 & 0.13 & 0.10 & $\mathrm{NC}$ \\
\hline $\mathrm{MnO}$ & 0.61 & 0.55 & 0.55 & 0.54 & 0.53 & 0.53 & 0.54 & 0.51 & 0.54 & 0.56 & 0.60 & 0.59 & 0.58 & $\mathrm{NC}$ \\
\hline $\mathrm{Na}_{2} \mathrm{O}$ & 9.07 & 9.33 & 9.98 & 9.84 & 10.04 & 9.46 & 9.55 & 10.19 & 10.03 & 9.42 & 9.58 & 10.12 & 9.48 & 3.87 \\
\hline $\mathrm{Nd}_{2} \mathrm{O}_{3}$ & 0.28 & 0.29 & 0.30 & 0.29 & 0.29 & 0.30 & 0.30 & 0.29 & 0.30 & 0.31 & 0.30 & 0.30 & 0.30 & $\mathrm{NC}$ \\
\hline $\mathrm{NiO}$ & 0.76 & 0.34 & 0.34 & 0.34 & 0.33 & 0.34 & 0.35 & 0.33 & 0.34 & 0.37 & 0.29 & 0.28 & 0.28 & $\mathrm{NC}$ \\
\hline $\mathrm{P}_{2} \mathrm{O}_{5}$ & 0.04 & 0.10 & 0.09 & 0.09 & 0.09 & 0.08 & 0.08 & 0.08 & 0.08 & 0.08 & 0.09 & 0.10 & 0.09 & $\mathrm{NC}$ \\
\hline $\mathrm{PbO}$ & 0.12 & 0.10 & 0.10 & 0.10 & 0.10 & 0.10 & 0.10 & 0.09 & 0.10 & 0.10 & 0.10 & 0.10 & 0.10 & $\mathrm{NC}$ \\
\hline $\mathrm{SiO}_{2}$ & 33.46 & 35.39 & 34.89 & 35.32 & 35.43 & 35.47 & 35.19 & 35.70 & 34.97 & 34.46 & 35.15 & 35.03 & 35.92 & 2.99 \\
\hline $\mathrm{SO}_{3}$ & 0.07 & 0.15 & 0.15 & 0.14 & 0.14 & 0.13 & 0.12 & 0.12 & 0.12 & 0.11 & 0.22 & 0.22 & 0.23 & $\mathrm{NC}$ \\
\hline $\mathrm{TiO}_{2}$ & $\S$ & 0.07 & 0.07 & 0.08 & 0.08 & 0.08 & 0.07 & 0.08 & 0.07 & 0.08 & 0.08 & 0.08 & 0.08 & $\mathrm{NC}$ \\
\hline $\mathrm{ZnO}$ & 0.02 & 0.05 & 0.05 & 0.05 & 0.05 & 0.04 & 0.04 & 0.04 & 0.04 & 0.05 & 0.08 & 0.07 & 0.07 & $\mathrm{NC}$ \\
\hline $\mathrm{ZrO}_{2}$ & 3.01 & 2.65 & 2.60 & 2.58 & 2.57 & 2.62 & 2.67 & 2.53 & 2.65 & 2.85 & 2.74 & 2.73 & 2.67 & -5.20 \\
\hline Sum & 100.00 & 100.00 & 100.00 & 100.00 & 100.00 & 100.00 & 100.00 & 100.00 & 100.00 & 100.00 & 100.00 & 100.00 & 100.00 & $\mathrm{NC}$ \\
\hline
\end{tabular}

$\S$ - Not a target constituent; * - Target values calculated using simple well-stirred tank model based on the DCP results of the first discharge;

\$ Calculated on ABL-G-54A (last discharge prior to idling) 
ORP-56294 Rev. 0

Table 4.7. XRF Analyzed Composition for Glass Discharged During DM100 Tests (wt\%) (continued).

\begin{tabular}{|c|c|c|c|c|c|c|c|c|c|c|c|c|c|c|c|c|}
\hline Test & \multicolumn{16}{|c|}{3 (HLW-E-M-03) } \\
\hline Glass (kg) & \multirow{3}{*}{ Target } & 905.52 & 933.14 & 960.18 & 987.84 & 1017.82 & 1048.84 & 1074.72 & 1098.50 & 1122.70 & 1146.30 & 1175.54 & 1227.82 & 1253.60 & 1278.22 & 1300.68 \\
\hline \multirow{2}{*}{ Constituent } & & ABL-G- & ABL-G- & ABL-G- & ABL-G- & ABL-G- & ABL-G- & ABL-G- & ABL-G- & ABL-G- & ABL-G- & ABL-G- & ABL-G- & ABL-G- & ABL-G- & ABL-G- \\
\hline & & $86 \mathrm{~A}$ & $87 \mathrm{~B}$ & $91 \mathrm{~B}$ & $95 \mathrm{~A}$ & 97A & $102 \mathrm{~A}$ & $105 \mathrm{~A}$ & $106 \mathrm{~B}$ & $111 \mathrm{~A}$ & $112 \mathrm{~B}$ & $114 \mathrm{~B}$ & $119 \mathrm{~A}$ & $120 \mathrm{~B}$ & $123 \mathrm{~B}$ & $125 \mathrm{~A}$ \\
\hline $\mathrm{Al}_{2} \mathrm{O}_{3}$ & 12.17 & 10.91 & 10.92 & 11.27 & 11.36 & 11.40 & 11.51 & 11.46 & 11.58 & 11.56 & 11.86 & 11.80 & 12.04 & 11.86 & 11.90 & 11.92 \\
\hline $\mathrm{B}_{2} \mathrm{O}_{3}{ }^{*}$ & 13.34 & 12.58 & 12.69 & 12.78 & 12.86 & 12.94 & 13.00 & 13.05 & 13.08 & 13.12 & 13.14 & 13.17 & 13.22 & 13.23 & 13.25 & 13.26 \\
\hline $\mathrm{BaO}$ & 0.01 & 0.01 & 0.01 & 0.02 & 0.01 & 0.01 & 0.01 & 0.02 & 0.01 & 0.02 & 0.02 & 0.02 & 0.02 & 0.02 & 0.02 & 0.02 \\
\hline $\mathrm{Bi}_{2} \mathrm{O}_{3}$ & 3.47 & 1.21 & 1.50 & 1.71 & 1.93 & 2.09 & 2.29 & 2.48 & 2.57 & 2.65 & 2.52 & 2.79 & 2.65 & 2.87 & 2.95 & 2.94 \\
\hline $\mathrm{CaO}$ & 1.18 & 0.82 & 0.87 & 0.90 & 0.93 & 0.98 & 0.99 & 1.03 & 1.03 & 1.06 & 1.03 & 1.08 & 1.06 & 1.11 & 1.12 & 1.11 \\
\hline $\mathrm{CdO}$ & $\S$ & 0.10 & 0.09 & 0.08 & 0.07 & 0.06 & 0.05 & 0.05 & $<0.01$ & $<0.01$ & $<0.01$ & $<0.01$ & $<0.01$ & $<0.01$ & $<0.01$ & $<0.01$ \\
\hline $\mathrm{Cr}_{2} \mathrm{O}_{3}$ & 3.00 & 1.18 & 1.44 & 1.62 & 1.81 & 1.97 & 2.11 & 2.26 & 2.33 & 2.45 & 2.34 & 2.52 & 2.51 & 2.65 & 2.70 & 2.75 \\
\hline $\mathrm{Cs}_{2} \mathrm{O}$ & $\S$ & 0.05 & 0.04 & 0.04 & 0.03 & 0.03 & 0.02 & 0.02 & 0.02 & 0.02 & 0.01 & $<0.01$ & 0.01 & $<0.01$ & 0.01 & $<0.01$ \\
\hline $\mathrm{F}$ & 0.95 & $0.30 \#$ & 0.38 & $0.45 \#$ & 0.46 & $0.47 \#$ & 0.52 & 0.56 & $0.60 \#$ & 0.62 & 0.64 & $0.66 \#$ & 0.64 & 0.63 & $0.62 \#$ & 0.64 \\
\hline $\mathrm{Fe}_{2} \mathrm{O}_{3}$ & 6.26 & 14.12 & 13.42 & 12.07 & 11.21 & 10.37 & 9.73 & 9.67 & 9.18 & 8.99 & 8.01 & 8.32 & 7.24 & 7.43 & 7.35 & 7.23 \\
\hline $\mathrm{K}_{2} \mathrm{O}$ & 4.54 & 5.50 & 5.38 & 5.15 & 5.00 & 4.86 & 4.85 & 4.81 & 4.72 & 4.73 & 4.48 & 4.56 & 4.34 & 4.43 & 4.40 & 4.41 \\
\hline $\mathrm{La}_{2} \mathrm{O}_{3}$ & $\S$ & 0.24 & 0.22 & 0.18 & 0.15 & 0.13 & 0.11 & 0.10 & 0.09 & 0.09 & 0.07 & 0.07 & 0.05 & 0.02 & 0.04 & $<0.01$ \\
\hline $\mathrm{Li}_{2} \mathrm{O}^{*}$ & 2.60 & 1.33 & 1.51 & 1.66 & 1.79 & 1.92 & 2.02 & 2.10 & 2.16 & 2.22 & 2.26 & 2.31 & 2.38 & 2.41 & 2.44 & 2.45 \\
\hline $\mathrm{MgO}$ & 0.08 & 0.14 & 0.14 & 0.13 & 0.13 & 0.14 & 0.10 & 0.14 & 0.15 & 0.18 & 0.14 & 0.14 & 0.13 & 0.15 & 0.15 & 0.12 \\
\hline $\mathrm{MnO}$ & 0.75 & 0.63 & 0.66 & 0.65 & 0.65 & 0.65 & 0.64 & 0.69 & 0.67 & 0.69 & 0.64 & 0.69 & 0.65 & 0.68 & 0.68 & 0.69 \\
\hline $\mathrm{Na}_{2} \mathrm{O}$ & 9.57 & 10.13 & 9.69 & 9.90 & 10.00 & 10.13 & 9.71 & 9.43 & 9.70 & 9.33 & 10.09 & 9.17 & 10.03 & 9.96 & 9.62 & 9.94 \\
\hline $\mathrm{Nd}_{2} \mathrm{O}_{3}$ & $\S$ & 0.12 & 0.15 & 0.14 & 0.11 & 0.09 & 0.08 & 0.07 & 0.06 & 0.05 & 0.05 & 0.05 & 0.03 & 0.03 & 0.02 & 0.02 \\
\hline $\mathrm{NiO}$ & 0.75 & 0.40 & 0.44 & 0.46 & 0.48 & 0.50 & 0.52 & 0.56 & 0.58 & 0.60 & 0.56 & 0.60 & 0.57 & 0.59 & 0.60 & 0.61 \\
\hline $\mathrm{P}_{2} \mathrm{O}_{5}$ & 1.59 & 0.68 & 0.81 & 0.96 & 1.04 & 1.12 & 1.24 & 1.29 & 1.31 & 1.40 & 1.40 & 1.43 & 1.49 & 1.48 & 1.52 & 1.51 \\
\hline $\mathrm{PbO}$ & 0.23 & 0.14 & 0.15 & 0.15 & 0.16 & 0.15 & 0.15 & 0.16 & 0.16 & 0.16 & 0.15 & 0.16 & 0.15 & 0.16 & 0.16 & 0.16 \\
\hline $\mathrm{SiO}_{2}$ & 39.45 & 37.42 & 37.70 & 38.22 & 38.52 & 38.88 & 39.38 & 39.14 & 39.18 & 39.35 & 40.00 & 39.87 & 40.34 & 39.87 & 40.04 & 39.86 \\
\hline $\mathrm{SO}_{3}$ & $\S$ & 0.19 & 0.17 & 0.14 & 0.12 & 0.12 & 0.10 & 0.10 & 0.09 & 0.08 & 0.07 & 0.07 & 0.07 & 0.06 & 0.07 & 0.06 \\
\hline $\mathrm{TiO}_{2}$ & $\S$ & 0.07 & 0.07 & 0.06 & 0.06 & 0.06 & 0.05 & 0.05 & 0.05 & 0.05 & 0.05 & 0.05 & 0.05 & 0.04 & 0.05 & 0.02 \\
\hline $\mathrm{ZnO}$ & $\S$ & 0.06 & 0.05 & 0.04 & 0.04 & 0.03 & 0.03 & 0.03 & 0.03 & 0.03 & 0.02 & 0.02 & 0.02 & 0.01 & 0.02 & 0.01 \\
\hline $\mathrm{ZrO}_{2}$ & 0.05 & 1.67 & 1.50 & 1.24 & 1.07 & 0.91 & 0.77 & 0.73 & 0.63 & 0.57 & 0.46 & 0.45 & 0.32 & 0.30 & 0.29 & 0.26 \\
\hline Sum & 100.00 & 100.00 & 100.00 & 100.00 & 100.00 & 100.00 & 100.00 & 100.00 & 100.00 & 100.00 & 100.00 & 100.00 & 100.00 & 100.00 & 100.00 & 100.00 \\
\hline
\end{tabular}

$\S$ - Not a target constituent; * - Target values calculated using simple well-stirred tank model based on the DCP results of the first discharge

\# - Fluorine was measured by XRF on polished samples, values for other samples calculated by interpolation 
Table 4.7. XRF Analyzed Composition for Glass Discharged During DM100 Tests (wt\%) (continued).

\begin{tabular}{|c|c|c|c|c|c|c|c|c|c|c|c|c|c|c|c|c|}
\hline Test & \multicolumn{8}{|c|}{3 (HLW-E-M-03) } & \multicolumn{8}{|c|}{4 (HLW-E-ES-05) } \\
\hline Glass (kg) & \multirow[b]{2}{*}{ Target } & 1324.46 & 1349.84 & 1378.46 & 1395.66 & 1425.36 & 1450.16 & \multirow{2}{*}{$\begin{array}{c}\% \text { Dev. } \\
\text { from } \\
\text { Target\$ }\end{array}$} & \multirow[b]{2}{*}{ Target } & 1475.72 & 1502.48 & 1526.16 & 1549.96 & 1570.88 & 1593.50 & 1614.96 \\
\hline Constituent & & $\begin{array}{c}\text { ABL-G- } \\
126 \mathrm{~A}\end{array}$ & $\begin{array}{c}\text { ABL-G- } \\
131 \mathrm{~A}\end{array}$ & $\begin{array}{c}\text { ABL-G- } \\
131 \mathrm{~B}\end{array}$ & $\begin{array}{c}\text { ABL-G- } \\
141 \mathrm{~A}\end{array}$ & $\begin{array}{c}\text { ABL-G- } \\
141 \mathrm{~B}\end{array}$ & $\begin{array}{c}\text { ABL-G- } \\
141 \mathrm{C}\end{array}$ & & & $\begin{array}{c}\text { BBL-G- } \\
10 \mathrm{~A}\end{array}$ & $\begin{array}{c}\text { BBL-G- } \\
12 \mathrm{~A}\end{array}$ & $\begin{array}{c}\text { BBL-G- } \\
13 \mathrm{~B}\end{array}$ & $\begin{array}{c}\text { BBL-G- } \\
17 \mathrm{~B}\end{array}$ & $\begin{array}{c}\text { BBL-G- } \\
20 \mathrm{~B}\end{array}$ & $\begin{array}{c}\text { BBL-G- } \\
23 \mathrm{~A}\end{array}$ & $\begin{array}{c}\text { BBL-G- } \\
23 \mathrm{C}\end{array}$ \\
\hline $\mathrm{Al}_{2} \mathrm{O}_{3}$ & 12.17 & 11.88 & 11.85 & 11.98 & 11.90 & 11.83 & 11.92 & -1.51 & 10.86 & 11.39 & 11.39 & 11.29 & 11.14 & 11.10 & 10.95 & 10.90 \\
\hline $\mathrm{B}_{2} \mathrm{O}_{3}{ }^{*}$ & 13.34 & 13.27 & 13.28 & 13.28 & 13.28 & 13.28 & 13.28 & $\mathrm{NC}$ & 14.80 & 13.48 & 13.66 & 13.80 & 13.93 & 14.02 & 14.11 & 14.19 \\
\hline $\mathrm{BaO}$ & 0.01 & 0.01 & 0.02 & 0.03 & 0.02 & 0.01 & 0.02 & $\mathrm{NC}$ & 0.01 & 0.02 & 0.02 & 0.01 & 0.01 & 0.02 & 0.01 & 0.02 \\
\hline $\mathrm{Bi}_{2} \mathrm{O}_{3}$ & 3.47 & 2.99 & 3.08 & 3.05 & 3.12 & 3.08 & 2.98 & -12.25 & 3.53 & 3.23 & 3.12 & 3.14 & 3.21 & 3.22 & 3.35 & 3.39 \\
\hline $\mathrm{CaO}$ & 1.18 & 1.13 & 1.13 & 1.12 & 1.14 & 1.13 & 1.12 & -5.13 & 1.20 & 1.17 & 1.15 & 1.13 & 1.15 & 1.14 & 1.17 & 1.20 \\
\hline $\mathrm{CdO}$ & $\S$ & $<0.01$ & $<0.01$ & $<0.01$ & $<0.01$ & $<0.01$ & $<0.01$ & $\mathrm{NC}$ & $\S$ & $<0.01$ & $<0.01$ & $<0.01$ & $<0.01$ & $<0.01$ & $<0.01$ & $<0.01$ \\
\hline $\mathrm{Cr}_{2} \mathrm{O}_{3}$ & 3.00 & 2.73 & 2.76 & 2.83 & 2.78 & 2.79 & 2.72 & -5.76 & 3.00 & 2.94 & 2.89 & 2.90 & 2.95 & 2.91 & 3.00 & 3.02 \\
\hline $\mathrm{Cs}_{2} \mathrm{O}$ & $\S$ & $<0.01$ & 0.01 & 0.01 & $<0.01$ & $<0.01$ & 0.01 & $\mathrm{NC}$ & $\S$ & $<0.01$ & $<0.01$ & $<0.01$ & $<0.01$ & $<0.01$ & $<0.01$ & $<0.01$ \\
\hline $\mathrm{F}$ & 0.95 & 0.66 & $0.68 \#$ & 0.68 & 0.68 & 0.68 & 0.68 & $\mathrm{NC}$ & 0.97 & $0.68 \#$ & 0.68 & $0.67 \#$ & 0.69 & 0.71 & $0.73 \#$ & 0.73 \\
\hline $\mathrm{Fe}_{2} \mathrm{O}_{3}$ & 6.26 & 7.14 & 7.09 & 6.81 & 7.07 & 7.25 & 7.12 & 8.85 & 6.36 & 7.01 & 6.79 & 6.74 & 6.95 & 6.70 & 6.91 & 6.92 \\
\hline $\mathrm{K}_{2} \mathrm{O}$ & 4.54 & 4.43 & 4.41 & 4.37 & 4.38 & 4.43 & 4.34 & -3.81 & 5.61 & 4.88 & 4.84 & 4.92 & 4.99 & 4.94 & 5.08 & 5.13 \\
\hline $\mathrm{La}_{2} \mathrm{O}_{3}$ & $\S$ & $<0.01$ & 0.03 & 0.02 & $<0.01$ & 0.03 & 0.04 & $\mathrm{NC}$ & $\S$ & 0.02 & 0.02 & 0.02 & 0.01 & 0.02 & 0.02 & 0.02 \\
\hline $\mathrm{Li}_{2} \mathrm{O}^{*}$ & 2.60 & 2.47 & 2.49 & 2.49 & 2.49 & 2.49 & 2.49 & -4.14 & 3.14 & 2.57 & 2.65 & 2.71 & 2.76 & 2.80 & 2.84 & 2.88 \\
\hline $\mathrm{MgO}$ & 0.08 & 0.15 & 0.14 & 0.13 & 0.13 & 0.13 & 0.12 & $\mathrm{NC}$ & 0.08 & 0.15 & 0.13 & 0.14 & 0.13 & 0.16 & 0.14 & 0.15 \\
\hline $\mathrm{MnO}$ & 0.75 & 0.68 & 0.70 & 0.69 & 0.69 & 0.69 & 0.69 & $\mathrm{NC}$ & $\S$ & 0.41 & 0.38 & 0.32 & 0.30 & 0.26 & 0.24 & 0.23 \\
\hline $\mathrm{Na}_{2} \mathrm{O}$ & 9.57 & 9.50 & 9.62 & 9.77 & 9.69 & 9.56 & 9.44 & 2.04 & 9.72 & 9.45 & 9.80 & 9.89 & 9.92 & 9.80 & 9.79 & 9.08 \\
\hline $\mathrm{Nd}_{2} \mathrm{O}_{3}$ & $\S$ & 0.02 & 0.02 & 0.01 & 0.02 & 0.02 & 0.02 & $\mathrm{NC}$ & $\S$ & 0.01 & 0.01 & $<0.01$ & 0.01 & 0.01 & 0.01 & 0.01 \\
\hline $\mathrm{NiO}$ & 0.75 & 0.61 & 0.63 & 0.62 & 0.62 & 0.65 & 0.63 & $\mathrm{NC}$ & $\S$ & 0.41 & 0.40 & 0.35 & 0.33 & 0.30 & 0.28 & 0.26 \\
\hline $\mathrm{P}_{2} \mathrm{O}_{5}$ & 1.59 & 1.56 & 1.56 & 1.57 & 1.56 & 1.57 & 1.58 & -1.39 & 1.62 & 1.62 & 1.63 & 1.65 & 1.61 & 1.65 & 1.60 & 1.63 \\
\hline $\mathrm{PbO}$ & 0.23 & 0.17 & 0.17 & 0.18 & 0.18 & 0.17 & 0.17 & $\mathrm{NC}$ & 0.23 & 0.19 & 0.18 & 0.18 & 0.19 & 0.19 & 0.19 & 0.20 \\
\hline $\mathrm{SiO}_{2}$ & 39.45 & 40.18 & 40.01 & 40.08 & 39.92 & 39.85 & 40.26 & 1.60 & 38.82 & 40.05 & 39.97 & 39.86 & 39.43 & 39.81 & 39.32 & 39.80 \\
\hline $\mathrm{SO}_{3}$ & $\S$ & 0.17 & 0.05 & 0.06 & 0.08 & 0.08 & 0.09 & $\mathrm{NC}$ & $\S$ & 0.08 & 0.07 & 0.07 & 0.07 & 0.06 & 0.07 & 0.07 \\
\hline $\mathrm{TiO}_{2}$ & $\S$ & $<0.01$ & 0.04 & 0.04 & 0.03 & 0.05 & 0.04 & $\mathrm{NC}$ & $\S$ & 0.04 & 0.04 & 0.04 & 0.04 & 0.04 & 0.04 & 0.04 \\
\hline $\mathrm{ZnO}$ & $\S$ & 0.01 & 0.01 & 0.01 & 0.02 & 0.02 & 0.02 & $\mathrm{NC}$ & $\S$ & 0.02 & 0.02 & 0.01 & 0.01 & 0.01 & 0.01 & 0.01 \\
\hline $\mathrm{ZrO}_{2}$ & 0.05 & 0.24 & 0.22 & 0.19 & 0.22 & 0.23 & 0.23 & $\mathrm{NC}$ & 0.05 & 0.17 & 0.15 & 0.14 & 0.15 & 0.13 & 0.13 & 0.13 \\
\hline Sum & 100.00 & 100.00 & 100.00 & 100.00 & 100.00 & 100.00 & 100.00 & $\mathrm{NC}$ & 100.00 & 100.00 & 100.00 & 100.00 & 100.00 & 100.00 & 100.00 & 100.00 \\
\hline
\end{tabular}

$\S$ - Not a target constituent; * - Target values calculated using simple well-stirred tank model based on the DCP results of the first discharge; $\$$ calculated on ABL-G-131B (last discharge prior to idling); NC - Not calculated; \# - Fluorine was measured by XRF on polished samples, values for other samples calculated by interpolation 
Table 4.7. XRF Analyzed Composition for Glass Discharged During DM100 Tests (wt\%) (continued).

\begin{tabular}{|c|c|c|c|c|c|c|c|c|c|c|c|c|c|c|c|}
\hline Test & \multicolumn{15}{|c|}{4 (HLW-E-ES-05) } \\
\hline Glass (kg) & \multirow[b]{2}{*}{ Target } & 1636.58 & 1660.66 & 1688.86 & 1712.14 & 1729.20 & 1756.82 & 1789.28 & 1816.30 & 1840.56 & 1895.12 & 1923.88 & 1945.76 & 1965.26 & 1972.26 \\
\hline Constituent & & $\begin{array}{c}\text { BBL-G- } \\
\text { 25B }\end{array}$ & $\begin{array}{c}\text { BBL-G- } \\
30 \mathrm{~A}\end{array}$ & $\begin{array}{c}\text { BBL-G- } \\
30 \mathrm{C}\end{array}$ & $\begin{array}{c}\text { BBL-G- } \\
\text { 35A }\end{array}$ & $\begin{array}{c}\text { BBL-G- } \\
35 \mathrm{C}\end{array}$ & $\begin{array}{c}\text { BBL-G- } \\
\text { 38A }\end{array}$ & $\begin{array}{c}\text { BBL-G- } \\
\text { 39B }\end{array}$ & $\begin{array}{c}\text { BBL-G- } \\
42 \mathrm{~B}\end{array}$ & $\begin{array}{c}\text { BBL-G- } \\
\text { 43B }\end{array}$ & $\begin{array}{c}\text { BBL-G- } \\
47 \mathrm{~B}\end{array}$ & \begin{tabular}{|c|} 
BBL-G- \\
$51 \mathrm{~B}$
\end{tabular} & $\begin{array}{c}\text { BBL-G- } \\
53 \mathrm{~B}\end{array}$ & $\begin{array}{c}\text { BBL-G- } \\
57 \mathrm{~A}\end{array}$ & $\begin{array}{c}\text { BBL-G- } \\
60 \mathrm{~B}\end{array}$ \\
\hline $\mathrm{Al}_{2} \mathrm{O}_{3}$ & 10.86 & 11.02 & 10.91 & 10.96 & 10.80 & 10.85 & 10.94 & 10.78 & 10.83 & 11.01 & 10.86 & 10.80 & 10.77 & 10.71 & 10.89 \\
\hline $\mathrm{B}_{2} \mathrm{O}_{3}{ }^{*}$ & 14.80 & 14.26 & 14.33 & 14.40 & 14.45 & 14.48 & 14.52 & 14.57 & 14.60 & 14.63 & 14.67 & 14.69 & 14.71 & 14.71 & 14.71 \\
\hline $\mathrm{BaO}$ & 0.01 & 0.01 & 0.02 & 0.02 & 0.02 & 0.02 & 0.02 & 0.02 & 0.01 & 0.01 & 0.02 & 0.01 & 0.02 & 0.01 & 0.01 \\
\hline $\mathrm{Bi}_{2} \mathrm{O}_{3}$ & 3.53 & 3.25 & 3.43 & 3.36 & 3.50 & 3.30 & 3.30 & 3.46 & 3.45 & 3.04 & 3.19 & 3.35 & 3.49 & 3.42 & 3.19 \\
\hline $\mathrm{CaO}$ & 1.20 & 1.14 & 1.20 & 1.18 & 1.21 & 1.15 & 1.17 & 1.19 & 1.20 & 1.11 & 1.15 & 1.18 & 1.19 & 1.17 & 1.17 \\
\hline $\mathrm{CdO}$ & $\S$ & $<0.01$ & $<0.01$ & $<0.01$ & $<0.01$ & $<0.01$ & $<0.01$ & $<0.01$ & $<0.01$ & $<0.01$ & $<0.01$ & $<0.01$ & $<0.01$ & $<0.01$ & $<0.01$ \\
\hline $\mathrm{Cr}_{2} \mathrm{O}_{3}$ & 3.00 & 2.94 & 3.04 & 2.97 & 3.05 & 2.90 & 2.90 & 2.99 & 2.96 & 2.75 & 2.76 & 2.91 & 2.94 & 2.90 & 2.76 \\
\hline $\mathrm{Cs}_{2} \mathrm{O}$ & $\S$ & $<0.01$ & $<0.01$ & $<0.01$ & $<0.01$ & $<0.01$ & $<0.01$ & $<0.01$ & $<0.01$ & $<0.01$ & $<0.01$ & $<0.01$ & $<0.01$ & $<0.01$ & $<0.01$ \\
\hline $\mathrm{F}$ & 0.97 & 0.72 & $0.72 \#$ & 0.69 & 0.66 & $0.64 \#$ & 0.63 & 0.61 & 0.60 & $0.59 \#$ & 0.60 & $0.60 \#$ & 0.60 & 0.60 & 0.60 \\
\hline $\mathrm{Fe}_{2} \mathrm{O}_{3}$ & 6.36 & 6.60 & 6.84 & 6.73 & 6.89 & 6.56 & 6.50 & 6.78 & 6.62 & 6.06 & 6.27 & 6.53 & 6.67 & 6.52 & 6.46 \\
\hline $\mathrm{K}_{2} \mathrm{O}$ & 5.61 & 5.04 & 5.15 & 5.14 & 5.23 & 5.13 & 5.15 & 5.24 & 5.23 & 4.92 & 5.07 & 5.17 & 5.24 & 5.16 & 5.11 \\
\hline $\mathrm{La}_{2} \mathrm{O}_{3}$ & $\S$ & 0.02 & 0.02 & 0.02 & 0.02 & 0.02 & 0.01 & 0.02 & 0.01 & 0.01 & $<0.01$ & 0.01 & 0.02 & 0.02 & 0.02 \\
\hline $\mathrm{Li}_{2} \mathrm{O}^{*}$ & 3.14 & 2.91 & 2.94 & 2.96 & 2.99 & 3.00 & 3.02 & 3.04 & 3.05 & 3.06 & 3.08 & 3.09 & 3.10 & 3.10 & 3.10 \\
\hline $\mathrm{MgO}$ & 0.08 & 0.18 & 0.15 & 0.15 & 0.18 & 0.16 & 0.16 & 0.15 & 0.17 & 0.18 & 0.15 & 0.13 & 0.16 & 0.17 & 0.14 \\
\hline $\mathrm{MnO}$ & $\S$ & 0.18 & 0.17 & 0.15 & 0.14 & 0.13 & 0.11 & 0.09 & 0.08 & 0.07 & 0.06 & 0.05 & 0.05 & 0.04 & 0.07 \\
\hline $\mathrm{Na}_{2} \mathrm{O}$ & 9.72 & 9.56 & 9.25 & 9.27 & 9.10 & 9.80 & 9.31 & 9.34 & 9.21 & 10.39 & 10.08 & 9.86 & 9.48 & 9.82 & 9.71 \\
\hline $\mathrm{Nd}_{2} \mathrm{O}_{3}$ & $\S$ & $<0.01$ & 0.01 & 0.01 & $<0.01$ & $<0.01$ & $<0.01$ & $<0.01$ & $<0.01$ & $<0.01$ & $<0.01$ & $<0.01$ & $<0.01$ & $<0.01$ & $<0.01$ \\
\hline $\mathrm{NiO}$ & $\S$ & 0.22 & 0.20 & 0.18 & 0.18 & 0.15 & 0.13 & 0.12 & 0.11 & 0.09 & 0.08 & 0.08 & 0.07 & 0.07 & 0.22 \\
\hline $\mathrm{P}_{2} \mathrm{O}_{5}$ & 1.62 & 1.64 & 1.64 & 1.63 & 1.67 & 1.65 & 1.66 & 1.63 & 1.64 & 1.63 & 1.62 & 1.63 & 1.62 & 1.60 & 1.59 \\
\hline $\mathrm{PbO}$ & 0.23 & 0.19 & 0.20 & 0.19 & 0.20 & 0.18 & 0.18 & 0.20 & 0.19 & 0.17 & 0.18 & 0.18 & 0.19 & 0.18 & 0.18 \\
\hline $\mathrm{SiO}_{2}$ & 38.82 & 39.89 & 39.55 & 39.77 & 39.49 & 39.68 & 40.09 & 39.55 & 39.83 & 40.07 & 39.95 & 39.55 & 39.48 & 39.57 & 39.83 \\
\hline $\mathrm{SO}_{3}$ & $\S$ & 0.06 & 0.06 & 0.06 & 0.08 & 0.06 & 0.06 & 0.07 & 0.05 & 0.06 & 0.07 & 0.06 & 0.06 & 0.08 & 0.09 \\
\hline $\mathrm{TiO}_{2}$ & $\S$ & 0.04 & 0.05 & 0.05 & 0.04 & 0.04 & 0.04 & 0.05 & 0.04 & 0.04 & 0.04 & 0.04 & 0.04 & 0.05 & 0.05 \\
\hline $\mathrm{ZnO}$ & $\S$ & 0.01 & 0.01 & 0.01 & 0.01 & $<0.01$ & 0.01 & $<0.01$ & 0.01 & 0.01 & 0.01 & $<0.01$ & 0.01 & 0.01 & 0.02 \\
\hline $\mathrm{ZrO}_{2}$ & 0.05 & 0.11 & 0.12 & 0.11 & 0.11 & 0.10 & 0.10 & 0.10 & 0.10 & 0.08 & 0.09 & 0.09 & 0.09 & 0.09 & 0.11 \\
\hline Sum & 100.00 & 100.00 & 100.00 & 100.00 & 100.00 & 100.00 & 100.00 & 100.00 & 100.00 & 100.00 & 100.00 & 100.00 & 100.00 & 100.00 & 100.00 \\
\hline
\end{tabular}

$\S$ - Not a target constituent; $*$ - Target values calculated using simple well-stirred tank model based on the DCP results of the first discharge; \# - Fluorine was measured by XRF on polished samples, values for other samples calculated by interpolation 
ORP-56294 Rev. 0

Table 4.7. XRF Analyzed Composition for Glass Discharged During DM100 Tests (wt \%) (continued).

\begin{tabular}{|c|c|c|c|c|c|c|c|c|c|c|c|c|c|c|c|c|}
\hline Test & \multicolumn{5}{|c|}{4 (HLW-E-ES-05) } & \multicolumn{11}{|c|}{5 (HLW-E-M-09) } \\
\hline Glass (kg) & \multirow[b]{2}{*}{ Target } & \multirow{2}{*}{\begin{tabular}{|c|}
2003.90 \\
BBL-G- \\
$60 \mathrm{C}$ \\
\end{tabular}} & \multirow{2}{*}{\begin{tabular}{|c}
2033.06 \\
BBL-G- \\
$61 \mathrm{~A}$ \\
\end{tabular}} & \multirow{2}{*}{\begin{tabular}{|c|}
2043.72 \\
BBL-G- \\
$61 \mathrm{~B}$ \\
\end{tabular}} & \multirow{2}{*}{$\begin{array}{c}\text { \%Dev. } \\
\text { From } \\
\text { Target } \$\end{array}$} & \multirow[b]{2}{*}{ Target } & \multirow{2}{*}{\begin{tabular}{|c|}
2070.58 \\
BBL-G- \\
$80 \mathrm{~A}$ \\
\end{tabular}} & \multirow{2}{*}{\begin{tabular}{|c|}
2089.86 \\
BBL-G- \\
$83 \mathrm{~A}$ \\
\end{tabular}} & \multirow{2}{*}{\begin{tabular}{|c|}
2113.62 \\
BBL-G- \\
$86 \mathrm{~B}$ \\
\end{tabular}} & \multirow{2}{*}{\begin{tabular}{|c|}
2141.34 \\
BBL-G- \\
$88 B$ \\
\end{tabular}} & \multirow{2}{*}{\begin{tabular}{|c|}
2161.76 \\
BBL-G- \\
$89 B$ \\
\end{tabular}} & \multirow{2}{*}{\begin{tabular}{|c}
2184.40 \\
BBL-G- \\
$93 \mathrm{~B}$ \\
\end{tabular}} & \multirow{2}{*}{\begin{tabular}{|c|}
2203.92 \\
BBL-G- \\
$94 \mathrm{~B}$ \\
\end{tabular}} & \multirow{2}{*}{\begin{tabular}{|c}
2226.74 \\
BBL-G- \\
$95 \mathrm{~B}$ \\
\end{tabular}} & \multirow{2}{*}{\begin{tabular}{|c|}
2251.88 \\
BBL-G- \\
$101 \mathrm{~A}$ \\
\end{tabular}} & \multirow{2}{*}{\begin{tabular}{|c}
2277.64 \\
BBL-G- \\
$101 \mathrm{C}$ \\
\end{tabular}} \\
\hline Constituent & & & & & & & & & & & & & & & & \\
\hline $\mathrm{Al}_{2} \mathrm{O}_{3}$ & 10.86 & 10.76 & 10.81 & 11.02 & -1.34 & 10.69 & 10.85 & 10.68 & 10.73 & 10.62 & 10.75 & 10.82 & 10.81 & 10.70 & 10.58 & 10.78 \\
\hline $\mathrm{B}_{2} \mathrm{O}_{3}{ }^{*}$ & 14.80 & 14.71 & 14.71 & 14.71 & $\mathrm{NC}$ & 14.57 & 14.69 & 14.68 & 14.66 & 14.65 & 14.64 & 14.63 & 14.63 & 14.62 & 14.61 & 14.61 \\
\hline $\mathrm{BaO}$ & 0.01 & 0.02 & 0.02 & 0.03 & $\mathrm{NC}$ & 0.01 & 0.02 & 0.02 & 0.02 & 0.02 & 0.02 & 0.02 & 0.02 & 0.02 & 0.01 & 0.02 \\
\hline $\mathrm{Bi}_{2} \mathrm{O}_{3}$ & 3.53 & 3.29 & 3.21 & 3.15 & -2.99 & 3.47 & 3.26 & 3.35 & 3.25 & 3.32 & 3.18 & 3.12 & 3.13 & 3.31 & 3.38 & 3.24 \\
\hline $\mathrm{CaO}$ & 1.20 & 1.15 & 1.15 & 1.15 & -2.32 & 1.18 & 1.16 & 1.18 & 1.15 & 1.17 & 1.14 & 1.13 & 1.13 & 1.15 & 1.16 & 1.14 \\
\hline $\mathrm{CdO}$ & $\S$ & $<0.01$ & $<0.01$ & $<0.01$ & $\mathrm{NC}$ & $\S$ & $<0.01$ & $<0.01$ & $<0.01$ & $<0.01$ & $<0.01$ & $<0.01$ & $<0.01$ & $<0.01$ & $<0.01$ & $<0.01$ \\
\hline $\mathrm{Cr}_{2} \mathrm{O}_{3}$ & 3.00 & 2.87 & 2.78 & 2.65 & -3.35 & 3.00 & 2.84 & 2.94 & 2.90 & 2.98 & 2.88 & 2.85 & 2.87 & 2.96 & 2.96 & 2.92 \\
\hline $\mathrm{Cs}_{2} \mathrm{O}$ & $\S$ & $<0.01$ & $<0.01$ & 0.01 & $\mathrm{NC}$ & $\S$ & $<0.01$ & $<0.01$ & $<0.01$ & $<0.01$ & $<0.01$ & $<0.01$ & $<0.01$ & $<0.01$ & $<0.01$ & $<0.01$ \\
\hline $\mathrm{F}$ & 0.97 & 0.60 & 0.60 & 0.60 & $\mathrm{NC}$ & 0.95 & $0.63 \#$ & 0.62 & $0.61 \#$ & 0.61 & 0.60 & $0.60 \#$ & 0.61 & 0.61 & $0.62 \#$ & 0.62 \\
\hline $\mathrm{Fe}_{2} \mathrm{O}_{3}$ & 6.36 & 6.62 & 6.51 & 6.44 & 2.65 & 6.26 & 6.40 & 6.52 & 6.31 & 6.36 & 6.15 & 6.10 & 6.09 & 6.31 & 6.44 & 6.18 \\
\hline $\mathrm{K}_{2} \mathrm{O}$ & 5.61 & 5.15 & 5.07 & 4.95 & -7.95 & 5.52 & 5.04 & 5.12 & 5.03 & 5.14 & 5.02 & 4.99 & 5.03 & 5.10 & 5.14 & 5.05 \\
\hline $\mathrm{La}_{2} \mathrm{O}_{3}$ & $\S$ & 0.01 & 0.02 & $<0.01$ & $\mathrm{NC}$ & $\S$ & 0.02 & 0.01 & 0.01 & 0.01 & 0.01 & 0.01 & $<0.01$ & $<0.01$ & 0.01 & $<0.01$ \\
\hline $\mathrm{Li}_{2} \mathrm{O}^{*}$ & 3.14 & 3.10 & 3.10 & 3.10 & $\mathrm{NC}$ & 3.09 & 3.09 & 3.09 & 3.09 & 3.09 & 3.09 & 3.09 & 3.09 & 3.09 & 3.09 & 3.09 \\
\hline $\mathrm{MgO}$ & 0.08 & 0.16 & 0.17 & 0.17 & $\mathrm{NC}$ & 0.08 & 0.17 & 0.14 & 0.17 & 0.14 & 0.16 & 0.12 & 0.12 & 0.12 & 0.14 & 0.14 \\
\hline $\mathrm{MnO}$ & $\S$ & 0.07 & 0.08 & 0.09 & $\mathrm{NC}$ & $\S$ & 0.06 & 0.05 & 0.05 & 0.04 & 0.04 & 0.03 & 0.03 & 0.03 & 0.03 & 0.03 \\
\hline $\mathrm{Na}_{2} \mathrm{O}$ & 9.72 & 9.66 & 10.02 & 10.03 & 0.94 & 9.57 & 9.71 & 9.61 & 9.95 & 9.42 & 9.89 & 9.84 & 9.59 & 9.76 & 9.59 & 9.86 \\
\hline $\mathrm{Nd}_{2} \mathrm{O}_{3}$ & $\S$ & $<0.01$ & $<0.01$ & 0.01 & $\mathrm{NC}$ & $\S$ & $<0.010$ & 0.01 & $<0.01$ & $<0.01$ & 0.01 & $<0.01$ & $<0.01$ & $<0.01$ & $<0.01$ & $<0.01$ \\
\hline $\mathrm{NiO}$ & $\S$ & 0.10 & 0.10 & 0.11 & $\mathrm{NC}$ & $\S$ & 0.10 & 0.09 & 0.07 & 0.06 & 0.06 & 0.06 & 0.05 & 0.05 & 0.05 & 0.04 \\
\hline $\mathrm{P}_{2} \mathrm{O}_{5}$ & 1.62 & 1.60 & 1.62 & 1.59 & -0.99 & 1.59 & 1.62 & 1.61 & 1.63 & 1.63 & 1.63 & 1.65 & 1.68 & 1.62 & 1.64 & 1.63 \\
\hline $\mathrm{PbO}$ & 0.23 & 0.18 & 0.18 & 0.17 & $\mathrm{NC}$ & 0.23 & 0.17 & 0.17 & 0.16 & 0.17 & 0.16 & 0.16 & 0.15 & 0.16 & 0.16 & 0.16 \\
\hline $\mathrm{SiO}_{2}$ & 38.82 & 39.70 & 39.61 & 39.74 & 1.92 & 38.22 & 39.39 & 39.21 & 39.25 & 39.48 & 39.48 & 39.66 & 39.79 & 39.14 & 39.08 & 39.23 \\
\hline $\mathrm{SO}_{3}$ & $\S$ & 0.09 & 0.08 & 0.08 & $\mathrm{NC}$ & $\S$ & 0.07 & 0.06 & 0.05 & 0.06 & 0.05 & 0.05 & 0.05 & 0.05 & 0.05 & 0.05 \\
\hline $\mathrm{TiO}_{2}$ & $\S$ & 0.04 & 0.04 & 0.03 & $\mathrm{NC}$ & $\S$ & 0.03 & 0.03 & 0.03 & 0.03 & 0.03 & 0.02 & 0.02 & 0.02 & 0.02 & 0.02 \\
\hline $\mathrm{ZnO}$ & $\S$ & 0.02 & 0.02 & 0.03 & $\mathrm{NC}$ & 1.50 & 0.57 & 0.73 & 0.78 & 0.92 & 0.92 & 0.95 & 1.02 & 1.09 & 1.15 & 1.14 \\
\hline $\mathrm{ZrO}_{2}$ & 0.05 & 0.11 & 0.12 & 0.15 & $\mathrm{NC}$ & 0.05 & 0.11 & 0.09 & 0.09 & 0.08 & 0.08 & 0.07 & 0.07 & 0.07 & 0.07 & 0.07 \\
\hline Sum & 100.00 & 100.00 & 100.00 & 100.00 & $\mathrm{NC}$ & 100.00 & 100.00 & 100.00 & 100.00 & 100.00 & 100.00 & 100.00 & 100.00 & 100.00 & 100.00 & 100.00 \\
\hline
\end{tabular}

$\S$ - Not a target constituent; * - Target values calculated using simple well-stirred tank model based on the DCP results of the first discharge; $\$$ calculated on

BBL-G-57A (last discharge prior to idling); NC - Not calculated; \# - Fluorine was measured by XRF on polished samples, values for other samples calculated by interpolation 
ORP-56294 Rev. 0

Table 4.7. XRF Analyzed Composition for Glass Discharged During DM100 Tests (wt \%) (continued).

\begin{tabular}{|c|c|c|c|c|c|c|c|c|c|c|c|c|c|c|}
\hline Test & \multicolumn{14}{|c|}{5 (HLW-E-M-09) } \\
\hline Glass (kg) & & 2305.38 & 2329.72 & 2358.56 & 2378.98 & 2402.42 & 2429.62 & 2447.52 & 2475.64 & 2514.36 & 2530.60 & 2567.44 & 2610.66 & \%Dev. \\
\hline Constituent & Target & $\begin{array}{c}\text { BBL-G- } \\
103 B\end{array}$ & $\begin{array}{c}\text { BBL-G- } \\
105 B\end{array}$ & $\begin{array}{c}\text { BBL-G- } \\
109 A\end{array}$ & $\begin{array}{c}\text { BBL-G- } \\
111 \mathrm{~A}\end{array}$ & $\begin{array}{c}\text { BBL-G- } \\
112 \mathrm{~A}\end{array}$ & $\begin{array}{c}\text { BBL-G- } \\
113 \mathrm{~A}\end{array}$ & $\begin{array}{c}\text { BBL-G- } \\
117 \mathrm{~A}\end{array}$ & $\begin{array}{c}\text { BBL-G- } \\
117 \mathrm{C}\end{array}$ & $\begin{array}{c}\text { BBL-G- } \\
120 \mathrm{~A}\end{array}$ & $\begin{array}{c}\text { BBL-G- } \\
124 \mathrm{~A}\end{array}$ & $\begin{array}{c}\text { BBL-G- } \\
130 B\end{array}$ & $\begin{array}{c}\text { BBL-G- } \\
130 \mathrm{C}\end{array}$ & $\begin{array}{c}\text { From } \\
\text { Target\$ }\end{array}$ \\
\hline $\mathrm{Al}_{2} \mathrm{O}_{3}$ & 10.69 & 10.70 & 10.76 & 10.72 & 10.61 & 10.65 & 10.65 & 10.76 & 10.63 & 10.72 & 10.72 & 10.76 & 10.84 & 0.23 \\
\hline $\mathrm{B}_{2} \mathrm{O}_{3}{ }^{*}$ & 14.57 & 14.60 & 14.60 & 14.60 & 14.59 & 14.59 & 14.59 & 14.59 & 14.59 & 14.58 & 14.58 & 14.58 & 14.58 & $\mathrm{NC}$ \\
\hline $\mathrm{BaO}$ & 0.01 & 0.02 & 0.01 & 0.02 & 0.02 & 0.02 & 0.02 & 0.02 & 0.02 & 0.02 & 0.01 & 0.02 & 0.02 & $\mathrm{NC}$ \\
\hline $\mathrm{Bi}_{2} \mathrm{O}_{3}$ & 3.47 & 3.33 & 3.21 & 3.20 & 3.38 & 3.32 & 3.37 & 3.23 & 3.23 & 3.24 & 3.27 & 3.31 & 3.29 & -5.97 \\
\hline $\mathrm{CaO}$ & 1.18 & 1.17 & 1.15 & 1.12 & 1.17 & 1.16 & 1.15 & 1.14 & 1.14 & 1.14 & 1.14 & 1.14 & 1.14 & -3.51 \\
\hline $\mathrm{CdO}$ & $\S$ & $<0.01$ & $<0.01$ & $<0.01$ & $<0.01$ & $<0.01$ & $<0.01$ & $<0.01$ & $<0.01$ & $<0.01$ & $<0.01$ & $<0.01$ & $<0.01$ & $\mathrm{NC}$ \\
\hline $\mathrm{Cr}_{2} \mathrm{O}_{3}$ & 3.00 & 3.02 & 2.97 & 2.92 & 3.07 & 3.00 & 2.97 & 2.96 & 2.94 & 2.93 & 2.98 & 2.95 & 2.91 & -0.82 \\
\hline $\mathrm{Cs}_{2} \mathrm{O}$ & $\S$ & $<0.01$ & $<0.01$ & $<0.01$ & $<0.01$ & $<0.01$ & $<0.01$ & $<0.01$ & $<0.01$ & $<0.01$ & $<0.01$ & $<0.01$ & $<0.01$ & $\mathrm{NC}$ \\
\hline $\mathrm{F}$ & 0.95 & 0.61 & $0.61 \#$ & 0.62 & 0.62 & 0.62 & $0.63 \#$ & 0.62 & 0.61 & 0.59 & $0.58 \#$ & 0.58 & 0.58 & $\mathrm{NC}$ \\
\hline $\mathrm{Fe}_{2} \mathrm{O}_{3}$ & 6.26 & 6.33 & 6.09 & 6.05 & 6.32 & 6.28 & 6.35 & 6.16 & 6.11 & 6.12 & 6.18 & 6.34 & 6.32 & -1.21 \\
\hline $\mathrm{K}_{2} \mathrm{O}$ & 5.52 & 5.10 & 5.02 & 5.00 & 5.07 & 5.11 & 5.05 & 5.04 & 5.02 & 5.03 & 5.02 & 4.96 & 4.93 & -9.20 \\
\hline $\mathrm{La}_{2} \mathrm{O}_{3}$ & $\S$ & $<0.01$ & $<0.01$ & $<0.01$ & $<0.01$ & $<0.01$ & $<0.01$ & $<0.01$ & $<0.01$ & $<0.01$ & $<0.01$ & $<0.01$ & $<0.01$ & $\mathrm{NC}$ \\
\hline $\mathrm{Li}_{2} \mathrm{O}^{*}$ & 3.09 & 3.09 & 3.09 & 3.09 & 3.09 & 3.09 & 3.09 & 3.09 & 3.09 & 3.09 & 3.09 & 3.09 & 3.09 & $\mathrm{NC}$ \\
\hline $\mathrm{MgO}$ & 0.08 & 0.14 & 0.14 & 0.15 & 0.14 & 0.14 & 0.15 & 0.14 & 0.16 & 0.15 & 0.11 & 0.12 & 0.16 & $\mathrm{NC}$ \\
\hline $\mathrm{MnO}$ & $\S$ & 0.03 & 0.02 & 0.02 & 0.02 & 0.02 & 0.02 & 0.02 & 0.01 & 0.01 & 0.01 & 0.03 & 0.04 & $\mathrm{NC}$ \\
\hline $\mathrm{Na}_{2} \mathrm{O}$ & 9.57 & 9.24 & 9.62 & 10.09 & 9.54 & 9.33 & 9.43 & 9.49 & 9.71 & 9.65 & 9.58 & 9.74 & 9.51 & 0.05 \\
\hline $\mathrm{Nd}_{2} \mathrm{O}_{3}$ & $\S$ & 0.01 & $<0.01$ & $<0.01$ & $<0.01$ & $<0.01$ & $<0.01$ & $<0.01$ & $<0.01$ & $<0.01$ & $<0.01$ & $<0.01$ & $<0.01$ & $\mathrm{NC}$ \\
\hline $\mathrm{NiO}$ & $\S$ & 0.04 & 0.04 & 0.03 & 0.04 & 0.03 & 0.03 & 0.02 & 0.02 & 0.02 & 0.02 & 0.04 & 0.04 & $\mathrm{NC}$ \\
\hline $\mathrm{P}_{2} \mathrm{O}_{5}$ & 1.59 & 1.63 & 1.63 & 1.63 & 1.66 & 1.66 & 1.65 & 1.68 & 1.66 & 1.64 & 1.65 & 1.62 & 1.64 & 3.56 \\
\hline $\mathrm{PbO}$ & 0.23 & 0.16 & 0.15 & 0.15 & 0.16 & 0.16 & 0.16 & 0.15 & 0.16 & 0.15 & 0.15 & 0.16 & 0.16 & $\mathrm{NC}$ \\
\hline $\mathrm{SiO}_{2}$ & 38.22 & 39.45 & 39.56 & 39.22 & 39.07 & 39.37 & 39.24 & 39.45 & 39.50 & 39.46 & 39.45 & 39.08 & 39.29 & 3.22 \\
\hline $\mathrm{SO}_{3}$ & $\S$ & 0.04 & 0.05 & 0.05 & 0.05 & 0.05 & 0.05 & 0.05 & 0.04 & 0.04 & 0.04 & 0.06 & 0.06 & $\mathrm{NC}$ \\
\hline $\mathrm{TiO}_{2}$ & $\S$ & 0.02 & 0.02 & 0.02 & 0.02 & 0.02 & 0.01 & 0.02 & 0.02 & 0.01 & 0.02 & 0.02 & 0.02 & $\mathrm{NC}$ \\
\hline $\mathrm{ZnO}$ & 1.50 & 1.22 & 1.21 & 1.24 & 1.31 & 1.32 & 1.33 & 1.32 & 1.31 & 1.35 & 1.36 & 1.35 & 1.31 & -9.53 \\
\hline $\mathrm{ZrO}_{2}$ & 0.05 & 0.07 & 0.06 & 0.06 & 0.06 & 0.06 & 0.06 & 0.06 & 0.06 & 0.06 & 0.06 & 0.08 & 0.09 & $\mathrm{NC}$ \\
\hline Sum & 100.00 & 100.00 & 100.00 & 100.00 & 100.00 & 100.00 & 100.00 & 100.00 & 100.00 & 100.00 & 100.00 & 100.00 & 100.00 & $\mathrm{NC}$ \\
\hline
\end{tabular}

$\S$ - Not a target constituent; * - Target values calculated using simple well-stirred tank model based on the DCP results of the first discharge; $\$$ calculated on BBL-G-124A (last discharge prior to idling); NC - Not calculated; \# - Fluorine was measured by XRF on polished samples, values for other samples calculated by interpolation 
Table 4.8. Results of PCT (ASTM C1285, 7-days at $90^{\circ} \mathrm{C}$, Stainless Steel Vessel; $\mathrm{S} / \mathrm{V}=2000 \mathrm{~m}^{-1}$ ).

\begin{tabular}{|c|c|c|c|c|c|c|c|}
\hline & $\begin{array}{c}1 \text { (HLW-E-SP- } \\
06)\end{array}$ & $\begin{array}{c}2 \text { (HLW-E-SP- } \\
05 \text { ) }\end{array}$ & 3 (HLW-E-M03) & $\begin{array}{c}4 \text { (HLW-E-ES- } \\
05)\end{array}$ & 5 (HLW-E-M-09) & \multirow[t]{2}{*}{ DWPF-EA } \\
\hline \multicolumn{2}{|l|}{ Glass Samples } & BLZ-G-123A & ABL-G-54A & ABL-G-131B & BBL-G-57A & BBL-G-124A & \\
\hline \multirow{4}{*}{$\begin{array}{c}\text { 7-Day PCT } \\
\text { Concentration } \\
(\mathrm{mg} / \mathrm{L})\end{array}$} & $\mathrm{B}$ & 28.52 & 22.45 & 34.04 & 123.70 & 92.88 & 16695 \\
\hline & $\mathrm{Li}$ & 3.29 & 3.15 & 7.73 & 29.43 & 20.90 & 9565 \\
\hline & $\mathrm{Na}$ & 41.00 & 34.93 & 38.98 & 123.70 & 87.70 & 13346 \\
\hline & $\mathrm{Si}$ & 32.92 & 33.36 & 47.55 & 44.08 & 45.02 & 3920 \\
\hline \multirow{5}{*}{$\begin{array}{c}\text { 7-Day PCT Normalized } \\
\text { Concentrations } \\
(\mathrm{g} / \mathrm{L})\end{array}$} & $\mathrm{B}$ & 0.68 & 0.58 & 0.83 & 2.71 & 2.05 & \\
\hline & $\mathrm{Li}$ & 0.56 & 0.58 & 0.67 & 2.04 & 1.46 & \\
\hline & $\mathrm{Na}$ & 0.55 & 0.50 & 0.54 & 1.70 & 1.23 & \\
\hline & $\mathrm{Si}$ & 0.20 & 0.21 & 0.25 & 0.24 & 0.24 & \\
\hline & $\mathrm{pH}$ & 9.82 & 9.98 & 9.65 & 9.85 & 9.87 & \\
\hline \multirow{4}{*}{$\begin{array}{c}\text { 7-Day PCT Normalized } \\
\text { Mass Loss } \\
\left(\mathrm{g} / \mathrm{m}^{2}\right)\end{array}$} & $\mathrm{B}$ & 0.34 & 0.29 & 0.41 & 1.35 & 1.03 & \\
\hline & $\mathrm{Li}$ & 0.28 & 0.29 & 0.33 & 1.02 & 0.73 & \\
\hline & $\mathrm{Na}$ & 0.27 & 0.25 & 0.27 & 0.85 & 0.62 & \\
\hline & $\mathrm{Si}$ & 0.10 & 0.10 & 0.13 & 0.12 & 0.12 & \\
\hline \multirow{4}{*}{$\begin{array}{c}\text { 7-Day PCT Normalized } \\
\text { Loss Rate } \\
\left(\mathrm{g} / \mathrm{d} / \mathrm{m}^{2}\right)\end{array}$} & $\mathrm{B}$ & 0.05 & 0.04 & 0.06 & 0.19 & 0.15 & \\
\hline & $\mathrm{Li}$ & 0.04 & 0.04 & 0.05 & 0.15 & 0.10 & \\
\hline & $\mathrm{Na}$ & 0.04 & 0.04 & 0.04 & 0.12 & 0.09 & \\
\hline & $\mathrm{Si}$ & 0.01 & 0.01 & 0.02 & 0.02 & 0.02 & \\
\hline
\end{tabular}


Table 4.9. TCLP Results for Discharged Glass Samples (mg/L).

\begin{tabular}{|c|c|c|c|c|c|c|c|c|}
\hline \multirow{2}{*}{ Test } & Element & $\mathrm{Ba}$ & $\mathrm{Bi}$ & $\mathrm{Cd}$ & $\mathrm{Cr}$ & $\mathrm{Ni}$ & $\mathrm{Pb}$ & $\mathrm{Zn}$ \\
\cline { 2 - 9 } & UTS Limits* & 21 & $\mathrm{NA}$ & 0.11 & 0.60 & 11.00 & 0.75 & 4.3 \\
\cline { 2 - 9 } & $\begin{array}{c}\text { Delisting Limits } \\
{[35,36]}\end{array}$ & 100 & $\mathrm{NA}$ & 0.48 & 4.95 & 22.6 & 5.00 & 225 \\
\hline 1 & BLZ-G-123A & 0.12 & $<0.25$ & 0.06 & 0.05 & $<0.04$ & $<0.01$ & 0.05 \\
\hline 2 & ABL-G-54A & 0.12 & $<0.25$ & 0.07 & $<0.01$ & $<0.04$ & $<0.01$ & 0.06 \\
\hline 3 & ABL-G-131B & 0.13 & 0.44 & $<0.03$ & 0.01 & $<0.04$ & $<0.01$ & 0.06 \\
\hline 4 & BBL-G-57A & 0.12 & 0.82 & $<0.03$ & 0.12 & $<0.04$ & $<0.01$ & 0.06 \\
\hline 5 & BBL-G-124A & 0.12 & 0.87 & $<0.03$ & 0.14 & $<0.04$ & $<0.01$ & 0.34 \\
\hline
\end{tabular}

. NA - Not applicable

* Although many of these do not apply to vitrified Hanford HLW, they are provided for comparison 
Table 4.10. Representative Compositions of Major Crystalline Phases in Melter Glass Pool Sampled by Dipping (atom\%).

\begin{tabular}{|c|c|c|c|c|c|}
\hline Test\# & \multicolumn{2}{|c|}{1 (HLW-SP06) } & \multicolumn{3}{|c|}{2 (HLW-SP05) } \\
\hline Sample ID & \multicolumn{2}{|c|}{ BLZ-D-131A } & \multicolumn{3}{|c|}{ ABL-D-63B } \\
\hline Crystal phase & Hematite & Spinel & Hematite & & inel \\
\hline Formula & $(\mathrm{Fe}, \mathrm{Cr})_{2} \mathrm{O}_{3}$ & $(\mathrm{Ni}, \mathrm{Fe}, \mathrm{Mn})(\mathrm{Fe}, \mathrm{Cr})_{2} \mathrm{O}_{4}$ & $(\mathrm{Fe}, \mathrm{Cr})_{2} \mathrm{O}_{3}$ & $(\mathrm{Fe}, \mathrm{Ni}, \mathrm{Mn})(\mathrm{Fe}, \mathrm{Cr})_{2} \mathrm{O}_{4}$ & $(\mathrm{Fe}, \mathrm{Ni}, \mathrm{Mn})(\mathrm{Fe}, \mathrm{Cr})_{2} \mathrm{O}_{4}$ \\
\hline $\mathrm{Al}^{3+}$ & - & - & - & - & - \\
\hline $\mathrm{Cr}^{3+}$ & 0.43 & 1.42 & 0.82 & 1.35 & 10.46 \\
\hline $\mathrm{Fe}^{3+} *$ & 39.57 & 32.35 & 39.18 & 33.11 & 24.65 \\
\hline $\mathrm{Mg}^{2+}$ & - & - & - & - & - \\
\hline $\mathrm{Mn}^{2+}$ & - & 1.72 & - & 1.76 & 2.32 \\
\hline $\mathrm{Ni}^{2+}$ & - & 6.07 & - & 5.17 & 3.80 \\
\hline $\mathrm{Zn}^{2+}$ & - & - & - & $<0.01$ & - \\
\hline $\mathrm{O}^{2-}$ & 60.00 & 58.44 & 60.00 & 58.61 & 58.78 \\
\hline Sum & 100.00 & 100.00 & 100.00 & 100.00 & 100.00 \\
\hline
\end{tabular}

\begin{tabular}{|c|c|c|c|c|c|c|}
\hline Test\# & \multicolumn{3}{|c|}{3 (HLW-E-M03) } & \multicolumn{2}{|c|}{4 (HLW-E-ES05) } & 5 (HLW-M09) \\
\hline Sample ID & \multicolumn{3}{|c|}{ ABL-D-140A } & \multicolumn{2}{|c|}{ BBL-D-60B } & BBL-D-130B \\
\hline Crystal phase & Spinel & (large) & Spinel & $\mathrm{Cr}_{2} \mathrm{O}_{3}$ platelet & Spinel & Spinel \\
\hline Formula & $\begin{array}{c}(\mathrm{Ni}, \mathrm{Fe}, \mathrm{Mn})(\mathrm{Fe}, \mathrm{Cr})_{2} \mathrm{O}_{4} \\
\text { (Core) }\end{array}$ & $\begin{array}{c}(\mathrm{Fe}, \mathrm{Ni}, \mathrm{Mn})(\mathrm{Cr}, \mathrm{Fe})_{2} \mathrm{O}_{4} \\
\text { (Outer) }\end{array}$ & $(\mathrm{Fe}, \mathrm{Ni}, \mathrm{Mn})(\mathrm{Cr}, \mathrm{Fe})_{2} \mathrm{O}_{4}$ & $(\mathrm{Cr}, \mathrm{Fe})_{2} \mathrm{O}_{3}$ & $(\mathrm{Fe}, \mathrm{Ni})(\mathrm{Cr}, \mathrm{Fe})_{2} \mathrm{O}_{4}$ & $(\mathrm{Zn}, \mathrm{Fe}, \mathrm{Mg})(\mathrm{Cr}, \mathrm{Fe})_{2} \mathrm{O}_{4}$ \\
\hline $\mathrm{Al}^{3+}$ & 1.04 & - & - & - & - & - \\
\hline $\mathrm{Cr}^{3+}$ & 8.14 & 20.98 & 23.44 & 32.36 & 21.41 & $27 . .31$ \\
\hline $\mathrm{Fe}^{3+} *$ & 22.31 & 12.87 & 11.63 & 7.64 & 15.51 & 4.82 \\
\hline $\mathrm{Mg}^{2+}$ & - & - & & - & - & 0.75 \\
\hline $\mathrm{Mn}^{2+}$ & 1.12 & 2.47 & 2.69 & - & - & - \\
\hline $\mathrm{Ni}^{2+}$ & 9.52 & 5.21 & 3.47 & - & 3.85 & - \\
\hline $\mathrm{Zn}^{2+}$ & - & - & - & - & - & 9.08 \\
\hline $\mathrm{O}^{2-}$ & 57.87 & 58.46 & 58.77 & 60.00 & 59.23 & 58.03 \\
\hline Sum & 100.00 & 100.00 & 100.00 & 1000.00 & 100.00 & 100.00 \\
\hline
\end{tabular}

* Calculated as $\mathrm{Fe}^{3+}$. Actually iron is present partially in the form of $\mathrm{Fe}^{2+}$.

- Empty data field (below detection limit). 
ORP-56294 Rev. 0

The Catholic University of America

Table 5.1. Results from Melter Off-Gas Emission Samples.

\begin{tabular}{|c|c|c|c|c|c|c|c|c|c|}
\hline & \multicolumn{4}{|c|}{ Test 1} & \multicolumn{4}{|c|}{ Test 2} \\
\hline & & \multicolumn{4}{|c|}{$\begin{array}{c}09 / 19 / 0811: 32-12: 35 \\
14.6 \% \text { Moisture, } 103.2 \% \text { Isokinetic }\end{array}$} & \multicolumn{4}{|c|}{$\begin{array}{c}\text { 10/10/2008 11:57-13:00 } \\
\text { 9.4\% Moisture, 99.26\% Isokinetic }\end{array}$} \\
\hline & & $\begin{array}{c}\text { Feed Rate }^{\#} \\
(\mathrm{mg} / \mathrm{min})\end{array}$ & $\begin{array}{c}\text { Emissions } \\
\text { Rate } \\
\text { (mg/min) }\end{array}$ & $\%$ Feed & DF & $\begin{array}{c}\text { Feed Rate }^{\#} \\
(\mathrm{mg} / \mathrm{min})\end{array}$ & $\begin{array}{c}\text { Emissions } \\
\text { Rate } \\
\text { (mg/min) }\end{array}$ & $\%$ Feed & $\mathrm{DF}$ \\
\hline \multirow{24}{*}{ 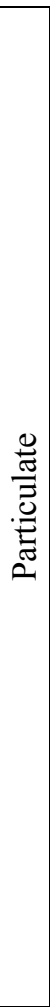 } & Total $^{\S}$ & 137382 & 2259 & 1.64 & 60.8 & 81848 & 1485 & 1.81 & 55.1 \\
\hline & $\mathrm{Al}$ & 5330 & 55.41 & 1.04 & 96.2 & 3455 & 35.68 & 1.03 & 96.8 \\
\hline & $\mathrm{Bi}$ & 0 & 0.52 & $\mathrm{NC}$ & $\mathrm{NC}$ & 0 & 0.14 & $\mathrm{NC}$ & $\mathrm{NC}$ \\
\hline & $\mathrm{B}$ & 4668 & 153.56 & 3.29 & 30.4 & 2580 & 83.47 & 3.24 & 30.9 \\
\hline & $\mathrm{Ba}$ & 0 & $<0.10$ & $\mathrm{NC}$ & $\mathrm{NC}$ & 0 & $<0.10$ & $\mathrm{NC}$ & $\mathrm{NC}$ \\
\hline & $\mathrm{Ca}$ & 299 & 5.07 & 1.69 & 59.0 & 197 & 4.12 & 2.09 & 47.8 \\
\hline & $\mathrm{Cd}$ & 182 & 4.46 & 2.45 & 40.8 & 117 & 2.86 & 2.44 & 41.0 \\
\hline & $\mathrm{Cl}^{*}$ & 0 & 22.91 & $\mathrm{NC}$ & $\mathrm{NC}$ & 0 & 16.20 & $\mathrm{NC}$ & $\mathrm{NC}$ \\
\hline & $\mathrm{Cr}$ & 116 & 3.29 & 2.83 & 35.3 & 71 & 1.61 & 2.28 & 43.8 \\
\hline & Cs & 85 & 5.35 & 6.26 & 16.0 & 52 & 3.63 & 6.99 & 14.3 \\
\hline & $\mathrm{F}^{*}$ & 0 & 4.92 & $\mathrm{NC}$ & $\mathrm{NC}$ & 0 & 1.58 & $\mathrm{NC}$ & $\mathrm{NC}$ \\
\hline & $\mathrm{Fe}$ & 15823 & 325.06 & 2.05 & 48.7 & 10251 & 245.17 & 2.39 & 41.8 \\
\hline & $\mathrm{K}$ & 6571 & 166.36 & 2.53 & 39.5 & 4005 & 107.93 & 2.69 & 37.1 \\
\hline & $\mathrm{Li}$ & 615 & 13.26 & 2.16 & 46.4 & 352 & 8.08 & 2.30 & 43.5 \\
\hline & $\mathrm{Mg}$ & 75 & 3.55 & 4.74 & 21.1 & 50 & 1.26 & 2.54 & 39.4 \\
\hline & $\mathrm{Mn}$ & 499 & 3.96 & 0.79 & 126.2 & 325 & 2.40 & 0.74 & 135.6 \\
\hline & $\mathrm{Na}$ & 8550 & 165.62 & 1.94 & 51.6 & 4632 & 104.19 & 2.25 & 44.5 \\
\hline & $\mathrm{Ni}$ & 631 & 8.55 & 1.35 & 73.8 & 411 & 4.89 & 1.19 & 84.1 \\
\hline & $\mathrm{P}$ & 20 & 0.44 & 2.23 & 44.8 & 12 & 0.24 & 2.01 & 49.6 \\
\hline & $\mathrm{Pb}$ & 115 & 2.90 & 2.51 & 39.8 & 77 & 1.82 & 2.38 & 42.1 \\
\hline & $\mathrm{S}^{*}$ & 32 & 3.23 & 10.1 & 9.9 & 19 & 2.09 & 11.0 & 9.1 \\
\hline & $\mathrm{Si}$ & 17609 & 154.34 & 0.88 & 114.1 & 10765 & 112.79 & 1.05 & 95.5 \\
\hline & $\mathrm{Zn}$ & 18 & 1.05 & 5.77 & 17.3 & 11 & 0.45 & 4.04 & 24.8 \\
\hline & $\mathrm{Zr}$ & 2369 & 17.85 & 0.75 & 132.7 & 1534 & 13.37 & 0.87 & 114.7 \\
\hline \multirow{4}{*}{$\tilde{E}$} & $\mathrm{~B}$ & 4668 & 19.50 & 0.42 & 239.3 & 2580 & 8.87 & 0.34 & 290.9 \\
\hline & $\mathrm{Cl}$ & 0 & 39.24 & $\mathrm{NC}$ & $\mathrm{NC}$ & 0 & 34.32 & $\mathrm{NC}$ & $\mathrm{NC}$ \\
\hline & $\mathrm{F}$ & 0 & 5.26 & $\mathrm{NC}$ & $\mathrm{NC}$ & 0 & 1.78 & $\mathrm{NC}$ & $\mathrm{NC}$ \\
\hline & $\mathrm{S}$ & 32 & 3.66 & 11.55 & 8.7 & 19 & 1.86 & 9.62 & 10.4 \\
\hline
\end{tabular}

$\$$ - From gravimetric analysis of filters and particulate nitric acid rinses

\# - Feed rate calculated from target composition and steady state production rate

* - Calculated from direct analysis of nitric acid rinses

NA - Not Available

$\mathrm{NC}-$ Not Calculated 
Table 5.1. Results from Melter Off-Gas Emission Samples (continued).

\begin{tabular}{|c|c|c|c|c|c|c|c|c|c|}
\hline & \multicolumn{4}{|c|}{ Test 3} & \multicolumn{4}{|c|}{ Test 4} \\
\hline & & \multicolumn{4}{|c|}{$\begin{array}{c}10 / 31 / 200813: 53-14: 53 \\
15.3 \% \text { Moisture, } 108.9 \% \text { Isokinetic }\end{array}$} & \multicolumn{4}{|c|}{$\begin{array}{c}11 / 13 / 2008 \text { 17:14 - 18:14 } \\
15.2 \% \text { Moisture, } 99.5 \% \text { Isokinetic }\end{array}$} \\
\hline & & $\begin{array}{c}\text { Feed Rate }^{\#} \\
(\mathrm{mg} / \mathrm{min})\end{array}$ & $\begin{array}{c}\text { Emissions } \\
\text { Rate } \\
\text { (mg/min) }\end{array}$ & $\%$ Feed & DF & $\begin{array}{c}\text { Feed Rate } \\
(\mathrm{mg} / \mathrm{min})\end{array}$ & $\begin{array}{c}\text { Emissions } \\
\text { Rate } \\
\text { (mg/min) }\end{array}$ & $\%$ Feed & $\mathrm{DF}$ \\
\hline \multirow{24}{*}{ 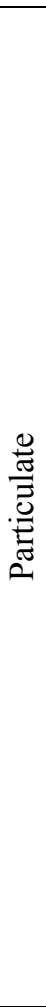 } & Total $^{\$}$ & 141233 & 656.9 & 0.47 & 215 & 160414 & 751.3 & 0.47 & 214 \\
\hline & $\mathrm{Al}$ & 7683 & 9.99 & 0.13 & 769.4 & 7610 & 7.86 & 0.10 & 968.1 \\
\hline & $\mathrm{Bi}$ & 1857 & 88.49 & 4.77 & 21.0 & 2097 & 21.65 & 1.03 & 96.8 \\
\hline & B & 4940 & 55.45 & 1.12 & 89.1 & 6084 & 55.44 & 0.91 & 109.7 \\
\hline & $\mathrm{Ba}$ & 11 & 0.18 & 1.67 & 59.8 & 12 & $<0.10$ & $<0.84$ & $>119$ \\
\hline & $\mathrm{Ca}$ & 1007 & 2.28 & 0.23 & 442.3 & 1136 & 3.20 & 0.28 & 355.3 \\
\hline & $\mathrm{Cd}$ & 0 & 0.76 & $\mathrm{NC}$ & $\mathrm{NC}$ & 0 & 0.21 & $\mathrm{NC}$ & $\mathrm{NC}$ \\
\hline & $\mathrm{Cl}^{*}$ & 0 & 18.20 & $\mathrm{NC}$ & $\mathrm{NC}$ & 0 & 23.98 & $\mathrm{NC}$ & $\mathrm{NC}$ \\
\hline & $\mathrm{Cr}$ & 2449 & 3.06 & 0.12 & 801.0 & 2719 & 21.47 & 0.79 & 126.6 \\
\hline & Cs & 0 & 0.20 & $\mathrm{NC}$ & $\mathrm{NC}$ & 0 & 0.14 & $\mathrm{NC}$ & $\mathrm{NC}$ \\
\hline & $\mathrm{F}^{*}$ & 1134 & 159.77 & 14.1 & 7.1 & 1285 & 94.17 & 7.33 & 13.6 \\
\hline & $\mathrm{Fe}$ & 5224 & 18.77 & 0.36 & 278.3 & 5891 & 18.66 & 0.32 & 315.6 \\
\hline & $\mathrm{K}$ & 4498 & 43.94 & 0.98 & 102.3 & 6169 & 79.10 & 1.28 & 78.0 \\
\hline & $\mathrm{Li}$ & 1441 & 5.97 & 0.41 & 241.5 & 1932 & 10.29 & 0.53 & 187.8 \\
\hline & $\mathrm{Mg}$ & 58 & 0.42 & 0.72 & 138.2 & 64 & 0.56 & 0.88 & 114.0 \\
\hline & $\mathrm{Mn}$ & 693 & 0.60 & 0.09 & 1164 & 0 & $<0.10$ & $\mathrm{NC}$ & $\mathrm{NC}$ \\
\hline & $\mathrm{Na}$ & 8473 & 49.58 & 0.59 & 170.9 & 9553 & 63.81 & 0.67 & 149.7 \\
\hline & $\mathrm{Ni}$ & 703 & 2.13 & 0.30 & 330.6 & 0 & $<0.10$ & $\mathrm{NC}$ & $\mathrm{NC}$ \\
\hline & $\mathrm{P}$ & 828 & 2.70 & 0.33 & 306.5 & 937 & 3.97 & 0.42 & 236.1 \\
\hline & $\mathrm{Pb}$ & 255 & 1.87 & 0.73 & 136.2 & 283 & 2.36 & 0.83 & 119.9 \\
\hline & $\mathrm{S}^{*}$ & 0 & 0.89 & $\mathrm{NC}$ & $\mathrm{NC}$ & 0 & 1.24 & $\mathrm{NC}$ & $\mathrm{NC}$ \\
\hline & $\mathrm{Si}$ & 22007 & 29.41 & 0.13 & 748.3 & 24038 & 24.55 & 0.10 & 979.0 \\
\hline & $\mathrm{Zn}$ & 0 & 0.22 & $\mathrm{NC}$ & $\mathrm{NC}$ & 0 & 0.15 & $\mathrm{NC}$ & $\mathrm{NC}$ \\
\hline & $\mathrm{Zr}$ & 44 & 0.37 & 0.84 & 119.4 & 49 & 0.17 & 0.34 & 292.8 \\
\hline \multirow{4}{*}{$\stackrel{\mathscr{0}}{0}$} & $\mathrm{~B}$ & 4940 & 45.48 & 0.92 & 108.6 & 6084 & 75.54 & 1.24 & 80.5 \\
\hline & $\mathrm{Cl}$ & 0 & 53.17 & $\mathrm{NC}$ & $\mathrm{NC}$ & 0 & 59.54 & $\mathrm{NC}$ & $\mathrm{NC}$ \\
\hline & $\mathrm{F}$ & 1134 & 88.41 & 7.80 & 12.8 & 1285 & 186.42 & 14.51 & 6.9 \\
\hline & $\mathrm{S}$ & 0 & 3.05 & $\mathrm{NC}$ & $\mathrm{NC}$ & 0 & 0.98 & $\mathrm{NC}$ & $\mathrm{NC}$ \\
\hline
\end{tabular}


Table 5.1. Results from Melter Off-Gas Emission Samples (continued).

\begin{tabular}{|c|c|c|c|c|c|}
\hline & \multicolumn{4}{|c|}{ Test 5} \\
\hline & & \multicolumn{4}{|c|}{$\begin{array}{c}12 / 11 / 2008 \text { 17:18 - 18:18 } \\
17.5 \% \text { Moisture, } 113.3 \% \text { Isokinetic }\end{array}$} \\
\hline & & $\begin{array}{l}\text { Feed Rate }^{\#} \\
(\mathrm{mg} / \mathrm{min})\end{array}$ & $\begin{array}{c}\text { Emissions Rate } \\
(\mathrm{mg} / \mathrm{min})\end{array}$ & $\%$ Feed & DF \\
\hline \multirow{24}{*}{ 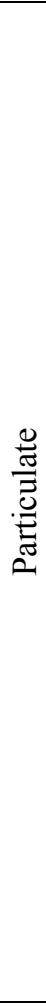 } & Total $^{\$}$ & 169231 & 1023 & 0.60 & 165 \\
\hline & $\mathrm{Al}$ & 7986 & 14.17 & 0.18 & 563.7 \\
\hline & $\mathrm{Bi}$ & 2198 & 32.65 & 1.49 & 67.3 \\
\hline & $\mathrm{B}$ & 6385 & 73.31 & 1.15 & 87.1 \\
\hline & $\mathrm{Ba}$ & 13 & 0.19 & 1.50 & 66.7 \\
\hline & $\mathrm{Ca}$ & 1191 & 4.88 & 0.41 & 244.3 \\
\hline & $\mathrm{Cd}$ & 0 & $<0.10$ & $\mathrm{NC}$ & $\mathrm{NC}$ \\
\hline & $\mathrm{Cl}^{*}$ & 0 & 20.63 & $\mathrm{NC}$ & $\mathrm{NC}$ \\
\hline & $\mathrm{Cr}$ & 2899 & 29.60 & 1.02 & 97.9 \\
\hline & Cs & 0 & $<0.10$ & $\mathrm{NC}$ & $\mathrm{NC}$ \\
\hline & $\mathrm{F}^{*}$ & 1342 & 120.02 & 8.94 & 11 \\
\hline & $\mathrm{Fe}$ & 6181 & 24.02 & 0.39 & 257.4 \\
\hline & $\mathrm{K}$ & 6471 & 99.23 & 1.53 & 65.2 \\
\hline & $\mathrm{Li}$ & 2027 & 13.54 & 0.67 & 149.8 \\
\hline & $\mathrm{Mg}$ & 68 & 0.71 & 1.04 & 95.9 \\
\hline & $\mathrm{Mn}$ & 0 & $<0.10$ & $\mathrm{NC}$ & $\mathrm{NC}$ \\
\hline & $\mathrm{Na}$ & 10027 & 86.14 & 0.86 & 116.4 \\
\hline & $\mathrm{Ni}$ & 0 & $<0.10$ & $\mathrm{NC}$ & $\mathrm{NC}$ \\
\hline & $\mathrm{P}$ & 980 & 1.83 & 0.19 & 536.4 \\
\hline & $\mathrm{Pb}$ & 302 & 2.24 & 0.74 & 134.9 \\
\hline & $\mathrm{S}^{*}$ & 0 & 1.48 & $\mathrm{NC}$ & $\mathrm{NC}$ \\
\hline & $\mathrm{Si}$ & 25230 & 50.26 & 0.20 & 502.0 \\
\hline & $\mathrm{Zn}$ & 1702 & 8.19 & 0.48 & 207.8 \\
\hline & $\mathrm{Zr}$ & 52 & 0.23 & 0.44 & 229.0 \\
\hline \multirow{4}{*}{$\stackrel{n}{0}$} & $\mathrm{~B}$ & 6385 & 90.44 & 1.42 & 70.6 \\
\hline & $\mathrm{Cl}$ & 0 & 49.69 & $\mathrm{NC}$ & $\mathrm{NC}$ \\
\hline & $\mathrm{F}$ & 1342 & 176.35 & 13.15 & 7.6 \\
\hline & $\mathrm{S}$ & 0 & 0.28 & $\mathrm{NC}$ & $\mathrm{NC}$ \\
\hline
\end{tabular}

$\$$ - From gravimetric analysis of filters and particulate nitric acid rinses

\# - Feed rate calculated from target composition and steady state production rate

* - Calculated from direct analysis of nitric acid rinses

$\mathrm{NC}$ - Not Calculated 
ORP-56294 Rev. 0

The Catholic University of America

Table 5.2. Concentrations [ppmv] of Selected Species in Off-Gas Measured by FTIR Spectroscopy.

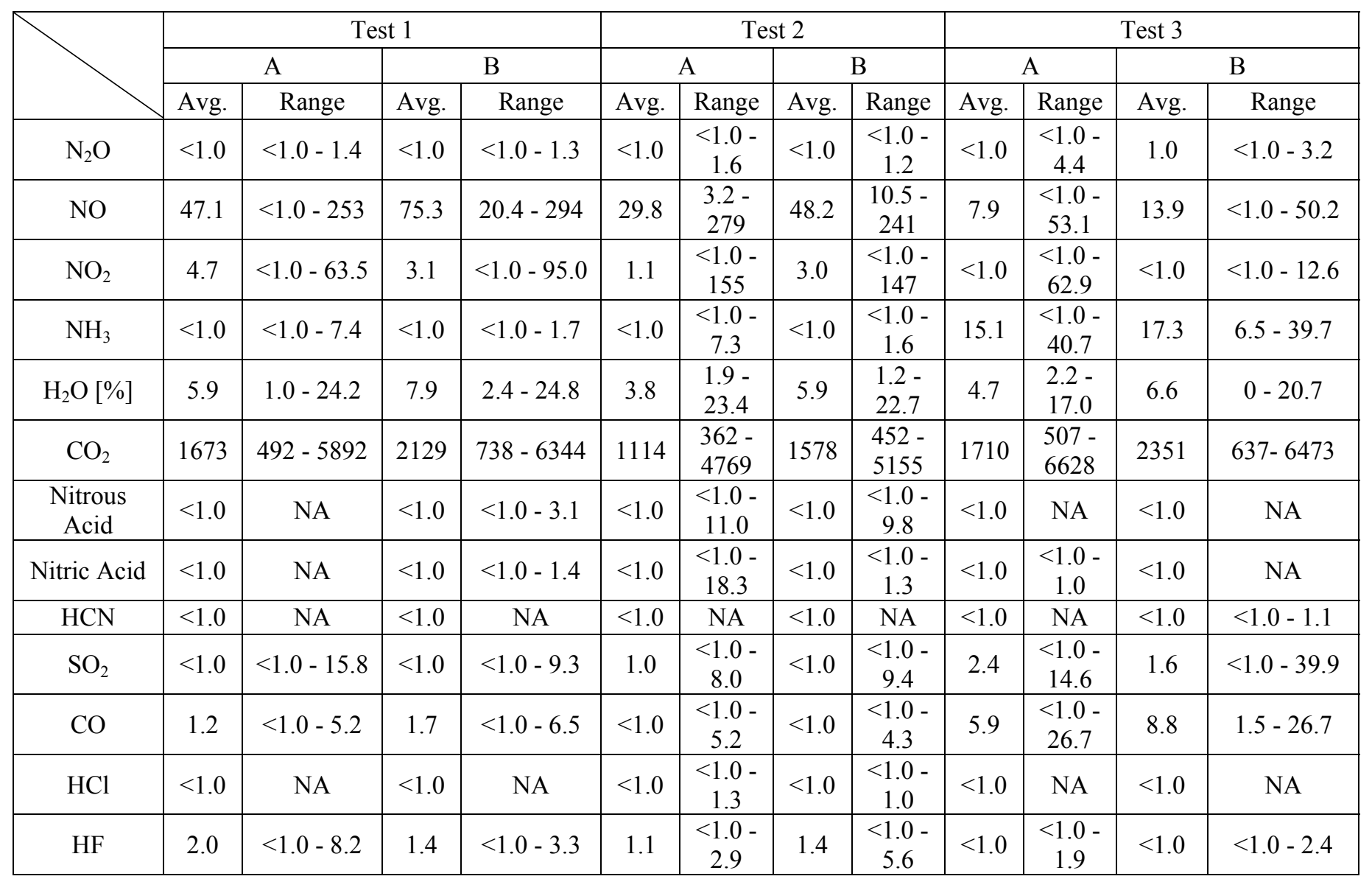

NA : Not applicable. 
ORP-56294 Rev. 0

The Catholic University of America

Table 5.2. Concentrations [ppmv] of Selected Species in Off-Gas Measured by FTIR Spectroscopy (continued).

\begin{tabular}{|c|c|c|c|c|c|c|c|c|}
\hline & \multicolumn{4}{|c|}{ Test 4} & \multicolumn{4}{|c|}{ Test 5} \\
\hline & \multicolumn{2}{|r|}{ A } & \multicolumn{2}{|r|}{ B } & \multicolumn{2}{|r|}{ A } & \multicolumn{2}{|r|}{ B } \\
\hline & Avg. & Range & Avg. & Range & Avg. & Range & Avg. & Range \\
\hline $\mathrm{N}_{2} \mathrm{O}$ & $<1.0$ & $<1.0-1.5$ & $<1.0$ & $<1.0-1.6$ & $<1.0$ & $<1.0-1.6$ & $<1.0$ & $<1.0-1.1$ \\
\hline NO & 63.0 & $35.2-273$ & 102 & $45.4-442$ & 78.6 & $33.4-317$ & 120 & $46.4-312$ \\
\hline $\mathrm{NO}_{2}$ & 4.2 & $<1.0-15.2$ & 6.0 & $<1.0-22.5$ & 4.6 & $<1.0-115$ & 12.7 & $<1.0-27.5$ \\
\hline $\mathrm{NH}_{3}$ & $<1.0$ & NA & $<1.0$ & NA & $<1.0$ & $<1.0-5.1$ & $<1.0$ & NA \\
\hline $\mathrm{H}_{2} \mathrm{O}[\%]$ & 5.5 & $2.4-13.7$ & 9.1 & $2.3-20.4$ & 6.6 & $2.0-17.2$ & 10.4 & $2.2-20.1$ \\
\hline $\mathrm{CO}_{2}$ & 2035 & $553-5814$ & 3348 & $1195-8409$ & 2325 & $543-7520$ & 3652 & $1285-6842$ \\
\hline Nitrous Acid & $<1.0$ & NA & $<1.0$ & NA & $<1.0$ & $<1.0-1.8$ & $<1.0$ & NA \\
\hline Nitric Acid & $<1.0$ & $<1.0-1.5$ & $<1.0$ & $<1.0-1.5$ & $<1.0$ & $<1.0-5.6$ & $<1.0$ & $<1.0-1.9$ \\
\hline $\mathrm{HCN}$ & $<1.0$ & NA & $<1.0$ & NA & $<1.0$ & NA & $<1.0$ & NA \\
\hline $\mathrm{SO}_{2}$ & 1.2 & $<1.0-6.5$ & 1.5 & $<1.0-16.8$ & 1.3 & $<1.0-83.3$ & 2.2 & $<1.0-62.7$ \\
\hline $\mathrm{CO}$ & 1.1 & $<1.0-3.5$ & 2.5 & $<1.0-7.2$ & $<1.0$ & $<1.0-5.1$ & 1.5 & $<1.0-2.8$ \\
\hline $\mathrm{HCl}$ & 2.0 & $<1.0-3.0$ & 2.9 & $<1.0-6.5$ & 1.9 & $<1.0-4.3$ & 3.3 & $<1.0-11.6$ \\
\hline $\mathrm{HF}$ & 15.9 & $4.8-23.7$ & 29.0 & $15.5-36.0$ & 26.9 & $7.4-41.0$ & 39.4 & $19.2-69.5$ \\
\hline
\end{tabular}

NA : Not applicable. 


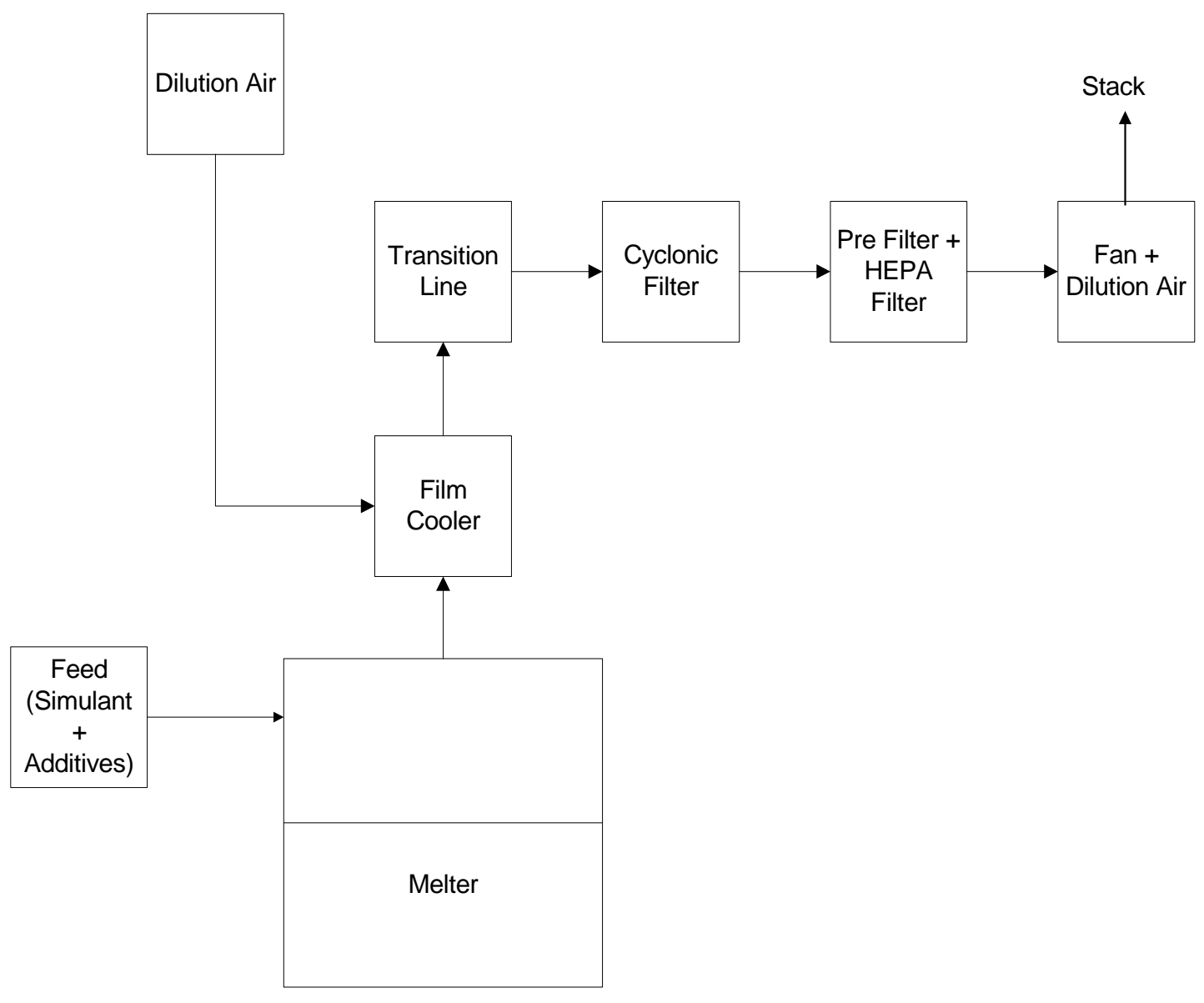

Figure 1.1. Schematic diagram of DuraMelter 100-BL vitrification system. 


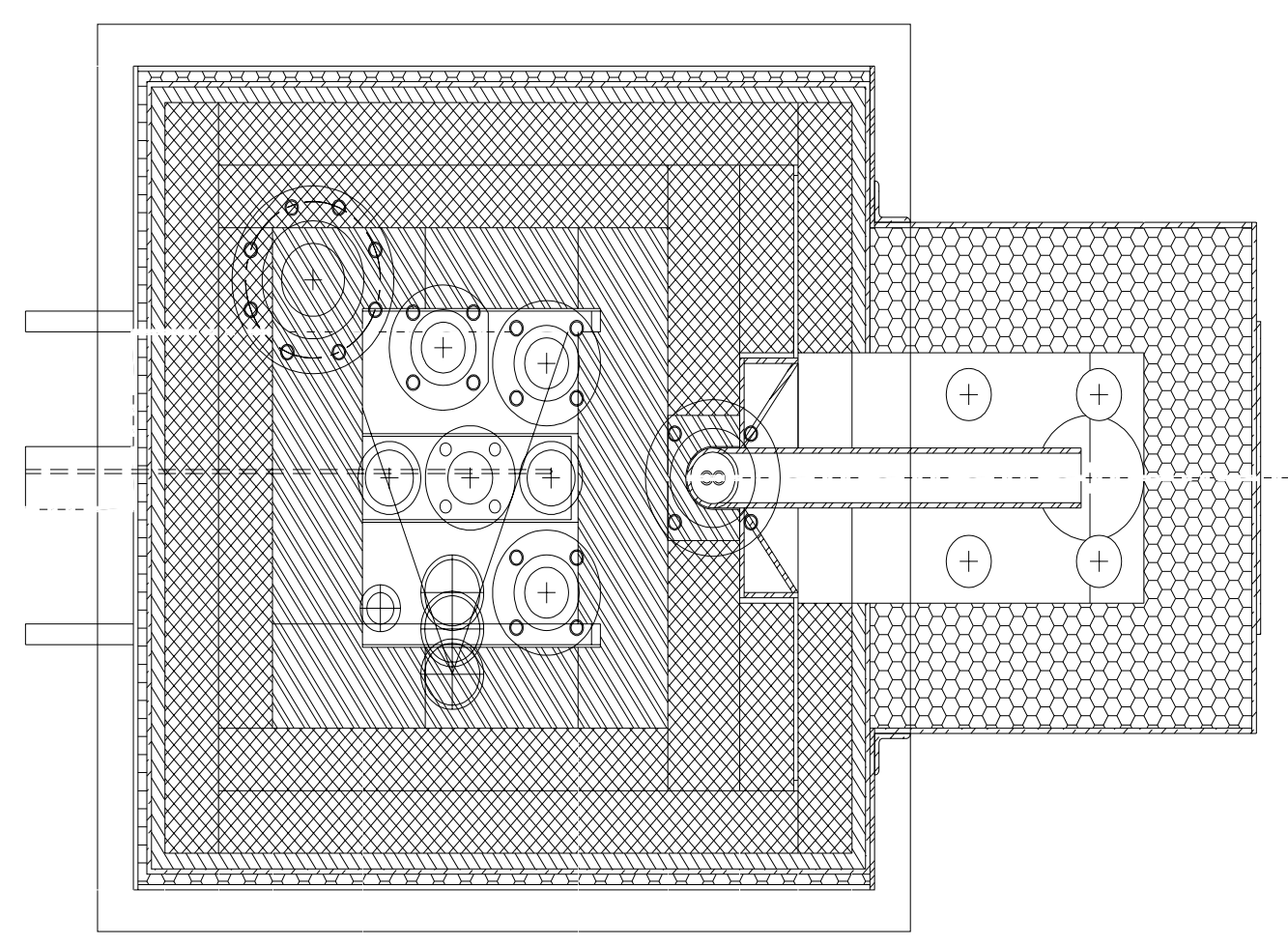

Figure 1.2.a. Schematic diagram showing cross-section through the DM100-BL-melter. Plan view showing locations of lid ports. 
ORP-56294 Rev. 0

The Catholic University of America Vitreous State Laboratory

Effects of High Crystal Content in HLW DM100 Melter Tests

Final Report, VSL-09R1520-1, Rev. 0

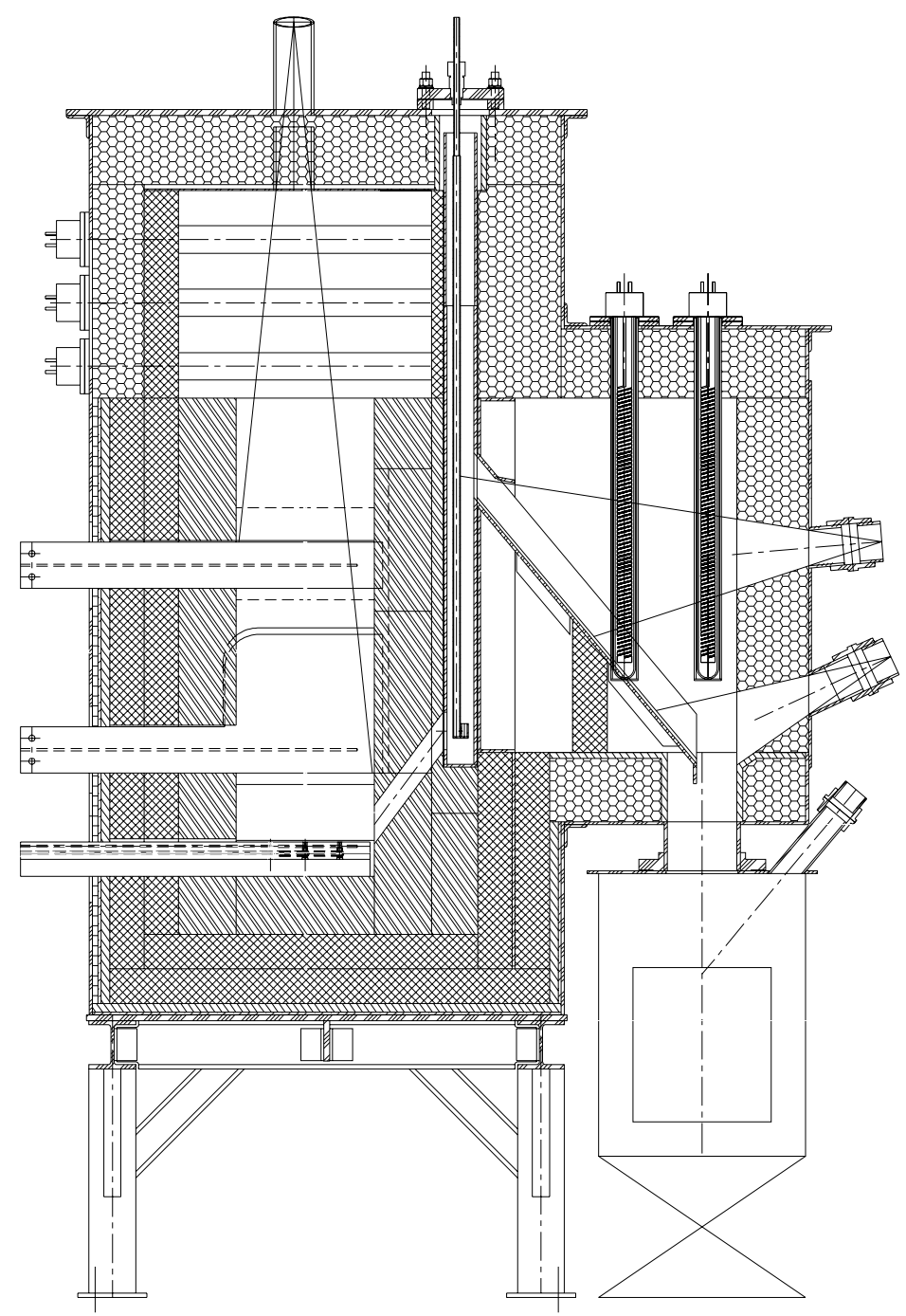

Figure 1.2.b. Schematic diagram showing cross-section through the DM100-BL melter. 
ORP-56294 Rev. 0

The Catholic University of America Vitreous State Laboratory

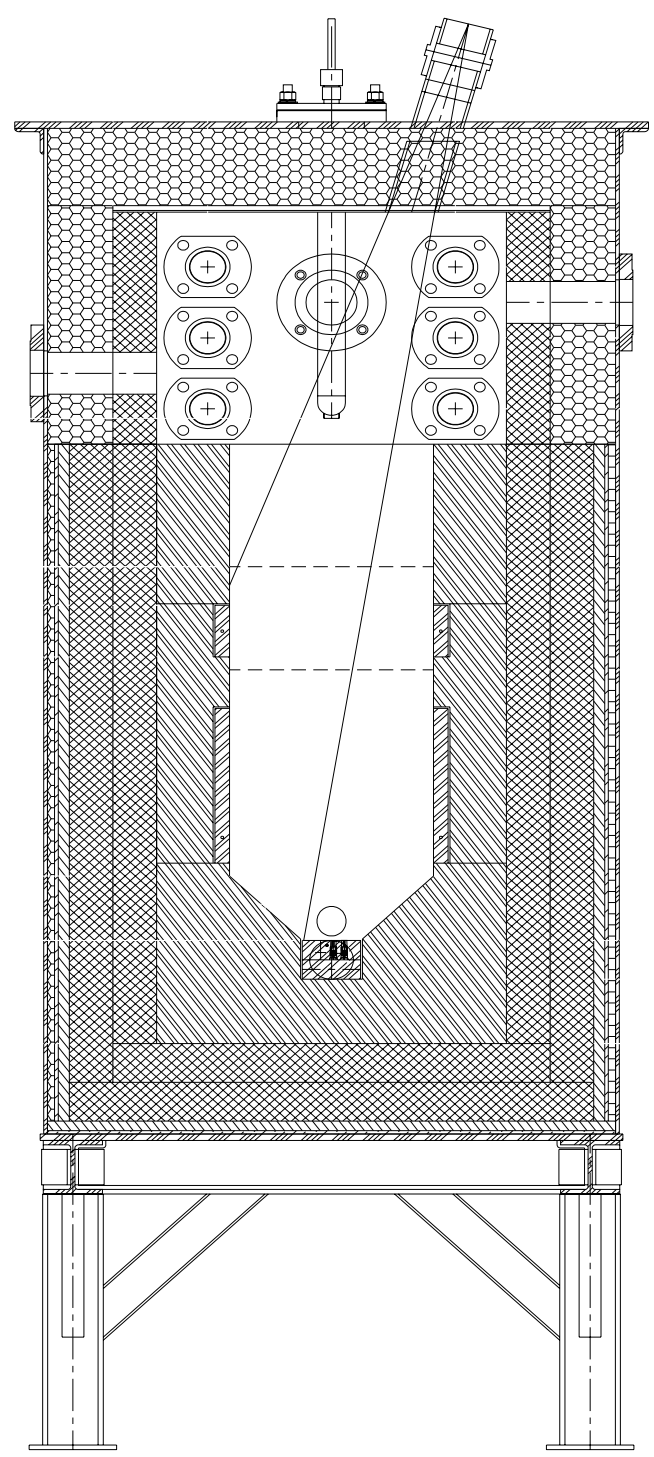

Figure 1.2.c. Schematic diagram showing cross-section through the DM100-BL melter. 


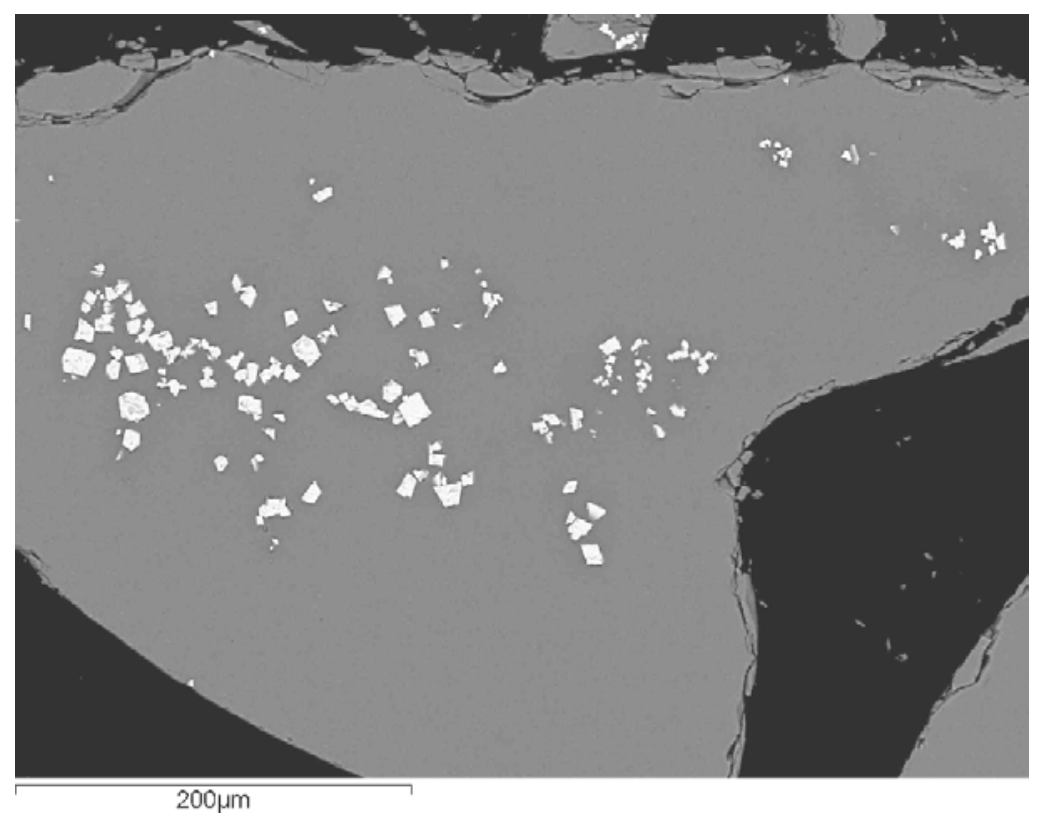

Figure 2.1. Electron micrograph of heat-treated HLW-E-SP-05 glass $\left(1150^{\circ} \mathrm{C}\right.$ for 70 hours) showing spinel crystals. 


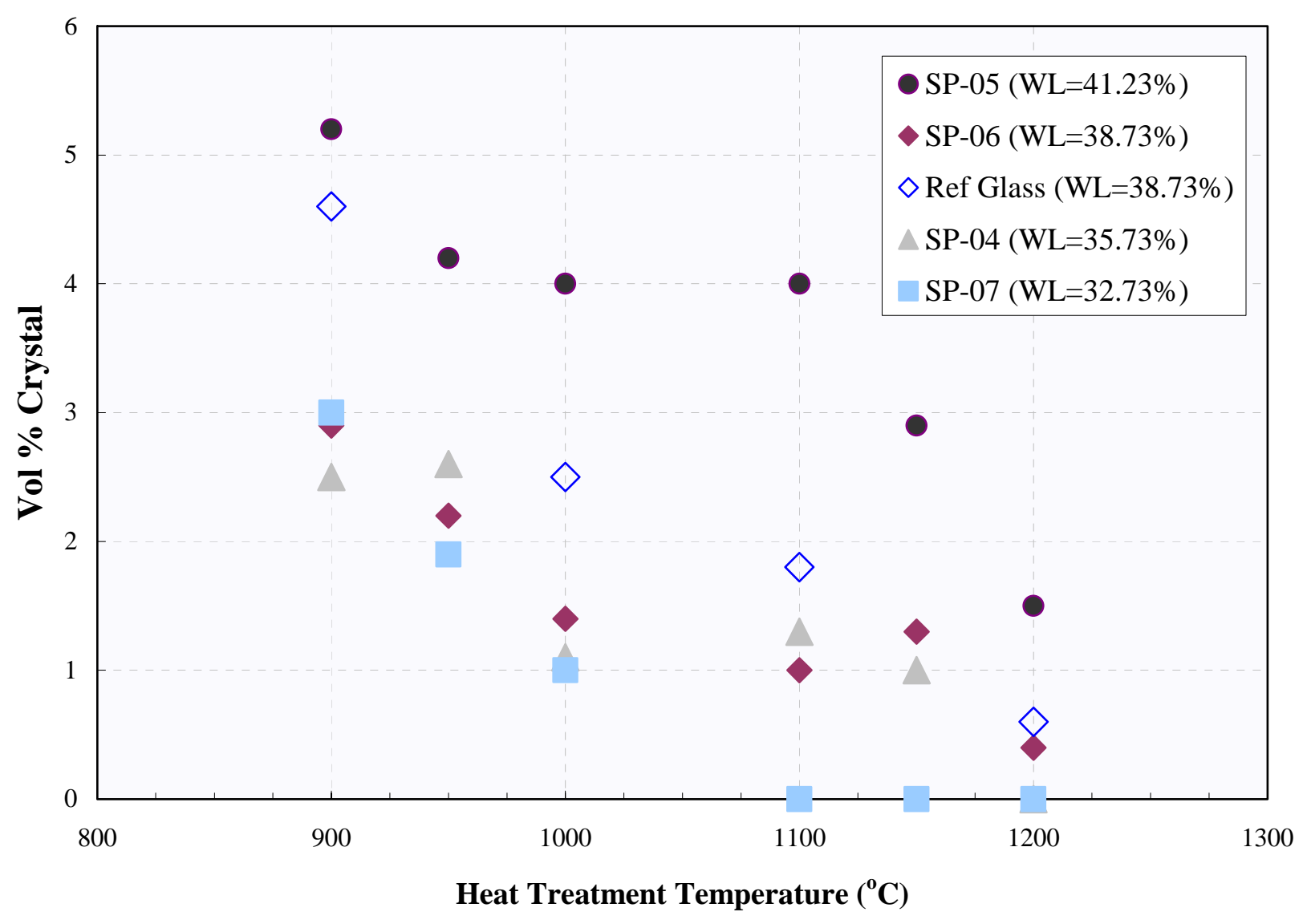

Figure 2.2. Spinel crystallization in HLW-E-SP glasses as a function of heat treatment temperature after 70 hours (Data for $1200^{\circ} \mathrm{C}$ were collected on as-melted glasses; melting time = 2 hours; WL = Waste Loading).

(Standard deviation of the vol\% crystals measurement is $0.5 \mathrm{vol} \%$ ) 


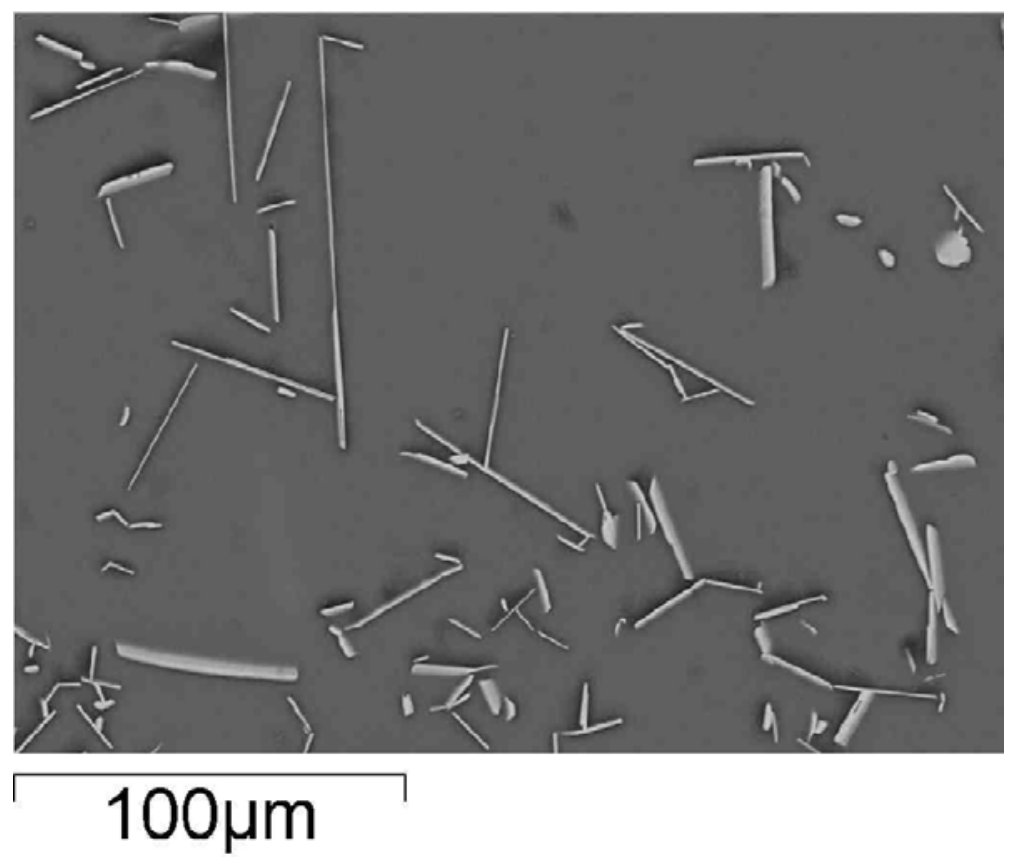

Figure 2.3. Electron micrograph of heat-treated HLW-E-ES-02 glass $\left(950^{\circ} \mathrm{C}\right.$ for 70 hours) showing chromium oxide crystals as elongated platelets. 


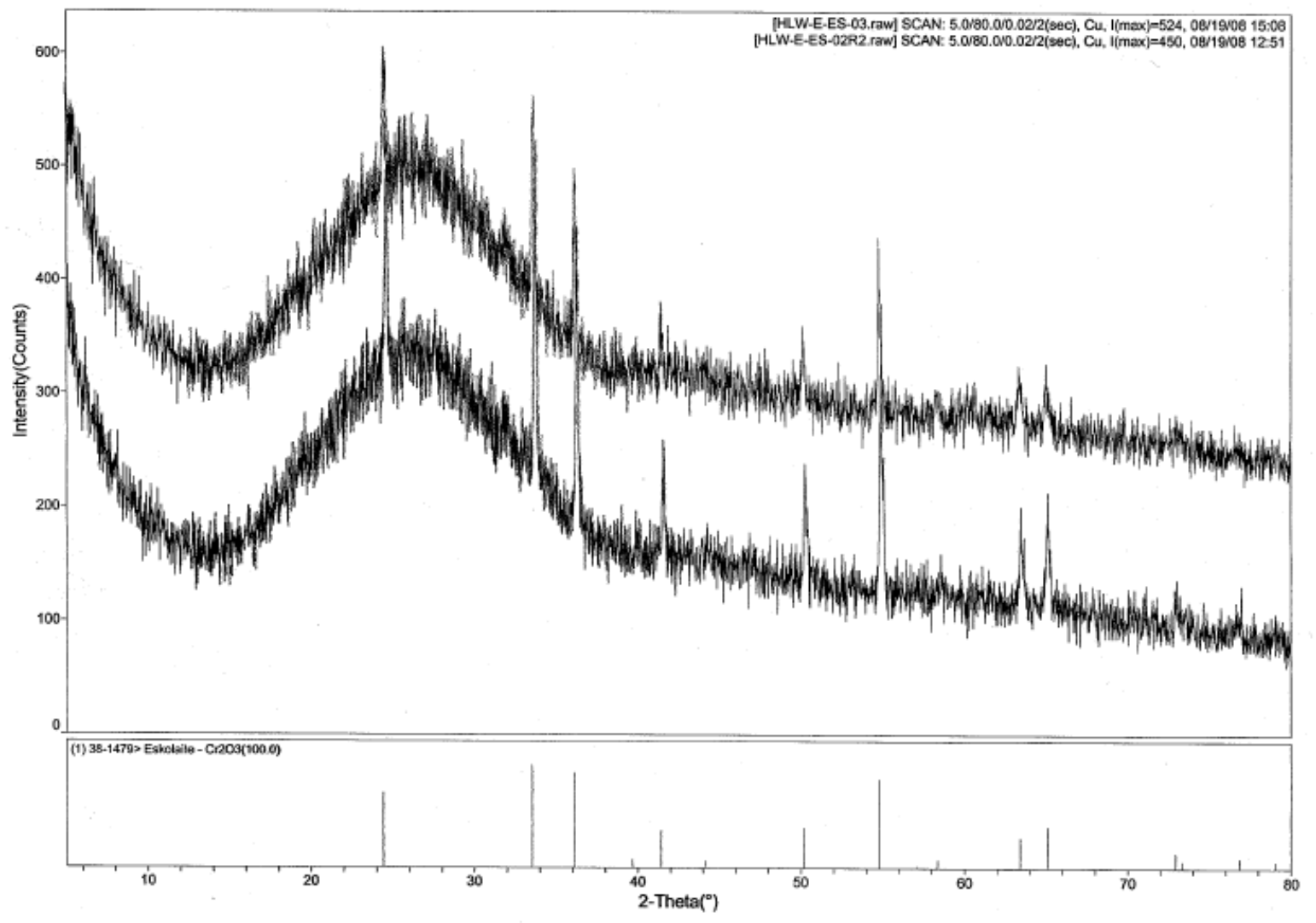

Figure 2.4. X-ray diffraction patterns of heat-treated samples of HLW-E-ES-03 (top) and HLW-E-ES-02 (bottom). 


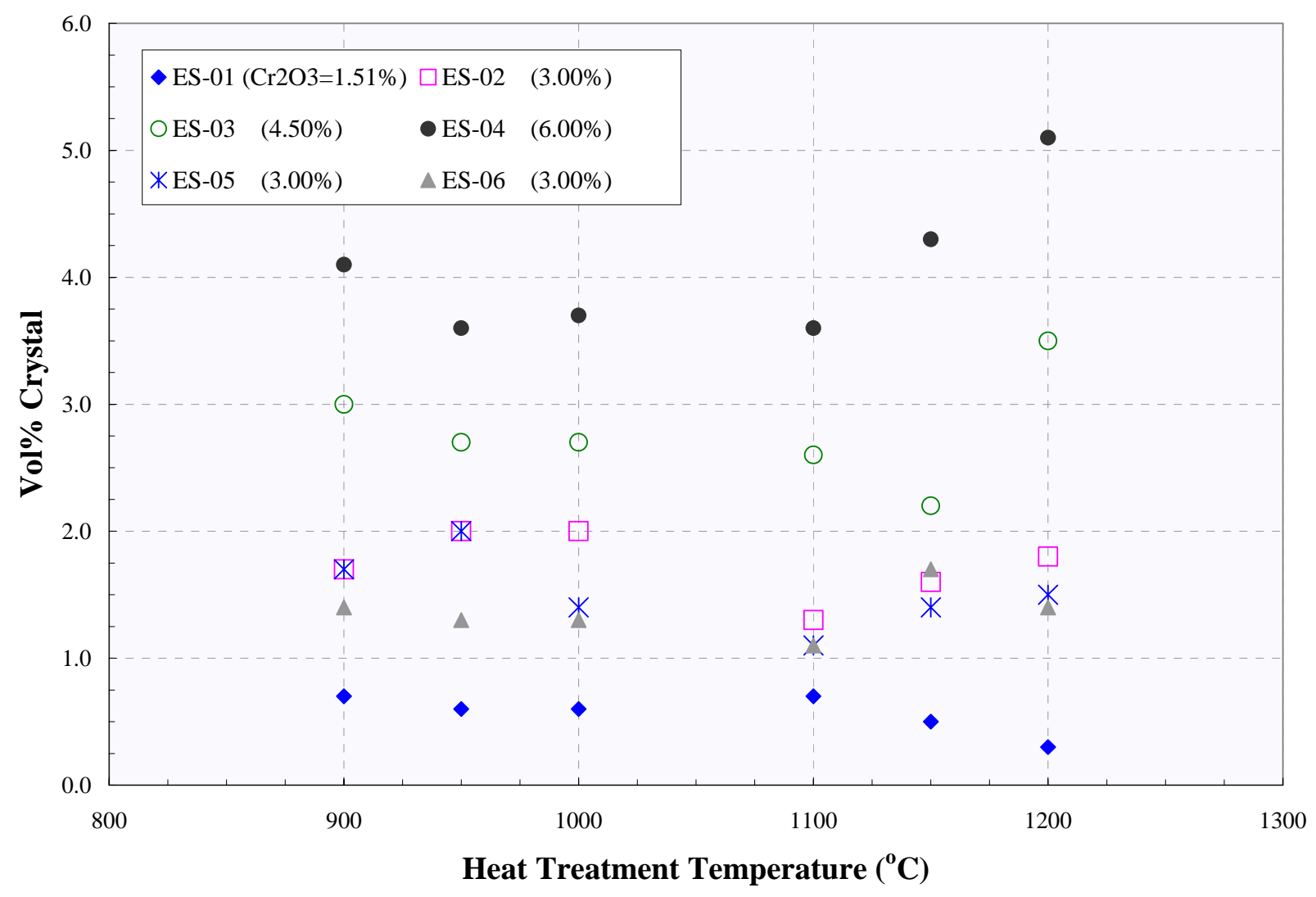

Figure 2.5. Eskolaite crystallization in HLW-E-ES glasses as a function of heat treatment temperature after 70 hours (Data for $1200^{\circ} \mathrm{C}$ were collected on as-melted glasses; melting time $=2$ hours]).

(Standard deviation of the vol\% crystals measurement is $0.5 \mathrm{vol} \%$ ) 
ORP-56294 Rev. 0

The Catholic University of America Vitreous State Laboratory

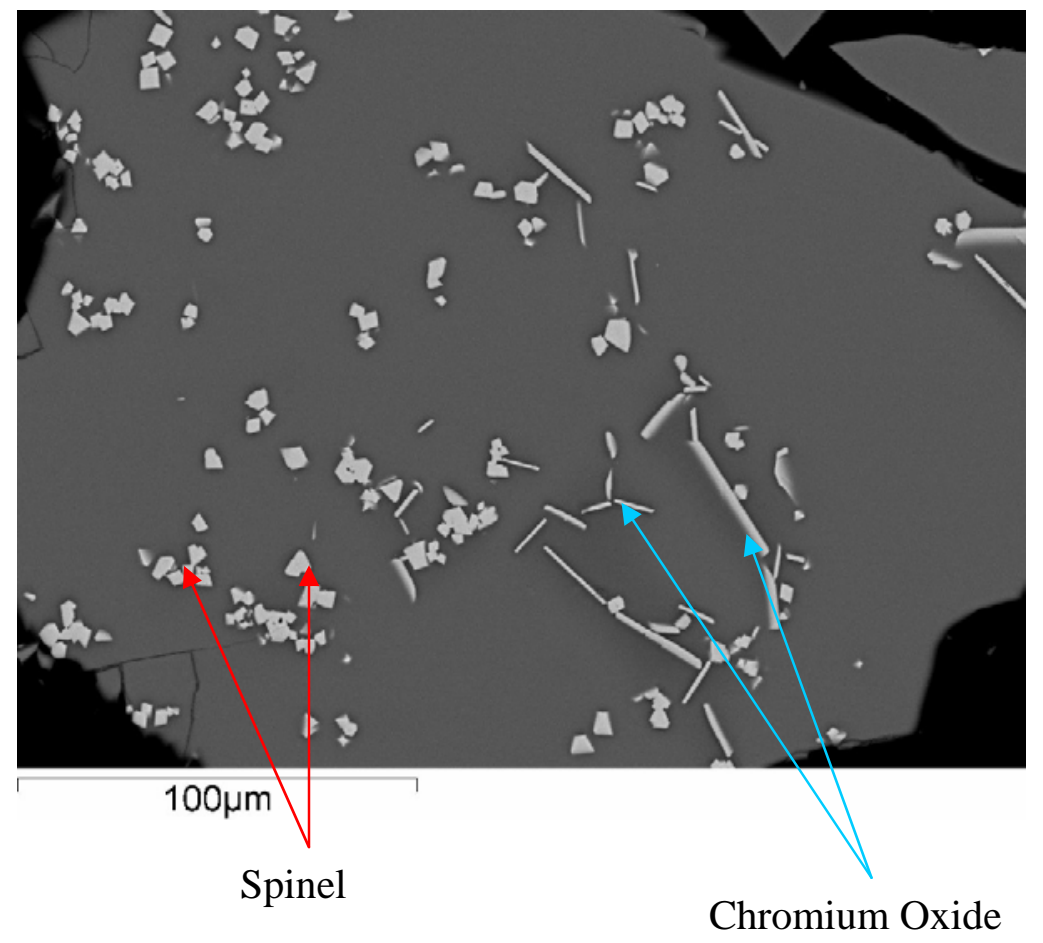

Figure 2.6. Electron micrograph of heat-treated $\mathrm{HLW}-\mathrm{E}-\mathrm{M}-03$ glass $\left(950^{\circ} \mathrm{C}\right.$ for 70 hours) showing spinel and chromium oxide crystals. 


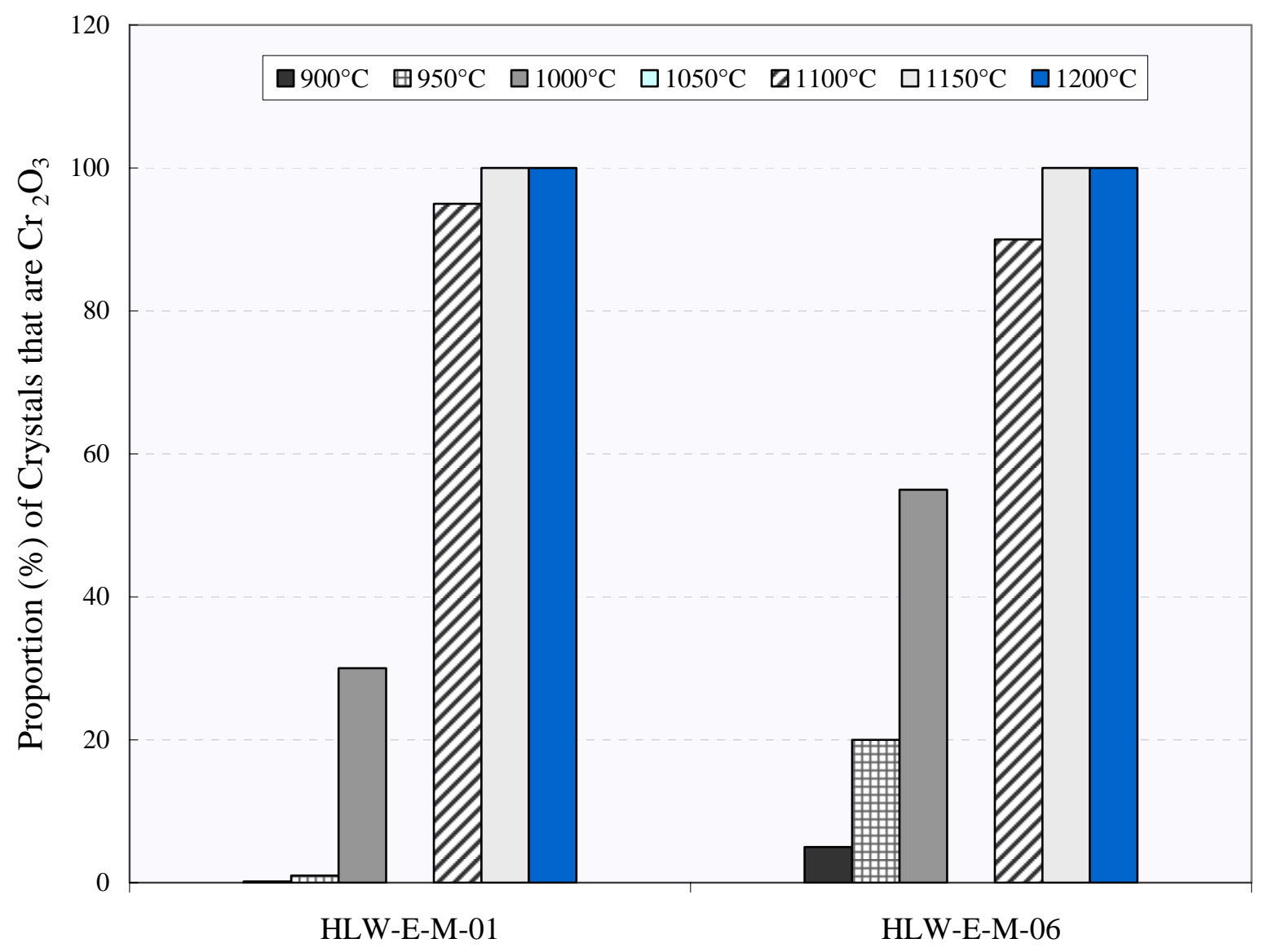

Figure 2.7. Estimated proportion of eskolaite observed in crystalline phases in HLW-E-M-01 and HLW-E-M-06 as a function of heat treatment temperature after 70 hours (Data were not collected for $1050^{\circ} \mathrm{C}$; Data for $1200^{\circ} \mathrm{C}$ were collected on as-melted glasses; melting time $=2$ hours $]$ ). 


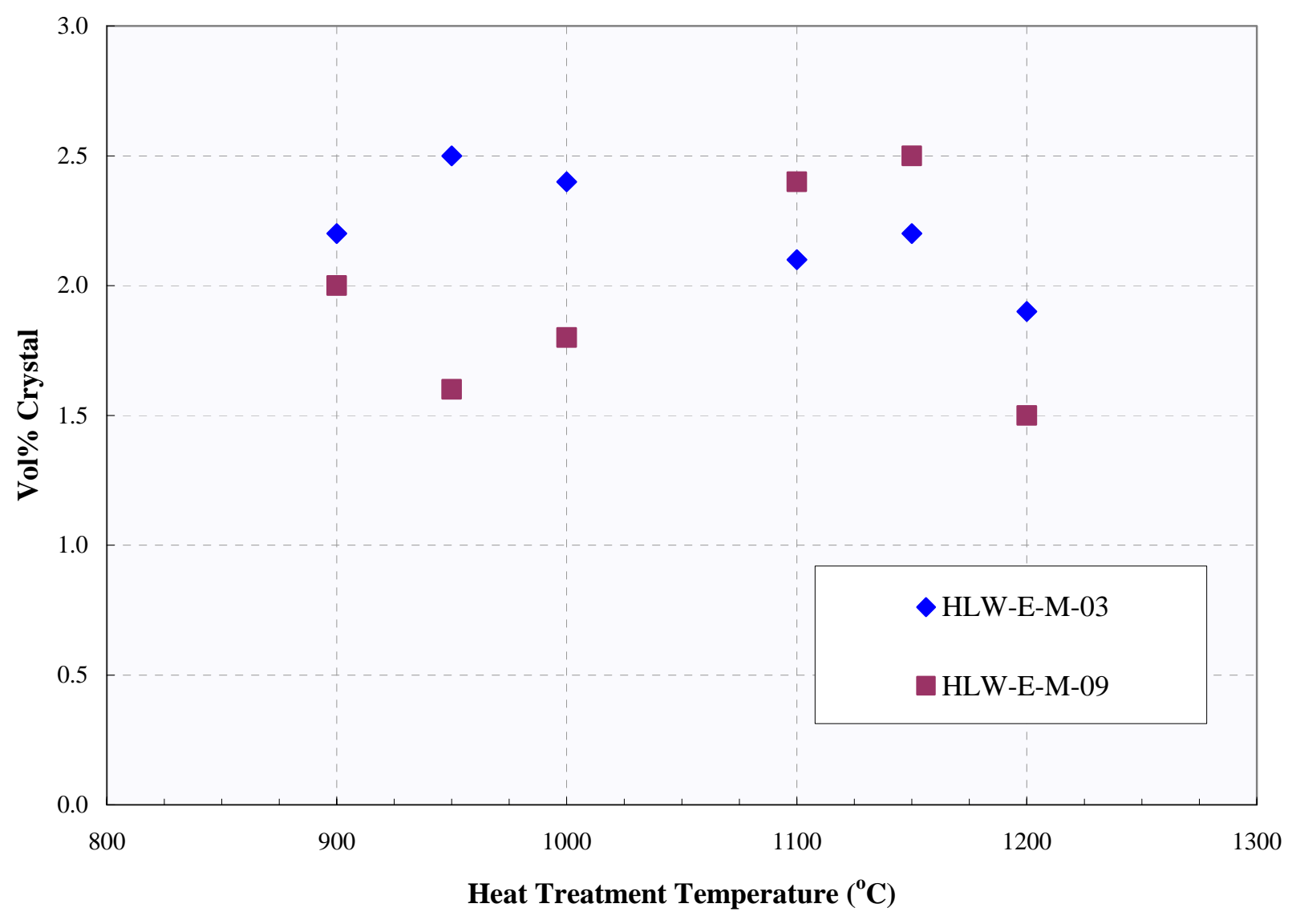

Figure 2.8. Crystallization in glasses selected for melter tests (HLW-E-M-03 and HLW-E-M-

09) as a function of heat treatment temperature after 70 hours (Data for $1200^{\circ} \mathrm{C}$ were collected on as-melted glasses; melting time $=2$ hours).

(Standard deviation of the vol\% crystals measurement is $0.5 \mathrm{vol} \%$ ) 


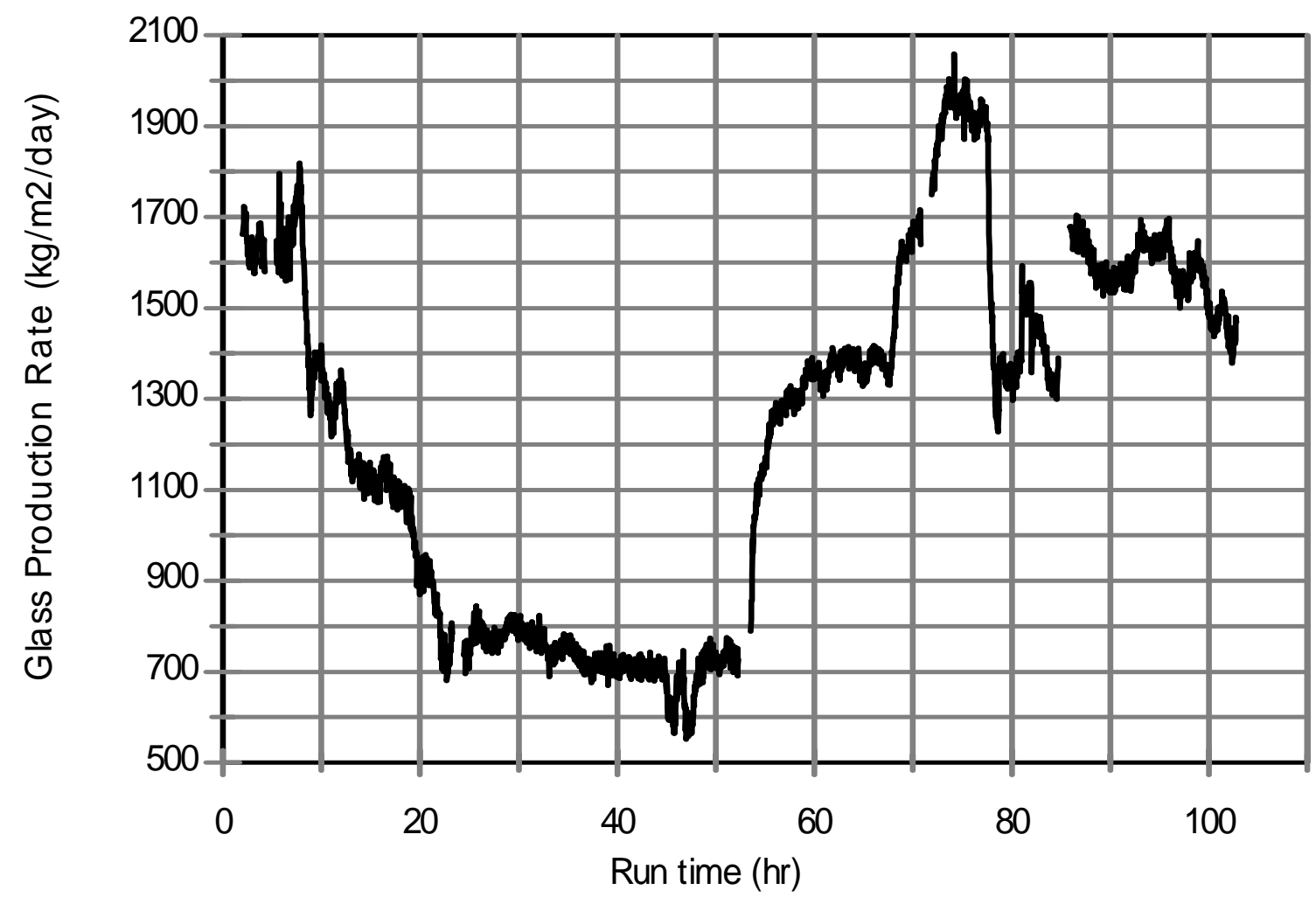

Figure 3.1.a. Glass production rates (hourly moving averages) for DM100 Tests 1a and $1 b$. 


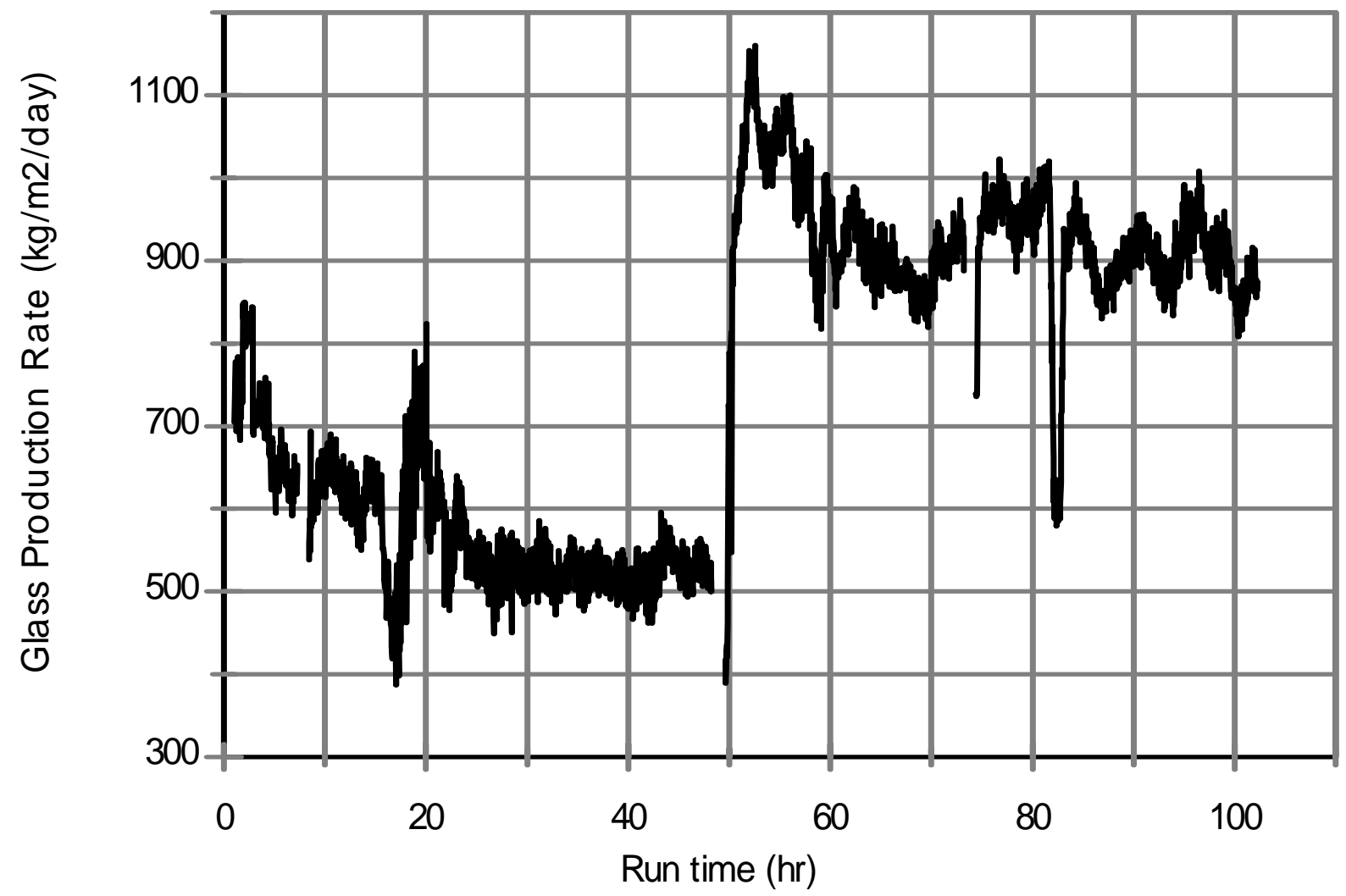

Figure 3.1.b. Glass production rates (hourly moving averages) for DM100 Tests 2a and 2b. 


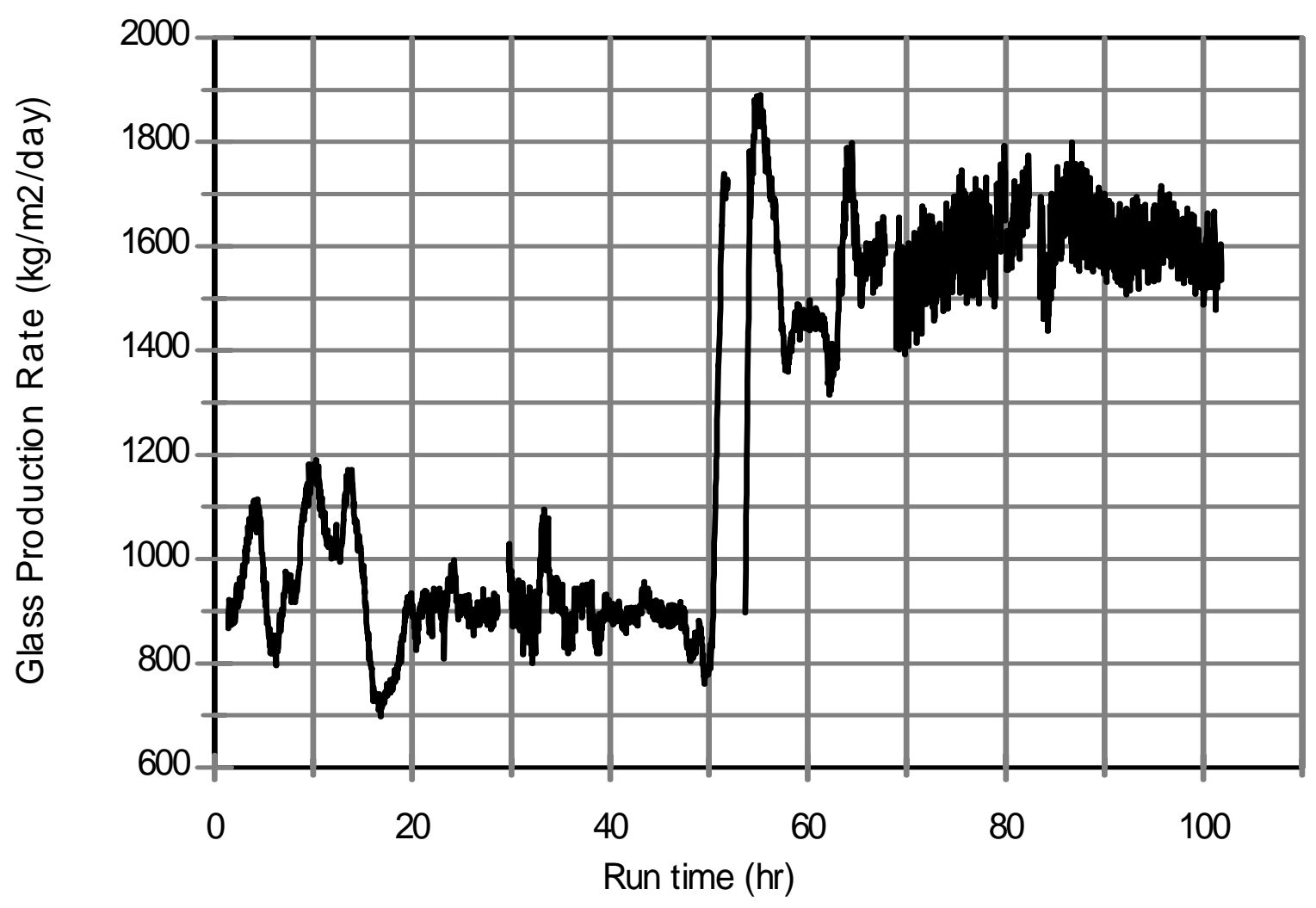

Figure 3.1.c. Glass production rates (hourly moving averages) for DM100 Tests 3a and $3 b$. 


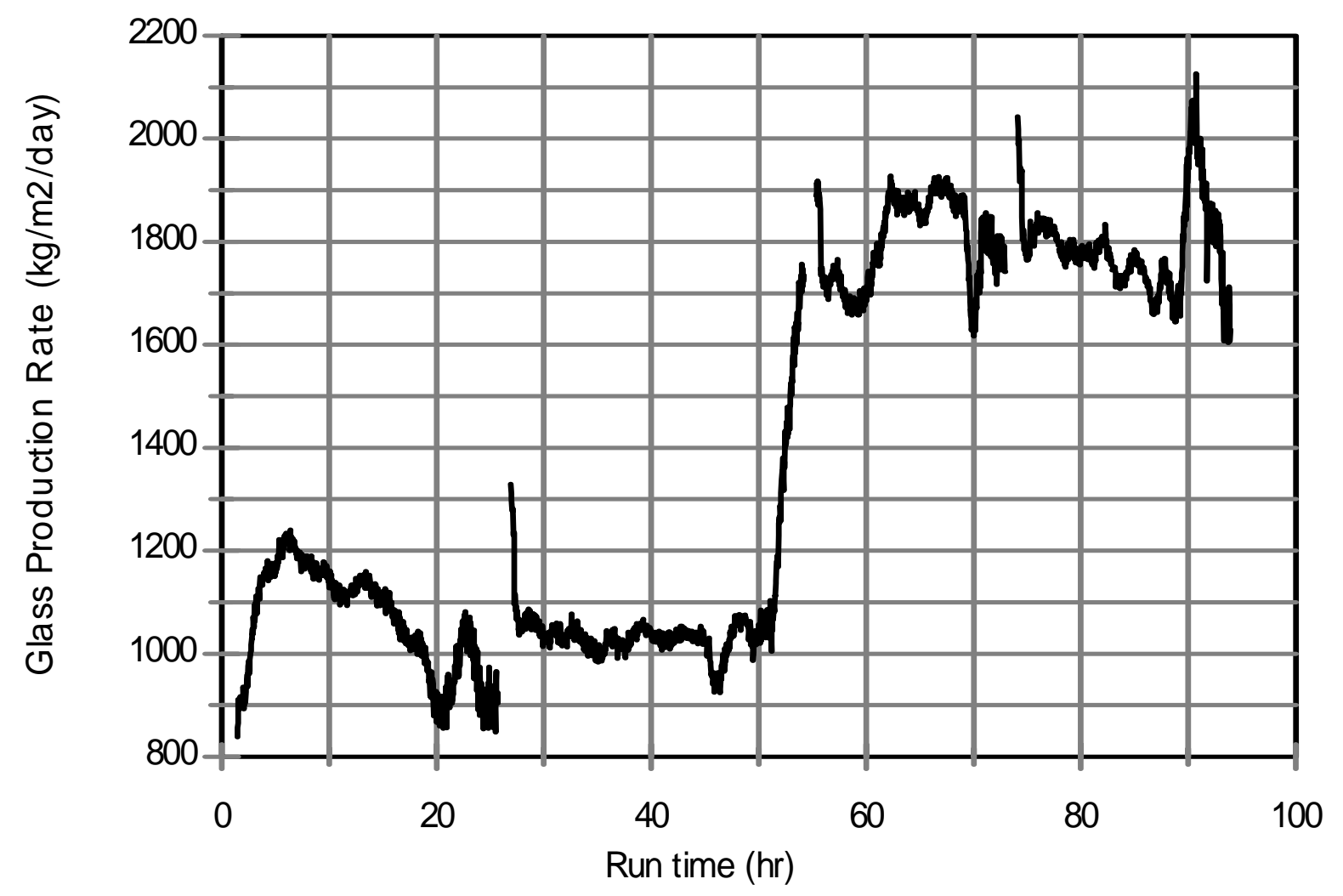

Figure 3.1.d. Glass production rates (hourly moving averages) for DM100 Tests 4a and 4 b. 


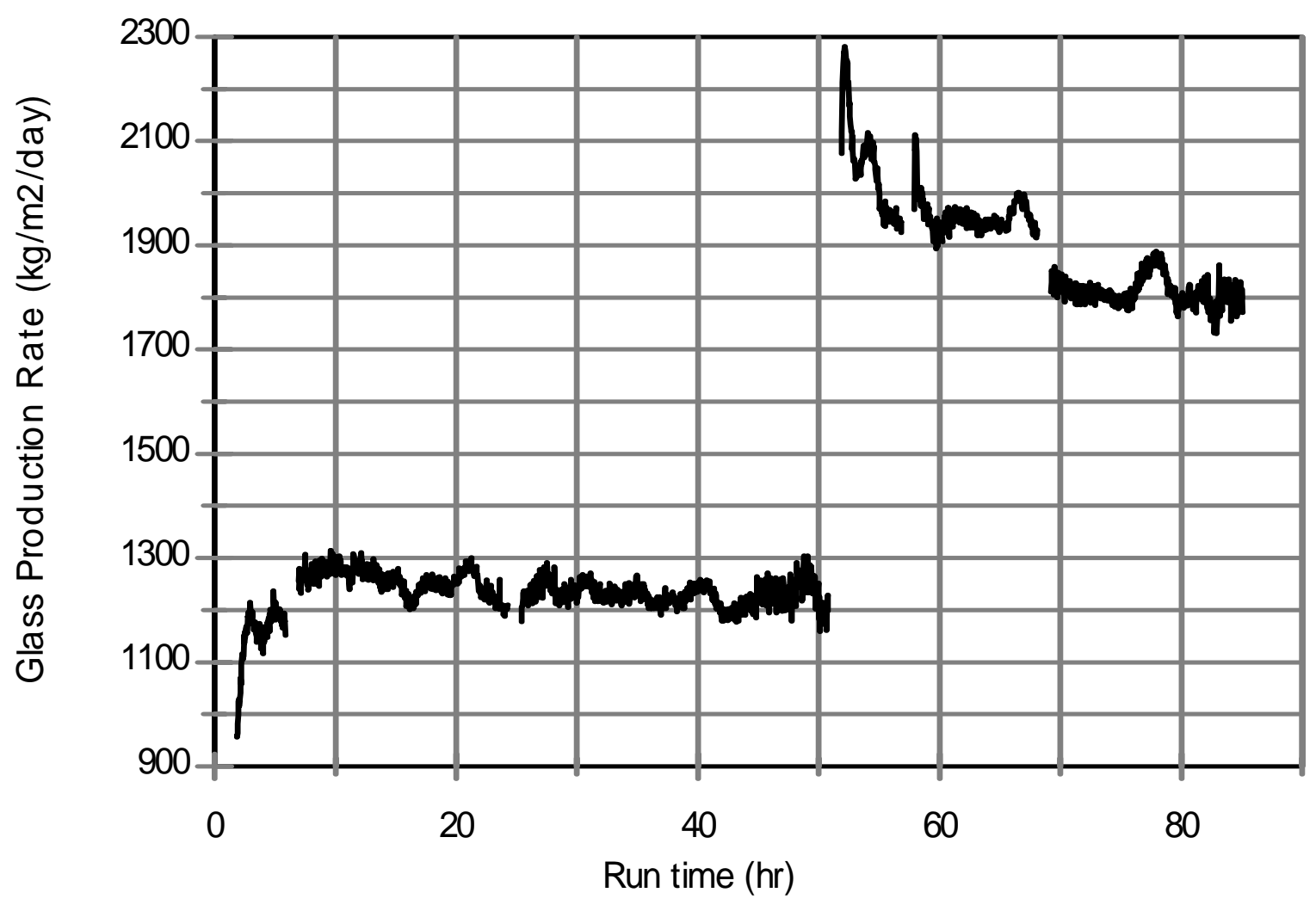

Figure 3.1.e. Glass production rates (hourly moving averages) for DM100 Tests 5a and 5 b. 


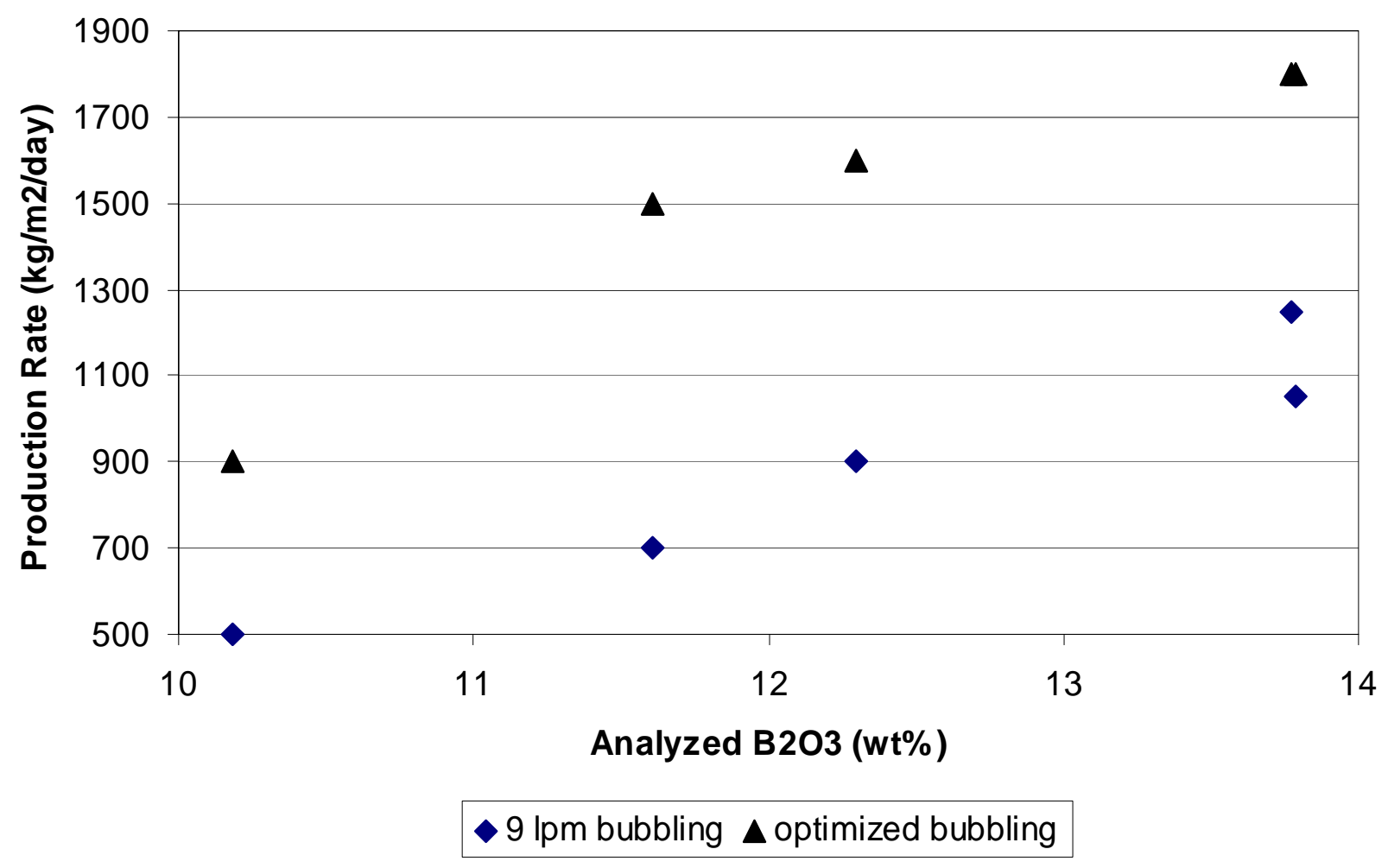

Figure 3.1.f. Steady state glass production rates and boron content for the five glass compositions processed on the DM100. 


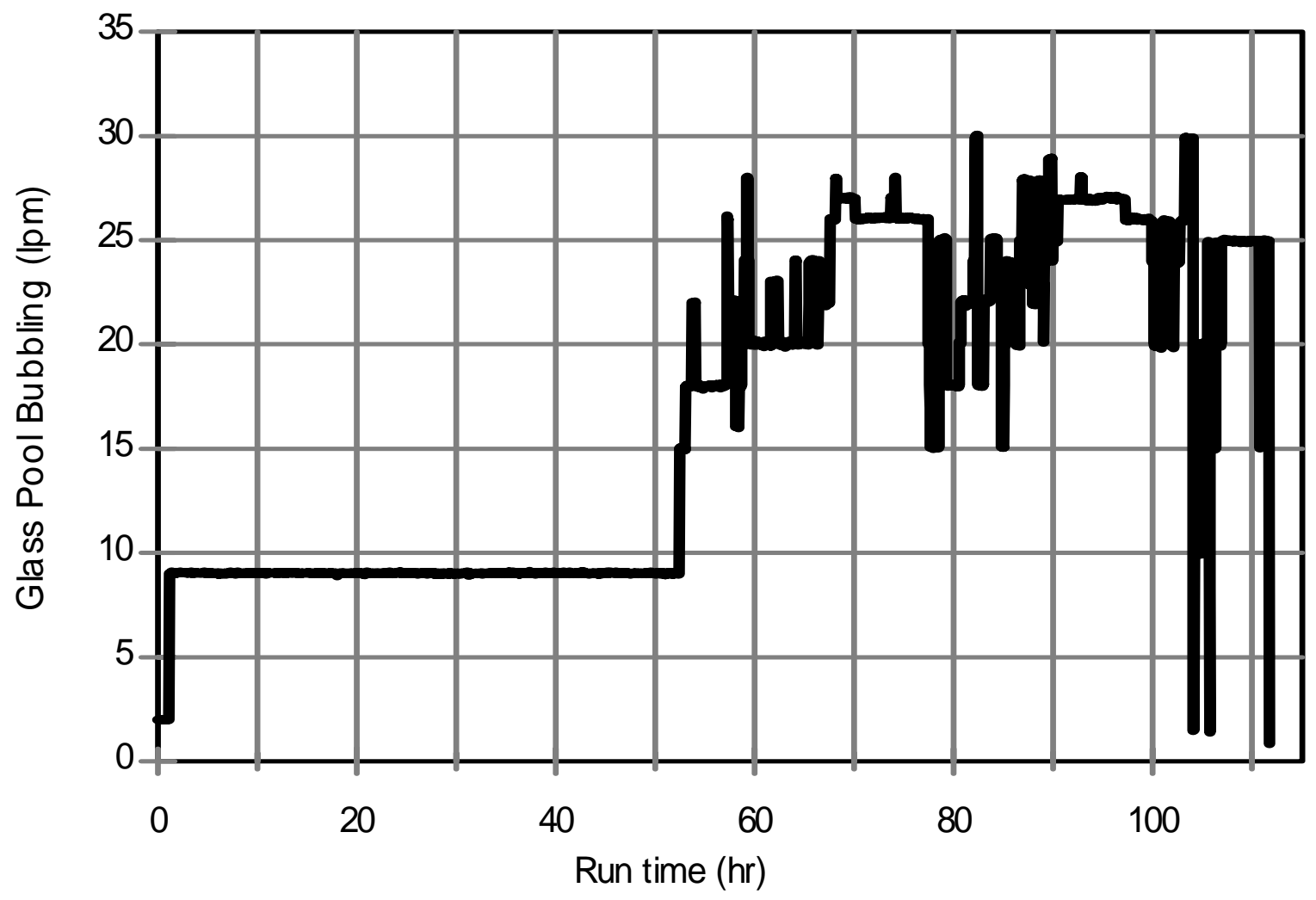

Figure 3.2.a. Glass pool bubbling rate for DM100 Tests $1 \mathrm{a}$ and $1 \mathrm{~b}$. 
ORP-56294 Rev. 0

The Catholic University of America Vitreous State Laboratory

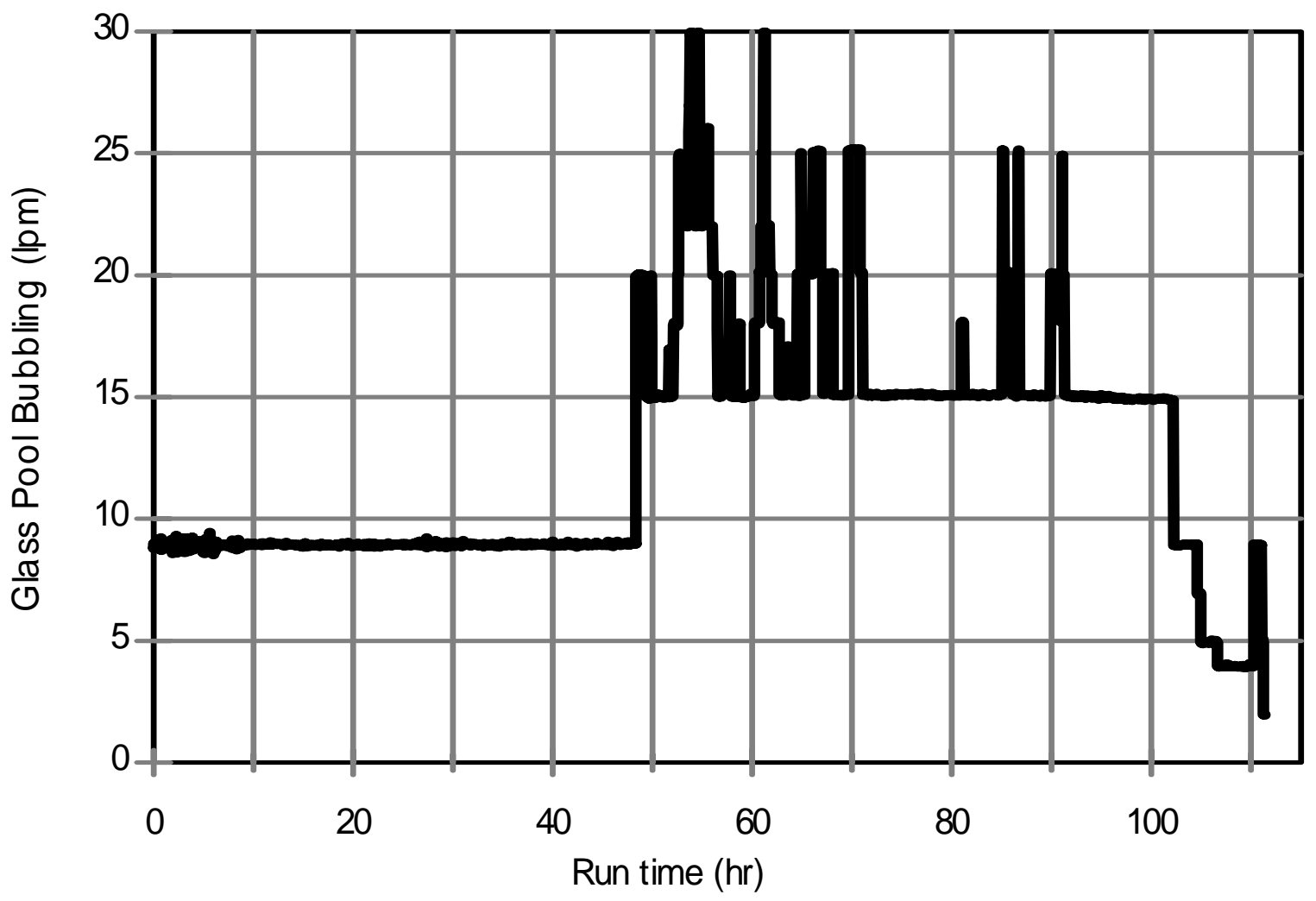

Figure 3.2.b. Glass pool bubbling rate for DM100 Tests $2 a$ and $2 b$. 


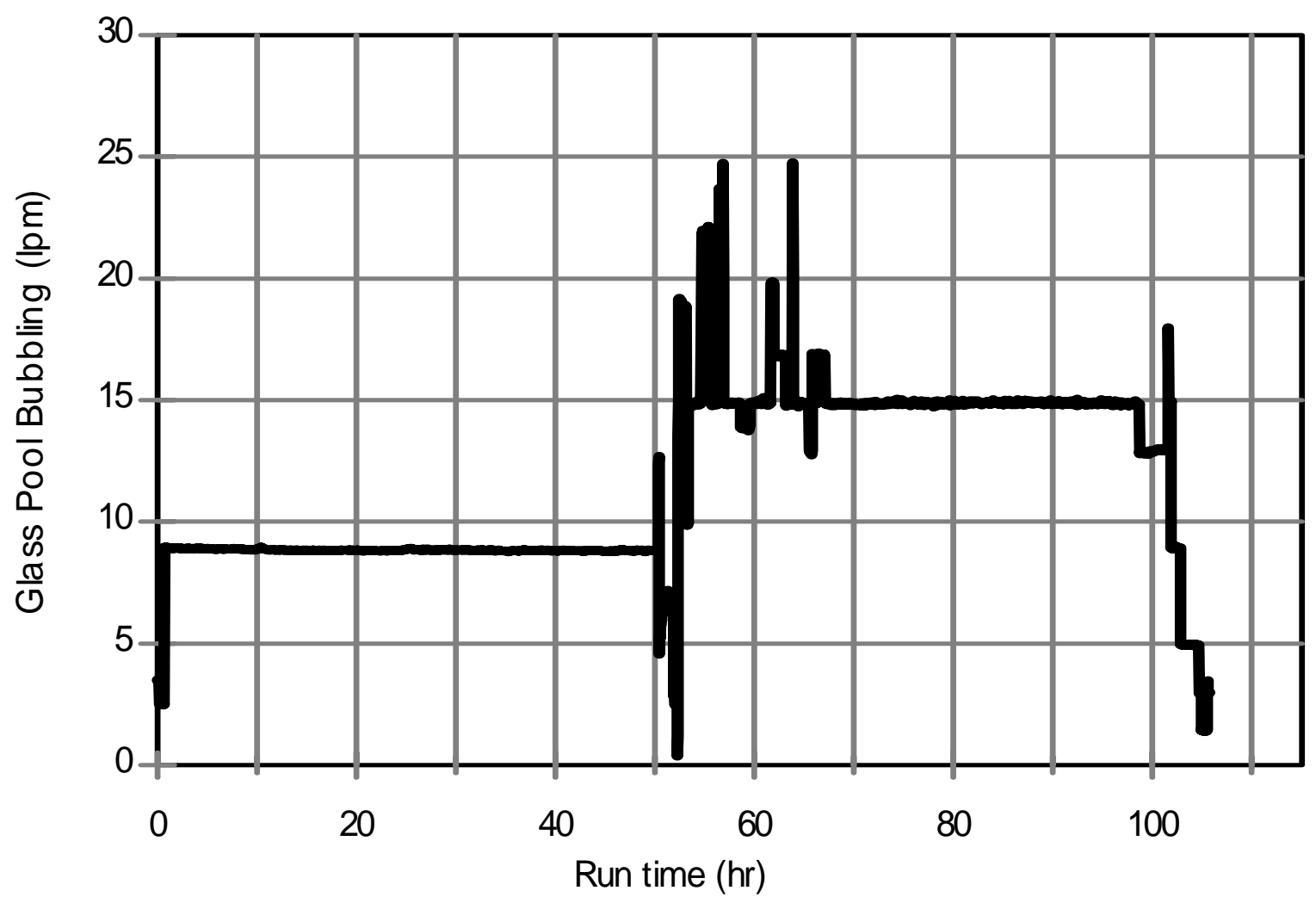

Figure 3.2.c. Glass pool bubbling rate for DM100 Tests 3a and 3b. 


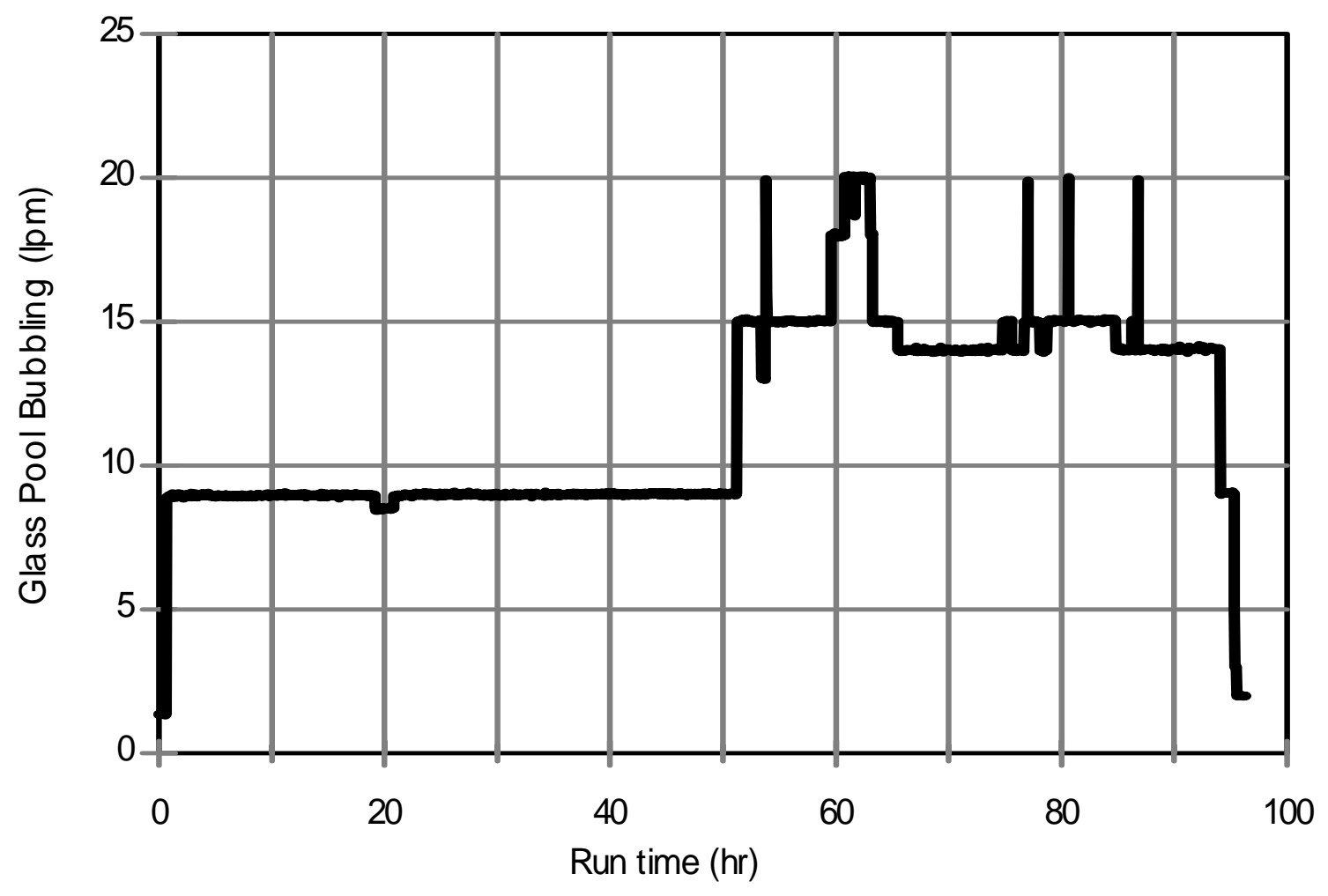

Figure 3.2.d. Glass pool bubbling rates for DM100 Tests 4a and 4b. 


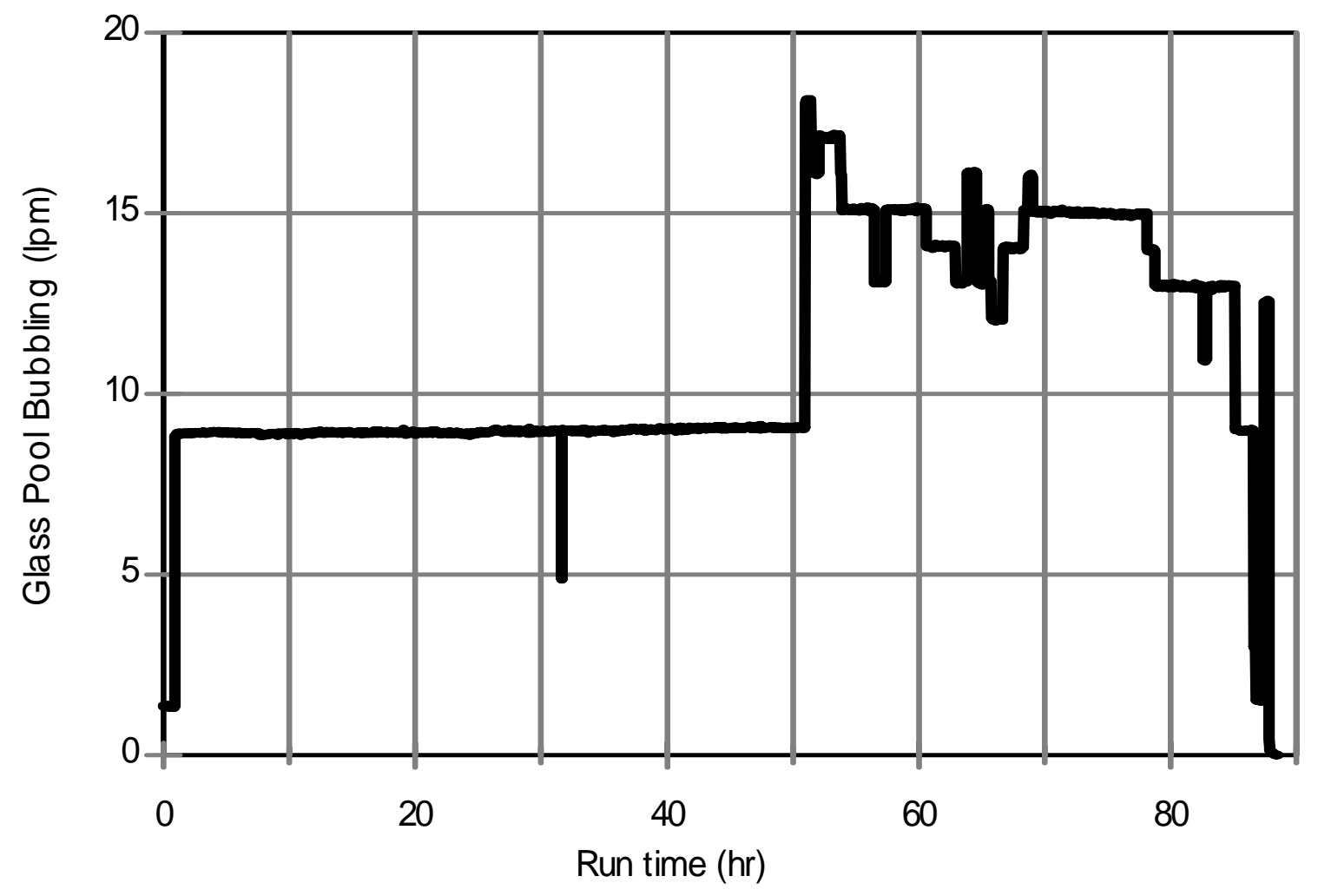

Figure 3.2.e. Glass pool bubbling rates for DM100 Tests 5a and 5b. 


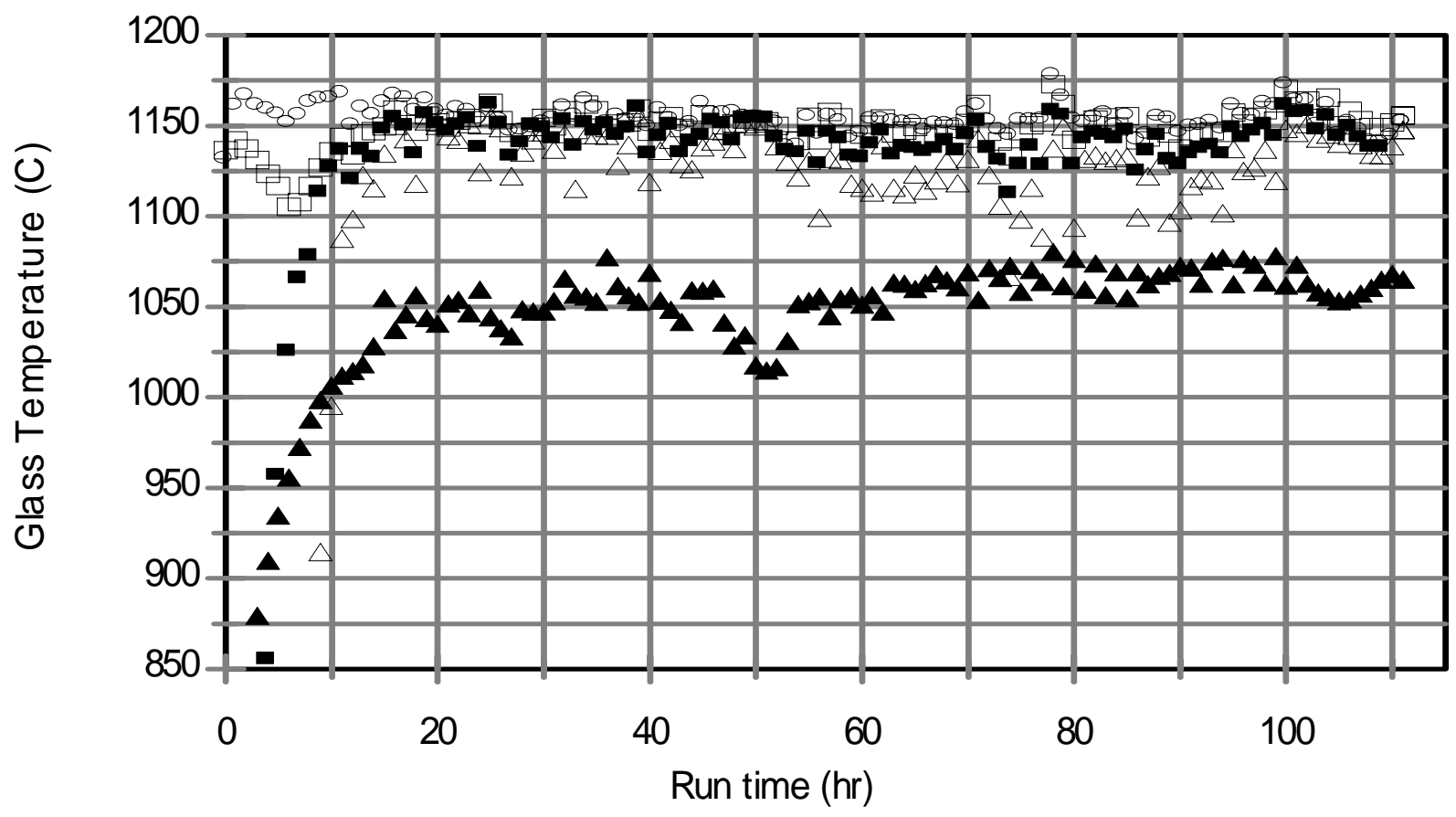
$\Delta \quad 27$ " from bottom
16 " from bottom
ㅁ 10 " from bottom
- 5" from bottom
- Airlift

Figure 3.3.a. Glass temperatures (hourly averages) during DM100 Tests 1a and $1 \mathrm{~b}$. (Temperature measurements are accurate to $\pm 5^{\circ} \mathrm{C}$ ) 


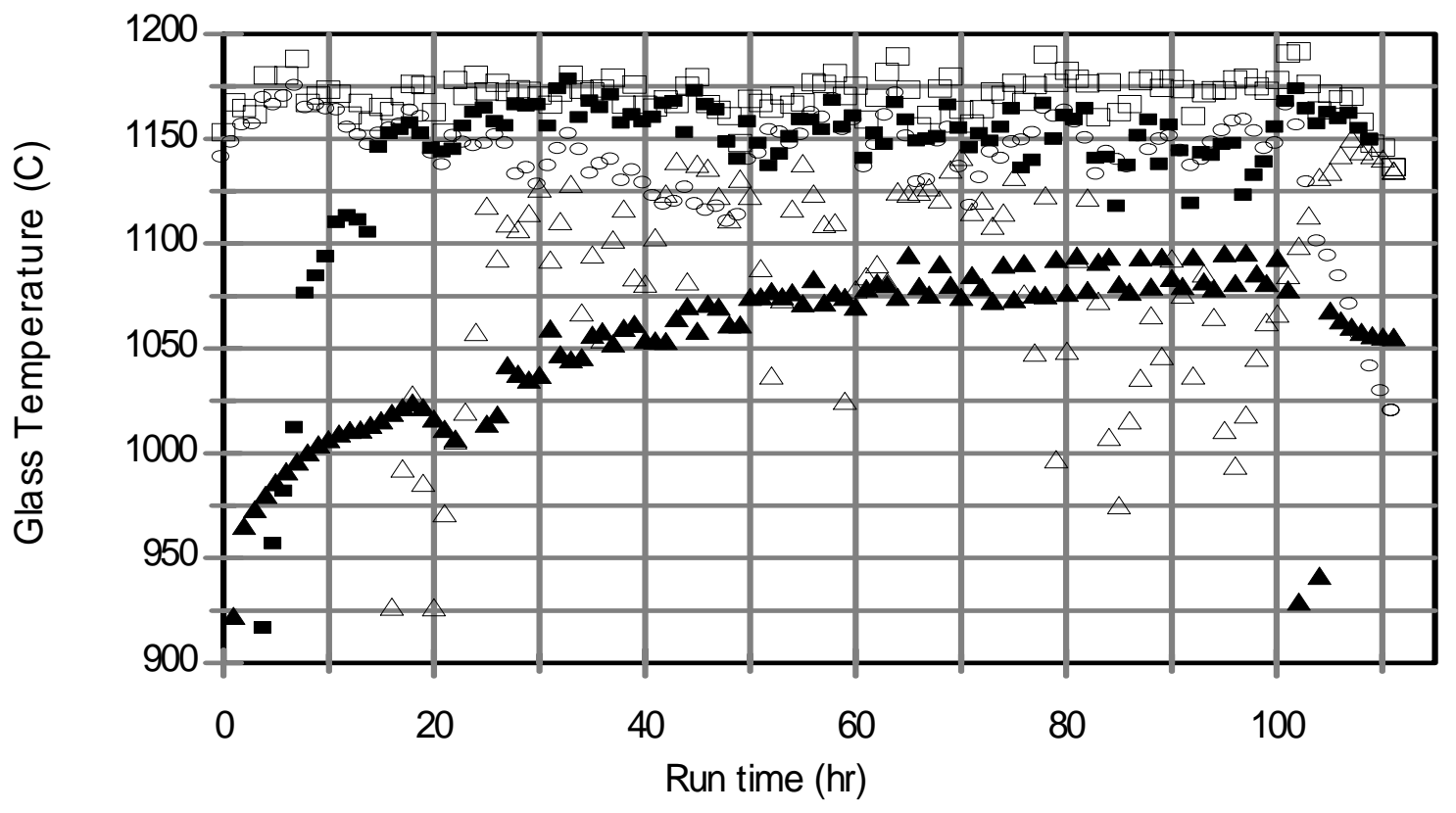
$\Delta \quad 27$ " from bottom
- 16 " from bottom
ㅁ 10 " from bottom
- 5" from bottom
$\Delta$ Airlift

Figure 3.3.b. Glass temperatures (hourly averages) during DM100 Tests 2a and 2b. (Temperature measurements are accurate to $\pm 5^{\circ} \mathrm{C}$ ) 
The Catholic University of America Vitreous State Laboratory
ORP-56294 Rev. 0

Effects of High Crystal Content in HLW DM100 Melter Tests

Final Report, VSL-09R1520-1, Rev. 0

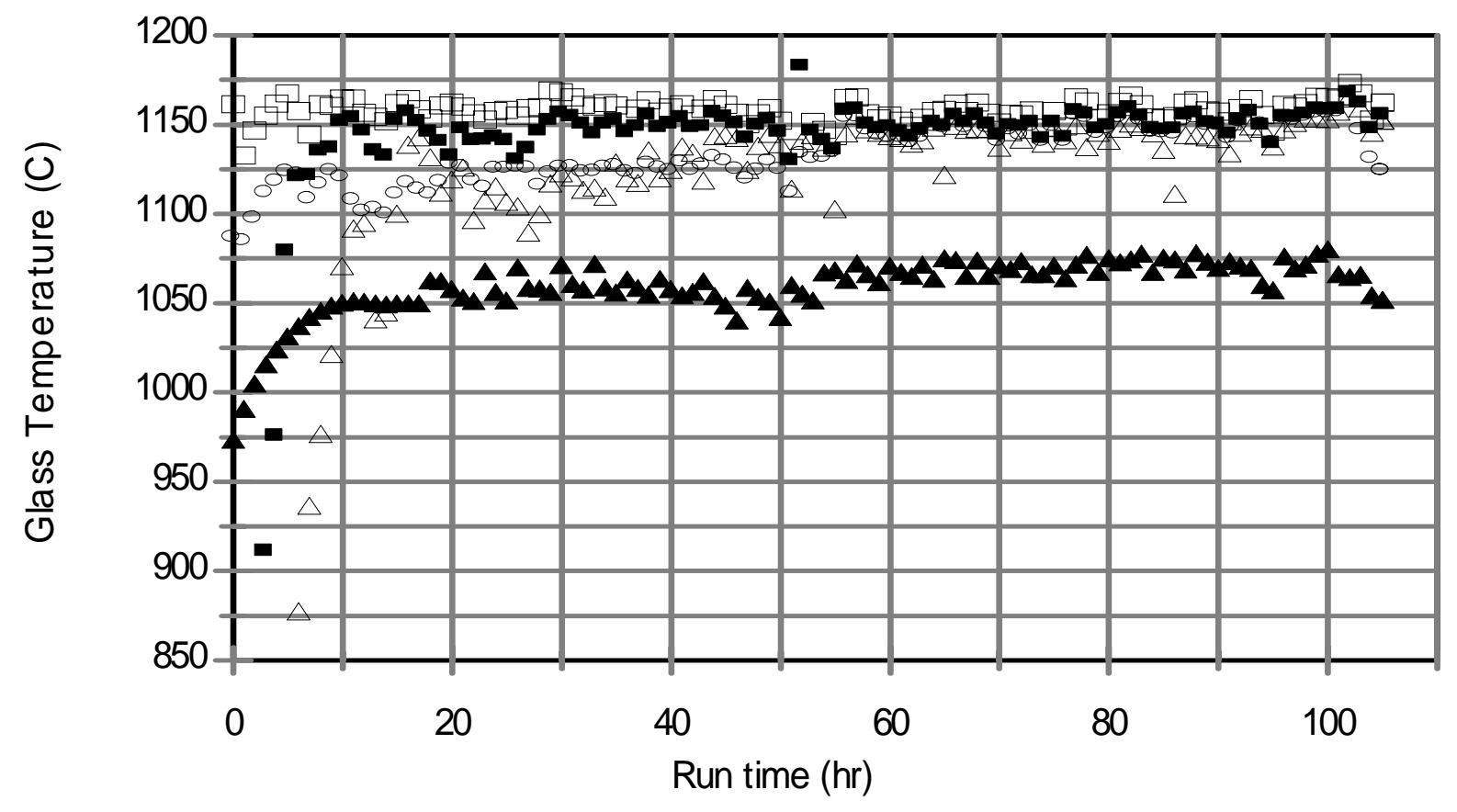

Figure 3.3.c. Glass temperatures (hourly averages) during DM100 Tests 3a and 3b. (Temperature measurements are accurate to $\pm 5^{\circ} \mathrm{C}$ ) 


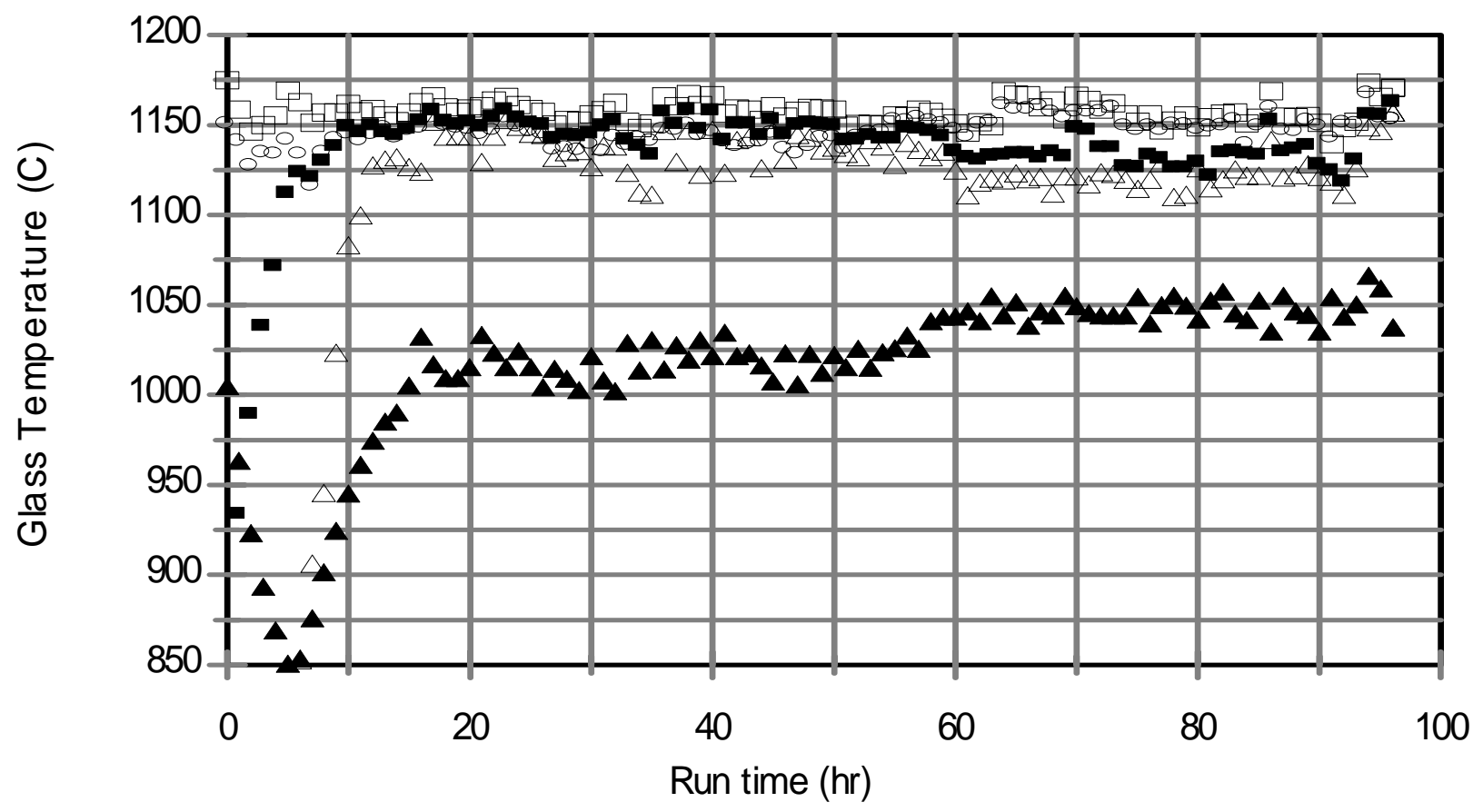
$\Delta \quad 27$ " from bottom
16 " from bottom
ㅁ 10 " from bottom
- 5" from bottom
- Airlift

Figure 3.3.d. Glass temperatures (hourly averages) during DM100 Tests 4a and 4b. (Temperature measurements are accurate to $\pm 5^{\circ} \mathrm{C}$ ) 


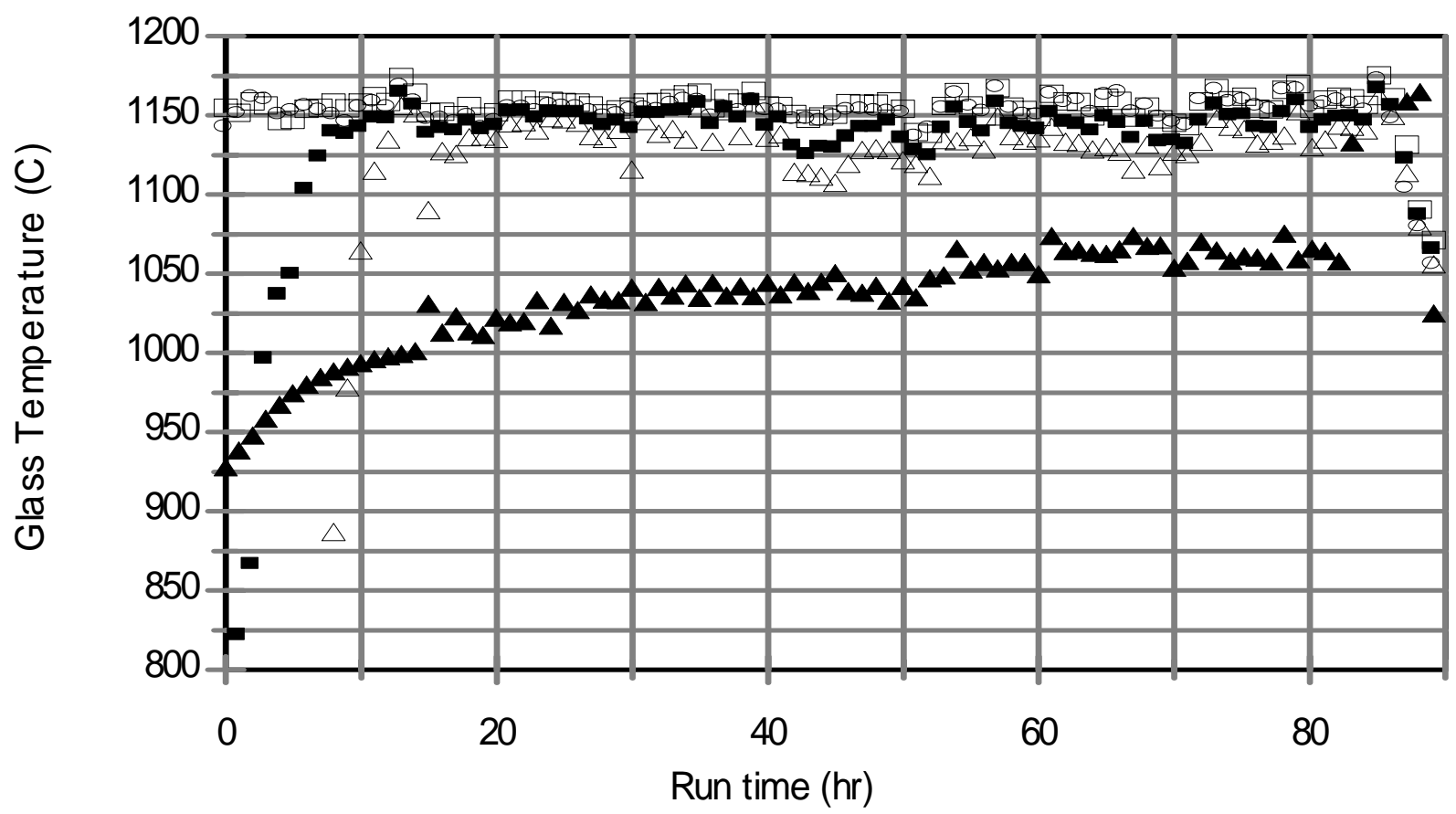
$\Delta \quad 27$ " from bottom
16 " from bottom
ㅁ 10 " from bottom
- 5" from bottom
- Airlift

Figure 3.3.e. Glass temperatures (hourly averages) during DM100 Tests $5 a$ and 5 b. (Temperature measurements are accurate to $\pm 5^{\circ} \mathrm{C}$ ) 


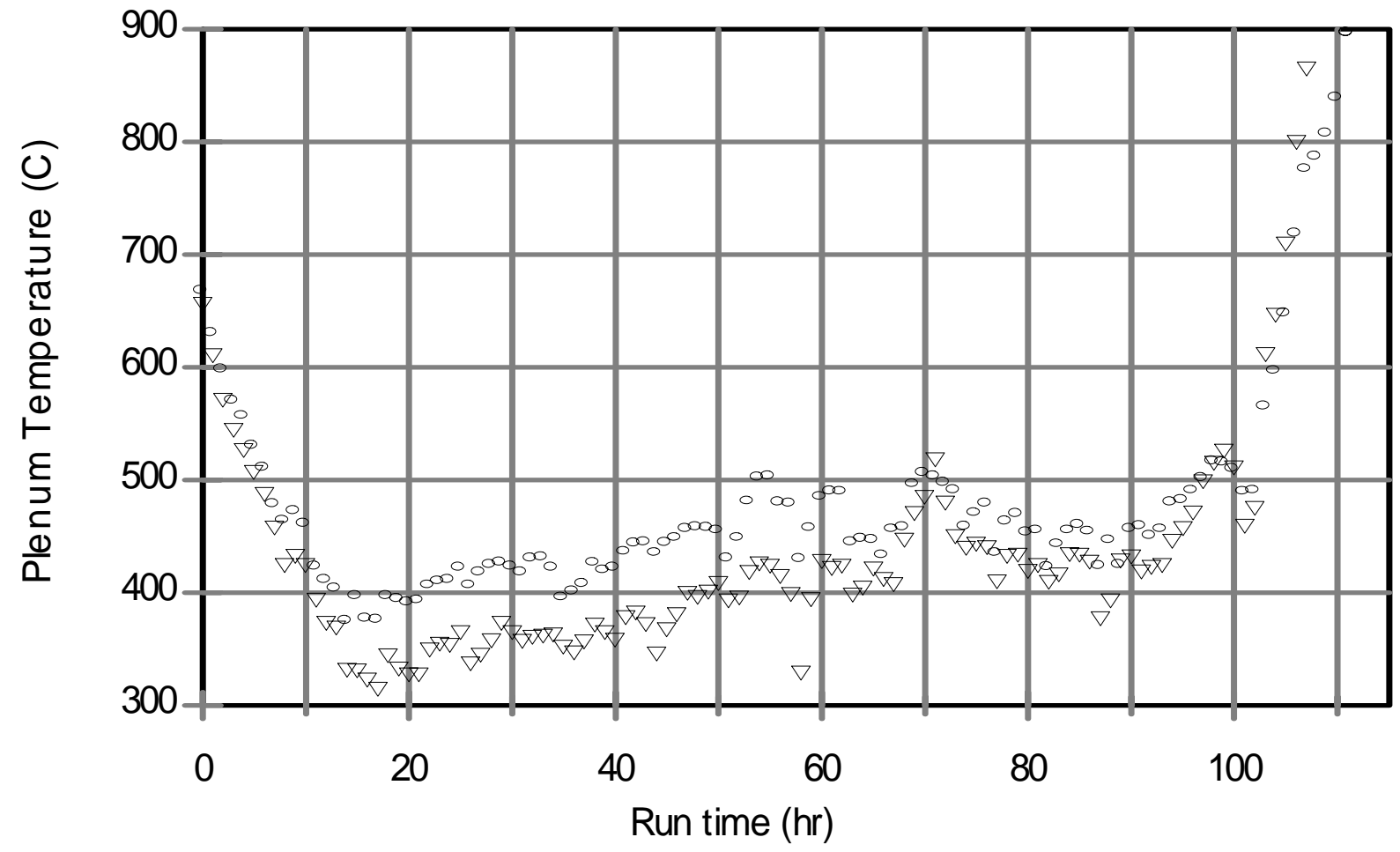

$\boldsymbol{\nabla} \quad 17^{\prime \prime}$ from top, Thermowell

- $17^{\prime \prime}$ from top, Exposed

Figure 3.4.a. Plenum temperatures (hourly averages) during DM100 Tests 1a and $1 \mathrm{~b}$. (Temperature measurements are accurate to $\pm 5^{\circ} \mathrm{C}$ ) 


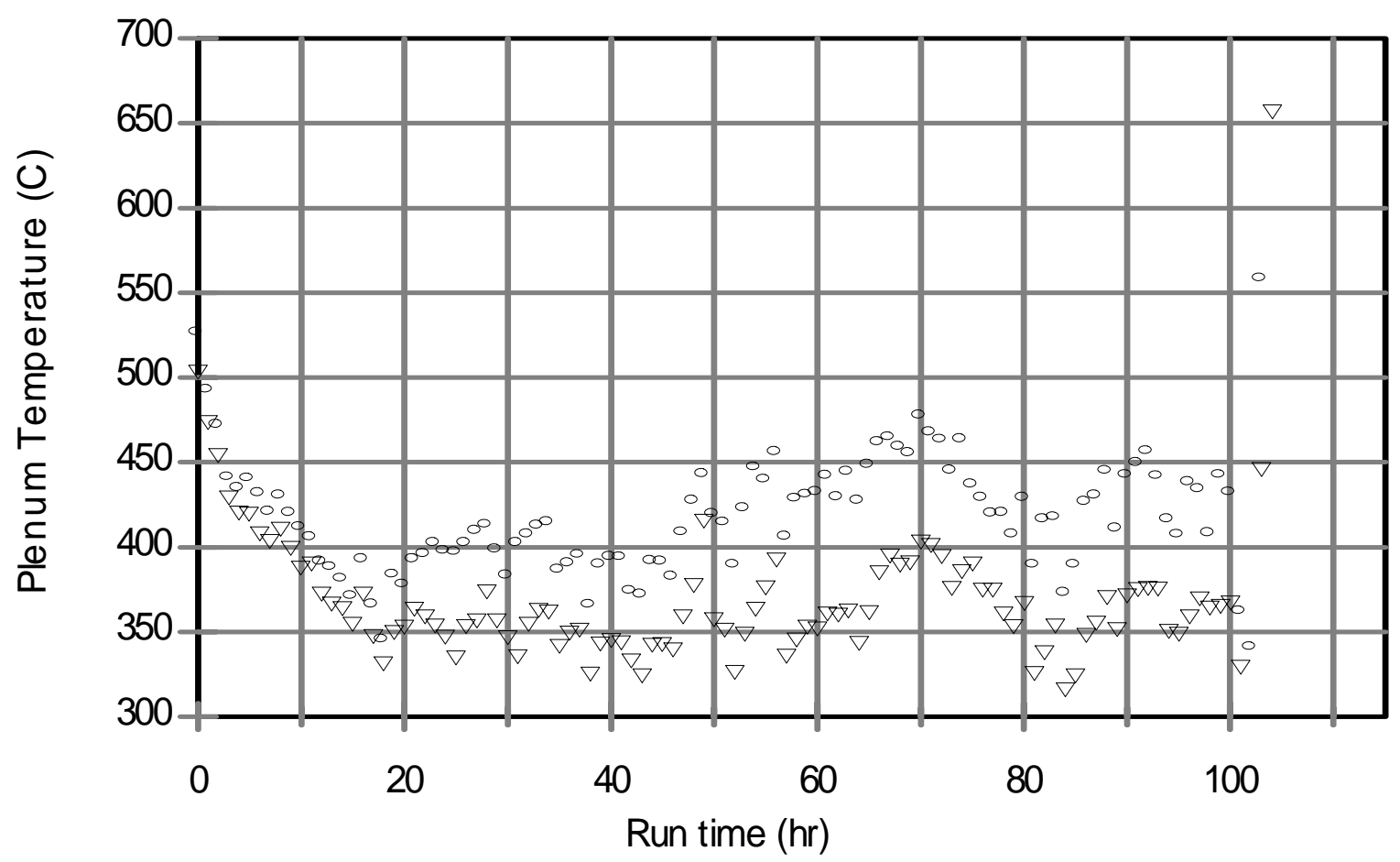

$\boldsymbol{\nabla} 17^{\prime \prime}$ from top, Thermowell - $\quad 17$ " from top, Exposed

Figure 3.4.b. Plenum temperatures (hourly averages) during DM100 Tests 2a and $2 \mathrm{~b}$. (Temperature measurements are accurate to $\pm 5^{\circ} \mathrm{C}$ ) 


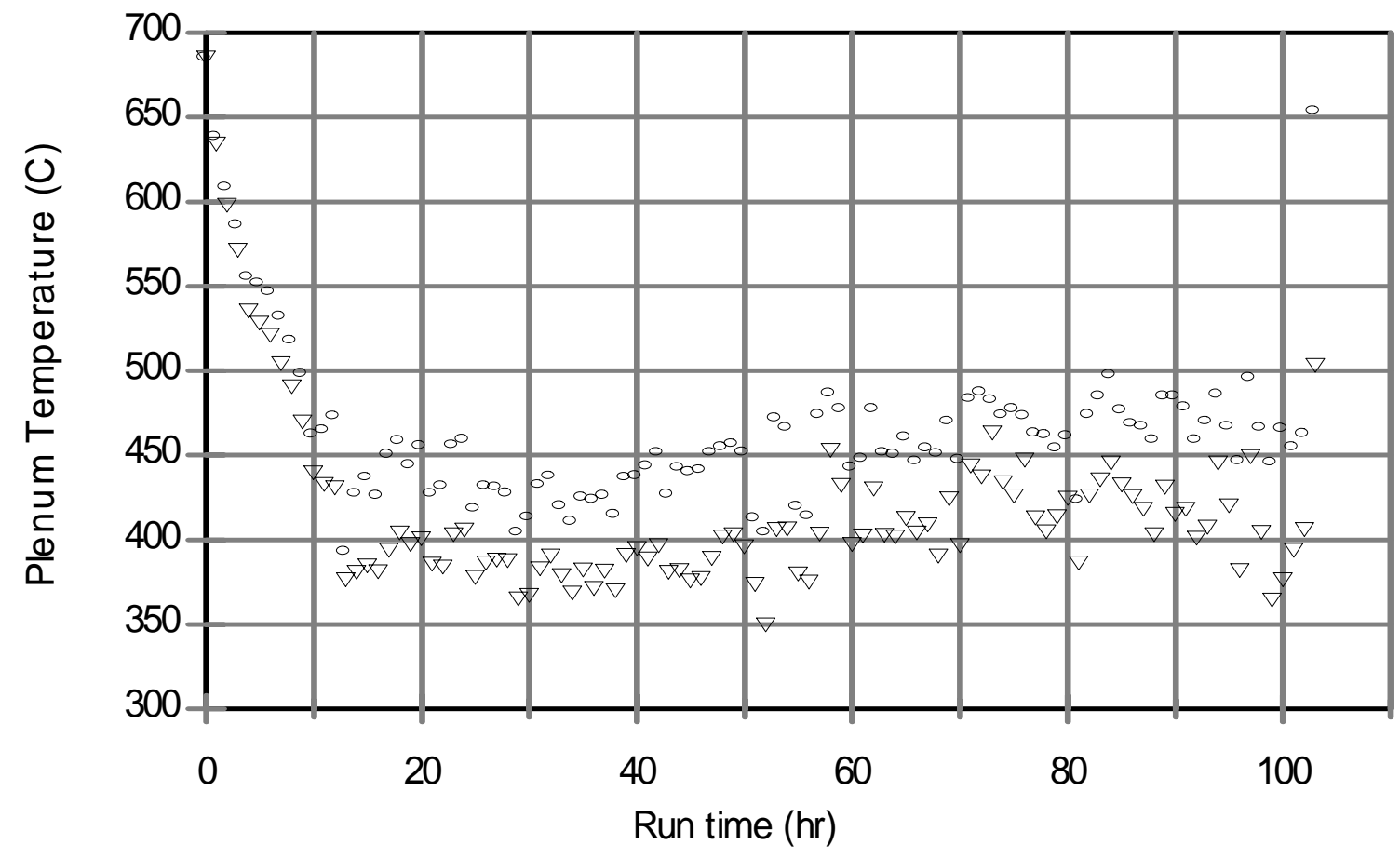

v 17" from top, Thermowell

- $\quad 17$ " from top, Exposed

Figure 3.4.c. Plenum temperatures (hourly averages) during DM100 Tests $3 a$ and $3 b$. (Temperature measurements are accurate to $\pm 5^{\circ} \mathrm{C}$ ) 


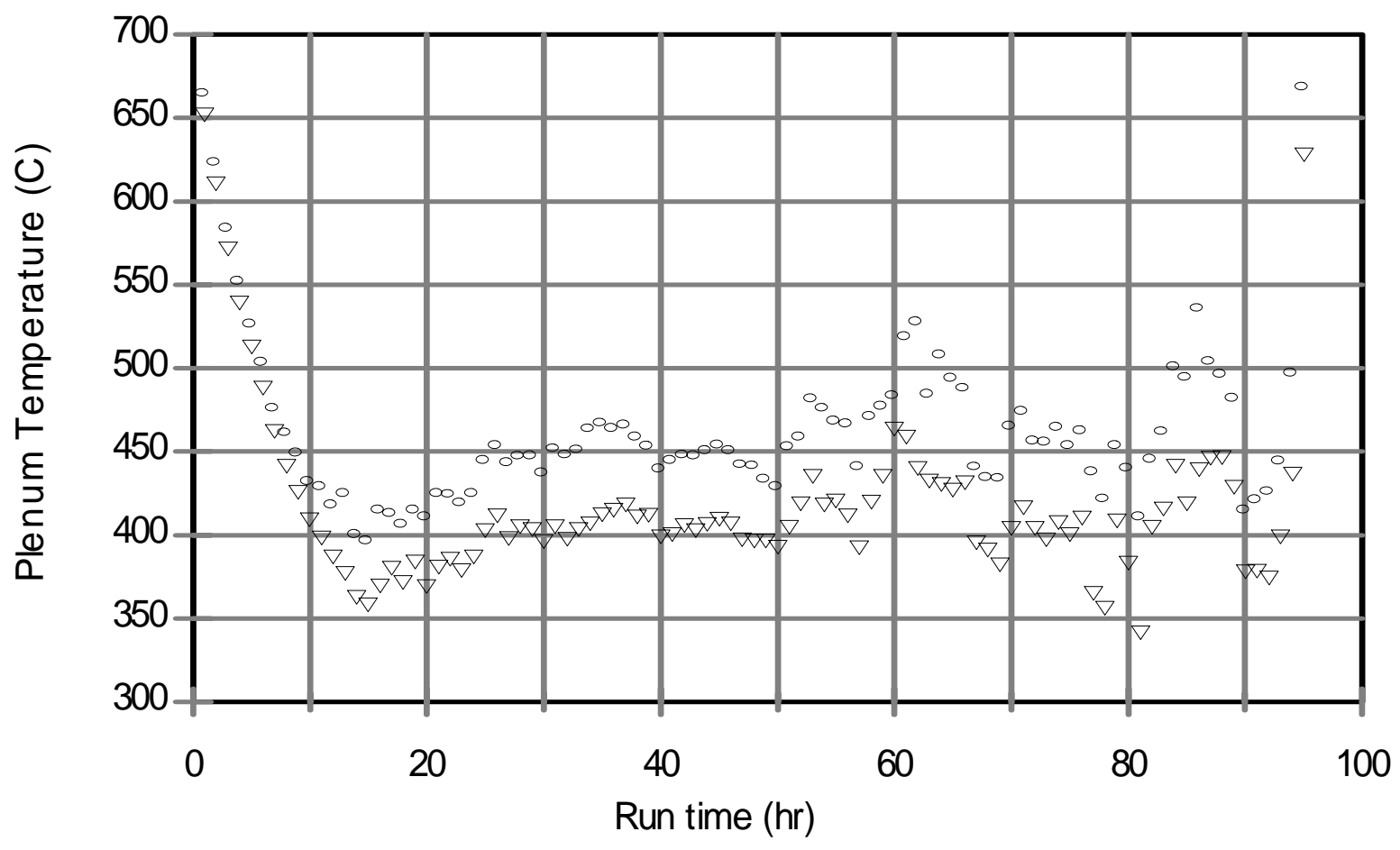

$\boldsymbol{\nabla}$ 17" from top, Thermowell

- 17 " from top, Exposed

Figure 3.4.d. Plenum temperatures (hourly averages) during DM100 Tests $4 a$ and $4 b$. (Temperature measurements are accurate to $\pm 5^{\circ} \mathrm{C}$ ) 


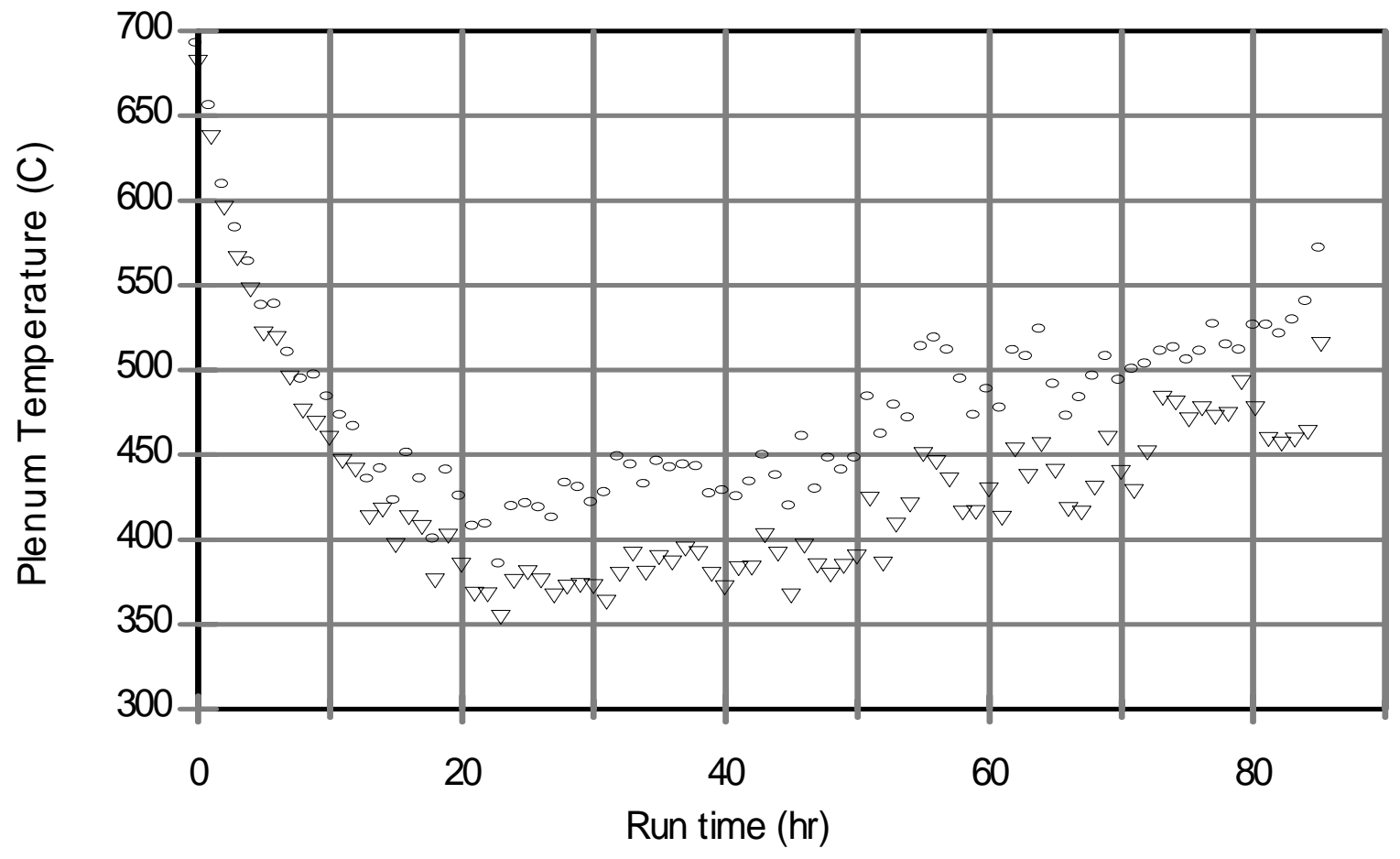

$\boldsymbol{\nabla} 17^{\prime \prime}$ from top, Thermowell

- 17 " from top, Exposed

Figure 3.4.e. Plenum temperatures (hourly averages) during DM100 Tests 5a and $5 b$. (Temperature measurements are accurate to $\pm 5^{\circ} \mathrm{C}$ ) 


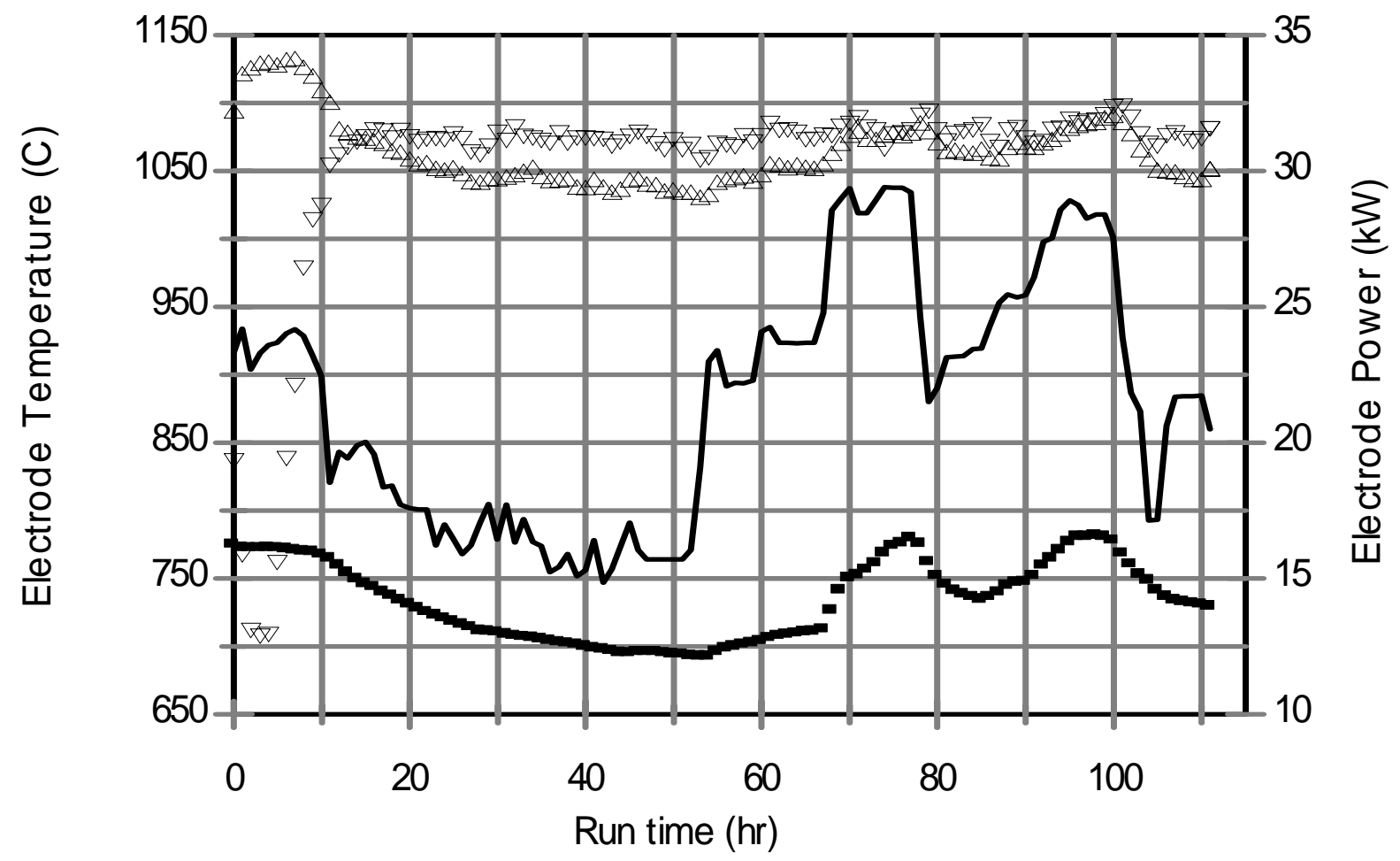

Figure 3.5.a. Electrode temperatures and power (hourly averages) during DM100 Tests 1a and $1 b$. 


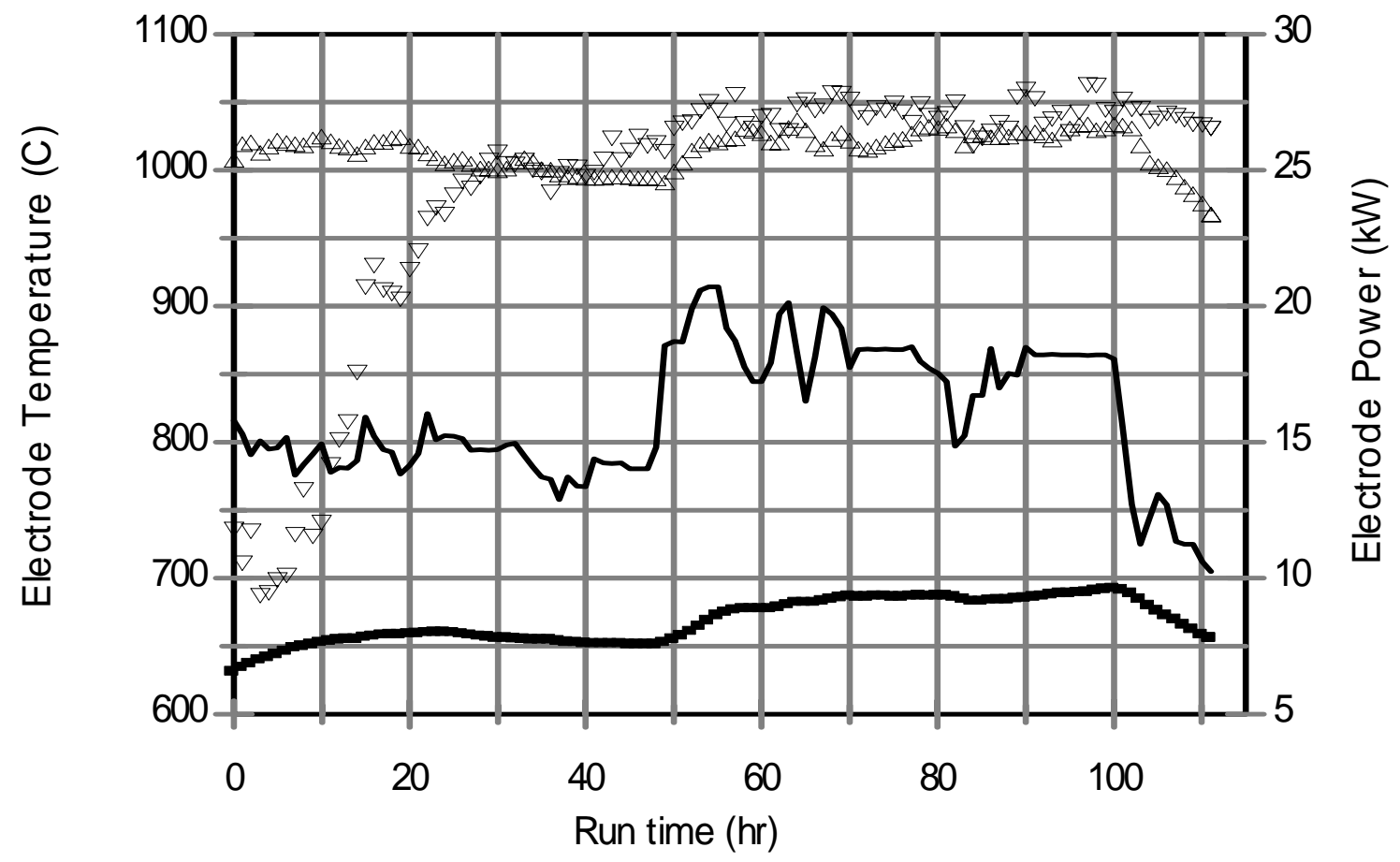

Figure 3.5.b. Electrode temperatures and power (hourly averages) during DM100 Tests $2 \mathrm{a}$ and $\mathbf{2 b}$. 


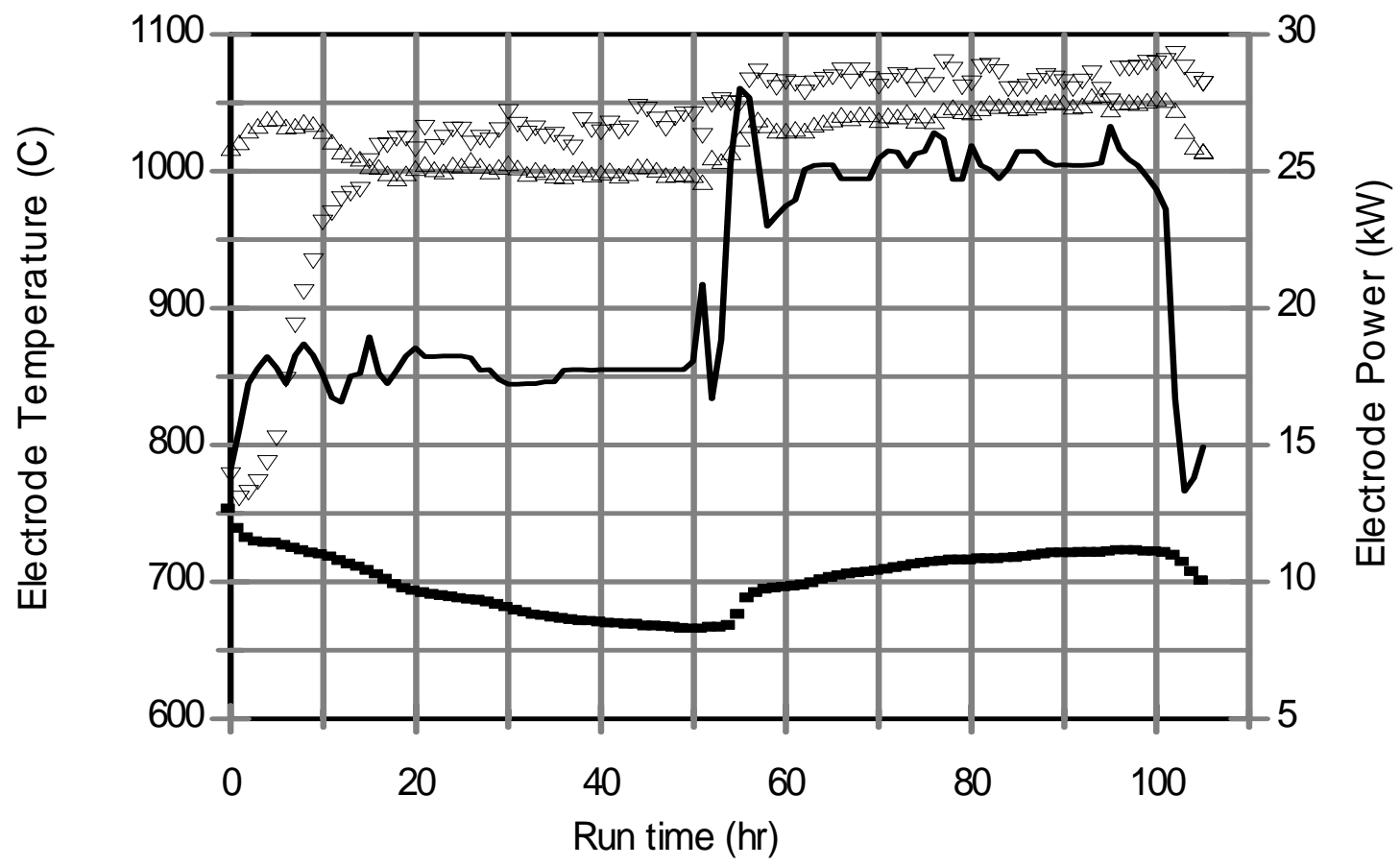

Figure 3.5.c. Electrode temperatures and power (hourly averages) during DM100 Tests $3 a$ and $3 b$. 


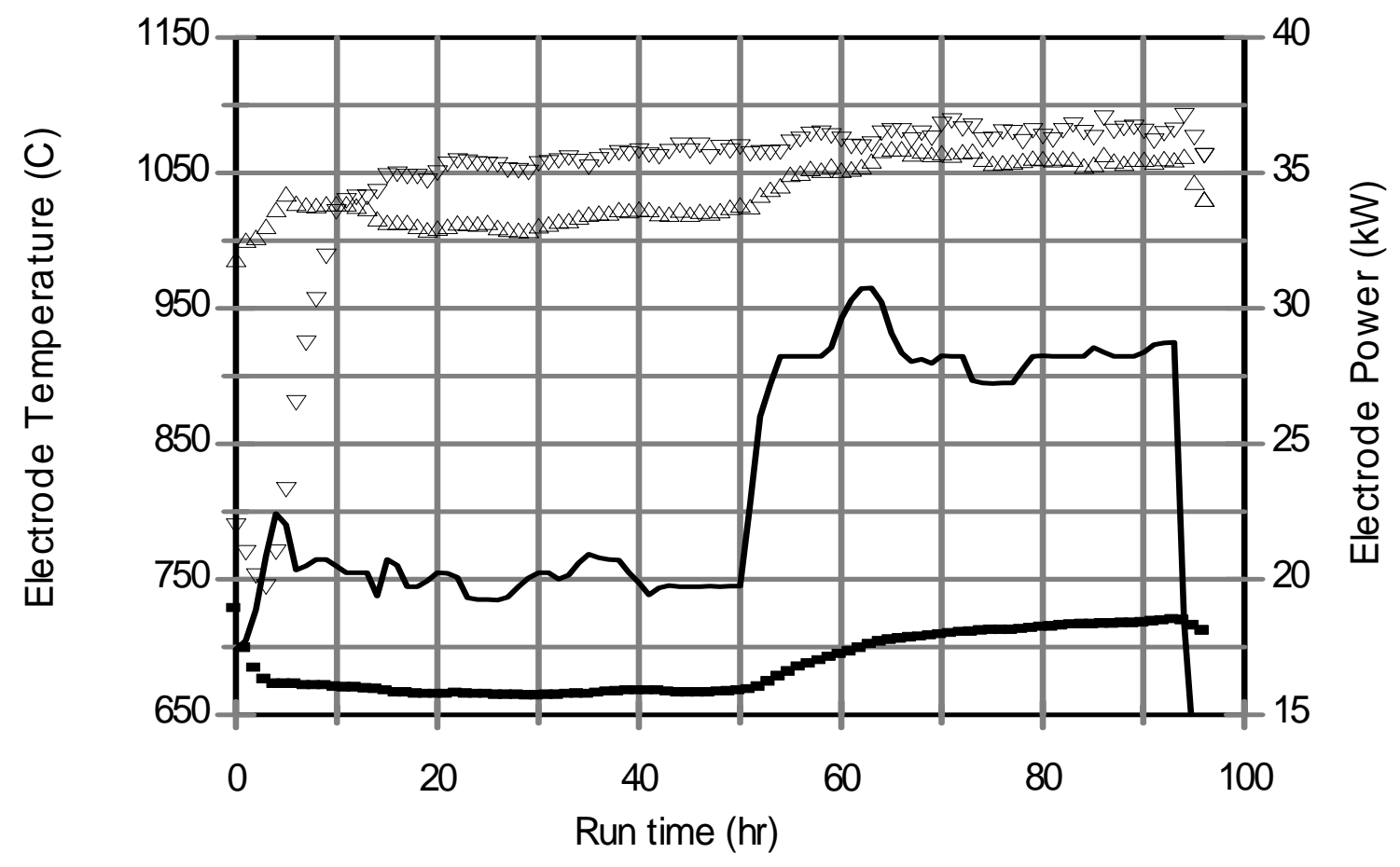

Figure 3.5.d. Electrode temperatures and power (hourly averages) during DM100 Tests $4 a$ and $4 b$. 

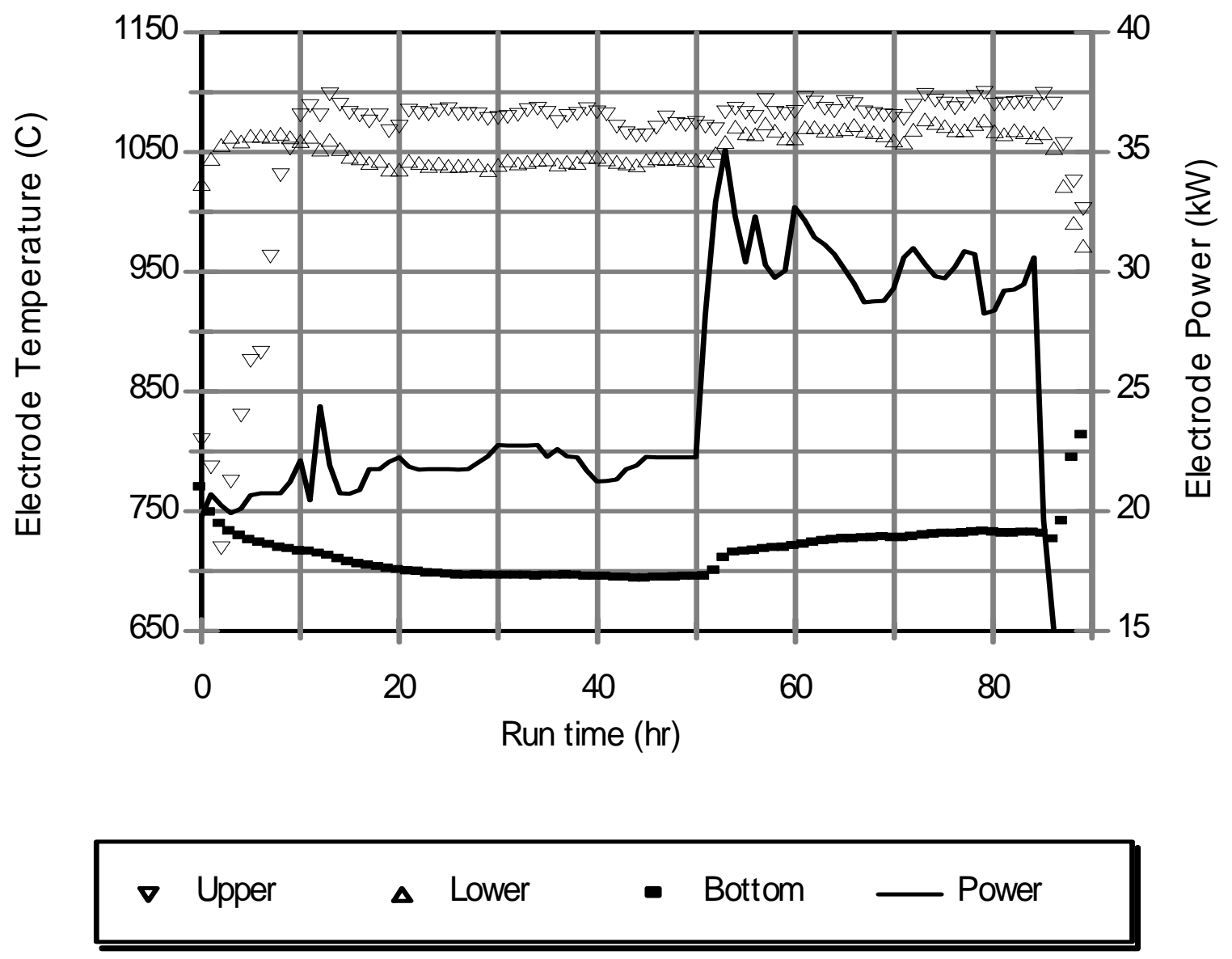

Figure 3.5.e. Electrode temperatures and power (hourly averages) during DM100 Tests $5 a$ and $5 b$. 


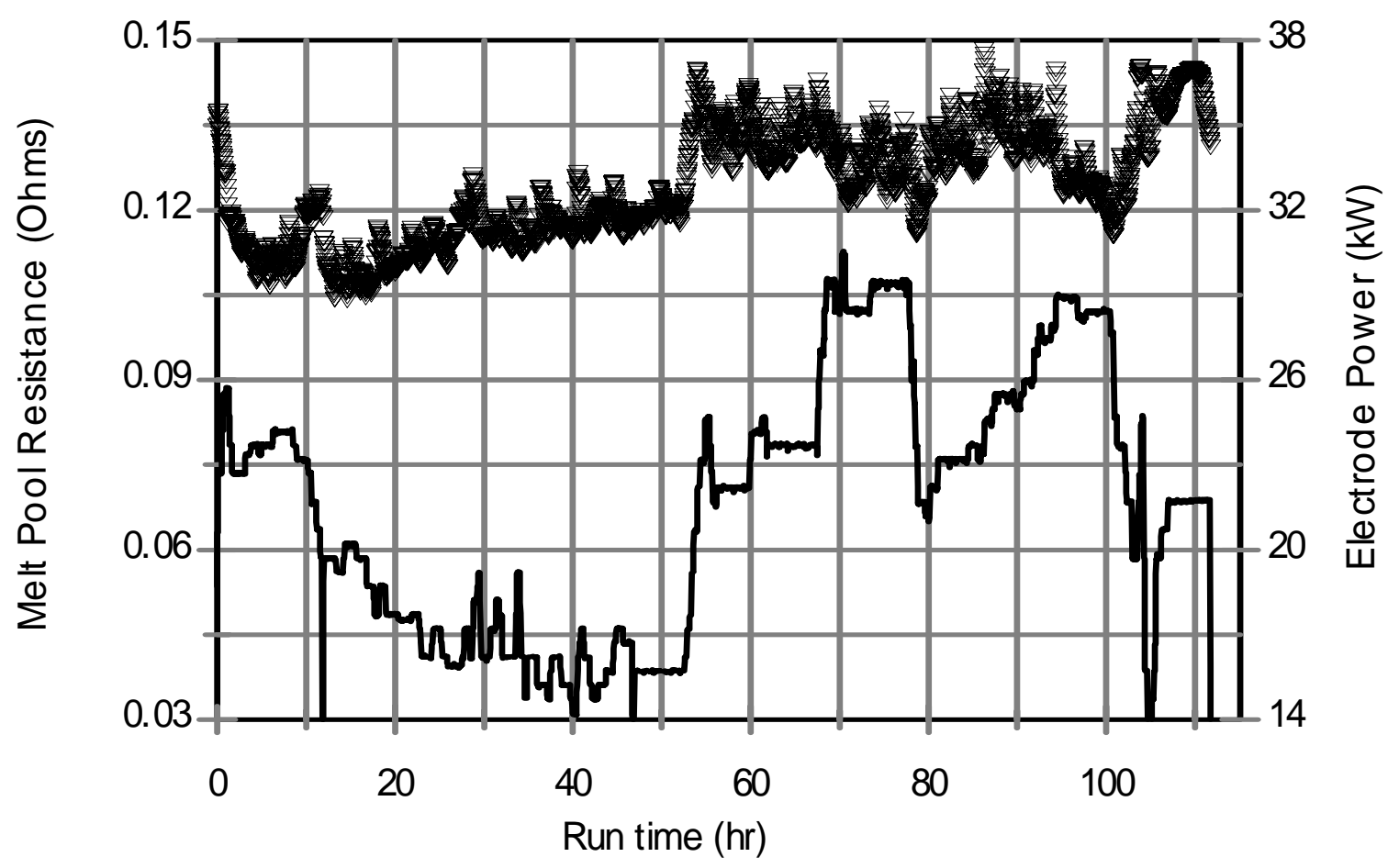

Figure 3.6.a. Melt pool resistance and total electrode power during DM100 Tests $1 \mathrm{a}$ and $1 \mathrm{~b}$. 


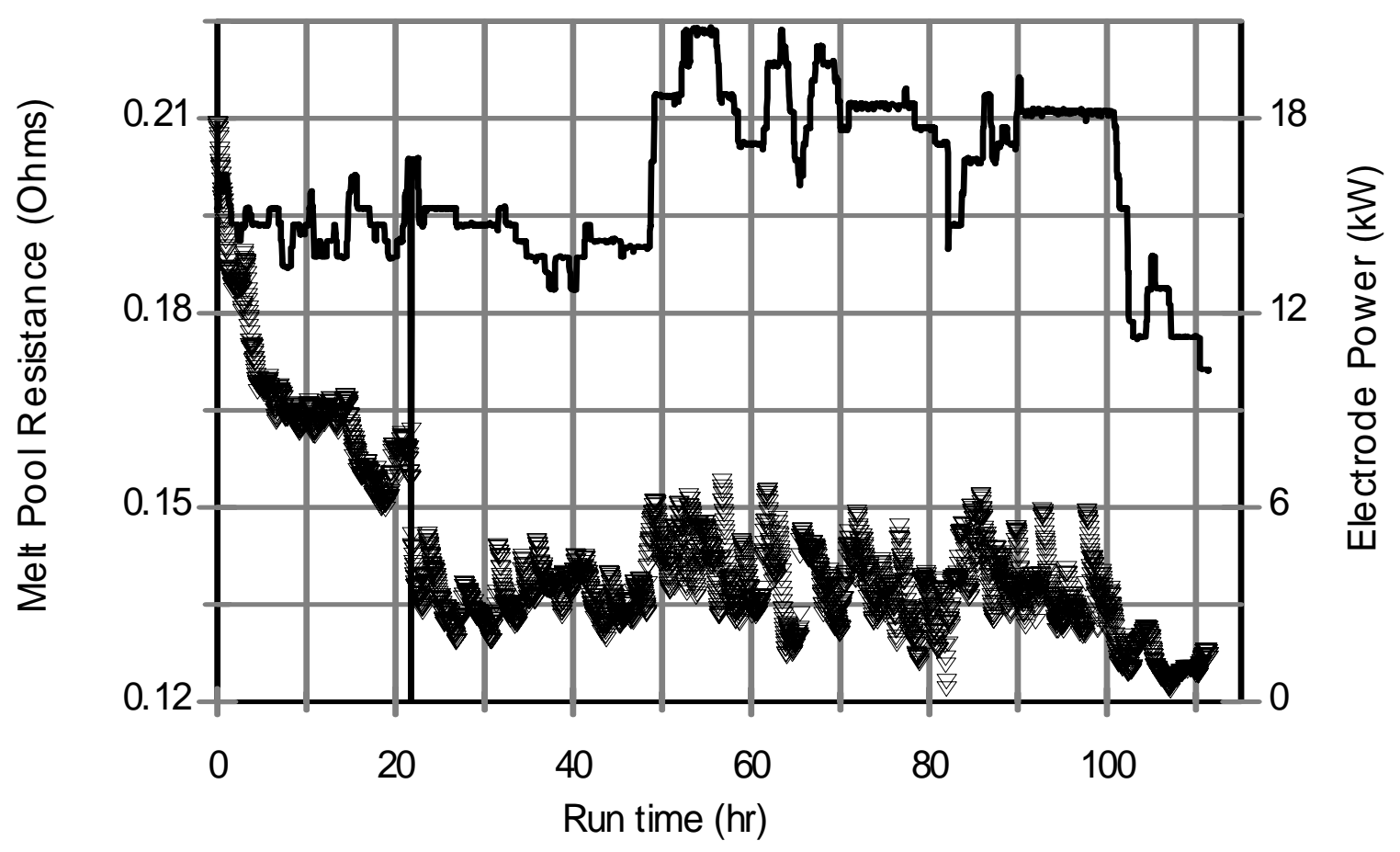

Figure 3.6.b. Melt pool resistance and total electrode power during DM100 Tests $2 a$ and $2 b$. 


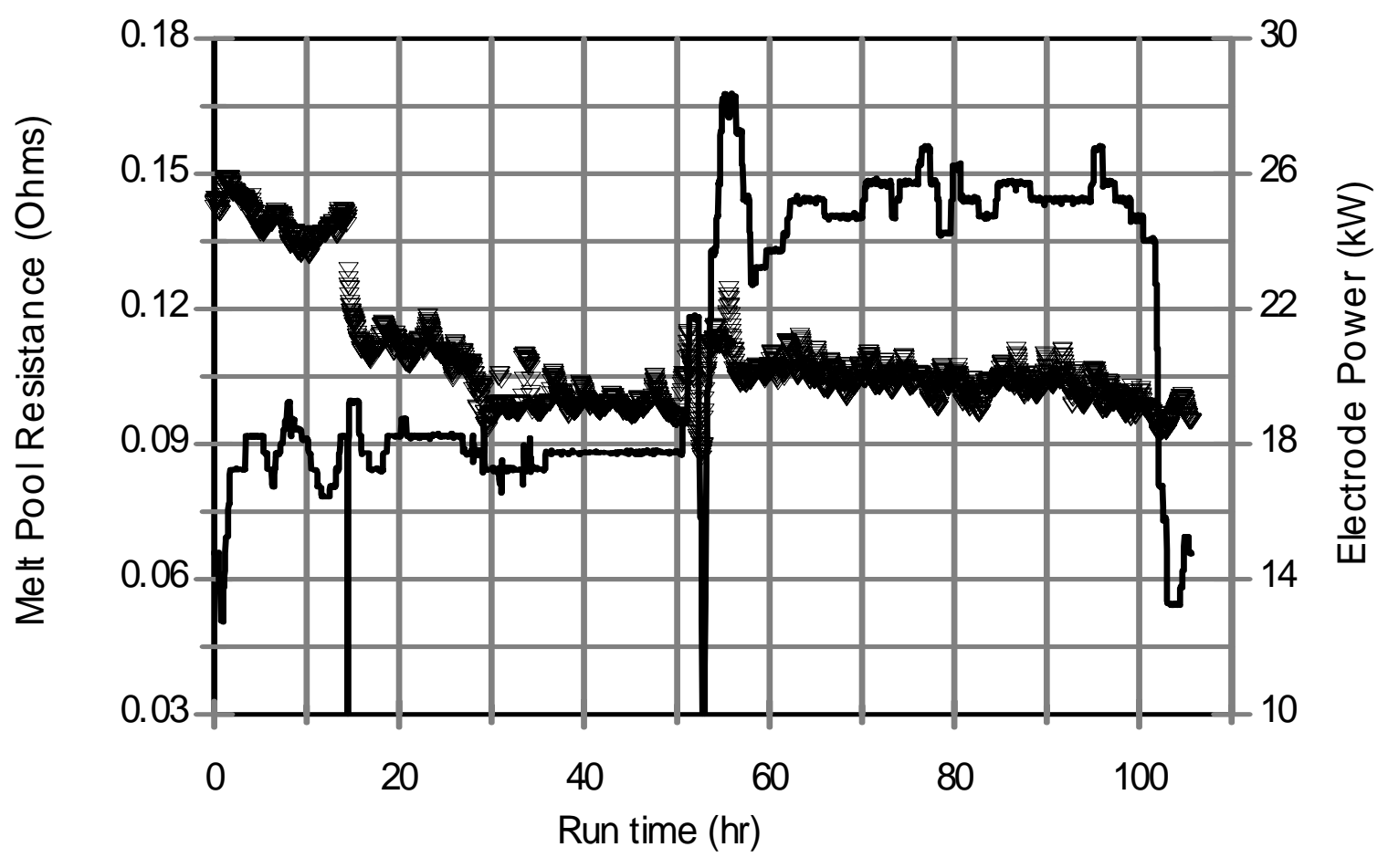

$\boldsymbol{\nabla}$ Resistance $\quad$ Power

Figure 3.6.c. Melt pool resistance and total electrode power during DM100 Tests $3 \mathbf{a}$ and $3 \mathbf{b}$. 


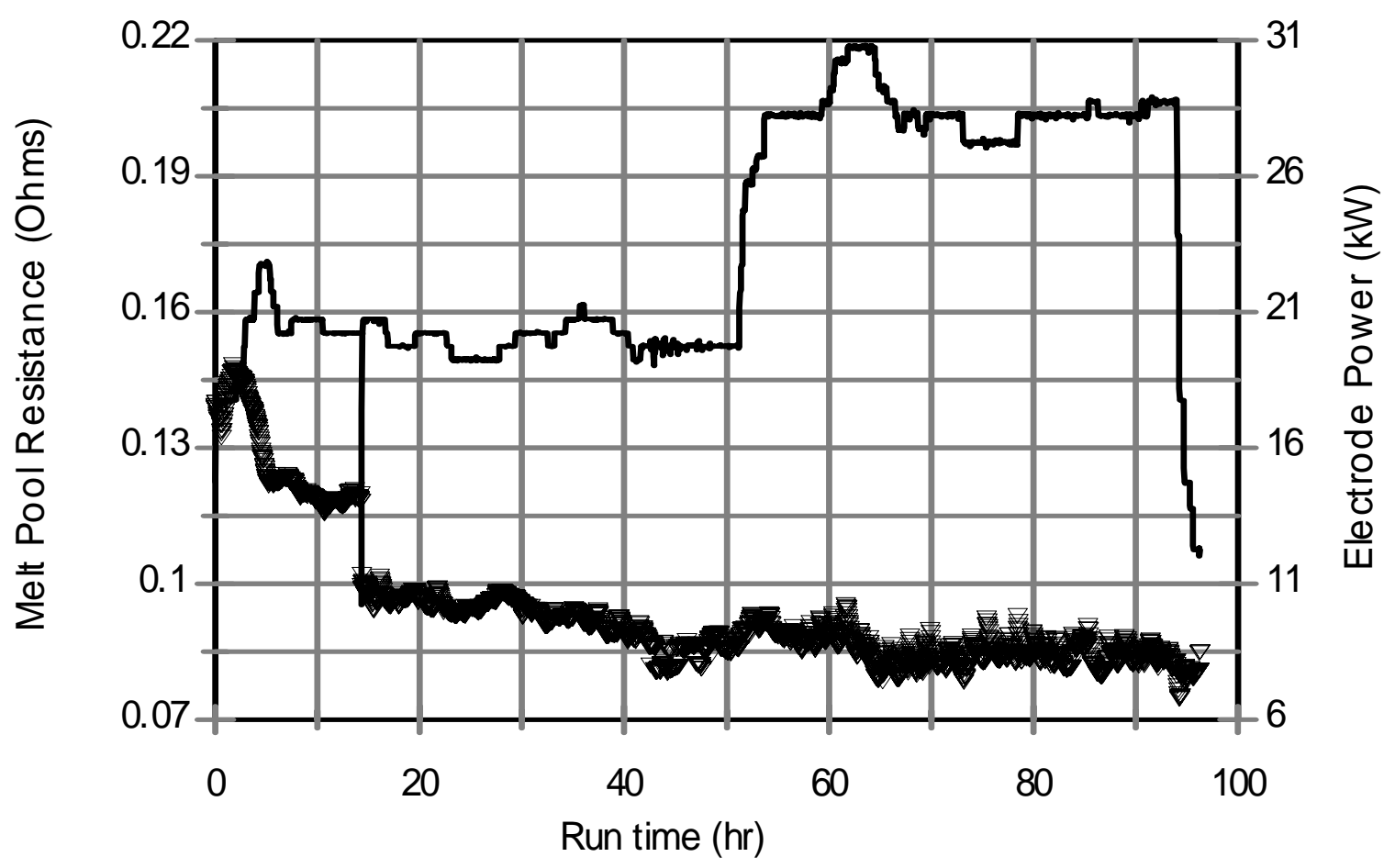

Figure 3.6.d. Melt pool resistance and total electrode power during DM100 Tests $4 a$ and $4 b$. 


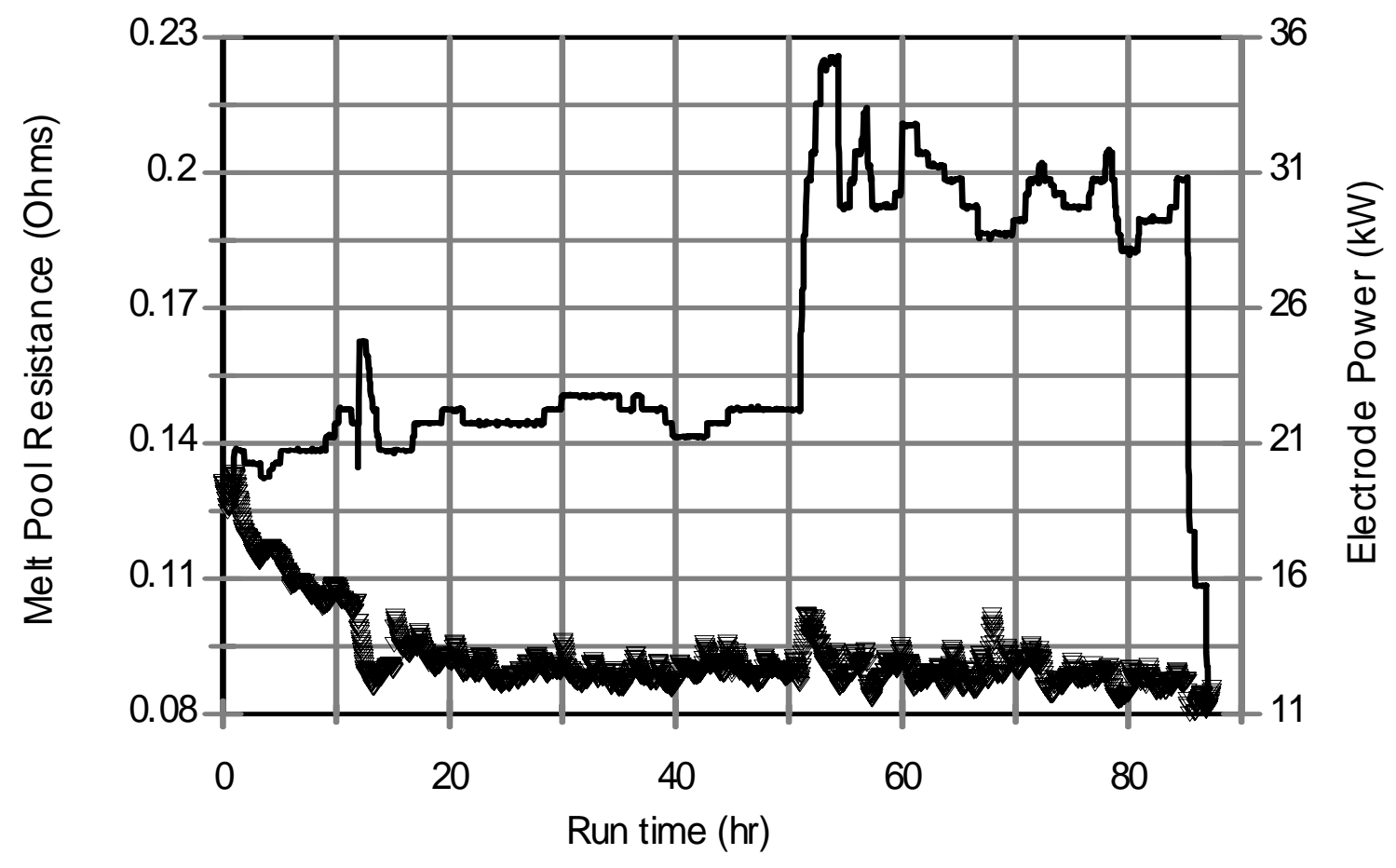

Figure 3.6.e. Melt pool resistance and total electrode power during DM100 Tests $5 a$ and $5 b$. 


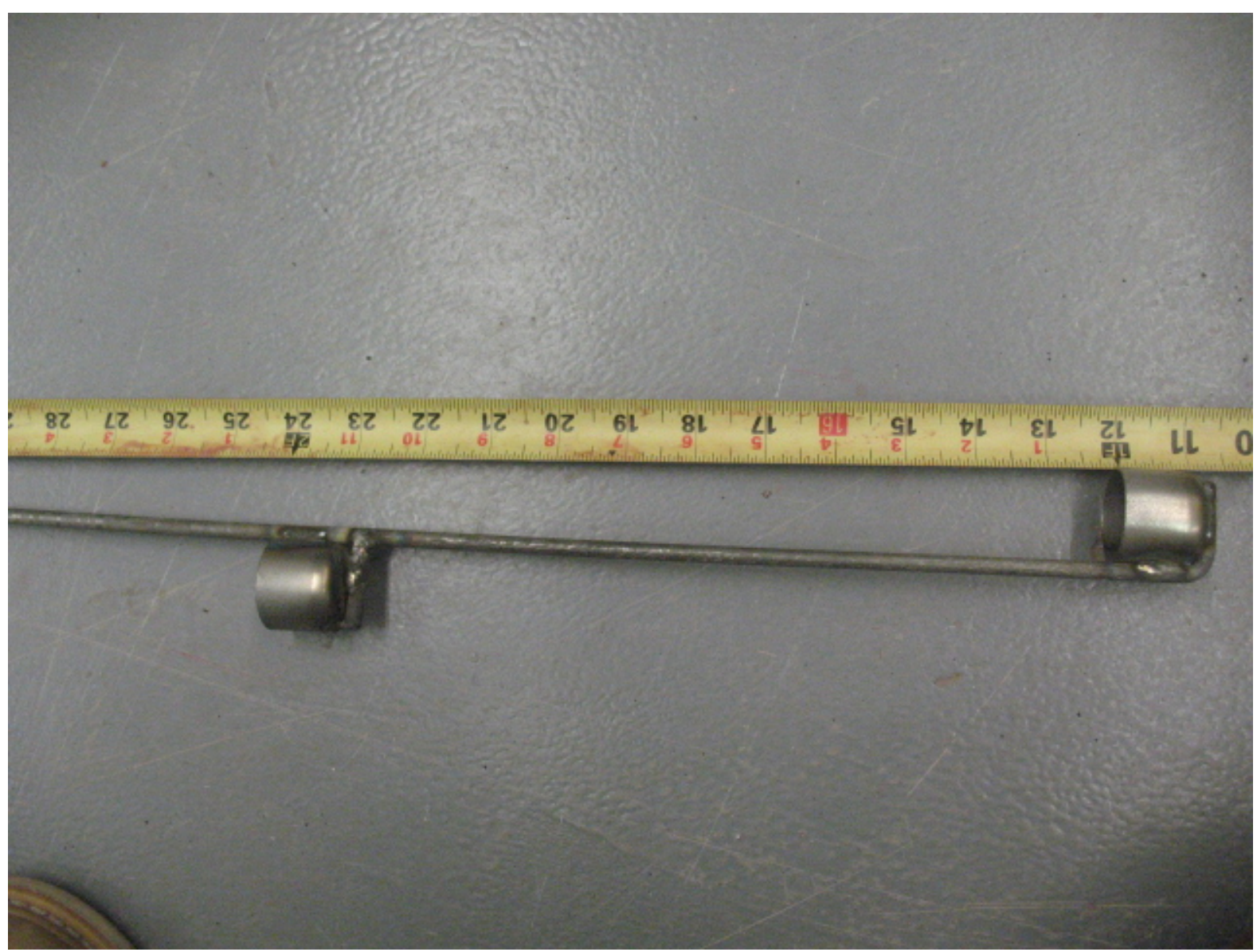

Figure 3.7. Typical sampling boats prior to installation during idling periods. 


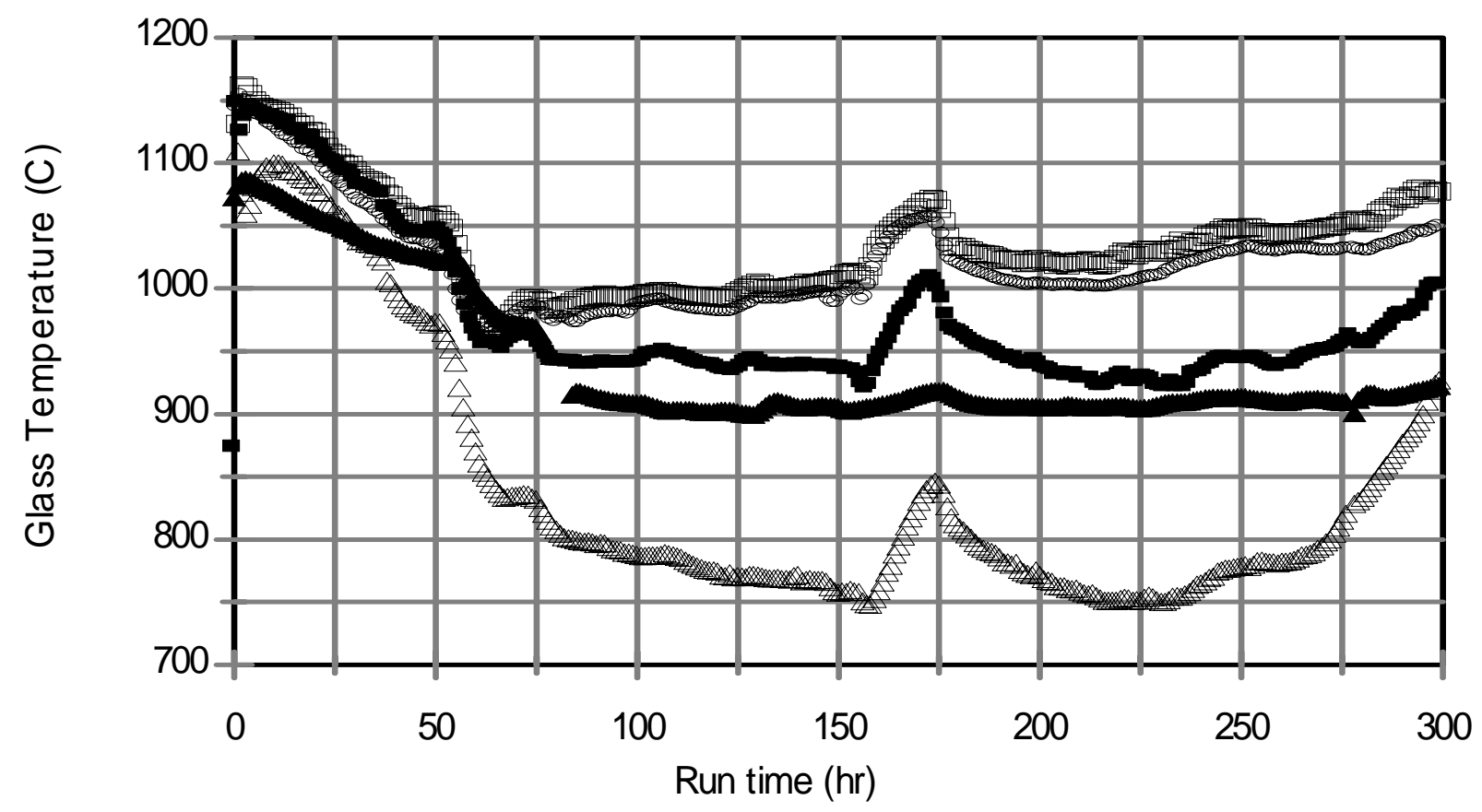
$\Delta \quad 27$ " from bottom
- 16 " from bottom
ㅁ 10" from bottom
- 5" from bottom
$\Delta$ Airlift

Figure 3.8.a. Glass temperatures (hourly averaged) during idling period after Test 1. (Temperature measurements are accurate to $\pm 5^{\circ} \mathrm{C}$ ) 


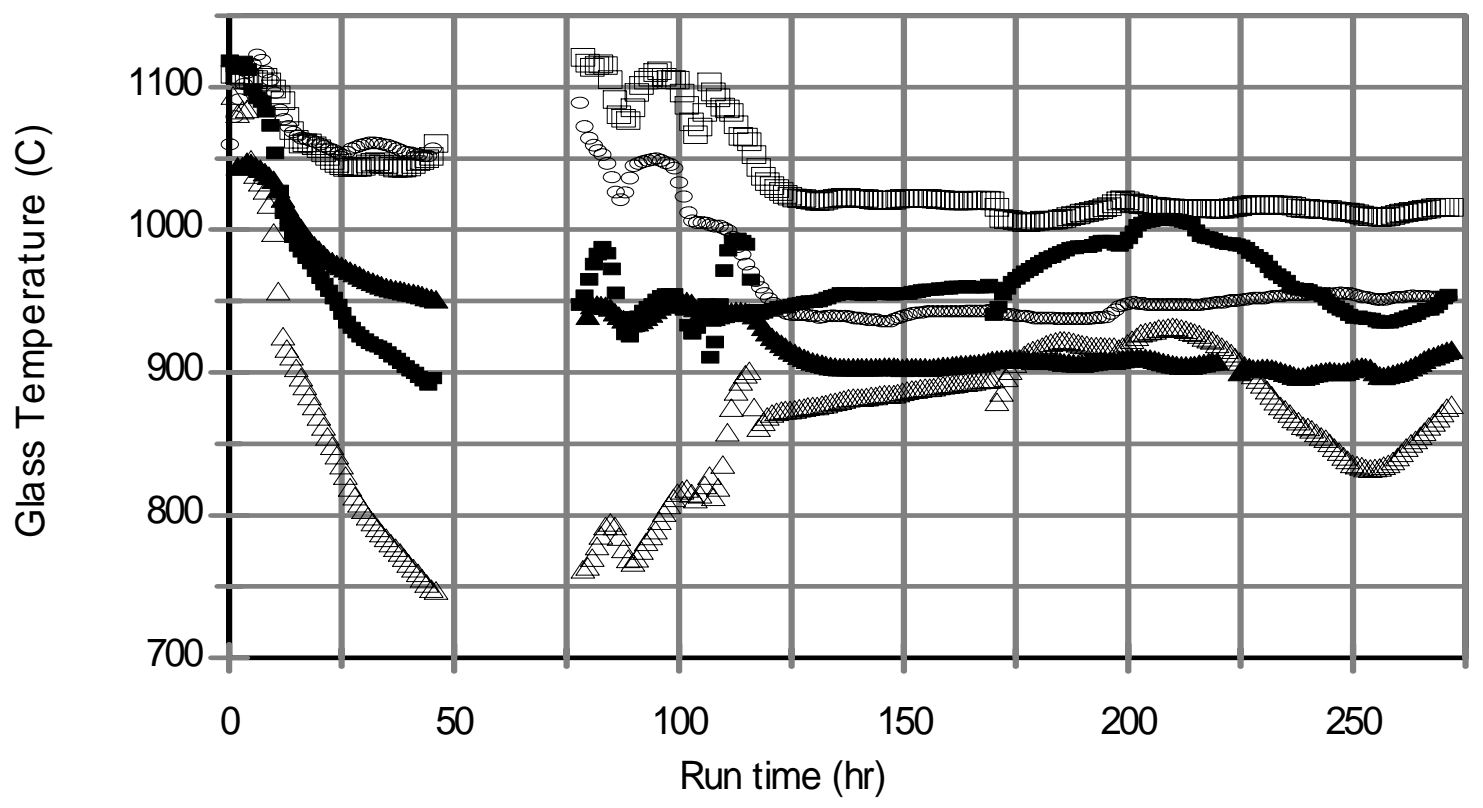

Figure 3.8.b. Glass temperatures (hourly averaged) during idling period after Test 2. (Temperature measurements are accurate to $\pm 5^{\circ} \mathrm{C}$ ) 


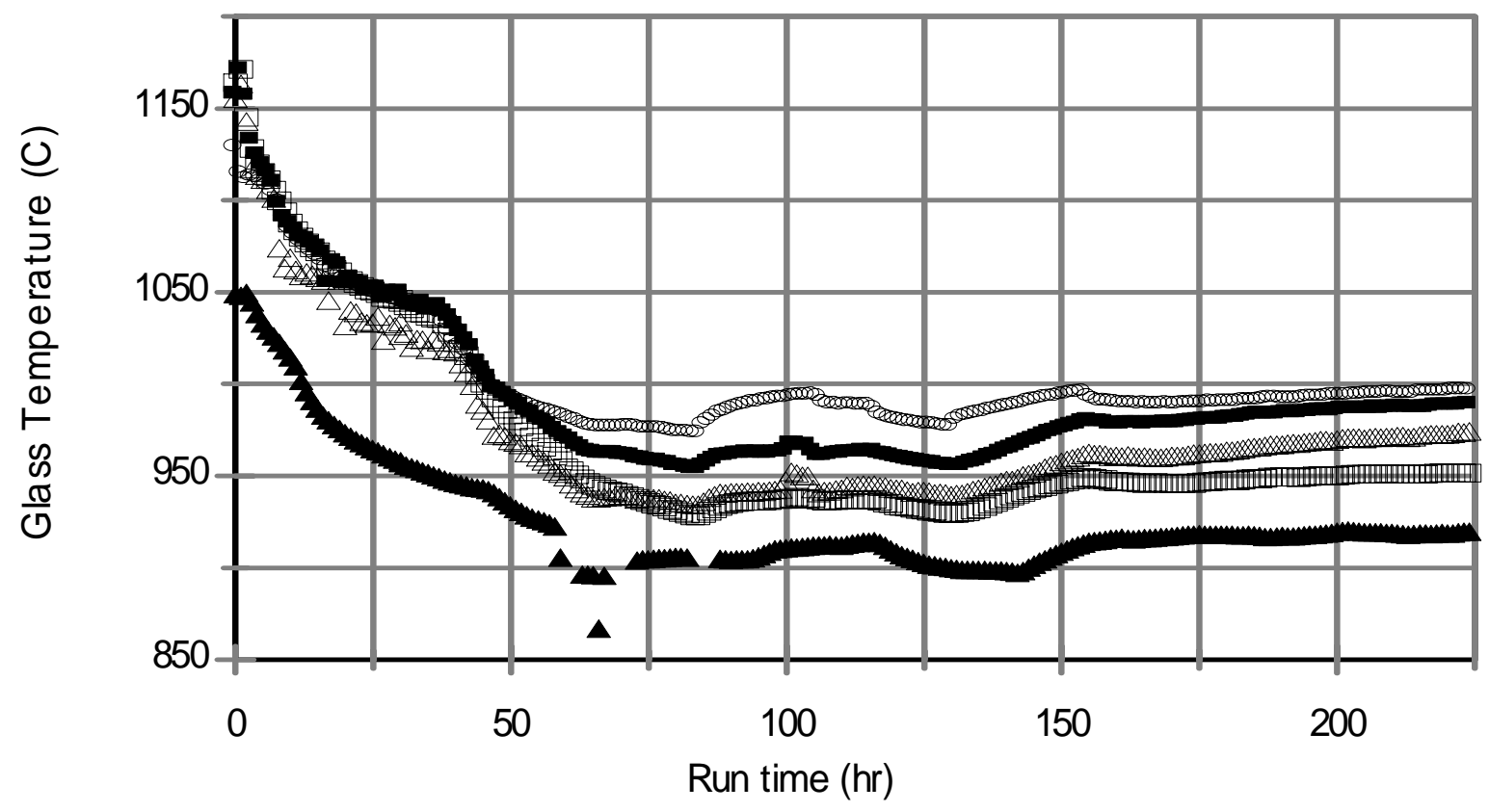

Figure 3.8.c. Glass temperatures (hourly averaged) during idling period after Test 3. (Temperature measurements are accurate to $\pm 5^{\circ} \mathrm{C}$ ) 


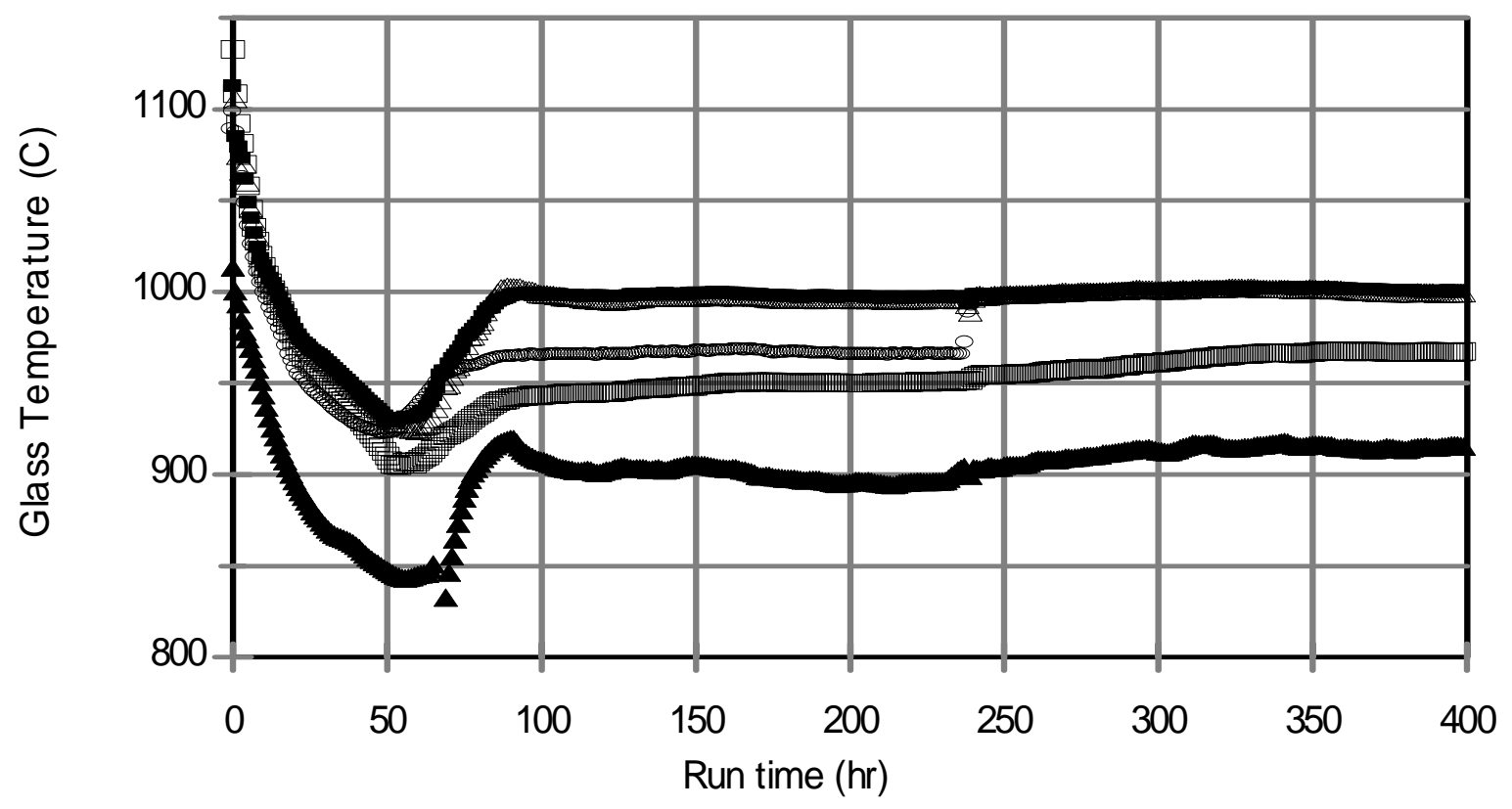

Figure 3.8.d. Glass temperatures (hourly averaged) during idling period after Test 4 . (Temperature measurements are accurate to $\pm 5^{\circ} \mathrm{C}$ ) 


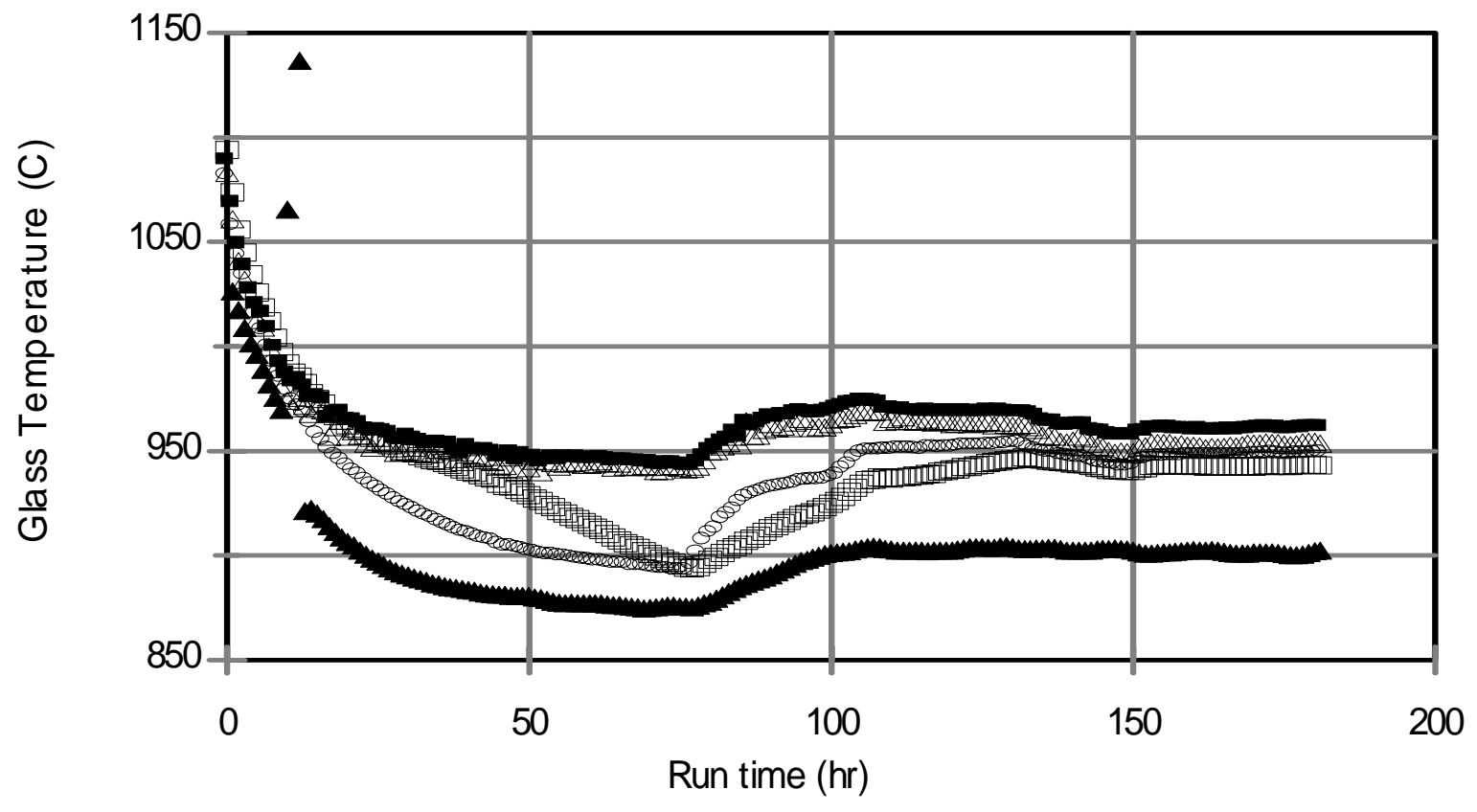

Figure 3.8.e. Glass temperatures (hourly averaged) during idling period after Test 5. (Temperature measurements are accurate to $\pm 5^{\circ} \mathrm{C}$ ) 


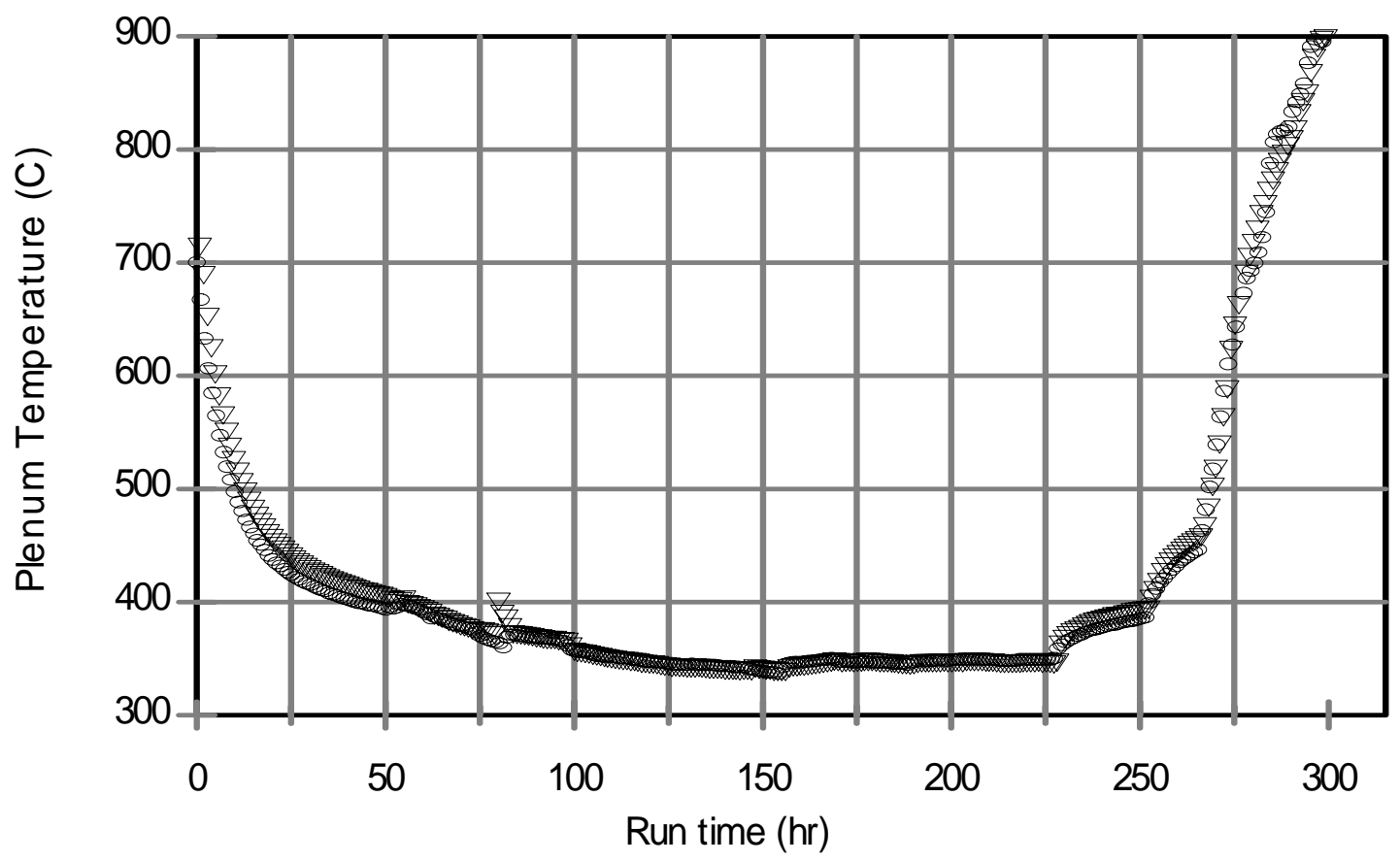

$\boldsymbol{\nabla}$ 17" from top, Thermowell

- 17 " from top, Exposed

Figure 3.9.a. Plenum temperatures (hourly averaged) during idling period after Test 1. (Temperature measurements are accurate to $\pm 5^{\circ} \mathrm{C}$ ) 


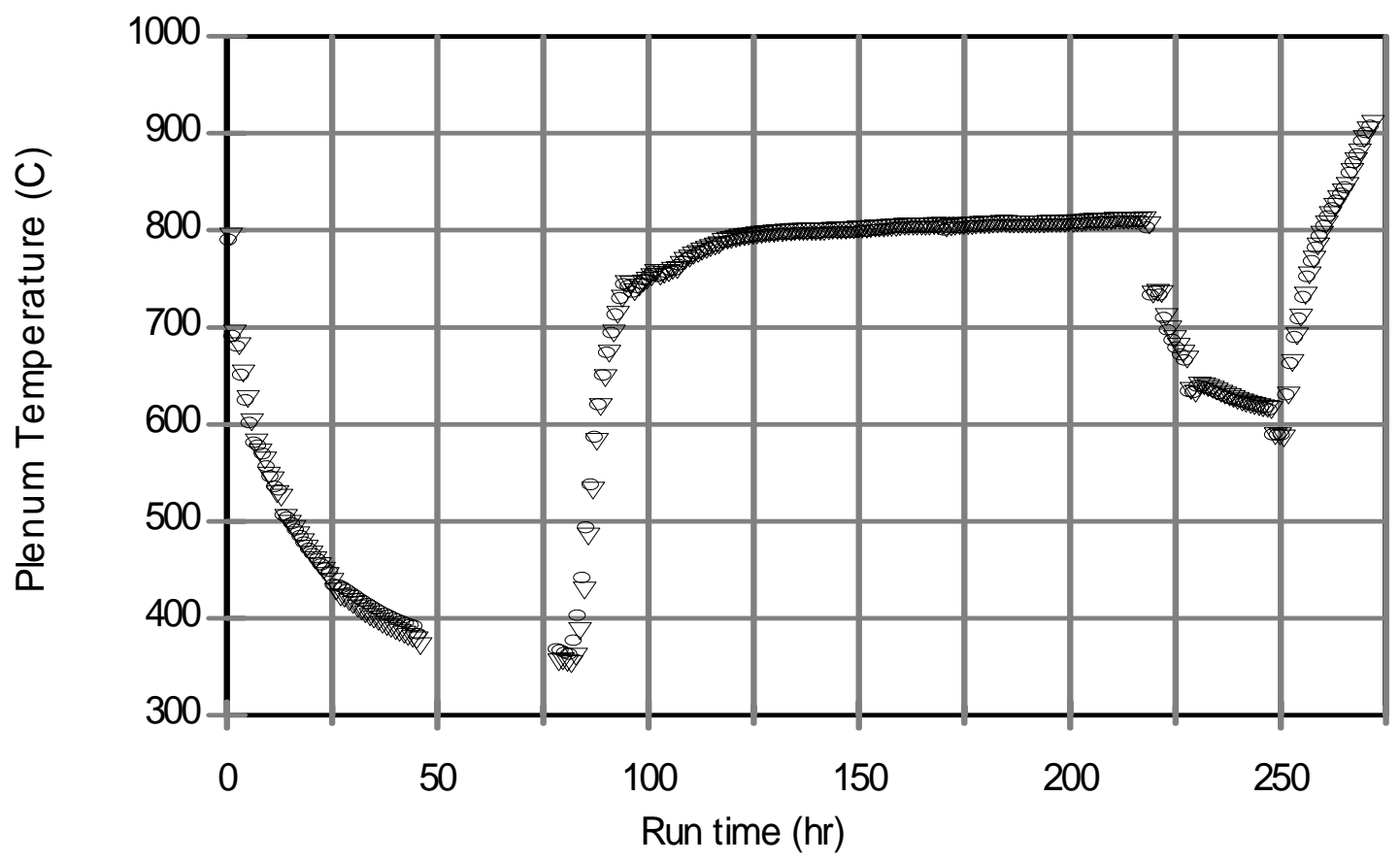

$\boldsymbol{\nabla}$ 17" from top, Thermowell

- 17 " from top, Exposed

Figure 3.9.b. Plenum temperatures (hourly averaged) during idling period after Test 2. (Temperature measurements are accurate to $\pm 5^{\circ} \mathrm{C}$ ) 


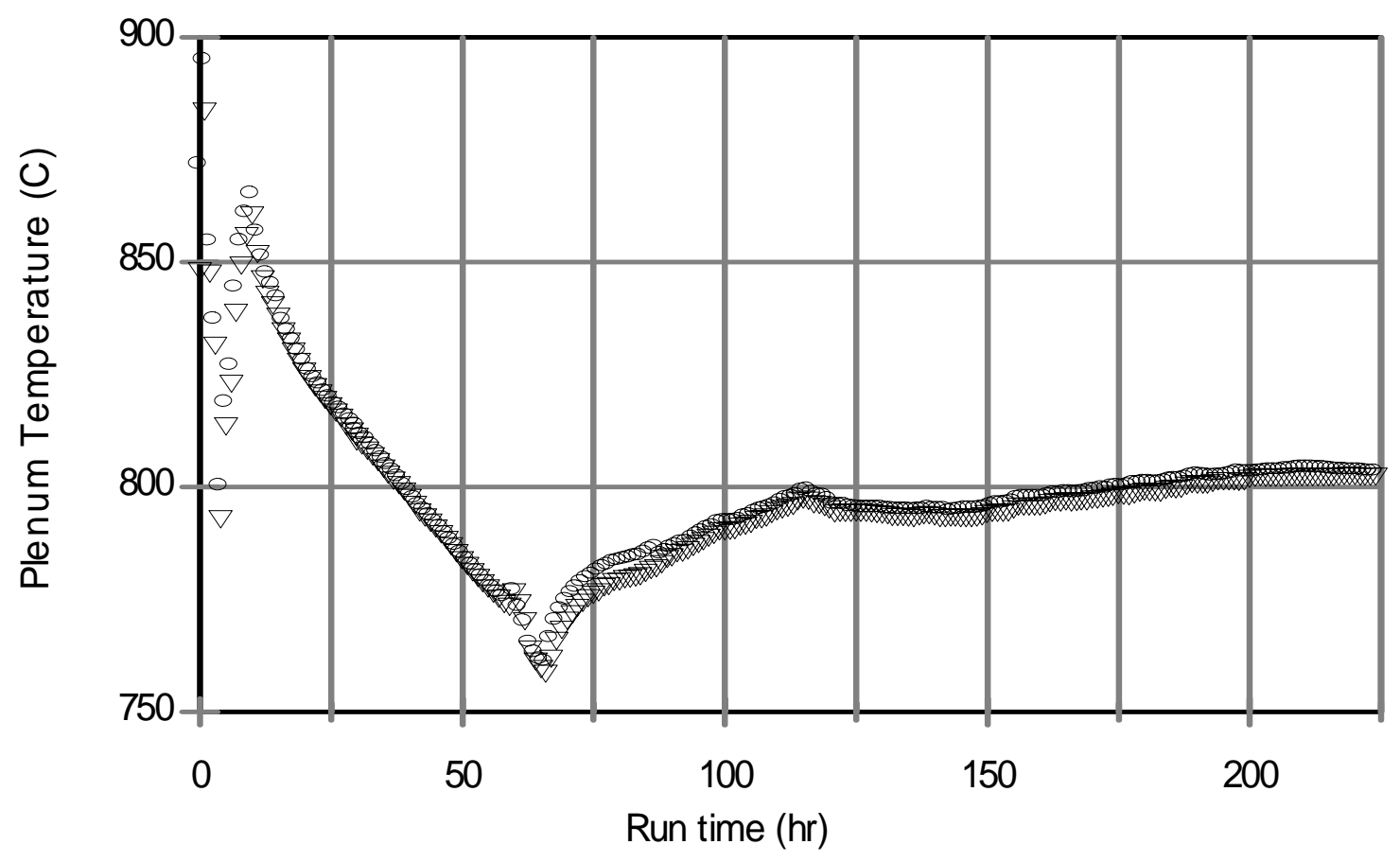

$\boldsymbol{\nabla} \quad 17$ " from top, Thermowell

- 17 " from top, Exposed

Figure 3.9.c. Plenum temperatures (hourly averaged) during idling period after Test 3. (Temperature measurements are accurate to $\pm 5^{\circ} \mathrm{C}$ ) 


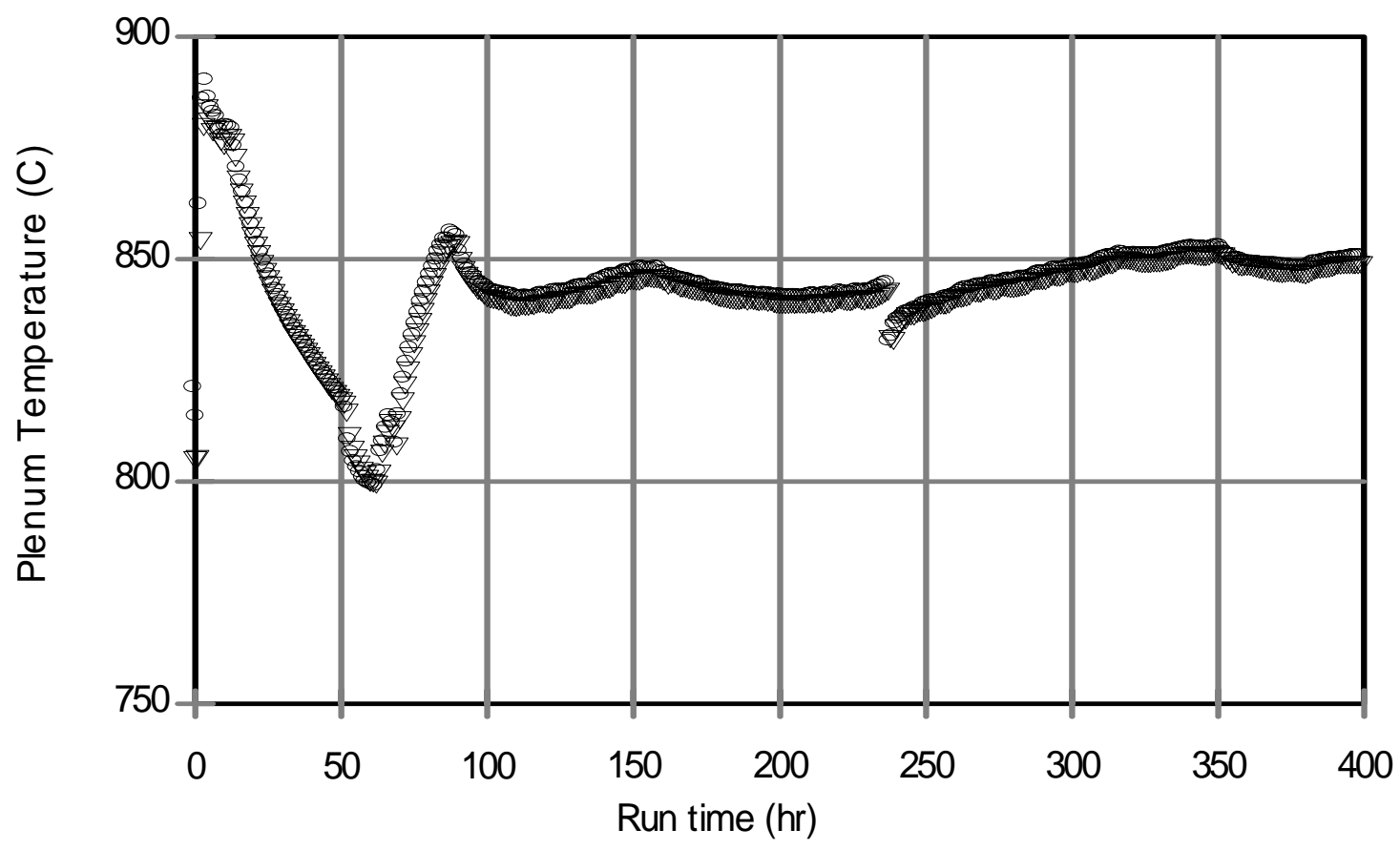

$\boldsymbol{\nabla}$ 17" from top, Thermowell

- 17 " from top, Exposed

Figure 3.9.d. Plenum temperatures (hourly averaged) during idling period after Test 4. (Temperature measurements are accurate to $\pm 5^{\circ} \mathrm{C}$ ) 


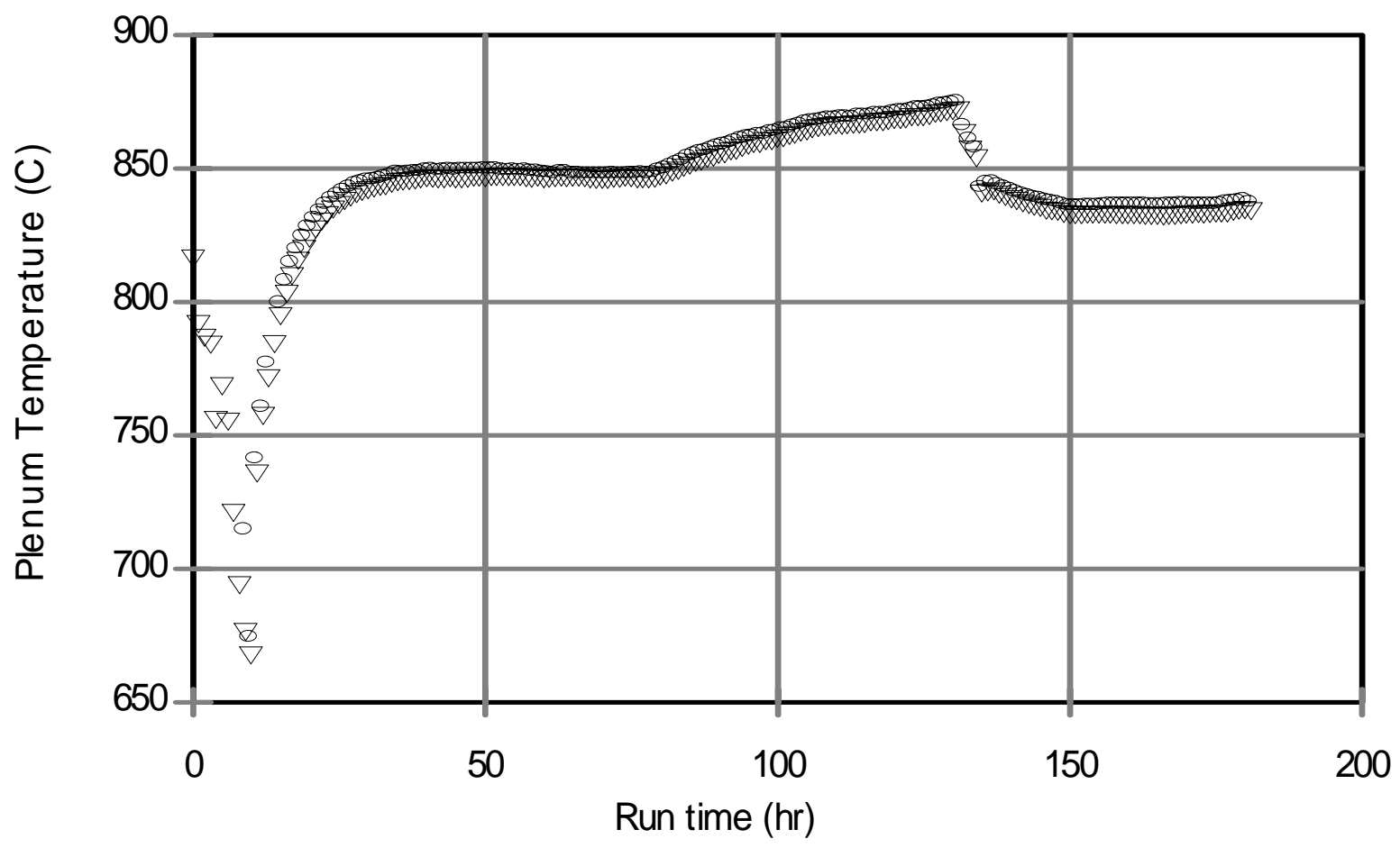

$\boldsymbol{\nabla} 17^{\prime \prime}$ from top, Thermowell

- $\quad 17$ " from top, Exposed

Figure 3.9.e. Plenum temperatures (hourly averaged) during idling period after Test 5.

(Temperature measurements are accurate to $\pm 5^{\circ} \mathrm{C}$ ) 

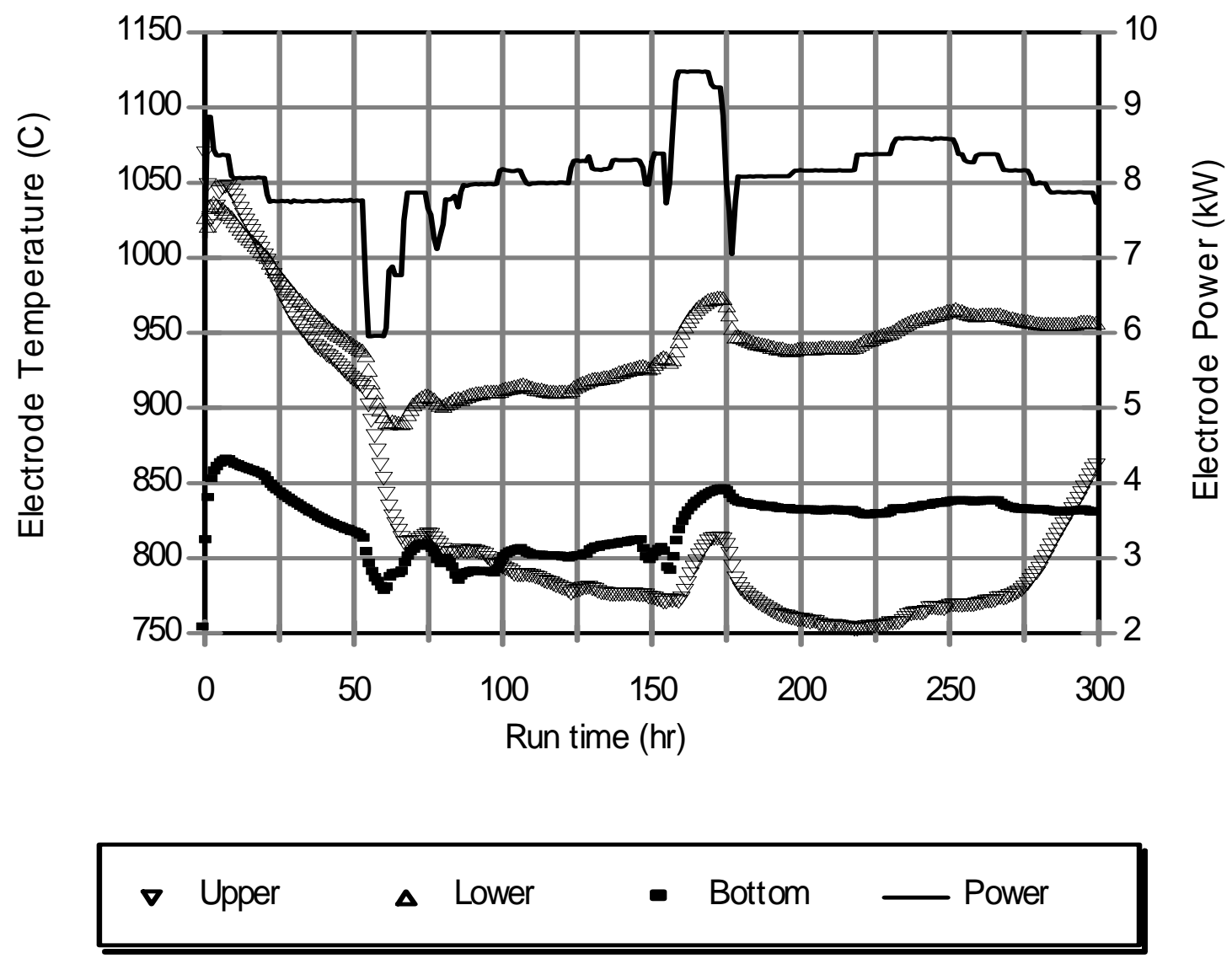

Figure 3.10.a. Electrode temperatures and power (hourly averaged) during idling period after Test 1. 


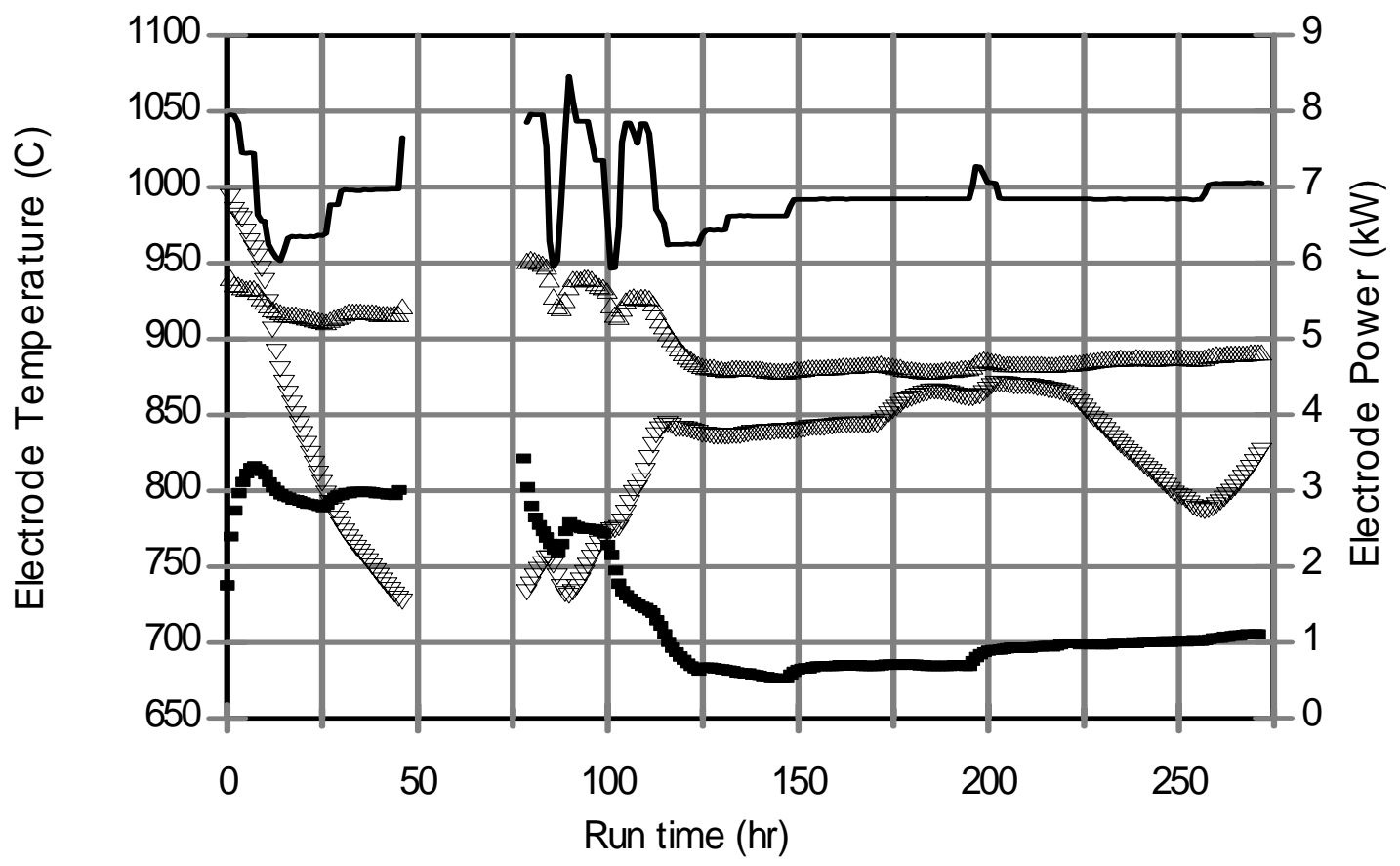

Figure 3.10.b. Electrode temperatures and power (hourly averaged) during idling period after Test 2 . 
The Catholic University of America Vitreous State Laboratory
ORP-56294 Rev. 0

Effects of High Crystal Content in HLW DM100 Melter Tests

Final Report, VSL-09R1520-1, Rev. 0
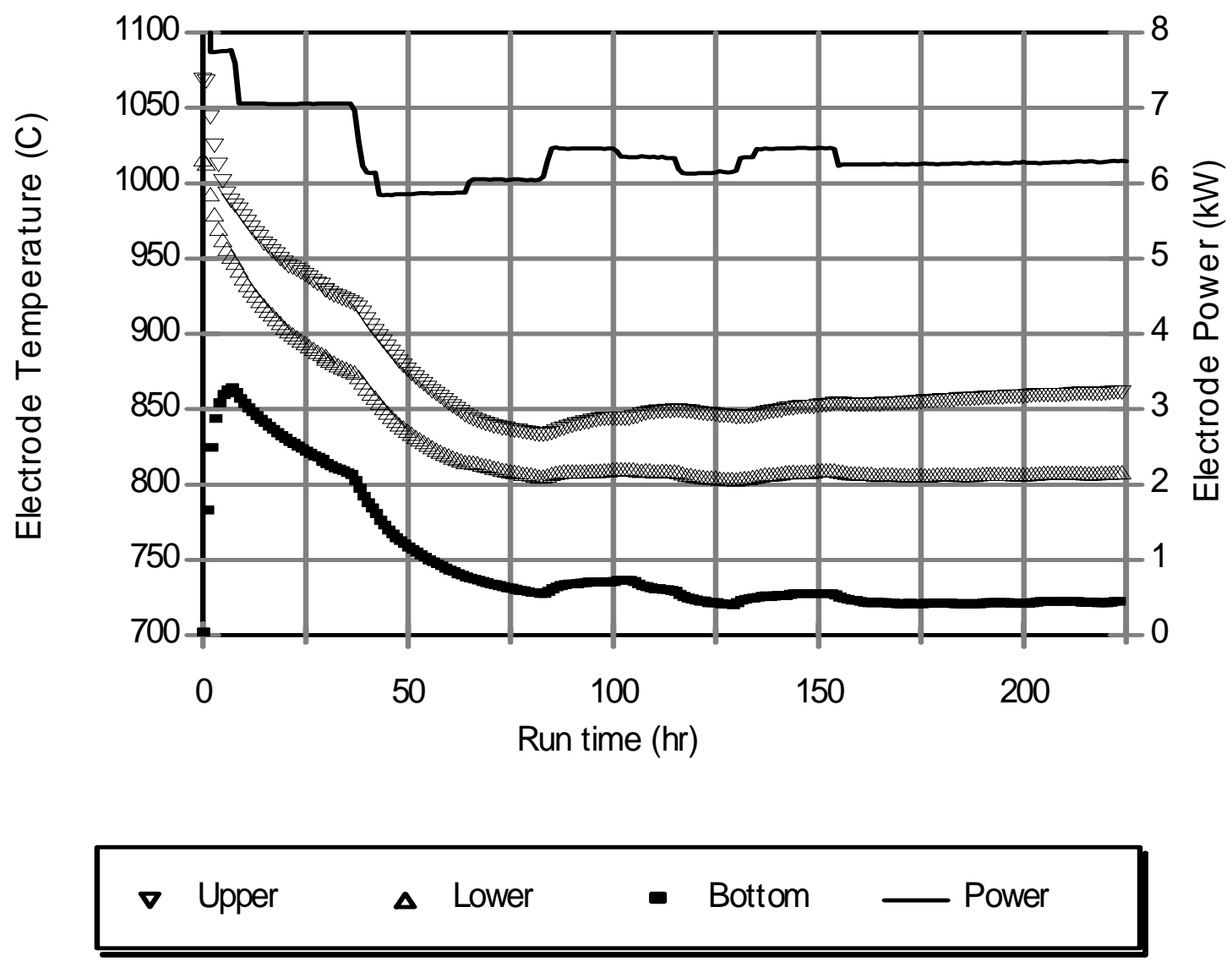

Figure 3.10.c. Electrode temperatures and power (hourly averaged) during idling period after Test 3. 
ORP-56294 Rev. 0

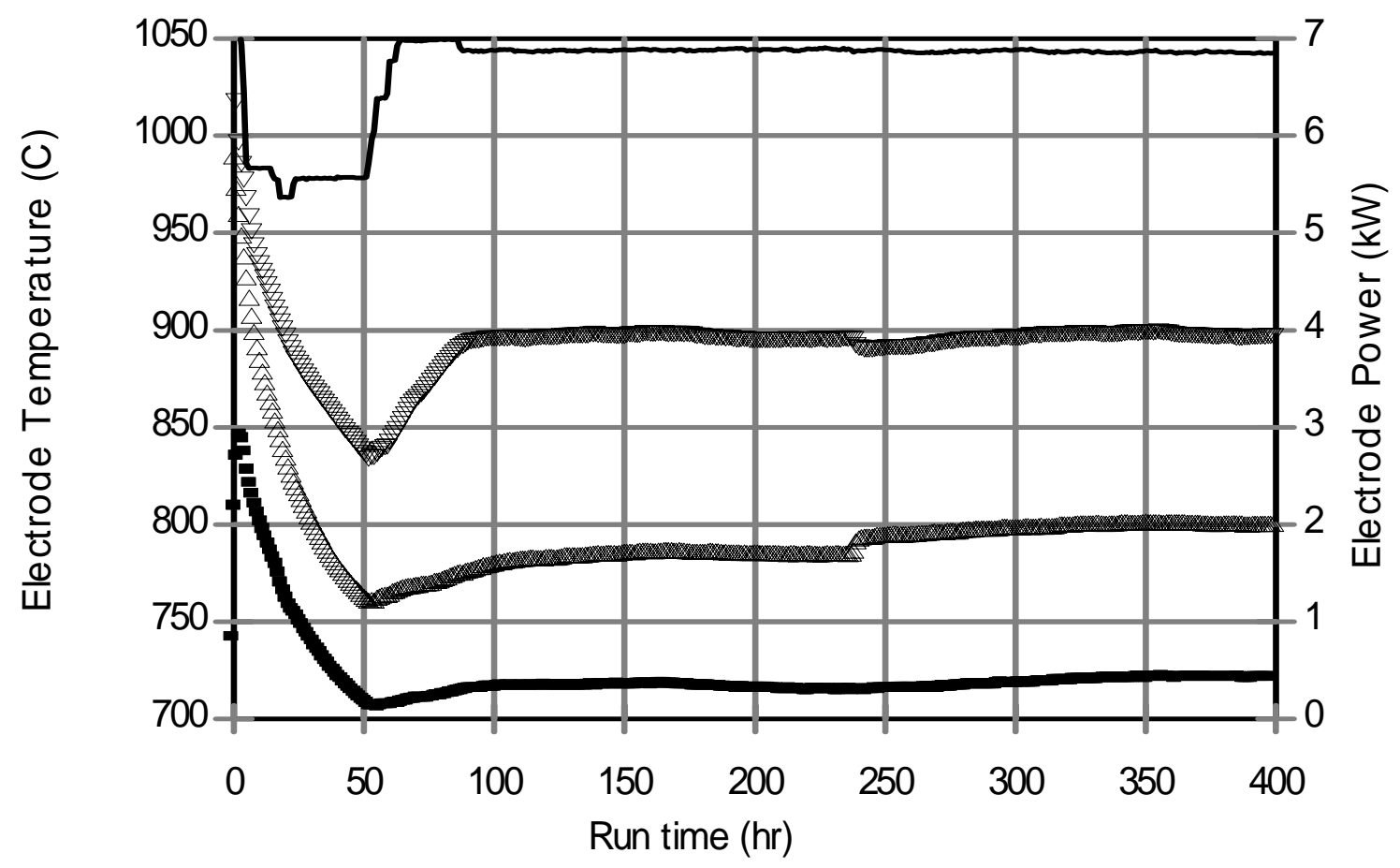
$\boldsymbol{\nabla}$ Upper
$\Delta$ Lower
- Bottom
Power

Figure 3.10.d. Electrode temperatures and power (hourly averaged) during idling period after Test 4. 

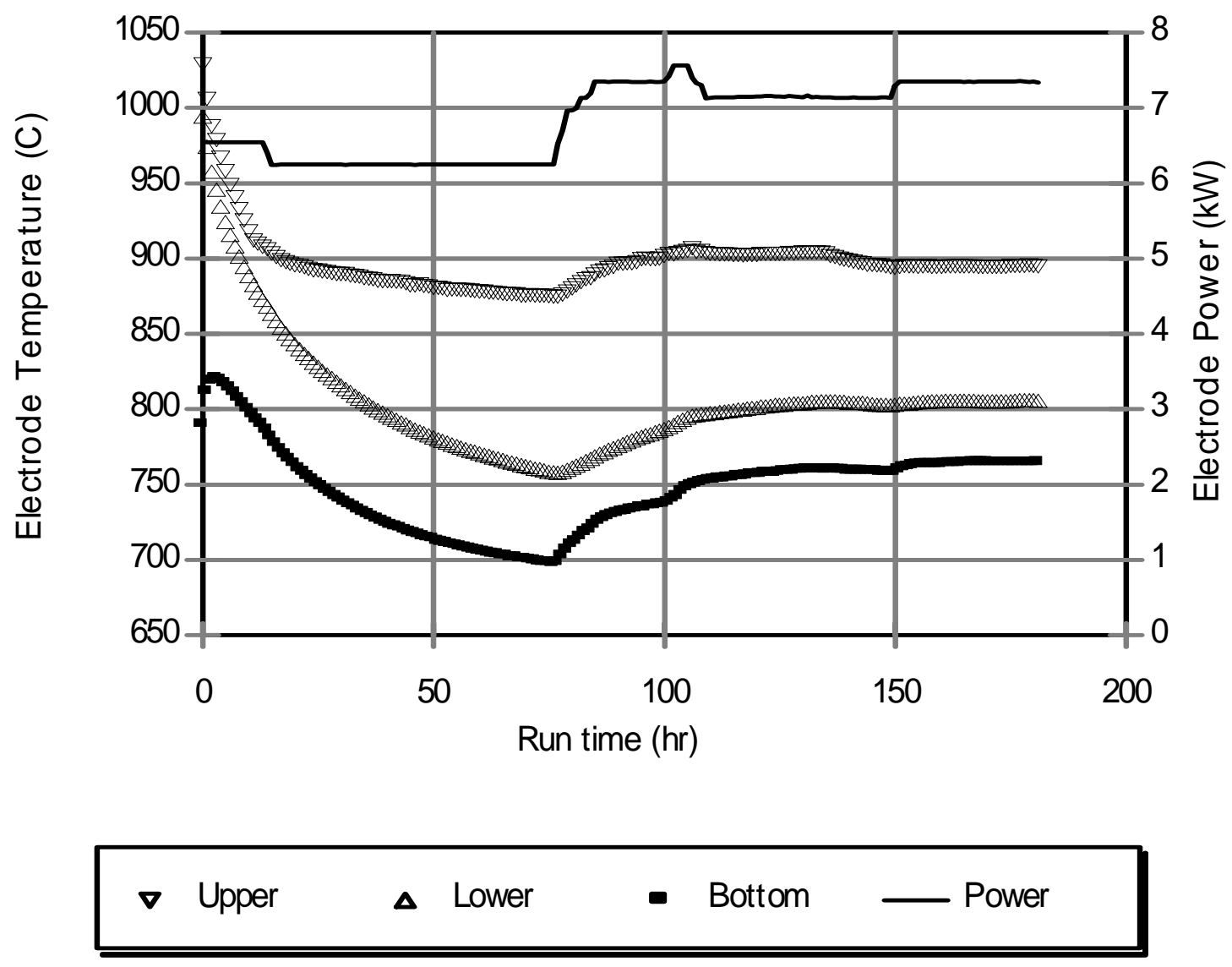

Figure 3.10.e. Electrode temperatures and power (hourly averaged) during idling period after Test 5 . 
ORP-56294 Rev. 0

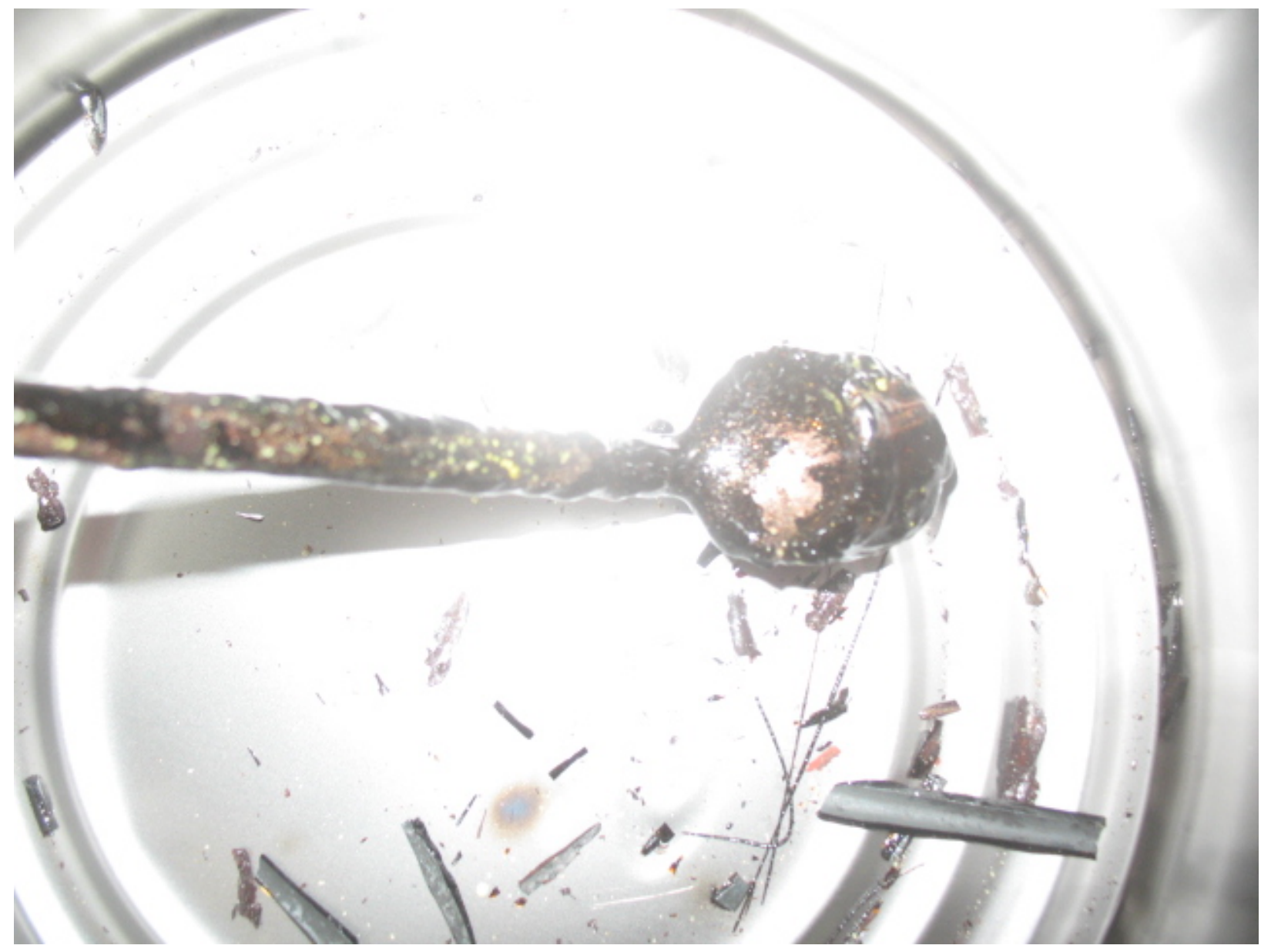

Figure 3.11. Single sample boat removed after Test 1 prior to idling period. Note secondary sulfur phases on external glass surface. 
ORP-56294 Rev. 0

The Catholic University of America Vitreous State Laboratory
Effects of High Crystal Content in HLW DM100 Melter Tests Final Report, VSL-09R1520-1, Rev. 0

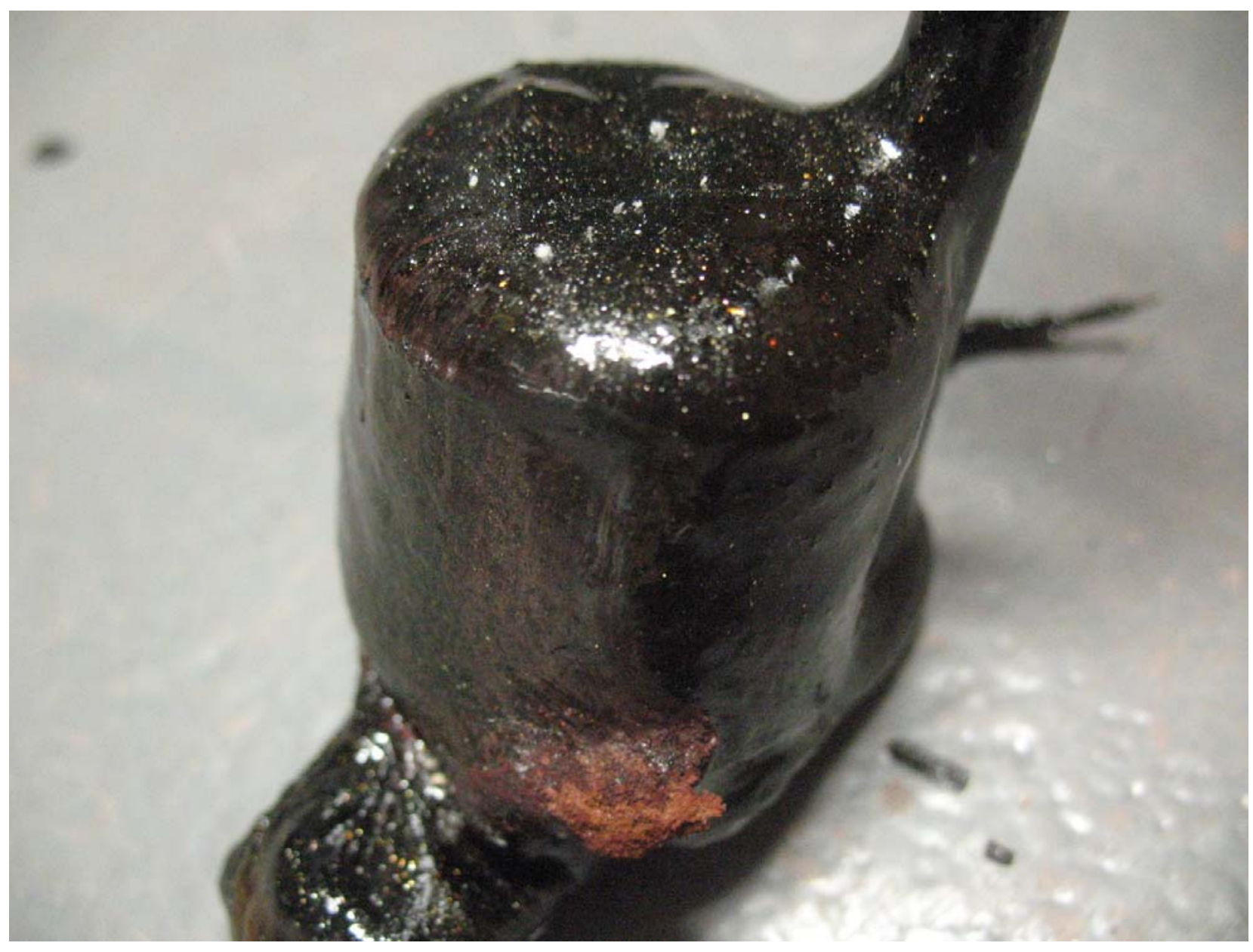

Figure 3.12. Lower sampling boat removed after Test 2 idling period. 


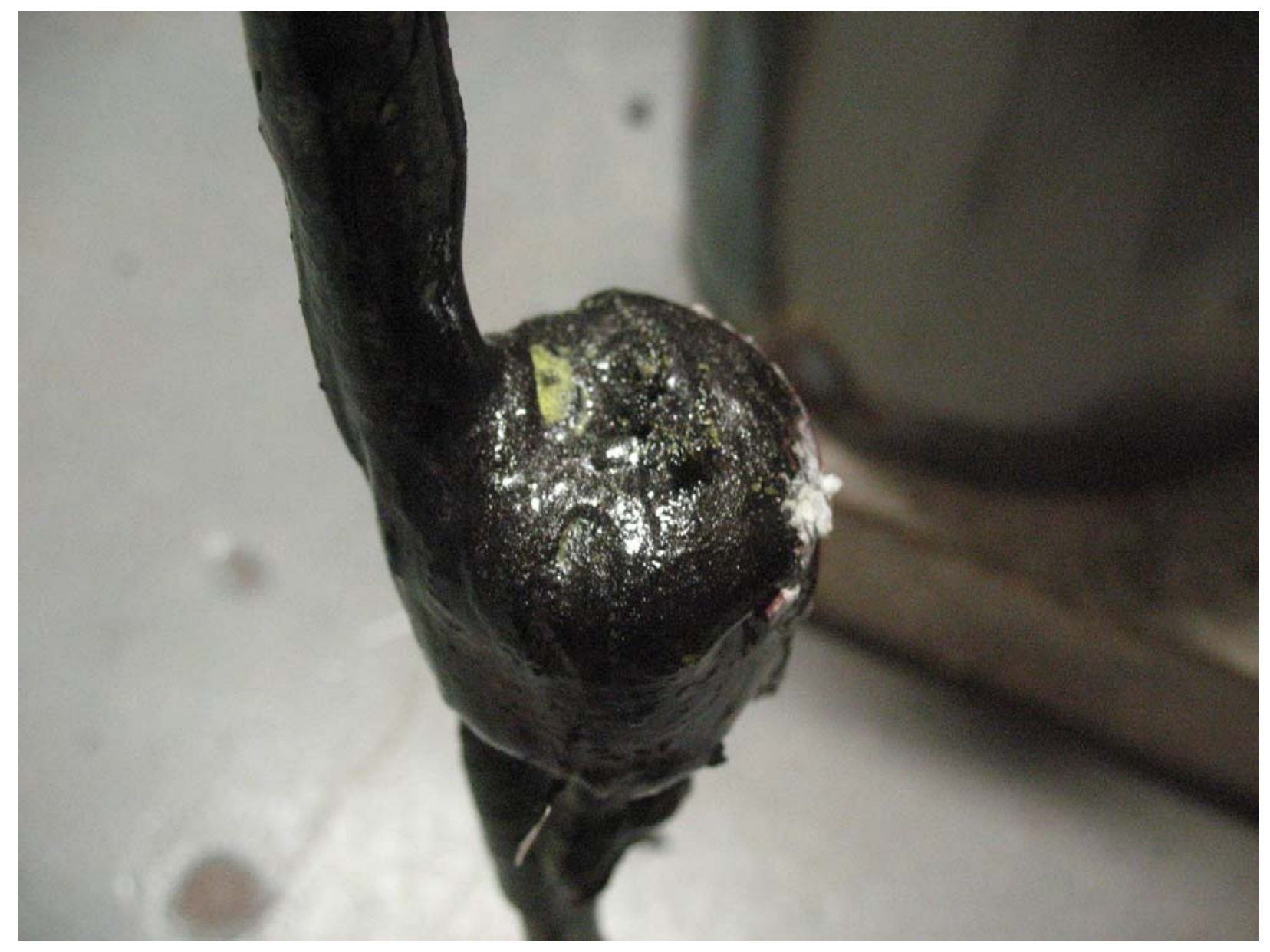

Figure 3.13. Upper sampling boat removed after Test 2 idling period. Note secondary sulfur phases on external glass surface. 

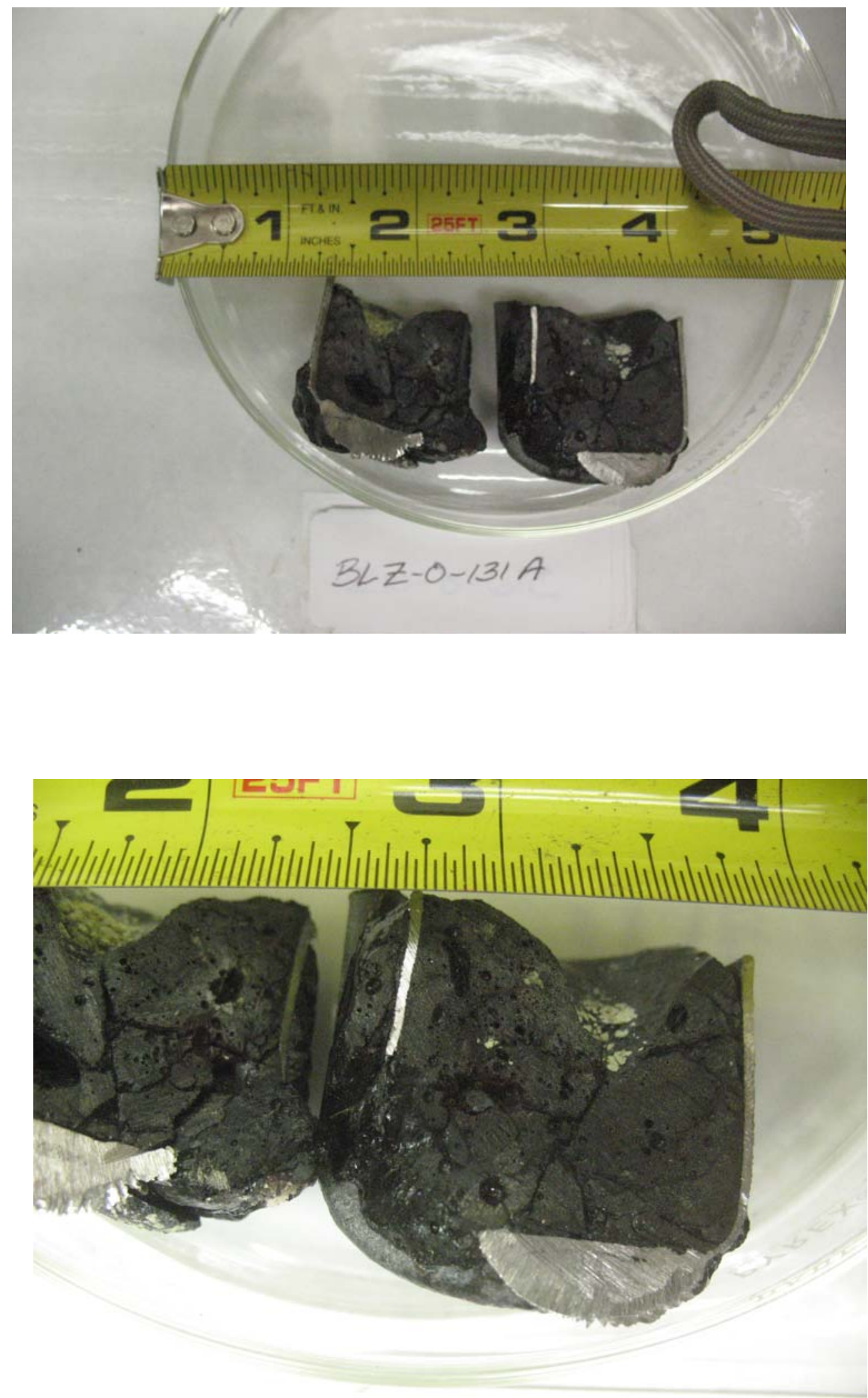

Figure 3.14. Cross-sectioned, lower sampling boat removed after Test 1 idling period. Note hole in the bottom of the boat. 


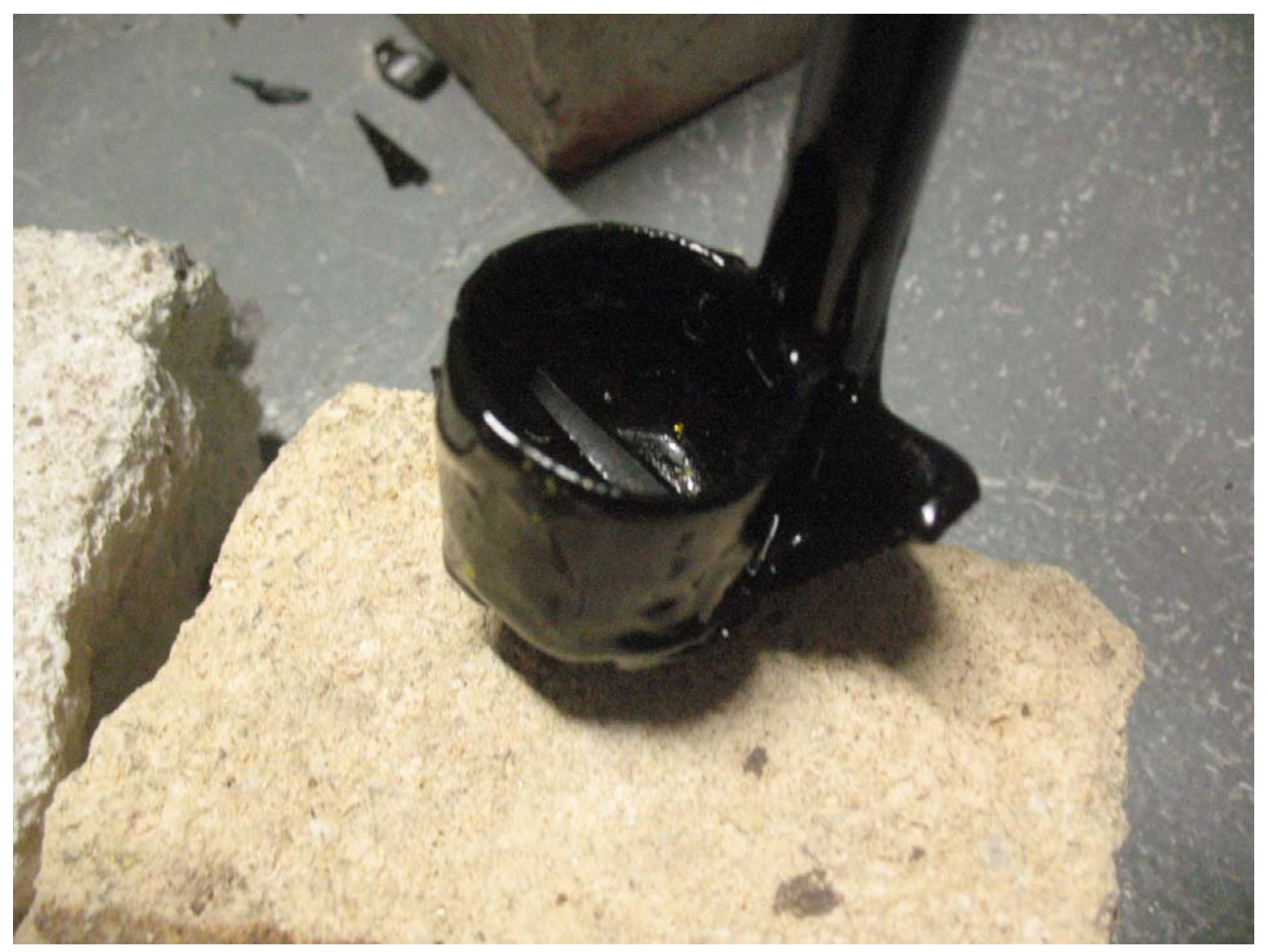

Figure 3.15. Lower sampling boat removed after Test 4 idling period. Note the lack of glass in the boat. 
The Catholic University of America Vitreous State Laboratory
Effects of High Crystal Content in HLW DM100 Melter Tests

Final Report, VSL-09R1520-1, Rev. 0

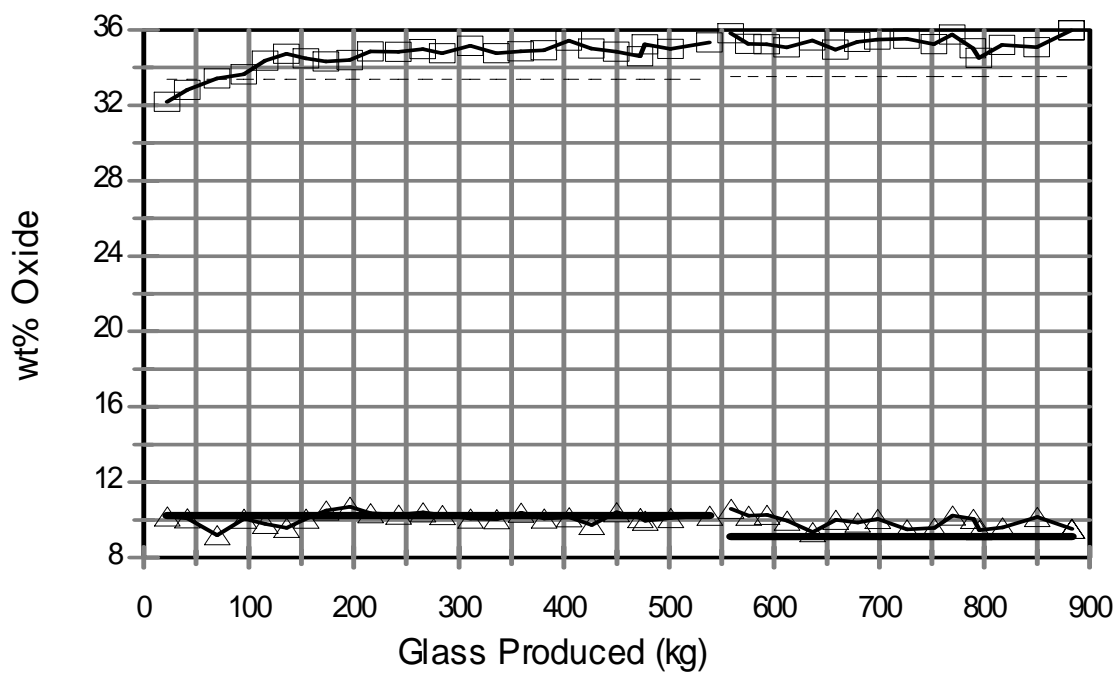

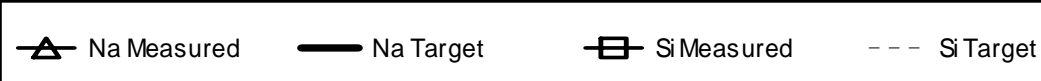

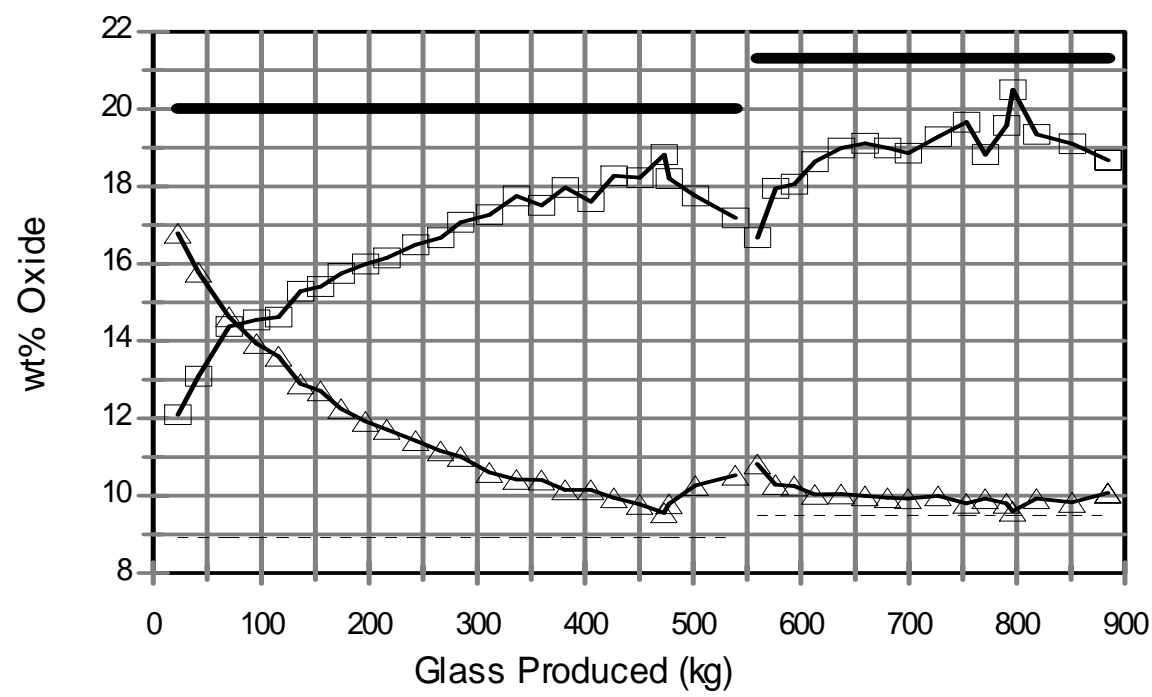

$\Delta$ A Measured $\quad--$ AlTarget $\quad$ Fe Measured $\quad$ Fe Target

Figure 4.1.a. Tests 1 and 2 (HLW-E-SP-06 and HLW-E-SP-05) product glass compositions determined by XRF.

(See Table 4.7 and Section 4.2 for details of composition analysis) 

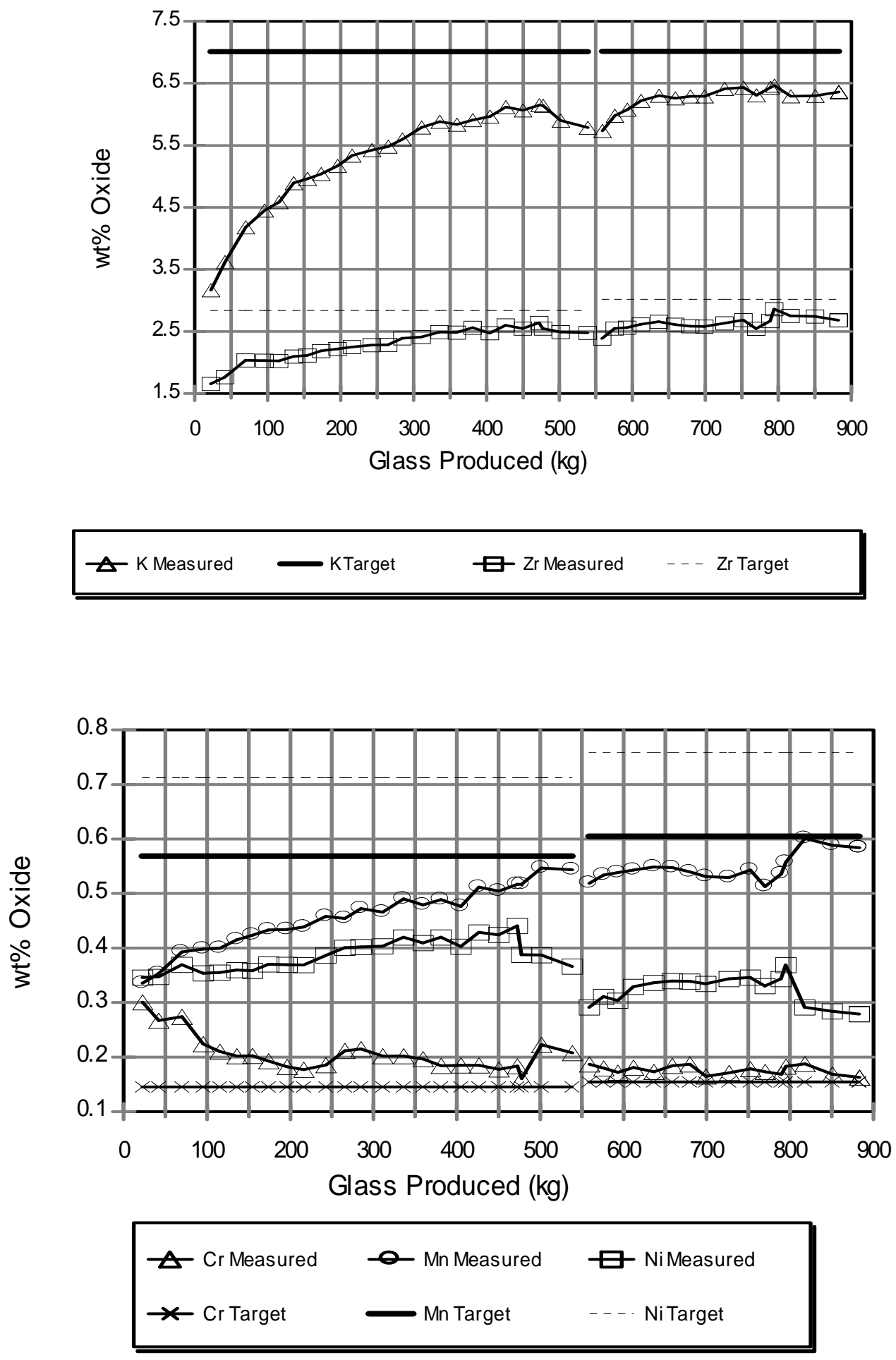

Figure 4.1.b. Tests 1 and 2 (HLW-E-SP-06 and HLW-E-SP-05) product glass compositions determined by XRF. (See Table 4.7 and Section 4.2 for details of composition analysis) 
The Catholic University of America Vitreous State Laboratory
ORP-56294 Rev. 0

Effects of High Crystal Content in HLW DM100 Melter Tests

Final Report, VSL-09R1520-1, Rev. 0

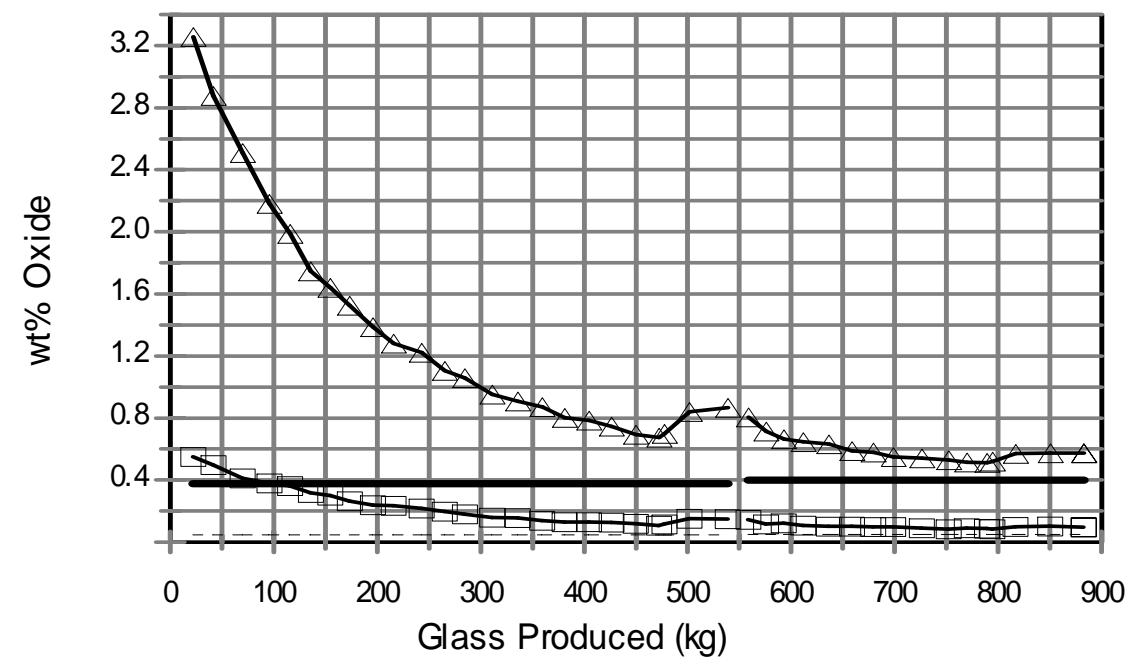

$\Delta$ Ca Measured $\longrightarrow$ Ca Target $\quad \boxminus$ PMeasured $\quad$ - - PTarget

Figure 4.1.c. Tests 1 and 2 (HLW-E-SP-06 and HLW-E-SP-05) product glass compositions determined by XRF.

(See Table 4.7 and Section 4.2 for details of composition analysis) 
The Catholic University of America Vitreous State Laboratory
ORP-56294 Rev. 0

Effects of High Crystal Content in HLW DM100 Melter Tests

Final Report, VSL-09R1520-1, Rev. 0

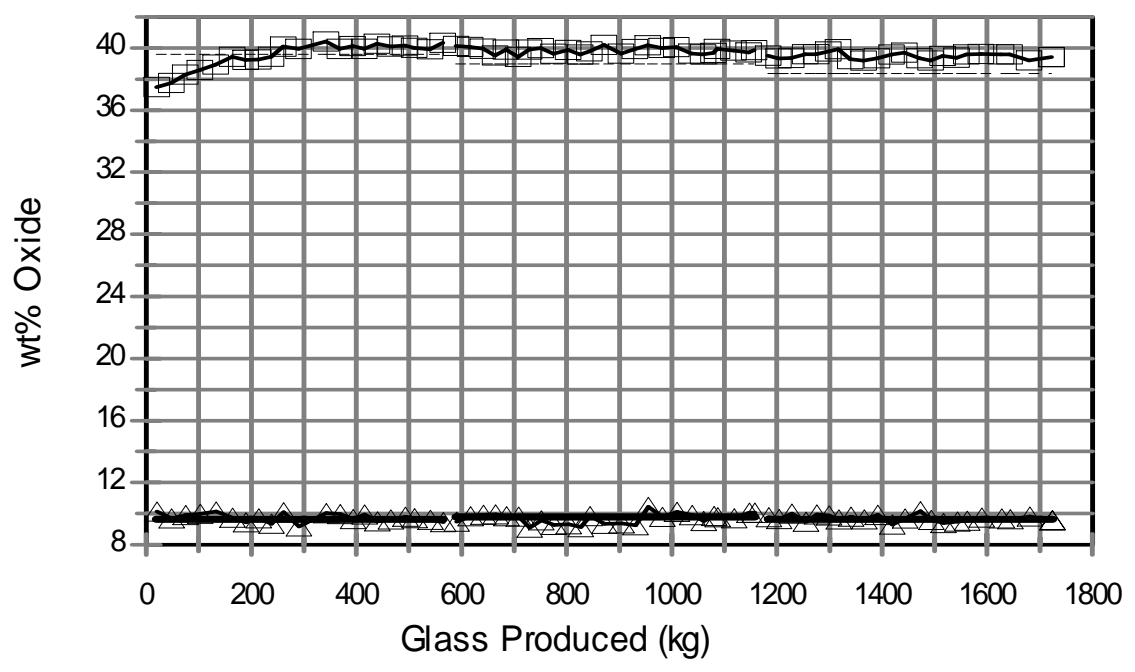

$\triangle$ Na Measured Na Target $\quad$ - Si Measured $\quad--$ Si Target

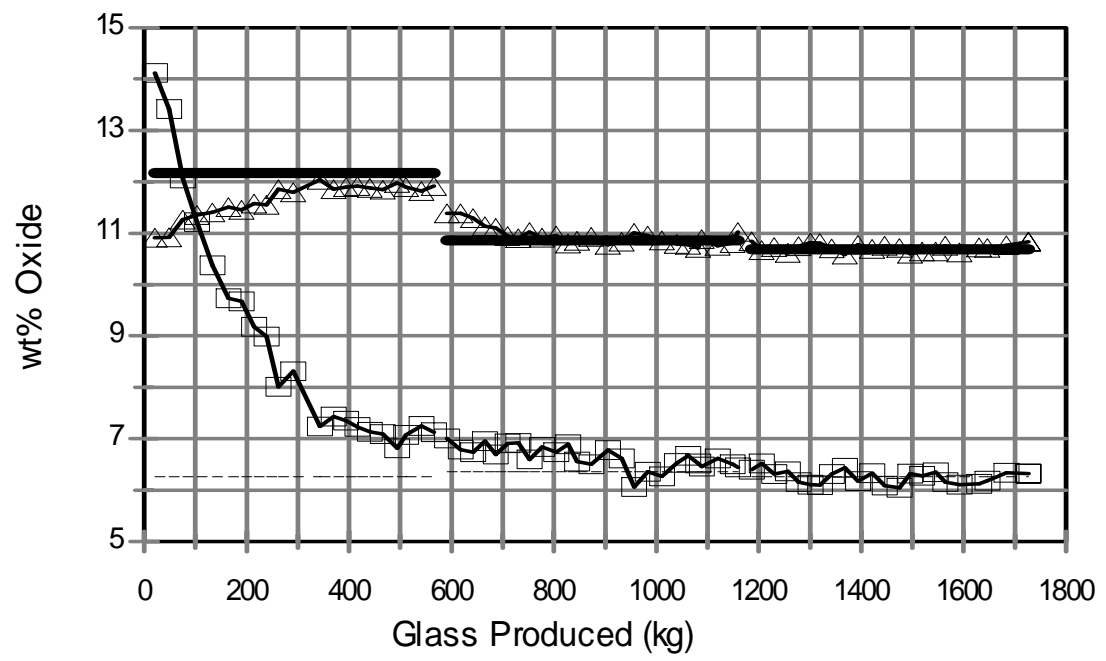

\begin{tabular}{|l|l|l|}
\hline Al Measured $\quad$ AlTarget $\quad$ Fe Measured $\quad--$ Fe Target \\
\hline \hline
\end{tabular}

Figure 4.2.a. Tests 3, 4 and 5 (HLW-E-M-03, HLW-ES-05 and HLW-E-M-09) product glass compositions determined by XRF.

(See Table 4.7 and Section 4.2 for details of composition analysis) 


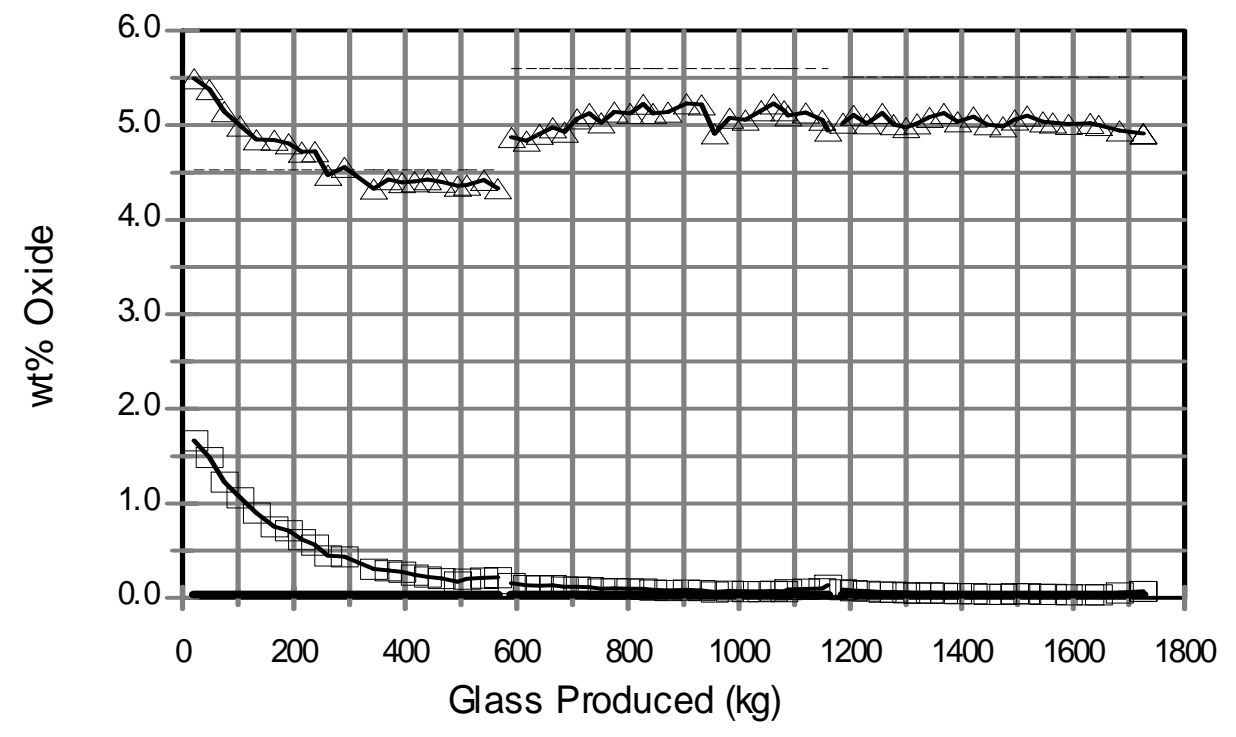

$\boldsymbol{\Delta}$ K Measured $\quad \ldots$ KTarget $\quad \boldsymbol{Z}$ Zr Measured Zr Target
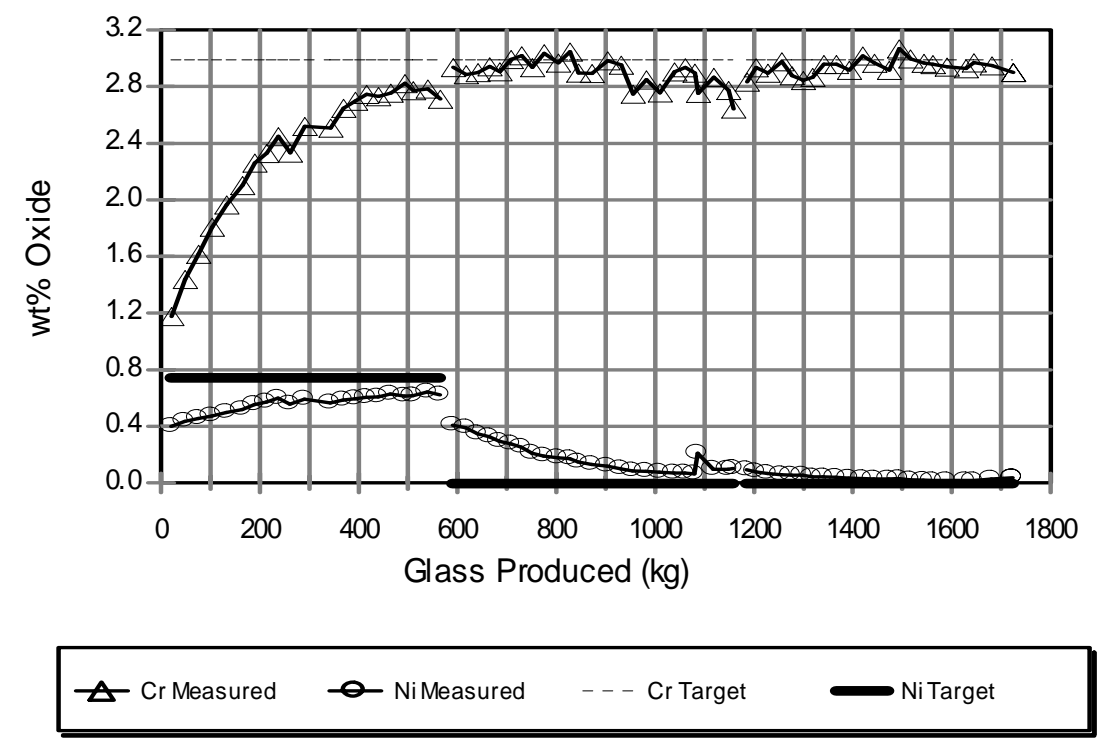

Figure 4.2.b. Tests 3, 4 and 5 (HLW-E-M-03, HLW-ES-05 and HLW-E-M-09) product glass compositions determined by XRF.

(See Table 4.7 and Section 4.2 for details of composition analysis) 
The Catholic University of America Vitreous State Laboratory
ORP-56294 Rev. 0

Effects of High Crystal Content in HLW DM100 Melter Tests

Final Report, VSL-09R1520-1, Rev. 0

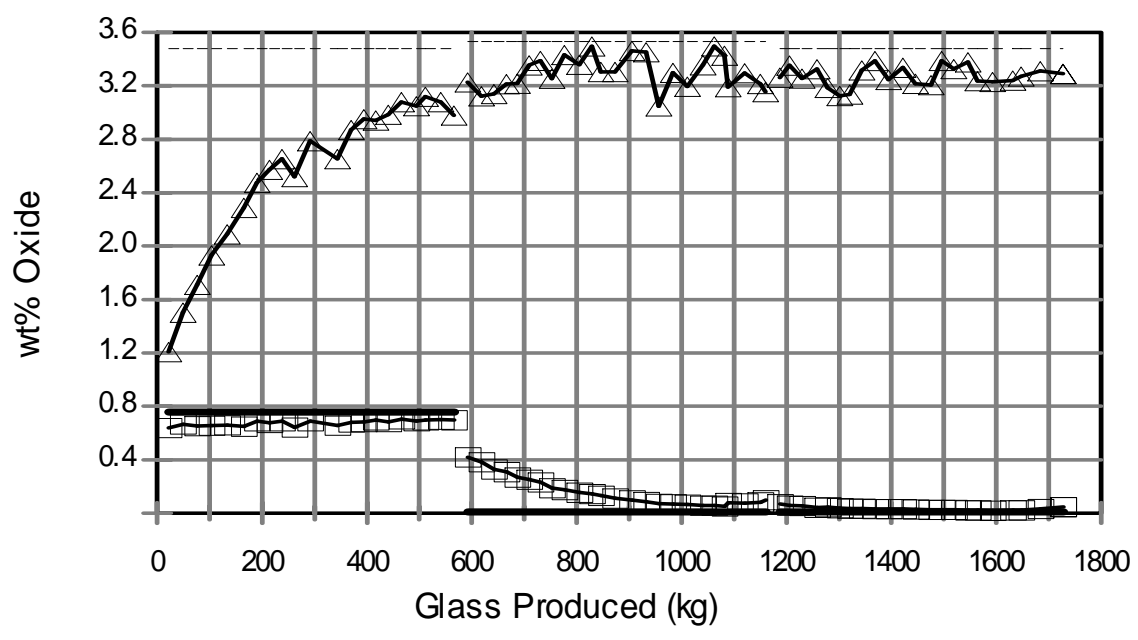

$\boldsymbol{A}$ Bi Measured $\quad---$ Bi Target $\quad$ Mn Measured $\quad$ Mn Target

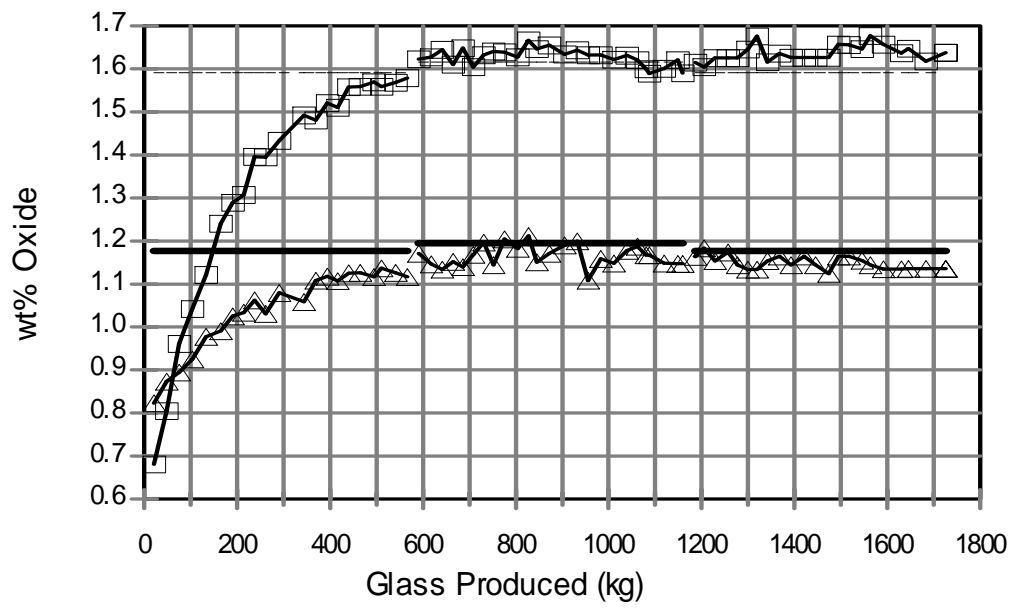

$\triangle$ Ca Measured $\quad$ Ca Target $\quad$ - PMeasured $\quad$ - - PTarget

Figure 4.2.c. Tests 3, 4 and 5 (HLW-E-M-03, HLW-ES-05 and HLW-E-M-09) product glass compositions determined by XRF.

(See Table 4.7 and Section 4.2 for details of composition analysis) 

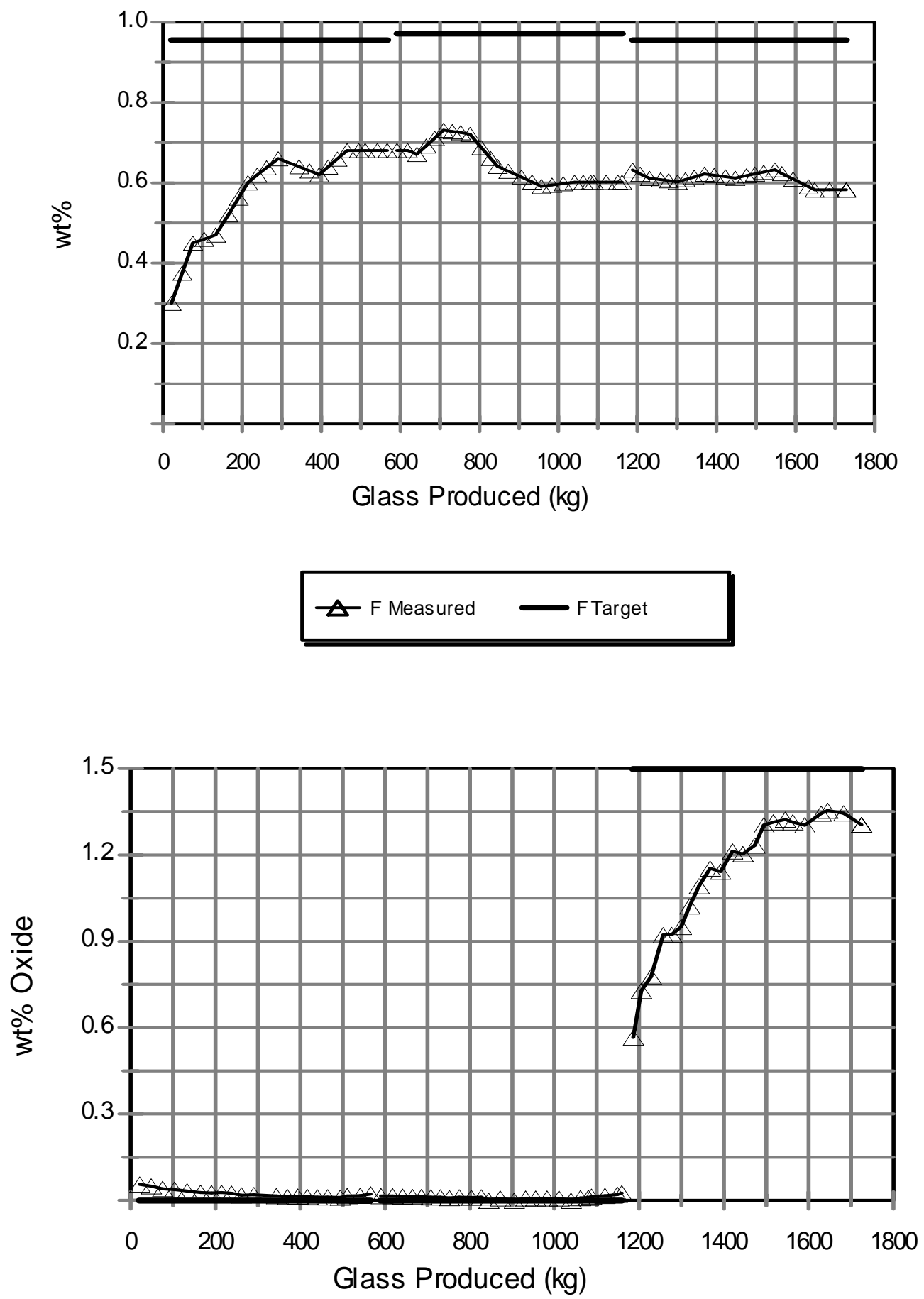

Figure 4.2.d. Tests 3, 4 and 5 (HLW-E-M-03, HLW-ES-05 and HLW-E-M-09) product glass compositions determined by XRF.

(See Table 4.7 and Section 4.2 for details of composition analysis) 


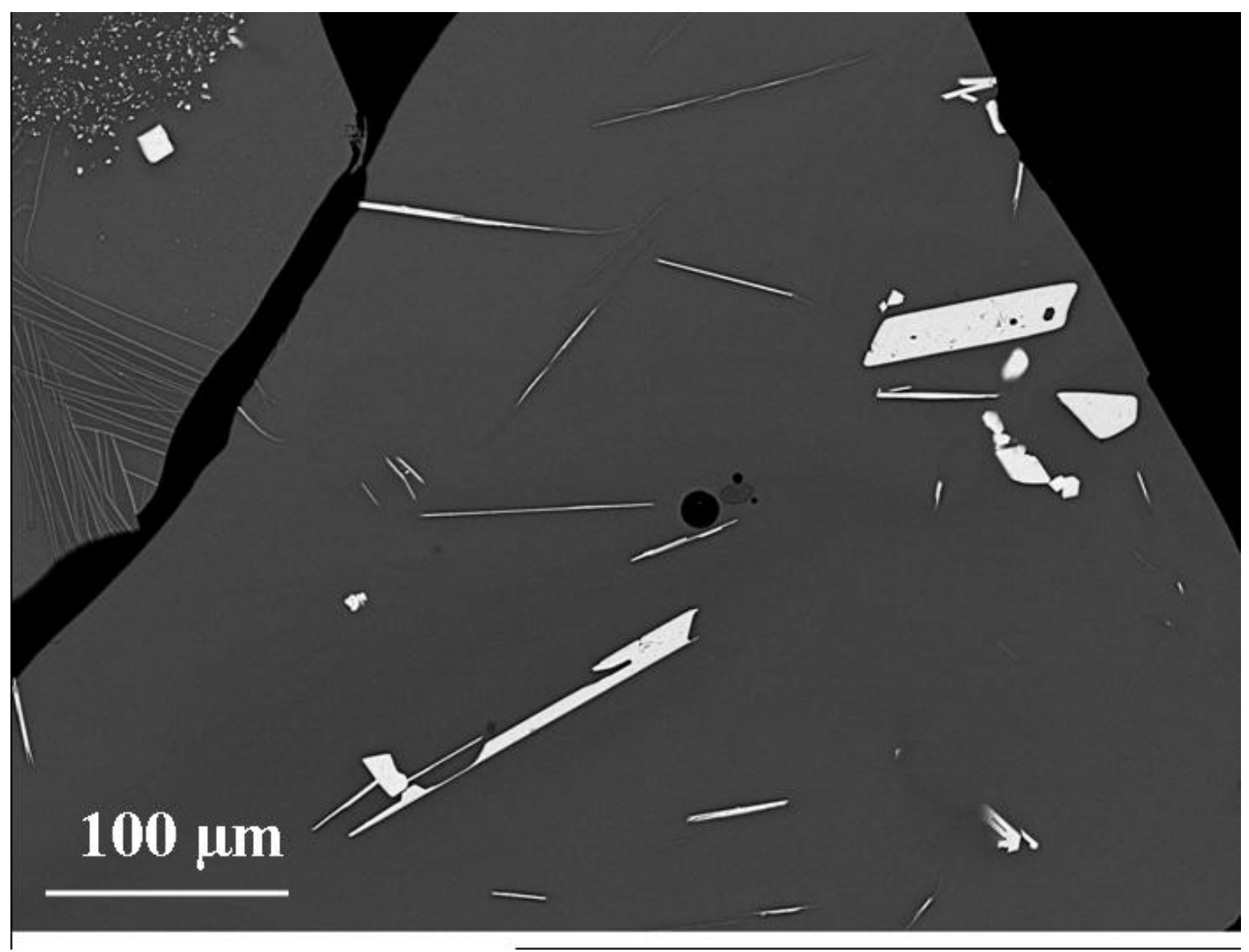

Figure 4.3a. SEM image showing hematite and spinel crystallization in discharge glass after idling for $302 \mathrm{~h}$ (Test 1, BLZ-G-131A). 


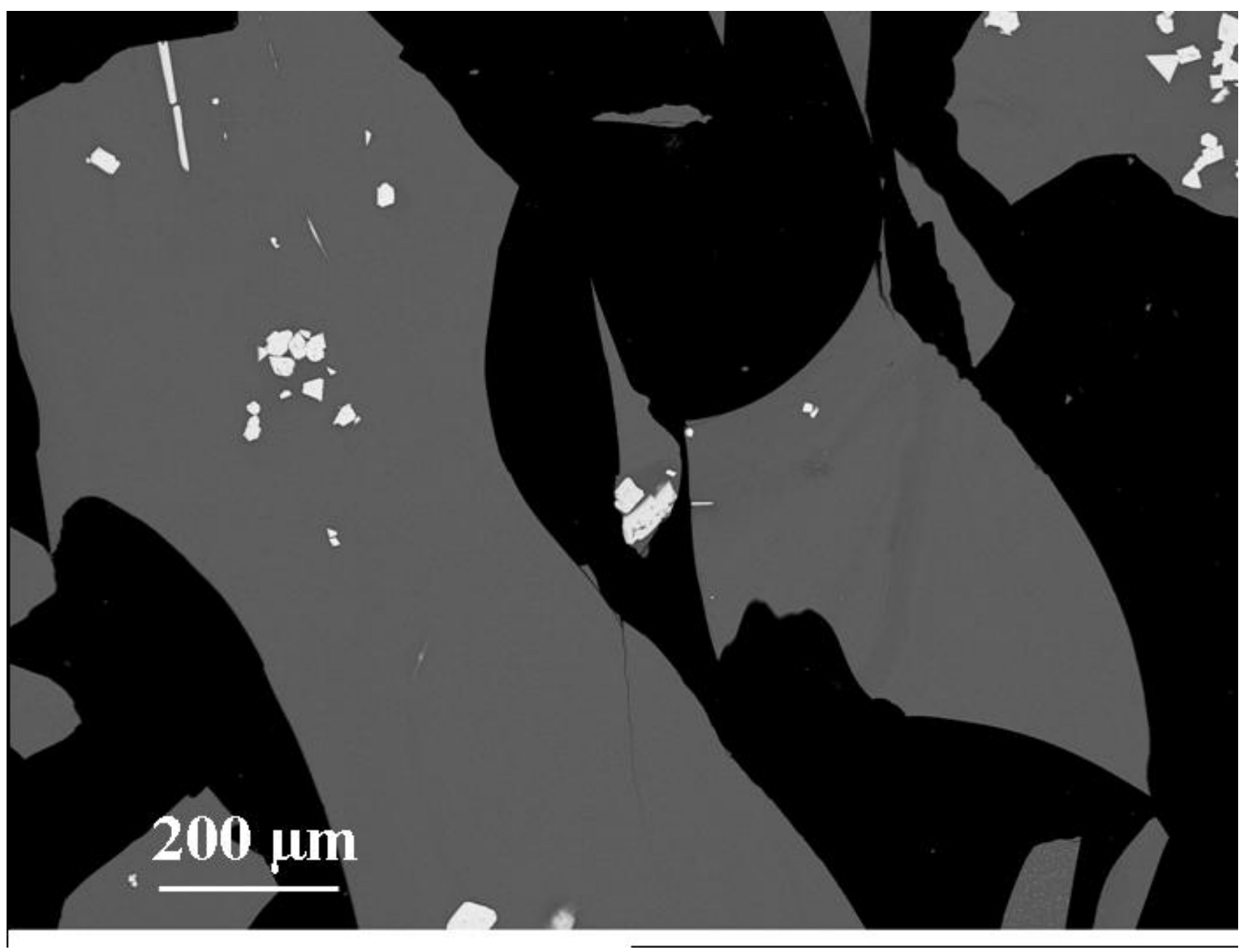

Figure 4.3b. SEM image showing hematite and spinel crystallization in discharge glass after idling for 302 h; lower magnification (Test 1, BLZ-G-131A). 


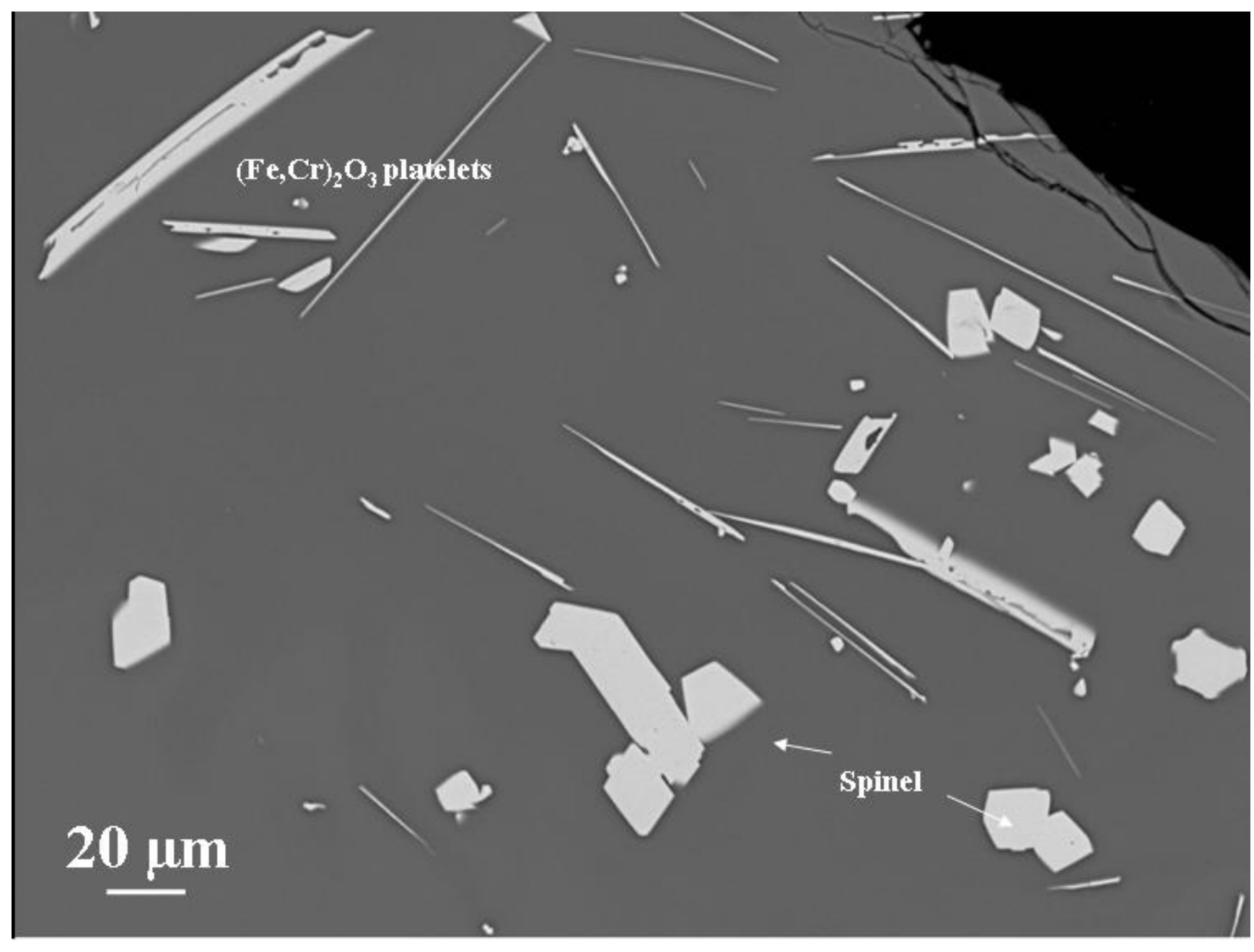

Figure 4.4a. SEM image showing hematite and spinel crystallization in dip sample after idling for $303 \mathrm{~h}$ (Test 1, BLZ-D-131A). 
The Catholic University of America Vitreous State Laboratory
ORP-56294 Rev. 0

Effects of High Crystal Content in HLW DM100 Melter Tests

Final Report, VSL-09R1520-1, Rev. 0

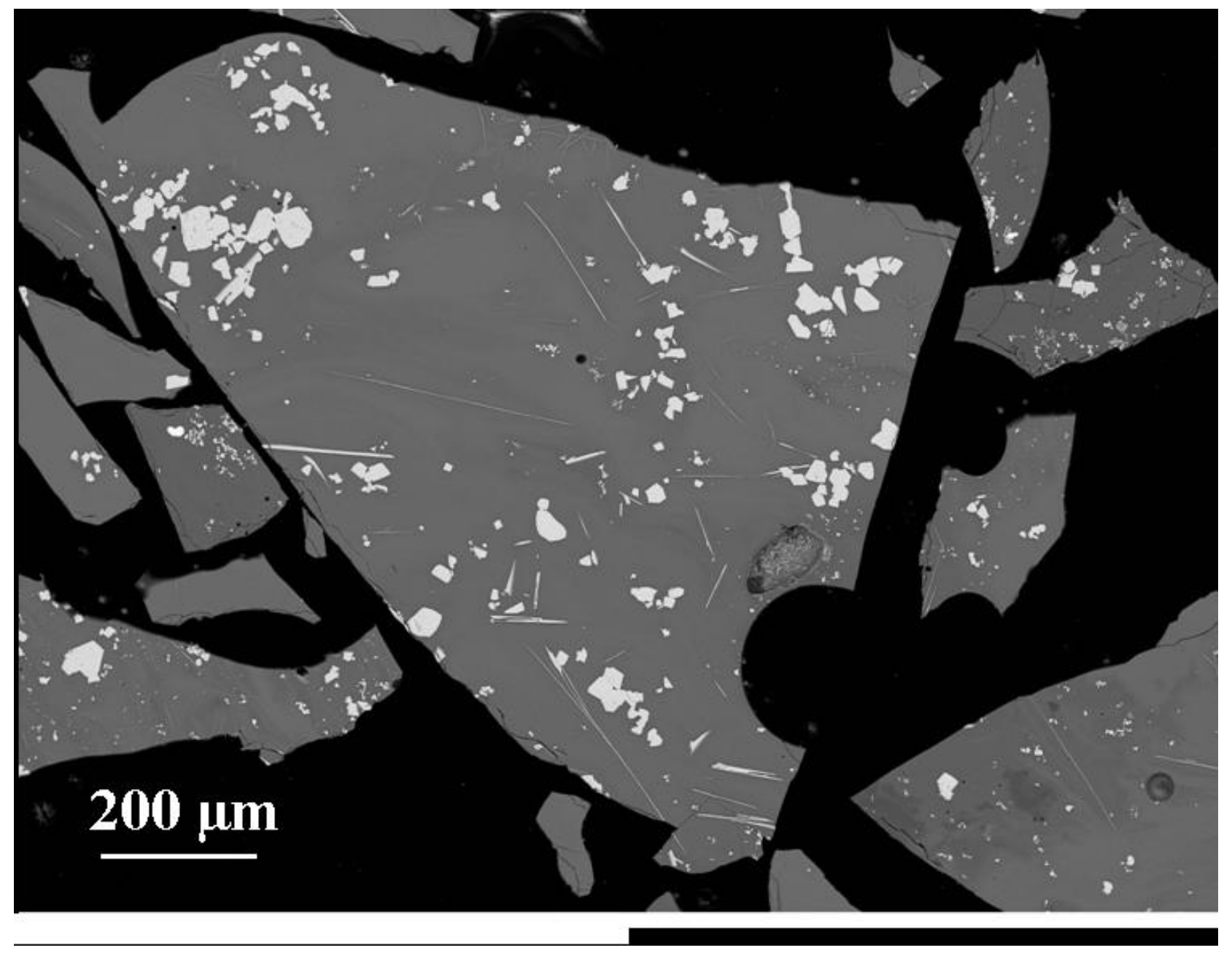

Figure 4.4b. SEM image showing hematite and spinel crystallization in dip sample after idling for $303 \mathrm{~h}$; lower magnification (Test 1, BLZ-D-131A). 


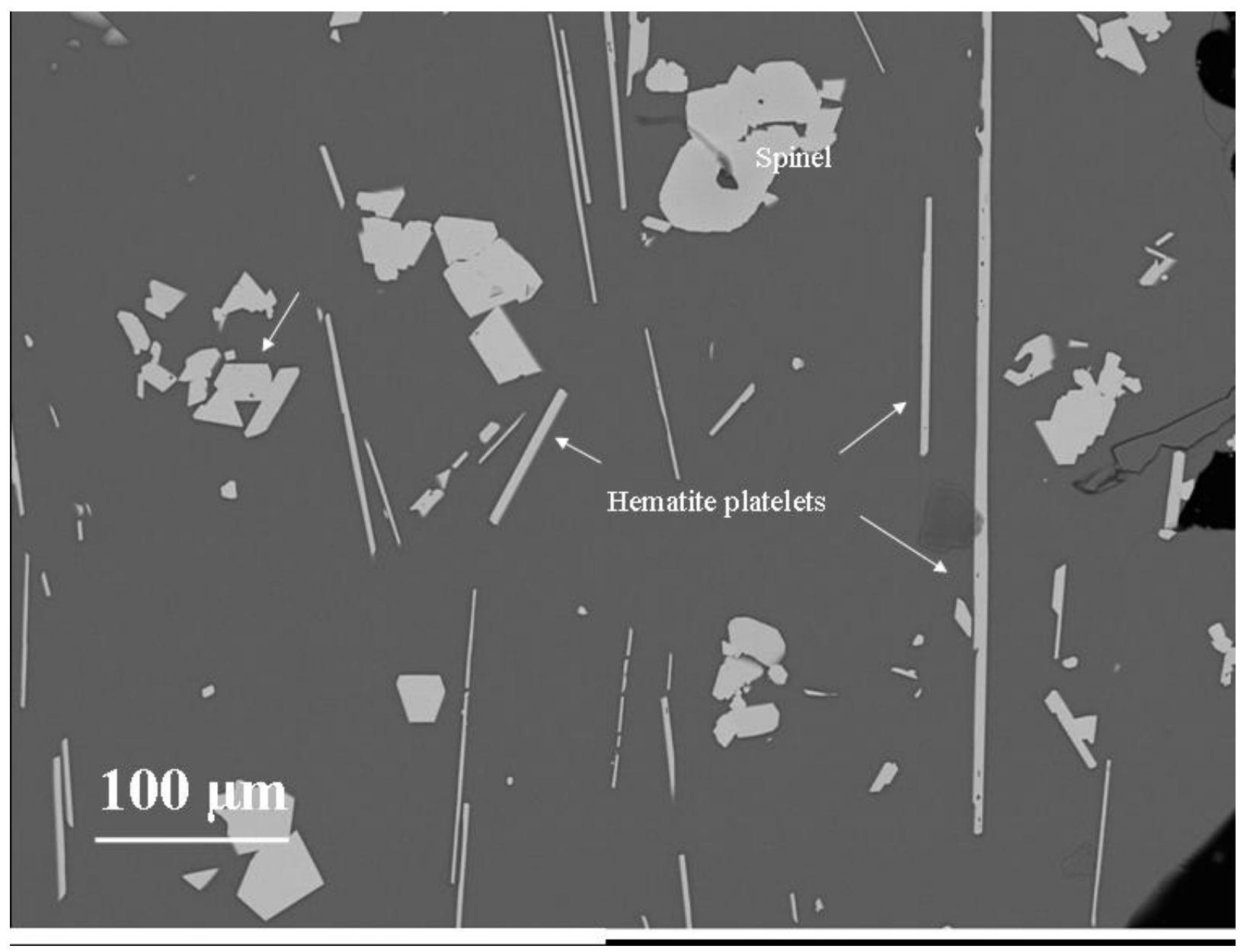

Figure 4.5a. SEM image showing hematite and spinel crystallization in dip sample after idling for $222 \mathrm{~h}$ (Test 2, ABL-D-63B). 


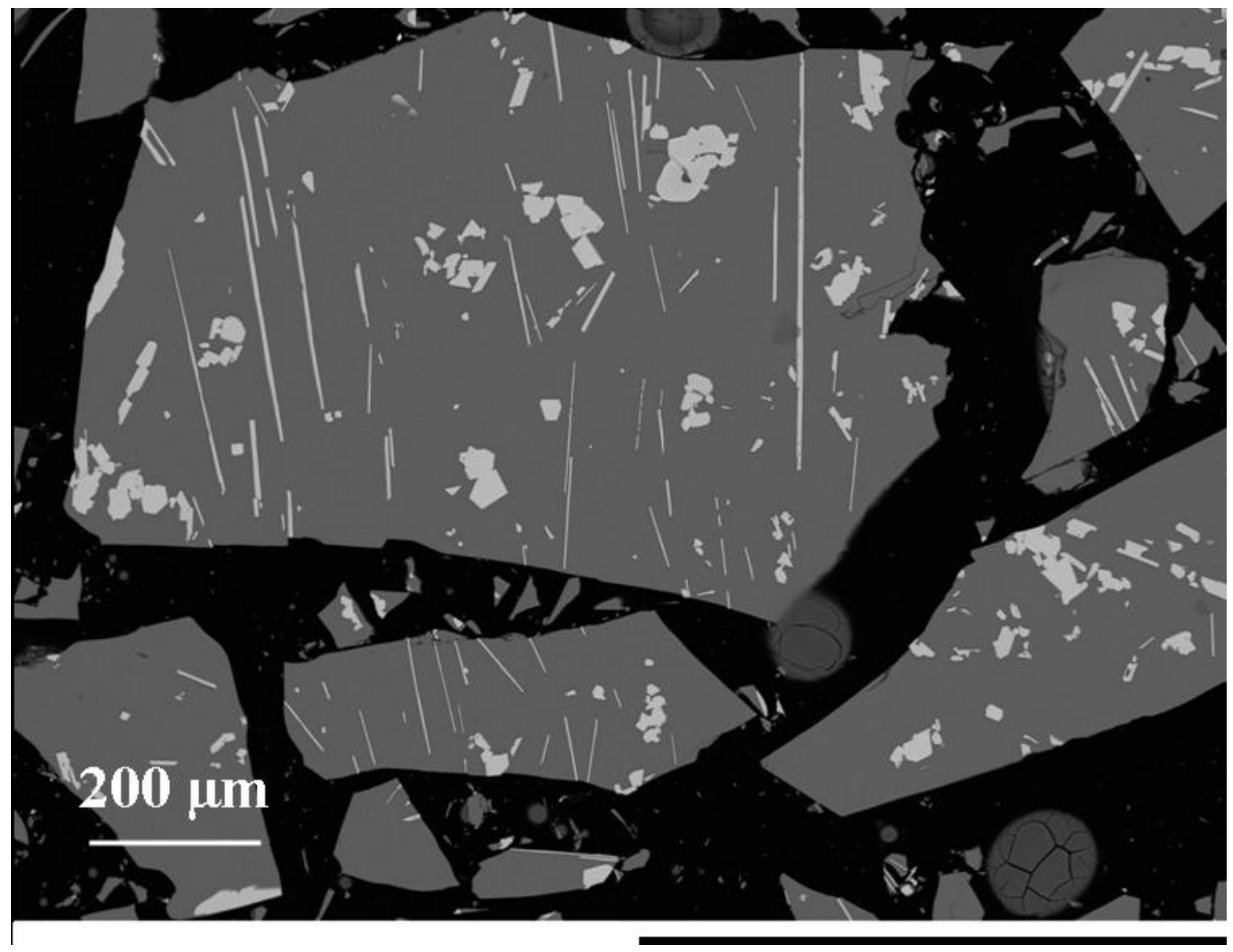

Figure 4.5b. SEM image showing hematite and spinel crystallization in dip sample after idling for $222 \mathrm{~h}$; lower magnification (Test 2, ABL-D-63B). 


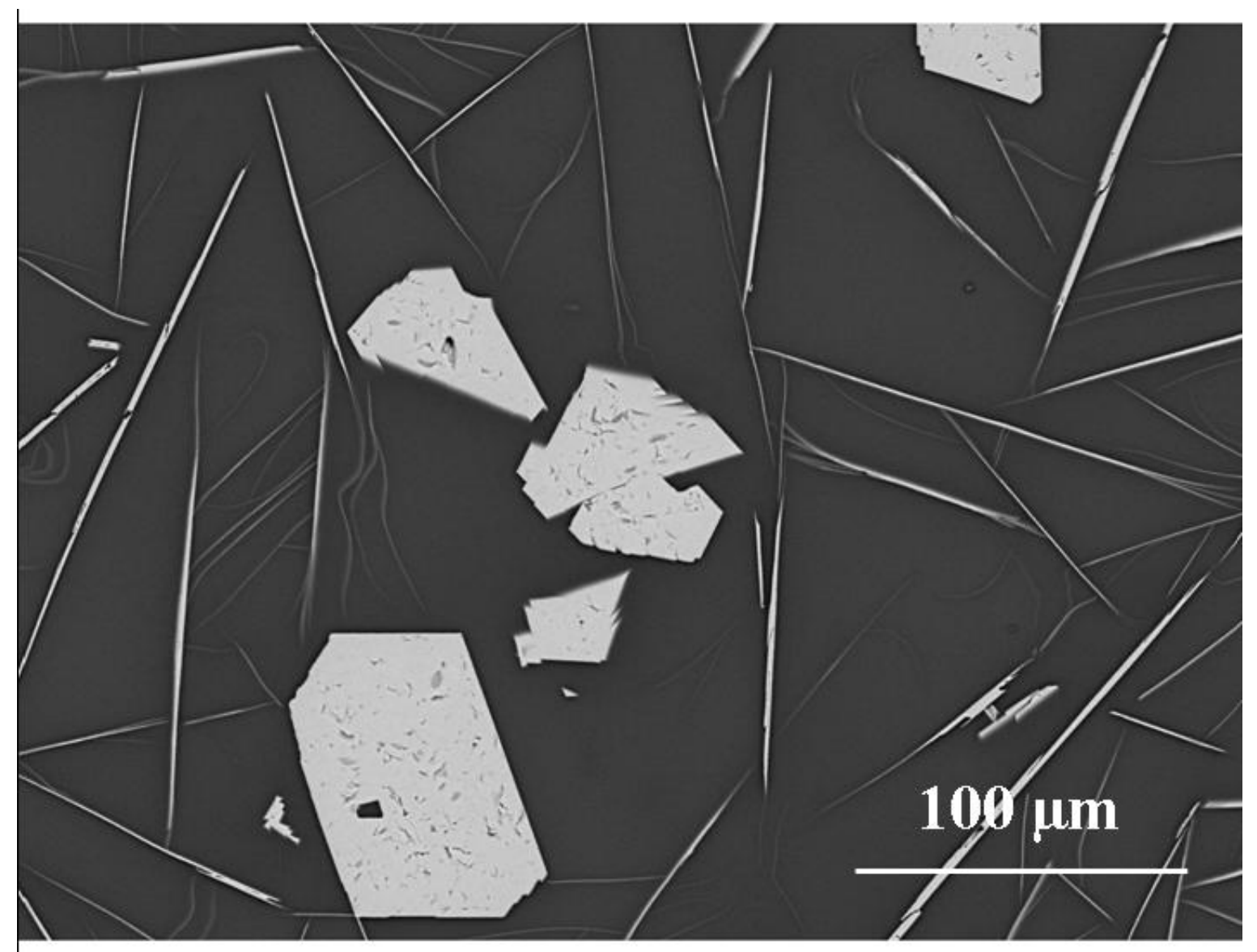

Figure 4.6a. SEM image showing hematite and spinel crystallization in glass discharge after idling for $230 \mathrm{~h}$ (Test 2, ABL-G-71A). 


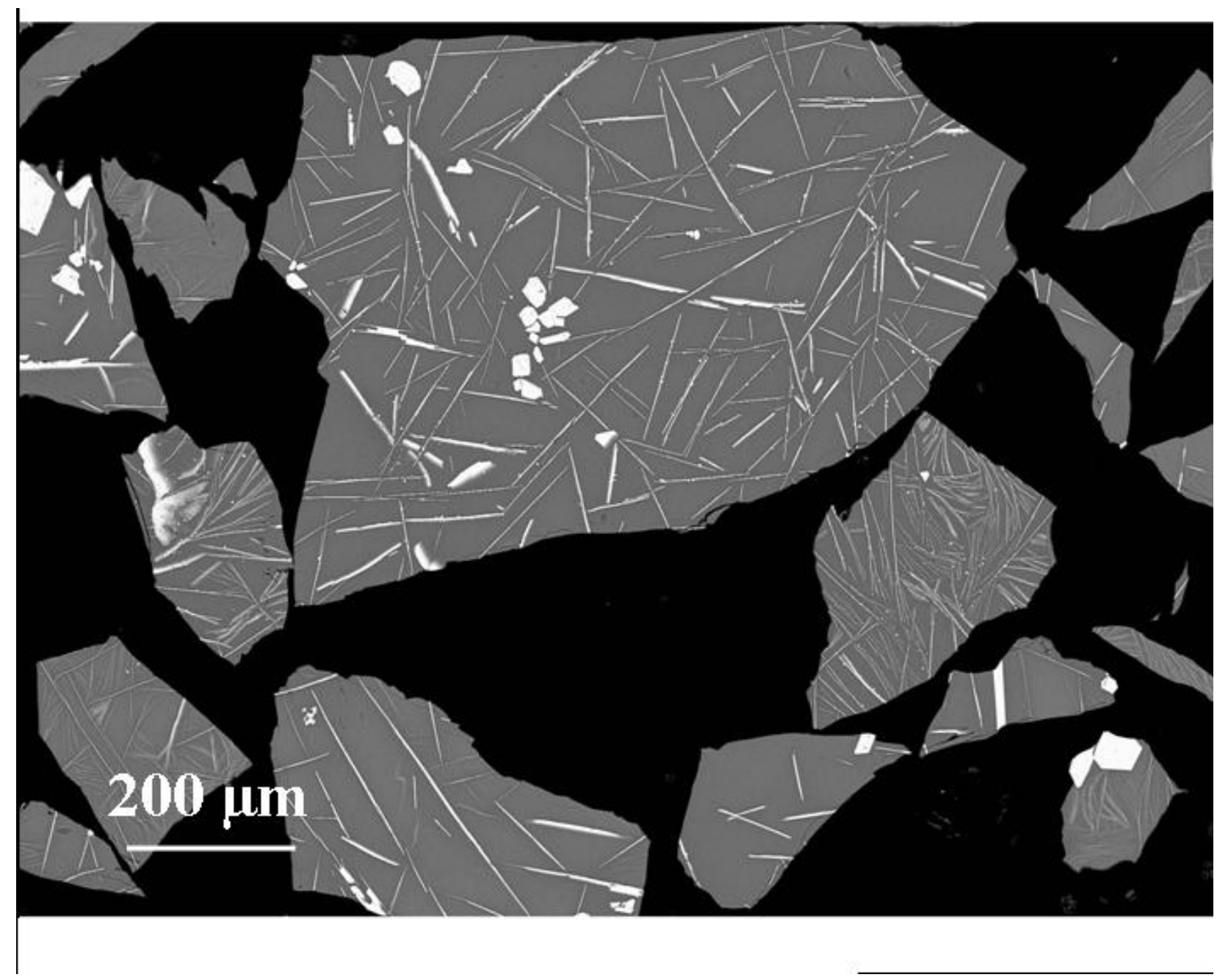

Figure 4.6b. SEM image showing hematite and spinel crystallization in glass discharge after idling for $230 \mathrm{~h}$; lower magnification (Test 2, ABL-G-71A). 


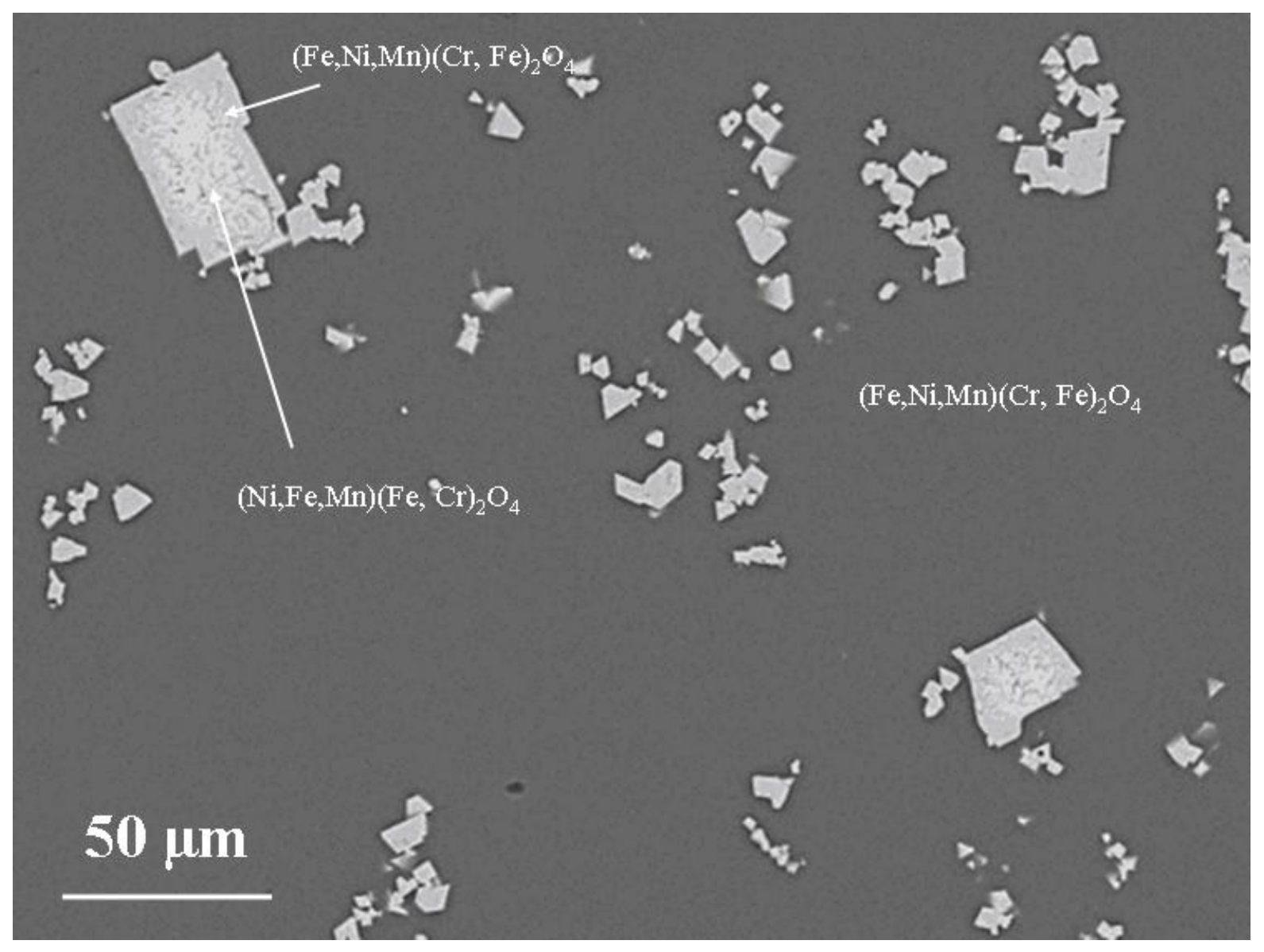

Figure 4.7a. SEM image showing spinel crystallization in dip sample after idling for $60 \mathrm{~h}$ (Test 3, ABL-D-140A). See chemical zoning in a large spinel crystal. 


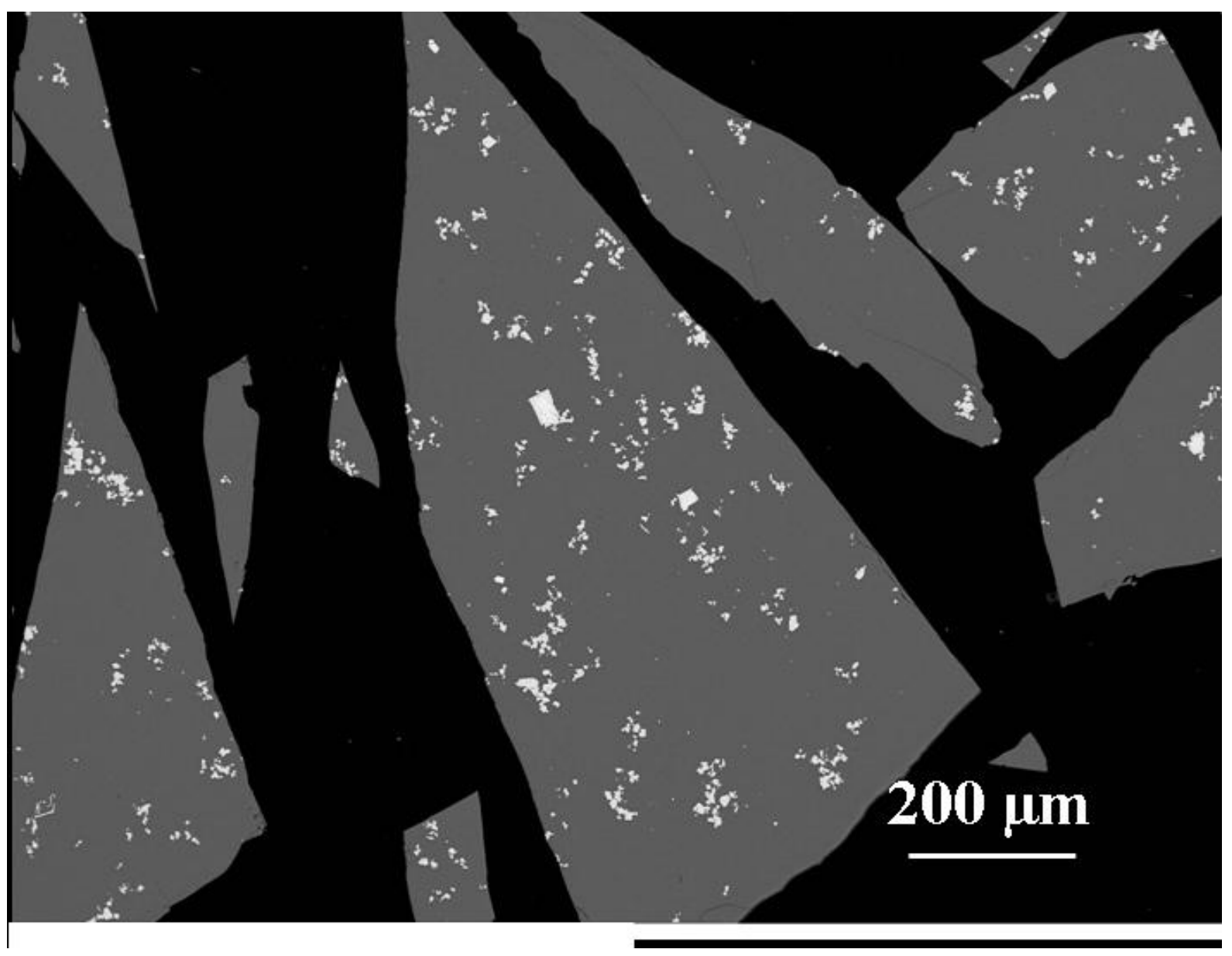

Figure 4.7b. SEM image showing primary spinel crystallization in dip sample after idling for $60 \mathrm{~h}$; lower magnification (Test 3, ABL-D-140A). 


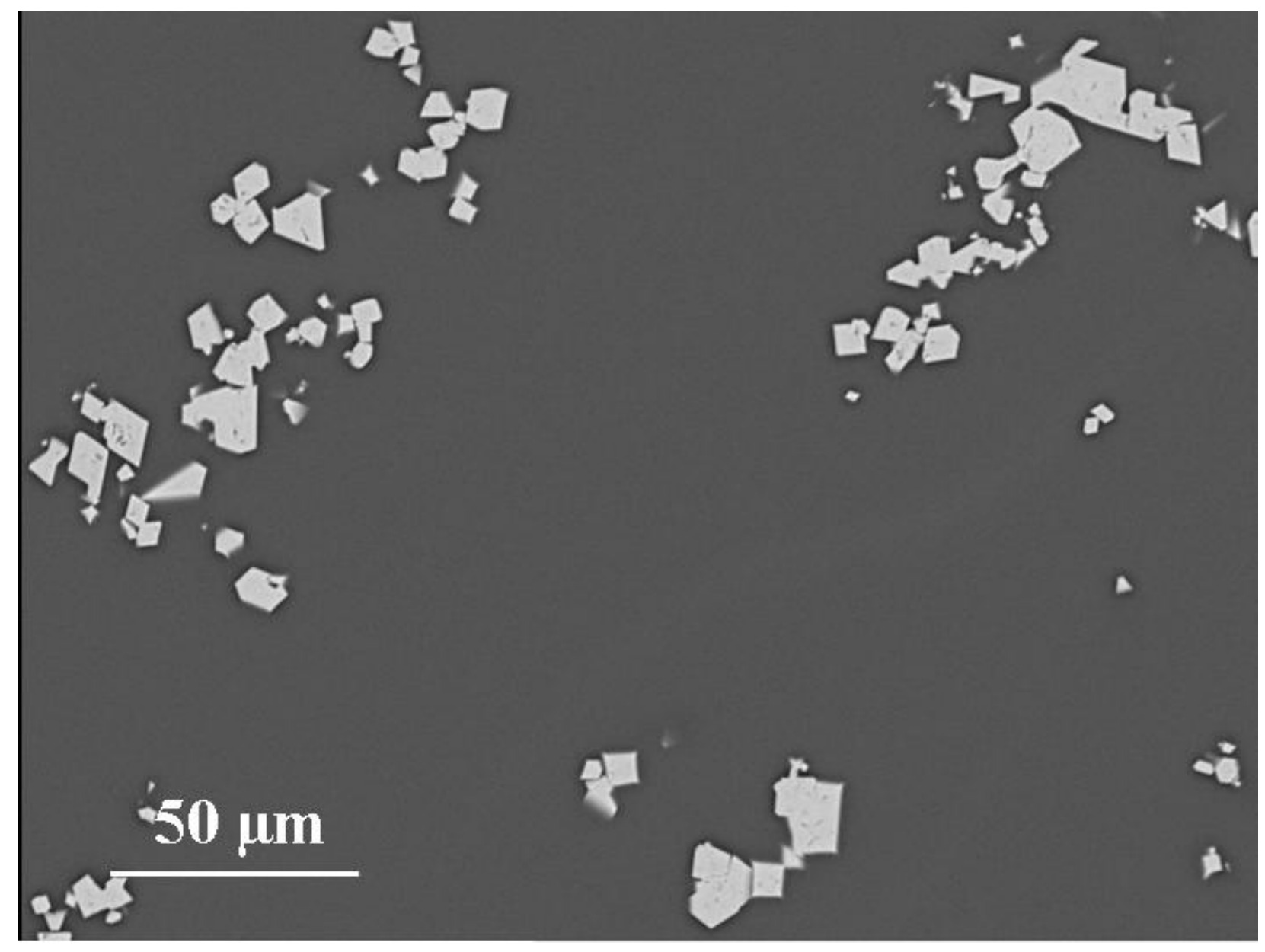

Figure 4.8a. SEM image showing primary spinel crystallization in glass discharge after idling for $231 \mathrm{~h}$ (Test 3, ABL-G-141B). 


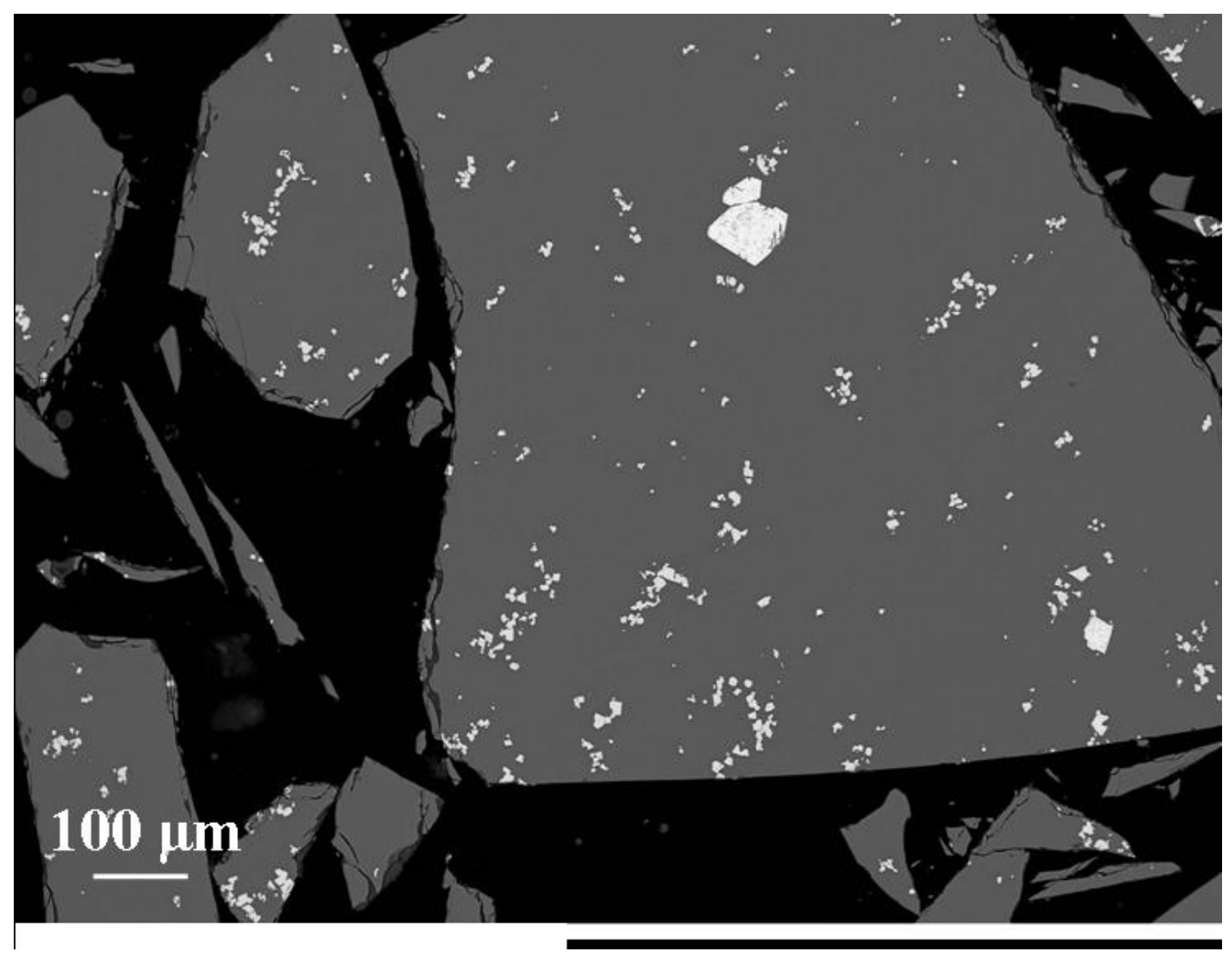

Figure 4.8b. SEM image showing primary spinel crystallization in glass discharge after idling for $231 \mathrm{~h}$; lower magnification (Test 3, ABL-G-141B). 
ORP-56294 Rev. 0

The Catholic University of America Vitreous State Laboratory
Effects of High Crystal Content in HLW DM100 Melter Tests Final Report, VSL-09R1520-1, Rev. 0

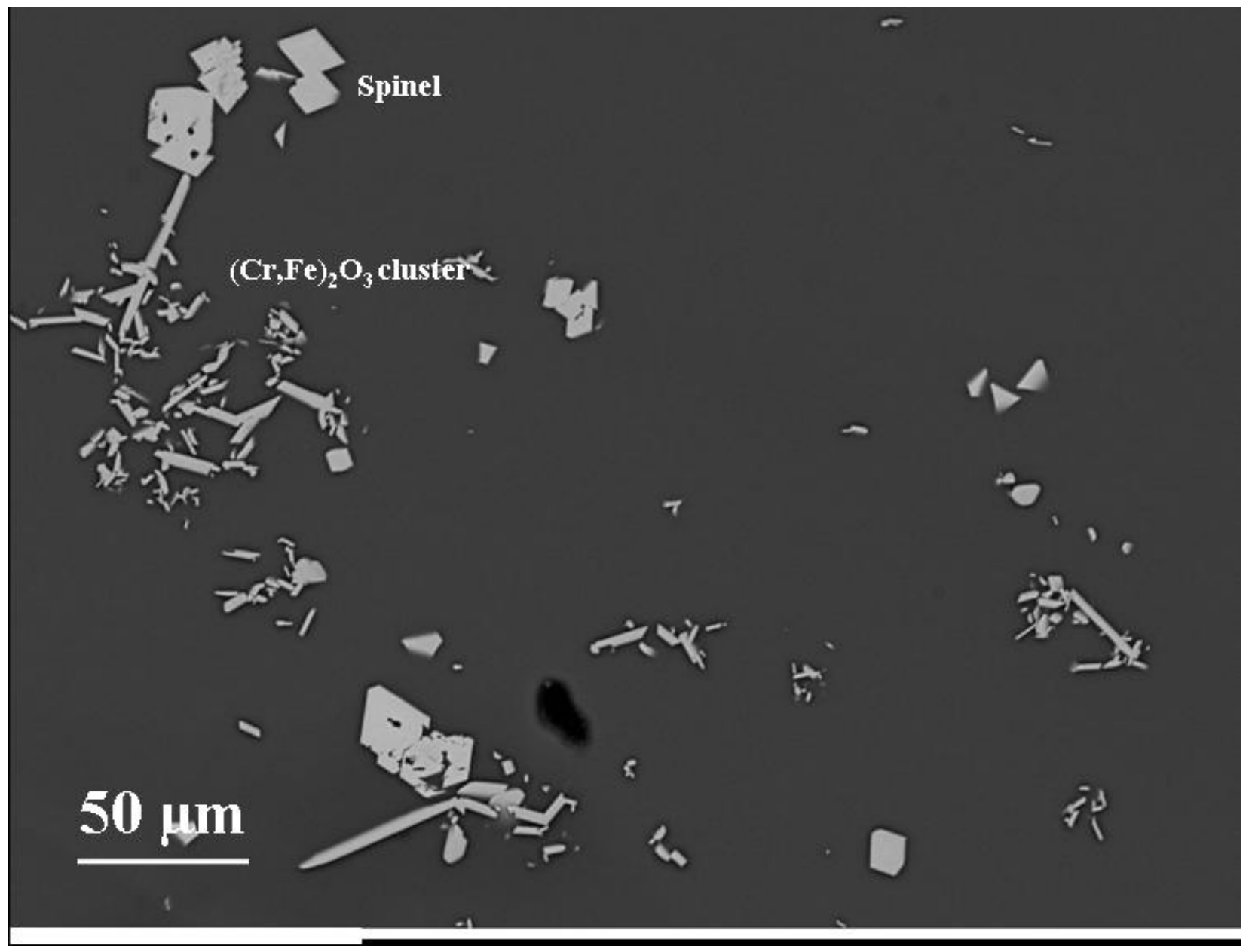

Figure 4.9a. SEM image showing primary eskolaite crystallization in dip sample after idling for $239 \mathrm{~h}$ (Test 4, BBL-D-60B). Some spinel crystals are present. 


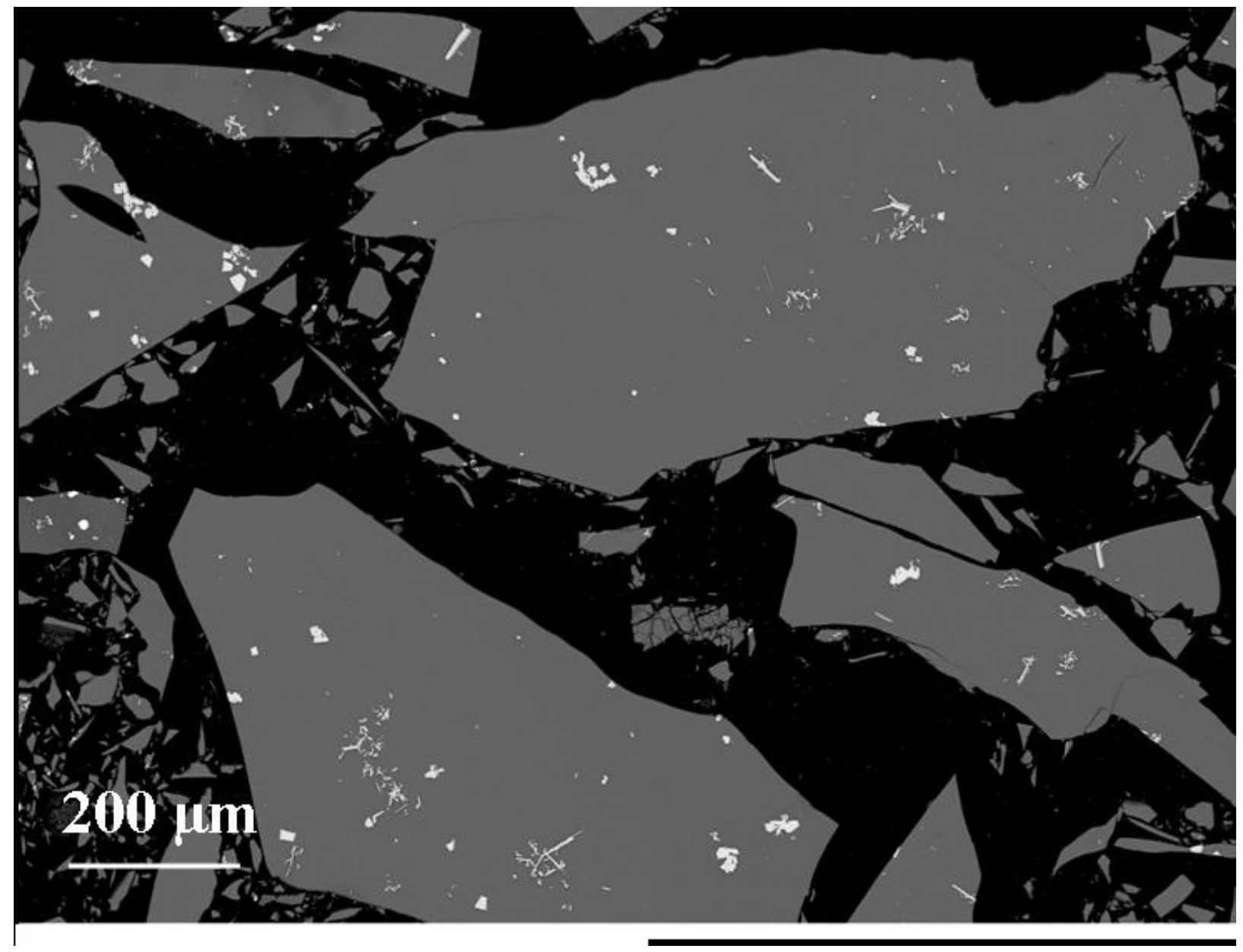

Figure 4.9b. SEM image showing primary eskolaite crystallization in dip sample after idling for 239 h; lower magnification (Test 4, BBL-D-60B). Some spinel crystals are present. 


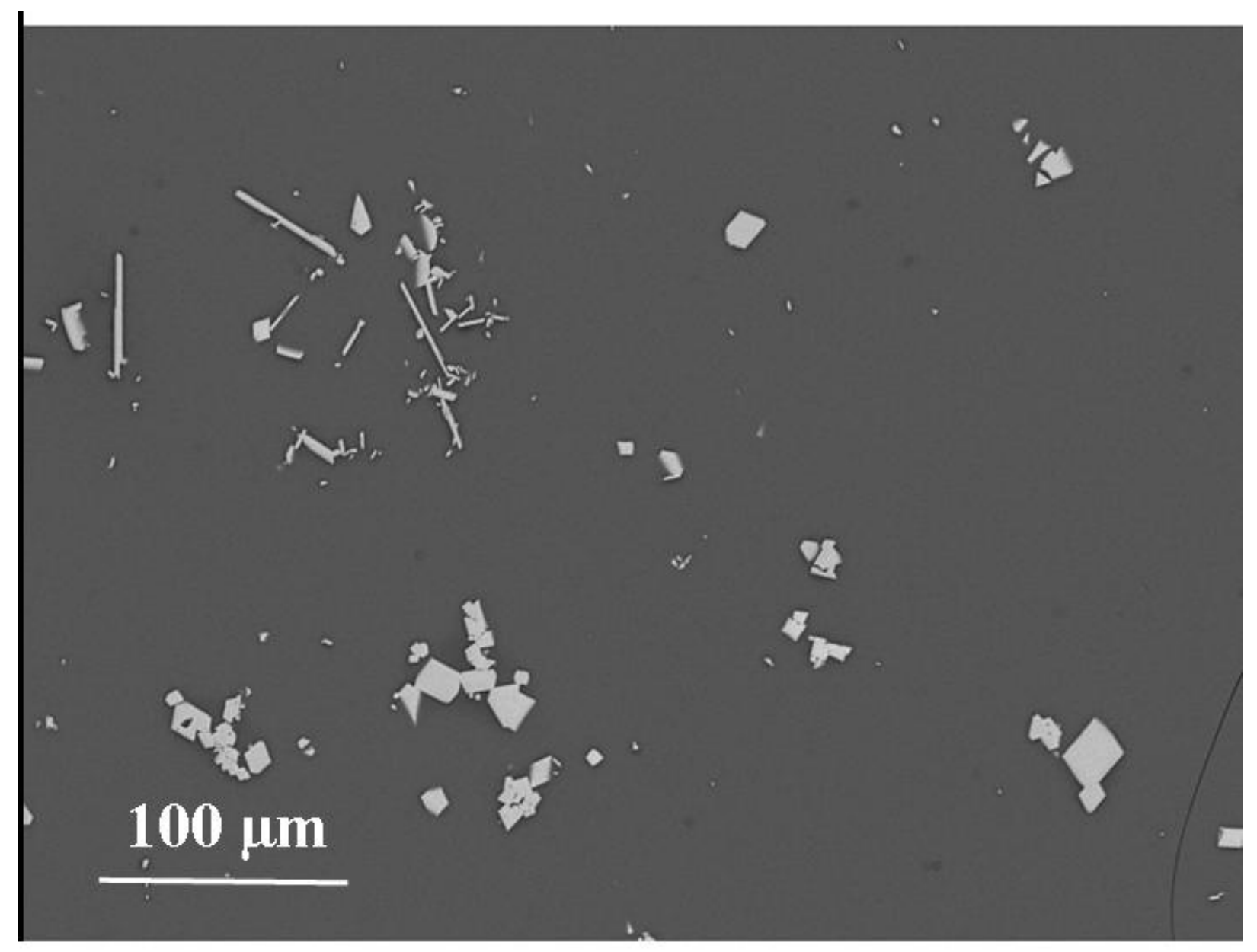

Figure 4.10a. SEM image showing primary eskolaite and spinel crystallization in glass discharge after idling for 404h (Test 4, BBL-G-60B). 


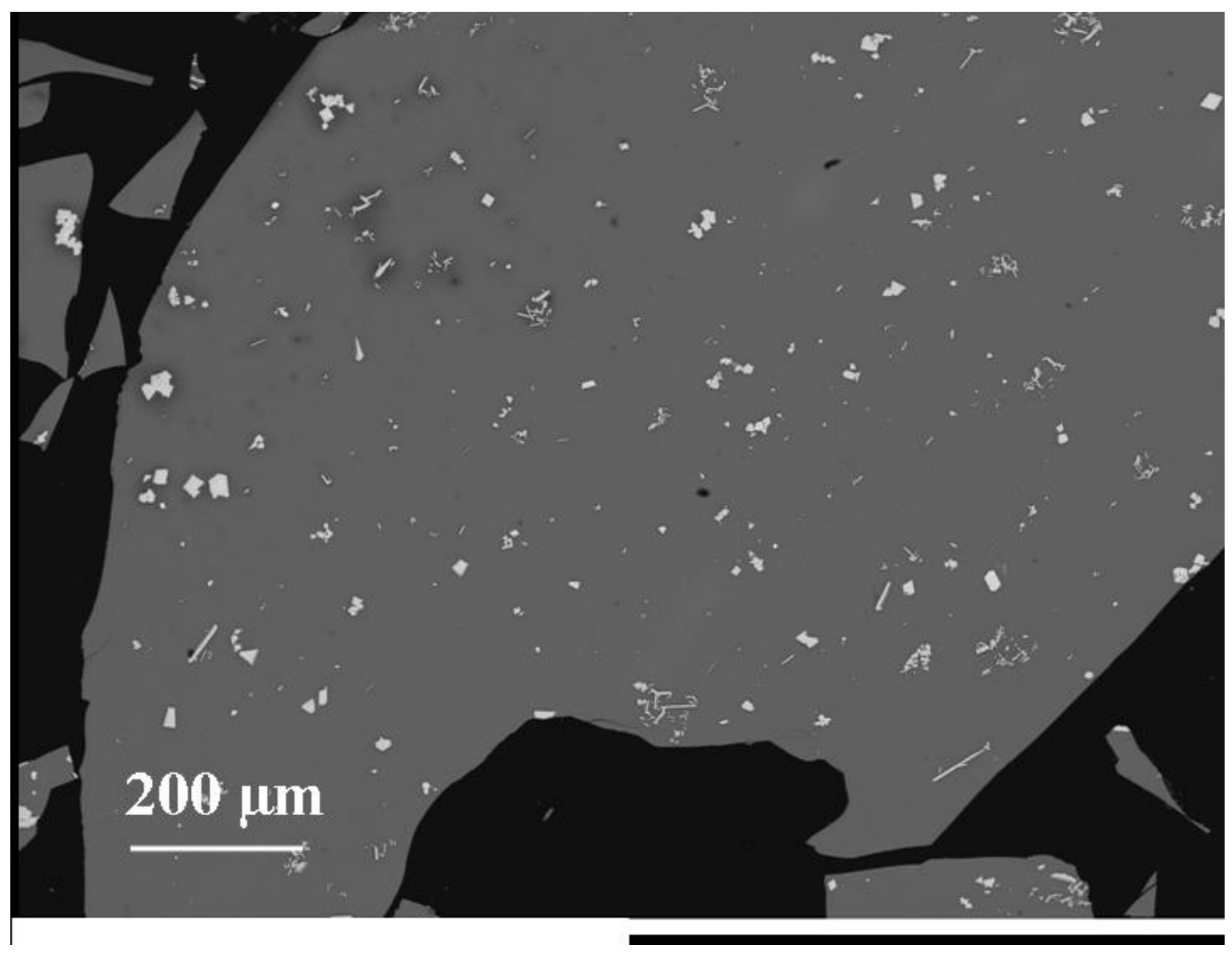

Figure 4.10b. SEM image showing primary eskolaite and spinel crystallization in glass discharge after idling for 404h; lower magnification (Test 4, BBL-G-60B). 
ORP-56294 Rev. 0

The Catholic University of America Vitreous State Laboratory
Effects of High Crystal Content in HLW DM100 Melter Tests

Final Report, VSL-09R1520-1, Rev. 0

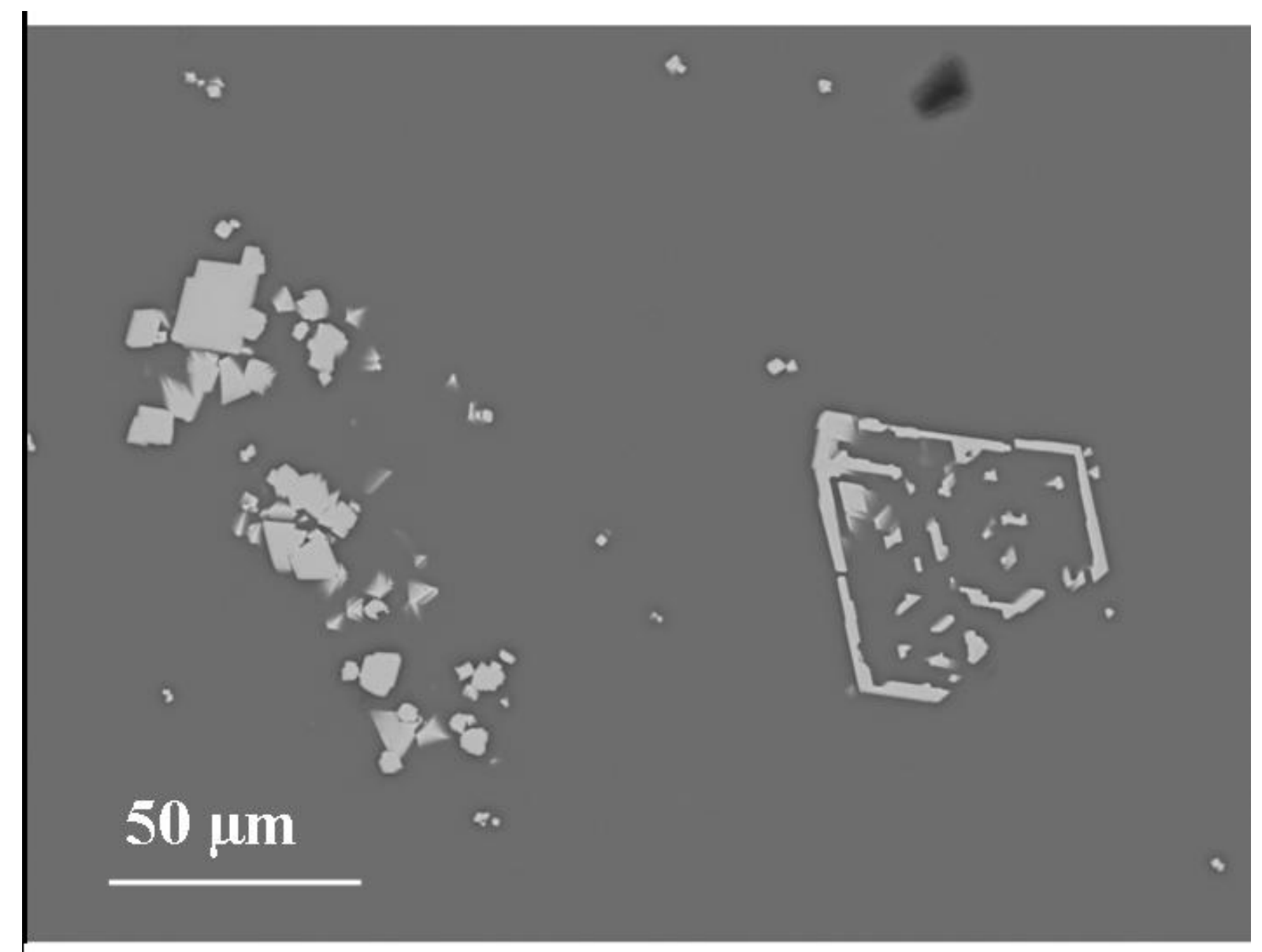

Figure 4.11a. SEM image showing primary spinel crystallization in glass discharge after idling for $181 \mathrm{~h}$ (Test 5, BBL-G-130A). Note skeleton crystal of spinel. 


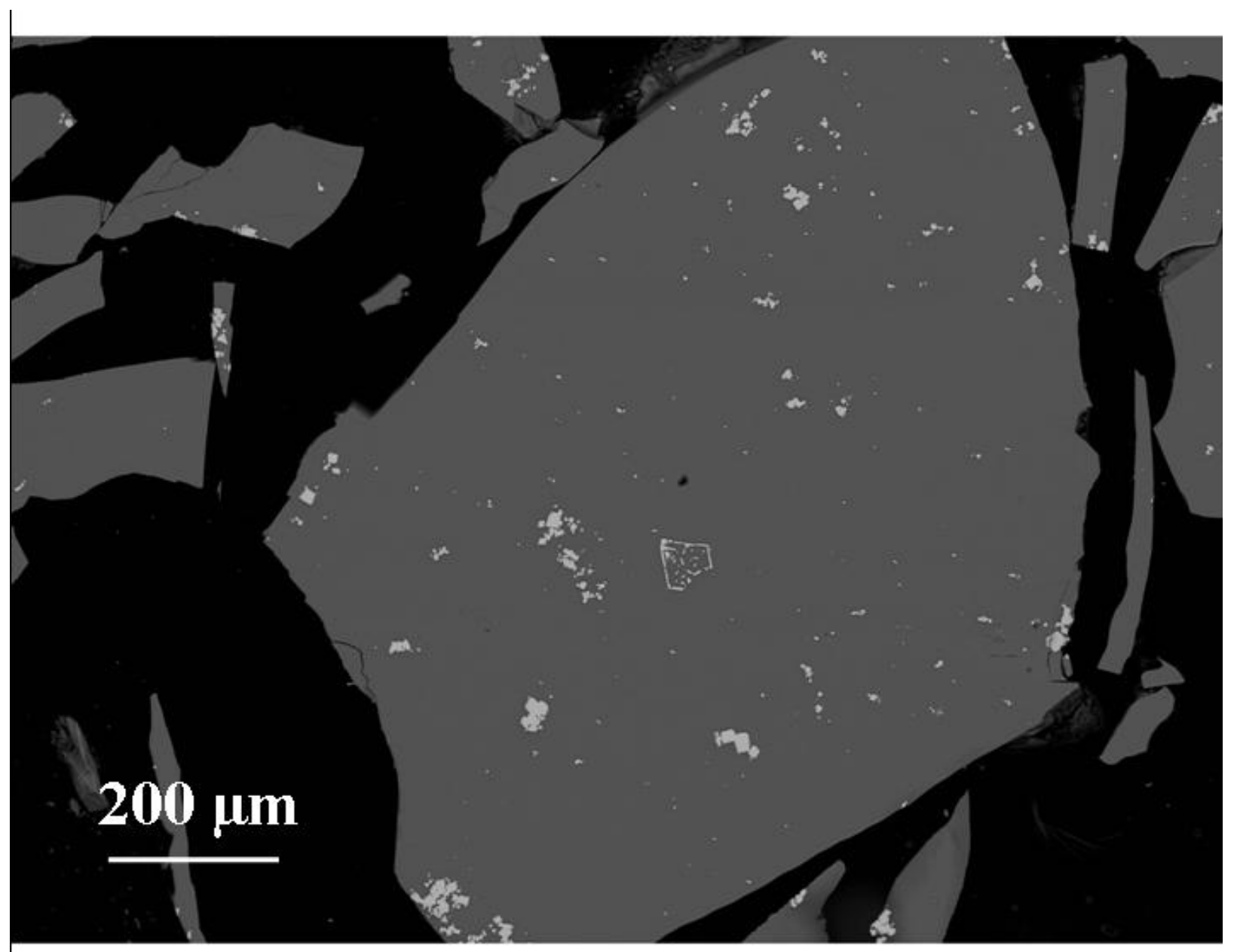

Figure 4.11b. SEM image showing primary spinel crystallization in glass discharge after idling for $181 \mathrm{~h}$; lower magnification (Test 5, BBL-G-130A). 


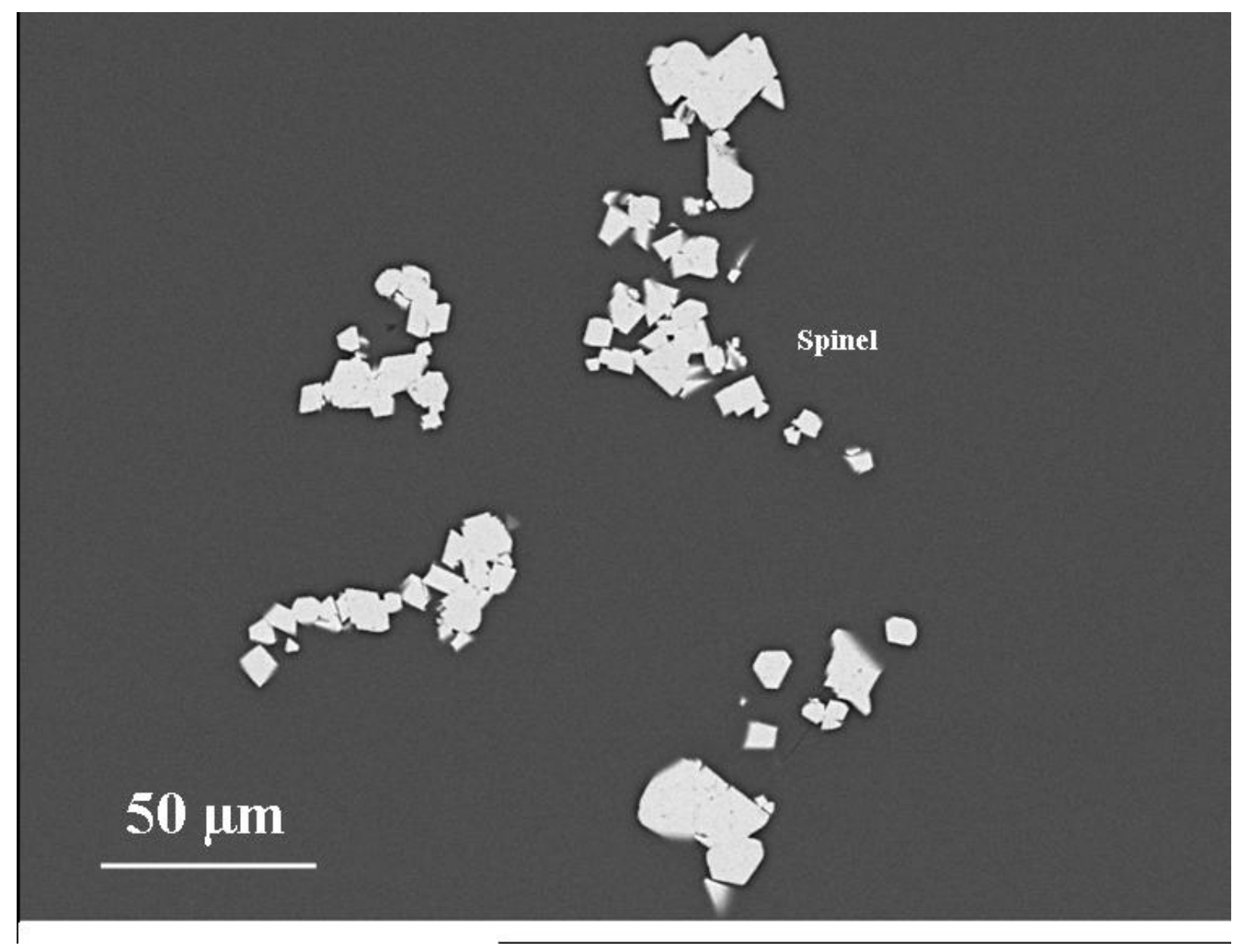

Figure 4.12a. SEM image showing primary spinel crystallization in dip sample after idling for $186 \mathrm{~h}$ (Test 5, BBL-D-130B). 


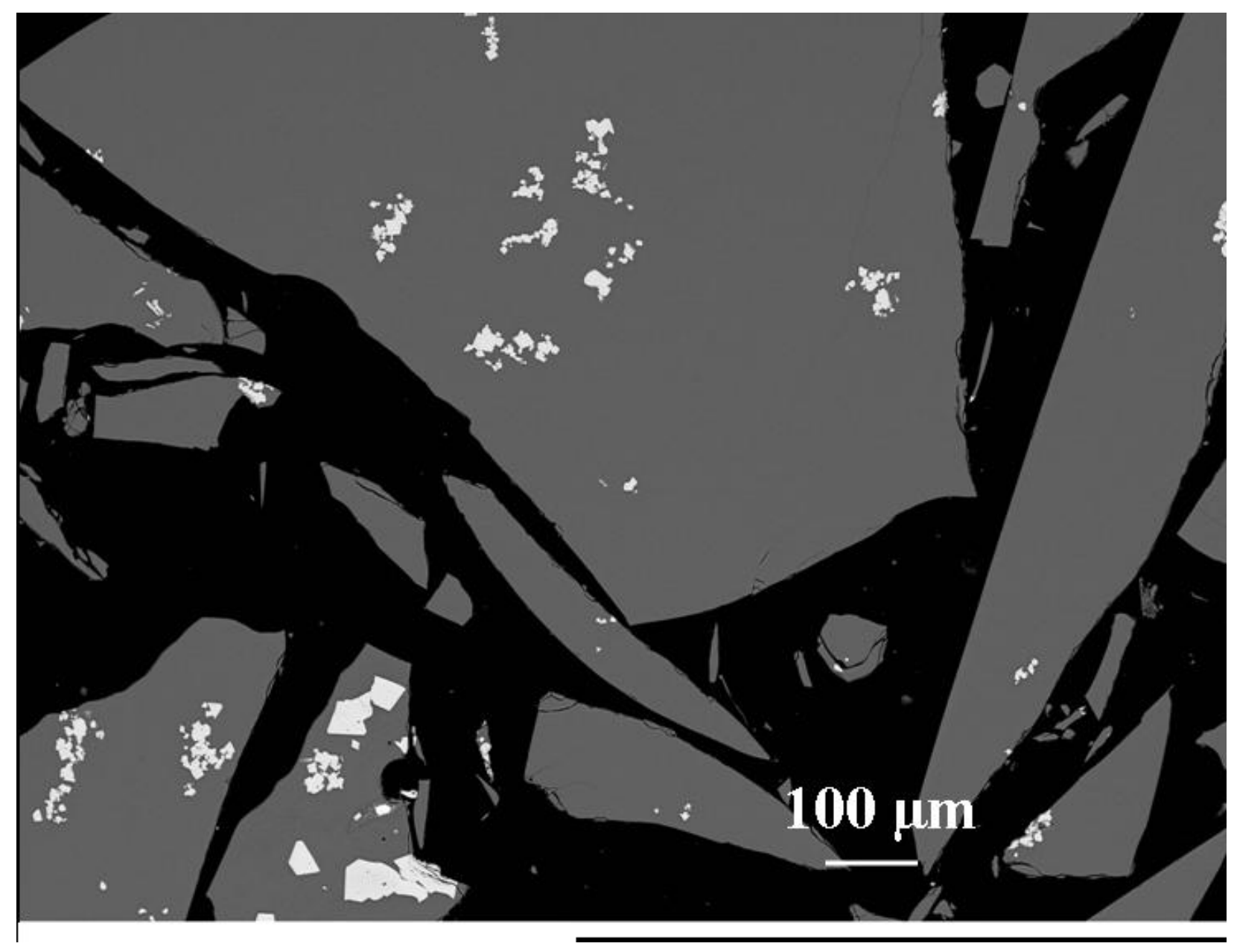

Figure 4.12b. SEM image showing primary spinel crystallization in dip sample after idling for $186 \mathrm{~h}$; lower magnification (Test 5, BBL-D-130B). 


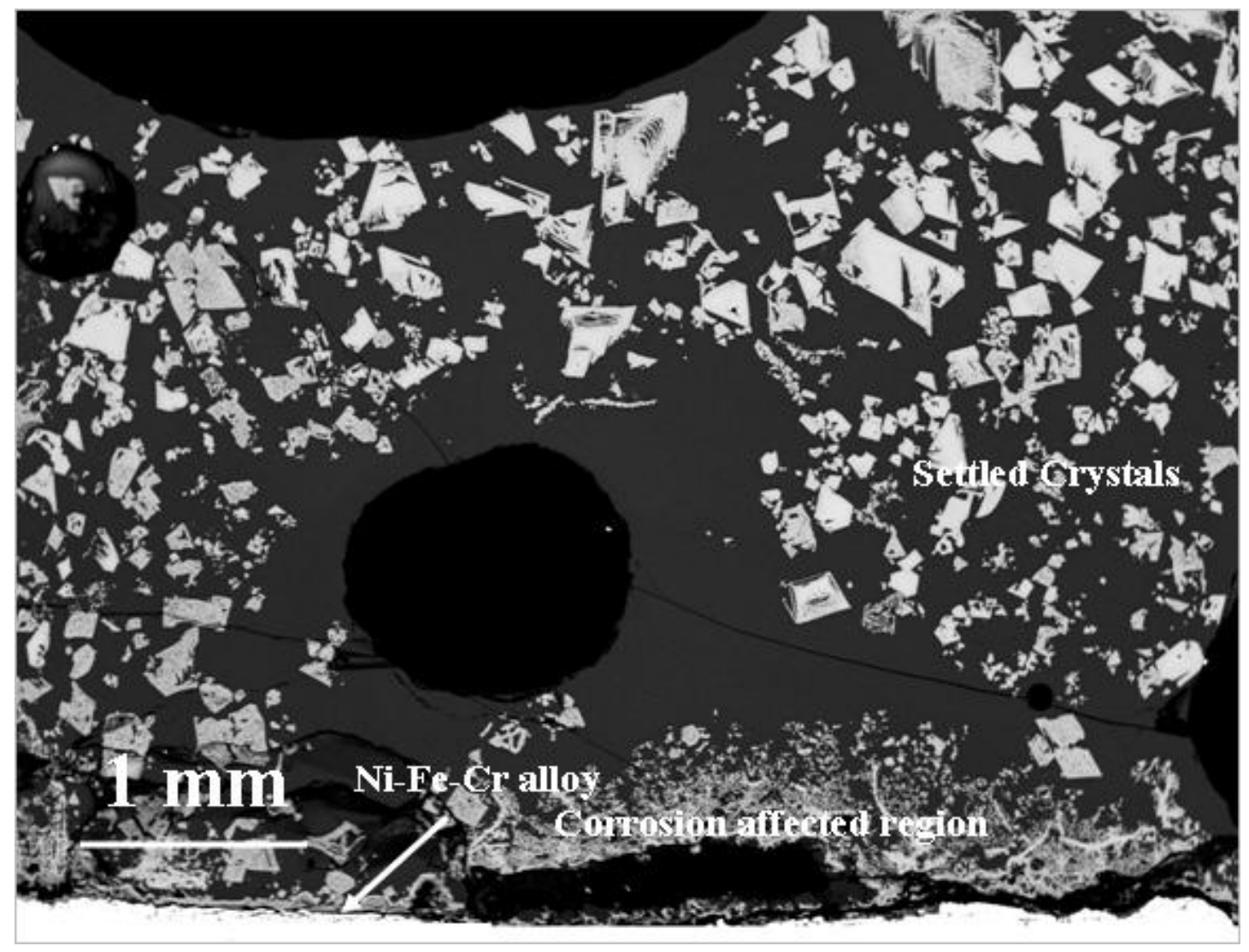

Figure 4.13a. SEM image showing microstructure of spinel settling on the boat bottom during testing (Test 1, BLZ-O-130A, 1" from bottom). Spinel crystals are very large in size. 


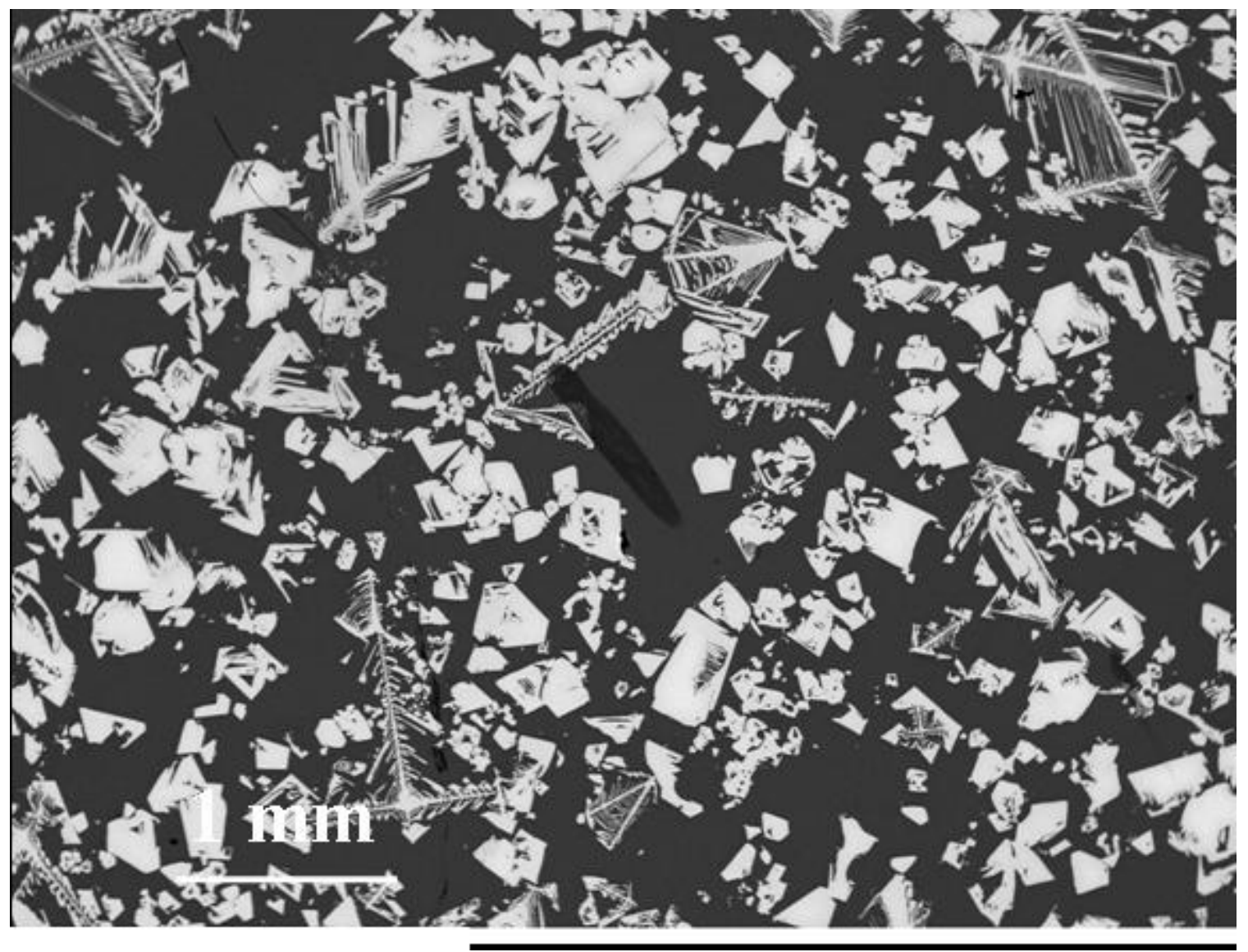

Figure 4.13b. SEM image showing primary spinel crystallization in the settling zone 1 " from bottom of the boat (Test 1, BLZ-O-130A). 


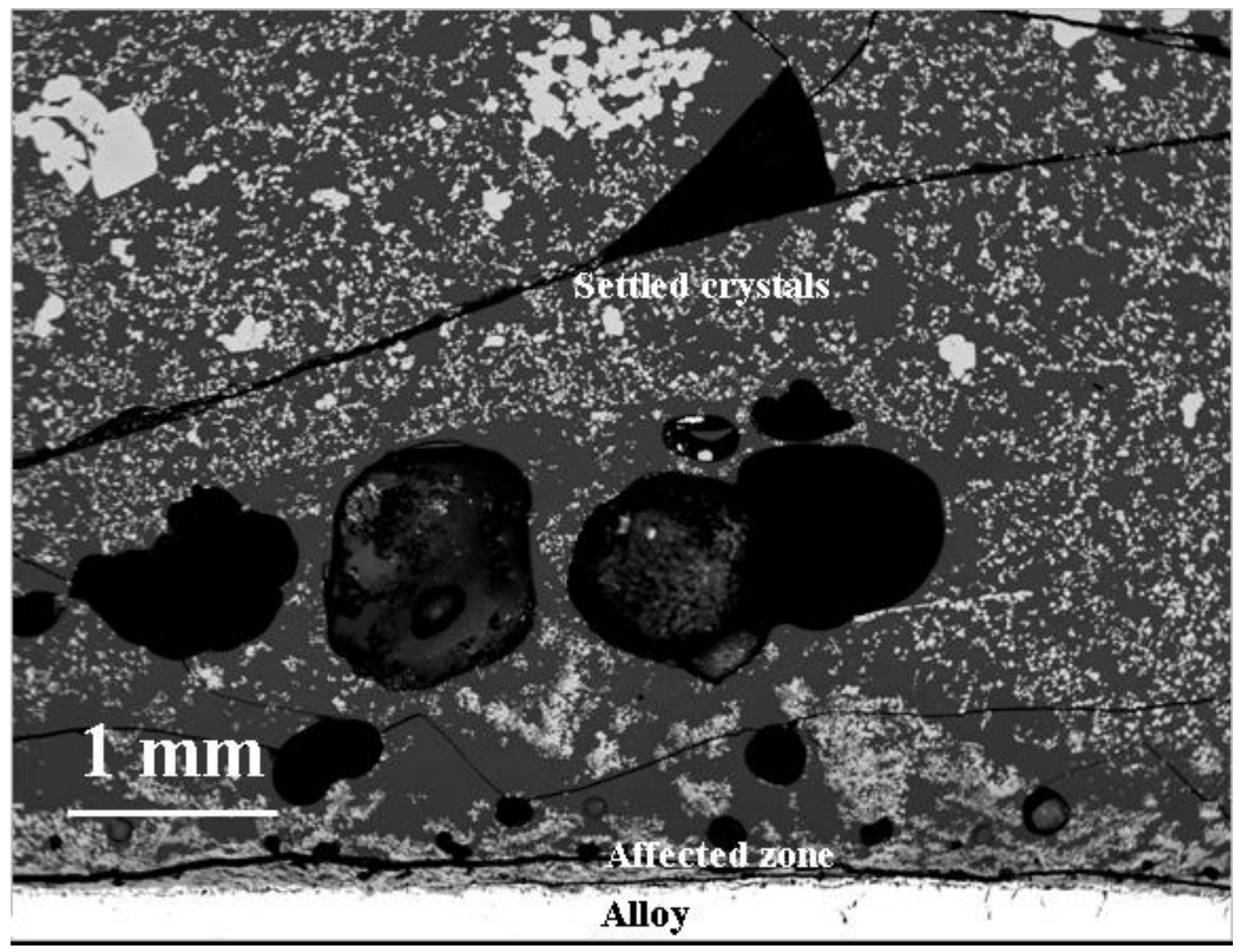

Figure 4.14a. SEM image showing microstructure of spinel settling on the boat bottom after idling (Test 1, BLZ-O-131B, 13" from bottom). Note clusters of large spinel crystals in highly dense settling zone composed of smaller spinel crystals. 
ORP-56294 Rev. 0

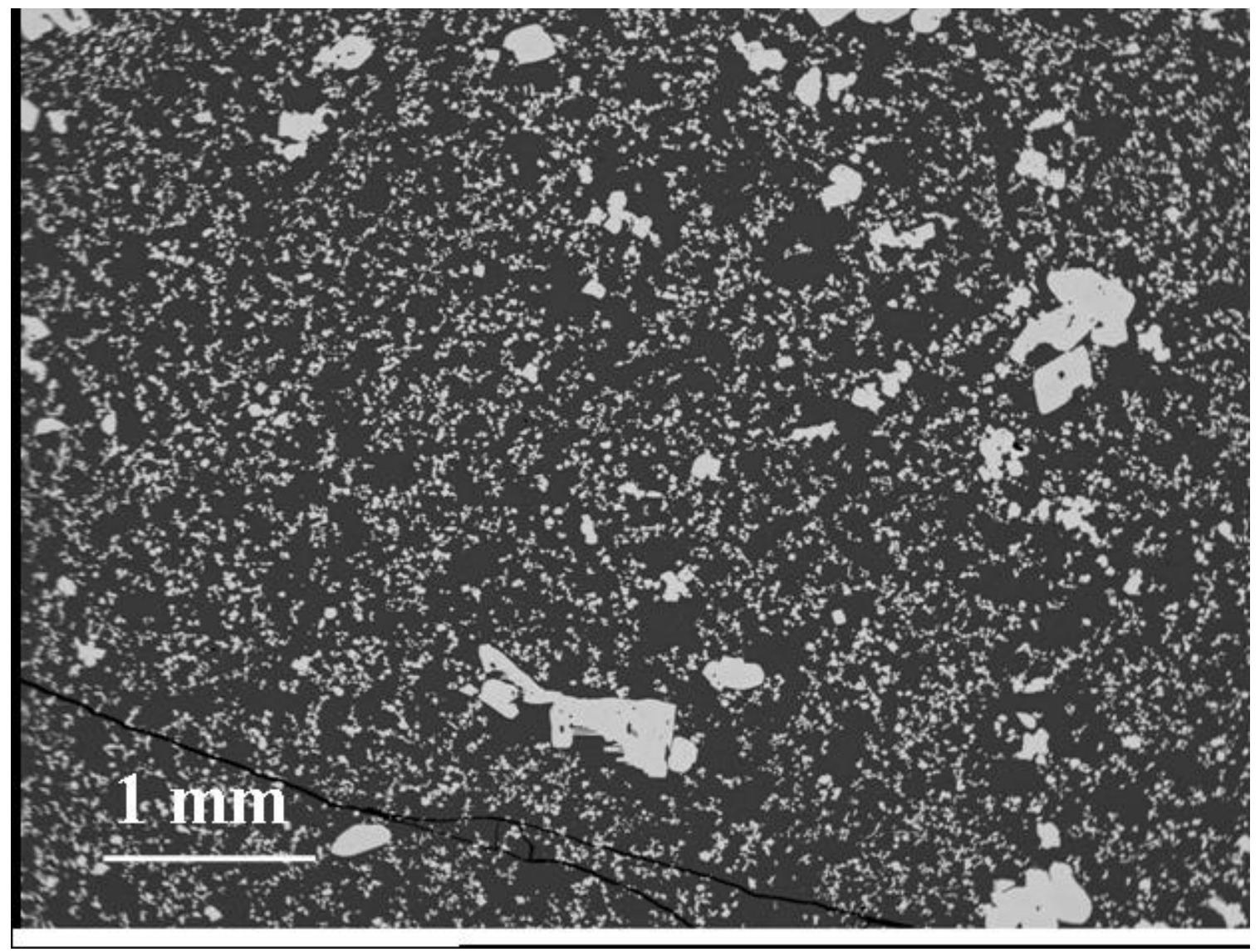

Figure 4.14b. SEM image showing typical microstructure of spinel settling zone away from the affected zone (Test 1, after idling, BLZ-O-131B, 13” from bottom). 


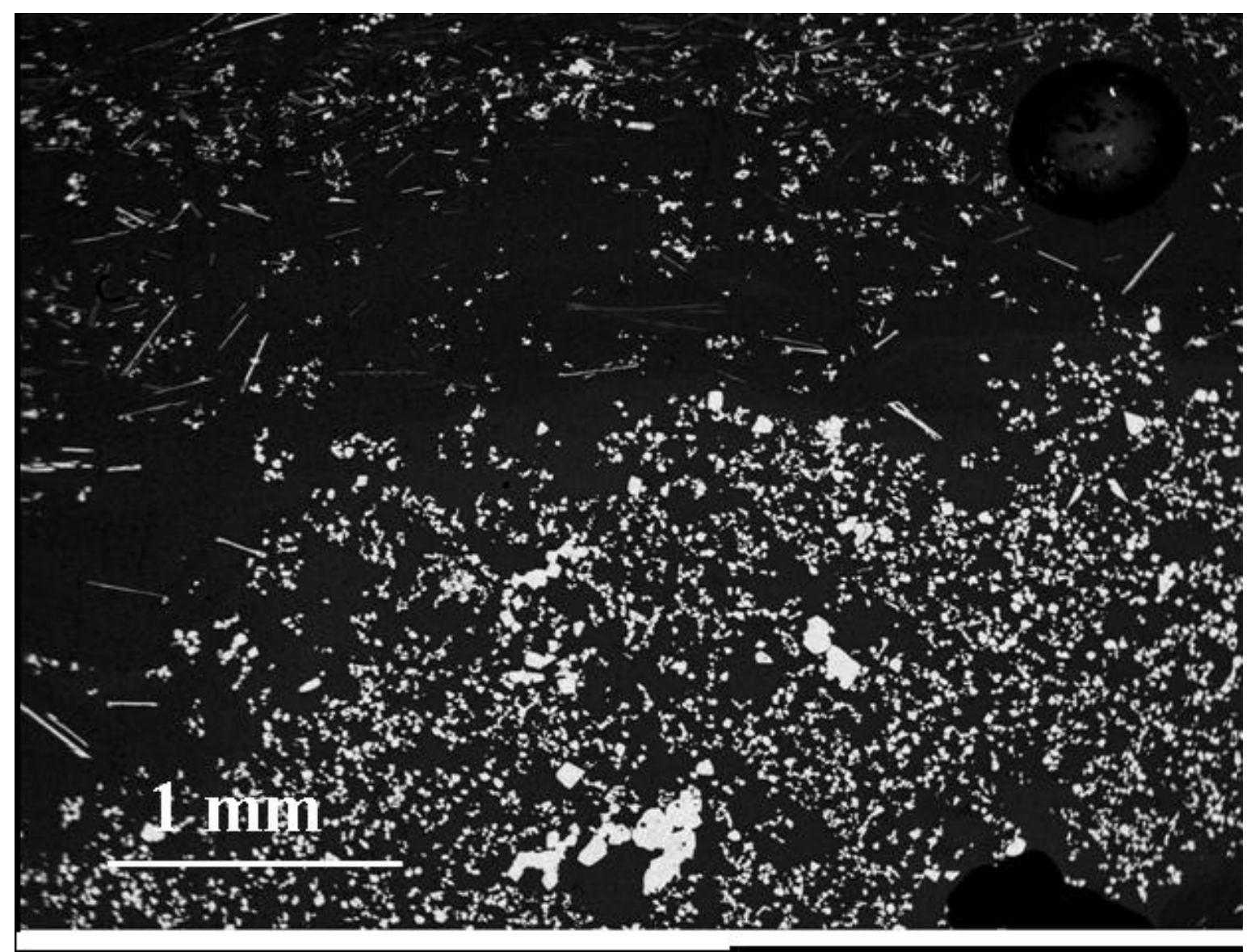

Figure 4.14c. SEM image showing typical microstructure of the upper settling zone (Test 1, after idling, BLZ-O-131B, 13" from bottom). Note hematite platelet rich region near top of image. 


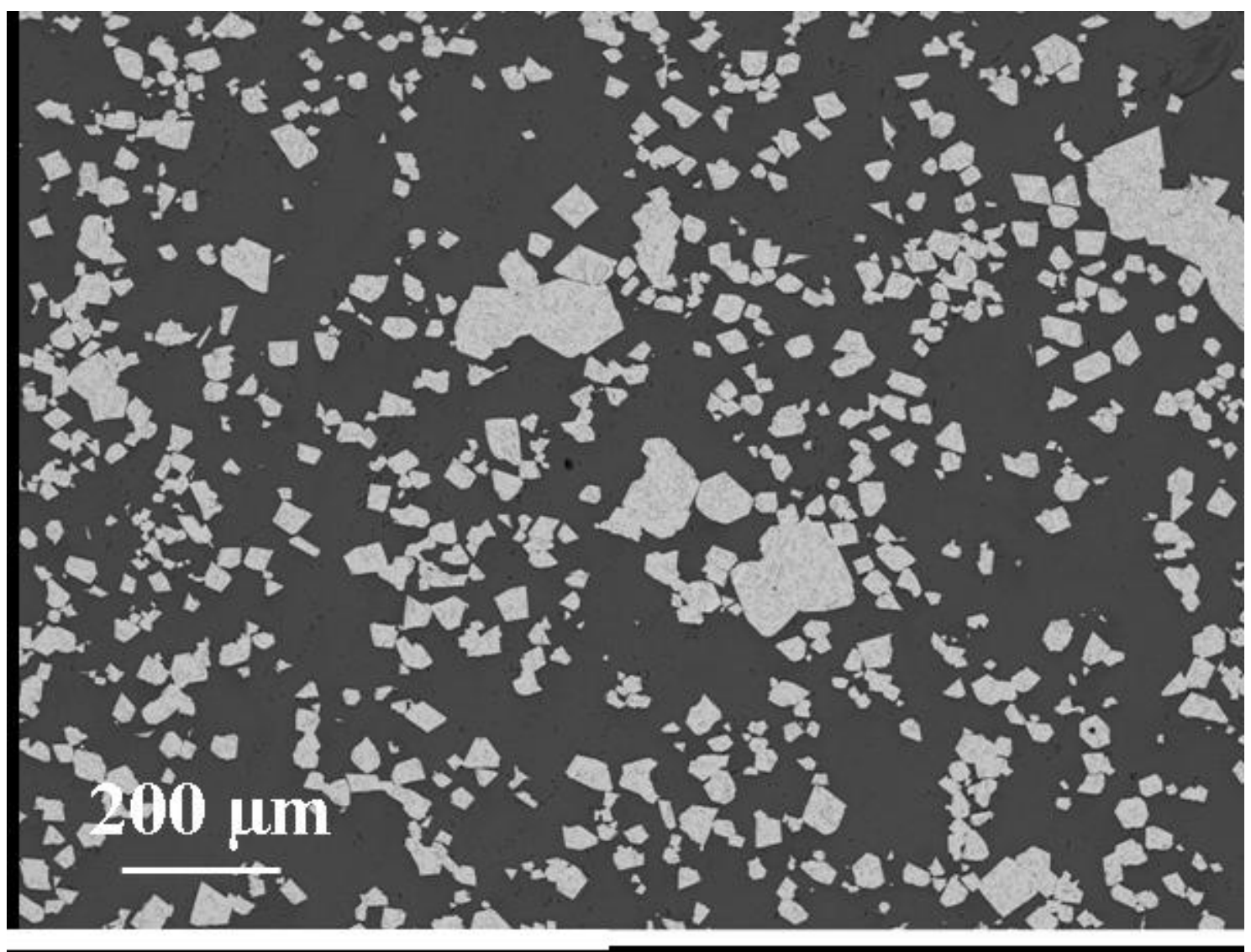

Figure 4.14d. SEM image showing typical microstructure of the upper spinel settling zone at higher magnification (Test 1, after idling, BLZ-O-131B, 13” from bottom). 


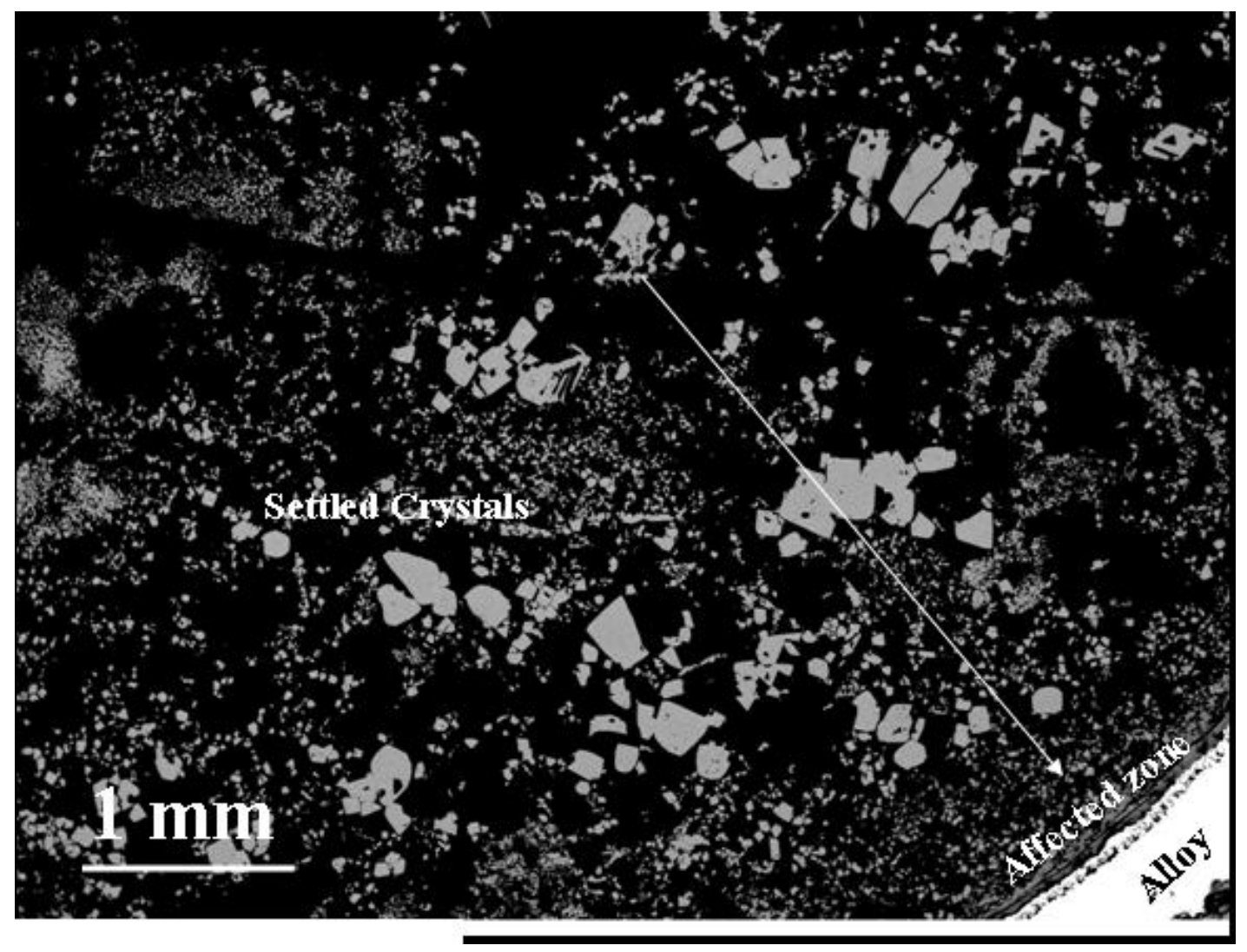

Figure 4.15a. SEM image showing cross-sectional microstructure of the settling zone on the boat bottom after idling (Test 1, BLZ-O-131A, 1" from bottom). Note large spinel crystals in a settling zone composed of smaller spinel crystals. The arrow shows the direction of settling. 


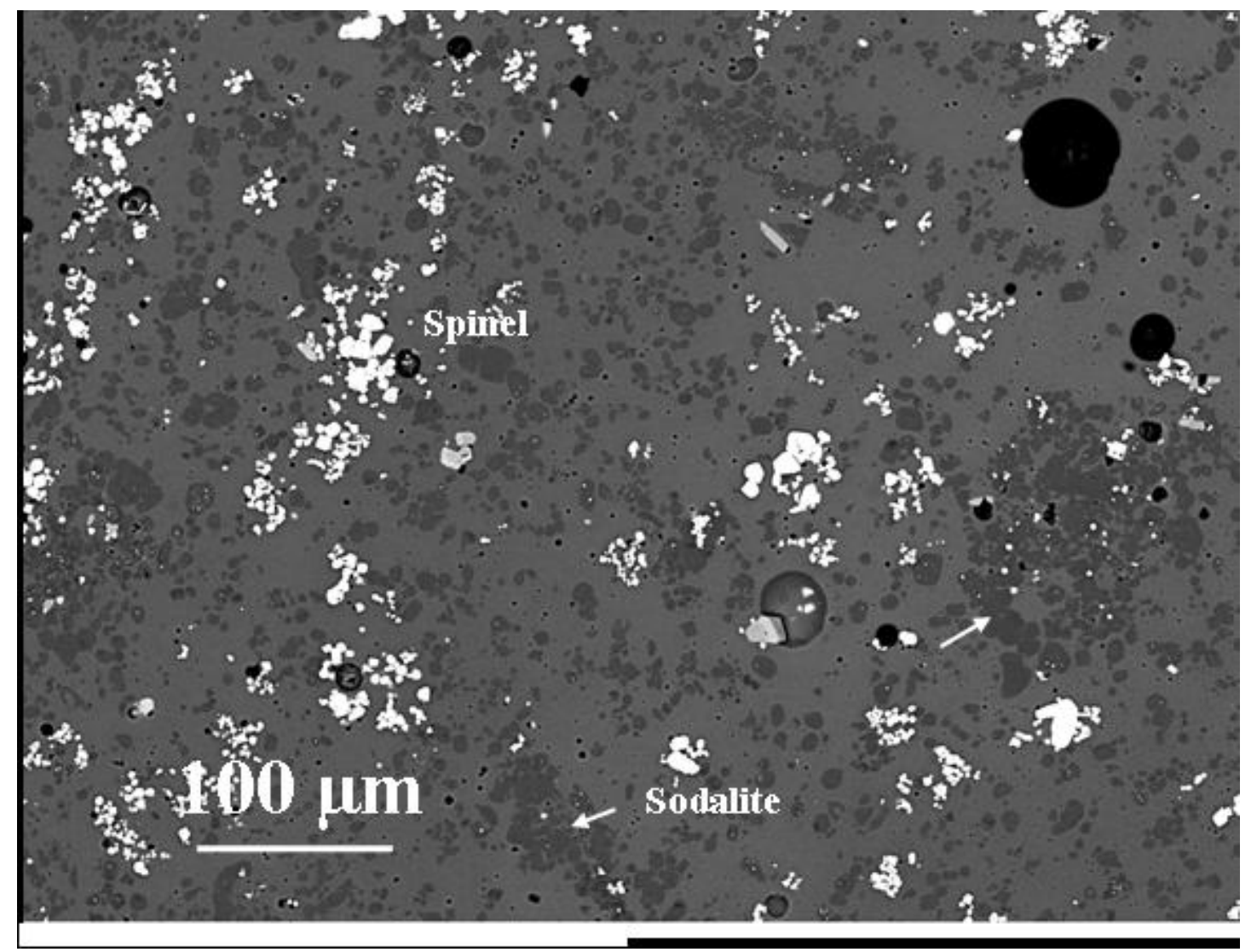

Figure 4.15b. SEM image showing sodalite crystallization in the settling zone (Test 1, BLZ-O-131A, 1" from bottom). Sodalite crystals are in dark grey as indicated by the arrow. 


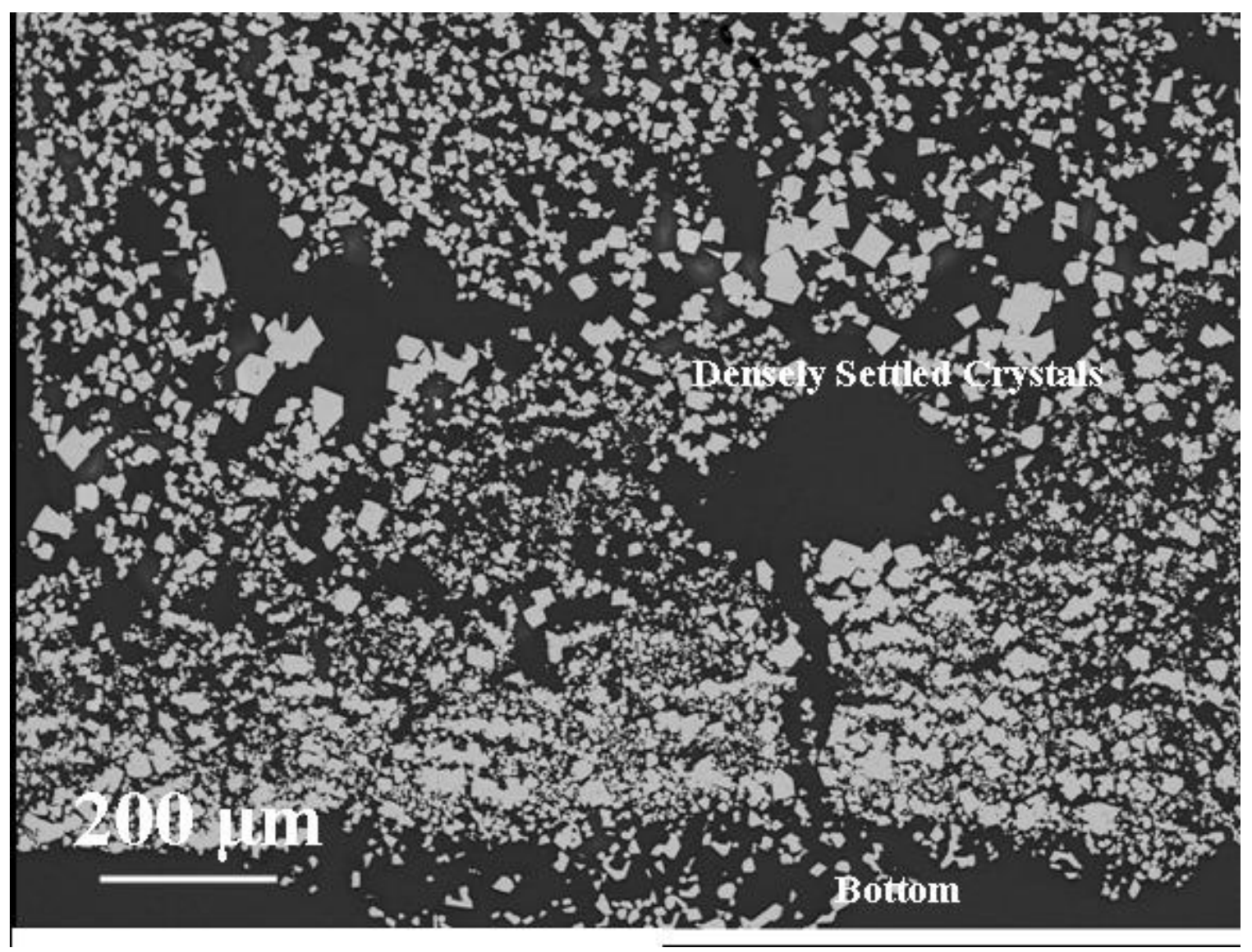

Figure 4.16a. SEM image showing cross-sectional microstructure of the settling zone on the boat bottom after idling (Test 2, ABL-O-71A, 1" from bottom). The settling zone is composed of spinel crystals in high packing density close to the bottom of the boat. 


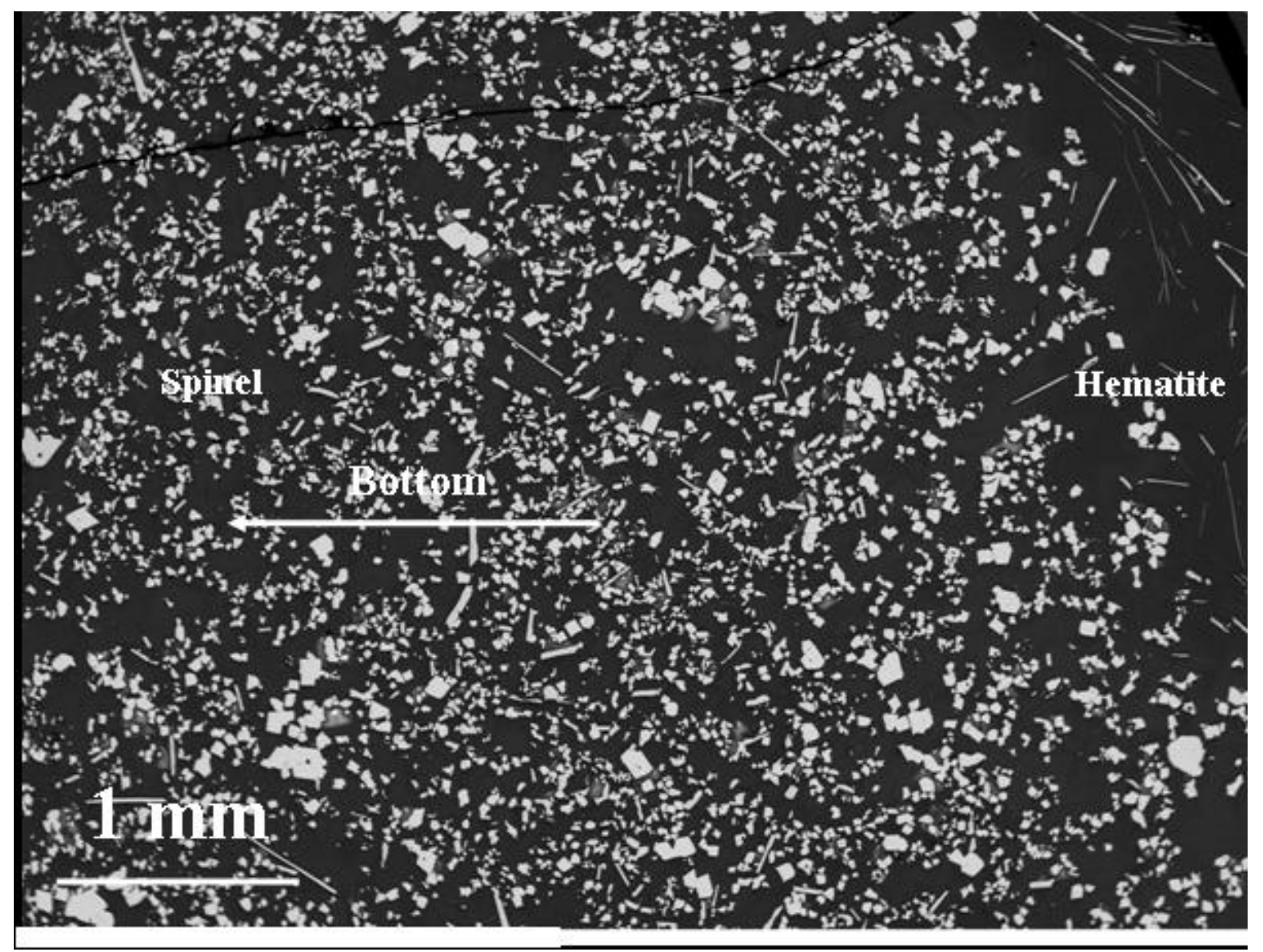

Figure 4.16b. SEM image showing a cross-sectional microstructure of the settling zone (upper region, Test 2, ABL-O-71A, 1" from bottom). The settling zone is composed of spinel crystals and hematite platelets. Hematite platelets dominate the region above primary spinel setting zone. 


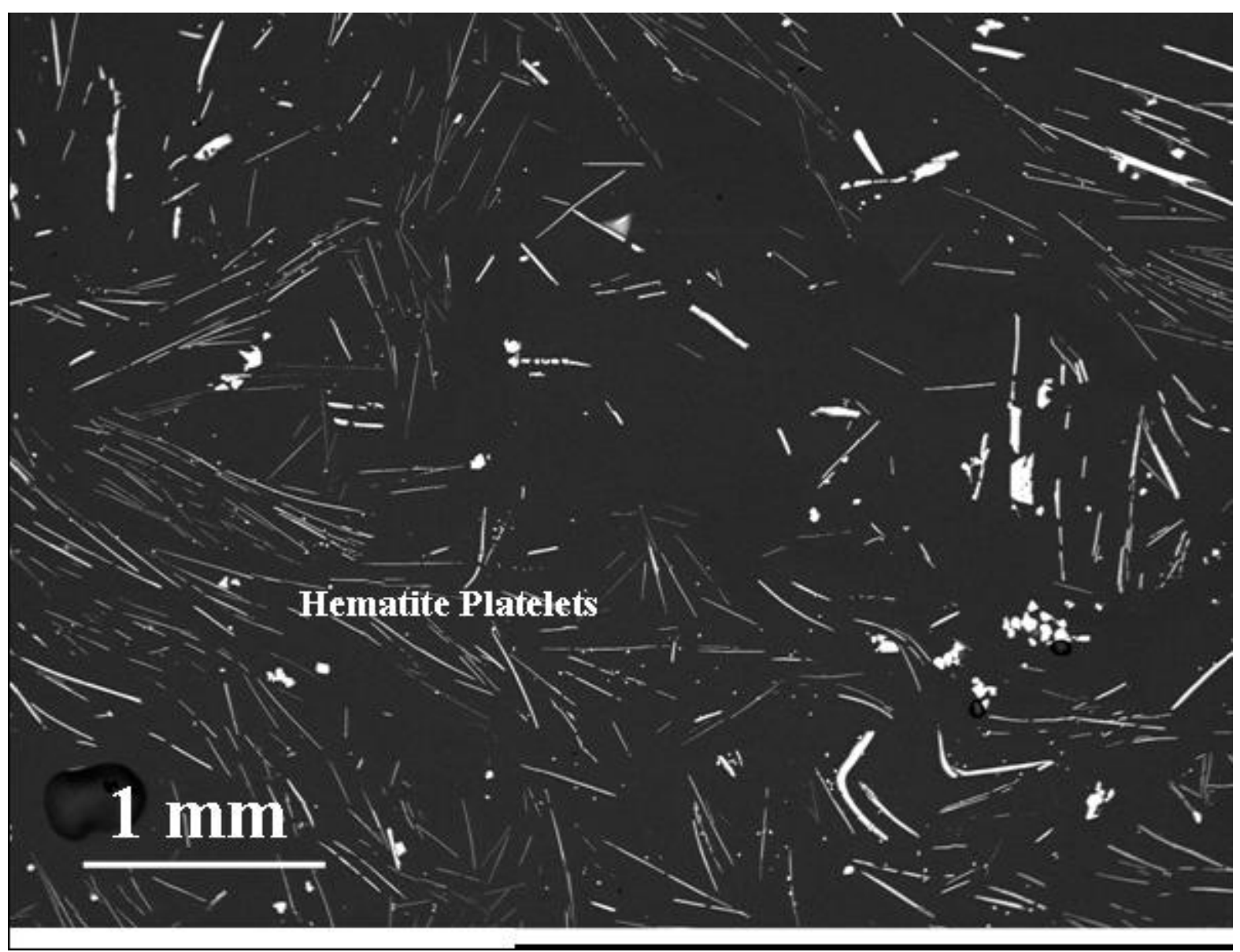

Figure 4.16c. SEM image showing microstructure of the top region of the settling zone (Test 2, ABL-O-71A, 1" from bottom). Hematite platelets dominate the settling zone. 


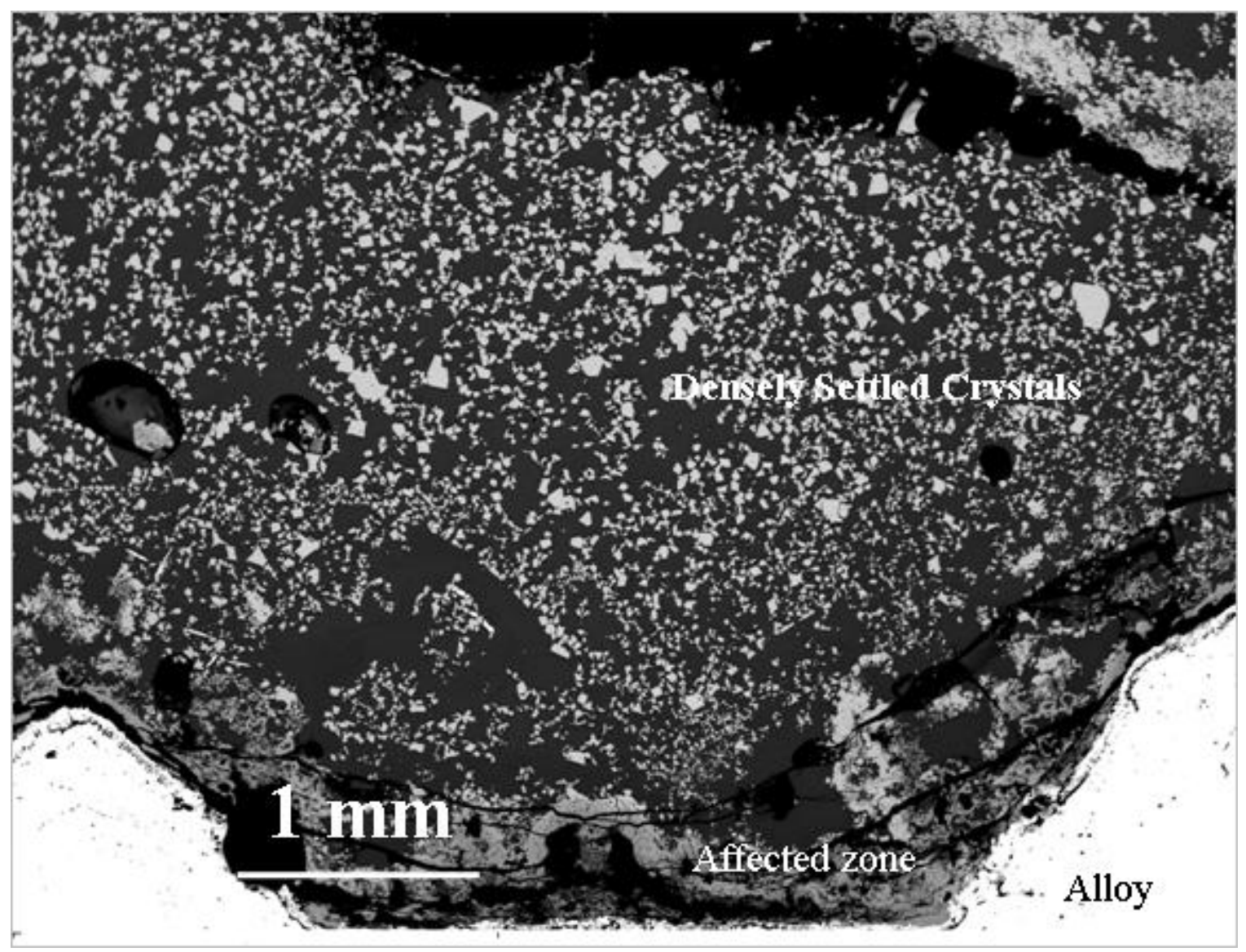

Figure 4.17a. SEM image showing cross-sectional microstructure of the settling zone close to bottom of the boat after idling (Test 2, ABL-O-71B, 13" from bottom). The settling zone is composed of spinel crystals in high packing density. 


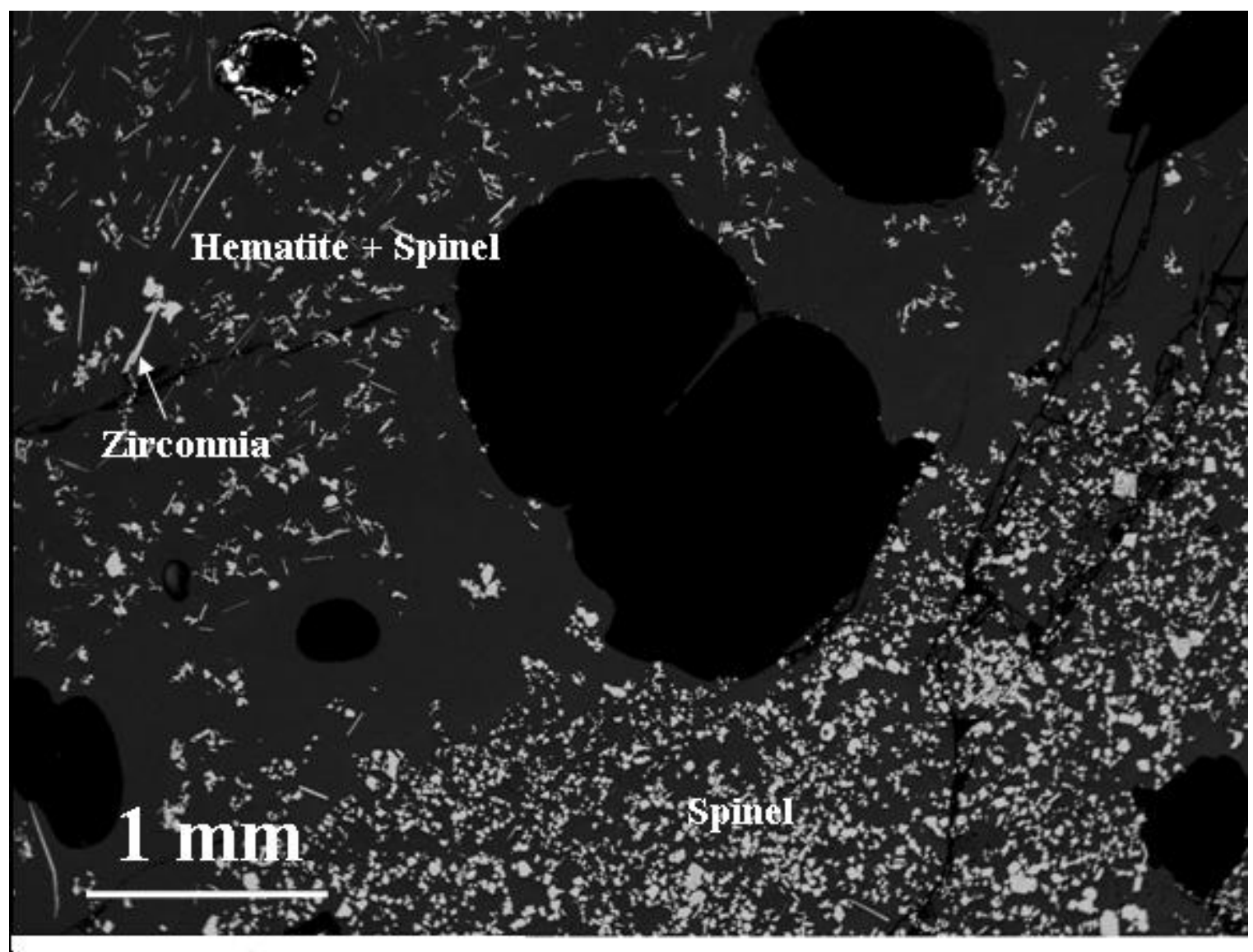

Figure 4.17b. SEM image showing cross-sectional microstructure of the settling zone in the upper region (Test 2, ABL-O-71B, 13" from bottom). Hematite platelets are abundant in the region above the primary spinel settling zone. 


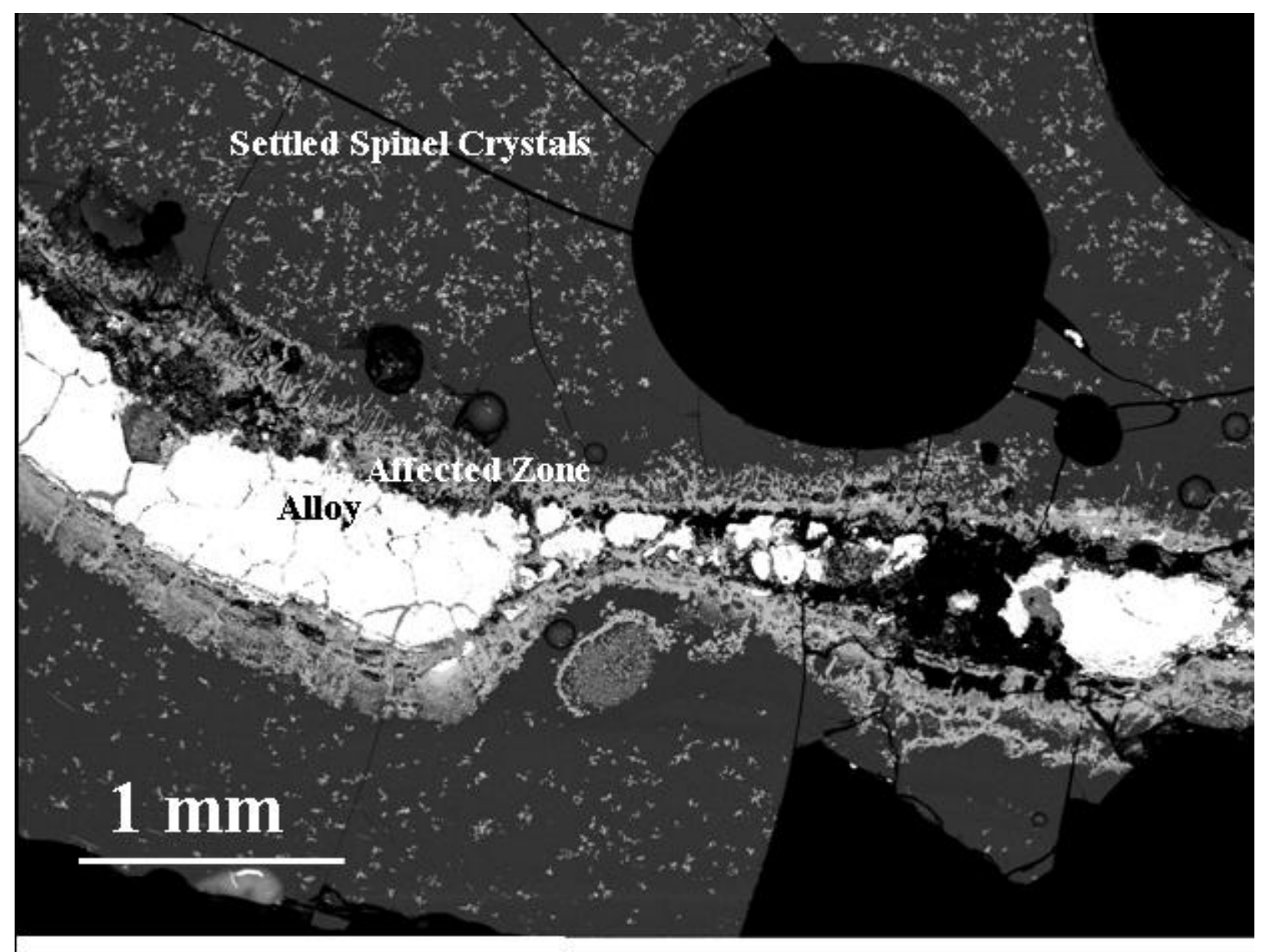

Figure 4.18. SEM image showing cross-sectional microstructure of the settling zone close to bottom of the boat after idling (Test 3, ABL-O-141A, 13" from bottom). The settling zone is composed of smaller spinel crystals at lower packing density. The reaction of the boat alloy with glass melt is extensive. 


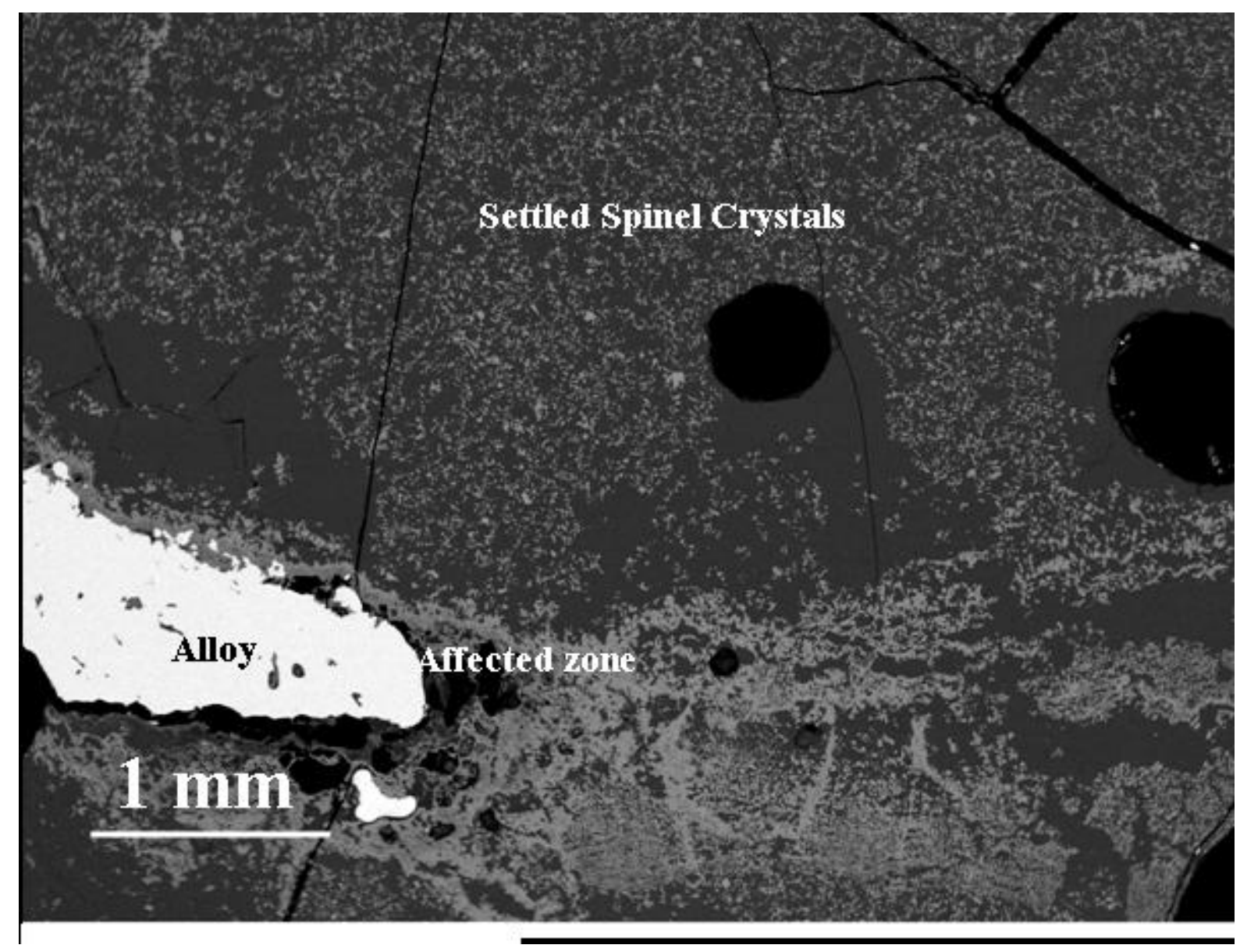

Figure 4.19a. SEM image showing cross-sectional microstructure of the settling zone close to bottom of the boat after idling (Test 3, ABL-O-141B, 1" from bottom). The settling zone is composed of smaller spinel crystals at lower packing density. The reaction of the boat alloy with glass melt is extensive. 


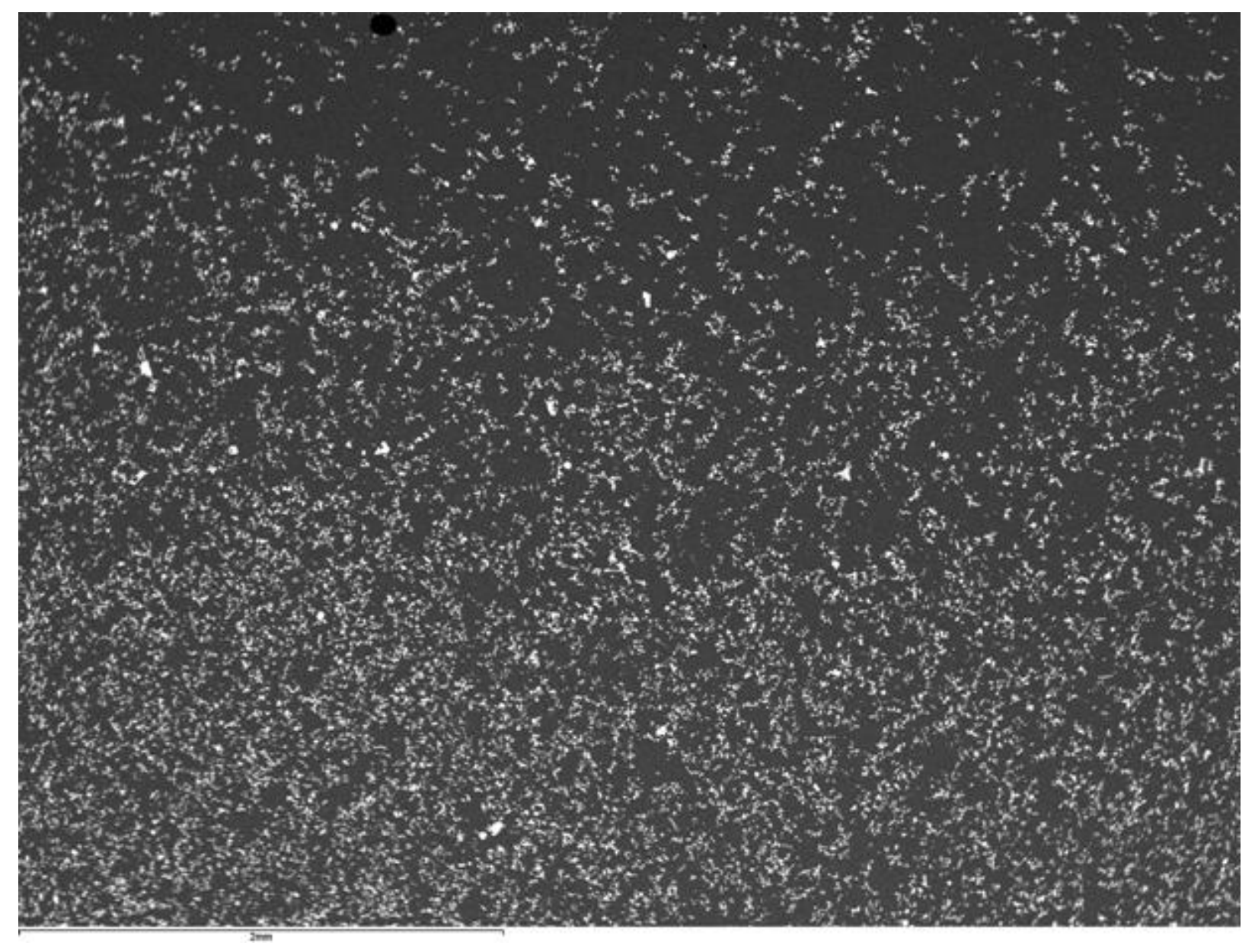

Figure 4.19b. SEM image showing cross-sectional microstructure of the settling zone in the upper region after idling (Test 3, ABL-O-141B, 1 ” from bottom). The concentration gradient in smaller spinel crystals is visible. 


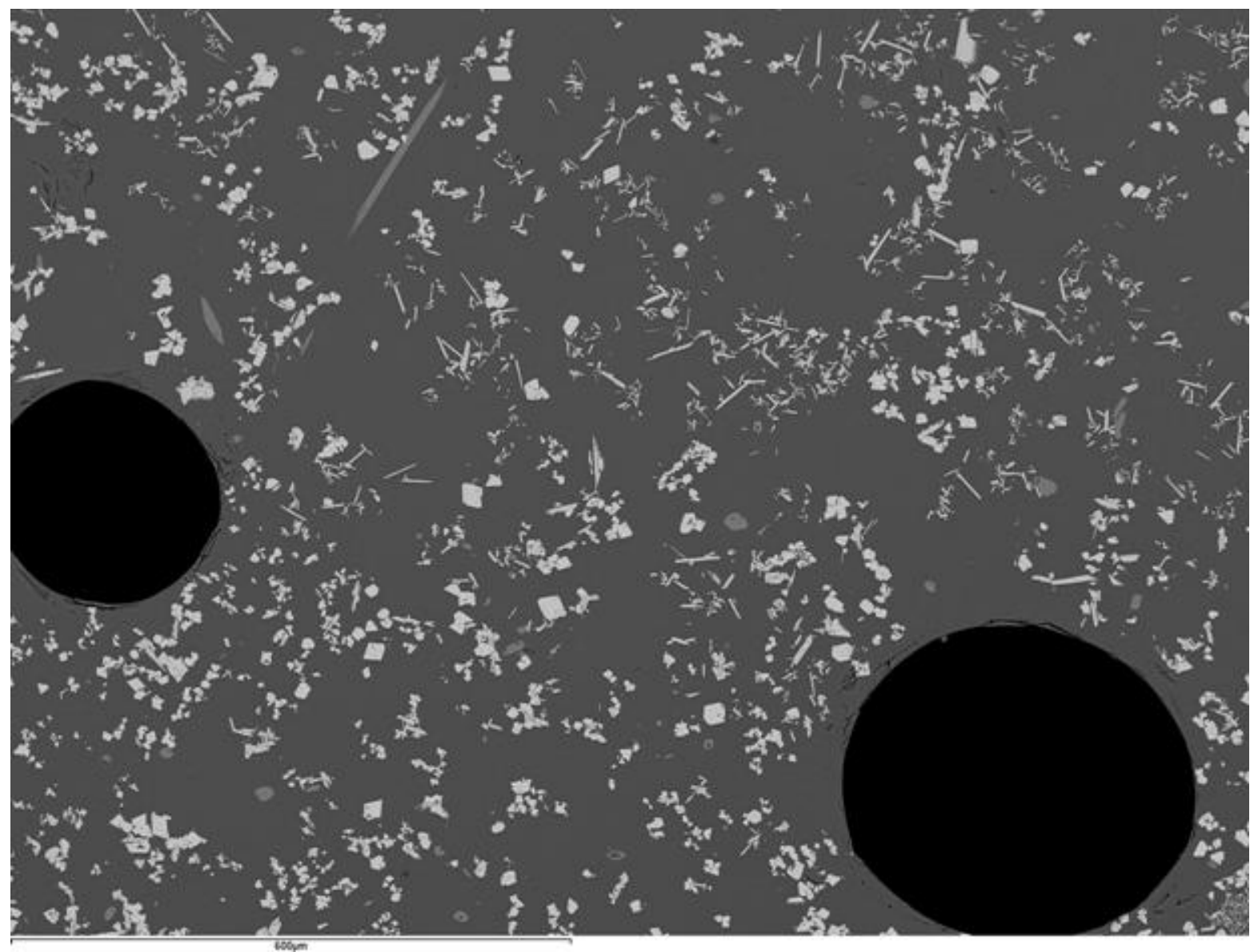

Figure 4.20a. SEM image showing microstructure of a partial settling zone (Test 4, BBL-O-60B, 13” from bottom). More eskolaite platelets are present in the upper region in this image. 


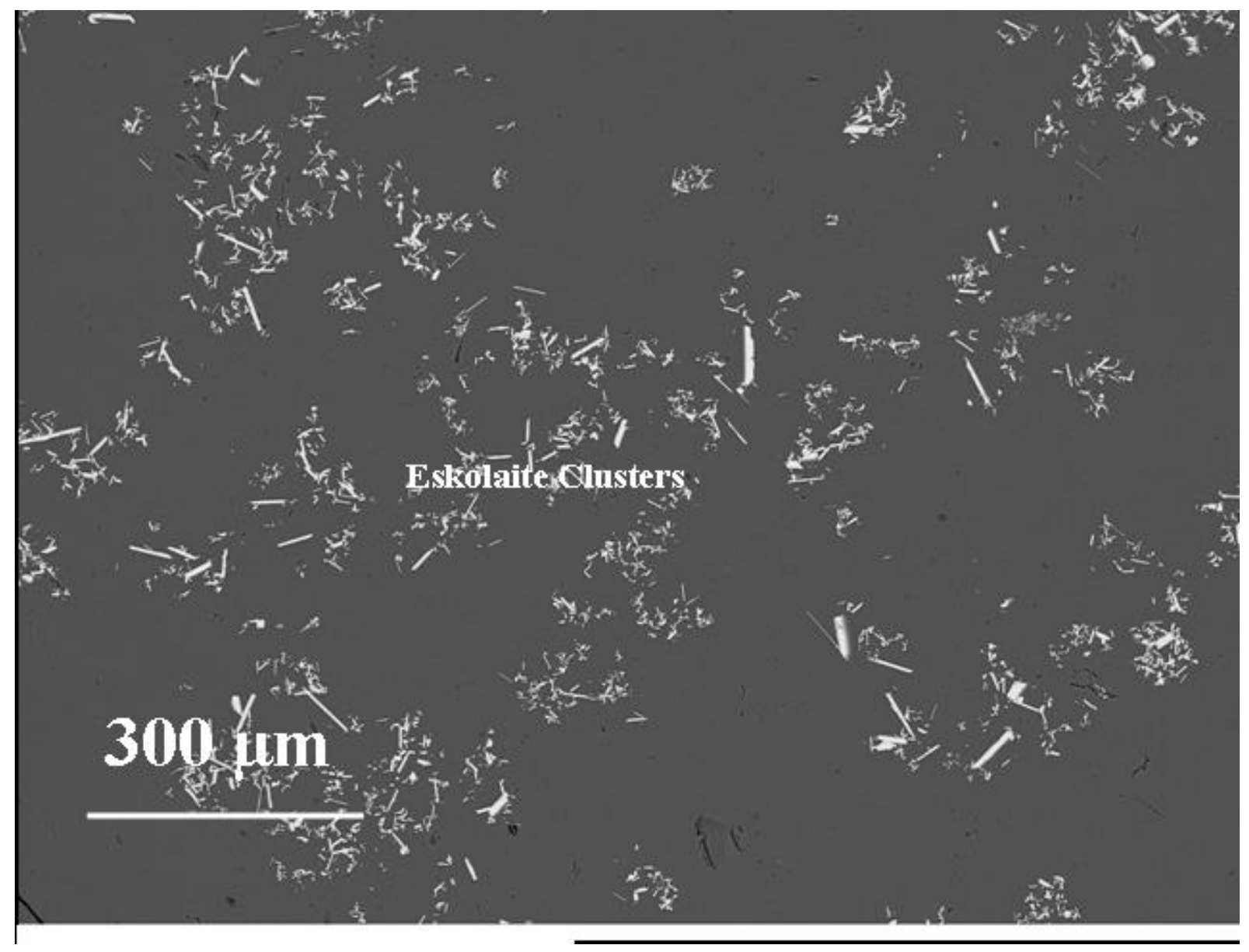

Figure 4.20b. SEM image showing microstructure of the region above the primary spinel settling zone. (Test 4, BBL-O-60B, 13" from bottom). The eskolaite platelets dominate in the form of clusters of $50-150 \mu \mathrm{m}$ in size. 


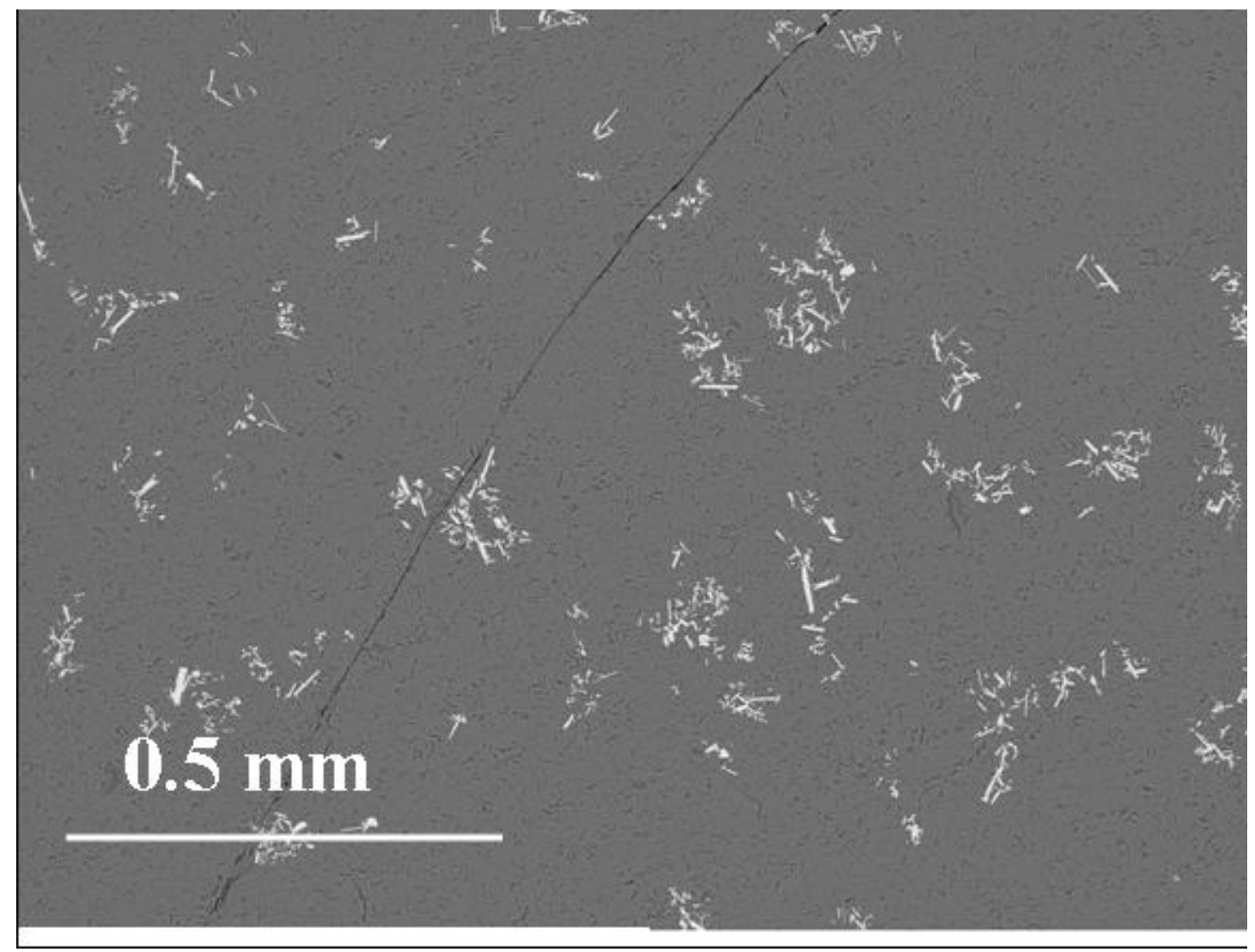

Figure 4.21. SEM image showing microstructure of a suction sample 1" from bottom of the melter (Test 4, BBL-O-60C). The eskolaite platelets are present in clusters. 


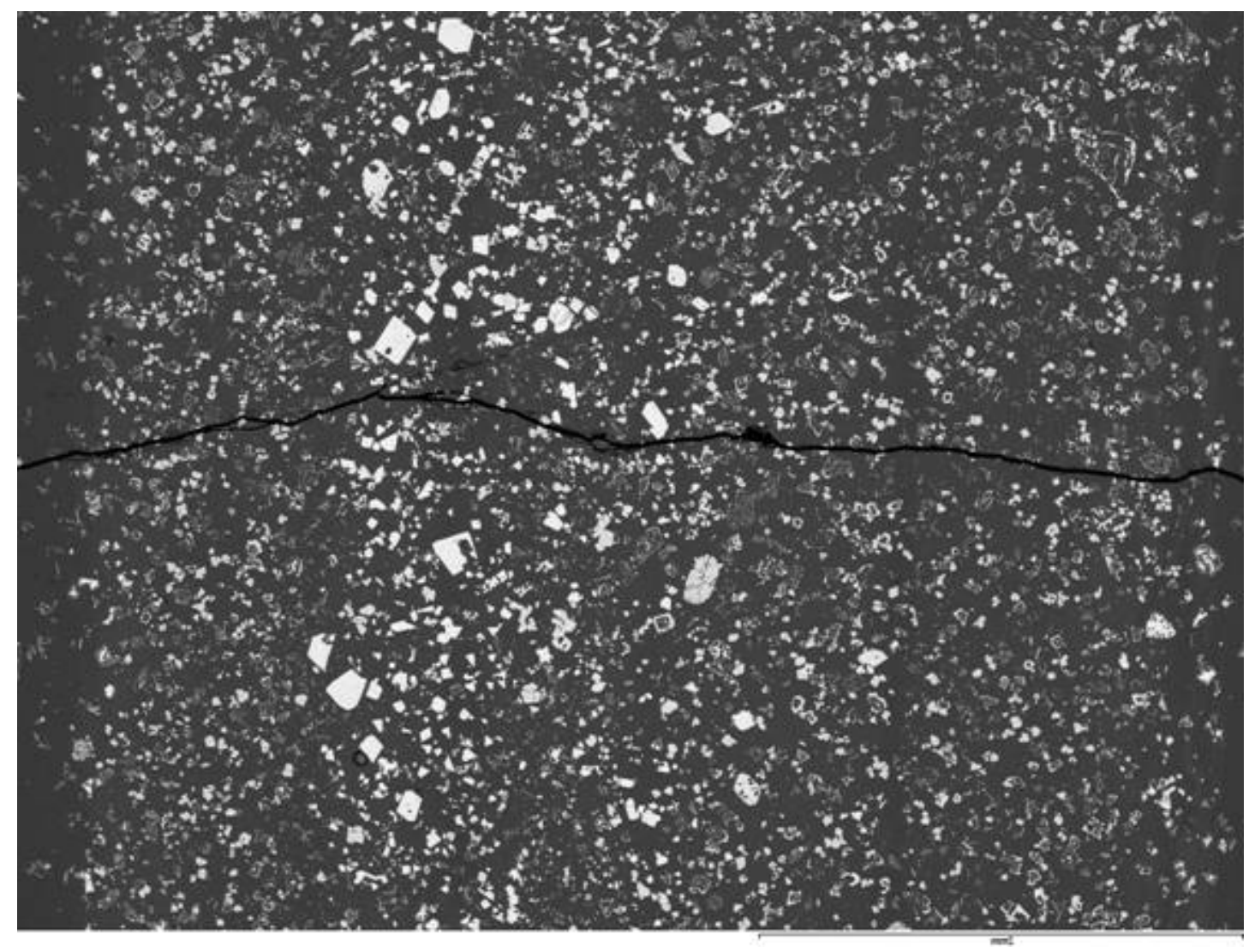

Figure 4.22a. SEM image showing microstructure in a partial cross-section of the settling zone in a suction sample (Test 4, after idling, BBL-O-60D, just off bottom of melter). The primary phase is spinel. 


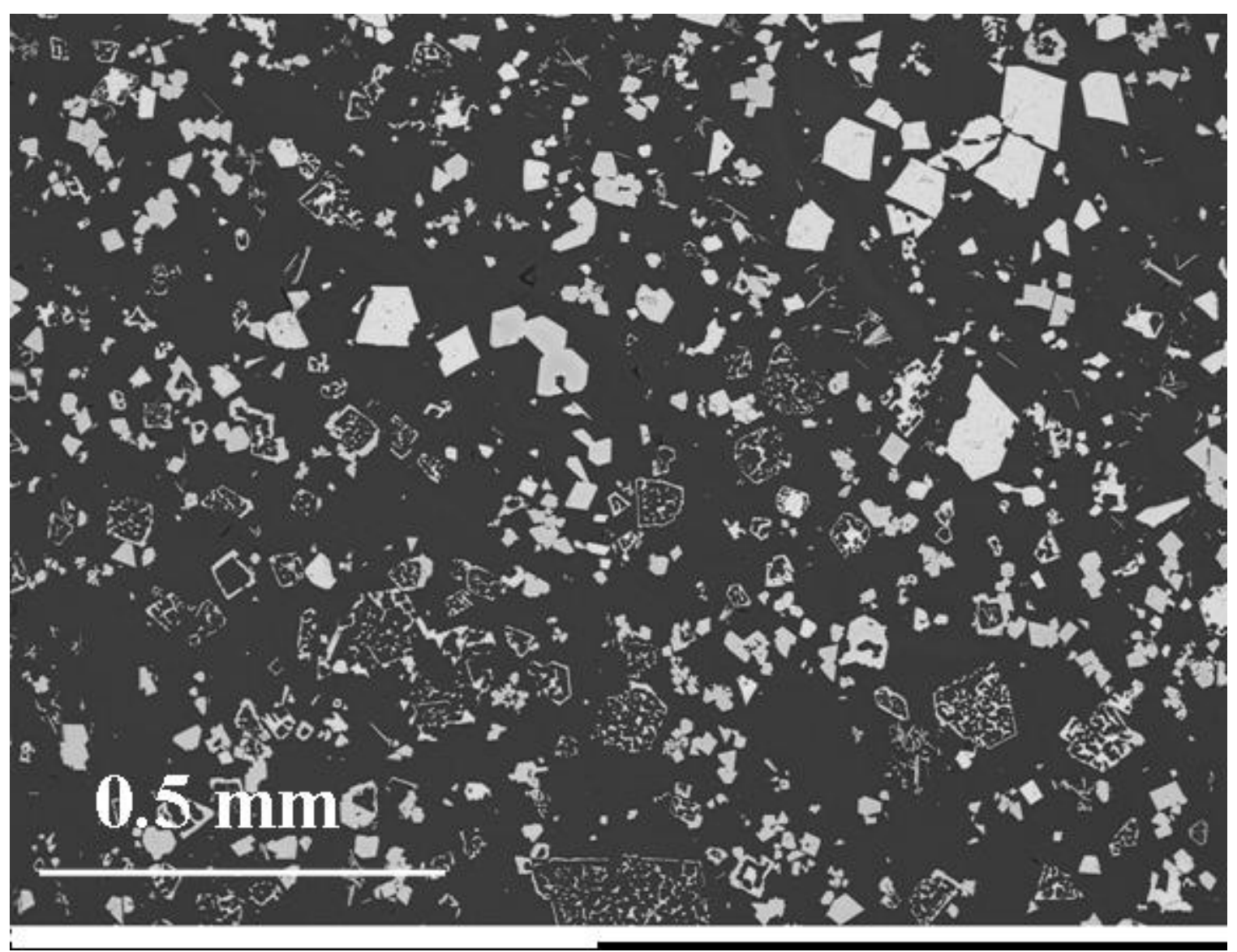

Figure 4.22b. SEM image showing typical microstructure of the settling zone in a suction sample (Test 4, after idling, BBL-O-60D, just off bottom of melter). Some of these large crystals of spinel are present in a skeleton form. 


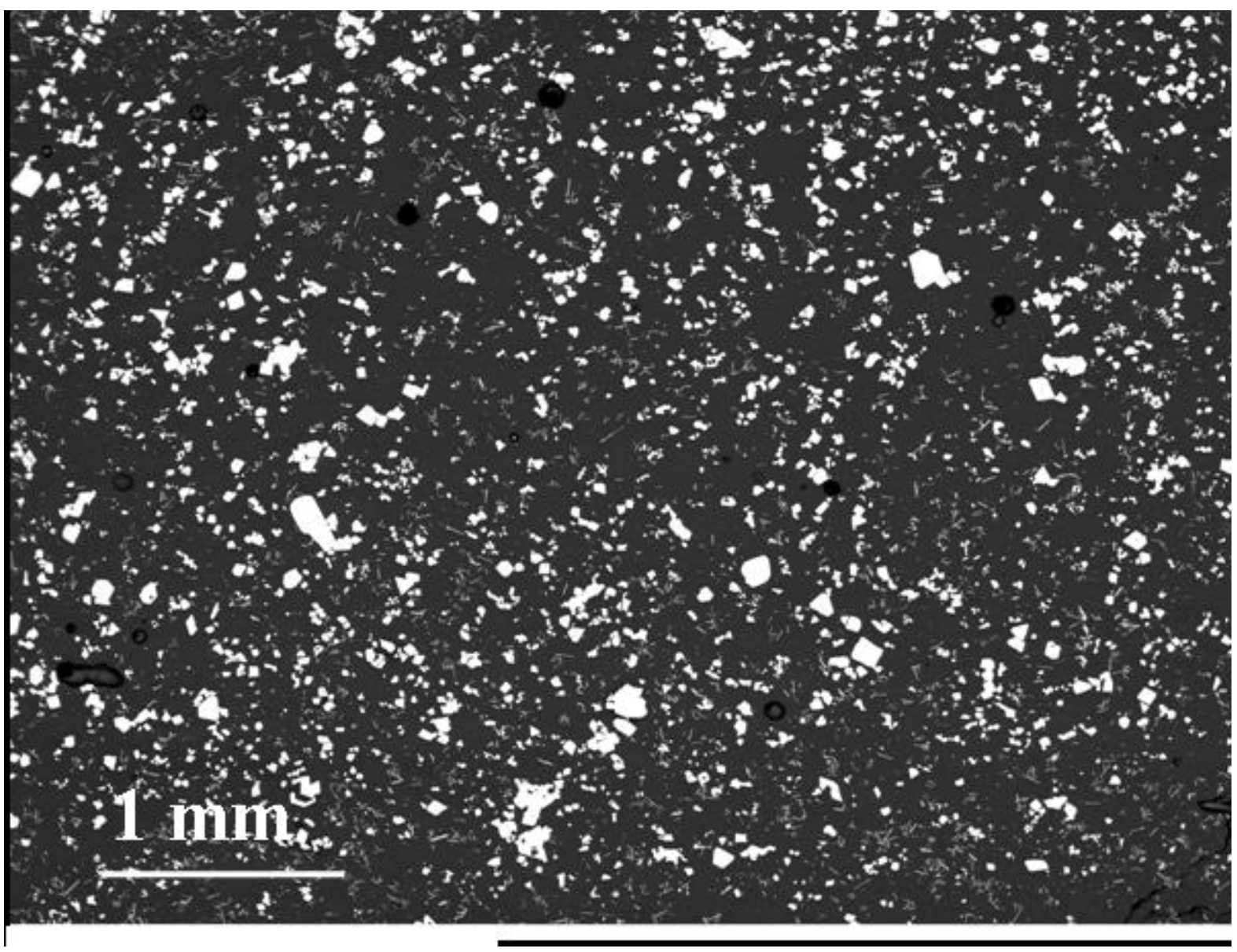

Figure 4.23a. SEM image showing typical microstructure of a partial cross-section of the settling zone at 1 " from bottom of melter in a suction sample (Test 5 , end of test, BBL-O-124B). The settling zone is composed primarily of spinel crystals. 


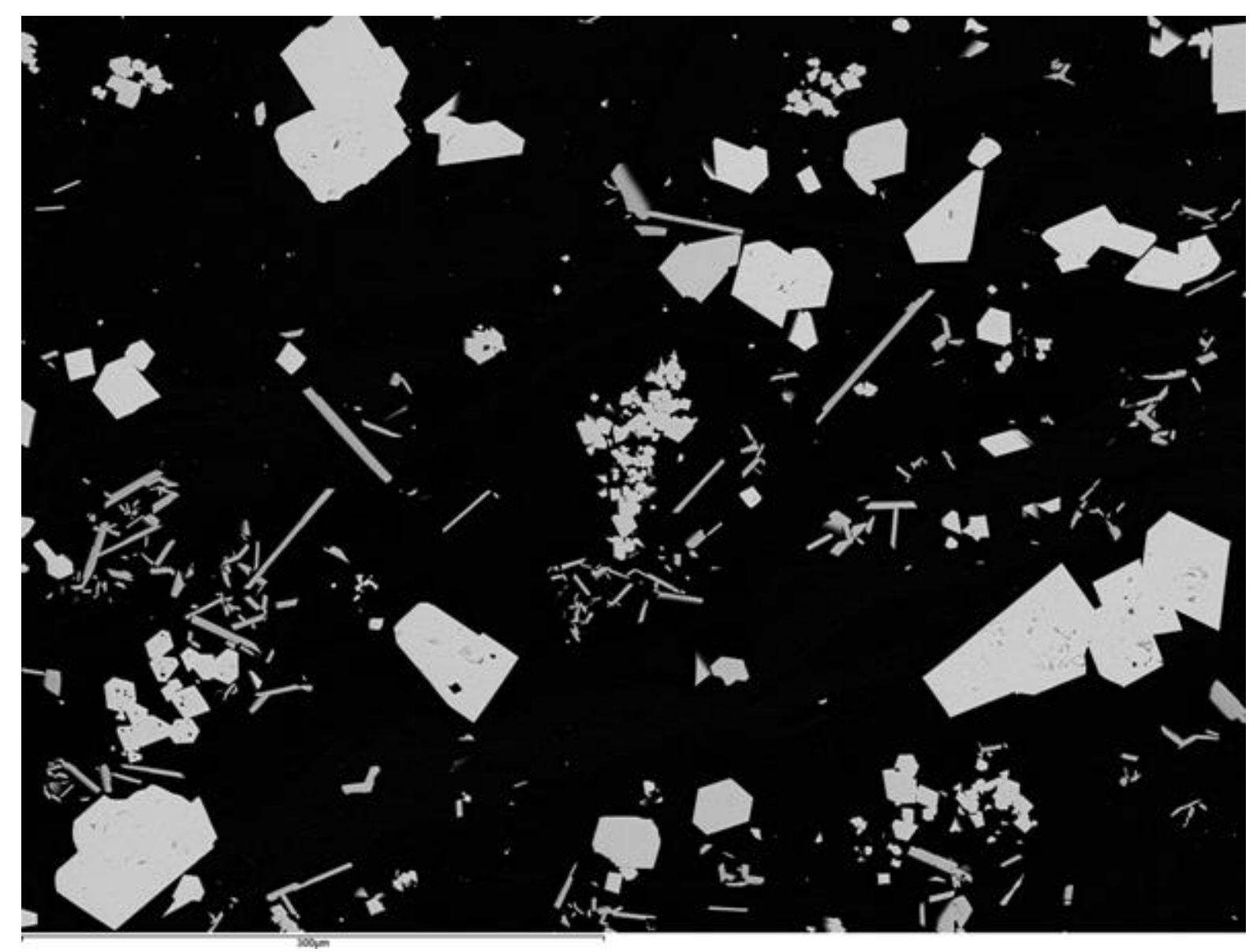

Figure 4.23b. SEM image showing typical microstructure of the settling zone at 1" from bottom of melter in a suction sample at higher magnification (Test 5 , end of test, BBL-O-124B). The settling zone is composed primarily of spinel crystals and eskolaite platelets. 


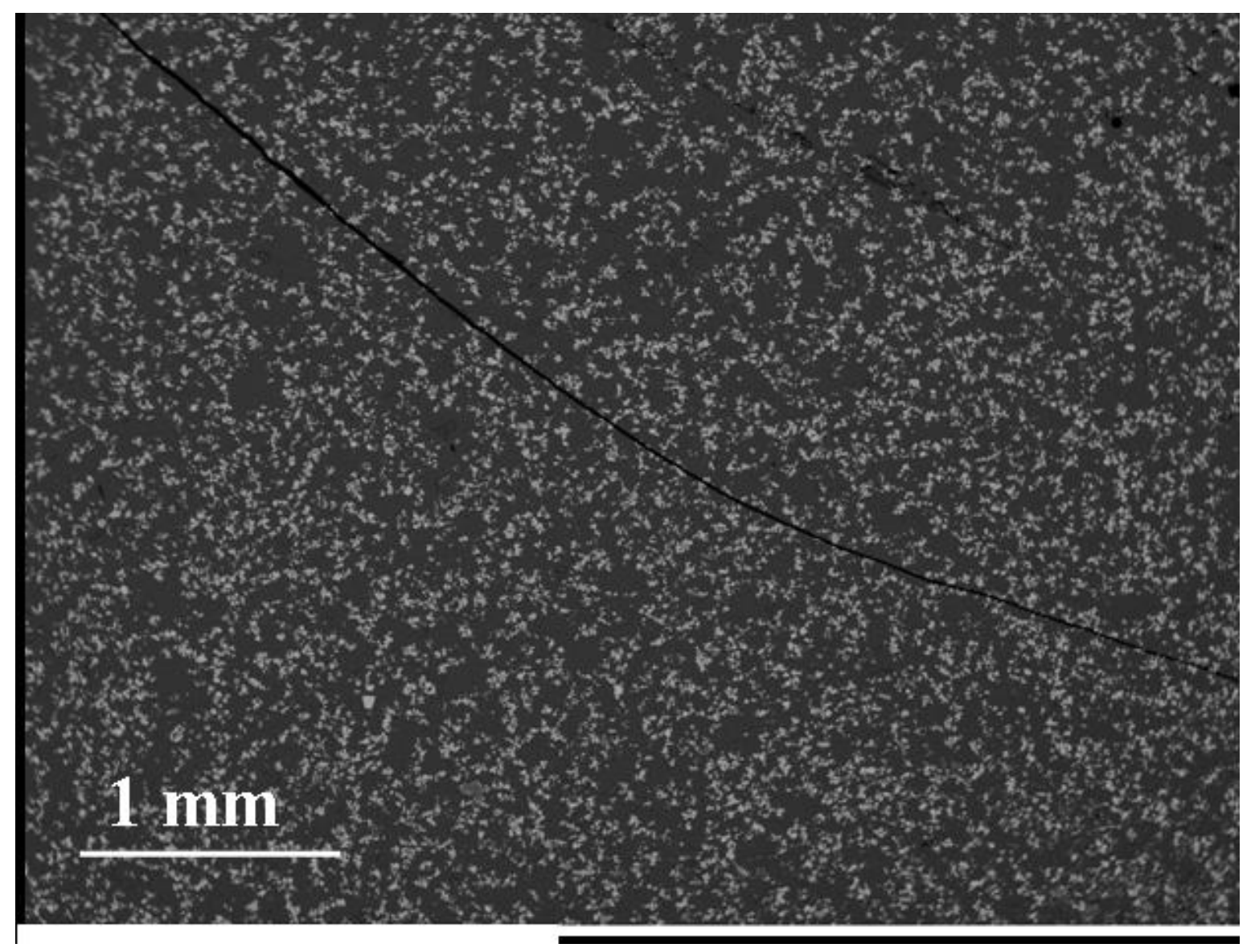

Figure 4.24a. SEM image showing typical microstructure of a partial settling zone (Test 5, after idling, BBL-O-124D). The studied region is near the bottom of the boat. The settling zone is composed primarily of small spinel crystals. 


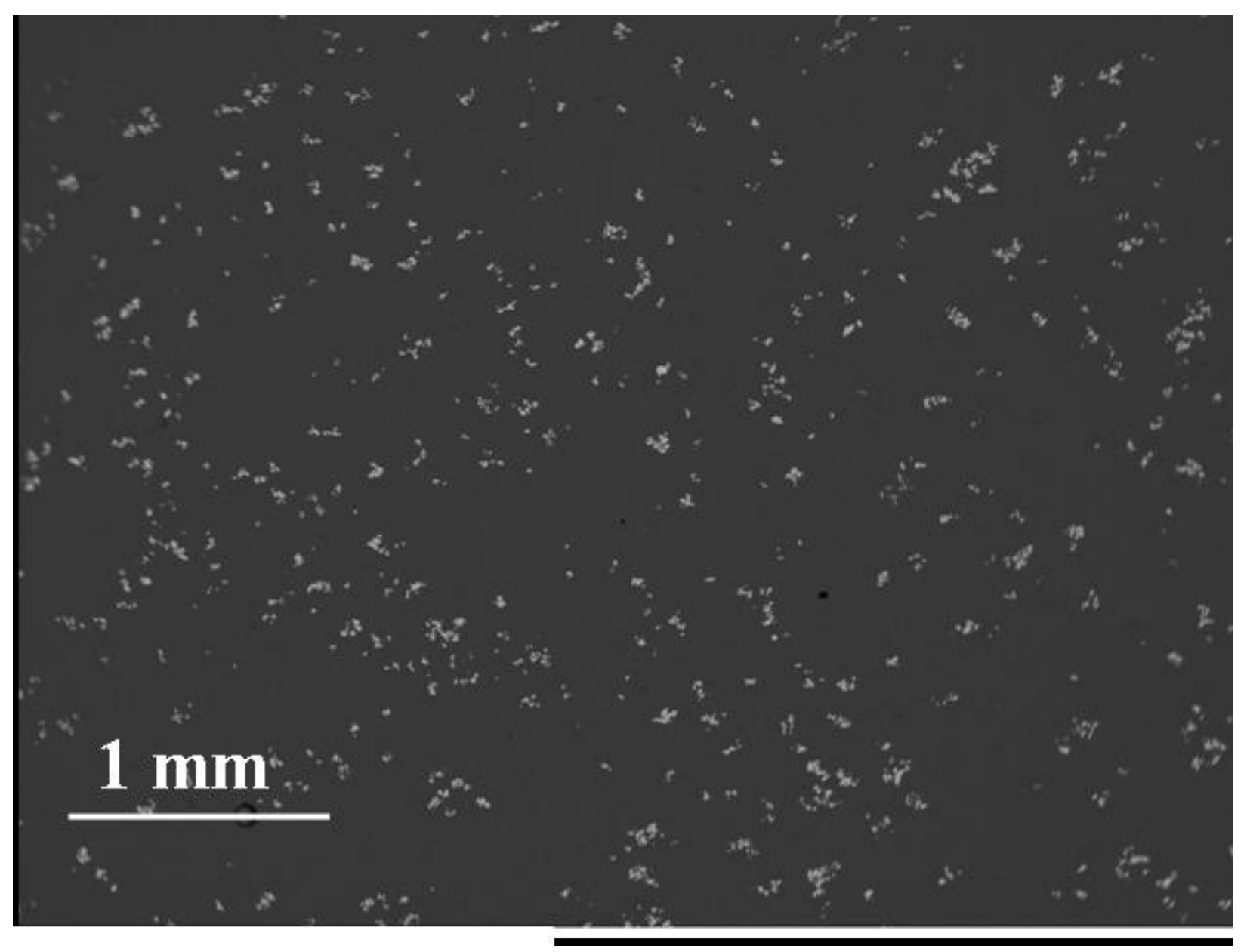

Figure 4.24b. SEM image showing typical microstructure of a partial settling zone (Test 5, after idling, BBL-O-124D). The studied region is away from the bottom of the boat. The concentration of spinel is much less compared to that near the bottom. 


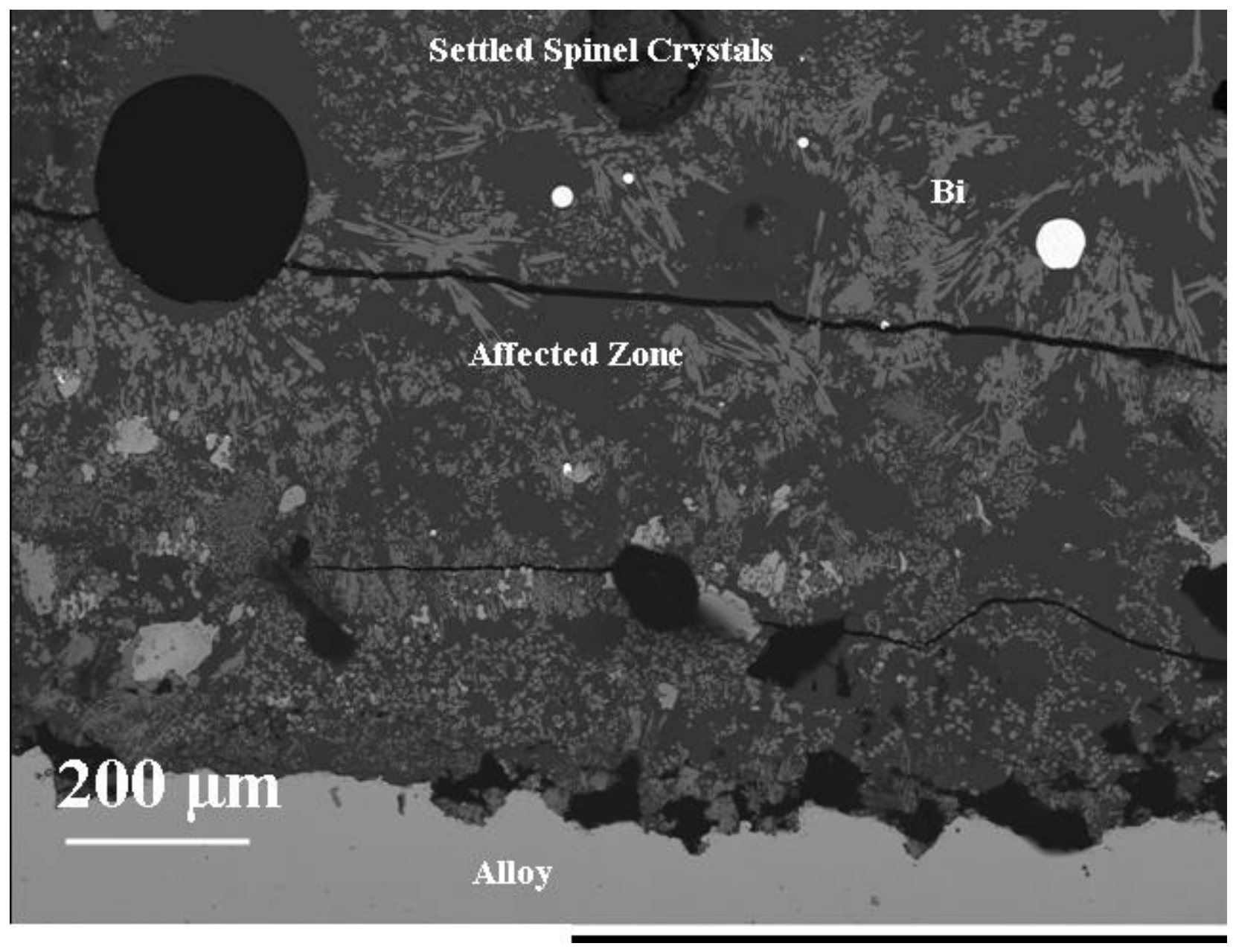

Figure 4.25a. SEM image showing typical microstructure of the affected zone between the settling zone and the boat alloy (Test 5, after idling, BBL-O-124E, 13” from bottom). The bright particles are $\mathrm{Bi}$ rich phases. 


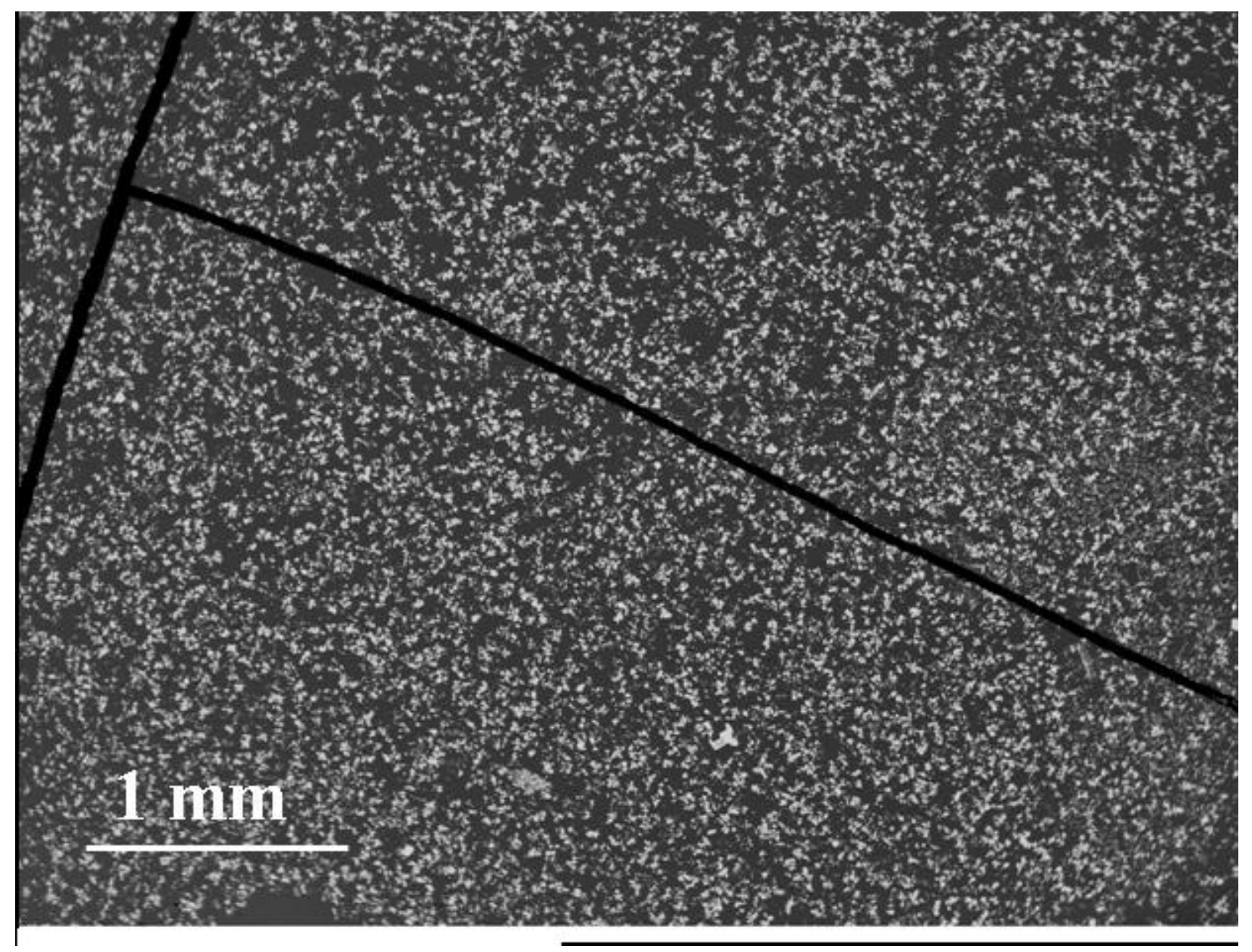

Figure 4.25b. SEM image showing typical microstructure of the settling zone composed primarily of spinel at high packing density (Test 5, after idling, BBL-O-124E, 13" from bottom). 


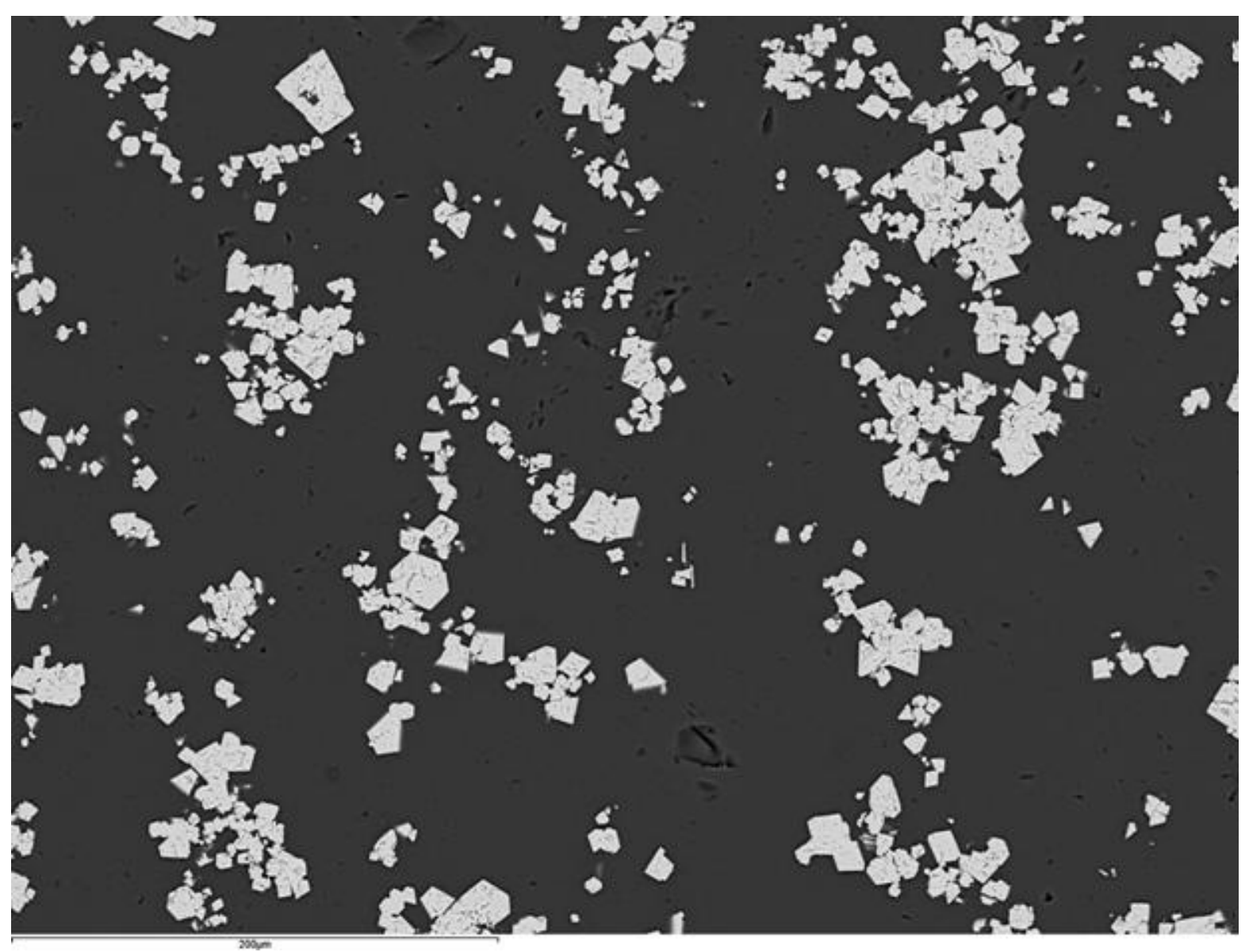

Figure 4.25c. SEM image showing typical microstructure of the settling zone primarily in the upper region (Test 5, after idling, BBL-O-124E, 13” from bottom). 


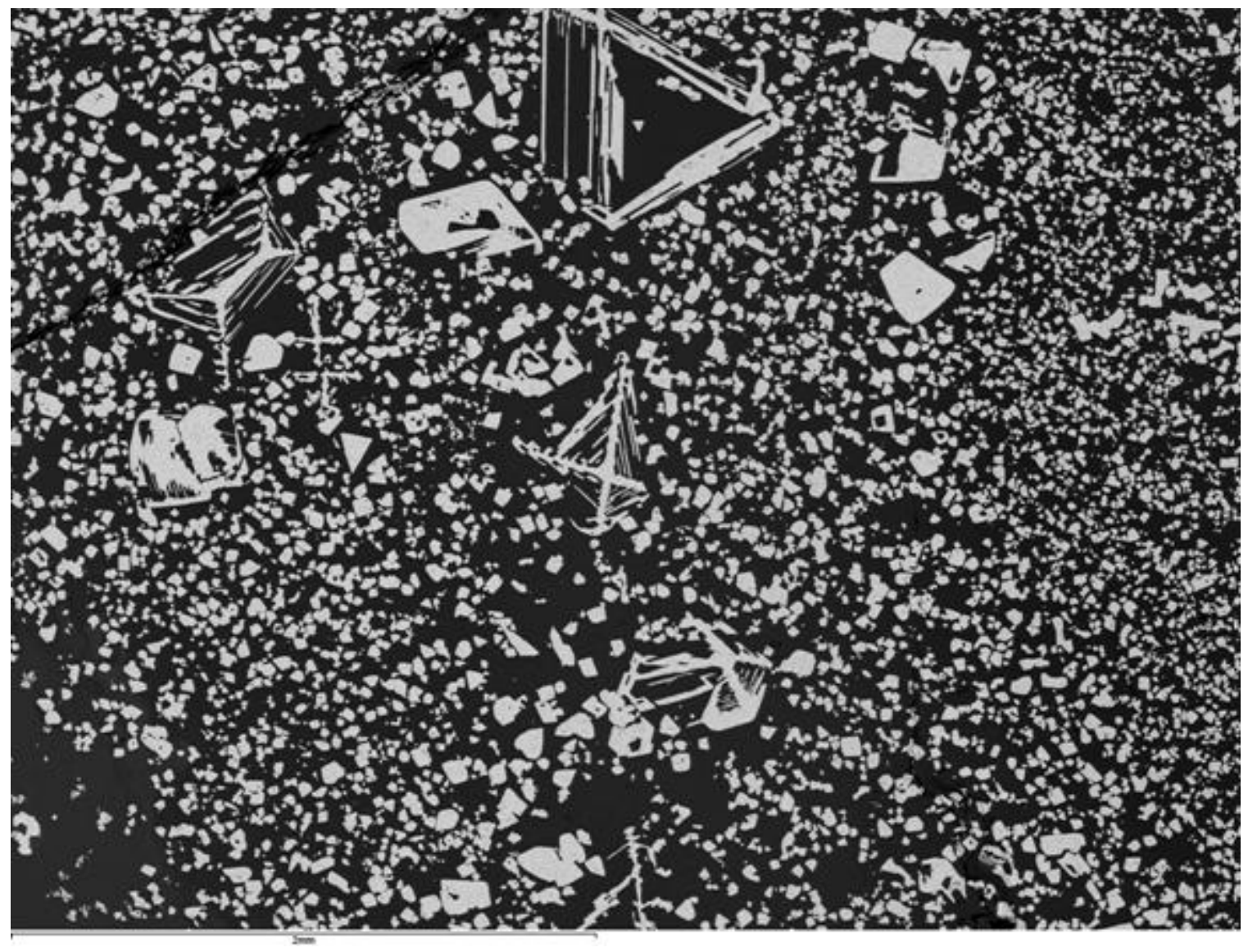

Figure 4.26. SEM image showing typical microstructure of the dense settling zone in a suction sample (Test 5 , after idling, BBL-O-130B, 1" from bottom of melter). The settling zone is a mixture of large skeletons and smaller spinel crystals. 


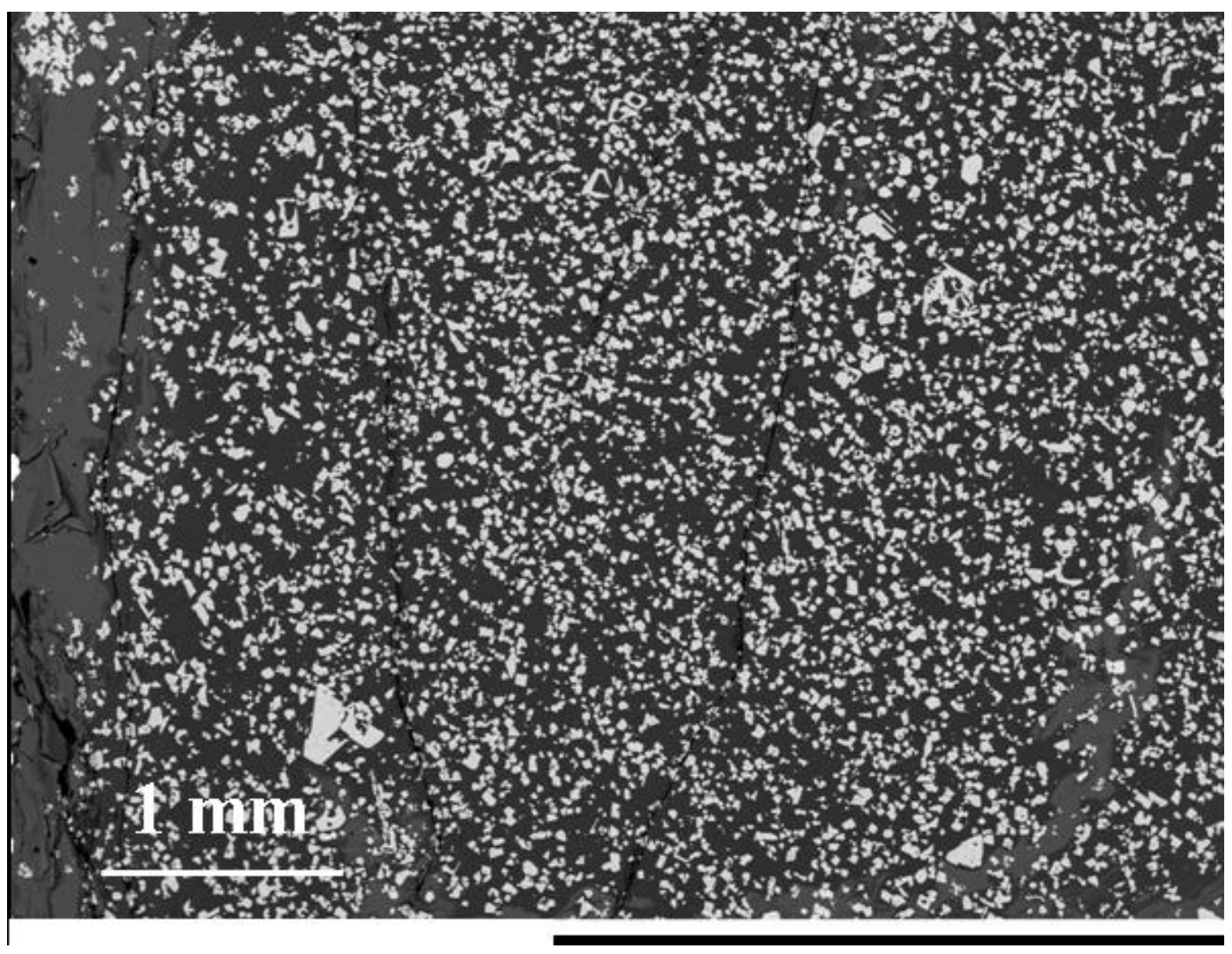

Figure 4.27a. SEM image showing typical microstructure in a cross-section of the settling zone composed primarily of spinel at high packing density (Test 5 , after idling, BBL-O-130A, just from bottom). 


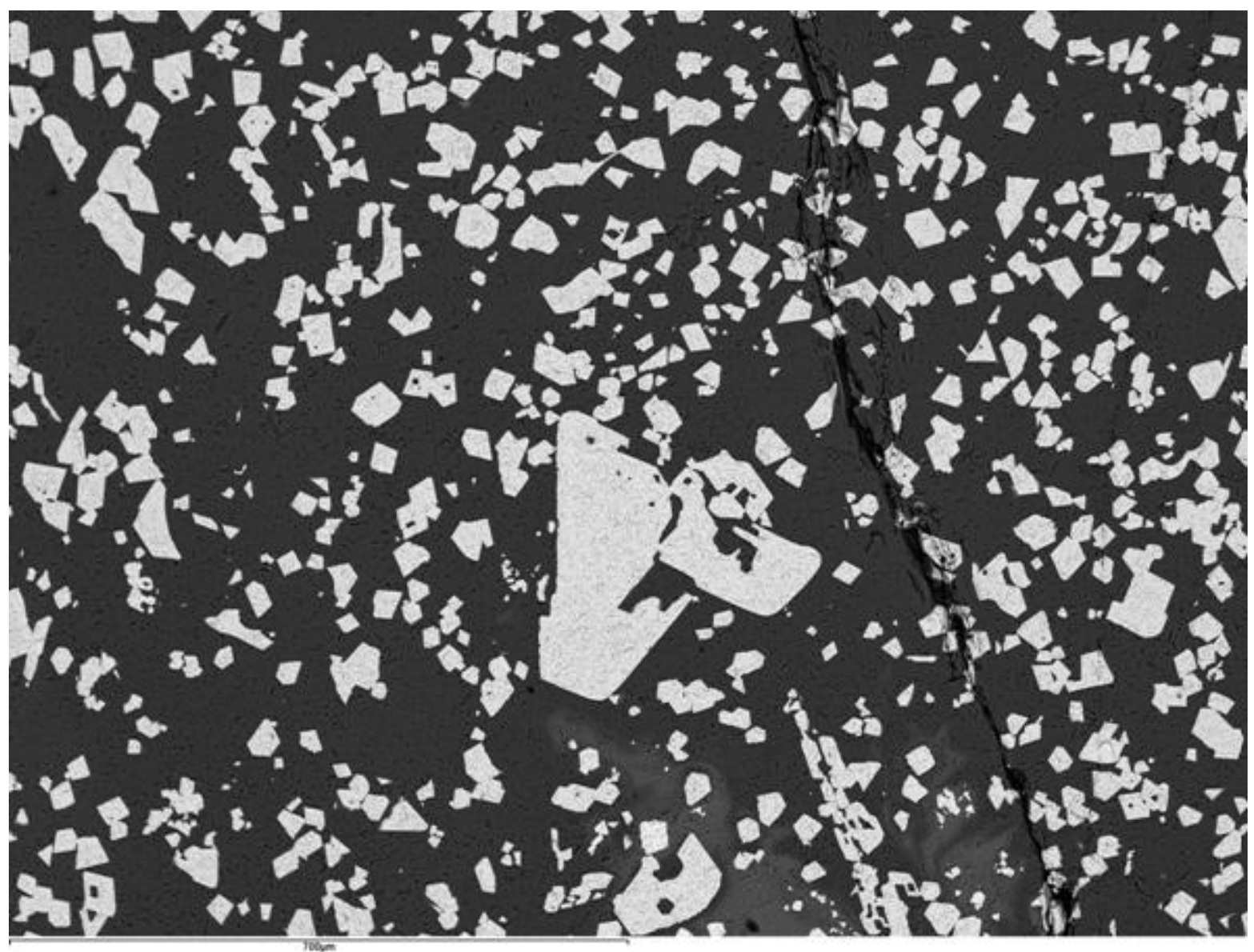

Figure 4.27b. SEM image showing typical microstructure of the settling zone composed primarily of spinel at high packing density (Test 5, after idling, BBL-O130A, just from bottom). 
The Catholic University of America Vitreous State Laboratory
ORP-56294 Rev. 0

Effects of High Crystal Content in HLW DM100 Melter Tests

Final Report, VSL-09R1520-1, Rev. 0

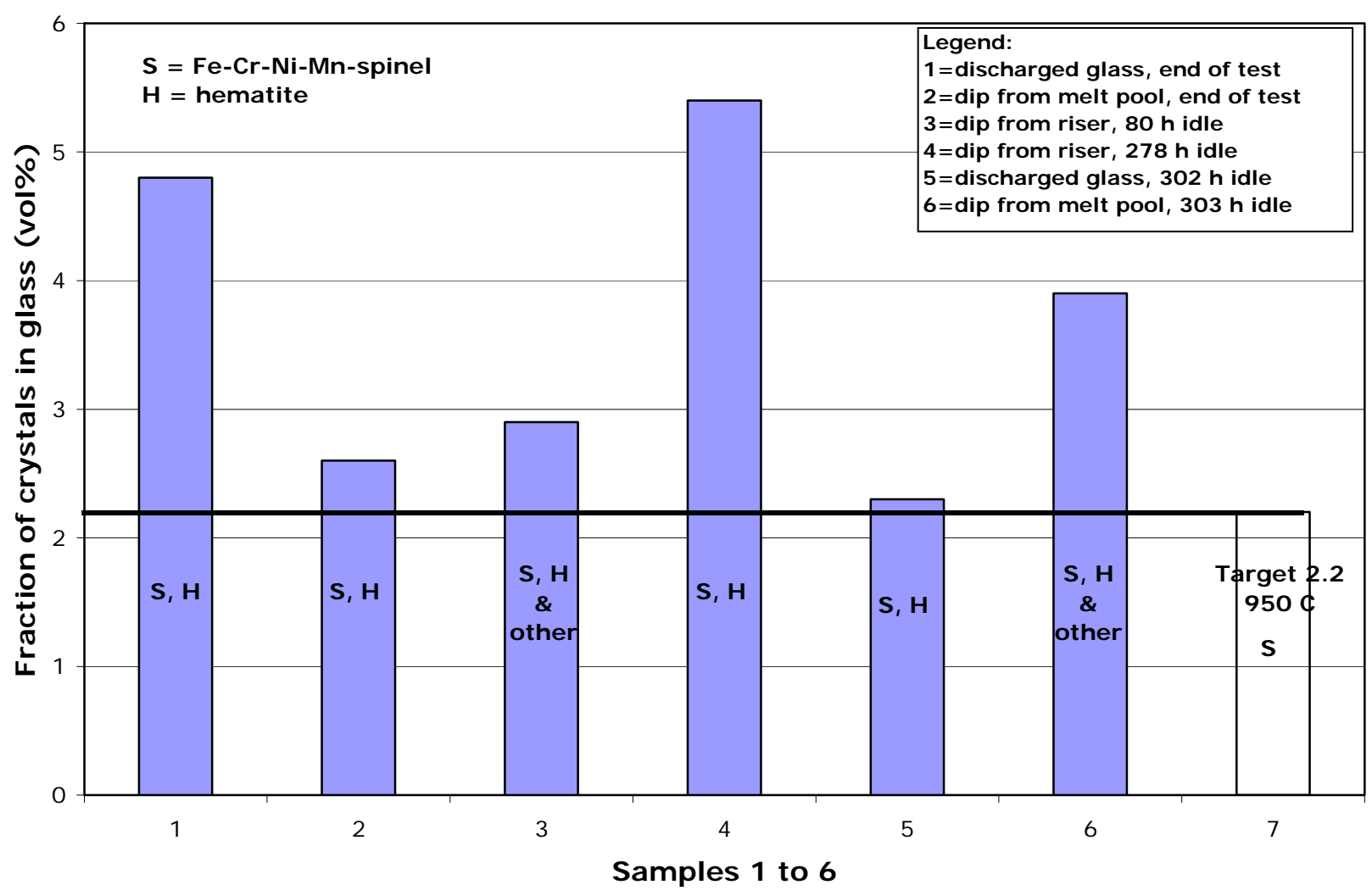

Figure 4.28. Fractions of crystals in dip and discharge glass samples taken at the end of Test 1 and during subsequent melter idling. (Standard deviation of the vol\% crystals measurement is $0.5 \mathrm{vol} \%$ ) 


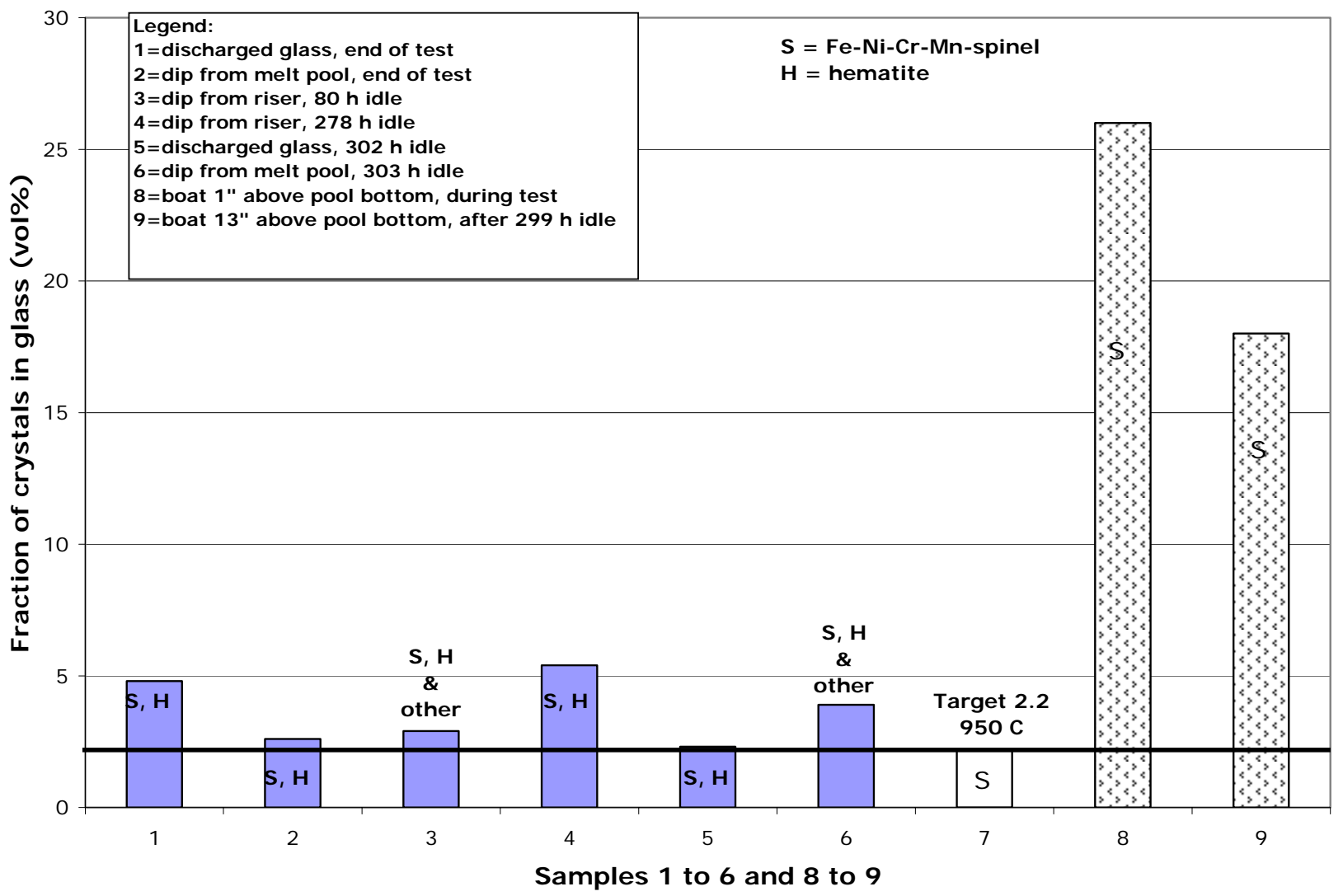

Figure 4.29. Fractions of crystals in dip, discharge, and boat glass samples taken during and at the end of Test 1 , and during subsequent melter idling. (Standard deviation of the vol\% crystals measurement is $0.5 \mathrm{vol} \%$ ) 


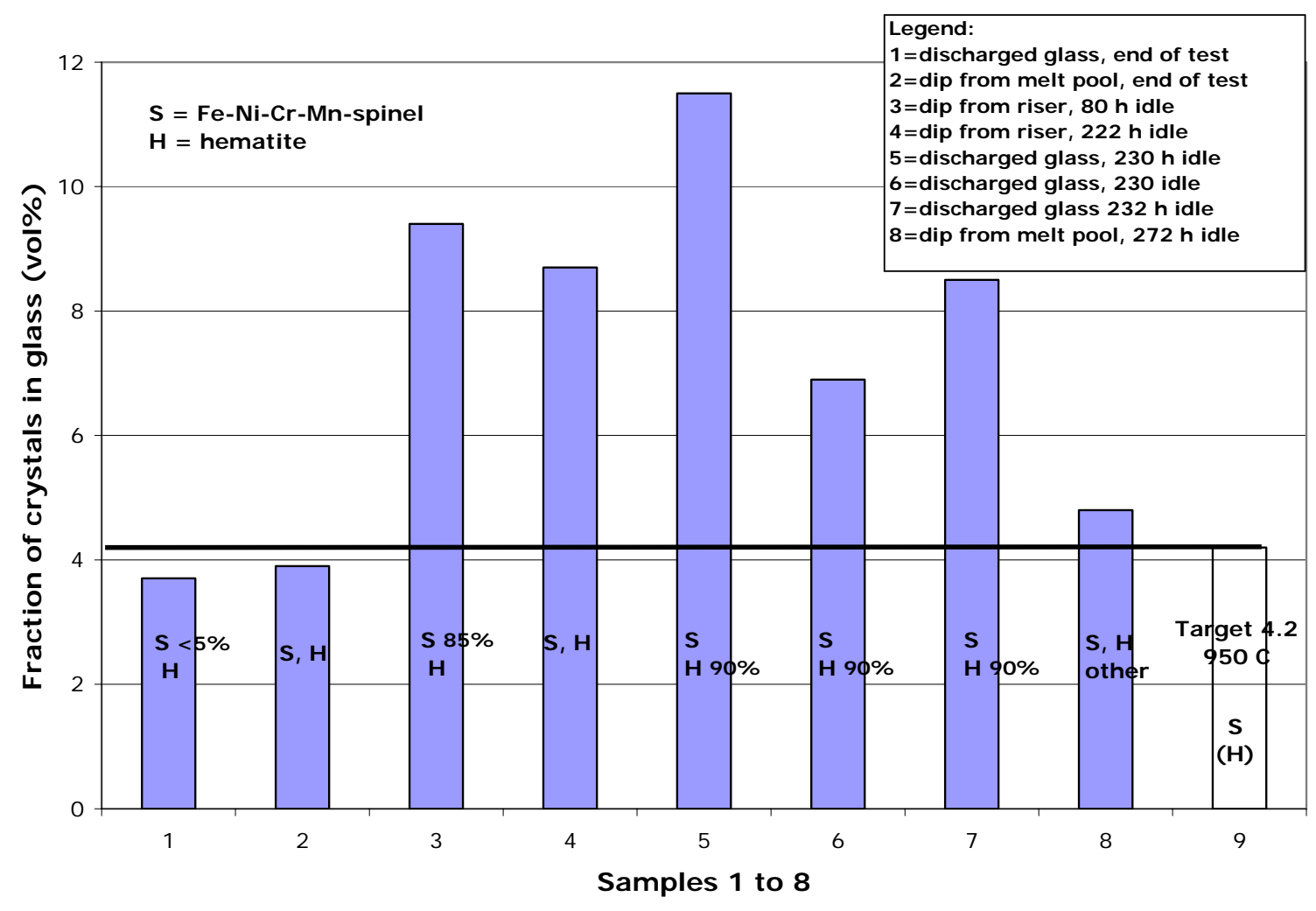

Figure 4.30. Fractions of crystals in dip and discharge glass samples taken at the end of Test 2 and during subsequent melter idling. (Standard deviation of the vol\% crystals measurement is $0.5 \mathrm{vol} \%$ ) 


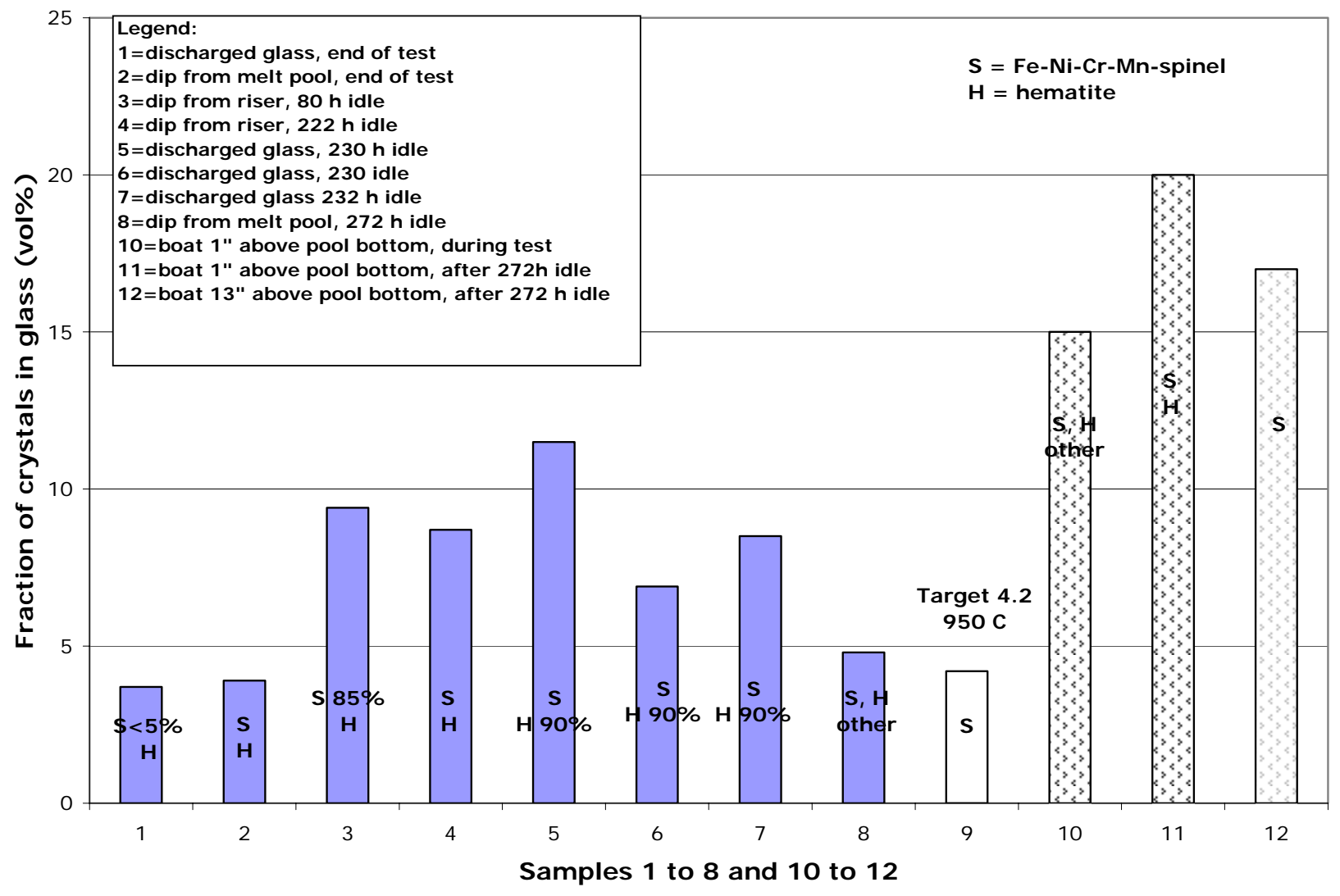

Figure 4.31. Fraction of crystals in dip, discharge, and boat glass samples during and at the end of Test 2, and during subsequent melter idling. (Standard deviation of the vol\% crystals measurement is $0.5 \mathrm{vol} \%$ ) 


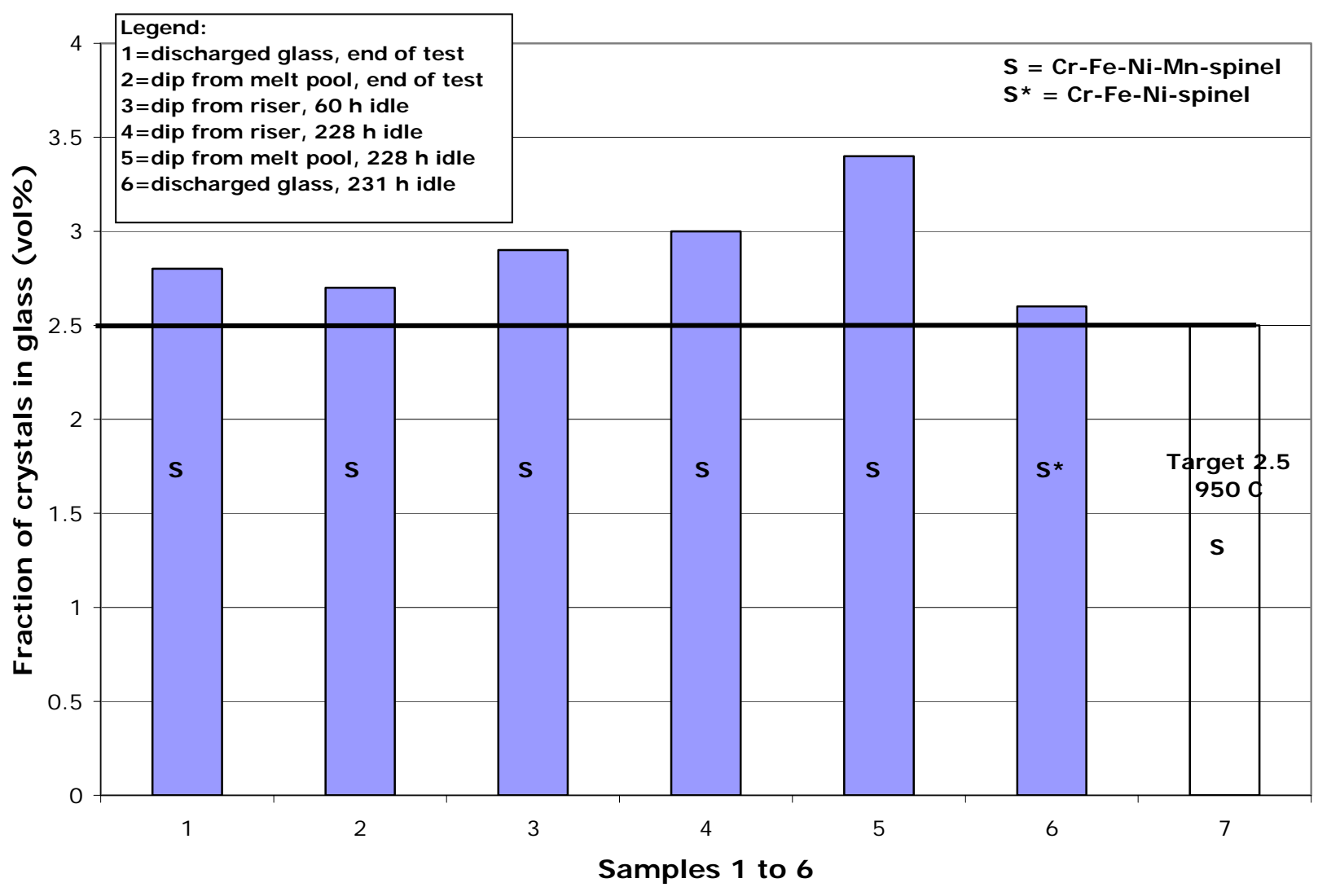

Figure 4.32. Fractions of crystals in dip and discharge glass samples taken at the end of Test 3 and during subsequent melter idling.

(Standard deviation of the vol\% crystals measurement is 0.5 vol\%) 


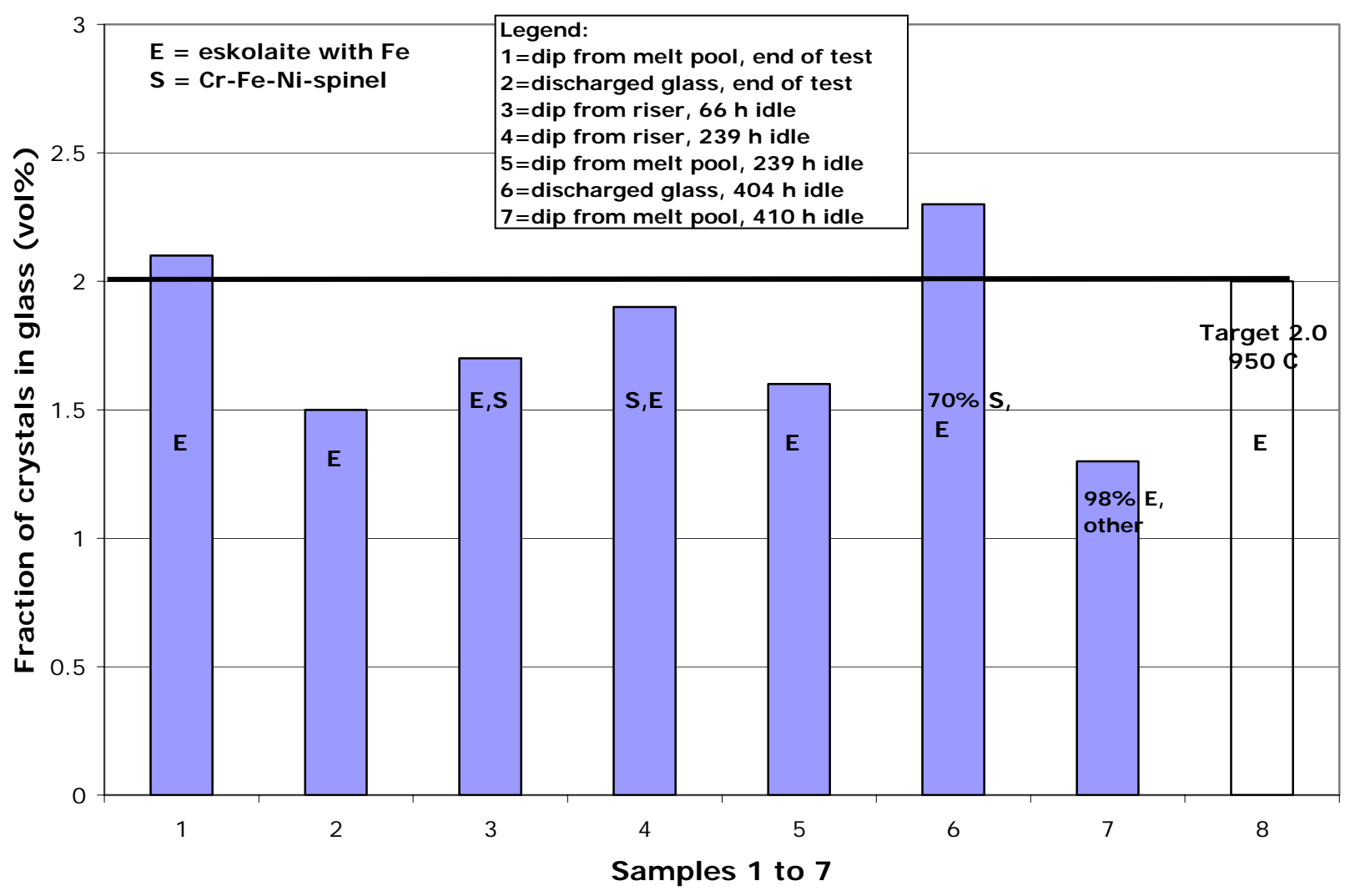

Figure 4.33. Fractions of crystals in dip and discharge glass samples taken at the end of Test 4 and during subsequent melter idling. (Standard deviation of the vol\% crystals measurement is $0.5 \mathrm{vol} \%$ ) 


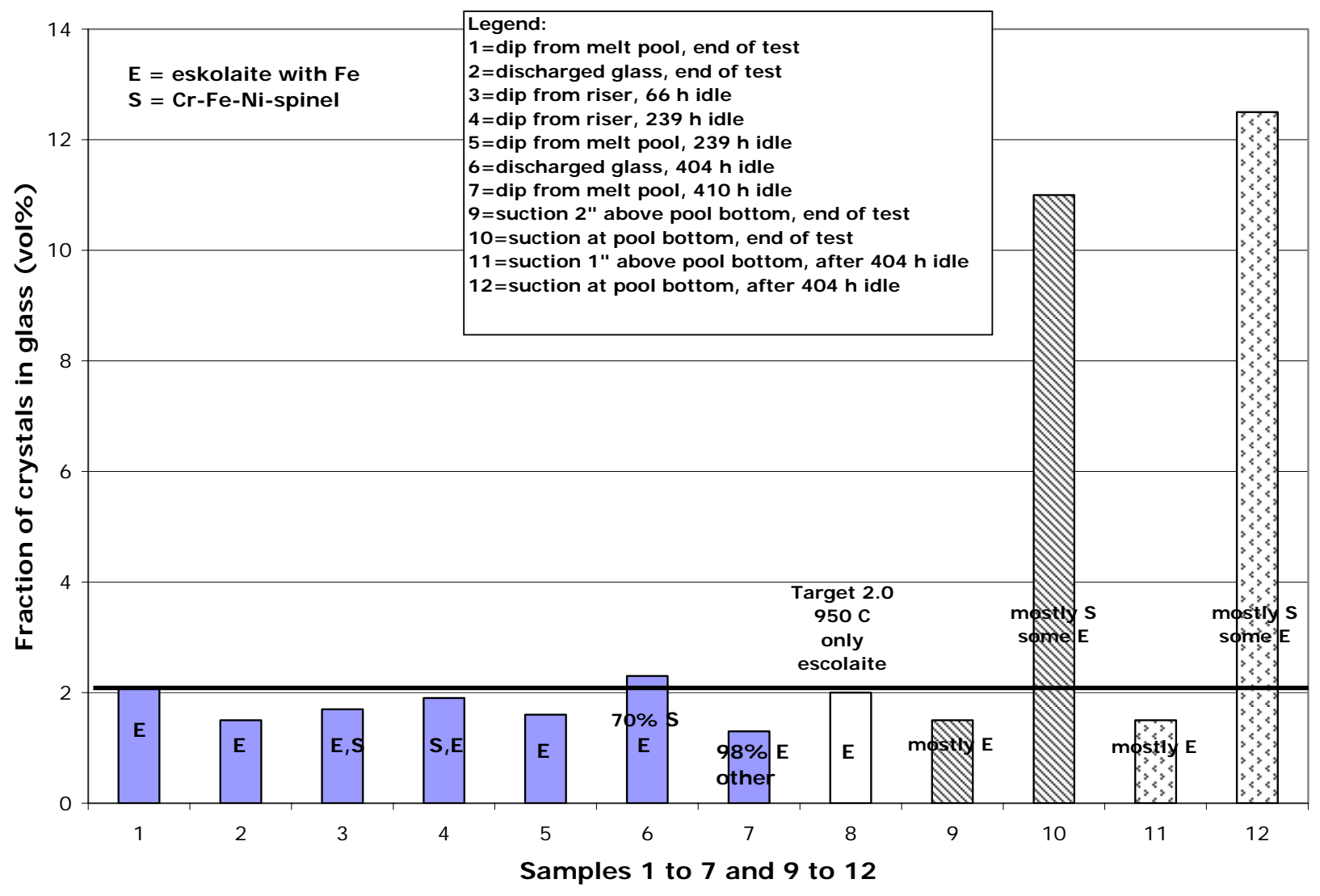

Figure 4.34. Fractions of crystals in dip, discharge, and suction glass samples taken at the end of Test 4 and during subsequent melter idling. (Standard deviation of the vol\% crystals measurement is $0.5 \mathrm{vol} \%$ ) 
The Catholic University of America Vitreous State Laboratory
ORP-56294 Rev. 0

Effects of High Crystal Content in HLW DM100 Melter Tests

Final Report, VSL-09R1520-1, Rev. 0

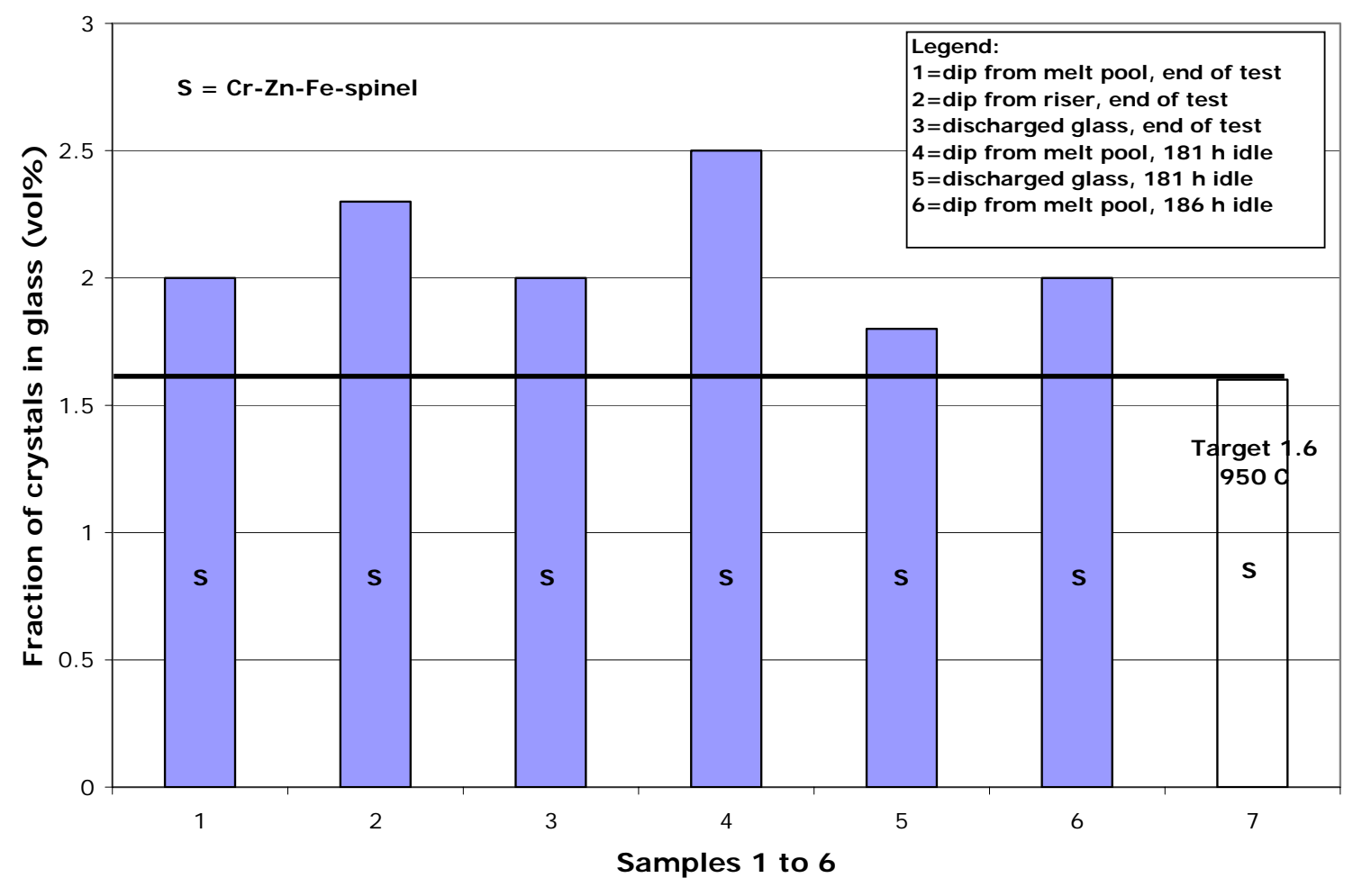

Figure 4.35. Fractions of crystals in dip and discharge glass samples taken at the end of Test 5 and during subsequent melter idling.

(Standard deviation of the vol\% crystals measurement is $0.5 \mathrm{vol} \%$ ) 


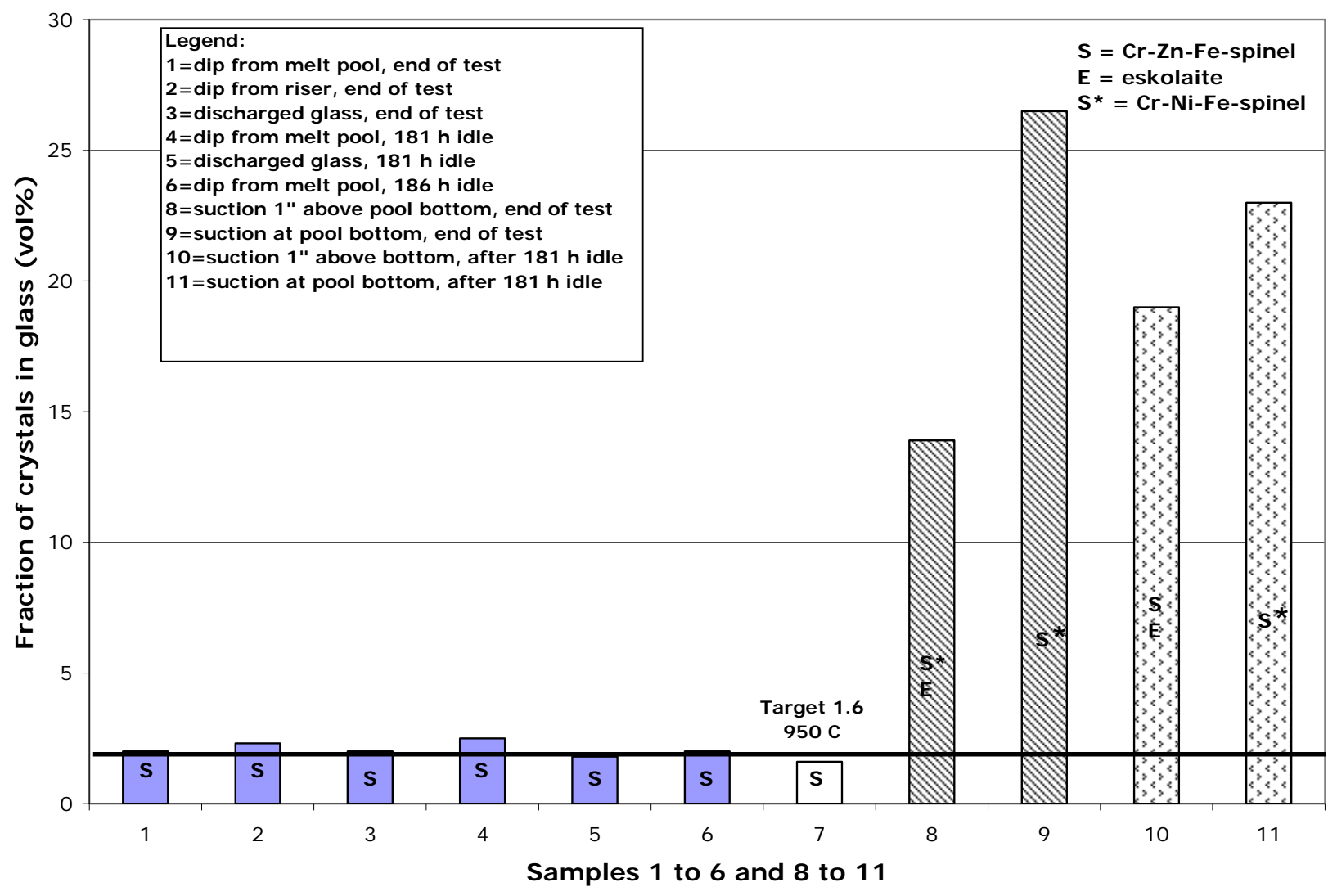

Figure 4.36. Fractions of crystals in dip, discharge, and suction glass samples taken at the end of Test 5 and during subsequent melter idling. (Standard deviation of the vol\% crystals measurement is $0.5 \mathrm{vol} \%$ ) 

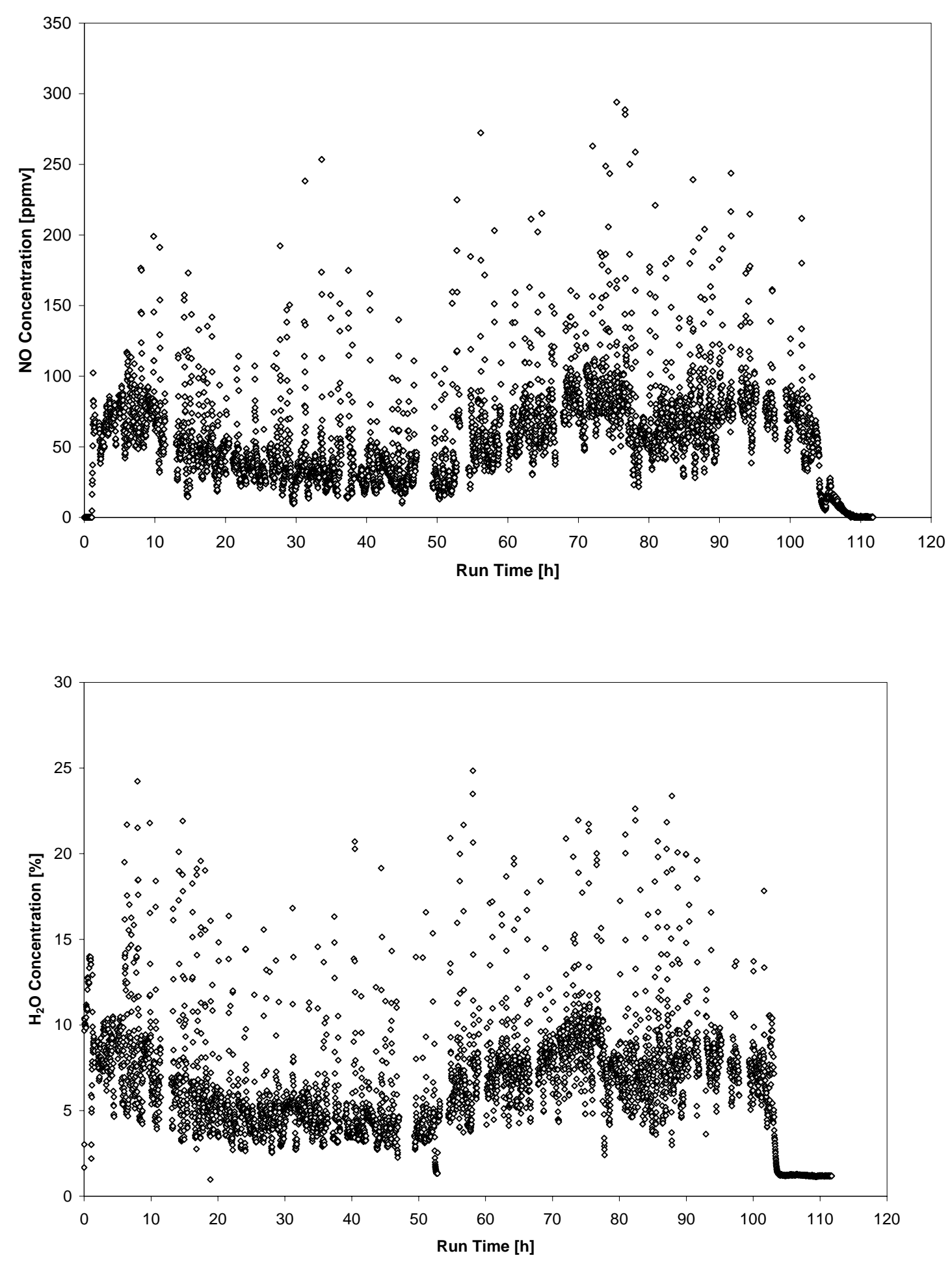

Figure 5.1. FTIR monitored NO and water emissions during Tests 1a and 1b. 

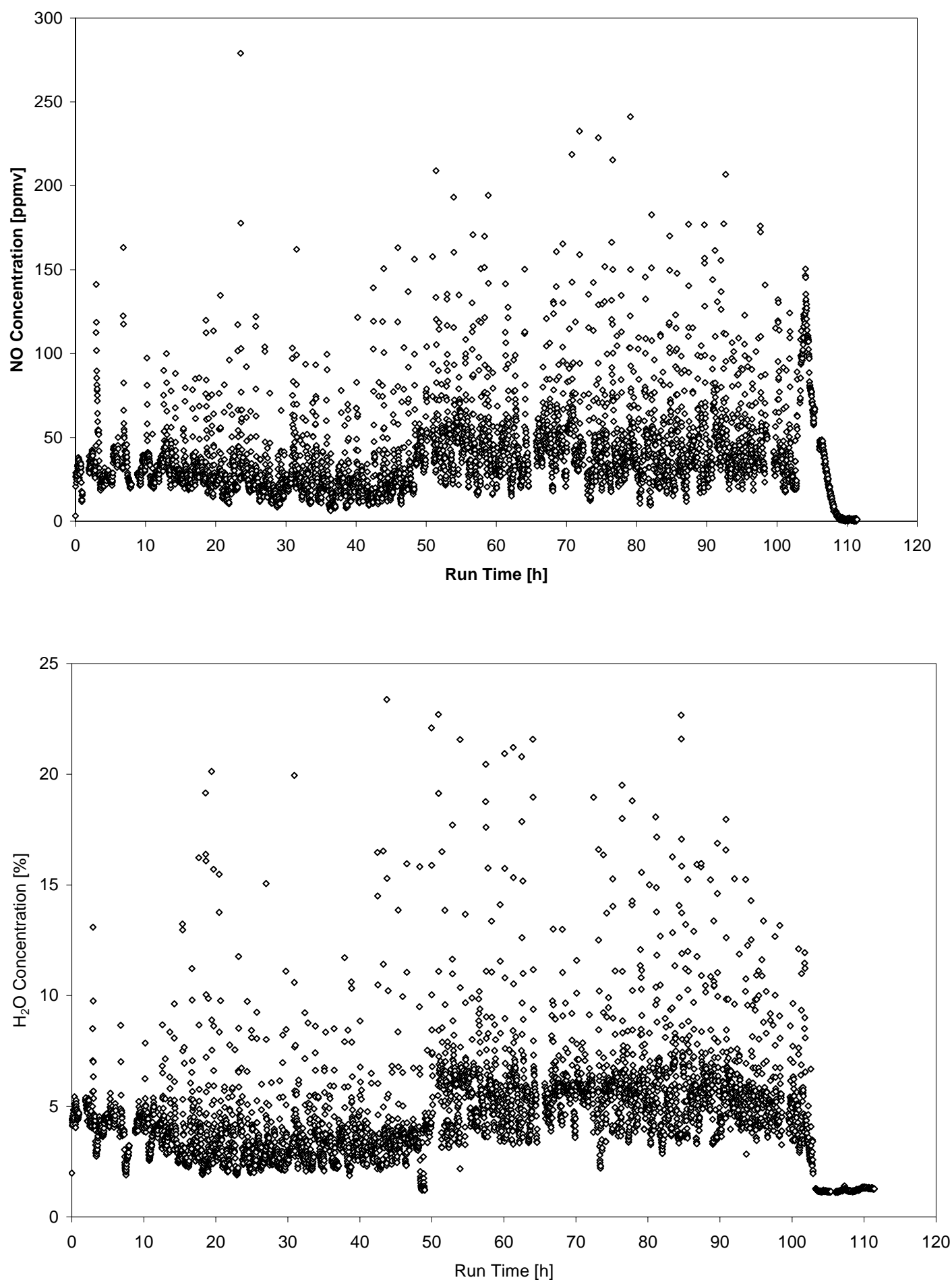

Figure 5.2. FTIR monitored NO and water emissions during Tests $2 a$ and $2 b$. 

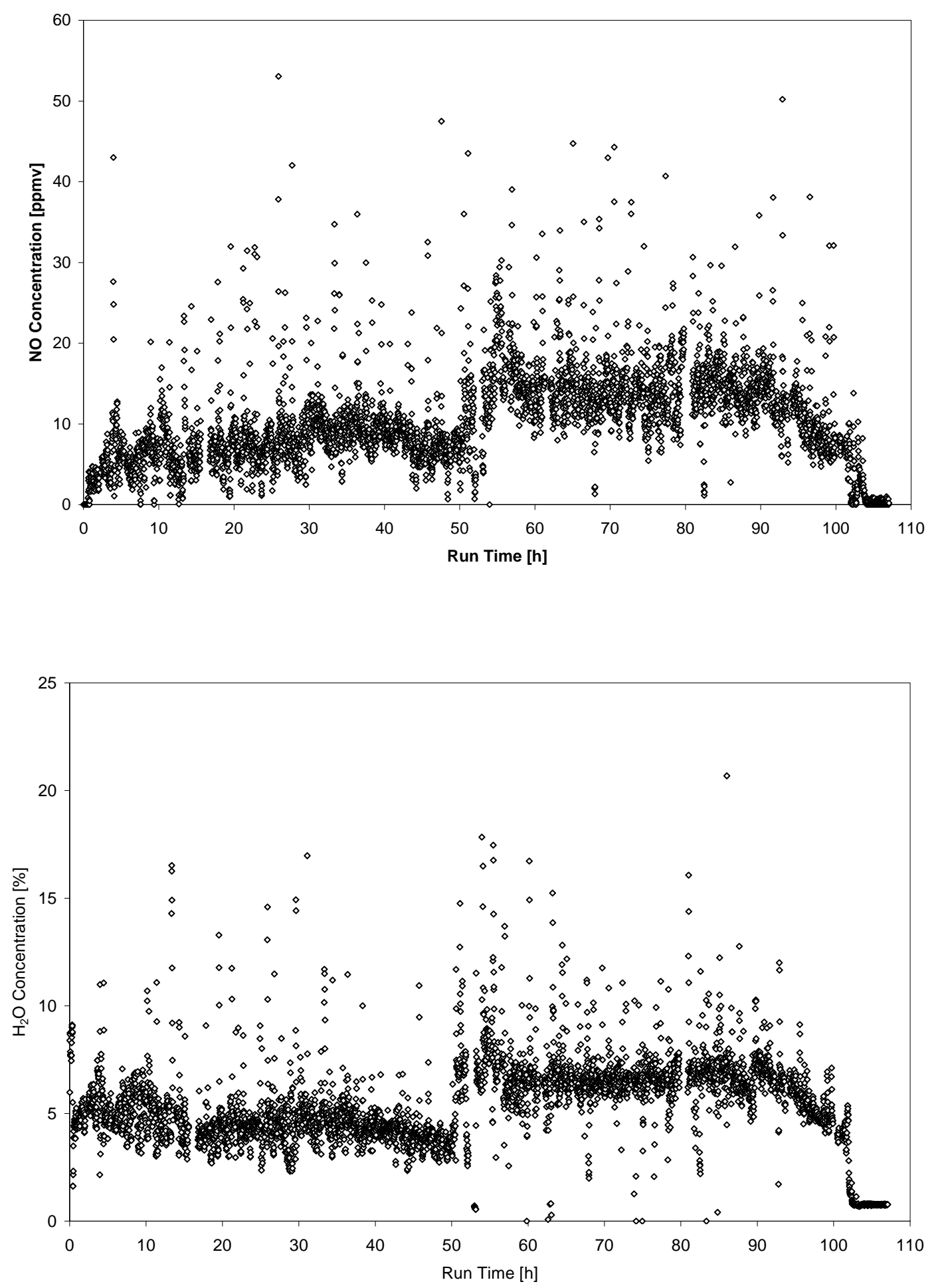

Figure 5.3. FTIR monitored NO and water emissions during Tests $3 a$ and $3 b$. 

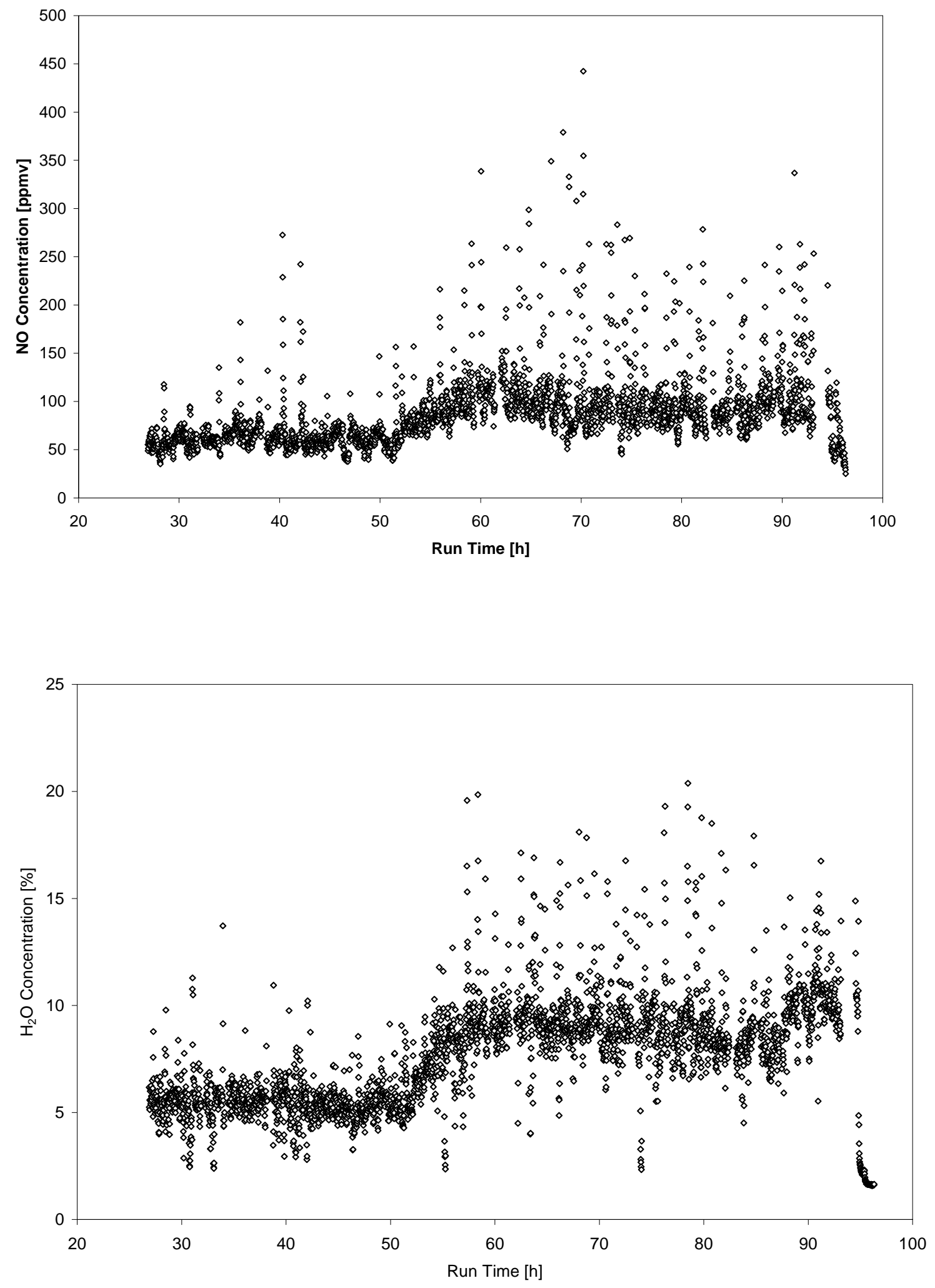

Figure 5.4. FTIR monitored NO and water emissions during Tests $4 a$ and 4 b. 

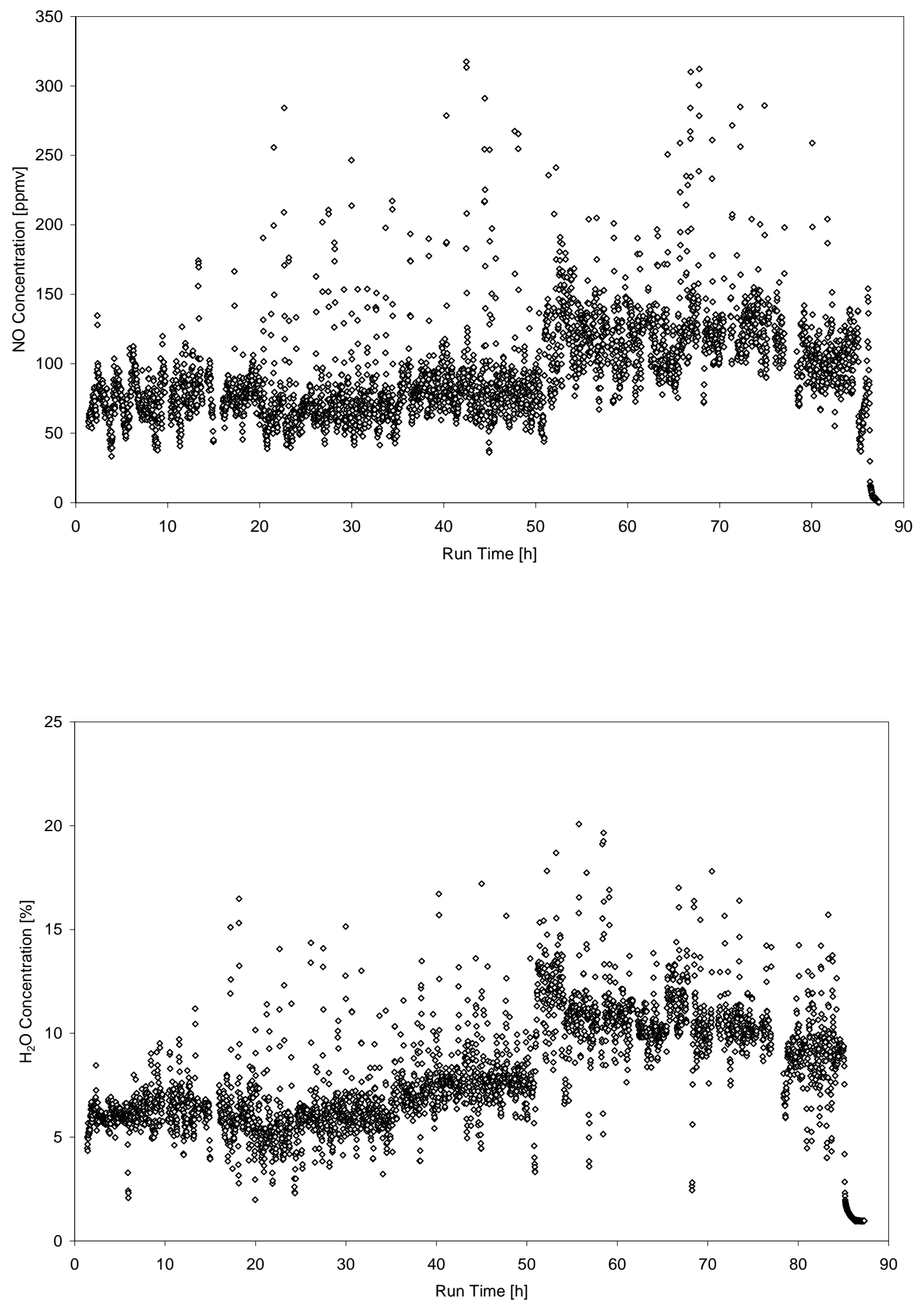